\title{
Microstructure and Phase Assemblage of Low-Clinker Cements during Early Stages of Carbonation
}

\author{
Julia Alexandra Herterich
}

Submitted in accordance with the requirements for the degree of Doctor of Philosophy

The University of Leeds

School of Civil Engineering

February 2017 
The candidate confirms that the work submitted is her own and that appropriate credit has been given where reference has been made to the work of others.

This copy has been supplied on the understanding that it is copyright material and that no quotation from the thesis may be published without proper acknowledgement.

(C) 2017 The University of Leeds Julia Herterich

The right of Julia Herterich to be identified as Author of this work has been asserted by her in accordance with the Copyright, Designs and Patents Act 1988. 


\section{Acknowledgements}

I would like to thank my supervisors, Dr Leon Black and Professor lan Richardson, for their guidance and support and helpful discussions which have been of great value.

I would like to thank Nanocem for the opportunity to work on this project, and all the members who have been involved in valuable discussions of my work, particularly Veronique Baroghel-Bouny, Matthieu Bertin, Fabrizio Moro, Maurizio Marchi, Bruno Huet, Jan Skocek and Katja Fridh.

My thanks and appreciation to all the civil engineering technical staff at the University of Leeds and to the rest of my research group, Mark, Josh, James, Sam, Suma, Sultan, Sola and Joe who have always offered their help and support. Thanks to the staff in LEMAS for their valuable help and training and to the staff in the solid state NMR service at Durham University for the collection of MAS NMR spectra.

Finally, to my family and friends who have listened to me moan and sent me food (mainly cheese pies) and who still don't understand why I correct them when they say concrete instead of cement.

And hello to Jason Isaacs. 


\section{Abstract}

Though it is well established that a reduced rate of hydration is observed in composite cement materials, both the PC and the SCM will hydrate simultaneously, there is still a significant lack of knowledge regarding the early age kinetics of the reactions taking place. This becomes of great importance when considering the early removal of formwork in practice, where the reliance is on models established for PC systems. A comprehensive understanding of the complex relationship between slower composite hydration, drying of the sample surface and phase carbonation kinetics is imperative. Current models derived from idealistic, i.e. fully hydrated and non-carbonated, materials, are ineffective for durability predictions. In addition to this, the existing models do not consider the effects that insufficient curing and phase carbonation have on the phase assemblage composition, development of the microstructure and the subsequent consequences for the transport properties.

This study investigates the effects of carbonation following short curing periods (72 hours) on CEMI and composite cement systems (30\% PFA, 30\% \& 60\% GGBS) at a low (0.40) and high (0.57) w/b ratio. Modifications in carbonation behaviour were observed compared to idealised/28 day cured samples and natural carbonation studies in the literature. Although the carbonation of the hydrate phases was observed to occur simultaneously, it was only once $\mathrm{CH}$ had been completely consumed, or was no longer accessible, that carbonation of the other hydrate phases ( $\mathrm{C}-\mathrm{S}-\mathrm{H}, \mathrm{AFt}$ and $\mathrm{AFm}$ ) was permitted to occur more extensively. Decalcification and dealumination of the C-S-H phase occurred following exposure to ambient $\left[\mathrm{CO}_{2}\right]$, and $\mathrm{CaCO}_{3}$ microcrystals were observed in the outer product (Op) regions only. A reduction in the $\mathrm{Ca} / \mathrm{Si}$ ratio of the Ip C-S-H appeared to be a result of migration of the $\mathrm{Ca}$ ions, driven by a concentration gradient. Furthermore, the rate and extent of carbonation and the nature of the carbonate species formed was dependent on the level of replacement, the replacement material and the degree of hydration. The formation of vaterite appeared to be related to the carbonation of $\mathrm{C}-\mathrm{S}-\mathrm{H}$, particularly low $\mathrm{Ca} \mathrm{C}-\mathrm{S}-\mathrm{H}$, and silica gel was observed to form in the $\mathrm{CEMI}$ and blended materials following carbonation at ambient $\mathrm{CO}_{2}$ concentrations for 60 days. AFt was determined to be more resilient to carbonation compared to the AFm phases, remaining in heavily carbonated CEMI pastes in which portlandite was absent. The carbonation of the AFm phases was observed to occur in two stages; first, phase transformation from $\mathrm{SO}_{4}$ 
(monosulfoaluminate) to $\mathrm{CO}_{3}$ (hemi- and monocarboaluminate) bearing species was observed to occur, ultimately decomposing by decalcification. The availability of $\mathrm{CH}$, however, prevented complete decomposition. Low $\mathrm{w} / \mathrm{b}$ ratios were unable to mitigate the effects of short curing periods for systems with high levels of substitution but improved the carbonation resistance of cement systems with moderate levels of substitution (30\%). The availability of $\mathrm{CH}$ was determined to be the rate determining factor for carbonation, but its consumption is primarily controlled by the ability of $\mathrm{CO}_{2}$ to diffuse through the microstructure. 


\section{Table of Contents}

$\begin{array}{ll}\text { Chapter } 1 \text { - Introduction } & 1\end{array}$

1.1 Research objectives $\quad 2$

Chapter 2 - Literature Review 3

2.1 Portland cement 3

2.1.1 Hydration kinetics 3

2.1.2 The hydration products and their microstructure 5

2.2 Pulverised fuel ash (PFA) and ground granulated blast-furnace slag (GGBS) composite cements $\quad 8$

2.2.1 PFA cement hydration $\quad 8$

2.2.2 The hydration products and their microstructure 10

2.2.3 GGBS cement hydration 12

2.2.4 The hydration products and their microstructure 13

2.2.5 Engineering properties and durability of PFA and GGBS cements 16

$\begin{array}{ll}2.3 \text { Carbonation } & 17\end{array}$

2.3.1 The carbonation reaction $\quad 17$

2.3.2 Carbonation of Portland cement 19

2.3.2.1 Carbonation of the hydrate phases and the effects on the phase $\begin{array}{ll}\text { assemblage and the microstructure } & 19\end{array}$

2.3.2.2 The effect on engineering properties and durability 22

2.3.3 Carbonation of PFA and GGBS composite cements 23

2.3.3.1 Carbonation of the hydrate phases and the effects on the phase assemblage and the microstructure 23

2.3.3.2 The effect on engineering properties and durability 25

$\begin{array}{ll}2.4 \text { Curing } & 27\end{array}$

$\begin{array}{ll}\text { 2.4.1 Guidelines on curing } & 27\end{array}$

2.4.2 The effects of curing on carbonation resistance of composite cements 28

2.5 Conclusions from literature review and research objectives 29 
$\begin{array}{ll}\text { Chapter 3-Materials and Methods } & 31\end{array}$

$\begin{array}{ll}3.1 \text { Raw materials } & 31\end{array}$

3.2 Sample preparation and conditioning 33

3.2.1 Preparation of mortar samples 33

3.2.2 Preparation of mortar samples $\quad 37$

3.3 Hydration stopping 38

3.3.1 Principle of hydration stopping 38

3.3.2 Experimental procedure $\quad 39$

3.4 Phase assemblage characterisation $\quad 40$

3.4.1 Isothermal conduction calorimetry (ICC) 40

3.4.1.1 Principle of isothermal conduction calorimetry 40

3.4.4.2 Experimental setup $\quad 40$

3.4.2 Simultaneous thermal analysis (STA) 40

3.4.2.1 Principle of simultaneous thermal analysis 40

3.4.2.2 Experimental setup $\quad 42$

3.4.2 Attenuated total reflectance - Fourier transform infrared spectroscopy (ATR-FTIR) 44

3.4.2.1 Principle of Attenuated total reflectance - FTIR 44

3.4.3.2 Experimental setup $\quad 45$

3.4.4 Magic angle spinning nuclear magnetic resonance (MAS NMR) 45

3.4.4.1 Principle of magic angle spinning nuclear magnetic resonance $\quad 45$

3.4.4.2 Experimental setup $\quad 47$

3.4.5 X-ray diffraction (XRD) 48

3.4.5.1 Principle of x-ray diffraction 48

3.4.5.1 Experimental setup - qualitative XRD 49

3.4.5.2 Principle of Rietveld method 49

3.4.5.3 Selective dissolution $\quad 50$

3.4.5.4 Control file $\quad 51$

3.4.5.5 Quantification using the G-factor method 54

3.4.5.6 Experimental setup $\quad 55$

3.5 Microstructural characterisation $\quad 56$

3.5.1 Analytical transmission electron microscopy (TEM) 56 
3.5.1.1 Principle of analytical transmission electron microscopy 56

3.5.1.2 Experimental setup $\quad 57$

3.5.2 Scanning electron microscopy $\quad 59$

3.5.3 Principle of scanning electron microscopy

- back scattered electron (SEM-BSE) imaging 59

3.5.4 Determining degree of hydration 60

3.5.5 Experimental setup 63

3.6 Analysis of engineering performance 63

3.6.1 Unconfined compressive strength (UCS) 63

3.6.2 Carbonation depth 63

Chapter 4 - Experimental Scoping $\quad 64$

4.1 Curing length $\left(t_{0}\right) \quad 64$

4.2 Isothermal Conduction Calorimetry 65

$\begin{array}{ll}4.3 \text { Simultaneous Thermal Analysis } & 70\end{array}$

4.4 Attenuated Total Reflectance - Fourier Transform Infrared Spectroscopy 74

$\begin{array}{ll}\text { 4.5 X-Ray Diffraction } & 75\end{array}$

4.6 Discussion and Selection of Experimental Conditions 76

4.6.1 Curing length $\left(\mathrm{t}_{0}\right) \quad 76$

$\begin{array}{ll}\text { 4.6.2 RH level } & 77\end{array}$

Chapter 5 - Characterisation of $t_{0}$ samples $\quad 78$

$\begin{array}{ll}5.1 \text { Extent of reaction } & 78\end{array}$

5.1.1 Hydration kinetics and degree of reaction of cement clinker $\quad 78$

5.1.2 Degree of reaction of the PFA and GGBS cement systems 85

5.1.2.1 Degree of reaction of the PFA and GGBS 85

5.1.2.2 Weighted degree of reaction of the GGBS cement systems $\quad 89$

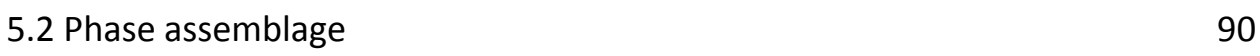

5.2.1 Crystalline phase assemblage 90

5.2.2 Aluminium bearing phases 95

$\begin{array}{ll}5.3 \text { Microstructure } & 97\end{array}$

$\begin{array}{ll}\text { 5.3.1 TEM-EDX } & 97\end{array}$

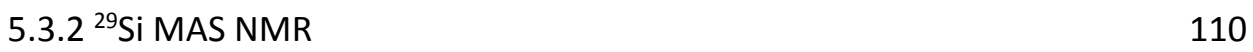


$\begin{array}{ll}\text { 5.3 Conclusions } & 116\end{array}$

$\begin{array}{lr}\text { Chapter 6 - Early age carbonation behaviour } & 119\end{array}$

6.1 Carbonation of systems at w/b ratio $0.57 \quad 119$

6.1.1 Thermal analysis 119

$\begin{array}{ll}\text { 6.1.2 XRD } & 131\end{array}$

6.1.3 ATR-FTIR 136

6.1.4 ${ }^{27} \mathrm{Al}$ MAS NMR 142

6.1.5 TEM - EDX 145

6.1.6 ${ }^{29}$ Si MAS NMR 152

6.2 Carbonation of systems at $\mathrm{w} / \mathrm{b}$ ratio $0.40 \quad 156$

6.2.1 Thermal analysis 156

$\begin{array}{ll}6.2 .2 X R D & 158\end{array}$

$\begin{array}{ll}\text { 6.2.3 ATR-FTIR } & 160\end{array}$

$\begin{array}{ll}6.3 \text { Conclusions } & 161\end{array}$

$\begin{array}{ll}\text { Chapter } 7 \text { - Later age carbonation behaviour } & 163\end{array}$

7.1 Carbonation of systems at w/b ratio 0.57

7.1.1 Thermal analysis 163

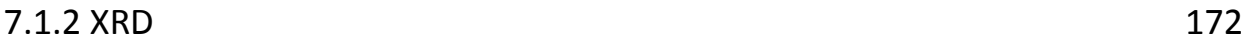

$\begin{array}{ll}\text { 7.1.3 ATR-FTIR } & 177\end{array}$

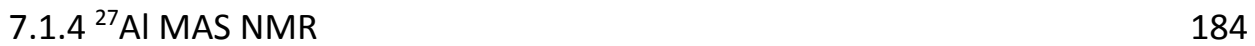

$\begin{array}{ll}\text { 7.1.5 TEM - EDX } & 186\end{array}$

7.1.6 ${ }^{29}$ Si MAS NMR 193

7.2 Carbonation of systems at w/b ratio $0.40 \quad 200$

7.2.1 Thermal analysis 200

$\begin{array}{ll}7.2 .2 X R D & 202\end{array}$

$\begin{array}{ll}7.2 .3^{27} \text { AI MAS NMR } & 203\end{array}$

$\begin{array}{ll}7.3 \text { Conclusions } & 204\end{array}$

Chapter 8 - The effect of carbonation on engineering properties and its implications for $\begin{array}{ll}\text { durability and cover depth } & 207\end{array}$

8.1 Carbonation depth of mortar samples 207

8.2 Durability implications 212

Chapter 9-Conclusions and further work 220 
$\begin{array}{ll}9.1 \text { Conclusions } & 220\end{array}$

9.2 Further work 223

$\begin{array}{ll}\text { References } & 225\end{array}$

$\begin{array}{ll}\text { Appendices } & \mathbf{2 4 0}\end{array}$

A.1 Appendix A - $\mathrm{RH}$ and $\mathrm{CO}_{2}$ measurements 240

B.1 Appendix B - UCS and carbonation depth 241 


\section{List of figures}

Figure 2.1. Typical heat evolution curve for hydrating Portland cement.

Figure 2.2. Chemical structure of (a) $1.4 \mathrm{~nm}$ Tobermorite and (b) Jennite taken from.

Figure 2.3. TEM micrograph showing regions of Ip \& Op C-S-H in mature $\mathrm{C}_{3} \mathrm{~S}$ pastes.

Figure 2.4. $\mathrm{CaO}-\mathrm{Al}_{2} \mathrm{O}_{3}-\mathrm{SiO}_{2}$ ternary diagram of Portland cement and different supplementary cementitious materials.

Figure 2.5. TEM micrograph of 30\% PFA sample showing both fibrillar and foil-like morphology of Op C-S-H.

Figure 2.6. TEM micrograph showing foil-like morphology of Op C-S-H in a neat slag paste.

Figure 3.1. Particle size distribution of CEM 52.5R, PFA and GGBS.

Figure 3.2. Schematic diagram of prepared section for sample conditioning.

Figure 3.3. Schematic diagram showing experimental configuration of carbonation chamber.

Figure 3.4. (a) Carbonation chamber for ambient carbonation of paste samples and (b) prepared paste samples in sample stand.

Figure 3.5. The effects of varying length of solvent exchange in isopropanol for a CEMI $0.57-72$ hour cured system.

Figure 3.6. TG and DTA plots for CEMI ( $w / b$ 0.57) sample cured for 72 hours and exposed to ambient $\left[\mathrm{CO}_{2}\right]$ for 7 days highlighting temperature ranges in which mass loss due to decomposition of the hydrate phases and $\mathrm{CaCO}_{3}$ is expected to occur.

Figure 3.7. Example of determination of mass loss due to decomposition of $\mathrm{CH}$ using the tangent method.

Figure 3.8. Energy level diagram for nucleus with spin $\mathrm{I}=1 / 2$.

Figure 3.9. XRD patterns of as received CEM 52.5R, potassium hydroxide/sugar $(\mathrm{KOH} / \mathrm{S})$ selective extraction residue and salicylic acid/methanol (SA/M) selective extraction residue.

Figure 3.10. Rietveld refinement of anhydrous CEM52.5R showing the experimental data, the calculated pattern and the difference plot.

Figure 3.11. Selected area electron diffraction pattern collected on an area of C-S-H showing area is completely free of microcrystalline phases.

Figure 3.12. SEM-BSE image of $30 \%$ GGBS sample cured for 72 hours ( $w / b 0.40$ ) and accompanying grey level histogram.

Figure 3.13. SEM-BSE image of $30 \%$ GGBS sample cured for 28 days ( $w / b$ 0.57) with corresponding Mg map and mask showing position and area of anhydrous slag fraction.

Figure 4.1. Isothermal calorimetry data showing the total heat evolution between $0-72$ hours.

Figure 4.2. Isothermal calorimetry data showing rate of heat evolution between $0-72$ hours. 
Figure 4.3. Isothermal calorimetry data between $0-72$ hours showing rate of heat evolution normalised to cement content.

Figure 4.4. Isothermal calorimetry data showing the total heat evolution normalised to cement content between $0-72$ hours.

Figure 4.5. Calculated $\mathrm{CaCO}_{3}$ content from TGA data showing change in $\mathrm{CaCO}_{3}$ content from $\mathrm{t}_{0}$ following curing periods of (a(i)) 11MPa equivalent, (b(i)) 24 hours and (c(i)) 72 hours. Figures (a(ii)), (b(ii)) and (c(ii)) display the $\mathrm{CaCO}_{3}$ content normalised to cement content.

Figure 4.6. TGA and DTA plots for $30 \%$ GGBS - 72 hours cured after 48 hours exposure to ambient $\left[\mathrm{CO}_{2}\right]$ at $\mathrm{RH}$ levels of $30 \%, 55 \%$ and $75 \%$.

Figure 4.7 ATR-FTIR data showing $\mathrm{CaCO}_{3}$ content between $1100-1800 \mathrm{~cm}^{-1}$ for $30 \%$ GGBS -72 hours cured after 48 hours exposure to ambient $\left[\mathrm{CO}_{2}\right]$ at RH levels of $40 \%, 55 \%$ and $75 \%$.

Figure 4.8. Infrared spectra of (a) amorphous $\mathrm{CaCO}_{3}$ and (b) calcite.

Figure 4.9. XRD traces for $30 \% \mathrm{GGBS}-72$ hours cured after 48 hours exposure to ambient $\left[\mathrm{CO}_{2}\right]$ at RH levels of $30 \%, 40 \%, 55 \%, 75 \%$ and $85 \%$. Standard traces for calcite and $\mathrm{CH}$ are shown in blue.

Figure 5.1. Changes in $\mathrm{C}_{3} \mathrm{~S}$ content with curing length measured by XRD - Rietveld refinement for systems with $w / b$ ratio (a) 0.40 and (b) 0.57 .

Figure 5.2. Changes in $\mathrm{C}_{2} S$ content with curing length measured by XRD - Rietveld refinement for systems with $\mathrm{w} / \mathrm{b}$ ratio (a) 0.40 and (b) 0.57 .

Figure 5.3. Changes in $\mathrm{C}_{4} \mathrm{AF}$ content with curing length measured by XRD - Rietveld refinement for systems with $\mathrm{w} / \mathrm{b}$ ratio (a) 0.40 and (b) 0.57 .

Figure 5.4. Degree of hydration of the cement clinker measured by SEM-IA.

Figure 5.5. Degree of hydration of the cement clinker measured by SEM-IA and XRD - Rietveld refinement (agreement typically within $+/-5 \%$ ).

Figure 5.6. $\mathrm{CH}$ content at $\mathrm{t}_{0}$ measured by TGA.

Figure 5.7. Measured $\mathrm{CH}$ contents divided by expected $\mathrm{CH}$ contents - values $>1$ and $<1$ indicating more $\mathrm{CH}$ and less $\mathrm{CH}$ than expected respectively on the basis of dilution: (a) w/b ratio 0.40 and (b) $\mathrm{w} / \mathrm{b}$ ratio 0.57 .

Figure 5.8. Degree of hydration of the GGBS measured by SEM-IA.

Figure 5.9. Weighted of hydration of the CEMI and GGBS cement systems measured by SEM-IA.

Figure 5.10. XRD patterns between $7-13^{\circ} 2 \theta$ for $t_{0}$ samples following 72 hours and 28 days hydration.

Figure 5.11. CH content measured by TGA and XRD - Rietveld refinement (agreement typically within +/- 2.5\%).

Figure 5.12. DTA plots between $0-250^{\circ} \mathrm{C}$ for each system at $t_{0} ;(a) w / b \quad 0.40, t_{0} 72$ hours (b) $w / b$ $0.40, \mathrm{t}_{0} 28$ days (c) w/b 0.57, $\mathrm{t}_{0} 72$ hours (d) w/b 0.57, to 28 days.

Figure 5.13. Single-pulse ${ }^{27} A L$ MAS NMR spectra for each system at $t_{0} ;(a) w / b 0.40, t_{0} 72$ hours (b) $\mathrm{w} / \mathrm{b} 0.40, \mathrm{t}_{0} 28$ days (c) w/b 0.57, $\mathrm{t}_{0} 72$ hours (d) w/b 0.57, $\mathrm{t}_{0} 28$ days. 
Figure 5.14. TEM micrographs of CEMI $0.57(72 \mathrm{hr})-\mathrm{t}_{0}$ sample showing fibrillar Op regions with relicts of $A F t((a) \&(b))$ and fine Ip regions $((c) \&(d))$.

Figure 5.15. TEM micrographs of 30\% PFA 0.57 (72hr) $-t_{0}$ sample showing fibrillar and foil-like Op regions, fine Ip regions and slight reaction rims on PFA particles.

Figure 5.16. TEM micrographs of 30\% GGBS $0.57(72 \mathrm{hr})-t_{0}$ sample showing fibrillar and foil-like Op regions, fine Ip regions and $\mathrm{AFm}$ plates.

Figure 5.17. TEM micrographs of $30 \%$ PFA 0.57 (28d) - $t_{0}$ sample showing fibrillar and foil-like Op regions, fine Ip regions, PFA reaction rims, AFM plates and AFt relicts.

Figure 5.18. TEM micrographs of $30 \%$ GGBS $0.57(28 d)-t_{0}$ sample showing fine textured Ip regions intermixed with laths of hydrotalcite, foil-like and fine fibrillar Op and AFm plates.

Figure 5.19. TEM micrographs of $60 \%$ GGBS $0.57(28 d)-t_{0}$ sample showing fine textured Ip regions intermixed with laths of hydrotalcite, foil-like and fine fibrillar Op C-S-H and AFm plates.

Figure 5.20. Ca-Al-Si ternary diagrams for (a) CEMI, (b) 30\% PFA, (c) 30\% GGBS and (d) 60\% GGBS systems with $\mathrm{w} / \mathrm{b}$ ratio 0.57 at time $t_{0}$. Values are plotted as atomic percentages normalised to $100 \%$ where empty markers indicate samples cured for 72 hours and solid markers indicate samples cured for 28 days.

Figure 5.21. TEM micrograph with SAED pattern collected for circled Op C-S-H region showing presence of microcrystalline $\mathrm{CH}$.

Figure 5.22. $\mathrm{Mg} / \mathrm{Si}$ against $\mathrm{Al} / \mathrm{Si}$ atomic ratio plots of TEM-EDX analyses of Ip and Op C-S-H in slag containing systems.

Figure 5.23. Single pulse ${ }^{29} \mathrm{Si}$ MAS NMR spectra for samples at $\mathrm{w} / \mathrm{b}$ ratio 0.40 and cured for 72 hours; (a) CEMI, (b) 30\% PFA, (c) 30\% GGBS, (d) 60\% GGBS.

Figure 5.24. Single pulse ${ }^{29} \mathrm{Si}$ MAS NMR spectra for samples at $\mathrm{w} / \mathrm{b}$ ratio 0.40 and cured for 28 days; (a) CEMI, (b) 30\% PFA, (c) 30\% GGBS, (d) $60 \%$ GGBS.

Figure 5.25. Single pulse ${ }^{29} \mathrm{Si}$ MAS NMR spectra for samples at $\mathrm{w} / \mathrm{b}$ ratio 0.57 and cured for 72 hours; (a) CEMI, (b) 30\% PFA, (c) 30\% GGBS, (d) 60\% GGBS.

Figure 5.26. Single pulse ${ }^{29} \mathrm{Si}$ MAS NMR spectra for samples at $\mathrm{w} / \mathrm{b}$ ratio 0.57 and cured for 28 days; (a) CEMI, (b) $30 \%$ PFA, (c) $30 \%$ GGBS, (d) $60 \%$ GGBS.

Figure 6.1. $\mathrm{CH}$ contents determined from TGA data for samples cured for 72 hours and conditioned at $0 \%\left[\mathrm{CO}_{2}\right]$.

Figure 6.2. $\mathrm{CH}$ and $\mathrm{CaCO}_{3}$ contents determined from TGA data for 72 hour cured (a) and 28 day cured (b) systems following exposure to ambient $\left[\mathrm{CO}_{2}\right]$ for up to 7 days. Values are shown in $\mathrm{mol} / 100 \mathrm{~g}$.

Figure 6.3. TGA plot from a synthetic C-S-H (Ca/Si ratio 1.33$)$ sample before and carbonation $\left(24^{\circ} \mathrm{C}\right.$, $72.6 \% \mathrm{RH}$, ambient $\left[\mathrm{CO}_{2}\right]$, exposure time 4 days).

Figure 6.4. TG-FTIR plots for $30 \%$ GGBS $0.57(72 \mathrm{hr})$ sample exposed to ambient $\left[\mathrm{CO}_{2}\right]$ for 4 days. FTIR spectra shown for $\mathrm{H}_{2} \mathrm{O}$ (blue) and $\mathrm{CO}_{2}$ (red). 
Figure 6.5. DTA plots between $0-250^{\circ} \mathrm{C}$ for 72 hour cured CEMI (a), 30\% PFA (b), 30\% GGBS and $60 \%$ GGBS (d) systems exposed to ambient $\left[\mathrm{CO}_{2}\right]$ for up to 7 days.

Figure 6.6. DTA plots between $0-250^{\circ} \mathrm{C}$ for 28 day cured CEMI (a), 30\% PFA (b), 30\% GGBS and $60 \%$ GGBS (d) systems exposed to ambient $\left[\mathrm{CO}_{2}\right]$ for up to 7 days.

Figure 6.7. XRD patterns between $7-19^{\circ} 2 \theta$ and $26-35^{\circ} 2 \theta$ showing the changes in the crystalline phase assemblage with increasing exposure to ambient $\left[\mathrm{CO}_{2}\right]\left(\mathrm{t}_{0}-7\right.$ days) for 72 hour cured samples (a) CEMI, (b) 30\% PFA, (c) 30\% GGBS, (d) 60\% GGBS.

Figure 6.8. XRD patterns between $7-19^{\circ} 2 \theta$ and $26-35^{\circ} 2 \theta$ showing the changes in the crystalline phase assemblage with increasing exposure to ambient $\left[\mathrm{CO}_{2}\right]\left(\mathrm{t}_{0}-7\right.$ days) for 28 day cured samples (a) CEMI, (b) $30 \%$ PFA, (c) $30 \%$ GGBS, (d) $60 \%$ GGBS.

Figure 6.9. ATR-FTIR spectra for $72 \mathrm{hr}$ CEMI (top) and 30\% PFA (bottom) blends showing carbonate $\left(1400-1500 \mathrm{~cm}^{-1}\right)$, AFt $\left(\sim 1120 \mathrm{~cm}^{-1}\right)$, silicate $\left(\sim 950-1000 \mathrm{~cm}^{-1}\right)$ and calcite $\left(\sim 870 \mathrm{~cm}^{-1}\right)$ bands.

Figure 6.10. ATR-FTIR spectra showing normalised silicate $\left(\sim 950 \mathrm{~cm}^{-1}\right)$ and hydroxide $\left(3643 \mathrm{~cm}^{-1}\right)$ (i.e. $\mathrm{CH}$ ) bands for 72 hour cured systems with increasing exposure to ambient $\mathrm{CO}_{2}$ for (a) $\mathrm{CEMI}$, (b) $30 \%$ PFA.

Figure 6.11. ATR-FTIR spectra for 28 day 30\% (top) and 60\% GGBS (bottom) blends showing carbonate $\left(1400-1500 \mathrm{~cm}^{-1}\right)$, AFt $\left(\sim 1120 \mathrm{~cm}^{-1}\right)$, silicate $\left(\sim 950-1000 \mathrm{~cm}^{-1}\right)$ and calcite $\left(\sim 870 \mathrm{~cm}^{-1}\right)$ bands.

Figure 6.12. ATR-FTIR spectra showing normalised silicate bands $\left(\sim 950 \mathrm{~cm}^{-1}\right)$ and hydroxide $\left(3643 \mathrm{~cm}^{-1}\right.$ ) (i.e. $\mathrm{CH}$ ) bands for 28 day cured systems with increasing exposure to ambient $\mathrm{CO}_{2}$ for (a) $30 \%$ GGBS, (b) $60 \%$ GGBS.

Figure 6.13. Single-pulse ${ }^{27} \mathrm{AI}$ NMR spectra for non-carbonated $30 \%$ GGBS 0.57 ( $72 \mathrm{hr}$ ) samples at $\mathrm{t}_{0}$ and 60 days.

Figure 6.13. Single-pulse ${ }^{27} \mathrm{Al}$ NMR spectra $0.57-72 \mathrm{hr}$ cured (a) $\mathrm{t}_{0}$ samples and (b) early age carbonated samples in which $\mathrm{CH}$ had been consumed and uptake of $\mathrm{CO}_{2}$ had significantly increased.

Figure 6.14. Ca-Al-Si ternary diagrams for (a) 30\% GGBS 0.57 (72hr) and (b) 60\% GGBS 0.57 (28d) systems showing EDX data collected for $t_{0}$ and carbonated samples. Values are plotted as atomic percentages normalised to $100 \%$.

Figure 6.15. XRD scan between $10-36^{\circ} 2 \theta$ just below sample surface showing presence of $\mathrm{CH}$ in region used in TEM-EDX analysis - 60\% GGBS 0.57 (28d) - 2 days, ambient $\left[\mathrm{CO}_{2}\right]$.

Figure 6.16. $\mathrm{Mg} / \mathrm{Si}-\mathrm{Al} / \mathrm{Si}$ atomic ratio plots of TEM-EDX analyses of Ip and Op C-S-H in carbonated and non-carbonated (a) $30 \%$ GGBS $(0.57-72$ he cured) and (b) $60 \%$ GGBS $(0.57-28 \mathrm{~d}$ cured) samples.

Figure 6.17. TEM micrographs of $30 \%$ GGBS 0.57 (72hr) sample exposed to ambient $\left[\mathrm{CO}_{2}\right]$ for 4 days.

Figure 6.18. TEM micrographs of $60 \%$ GGBS 0.57 (28d) sample exposed to ambient $\left[\mathrm{CO}_{2}\right]$ for 2 days. 
Figure 6.19. Single pulse ${ }^{29}$ Si MAS NMR spectra for $30 \%$ GGBS $0.57-72$ hour cured samples (a) $t_{0}$ and (b) exposed to ambient $\left[\mathrm{CO}_{2}\right]$ for 4 days.

Figure 6.20. $\mathrm{CH}$ and $\mathrm{CaCO}_{3}$ contents determined from TGA data for 72 hour cured (a) and 28 day cured (b) systems following exposure to ambient $\left[\mathrm{CO}_{2}\right]$ for up to 7 days. Values are shown in $\mathrm{mol} / 100 \mathrm{~g}$.

Figure 6.21. TGA plots for 60\% GGBS $0.40-72$ hour cured sample at $t_{0}$ and following 2 and 4 days exposure to ambient $\left[\mathrm{CO}_{2}\right]$.

Figure 6.22. XRD patterns between $7-19^{\circ} 2 \theta$ and $26-35^{\circ} 2 \theta$ showing the crystalline phase assemblage of 72 hour cured systems at (a) $t_{0}$ and (b) following 7 days exposure to ambient $\mathrm{CO}_{2}$.

Figure 6.23. XRD patterns between $7-19^{\circ} 2 \theta$ and $26-35^{\circ} 2 \theta$ showing the crystalline phase assemblage of 28 days cured systems at (a) $t_{0}$ and (b) following 7 days exposure to ambient $\mathrm{CO}_{2}$.

Figure 6.24. ATR-FTIR spectra for $60 \%$ GGBS $(72 \mathrm{hr})$ system showing $\mathrm{CaCO}_{3}$ contents (1400$\left.1500 \mathrm{~cm}^{-1}\right)$, AFt band $\left(\sim 1120 \mathrm{~cm}^{-1}\right)$, silicate band $\left(\sim 950-1000 \mathrm{~cm}^{-1}\right)$ and calcite band $\left(\sim 870 \mathrm{~cm}^{-1}\right)$.

Figure 6.25. ATR-FTIR spectra showing normalised silicate $\left(\sim 950 \mathrm{~cm}^{-1}\right)$ and hydroxide $\left(3643 \mathrm{~cm}^{-1}\right)$ bands for 72 hour cured $60 \%$ GGBS system, upon increasing exposure to ambient $\mathrm{CO}_{2}$.

Figure 7.1. $\mathrm{CH}$ and $\mathrm{CaCO}_{3}$ contents determined from TGA data for 72 hour cured (a) and 28 day cured (b) systems following exposure to ambient $\left[\mathrm{CO}_{2}\right]$ between 7 and 60 days. Values are shown in $\mathrm{mol} / 100 \mathrm{~g}$.

Figure 7.2. TG plots for the 28 day cured systems following exposure to ambient $\left[\mathrm{CO}_{2}\right]$ for 60 days

Figure 7.3. DTA plots between $0-250^{\circ} \mathrm{C}$ for 72 hour cured CEMI (a), 30\% PFA (b), 30\% GGBS and $60 \%$ GGBS (d) systems exposed to ambient $\left[\mathrm{CO}_{2}\right]$ between 7 and 60 days.

Figure 7.4. DTA plots between $0-250^{\circ} \mathrm{C}$ for 28 day cured CEMI (a), 30\% PFA (b), 30\% GGBS and $60 \%$ GGBS (d) systems exposed to ambient $\left[\mathrm{CO}_{2}\right]$ between 7 and 60 days.

Figure 7.5. XRD patterns between $7-22^{\circ} 2 \theta$ and $26-35^{\circ} 2 \theta$ showing the changes in the crystalline phase assemblage with increasing exposure to ambient $\left[\mathrm{CO}_{2}\right]$ ( 7 - 60 days) for 72 hour cured samples (a) CEMI, (b) 30\% PFA, (c) 30\% GGBS, (d) 60\% GGBS.

Figure 7.6. XRD patterns between $7-22^{\circ} 2 \theta$ and $26-35^{\circ} 2 \theta$ showing the changes in the crystalline phase assemblage with increasing exposure to ambient $\left[\mathrm{CO}_{2}\right]$ (7 - 60 days) for 28 day cured samples (a) CEMI, (b) 30\% PFA, (c) 30\% GGBS, (d) 60\% GGBS.

Figure 7.7. ATR-FTIR spectra for $72 \mathrm{hr}$ CEMI (top) and 30\% PFA (bottom) blends showing carbonate $\left(1400-1500 \mathrm{~cm}^{-1}\right)$, AFt $\left(\sim 1120 \mathrm{~cm}^{-1}\right)$, silicate $\left(\sim 950-1000 \mathrm{~cm}^{-1}\right)$ and calcite $\left(\sim 870 \mathrm{~cm}^{-1}\right)$ bands.

Figure 7.8. ATR-FTIR spectra for 28d 30\% PFA (top) and 30\% GGBS (bottom) blends showing carbonate $\left(1400-1500 \mathrm{~cm}^{-1}\right)$, AFt $\left(\sim 1120 \mathrm{~cm}^{-1}\right)$, silicate $\left(\sim 950-1000 \mathrm{~cm}^{-1}\right)$ and calcite $\left(\sim 870 \mathrm{~cm}^{-1}\right)$ bands.

Figure 7.9. ATR-FTIR spectra showing normalised silicate $\left(\sim 950 \mathrm{~cm}^{-1}\right)$ and hydroxide $\left(3643 \mathrm{~cm}^{-1}\right)$ (i.e. $\mathrm{CH}$ ) bands for 28 day cured systems with increasing exposure to ambient $\mathrm{CO}_{2}$ for (a) $30 \%$ PFA and (b) $30 \%$ GGBS. 
Figure 7.10. Single pulse ${ }^{27} \mathrm{Al}$ NMR spectra $0.57-72 \mathrm{hr}$ cured (a) to samples and (b) following exposure to ambient $\left[\mathrm{CO}_{2}\right]$ for 60 days.

Figure 7.11. Single pulse ${ }^{27}$ AI NMR spectra $0.57-28 d$ cured (a) $t_{0}$ samples and (b) following exposure to ambient $\left[\mathrm{CO}_{2}\right]$ for 60 days.

Figure 7.12. $\mathrm{Mg} / \mathrm{Si}-\mathrm{Al} / \mathrm{Si}$ atomic plot ratios of TEM-EDX analyses of Ip product in $60 \% \mathrm{GGBS}(0.57$ $28 \mathrm{~d}$ cured) sample exposed to ambient $\left[\mathrm{CO}_{2}\right]$ for 60 days.

Figure 7.13. TEM micrographs of CEMI $0.57(72 \mathrm{hr})$ sample exposed to ambient [ $\left[\mathrm{CO}_{2}\right]$ for 60 days.

Figure 7.14. TEM micrographs of 30\% PFA 0.57 (72hr) sample exposed to ambient $\left[\mathrm{CO}_{2}\right]$ for 60 days. Figure 7.15. TEM micrographs of $30 \%$ GGBS 0.57 ( $72 \mathrm{hr}$ ) sample exposed to ambient $\left[\mathrm{CO}_{2}\right]$ for 60 days.

Figure 7.16. TEM micrographs of $30 \%$ GGBS 0.57 (28d) sample exposed to ambient $\left[\mathrm{CO}_{2}\right]$ for 60 days.

Figure 7.17. TEM micrographs of $60 \%$ GGBS 0.57 (28d) sample exposed to ambient $\left[\mathrm{CO}_{2}\right]$ for 60 days.

Figure 7.18. Single pulse ${ }^{29}$ Si NMR spectra for $72 \mathrm{hr}$ (a) CEMI, (b) $30 \%$ PFA, (c) $30 \%$ GGBS, (d) $60 \%$ GGBS samples exposed to ambient $\left[\mathrm{CO}_{2}\right]$ for 60 days.

Figure 7.19. Single pulse ${ }^{29} \mathrm{Si} N \mathrm{NMR}$ spectra for 28 day cured samples exposed to ambient $\left[\mathrm{CO}_{2}\right]$ for 60 days.

Figure 7.20. Single pulse ${ }^{29}$ Si NMR spectra for 28 day (a) 30\% PFA and (b) $30 \%$ GGBS samples exposed to ambient $\left[\mathrm{CO}_{2}\right]$ for 60 days.

Figure 7.21. $\mathrm{CH}$ and $\mathrm{CaCO}_{3}$ contents determined from TGA data for 72 hour cured (a) and 28 day cured (b) systems following exposure to ambient $\left[\mathrm{CO}_{2}\right]$ between 7 and 60 days.

Figure 7.22. XRD patterns between $7-22^{\circ} 2 \theta$ and $26-35^{\circ} 2 \theta$ showing the crystalline phase assemblage of 72 hour cured systems at (a) $t_{0}$ and (b) following 60 days exposure to ambient $\mathrm{CO}_{2}$.

Figure 7.23. XRD patterns between $7-22^{\circ} 2 \theta$ and $26-35^{\circ} 2 \theta$ showing the crystalline phase assemblage of 28 day cured systems at (a) $t_{0}$ and (b) following 60 days exposure to ambient $\mathrm{CO}_{2}$.

Figure 7.24. Single pulse ${ }^{27} \mathrm{Al}$ NMR spectra $0.40-72 \mathrm{hr}$ cured (a) to samples and (b) following exposure to ambient $\left[\mathrm{CO}_{2}\right]$ for 60 days.

Figure 8.1. Carbonation depth of mortar samples exposed to ambient $\mathrm{CO}_{2}$ concentrations for 18 months. Depth of carbonation was measured using phenolphthalein indicator.

Figure 8.2. Mortar samples with w/b 0.57 cured for 72 hours sprayed with phenolphthalein solution following exposure to ambient conditions for 18 months $\left(\mathrm{RH} 50 \%+/-10 \%,\left[\mathrm{CO}_{2}\right] \approx\right.$ 450ppm).

Figure 8.3. Mean compressive strength vs carbonation depth (measured by phenolphthalein indicator) of mortar samples exposed to ambient $\mathrm{CO}_{2}$ concentrations for 18 months ( $\mathrm{t}_{0} 72 \mathrm{hrs}$ open markers, $\mathrm{t}_{0} 28 \mathrm{~d}$ - solid markers). 
Figure 8.4. Schematic representation of the parameters affecting the carbonation coefficient $(\mathrm{k}) . \mathrm{k}$ values calculated from carbonation depth data (Appendix $A$ ) for systems with $\mathrm{w} / \mathrm{b} 0.57$ have been indicated on the diagram.

Figure A.1. $\mathrm{RH}$ and $\mathrm{CO}_{2}$ measurements taken over a 5 week period from sample conditioning chambers for (a) $0 \%\left[\mathrm{CO}_{2}\right]$ conditions $\left(\left[\mathrm{CO}_{2}\right]<10 \mathrm{ppm}, \mathrm{RH} 72.6 \%\right)$ and for (b) ambient [CO2] conditions ([CO $\left.\left.\mathrm{CO}_{2}\right] 300-450 \mathrm{ppm}, \mathrm{RH} 72.6 \%\right)$. Temperature remained at approx. $24^{\circ} \mathrm{C}+/-2^{\circ}$.

Figure B.1. Mean compressive strength of mortar prisms following exposure to ambient $\left[\mathrm{CO}_{2}\right]$.

B.2. Carbonation depths measured on mortar samples exposed to ambient $\mathrm{CO}_{2}$ concentrations for up to 18 months ([CO $\left.\mathrm{CO}_{2}\right] \sim 450 \mathrm{ppm}, \mathrm{RH} \sim 50 \%$ ) using phenolphthalein and thymolphthalein indicator solutions. The carbonation coefficients $(\mathrm{k})$ determined from the linear fit of the data (shown as dashed line) are given in Table A.1. 


\section{List of tables}

Table 2.1. BS EN 13670:2009 curing class guidelines.

Table 2.2. Japanese recommendations for moist curing of GGBS containing concrete.

Table 3.1. Elemental composition of materials determined by XRF analysis, density measurements and GGBS basicity ratios. Note, the GGBS showed a gain in mass upon heating due to oxidation of the sulphides present within the as-received sample.

Table 3.2. Phase composition of CEM 52.5R.

Table 3.3. Volume distribution of CEM 52.5R, PFA and GGBS.

Table 3.4. Sample matrix for detailed characterisation.

Table 3.5. Sample matrix for general characterisation.

Table 3.6. Table of structures and phase dependent parameters used in Rietveld refinement.

Table 4.1. Age (hrs) by which samples had developed approximately 11MPa of compressive.

Table 4.2. Sample matrix and experimental parameters used for scoping study.

Table 5.1 Comparison of phase composition of CEM 52.5R determined from the Bogue formula.

Table 5.2. $\mathrm{CH}$ (error +/-2.5\%) content, AFt content and degree of hydration of cement clinker (error $+/-5 \%$ ), slag and weighted degree of reaction following 72 hours and 28 days.

Table 5.3. Mean $\mathrm{Ca} / \mathrm{Si}$ and $\mathrm{Al} / \mathrm{Si}$ ratios for selected samples analysed by TEM-EDX.

Table 5.4. Results from deconvolution of single pulse ${ }^{29} \mathrm{Si}$ NMR spectra for each of the systems at $t_{0}$.

Table 6.1. Consumption of $\mathrm{CH}$ versus production of $\mathrm{CaCO}_{3}$ calculated from TGA data between $\mathrm{t}_{0}-7$ days for 72 hour cured systems. Values are shown in $\mathrm{mol} / 100 \mathrm{~g}$.

Table 6.2. Consumption of $\mathrm{CH}$ versus production of $\mathrm{CaCO}_{3}$ calculated from TGA data following 7 days' exposure to ambient $\left[\mathrm{CO}_{2}\right]$ for 28 day cured systems. Values are shown in mol/100g.

Table 6.3. Temperature at which mass loss due to $\mathrm{CaCO}_{3}$ decomposition begins.

Table 6.4. Mean $\mathrm{Ca} / \mathrm{Si}$ and $\mathrm{Al} / \mathrm{Si}$ ratios for selected samples analysed by TEM-EDX.

Table 6.5. Results from deconvolution of single pulse ${ }^{29} \mathrm{Si}$ NMR spectra for $30 \%$ PFA and $30 \%$ GGBS systems $\left(0.57-72 \mathrm{hr}\right.$ cured) following 2 and 4 days exposure to ambient $\left[\mathrm{CO}_{2}\right]$.

Table 6.6. Consumption of $\mathrm{CH}$ versus production of $\mathrm{CaCO}_{3}$ calculated from TGA data following 7 days exposure to ambient $\left[\mathrm{CO}_{2}\right]$ for $72 \mathrm{hr}$ and 28 day cured systems.

Table 7.1. The $\mathrm{CaO}$ available in hydrate phases for reaction with $\mathrm{CO}_{2} \cdot \mathrm{CaO}_{\text {reactive }}$ value is given as a fraction relating to $/ 100 \mathrm{~g}$ anhydrous binder.

Table 7.2. Consumption of $\mathrm{CH}$ versus production of $\mathrm{CaCO}_{3}$ calculated from TGA data between 7 and 60 days exposure to ambient $\left[\mathrm{CO}_{2}\right]$ for 28 day cured systems. Values are shown in mol/100g.

Table 7.3. Mean $\mathrm{Ca} / \mathrm{Si}$ and $\mathrm{Al} / \mathrm{Si}$ ratios for Ip regions of $60 \% \mathrm{GGBS} 0.57$ (28d) sample exposed to ambient $\left[\mathrm{CO}_{2}\right]$ for $0\left(\mathrm{t}_{0}\right), 2$ and 60 days. 
Table 7.4. Results from deconvolution of single pulse ${ }^{29} \mathrm{Si}$ NMR spectra at ages $t_{0}$ and following 60 days exposure to ambient $\left[\mathrm{CO}_{2}\right]$ (0.57).

Table B.1. Carbonation coefficients (k) for mortar samples 


\begin{tabular}{cc}
\multicolumn{2}{c}{ Cement $\mathrm{No}$} \\
$\mathrm{C}$ & $\mathrm{CaO}$ \\
$\mathrm{S}$ & $\mathrm{SiO}_{2}$ \\
$\mathrm{~A}$ & $\mathrm{Al}_{2} \mathrm{O}_{3}$ \\
$\mathrm{M}$ & $\mathrm{MgO}$ \\
$\mathrm{F}$ & $\mathrm{Fe}_{2} \mathrm{O}_{3}$ \\
$\mathrm{~N}$ & $\mathrm{Na}_{2} \mathrm{O}$ \\
$\mathrm{K}$ & $\mathrm{K}_{2} \mathrm{O}$ \\
$\mathrm{H}$ & $\mathrm{H}_{2} \mathrm{O}$
\end{tabular}

Cement clinker and hydrate phases

Alite / $\mathrm{C}_{3} \mathrm{~S}$

$3 \mathrm{CaO} . \mathrm{SiO}_{2}$

Belite / $\mathrm{C}_{2} \mathrm{~S}$

$2 \mathrm{CaO} . \mathrm{SiO}_{2}$

Tricalcium Aluminate / $\mathrm{C}_{3} \mathrm{~A}$

$3 \mathrm{CaO} . \mathrm{Al}_{2} \mathrm{O} 3$

Tetracalcium aluminoferrite $/ \mathrm{C}_{4} \mathrm{AF}$

$4 \mathrm{CaO} . \mathrm{Al}_{2} \mathrm{O}_{3} \cdot \mathrm{Fe}_{2} \mathrm{O}_{3}$

Gypsum

$\mathrm{CaSO}_{4} \cdot 2 \mathrm{H}_{2} \mathrm{O}$

Portlandite

$\mathrm{Ca}(\mathrm{OH})_{2} / \mathrm{CH}$

Calcium Silicate Hydrate

C-S-H

Ettringite / AFt

$3 \mathrm{CaO} . \mathrm{Al}_{2} \mathrm{O}_{3} .3 \mathrm{CaSO}_{4} .32 \mathrm{H}_{2} \mathrm{O}$

Monosulfoaluminate / Ms

$3 \mathrm{CaO} \cdot \mathrm{Al}_{2} \mathrm{O}_{3} \cdot \mathrm{CaSO}_{4} \cdot 12 \mathrm{H}_{2} \mathrm{O}$

Hemicarboaluminate / Hc

$3 \mathrm{CaO} . \mathrm{Al}_{2} \mathrm{O}_{3} \cdot 0.5 \mathrm{Ca}(\mathrm{OH})_{2} \cdot 0.5 \mathrm{CaCO}_{3} \cdot 11.5 \mathrm{H}_{2} \mathrm{O}$

Monocarboaluminate / Mc

$3 \mathrm{CaO} . \mathrm{Al}_{2} \mathrm{O}_{3} \cdot \mathrm{CaCO}_{3} \cdot 11 \mathrm{H}_{2} \mathrm{O}$

Hydrotalcite / Ht

$\mathrm{Mg}_{6} \mathrm{Al}_{2}(\mathrm{OH}) 16 . \mathrm{CO}_{3} \cdot 4 \mathrm{H}_{2} \mathrm{O}$

\section{List of abbreviations and symbols}

PC Portland cement

GGBS Ground granulated blast-furnace slag

PFA Pulverised fuel ash 


$\begin{array}{ll}\text { SCM } & \text { Supplementary cementitious material } \\ \text { DoH } & \text { degree of hydration } \\ \text { w/c } & \text { water/cement ratio } \\ \text { w/b } & \text { water/binder ratio } \\ \text { Ip } & \text { Inner product C-S-H } \\ \text { Op } & \text { Outer product C-S-H }\end{array}$

\section{Techniques}

ICC Isothermal conduction calorimetry

STA Simultaneous thermal analysis

DTA Differential thermal analysis

TGA Thermogravimetric analysis

MAS NNMR Magic angle spinning nuclear magnetic resonance

XRD X-ray diffraction

TEM Transmission electron microscopy

EDX Energy dispersive $x$-ray

SAED Selected area electron diffraction

SEM Scanning electron microscopy

BSE Back scattered electron

SEM-IA Scanning electron microscopy - Image analysis

UCS Unconfined compressive strengt 


\section{Chapter 1}

\section{Introduction}

The increasing and widespread use of supplementary cementitious materials (SCMs) in the cement industry has become common practice. The use of such composite cements is valuable in terms of both environmental and engineering aspects, acknowledging the ever-rising pressures to further reduce carbon emissions associated with cement manufacture as well as an improving material durability via enhancement of the cement microstructure. However, composite cements exhibit reduced rates of hydration, making their improved technological properties dependant on extended periods of moist curing. The need for appropriate curing procedures is recognised in concrete standards where modified curing periods and regimes are recommended in relation to the development of particular properties within the surface region (BS EN 13670:2009). It is also demonstrated extensively throughout the literature [1-4], which highlights the amplified adverse effects which inadequate curing methods can have on composite cement materials compared to traditional Portland cement systems. Failure to adhere to these prolonged curing guidelines by the early removal of formwork in construction practice may cause fundamental problems in regard to material performance, exposing a microstructure in which hydration is very much incomplete. Consequently, additional information regarding material performance is needed, especially at these very early ages.

Pulverised fuel ash (PFA) and ground granulated blast furnace slag (GGBS) are industrial by-products commonly used as SCMs. Though the reduced rate of hydration is well established, both the Portland cement (PC) and the SCM will hydrate simultaneously, yet there still remains a lack of knowledge regarding the early age kinetics of the reactions taking place. This becomes of great importance when considering the early removal formwork where the reliance on models established for Portland cement systems may no longer be suitable. Under such conditions, hydration will be very much incomplete, with previous research indicating minor or no reaction of PFA over the first 7 days [5, 6] and only slightly faster reaction rates for GGBS [7].In both cases the result will be an underdeveloped and exposed microstructure, susceptible to ingress and attack from aggressive species. 
Furthermore, the reduced $\mathrm{Ca}(\mathrm{OH})_{2}$, content characteristic of composite cement materials presents additional limitations when considering resistance to carbonation induced corrosion. The decrease in portlandite content, the main alkalinity buffer within hardened cement paste, results in a reduced $\mathrm{pH}$ level of the cement pore solution. This allows carbonation to occur at elevated rates and to greater extents; behaviour likely to become more pronounced with increasing levels of replacement. Moreover, the expected retardation of the rate of $\mathrm{CO}_{2}$ ingress typically observed in PC systems is a result of densification of the microstructure. This, however, is not concurrent with the behaviour exhibited in composite cements with high replacement levels which are adversely affected by a coarser microstructure and a greater porosity.

This project has examined the early stage carbonation behaviour of immature low-clinker binders, focusing on the effects that insufficient curing and phase carbonation have on the phase assemblage composition and the development of the microstructure. The work will attempt to examine differences between these systems and conventional studies on mature samples.

\subsection{Research objectives}

The main objective of this project was to develop an understanding of the changes and development of the early stage morphology and phase assemblage of composite systems as a result of carbonation. The project aimed to establish how the systems evolved over time during these very early ages as a result of the ongoing interplay between slower composite cement hydration, sample desiccation and phase carbonation kinetics via the objectives listed below.

1. Determination of the microstructure and phase assemblage of early age hydration products in composite cement pastes and the evolution of the microstructure and phase assemblage as a function of time.

2. Characterisation of carbonated phases and rate of carbonation, studying changes in the morphology and phase assemblage of composite systems as a result of carbonation and modifications in carbonation behaviour with replacement material and level as well as with degree of hydration (curing length) and water content ( $\mathrm{w} / \mathrm{b}$ ratio).

3. Relate the effects of carbonation at a microstructural level to the effects on engineering properties of early age composite cement mortars - compressive strength and depth of carbonation as measured by Phenolphthalein and Thymolphthalein indicators. 


\section{Chapter 2}

\section{Literature Review}

\subsection{Portland cement}

\subsubsection{Hydration kinetics}

Portland cement is composed of four major phases: tricalcium silicate $\left(C_{3} S\right.$, alite), dicalcium silicate $\left(C_{2} S\right.$, belite $)$, tricalcium aluminate $\left(C_{3} A\right.$, aluminate $)$ and tetracalcium aluminoferrite $\left(C_{4} A F\right.$, ferrite). Each of these phases are described as being impure variations of their chemical structures due to substitution of foreign ionic species such as $\mathrm{Mg}^{2+}, \mathrm{Al}^{3+}$ and $\mathrm{Fe}^{3+}$, alite and belite being the impure forms of tri- and dicalcium silicate respectively. Calcium sulphate and alkali oxides are minor phases and make up the remaining composition [8].

As the hydration of Portland cement is an exothermic reaction, the kinetics of hydration are typically discussed in relation to the rate of heat evolution obtained from calorimetric measurements. Figure 2.1 displays a characteristic heat evolution curve for hydrating Portland cement taken from [9].

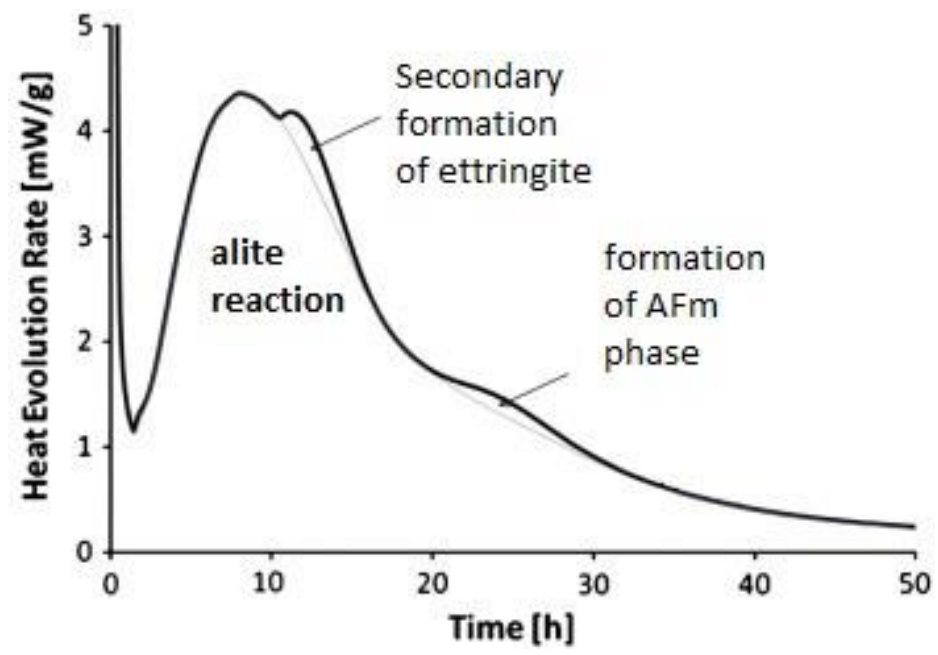

Figure 2.1. Typical heat evolution curve for hydrating Portland cement (taken from [9]) 
Following mixing with water a very high initial heat output is observed, typically lasting a few minutes. This high heat rate results from the rapid dissolution of $\mathrm{C}_{3} \mathrm{~S}, \mathrm{C}_{3} \mathrm{~A}$ and $\mathrm{CaSO}_{4}$ phases, however it quickly decreases to a period of low heat, or low rate of reaction, for several hours ( $3 \mathrm{hrs})$. It is this induction, or dormant, period when the cement maintains sufficient plasticity that allows for proper placing and compaction to be performed.

The period of low reaction had widely been accepted to occur following the formation of a hydration product on particle surfaces which inhibited further reaction of the clinker grains [8]. However, recent publications have shown strong evidence for a geochemical dissolution reaction that relates dissolution rate to the degree of undersaturation of the solution $[10,11]$. Upon initial mixing with water, the degree of undersaturation of the solution with respect to $\mathrm{Ca}$ is high and the dissolution rate is rapid. A critical degree of undersaturation is then reached and the rate slows dramatically resulting in minimal subsequent reaction.

The end of the dormant period is marked by the beginning of the main hydration peak, when the hydration reaction begins to accelerate and the cement begins to stiffen and harden. The main hydration peak is dominated by the formation of the hydrate phases $\mathrm{C}-\mathrm{S}-\mathrm{H}$ and $\mathrm{Ca}(\mathrm{OH})_{2}$.

Both calcium silicate phases react with water to form the poorly crystalline calcium silicate hydrate phase of variable composition (denoted by the use of dashes - ' $\mathrm{C}-\mathrm{S}-\mathrm{H}^{\prime}$ ) and portlandite $\left(\mathrm{Ca}(\mathrm{OH})_{2}\right)$. Alite is the principal phase present in cement clinker, making up between $50-80 \%$ of the anhydrous material and its rapid reaction dominates the development of the early age material properties, contributing the majority of the heat evolved for the main peak in Figure 2.1. Although belite contributes to strength, its reaction is much slower and has been shown to have little measurable reaction (<20\%) up to hydration periods of 7-10 days [12]. Belite is responsible for the period of slow continued hydration observed after the reaction of alite, which has typically extensively reacted ( $80 \%$ ) within the first 28 days.

The reaction kinetics of $\mathrm{C}_{3} \mathrm{~A}$ with $\mathrm{CaSO}_{4}$ produce similar trends to that of alite. $\mathrm{CaSO}_{4}$ prevents the very rapid reaction of aluminate and water occurring, avoiding undesirable 'flash set' taking place, and as with alite initiates a period of slow reaction following initial and brief dissolution and heat release. $\mathrm{C}_{3} \mathrm{~A}$ and $\mathrm{CaSO}_{4}$ initially form ettringite $\left(\mathrm{AFt}\left(\mathrm{C}_{3} \mathrm{~A} \cdot 3 \mathrm{CaSO}_{4} \cdot 32 \mathrm{H}_{2} \mathrm{O}\right)\right)$, a calcium sulfoaluminate hydrate phase. The early formation of AFt on particle surfaces had previously been accepted to be 
the mechanism causing the reduced rate of reaction [8], however Minard [13] recently proposed that this behaviour is caused by adsorption of sulphate on reactive dissolution sites. Once sulphate has been depleted, secondary ettringite formation is observed to occur and appears in the calorimetry trace as a small peak following the maxima of the main hydration peak in properly sulphated cement systems. At later ages further sulphate depletion results in conversion of AFt to monosulfate $\left(\mathrm{AFm}\left(\mathrm{C}_{3} \mathrm{~A} \cdot \mathrm{CaSO}_{4} \cdot 12 \mathrm{H}_{2} \mathrm{O}\right)\right)$ and is sometimes detected in calorimetry plots as a low broad hump from $\sim 24$ hours onwards.

The reaction from 24 hours onwards is described as long term hydration and although the mechanisms governing the long term reactions are still not fully understood, the kinetics appear to be controlled by the availability of space for the cement hydrates $[14,15]$.

\subsubsection{The hydration products and their microstructure}

$\mathrm{C}-\mathrm{S}-\mathrm{H}$ is the main binding phase in Portland cement systems, however its poorly crystalline nature and considerable compositional variation makes determination of its structure somewhat difficult. Many researchers have proposed structural models based on the naturally occurring crystalline calcium silicate hydrate minerals jennite and tobermorite, the chemical structures of which are shown in Figure 2.2 (taken from [16]). Both jennite and tobermorite have $\mathrm{Ca} / \mathrm{Si}$ ratios much lower, (1.5 and 0.83 respectively) than the expected value of neat Portland cement or $C_{3} S$ pastes (1.7 - 1.8 $[17,18])$ meaning modified structural models that increase the $\mathrm{Ca} / \mathrm{Si}$ ratio to values observed experimentally are used for C-S-H produced during cement hydration. The various nanostructural models are summarised by Richardson in [19] but can be fundamentally split into two categories: tobermorite/jennite $(\mathrm{T} / \mathrm{J})$ structure and tobermorite/Ca(OH) $(\mathrm{T} / \mathrm{CH})$ structure $[20]$.

It is generally agreed that C-S-H is a layered structure in which silicate chains are attached to a central $\mathrm{Ca}-\mathrm{O}$ sheet. The silicate tetrahedra form a kinked repetition pattern every three tetrahedra known as 'dreierkette' form.

In the $\mathrm{T} / \mathrm{J}$ structural model the tobermorite-like structure is intermixed with components of the jennite-like structure while the $\mathrm{T} / \mathrm{CH}$ model incorporates $\mathrm{CH}$ in a tobermorite-like structure. Both models are discussed extensively in [20]. 


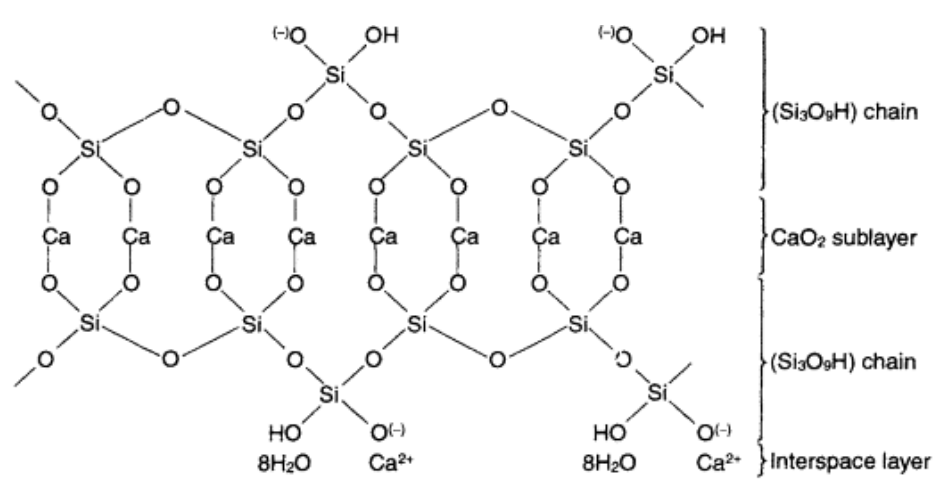

(a)

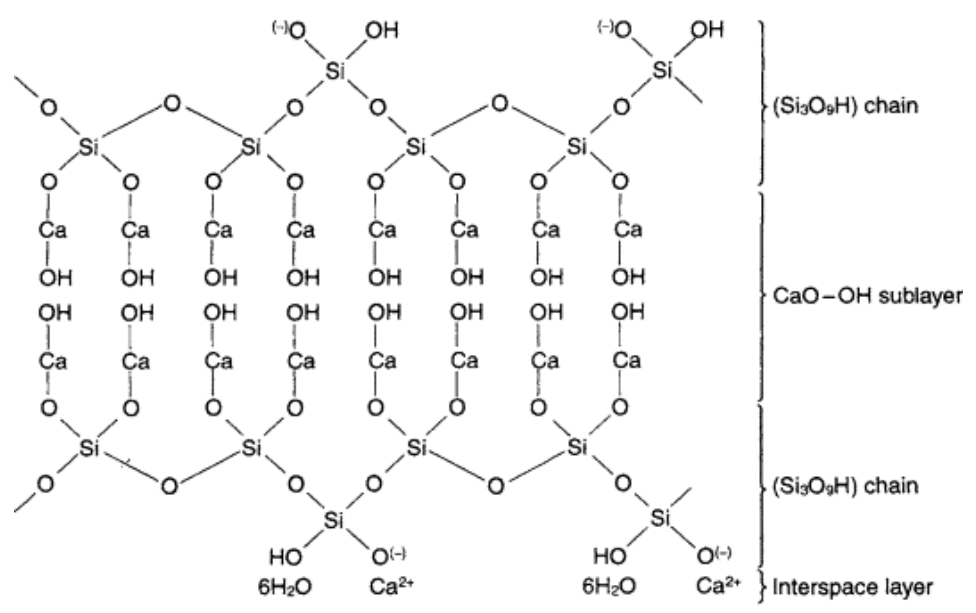

(b)

Figure 2.2. Chemical structure of (a) $1.4 \mathrm{~nm}$ Tobermorite and (b) Jennite taken from [16]

C-S-H is described as forming in two distinct regions denoted as inner product (Ip) C-S-H and outer product (Op) $\mathrm{C}-\mathrm{S}-\mathrm{H}$, the first forming within the original $\mathrm{C}_{3} \mathrm{~S}$ or $\mathrm{C}_{2} \mathrm{~S}$ grain boundary and the latter forming in originally water filled regions [21]. Although Richardson and Groves [17] observed a bimodal distribution of the $\mathrm{Ca} / \mathrm{Si}$ ratio of the $\mathrm{C}-\mathrm{S}-\mathrm{H}$ in young pastes, this behaviour disappeared as compositional equilibrium was reached, becoming unimodal with time. Little variation of the $\mathrm{Ca} / \mathrm{Si}$ ratio in Portland cement pastes is expected with age [22].

Ip C-S-H displays a fine-scale homogenous microstructure in which the C-S-H contains only gel porosity (pores $<10 \mathrm{~nm}$ in size), whereas the morphology of the Op C-S-H is dependent on the available space. Where sufficient space is available, a coarse fibrillar morphology is exhibited 
forming larger pores and, conversely, smaller areas are observed to form a fine fibrillar more space efficient C-S-H. Figure 2.3 illustrates the morphology of Ip and Op regions.

The Op C-S-H fibrils interconnect forming a three-dimensional pore network called the capillary porosity and it is this system of pores that is predominantly responsible for the strength, transport properties and durability of cementitious systems [22].

Capillary porosity ranges from $10 \mathrm{~nm}-10 \mu \mathrm{m}$ and can be approximately divided into fine and coarse, where fine porosity is $\sim 10-50 \mathrm{~nm}$. Various factors such as $\mathrm{w} / \mathrm{c}$ ratio and curing duration affect the capillary porosity, subsequently affecting the strength, porosity and permeability of the material. As the permeability and total porosity increase, for example with decreasing length of curing and increasing w/c ratio, both strength and durability decrease, the higher connectivity and porous volume allowing for easier and faster ingress of potentially aggressive and deleterious species [23, 24].

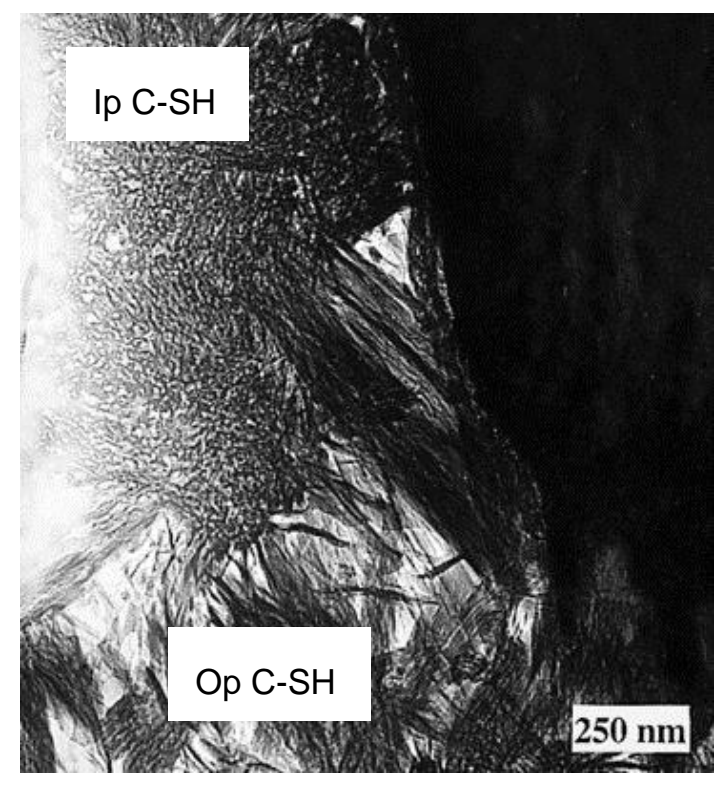

Figure 2.3. TEM micrograph showing regions of Ip \& $\mathrm{Op} C-\mathrm{S}-\mathrm{H}$ in mature $\mathrm{C}_{3} \mathrm{~S}$ pastes (adapted from [22]) 
It is expected that the microstructure will be reasonably well developed following hydration for 24 hours, already exhibiting both fine-scale Ip and coarse and fine fibrillar Op C-S-H. The Op regions will display a relatively open morphology in which crystals of $\mathrm{CH}$ and AFt will be present. As hydration continues the microstructure will become better developed and capillary porosity will continually decrease. $\mathrm{CH}$ bonds to $\mathrm{Op}$ fibrils and exists as large crystals (micrometres in length). The amount of AFt and AFm phases formed is relative to the degree of hydration and are observed in Op regions only as thin hexagonal prism shaped needles $(10 \mu \mathrm{m}$ in length) and large irregular plates respectively $[17,22]$.

\subsection{Pulverised fuel ash (PFA) and ground granulated blast furnace slag (GGBS) composite cements}

The use supplementary cementitious materials ( $\mathrm{SCMs}$ ) to partially replace Portland cement has become common practice in the cement industry. These composite (or blended) cements not only reduce the associated $\mathrm{CO}_{2}$ emissions of cement systems but also have the potential to produce materials with superior engineering properties such as increased strength development and improved levels of durability. However, SCMs hydrate more slowly than Portland cement and their rate of reaction is heavily dependent on the chemical composition, the quantities of reactive phases present and the material fineness. Furthermore, the simultaneous set of hydration reactions poses additional complications when studying the hydration of composite systems where the reactions of the separate materials are not easily isolated $[25,26]$.

\subsubsection{PFA cement hydration}

PFA is heterogeneous material, a by-product from pulverised coal combustion, made up of glassy spherical particles mainly consisting of $\mathrm{SiO}_{2}, \mathrm{Al}_{2} \mathrm{O}_{3}$ and $\mathrm{Fe}_{2} \mathrm{O}_{3}$. Figure 2.4 illustrates its comparative composition to that of Portland cement. Although fly ash has a highly variable composition resulting from differences in coal composition and combustion and collection procedures, ASTM C618 identifies two main categories: class-C PFA (high calcium content) and class-F PFA (low calcium content). Low calcium (class-F) fly ashes are the most abundant, typically containing between 15 $35 \% \mathrm{Al}_{2} \mathrm{O}_{3}$, and it is this type of PFA that will be discussed here [25]. 


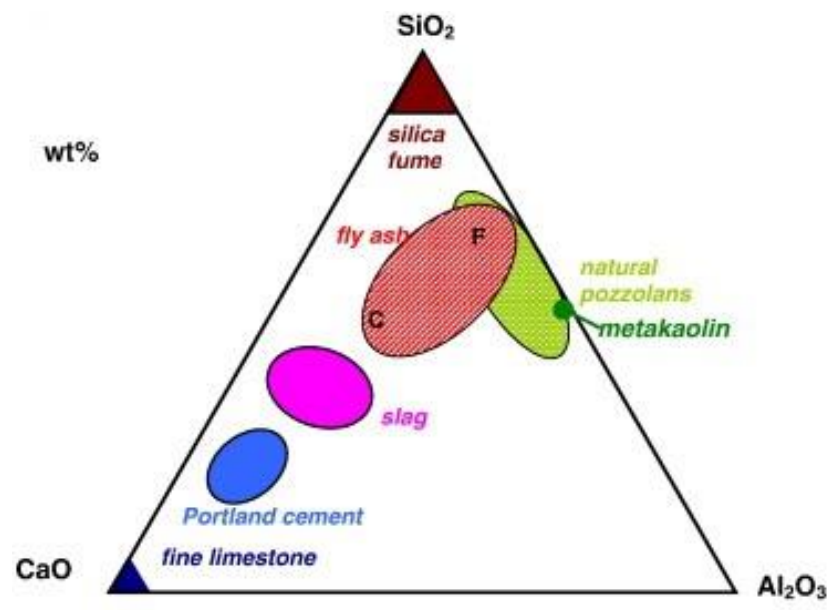

Figure 2.4. $\mathrm{CaO}-\mathrm{Al}_{2} \mathrm{O}_{3}-\mathrm{SiO}_{2}$ ternary diagram of Portland cement and different supplementary cementitious materials (taken from [25])

The reaction of PFA in cement systems is a pozzolanic reaction, $\mathrm{SiO}_{2}$ and $\mathrm{Al}_{2} \mathrm{O}_{3}$ react with water and $\mathrm{Ca}(\mathrm{OH})_{2}$ (produced from hydration of $\mathrm{C}_{3} \mathrm{~S}$ and $\mathrm{C}_{2} \mathrm{~S}$ ) to form additional C-S-H with a reduced $\mathrm{Ca} / \mathrm{Si}$ ratio and some incorporation of Al. The onset of the pozzolanic reaction is dependent on a highly alkaline environment and for water activated cement pastes at ambient temperatures, this reaction can be very slow. Reports in the literature regarding the beginning of the reaction vary from 3 days [27], to 7 days [6], to several weeks $[5,28]$ from the start of hydration and is usually measured by consumption of the initial $\mathrm{CH}$ content [25].

At early ages of hydration when the fly ash is relatively, or in some cases completely, inactive, it acts as an inert filler providing additional nucleation sites for the hydration of Portland cement as well as increasing the effective $\mathrm{w} / \mathrm{c}$ ratio and further promoting hydration of the cement clinker [15]. This filler effect accelerates Portland cement hydration during very early ages until the fly ash is activated as a pozzolanic material. It has been shown that PFA can also cause a retardation of the cement reaction at very early ages, however accelerated hydration does eventually take place [29, 30]. The phase assemblage is expected to be virtually the same as in a neat cement system, with increased $\mathrm{CH}$ contents (normalised to cement content) at early ages but a reduced total portlandite content observed overall. Some reaction of the alumina present in the PFA with $\mathrm{CaSO}_{4}$ may also be 
expected, leading to formation of AFt and monosulfate as well as additional aluminate rich hydrates such as calcium aluminate hydrate $\left(\mathrm{C}_{4} \mathrm{AH}_{13}\right)$ and strätlingite $\left(\mathrm{C}_{2} \mathrm{ASH}_{8}\right)$ [25]. Increased quantities of monosulfate and decreased quantities of AFt have been reported by some authors in PFA-cement materials, behaviour attributed to the higher $\mathrm{Al}_{2} \mathrm{O}_{3}$ content but lower $\mathrm{SO}_{3}$ content of fly ashes [6, 25]. Escalante-Garcia and Sharp [31] reported the presence of strätlingite in a 30\% PFA - Portland cement system after a reaction time of 1 year.

In blended cement systems the degree of reaction of the SCM is governed by various factors such as $w / c$ ratio, level of replacement and activation by water or alkali. Ben Haha et al. [32] measured the degree of hydration of PFA in a 35\% replacement system to be 2, 21 and 35\% at reaction ages of 1, 28 and 140 days. Kovacs [33] measured the reaction at hydration ages of 28 days and 1 year as $16-20$ and $30-37 \%$ in a $10 \%$ PFA blend, while the corresponding figures were $10-12 \%$ and $20-25 \%$ in a $40 \%$ blend. Although Girao et al. [34] were unable to quantify the extent of reaction using ${ }^{29} \mathrm{Si}$ NMR studies due to the unpredictability of the signal contained within the side and centre bands, comparisons of the $\mathrm{CH}$ and $\mathrm{Al} / \mathrm{Si}$ ratio of the $\mathrm{C}-\mathrm{S}-\mathrm{H}$ to neat systems indicated some reaction had occurred at 1 day and a considerable amount at 28 days.

\subsubsection{The hydration products and their microstructure}

The high Si content of PFA leads to an increased uptake of Si in the C-S-H. Silicate mean chain lengths increase and a C-S-H with a lower $\mathrm{Ca} / \mathrm{Si}$ ratio to that found in neat PC pastes is produced. The level of replacement and choice of activation (water or alkali) affects the final mean $\mathrm{Ca} / \mathrm{Si}$ ratio, higher degrees of reactivity and levels of replacement resulting in increased polymerisation and a subsequent decrease of this value $[6,8,25,34,35]$.

Deschner [6] reported a Ca/Si ratio of 1.3 for a 50\% PFA-PC sample, compared to 1.8 measured in a neat system, while Rodgers and Groves [35] determined $\mathrm{Ca} / \mathrm{Si}$ ratios of $1.4-1.5$ for a 30\% replacement system. Girao et al. [34] studied water and alkali activated 30\% PFA systems hydrated at $55^{\circ} \mathrm{C}$ in which $\mathrm{Ca} / \mathrm{Si}$ ratios of 1.46 and 1.10 were measured at an age of 28 days for water and $\mathrm{KOH}$ activated samples respectively. The increased chain lengths facilitate greater uptake of $\mathrm{Al}$ in the $\mathrm{C}-\mathrm{S}-\mathrm{H}$ which is incorporated into the bridging sites of the silicate chains. As with the $\mathrm{Ca} / \mathrm{Si}$ ratio, these effects are related to the reactivity and replacement level of the PFA, Girao et al. [34] 
illustrated this nicely determining an $\mathrm{Al} / \mathrm{Si}$ ratio of 0.16 at 28 days for the water activated system and a ratio of 0.21 at the same age for the alkali activated sample.

The C-S-H in PFA-cements will exhibit both fibrillar and foil-like morphology, foil-like morphology being characteristic of Op regions with low $\mathrm{Ca} / \mathrm{Si}$ (or $\mathrm{Ca} /(\mathrm{Al}+\mathrm{Si})$ ) ratios $[20,36]$. Figure 2.5 illustrates the combination of both fibrillar and foil-like Op C-S-H in a 28 day old water activated 30\% PFA paste (taken from [34]). Girao et al. also showed fully reacted particles with dense rims containing low density foil-like Ip. Deschner [6] reported similar observations, attributing the limited availability of Ca to the formation of a gel-like water rich Ip hydrate phase. Rodger and Groves [35] and Girao et al. [34] both described fibrillar Ip C-S-H within partially reacted fly-ash particles. TEM micrographs displayed radially fibrillar Ip reaction zones contained within an initial hydrate rim at the grain boundary. Dense crystalline regions were identified as hydrogarnet $\left(\mathrm{C}_{12} \mathrm{~A}_{3} \mathrm{FS}_{4} \mathrm{H}_{16}\right)$.

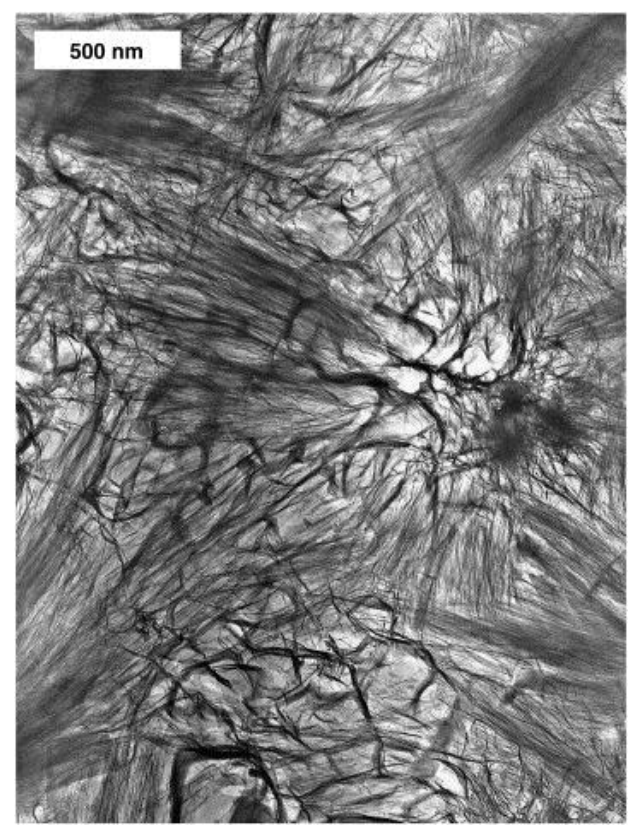

Figure 2.5. TEM micrograph of $30 \%$ PFA sample showing both fibrillar and foil-like morphology of Op C-S-H (taken from [34]) 


\subsubsection{GGBS cement hydration}

GGBS (commonly referred to as slag) is an industrial by-product produced from the manufacture of pig iron. It is a highly amorphous (glass content typically $>90 \%$ ) material with a chemical composition that lies between that of Portland cement and PFA or other pozzolans (Figure 2.4). The higher $\mathrm{CaO}$ contents of slags ( $\sim 40 \%)$ mean they are generally more reactive than fly ashes but contain notably less $\mathrm{Al}_{2} \mathrm{O}_{3}$ and small quantities of $\operatorname{MgO}(\sim 7-15 \%)[25,26]$. As with PFA, slags show variable composition which is related to the selection of raw materials and manufacturing processes, this was reviewed by Lang [37], who compared typical compositional ranges for different countries.

Slag is described as being a latently hydraulic material and although a reaction will occur in water, it will be extremely slow and activation by an alkaline environment is preferred. In cement-slag composites the production of $\mathrm{CH}$ from hydration of the calcium silicate phases and dissolution of alkali species from the cement into solution initiates the reaction of the slag, dissolving and breaking down the glass. Although some crystalline phases are present in GGBS, generally $<10 \%$, they are inert and it is the amorphous fraction that is reactive [38].

BS EN 197-1: 2011 [39] specifies that the chemical composition of a slag to be used in a cement system must be at least two thirds glass, that two thirds should be made up of $\mathrm{CaO}, \mathrm{SiO}_{2}$ and $\mathrm{MgO}$ and the ratio of $(\mathrm{CaO}+\mathrm{MgO}) / \mathrm{SiO}_{2}$ (by mass) should be greater than 1.0. Slag reactivity may loosely be related to its chemical composition, with more basic slags, i.e greater calcium and magnesium contents, believed to be more reactive. Table 3.1 summarises different basicity ratios derived for predicting the reactivity of slags based upon chemical composition alone. Although various studies have investigated the plausibility of these ratios, Mantel [40] reviewed the formulas by testing a range of slags and cements ultimately concluding no real correlation between the basicity ratios and performance, although the ratio stated in BS EN 197-1: 2011 gave an approximate estimation.

As with PFA, once activated the slag reacts to produce $\mathrm{C}-\mathrm{S}-\mathrm{H}$ of lower $\mathrm{Ca} / \mathrm{Si}$ and higher $\mathrm{Al} / \mathrm{Si}$ ratios to that of a neat Portland cement system [25, 41, 42]. Acceleration of cement hydration is expected at early ages in slag composites, resulting from filler effects promoting nucleation and growth of the hydrates as previously discussed, and a phase assemblage comprising of $\mathrm{C}-\mathrm{S}-\mathrm{H}$ and reduced quantities of $\mathrm{CH}, \mathrm{AFt}$ and AFm phases compared to a neat system [42-44]. Phase assemblage changes predicted by thermodynamic modelling with increasing level of substitution indicate the 
absence of portlandite from moderate levels of replacement in PFA systems (>25\%). However, due to slags' higher $\mathrm{CaO}$ content total $\mathrm{CH}$ consumption is only predicted to occur in slag blends at much higher replacement levels (>65\%) [25]. Additional phases in slag systems include a hydrotalcite-like phase $\left(\mathrm{Mg}_{6} \mathrm{Al}_{2}(\mathrm{OH})_{16} . \mathrm{CO}_{3} .4 \mathrm{H}_{2} \mathrm{O}\right)[25,41]$ and potentially strätlingite at high levels of slag replacement [25].

Increasing w/c ratio, curing length and temperature, and particle size fineness all improve slag reactivity [45], however increasing slag loading has been shown to reduce the proportion that hydrates or reacts. Taylor et al. [42] estimated that roughly two thirds, one third and one fifth of the GGBS in $<75 \%, 90 \%$ and $100 \%$ slag systems respectively had reacted in 20 year old paste samples. Degrees of reaction determined from selective dissolution experiments by Lumley et al. [45] showed reactions of between $30-55 \%$ at an age of 28 days and $45-75 \%$ at an age of 1 year for systems with $30-69 \%$ replacement by GGBS. Luke and Glasser [46] observed a $42 \%$ and $62 \%$ reaction at ages of 28 days and 1 year in a $30 \%$ slag system at a w/b ratio of 0.60 measured by selective dissolution. Both Kocaba et al. [43] and Whittaker et al. [47] used image analysis of back-scattered electron images to compare the degree of slag hydration of different slags at the same replacement levels (40\%). Kocaba reported reaction ranges of $12-18 \%$ and $30-37 \%$ at 3 days hydration for two slag materials, reporting a higher reactivity for the slag with the higher alumina and alkali content than the slag with the higher amorphous content. Whittaker measured the extent of hydration at ages of 2 days, 28 days and 1 year determining degrees of reaction of $24-34 \%, 42-52 \%$ and $56-$ $68 \%$ respectively for 2 different slag materials. Increased levels of reaction were reported to occur with increasing $\mathrm{Ca} / \mathrm{Si}$ and $\mathrm{Al}_{2} \mathrm{O}_{3}$ content.

\subsubsection{The hydration products and their microstructure}

The inclusion of slag produces a C-S-H with increased chain lengths, lower $\mathrm{Ca} / \mathrm{Si}$ and higher $\mathrm{Al} / \mathrm{Si}$ atomic ratios $[41,42,48,49]$, where the higher $\mathrm{Al}_{2} \mathrm{O}_{3}$ content of the slag and the longer silicate chains in the C-S-H allow for substitution of Al for $\mathrm{Si}$ in tetrahedral sites $[49,50]$. Various factors will affect the extent of C-S-H gel modification but in general (as with PFA) lower $\mathrm{Ca} / \mathrm{Si}$ and higher Al/Si ratios are observed for alkali activated systems, compared to water activated, and increasing slag reactivity, which is expected to decrease with increasing percentage replacement. 
Richardson and Groves [49] determined $\mathrm{Ca} / \mathrm{Si}$ and Al/Si ratios for 9:1 GGBS: white Portland cement pastes activated with water and $\mathrm{KOH}$. Ip and Op regions for water activated systems had $\mathrm{Ca} / \mathrm{Si}$ and $\mathrm{Al} / \mathrm{Si}$ compositions of 1.26/1.27 (Op/Ip) and 0.19/0.15 (Op/Ip) respectively. In $\mathrm{KOH}$ activated samples the values were determined to be 1.14/1.16 (Op/lp Ca/Si) and 0.19/0.16 (Op/lp Al/Si). Taylor et al. [42] studied the progressive changes of the C-S-H phase in blends containing $0 \%$ to $100 \%$ GGBS reporting mean Ca/Si ratios of 1.81 in neat Portland cement pastes to 1.08 in neat GGBS samples. Al/Si ratios ranged from 0.09 for $0 \%$ slag systems to 0.19 in the $100 \%$ slag system. A similar relationship between compositional variation of the C-S-H and slag loading was observed in [41]. Furthermore, it was reported that no significant difference in the mean $\mathrm{Ca} / \mathrm{Si}$ ratio was observed in Ip alite, Ip slag and Op regions. However, notable differences in alumina contents of Ip alite and Ip slag regions were detected, where more alumina was incorporated in the $\mathrm{C}-\mathrm{S}-\mathrm{H}$ formed in areas originally occupied by slag grains.

Changes in the morphology of the Op C-S-H are related to the Ca/Si ratio [36]. Taylor et al. [42] showed transformation from fibrillar C-S-H in a neat Portland cement system to an entirely foil-like morphology in a neat slag paste for 20 year old samples (Figure 2.6). Ip regions of partially reacted grains exhibited fine, dense microstructures surrounding unreacted cores while completely reacted particles displayed a coarser foil-like morphology. Richardson and Groves [41] reported the same behaviour for 14 month old samples, describing progressive replacement of fibrillar C-S-H with foillike $\mathrm{C}-\mathrm{S}-\mathrm{H}$ as the percentage replacement by slag increased. 


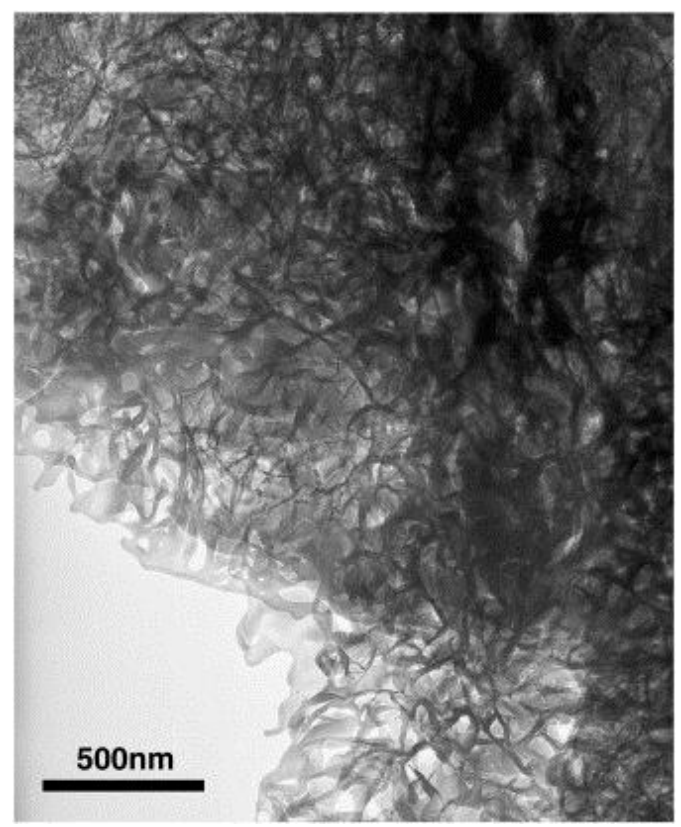

Figure 2.6. TEM micrograph showing foil-like morphology of Op C-S-H in a neat slag paste (taken from [42])

Portlandite is generally observed as large plates located in Op regions, however microcrystalline forms have been observed in slag-cement pastes during TEM analysis. Although it is more common for microcrystalline $\mathrm{CH}$ to form in alkali-activated pastes [49], Groves and Richardson [51] reported a microcrystalline form in a PC with low $\mathrm{w} / \mathrm{c}$ ratio as well as in pozzolanic pastes (calcium oxide and amorphous silica) with a high water/solids ratio and a $\mathrm{CH}$ activated slag paste. The formation of AFm phases with small average crystal sizes has also been observed when alkali-activation has been used, however, in general water activation produces crystals large enough to be resolved visually in the TEM [52].

Phase intermixing occurs at a much finer scale in Ip regions compared to the Op hydrates. The formation of a hydrotalcite-like phase (or Mg-Al layered double hydroxide) in Ip regions of slag particles exists as an intimate mixture with Al-substituted $\mathrm{C}-\mathrm{S}-\mathrm{H}$. If the level of intermixing is sufficiently fine the hydrotalcite-like microcrystals may not be resolved in TEM micrographs, however they exist on a range of scales and are sometimes observed as linear features, or laths, and clearly visible platelets $[41,42,52]$. 


\subsubsection{Engineering properties and durability of PFA and GGBS cements}

It is well accepted and demonstrated in the literature that enhanced, or superior, engineering properties are observed in blended cements compared to neat Portland cements. Improved long term strengths and durability properties are attributed to refinement of the pore structure, the foillike C-S-H is believed to fill space with a more finely distributed porosity which reduces the interconnectivity of the microstructure as the better connected fibrillar $\mathrm{C}-\mathrm{S}-\mathrm{H}$ is progressively replaced. This less well interconnected microstructure helps to explain the reduced diffusion rates observed in SCM-cement blends [41, 53].

Bijen [54] showed improved performance of fly-ash and slag concretes compared to a Portland cement system, reporting large reductions in diffusivity and penetration rates of chloride, behaviour attributed to densification of the microstructure. Pore size distribution measured by mercury intrusion porosimetry (MIP) was determined to be substantially finer in the composite materials, although a coarser distribution was initially observed in the fly-ash cements becoming finer than the neat system with time. Although the effect on total porosity was not majorly influenced, blended systems showed a higher percentage of gel pores and lower percentage of capillary pores.

Marsh et al. [55] demonstrated significant reductions in permeability for PFA cement pastes while Al-Almoundi et al. [56] highlighted the beneficial long term effects on durability, reporting greater permeability and porosity during initial curing periods (50 - 75 days) compared to neat Portland cement systems but improved performance after curing for 1 year. Canut [57] observed refinement of slag-cement pore structures with time compared to neat systems, showing a reduction in the threshold pore size from 28 days curing onwards in MIP measurements.

Improved long-term strength has also been extensively reported for composite cements. Bougara et al. [58] observed equivalent strength development at 28 days for $50 \%$ slag blends to that of a $100 \%$ Portland cement control system. Oner and Akyuz [59] investigated the effects of percentage replacement by GGBS on strength development showing increased compressive strengths with increased substitution by slag. However, this relationship was only observed to occur to an optimum value of $55 \%$, after which the excess of unreacted slag was deemed to cause a negative impact on further strength gain. 


\subsection{Carbonation}

\subsubsection{The carbonation reaction}

In reinforced concrete, the steel reinforcement is protected both physically and chemically by the surrounding concrete. Diffusion of harmful species is controlled by the physical microstructure of the Portland cement paste while the highly alkaline pore solution provides chemical resistance. Dissolution of alkali hydroxide species such as sodium, potassium and calcium and the buffering capacity of portlandite cause the $\mathrm{pH}$ level to be typically greater than 13 [60]. This alkali rich solution results in the development of a stable passive film (thin oxide layer) on the steel surface which protects it from corrosion. However, neutralisation of the pore water results in the passivation layer being destroyed, leaving the steel vulnerable to degradation from aggressive species. Such a reduction in alkalinity is caused by the reaction of atmospheric $\mathrm{CO}_{2}$ with the calcium bearing phases in cement, known as carbonation.

The carbonation reaction is termed a physiochemical process and it is primarily the carbonation of portlandite that results in lower levels of alkalinity. Atmospheric $\mathrm{CO}_{2}$ travels through the cement pore structure, dissolving in the pore solution as carbonic acid $\left(\mathrm{H}_{2} \mathrm{CO}_{3}\right)$. The ions present from dissolution of $\mathrm{CH}$ react with $\mathrm{H}_{2} \mathrm{CO}_{3}$ precipitating $\mathrm{CaCO}_{3}$ and releasing water as shown in the equations below.

$$
\begin{gathered}
\text { Dissolution of } \mathrm{CO}_{2} \\
\mathrm{CO}_{2}+\mathrm{H}_{2} \mathrm{O} \longrightarrow \mathrm{H}_{2} \mathrm{CO}_{3} \\
\text { Reaction of portlandite and carbonic acid } \\
\left(\mathrm{Ca}_{2}^{+}+\mathrm{OH}^{-}\right)+\left(\mathrm{HCO}_{3}^{-}+\mathrm{H}^{+}\right) \longrightarrow \mathrm{CaCO}_{3}+\mathrm{H}_{2} \mathrm{O} \\
\text { Overall reaction } \\
\mathrm{Ca}(\mathrm{OH})_{2}+\mathrm{CO}_{2} \longrightarrow \mathrm{CaCO}_{3}+\mathrm{H}_{2} \mathrm{O}
\end{gathered}
$$

As previously stated, $\mathrm{CO}_{2}$ reacts with each of the $\mathrm{Ca}$ bearing hydrates, progressively removing $\mathrm{Ca}$ to produce new phases and/or modifying existing ones. This is most evident for the C-S-H gel where decalcification modifies the $\mathrm{C}-\mathrm{S}-\mathrm{H}$ structure. The withdrawal of $\mathrm{Ca}$ results in increased 
polymerisation of the silicate chains, the formation of $\mathrm{CaCO}_{3}$ and $\mathrm{H}_{2} \mathrm{O}$ and ultimately the final product is an amorphous silica phase formed from condensation of the $\mathrm{SiO}_{4}$ tetrahedra as in the overall chemical equation below [61-64].

$$
\mathrm{C}-\mathrm{S}-\mathrm{H}+\mathrm{HCO}_{3}{ }^{-} \longrightarrow \mathrm{CaCO}_{3}+\mathrm{SiO}_{2} \cdot \mathrm{H}_{2} \mathrm{O}+\mathrm{H}_{2} \mathrm{O}
$$

Morandeau et al. [62], however, proposed that carbonation of C-S-H is not accompanied by a physical release of water but instead forms $\mathrm{CaCO}_{3}$ and a highly hydrated silica gel.

Studies on the carbonation of ettringite have shown that the decomposition products are $\mathrm{CaCO}_{3}$, gypsum and alumina gel as in the equation below.

$3 \mathrm{CaO} . \mathrm{Al}_{2} \mathrm{O}_{3} \cdot 3 \mathrm{CaSO}_{4} \cdot 32 \mathrm{H}_{2} \mathrm{O}+3 \mathrm{CO}_{2} \longrightarrow 3 \mathrm{CaCO}_{3}+\mathrm{CaSO}_{4} \cdot 2 \mathrm{H}_{2} \mathrm{O}+\mathrm{Al}_{2} \mathrm{O}_{3} \cdot \mathrm{xH}_{2} \mathrm{O}+(26-\mathrm{x}) \mathrm{H}_{2} \mathrm{O}$

Nishikawa et al. [65] and Zhou and Glasser [66] both investigated the carbonation of synthetic ettringite samples reporting that the disappearance of AFt was accompanied by increasing formation of $\mathrm{CaCO}_{3}$, alumina gel and gypsum. Zhou and Glasser observed only vaterite as the carbonate product to form while Nishikawa et al. described vaterite forming initially but aragonite being predominant at later ages. An endothermic peak in DTA data at $250^{\circ} \mathrm{C}$ was attributed to the dehydration of alumina gel by Nishikawa et al., whereas Zhou and Glasser only observed gibbsite $\left(\mathrm{Al}(\mathrm{OH})_{3}\right)$ in $\mathrm{XRD}$ data at $40^{\circ} \mathrm{C}$. Experiments performed at $25^{\circ} \mathrm{C}$ suggested alumina gel was present (intimated from mass balance equations) but the absence of the phase in XRD results suggested an amorphous species at this temperature.

Similar behaviour was reported by Fernández-Carrasco et al. [67] for ternary blends of calcium aluminate cement, fly ash and gypsum. Infrared spectra and XRD data showed the formation of aluminium hydroxide, gypsum and both vaterite and aragonite where the carbonate polymorph seemed to be dependent on the mix design. Vaterite formed predominantly in systems with lower initial $\mathrm{SO}_{4}$ contents (gypsum $\leq 10 \%$ ) while aragonite was the principal species for systems with higher initial quantities of gypsum (20\% \& $40 \%)$. 
The AFm phases undergo similar decomposition reactions. In the presence of carbonate species $\mathrm{OH}^{-}$ and $\mathrm{SO}^{2-}$ ions are displaced. Hemicarboaluminate $\left(\mathrm{C}_{3} \mathrm{~A} \cdot \mathrm{Ca}\left[(\mathrm{OH})\left(\mathrm{CO}_{3}\right) 0.5\right] \cdot \mathrm{xH}_{2} \mathrm{O}\right)$ tends to form instead of monosulfoaluminate $\left(\mathrm{C}_{3} \mathrm{~A} \cdot \mathrm{CaSO}_{4} \cdot \mathrm{xH}_{2} \mathrm{O}\right)$ and then transforms to monocarboaluminate $\left(\mathrm{C}_{3} \mathrm{~A} \cdot \mathrm{CaCO}_{3} \cdot \mathrm{xH}_{2} \mathrm{O}\right)[68,69]$. Decomposition by carbonation then produces similar products to those formed in the carbonation of AFt. Fernández-Carrasco et al. [67] observed complete reaction with $\mathrm{CO}_{2}$ of both monosulfate and hemicarbonate as well as hydrogarnet $\left(\mathrm{C}_{3} \mathrm{AH}_{6}\right)$.

The rate of carbonation of concrete is approximately related to Fick's law of diffusion where the diffusion rate is inversely proportional to the distance from the surface. BS EN 12390-10 [70] determines the rate of carbonation from average measured carbonation depth measurements using the equation below.

$$
\text { Average measured carbonation depth in } m m=k_{c} \sqrt{t}
$$

where:

$\mathrm{k}_{\mathrm{c}}=$ rate of carbonation in $\mathrm{mm} / \mathrm{year}^{0.5}$

$\sqrt{t}=$ effective time in years

In atmospheric conditions carbonation rate occurs at an optimum between humidity levels of 50 $70 \%$ [61]. Low levels of $\mathrm{RH}$ induce drying of the capillary pores preventing dissolution of $\mathrm{CO}_{2}$ and the hydrated phases whereas conversely, high levels of humidity cause condensation of water in the capillary pores, delaying diffusion of $\mathrm{CO}_{2}$.

\subsubsection{Carbonation of Portland cement}

\subsubsection{Carbonation of the hydrate phases and the effects on the phase assemblage and the}

\section{microstructure}

The carbonation of Portland cement has been extensively investigated. Studies on synthetic C-S-H, $\mathrm{C}_{3} \mathrm{~S}$ and Portland cement pastes all produce similar results and the expected changes in the microstructure and phase assemblage due to carbonation are well known. 
The investigation of partially carbonated $\mathrm{C}_{3} \mathrm{~S}$ pastes $(0.5 \mathrm{~mm}$ thick discs, $\mathrm{RH} 72.6 \%)$ following both accelerated (pure $\mathrm{CO}_{2}-1-16$ hours) and natural (air - 2 months) carbonation is discussed by Groves at al. [64]. Samples exposed to pure $\mathrm{CO}_{2}$ indicated a much faster initial rate of reaction of $\mathrm{CH}$ compared with C-S-H. However, once roughly half the portlandite was observed to have reacted, the rate of reaction became very slow while the reaction of $\mathrm{C}-\mathrm{S}-\mathrm{H}$ was observed to continue. The sudden decrease in reaction rate was attributed to the formation of microcrystalline $\mathrm{CaCO}_{3}$ (calcite and vaterite) around partially reacted $\mathrm{CH}$ crystals and although similar behaviour was reported for the pure $\mathrm{CO}_{2}$ carbonated pastes it is concluded that there is no direct evidence for the passivation of portlandite following natural carbonation.

Although both natural and accelerated carbonation conditions resulted in withdrawal of $\mathrm{Ca}$ from the $\mathrm{C}-\mathrm{S}-\mathrm{H}$ phase, evidenced by a decrease in the $\mathrm{Ca} / \mathrm{Si}$ ratio and increase in degree of polymerisation, the level of polymerisation was comparably much higher for the air carbonated samples for similar extents of carbonation. Furthermore the pastes exposed to pure $\mathrm{CO}_{2}$ were seen to have produced considerable amounts of silica gel while the naturally carbonated samples were not observed to have formed a silica rich phase. Generally a more homogenous C-S-H phase was observed for the air carbonated pastes demonstrated by TEM-EDX data in which a greater range of $\mathrm{Ca} / \mathrm{Si}$ ratios were recorded for Ip regions for the accelerated testing compared with those collected for air carbonated samples. The morphology of the original C-S-H was largely retained. The fine textured Ip regions remained generally unchanged and $\mathrm{Op}$ regions showed some relicts of $\mathrm{C}-\mathrm{S}-\mathrm{H}$ fibrils next to dense masses of $\mathrm{CaCO}_{3}$ microcrystals.

Richardson et al. [71] examined the carbonation of comparably treated Portland cement pastes ( $0.5 \mathrm{~mm}$ thick, RH 72.6\%) reporting results consistent with Groves et al. [64]. Richardson did note however, a lower overall level of carbonation for Portland cement pastes than for $\mathrm{C}_{3} \mathrm{~S}$ pastes.

Castellote et al. [72] studied chemical and phase assemblage changes of Portland cement pastes exposed to a range of accelerated $\mathrm{CO}_{2}$ conditions $(3 \%, 10 \% \& 100 \%)$ comparing the results with those of samples carbonated at ambient $\mathrm{CO}_{2}$ concentrations (0.03\%). Samples with w/c ratios of 0.5 were cured at room temperature for 28 days and exposed to elevated $\mathrm{CO}_{2}$ concentrations for 103 days ( $\mathrm{RH} 65 \%$ ) and ambient $\mathrm{CO}_{2}$ concentrations for 8 months ( $\left.\mathrm{RH} 30-60 \%\right)$. 
A C-S-H with a lower $\mathrm{Ca} / \mathrm{Si}$ ratio was reported to remain following testing for the $0.03 \%$ and $3 \% \mathrm{CO}_{2}$ samples, having $\mathrm{Ca} / \mathrm{Si}$ ratios of 1.23 and 1.18 respectively, whereas at elevated $\mathrm{CO}_{2}$ levels of 10 and $100 \%$ the C-S-H completely disappeared. Polymerisation was observed to increase with increasing $\mathrm{CO}_{2}$ concentration and although carbonation of $\mathrm{C}-\mathrm{S}-\mathrm{H}$ and $\mathrm{CH}$ was described as occurring simultaneously, the analysis techniques employed measure bulk samples rather than zones were $\mathrm{CH}$ may or may not still be present.

${ }^{29} \mathrm{Si}$ NMR confirmed the formation of Ca modified Si gel (formation of $Q^{3}$ and $Q^{4}$ peaks) following exposure to all the $\mathrm{CO}_{2}$ environments. Samples exposed to $100 \% \mathrm{CO}_{2}$ were also seen to lose any remaining anhydrous material ( $\mathrm{Q}^{0}$ peak) and complete decomposition of $\mathrm{C}-\mathrm{S}-\mathrm{H}$ was observed by loss of the $Q^{1}$ and $Q^{2}$ sites for the samples exposed to $10 \%$ and $100 \% \mathrm{CO}_{2}$ atmospheres. AFt (measured by $\mathrm{XRD}$ ) was reported to remain for the 0.03 and $3 \%$ samples only.

The results indicate similar changes in the microstructure for specimens carbonated at 0.03 and $3 \%$ $\mathrm{CO}_{2}$ concentrations, suggesting a threshold exists after which modifications in the carbonation mechanism occur due to accelerated testing.

Sevelsted and Skibsted [63] used solid-state NMR to investigate the effects of carbonation on the structure of synthetic C-S-H samples of varying $\mathrm{Ca} / \mathrm{Si}$ ratios $(0.66,1.0,1.5)$ under atmospheric conditions ([CO $\left.\mathrm{CO}_{2}\right], \mathrm{RH}$, temp) between 1 and 12 weeks.

The decomposition of C-S-H was determined to occur in 2 stages, and the rate of decomposition was reported to decrease with increasing $\mathrm{Ca} / \mathrm{Si}$ ratio. ${ }^{29} \mathrm{Si} \mathrm{NMR}$ showed that $\mathrm{Ca}$ is gradually removed from the interlayer until $\mathrm{Ca} / \mathrm{Si}$ ratio of 0.67 is reached, corresponding to infinite chain lengths. This is followed by withdrawal of Ca from the principal layers resulting in decomposition of the C-S-H and the formation of an amorphous silica phase denoted by the formation of $Q^{3}$ and $Q^{4}$ silicate tetrahedra. ${ }^{27} \mathrm{Al} \mathrm{NMR}$ demonstrated consumption of $\mathrm{Al}$ sites (AI(IV)) in the C-S-H phase during carbonation at a resonance of $\sim 65 \mathrm{ppm}$ and the subsequent formation of a new tetrahedral unit at $\sim 55 \mathrm{ppm}$ indicating the incorporation of the Al in the amorphous silica phase.

The carbonation of synthetic C-S-H samples of varying $\mathrm{Ca} / \mathrm{Si}$ ratios $(0.4-1.5)$ was also studied by Black et al. [73]. Carbonation ages of 1, 3 and 6 months were investigated as well as very early ages of 1 and 40 hours (for the 1.50 sample only). Raman spectroscopy revealed the formation of an amorphous carbonate species following 1 hour of exposure to ambient $\mathrm{CO}_{2}$ concentrations, 
attributed to the reaction of $\mathrm{CH}$. At slightly longer exposure lengths of 40 hours, further consumption of $\mathrm{CH}$ was observed as well as increased polymerisation of the $\mathrm{C}-\mathrm{S}-\mathrm{H}$ phase (transformation of $Q^{1}$ to $Q^{2}$ ).

At much longer exposure times (1, 3 \& 6 months) amorphous carbonate was only observed in the sample with initial $\mathrm{Ca} / \mathrm{Si}$ of 0.83 following carbonation for 1 month and calcite was absent from all the samples analysed. The formation of predominantly vaterite or aragonite appeared to be dependent upon the initial $\mathrm{Ca} / \mathrm{Si}$ ratio, with vaterite being prevalent at $\mathrm{Ca} / \mathrm{Si} \geq 0.67$ and aragonite being predominant for $\mathrm{Ca} / \mathrm{Si} \leq 0.50$. The total formation of carbonate species increased with increasing $\mathrm{Ca} / \mathrm{Si}$ ratio but was particularly apparent for sample with $\mathrm{Ca} / \mathrm{Si}>1.00$ where $\mathrm{CH}$ was present in the fresh samples. The formation of $Q^{4}$ silicates indicated compete decalcification to form an amorphous hydrated silica phase.

\subsubsection{The effects on engineering properties and durability}

The carbonation reaction reduces the alkalinity of the pore solution by reaction with Ca bearing phases, principally $\mathrm{CH}$ and $\mathrm{C}-\mathrm{S}-\mathrm{H}$, leading to depassivation and corrosion of steel reinforcement in concrete. However, in Portland cement systems positive differences in the molar volumes of the carbonation products and the reacting phases results in densification of the microstructure which has been shown to decrease the total porosity of the material $[62,74-76]$ consequently increasing strength $[8,77]$. The effects of carbonation on the porosity, pore size distribution, moisture and transport properties are not always easily predicted, making predictions for durability somewhat difficult. In the case of neat Portland cement systems however, a pronounced reduction in pore volume as a result of carbonation is expected, positively affecting durability.

In 1968 Pihlajavaara [74] observed a reduction in the total porosity of carbonated cement paste compared with a non-carbonated sample, reporting a greater effect on larger pores (capillary) than smaller ones (gel). However, Ngala and Page [76] studied the effects of drying and carbonation on chloride diffusivity observing a reduction in the total porosity for the neat Portland cement paste sample as a result of carbonation but a redistribution of pore sizes in which the proportion of pores with a diameter $>30 \mathrm{~nm}$ slightly increased. Although the effects on chloride diffusion were not as great as for the blended systems, increased diffusion rates were reported for the carbonated 
Portland cement samples. Johannesson and Utgenannt [78] also reported a redistribution of pore sizes upon carbonation in Portland cement mortar samples. The authors measured specific surface area and pore size distribution on non-carbonated and carbonated systems, stating that roughly twice the volume was attributed to small pores in the well carbonated mortar. The effects of carbonation on the specific surface area were comparably small. Morandeau et al. [62] measured the porosity of carbonated and non-carbonated cement pastes using both gamma-ray attenuation and mercury intrusion porosimetry (MIP) where a decrease in total porosity was observed using both measurement methods. Although MIP gives lower porosity values compared to gamma-ray attenuation (water is able to access a larger range of pores than mercury) both techniques showed an equivalent porosity variation between the carbonated and non-carbonated systems.

\subsubsection{Carbonation of PFA and GGBS composite cements}

\subsubsection{Carbonation of the hydrate phases and the effects on the phase assemblage and the} microstructure

The carbonation kinetics of composite cements are affected by the modifications in the phase assemblage. For PFA and GGBS cements this is primarily the lower contents of Portlandite and lower $\mathrm{Ca} / \mathrm{Si}$ ratio of the $\mathrm{C}-\mathrm{S}-\mathrm{H}$ gel.

The carbonation of $\mathrm{CH}$ and $\mathrm{C}-\mathrm{S}-\mathrm{H}$ is understood to occur simultaneously, however the more rapid dissolution of $\mathrm{CH}$ results in an initially much faster carbonation rate of Portlandite $[61,64,71,79]$. This behaviour soon reverses when the formation of microcrystalline $\mathrm{CaCO}_{3}$ around reacting $\mathrm{CH}$ crystals inhibits further accessibility and the reaction of the $\mathrm{C}-\mathrm{S}-\mathrm{H}$ is reported to increase or continue at a constant rate $[61,64,71]$. Without $\mathrm{CH}, \mathrm{C}-\mathrm{S}-\mathrm{H}$ alone is not sufficient to buffer the pore solution and maintain a high level of $\mathrm{pH}$.

Furthermore, decalcification of C-S-H leads to carbonation shrinkage, resulting in cracking and coarsening of porosity, first discussed by Groves et al. [79] for Portland cement pastes in 1990. Groves reported a lowering of both the $\mathrm{Op}$ and $\mathrm{Ip} \mathrm{Ca} / \mathrm{Si}$ ratios but no visual change in the finely microporous Ip microstructure, concluding that carbonation shrinkage was the likely cause. 
This phenomenon was experimentally supported by Chen et al. [80] who investigated decalcification shrinkage of $\mathrm{C}_{3} \mathrm{~S}$, white Portland cement (WPC) and WPC $+30 \%$ silica fume (WPC:SF) pastes decalcified by leaching. Irreversible volumetric changes resulting from removal of $\mathrm{Ca}$ and therefore considerable changes in the structure of the $\mathrm{C}-\mathrm{S}-\mathrm{H}$ phase were observed to occur in all the systems, but accelerated shrinkage was observed from $\mathrm{Ca} / \mathrm{Si}$ ratios of 1.2 and below (corresponding to point at which interlayer $\mathrm{Ca}$ is removed). For the $\mathrm{C}_{3} \mathrm{~S}$ and WPC pastes, an initial period of gradual shrinkage was reported, with increased polymerisation and shrinkage rates occurring from $\mathrm{Ca} / \mathrm{Si}$ ratios of 1.2 and lower. However, the WPC:SF samples did not undergo a period of gradual decalcification, exhibiting rapid decalcification induced shrinkage immediately. The almost $\mathrm{CH}$ free and low initial $\mathrm{Ca} / \mathrm{Si} \mathrm{C}-\mathrm{S}-\mathrm{H}$ (1.35) of the composite sample highlights the greater vulnerability of low $\mathrm{Ca} / \mathrm{Si}$ ratio pastes, such as blended cements display, to carbonation shrinkage effects.

This has important implications for concrete durability and corrosion of embedded steel in blended cement concrete materials in which lower initial $\mathrm{CH}$ contents and $\mathrm{C}-\mathrm{S}-\mathrm{H}$ with lower initial $\mathrm{Ca} / \mathrm{Si}$ ratios are expected. This becomes of particular importance if the kinetics of carbonation are the rate controlling factor, which might be the case for highly porous systems in which $\mathrm{CO}_{2}$ diffusion is continual. This behaviour is further exacerbated at high PFA or GGBS loadings where the pozzolanic reaction may eventually result in $\mathrm{CH}$-free systems. Thermodynamic calculations by Lothenbach et al. [25] predict depletion of $\mathrm{CH}$ at moderate replacement levels of PFA (>25\% - assuming 50\% reaction of the fly ash and complete reaction of the cement) and high levels of GGBS replacement (>65\% - assuming $75 \%$ reaction of the slag and complete reaction of the cement). Hanehara et al. [81] confirmed this experimentally for fly ash cement systems in which $\mathrm{CH}$ was consumed from hydration ages of 1 year.

In order to assess durability and suitability for nuclear waste encapsulation Borges et al. [82] investigated the effects of carbonation on $\mathrm{CH}$ and $\mathrm{C}-\mathrm{S}-\mathrm{H}$ in cement pastes with high slag loadings (30\% and 90\%). Following accelerated carbonation $\left(5 \% \mathrm{CO}_{2}\right)$ for 21 days, Borges reported that for the $30 \%$ slag pastes the $\mathrm{C}-\mathrm{S}$-H did not carbonate significantly due to the presence of a higher initial $\mathrm{CH}$ content. Complete consumption of $\mathrm{CH}$ in the $90 \%$ slag samples was observed from 7 days exposure to $\mathrm{CO}_{2}$ and greater extents of $\mathrm{C}-\mathrm{S}-\mathrm{H}$ carbonation were evident. It should be noted, however, that the level of carbonation of $\mathrm{C}-\mathrm{S}-\mathrm{H}$ was calculated from thermal analysis data where $\mathrm{CaCO}_{3}$ formed from the carbonation of $\mathrm{CH}$ was initially determined and additional carbonate 
contents were then attributed entirely to the reaction of C-S-H without consideration of AFt or AFm phases which are likely to have some (possibly minor at high loadings) contribution. This is of particular relevance when considering the findings of Castellote et al. [72] who reported complete decomposition of $\mathrm{AFt}$ at $\mathrm{CO}_{2}$ concentrations above a threshold value of $5 \%$. The mechanism of carbonation is linked to the initial phase assemblage in which the initial amount of $\mathrm{CH}$ appears to govern the extent, or severity, of the reaction.

Similar results were discussed in [83] for PFA cements, where C-S-H in composite systems was determined to be more vulnerable to carbonation, behaviour exacerbated with increasing levels of replacement.

\subsubsection{The effects on engineering properties and durability}

The effects of using blended cements on carbonation resistance can be somewhat contradictory. The reduced $\mathrm{CH}$ contents leave the microstructure more susceptible to the carbonation reaction, however the refinement of the pore structure expected in composite systems can potentially offset rates of diffusion and ingress of $\mathrm{CO}_{2}$. Despite this, many durability studies report poor resistance of SCM cement materials.

Following accelerated testing $\left(10 \% \mathrm{CO}_{2}\right)$ by Gruyaert et al. [84] on concrete samples with slag contents of $0,50,70$ and $85 \%$, carbonation resulted in reorganisation of the pore structure with slag containing materials suffering from coarsening of the microstructure and increased carbonation coefficients. Carbonation depths measured using phenolphthalein indicator showed no carbonation of the neat cement samples and carbonation coefficients close to zero. Increased carbonation rates and depths were measured with increasing levels of replacement with GGBS.

Similar behaviour was observed by Litvan and Meyer [85] for concrete cores taken from experimental houses following 20 years of exposure. MIP measurements showed a reduction in porosity for the Portland cement concrete while although porosity remained unchanged in the slag concrete, permeability increased due to coarsening of the pores. Pores with diameter $<0.009 \mu \mathrm{m}$ accounted for $55 \%$ of the total porosity in the central / least carbonated region of the test specimen, however this volume fraction decreased with decreasing distance to the surface and the volume fraction of medium $(0.019-0.35 \mu \mathrm{m})$ and large $(>18 \mu \mathrm{m})$ sized pores increased. A reduction in small 
pores with increasing levels of carbonation was also reported for the neat system, however the large and medium pores remained relatively unchanged.

Thermal analysis data confirmed that the Portland cement sample had more $\mathrm{CH}$ present at all depths compared with the slag system in which only a very small amount was detected at the centre. Carbonation depth was also measured using phenolphthalein indicator, again revealing greater penetration depths of $\mathrm{CO}_{2}$ for the blended material. The authors did note that significant carbonation was detected in regions beyond that shown by the phenolphthalein solution in both materials.

The creation of large capillary pores following carbonation was also observed for fly ash cement pastes by Morandeau et al. [86] and for fly ash and slag cements by Ngala and Page [76]. Morandeau et al. [86] studied the effects of accelerated carbonation $\left(10 \% \mathrm{CO}_{2}\right)$ on fly ash pastes $(0,30 \& 60 \%)$ cured for either $6(0 \%)$ or 11 months $(30 \% \& 60 \%)$ and exposed for up to 16 weeks. MIP measurements on non-carbonated systems indicated that the greater proportion of pore sizes were very fine pores and a much smaller population of coarse pores. This was more evident in the high replacement samples ( $\mathrm{w} / \mathrm{b} 0.45,60 \% \mathrm{PFA})$ and for the higher $\mathrm{w} / \mathrm{b}$ ratio ( $\mathrm{w} / \mathrm{b}$ 0.60, 30\% PFA). Upon carbonation the threshold radius (the radius before which the cumulative pore volume rises sharply) was observed to increase by one order of magnitude from $30 \mathrm{~nm}$ to $200 \mathrm{~nm}$. An increase in total porosity due to carbonation was not measured, however the formation of large pores typically greater than $50 \mathrm{~nm}$ was clear.

Ngala and Page [76] observed a reduction in total porosity for all systems investigated (Portland cement, 30\% PFA, 65\% GGBS) but again reported significant rearrangement of pore sizes for the composite samples. Slight coarsening of large capillary pores (diameter $>30 \mathrm{~nm}$ ) occurred for the neat system, however sizeable coarsening of the pore structure was evident for the fly ash and slag cements which had an average increase in capillary pores > 30nm of $140 \%$ and $230 \%$ respectively. These effects were reflected in diffusivity measurements which showed increases of two orders of magnitude for rates of chloride diffusion and one order of magnitude for rates of oxygen diffusion for the blended systems. 


\subsection{Curing}

\subsubsection{Guidelines on curing}

The need for appropriate curing procedures is recognised in concrete standards. BS EN 13670:2009 [87] recommends periods of curing based upon the development of particular properties within the surface zone. Curing classes are either defined by curing period or the development of a certain percentage of the characteristic strength in the surface region. Table 2.1 displays the curing classes in which curing lengths vary from 1 hour for concrete with rapid early age strength gain (determined from ratio of 2 day strength to 28 day strength) and a surface temperature $\geq 25^{\circ} \mathrm{C}$ to 11 hours for slow strength development and low surface temperatures $\left(10^{\circ}>t \geq 5^{\circ} \mathrm{C}\right)$ for curing class 2 . Curing classes 3 and 4 have curing periods ranging from $1.5-18$ hours and 3 - 30 hours respectively.

Table 2.1. BS EN 13670:2009 curing class guidelines replicated from [87]

\begin{tabular}{ccccc}
\hline & Curing class 1 & Curing class 2 & Curing class 3 & Curing class 4 \\
\cline { 2 - 5 } Period (hours) & $12^{\mathrm{a}}$ & $\mathrm{NA}$ & $\mathrm{NA}$ & $\mathrm{NA}$ \\
\hline $\begin{array}{l}\text { Percentage of specified } \\
\text { characteristic 28 days } \\
\text { compressive strength }\end{array}$ & Not applicable (NA) & $35 \%$ & $50 \%$ & $70 \%$ \\
\hline${ }^{\mathrm{a}}$ Provided the set does not exceed 5 hours, and the surface concrete temperature is equal to or above $5{ }^{\circ} \mathrm{C}$ \\
\hline
\end{tabular}

EN 12390-10:2015 [70] provides guidelines for the carbonation resistance of concrete at atmospheric levels of $\mathrm{CO}_{2}$ and stipulates a curing period of 28 days prior to exposure using a storage container and curing until $50 \%$ of the reference strength has been reached for carbonation on a naturally exposed site.

German standard DIN 1045-3 provides similar curing guidelines to that of BS EN 13670:2009 while Japanese recommendations specify curing guidelines specifically for GGBS cement systems. Table 2.2 displays the minimum period of moist curing for slag containing concrete with $\mathrm{w} / \mathrm{b}$ ratio 0.5 . Here replacement level, material fineness and temperature are considered. 
Table 2.2. Japanese recommendations for moist curing of GGBS containing concrete [88]

\begin{tabular}{|c|c|c|c|c|c|}
\hline$\gamma^{R}$ & $30-40$ & \multicolumn{3}{|c|}{50} & $55-70$ \\
\hline $\begin{array}{l}\text { Darily mean } \\
\text { temperature }\left({ }^{\circ} \mathrm{C}\right)\end{array}$ & $\begin{array}{c}\text { Ground slag } \\
4000\end{array}$ & $\begin{array}{c}\text { Ground slag } \\
4000\end{array}$ & $\begin{array}{c}\text { Ground slag } \\
6000\end{array}$ & $\begin{array}{c}\text { Ground slag } \\
8000\end{array}$ & $\begin{array}{c}\text { Ground slag } \\
4000\end{array}$ \\
\hline 17 & 6 days & 7 days & 7 days & 6 days & 8 days \\
\hline 10 & 9 days & 10 days & 9 days & 8 days & 11 days \\
\hline 5 & 12 days & 13 days & 12 days & 10 days & 14 days \\
\hline
\end{tabular}

Gruyaert et al. [84] cites a Belgian standard NBN B15-100 (2008) which takes into account the equivalent performance of alternative binder systems by recommending much longer curing lengths to allow for the slower rates of hydration, typically prescribing curing times of 55 days. The large differences that exist between different standards reflects the lack of certainty over curing requirements which can vary from several hours to several months.

\subsubsection{The effects of curing on carbonation resistance of composite cements}

Suitable curing lengths and regimes are necessary for the development of principal properties relating to strength and durability. It is demonstrated extensively throughout the literature where the amplified adverse effects of inadequate curing methods on composite cements compared to traditional Portland cement systems is clear.

Poon et al. [1] examined PFA cement pastes and mortars cured for 27 or 90 days either in water $\left(27^{\circ} \mathrm{C}\right)$ or air $\left(15^{\circ} \mathrm{C} \& 60 \% \mathrm{RH}\right)$. Air cured samples showed much poorer performance, with significant negative effects on strength and significant increases in water permeability (two orders of magnitude higher) and chloride penetration (two-fold increase) compared with ideally cured specimens.

The lower porosities and permeabilities of PFA and GGBS cement materials have the potential to counteract carbonation induced effects such as carbonation decalcification and shrinkage and lowering of the $\mathrm{pH}$ of the pore solution. This, as previously discussed, is not the case when tested experimentally where coarsening of the capillary porosity leads to increased and elevated rates of 
diffusion and initial $\mathrm{CH}$ contents are already much lower. If this is then coupled with much shorter periods of curing, which may occur in practice with the early removal of formwork, fundamental problems with material performance will ensue. Materials in which microstructures are far from developed will have further reduced chemical and microstructural resistance to carbonation induced corrosion and it is predicted that the effects of carbonation will be much more severe compared with studies in the literature based on well cured samples.

It is important, therefore, to gain additional information regarding the effects of very short curing periods on the carbonation resistance of these blended materials and to compare the behaviour observed for short and ideally cured (28 days in water) systems at different $\mathrm{w} / \mathrm{b}$ ratios and replacement levels.

\subsection{Conclusions from literature review and research objectives}

The early age reactions of PFA and GGBS in composite cement materials are highly variable, depending on various factors such as chemical composition, $w / b$ ratio and length of curing. Although many studies demonstrate the improved effects these materials can have on durability, these properties are reliant on considerable periods of hydration and during early stages of curing typically exhibit much higher levels of permeability compared to CEMI systems. Furthermore, the lower initial $\mathrm{CH}$ contents and lower $\mathrm{Ca} / \mathrm{Si}$ ratio $\mathrm{C}-\mathrm{S}-\mathrm{H}$ make composite systems more vulnerable to carbonation. This vulnerability is exacerbated further by the coarsening effect on the capillary porosity following reaction with $\mathrm{CO}_{2}$. The role of $\mathrm{CH}$ as an alkalinity, and carbonation, buffer has been discussed previously, but is of greater significance when considering the kinetics of carbonation to be the limiting factor, as for highly porous systems. While the carbonation reactions of AFt and AFm are understood, what governs the rate and extent which they decompose in cement samples is not well defined. Relatively little published work studying the carbonation resistance of poorly cured blended materials is available, with research focusing largely on mature microstructures. The aim of this thesis is to investigate the effects of short curing periods on the carbonation resistance of fly ash and slag containing paste and mortar samples, focusing on the changes in the phase assemblage and microstructure following exposure to ambient $\mathrm{CO}_{2}$ concentrations. Modifications in the carbonation behaviour of immature ( $72 \mathrm{hr}$ cured) and mature (28d) systems will be discussed, 
examining the rate determining factors that govern both the chemical and physical resistance at low (0.40) and high $(0.57) \mathrm{w} / \mathrm{b}$ ratios. 


\section{Chapter 3}

\section{Materials and Methods}

\subsection{Raw materials}

The cement used in this study was a CEM I 52.5R supplied by Italcementi. The cement contained no additional limestone, in order to prevent potential complications in characterisation of $\mathrm{CaCO}_{3}$ produced as a result of carbonation from that already present in the raw materials. The PFA selected contained a low level of Fe (2.24\% (Table 3.1)) for the purposes of solid state NMR studies, in which line broadening effects arising from the presence of paramagnetic material prevent useful spectra being obtained[89]. Finally, the slag utilised was primarily glassy (98.8\%) with a small quantity of crystalline phases (calcite $0.4 \%$, gehlenite $0.3 \%$, wollastonite $0.6 \%$ ) and a good chemical reactivity (basicity ratios Table 3.1). The elemental composition of each material as determined by $\mathrm{x}$-ray fluorescence (XRF) analysis is presented in Table 3.1. Density values for the materials (measured using Quantachrome ultrapycnometer 1000) and the basicity ratios for the slag are also provided. Table 3.2 provides the phase composition of the cement as calculated from the Bogue calculation. The volume and particle size distribution of the materials are shown in Table 3.3 and Figure 3.1 respectively, and indicate that in comparison to the cement the slag contains a higher volume of finer material, whereas the PFA is comparatively much coarser. 
Table 3.1. Elemental composition of materials determined by XRF analysis, density measurements and GGBS basicity ratios. Note, the GGBS showed a gain in mass upon heating due to oxidation of the sulphides present within the as-received sample.

\begin{tabular}{|c|c|c|c|c|}
\hline & & CEM52.5R & PFA & GGBS \\
\hline Loss on ignition & $\%$ & 1.50 & $\mathrm{n} / \mathrm{a}$ & 2.35 \\
\hline $\mathrm{SiO}_{2}$ & $\%$ & 20.50 & 70.83 & 35.71 \\
\hline $\mathrm{Al}_{2} \mathrm{O}_{3}$ & $\%$ & 4.60 & 24.36 & 10.65 \\
\hline $\mathrm{Fe}_{2} \mathrm{O}_{3}$ & $\%$ & 2.40 & 2.24 & 0.45 \\
\hline $\mathrm{TiO}_{2}$ & $\%$ & 0.30 & 1.48 & 0.73 \\
\hline $\mathrm{MnO}$ & $\%$ & 0.00 & 0.05 & 0.23 \\
\hline $\mathrm{CaO}$ & $\%$ & 63.40 & 0.06 & 43.32 \\
\hline $\mathrm{MgO}$ & $\%$ & 2.00 & 0.23 & 3.97 \\
\hline $\mathrm{SO}_{3}$ & $\%$ & 3.60 & 0.00 & 3.06 \\
\hline $\mathrm{K}_{2} \mathrm{O}$ & $\%$ & 0.74 & 0.64 & 0.45 \\
\hline $\mathrm{Na}_{2} \mathrm{O}$ & $\%$ & 0.13 & 0.10 & 0.16 \\
\hline $\mathrm{P}_{2} \mathrm{O}_{5}$ & $\%$ & 0.30 & 0.05 & 0.02 \\
\hline Total & $\%$ & 99.47 & 100.04 & 101.09 \\
\hline Density $\left(\mathrm{g} / \mathrm{cm}^{3}\right)$ & & 3.17 & 2.33 & 2.94 \\
\hline \multicolumn{5}{|l|}{ Basicity ratios } \\
\hline \multicolumn{4}{|l|}{$\mathrm{CaO} / \mathrm{SiO}_{2}>1.0$} & 1.21 \\
\hline \multicolumn{4}{|c|}{$\mathrm{CaO}+\mathrm{MgO} / \mathrm{SiO} 2>1.0 *$} & 1.32 \\
\hline \multicolumn{4}{|c|}{$\mathrm{CaO}+\mathrm{MgO} / \mathrm{SiO}_{2}+\mathrm{Al}_{2} \mathrm{O}_{3}=1.0-1.3$} & 1.02 \\
\hline \multicolumn{4}{|c|}{$\mathrm{CaO}+0.56 \mathrm{Al}_{2} \mathrm{O}_{3}+1.4 \mathrm{MgO} / \mathrm{SiO}_{2}>1.65$} & 1.54 \\
\hline \multicolumn{4}{|c|}{$\mathrm{CaO}+\mathrm{MgO}+\mathrm{Al}_{2} \mathrm{O}_{3} / \mathrm{SiO}_{2}>1$} & 1.62 \\
\hline
\end{tabular}

Basicity equations taken from $[37,90,91]$

*BS EN 197-1:2011 [39]

Table 3.2. Phase composition of CEM 52.5R

\begin{tabular}{cccccc}
\hline & & $\mathrm{C}_{3} \mathrm{~S}$ & $\mathrm{C}_{2} \mathrm{~S}$ & $\mathrm{C}_{3} \mathrm{~A}$ & $\mathrm{C}_{4} \mathrm{AF}$ \\
\hline CEM 52.5R & $\%$ & 68 & 10 & 9 & 7 \\
\hline
\end{tabular}

Table 3.3. Volume distribution of CEM 52.5R, PFA and GGBS

\begin{tabular}{lccc}
\cline { 2 - 4 } & \multicolumn{3}{c}{ Volume distribution $(\mu \mathrm{m})$} \\
\cline { 2 - 4 } & $\mathrm{d}(0.1)$ & $\mathrm{d}(0.5)$ & $\mathrm{d}(0.9)$ \\
\hline CEM 52.5R & 2.51 & 11.66 & 31.14 \\
PFA & 3.77 & 23.63 & 89.14 \\
GGBS & 1.74 & 7.44 & 32.59 \\
\hline
\end{tabular}




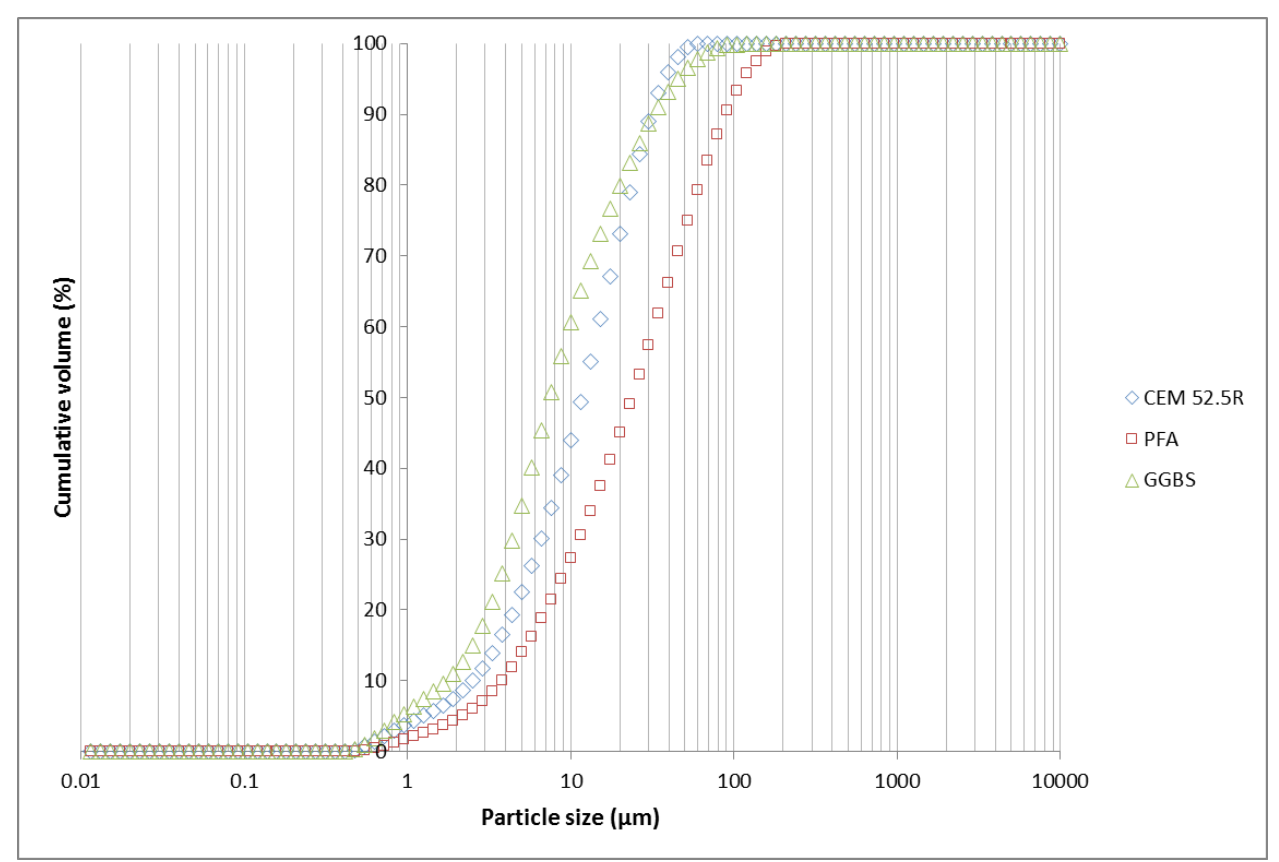

Figure 3.1. Particle size distribution of CEM 52.5R, PFA and GGBS

\subsection{Sample preparation and conditioning}

Binary systems were blended in a roller ball mill (Capco test Equipment Ball Mill Jar 2VS) using graded sizes of polypropylene balls for 2 hours. Replacement was by volume of the anhydrous materials.

Preparation techniques and procedures can be assumed to be identical as outlined below for the work undertaken in the experimental scoping study (Chapter 4) unless stated otherwise. Any changes to the methods for the preliminary testing have been highlighted and/or discussed as appropriate.

\subsubsection{Preparation of paste samples}

All detailed analysis, i.e. microstructural and phase assemblage characterisation, was performed on paste specimens. Samples were prepared by mixing the required quantity of anhydrous material with deionised water at the desired $\mathrm{w} / \mathrm{b}$ ratio (see Table 3.4 ) for 2 minutes by hand in a $\mathrm{CO}_{2}$ free $(<30 \mathrm{ppm})$ atmosphere. The samples were then sealed in small plastic vials $(\varnothing=12 \mathrm{~mm}, \mathrm{~h}=47 \mathrm{~mm})$ and rotated for a minimum of 24 hours in a temperature controlled laboratory $\left(22^{\circ}+/-2^{\circ} \mathrm{C}\right)$ before 
being vacuum sealed in plastic bags and cured in a water bath at $20^{\circ} \mathrm{C}\left(+/-2^{\circ} \mathrm{C}\right)$. Following the required curing time, the hardened paste samples were cut to a thickness of $0.5 \mathrm{~mm}$ and subjected to conditioning at either ambient $\mathrm{CO}_{2}$ conditions $\left(300-400 \mathrm{ppm} \mathrm{CO}_{2}\right.$, approx. $\left.24^{\circ} \mathrm{C}\right)$ or in a $\mathrm{CO}_{2}$ free sample chamber. Variations in $\mathrm{RH}$ and $\mathrm{CO}_{2}$ levels over a five week testing period are presented in Figure A.1 of Appendix A. Figure 3.2 displays a schematic diagram of a prepared sample section, the dimensions of which were selected in order to study the effects of carbonation on the phase assemblage and microstructure only. This approach allows the impact on the reaction kinetics to be investigated separately from effects on both the porosity and the transport properties, and although the author is aware of the importance of the effects of the transport properties on carbonation rate and behaviour, the methodology described here attempted to focus on the changes in the phase assemblage and microstructure when there is no, or very little, influence from porosity.

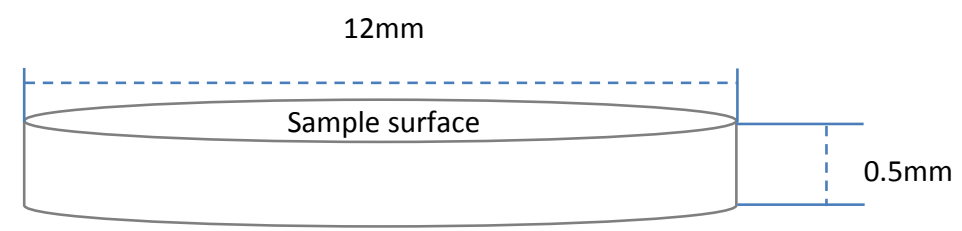

Figure 3.2. Schematic diagram of prepared section for sample conditioning

Detailed characterisation of paste samples was completed on four binder systems, at two w/b ratios (0.40 \& 0.57$)$, and for each system a carbonated (ambient $\left[\mathrm{CO}_{2}\right]$ ) and non-carbonated $\left(0 \%\left[\mathrm{CO}_{2}\right]\right)$ sample set were prepared. Details of the sample matrix are given in Table 3.4. In order to study the effect of water content on carbonation behaviour, both a low and a high $\mathrm{w} / \mathrm{b}$ ratio were selected. The selection of the high $\mathrm{w} / \mathrm{b}$ ratio of 0.57 allowed parallels to be drawn between the two water contents of the $30 \%$ replacement systems, the $\mathrm{w} / \mathrm{b}$ ratio of the 0.57 system having an equivalent value as the $w / c$ ratio of the lower $w / b$ ratio (i.e. $w / b 0.40=w / c 0.57$ ).

All samples were conditioned at a constant relative humidity $(\mathrm{RH})$, controlled using a saturated salt solution. The selection of the humidity level will be discussed further in Chapter 4 . Characterisation was performed on the samples at ages of 0 (t0), 1, 2, 4, $7 \& 14,28$ and 60 days. 
Table 3.4. Sample matrix for detailed characterisation

\begin{tabular}{|c|c|c|c|c|c|c|}
\hline \multirow[b]{2}{*}{ CEMI } & \multicolumn{2}{|c|}{$w / b$} & \multicolumn{2}{|c|}{$w / c$} & \multicolumn{2}{|c|}{$[\mathrm{CO} 2]$} \\
\hline & $0.40 *$ & $0.57^{\not x}$ & $0.40 *$ & $0.57^{\not x}$ & $0 \%$ & ambient \\
\hline CEMI + 30\% PFA & $0.40 *$ & $0.57^{x}$ & $0.57 *$ & $0.81^{\not x}$ & $0 \%$ & ambient \\
\hline CEMI + 30\% GGBS & $0.40 *$ & $0.57^{x}$ & $0.57 *$ & $0.81^{\not x}$ & $0 \%$ & ambient \\
\hline CEMI $+60 \%$ GGBS & $0.40 *$ & $0.57^{x}$ & $1.00 *$ & $1.43^{x}$ & $0 \%$ & ambient \\
\hline
\end{tabular}

$* / \not$ equivalent $w / b$ or $w / c$ ratio

$0 \%[\mathrm{CO} 2]=<30 \mathrm{ppm}$, ambient $[\mathrm{CO} 2]=\sim 300-400 \mathrm{ppm}$

Figures 3.3 and 3.4(a) below show the experimental configuration of the carbonation chamber. The sample chamber is an airtight container holding saturated salt solution and a sample stand. A peristaltic pump draws air in from the surrounding atmosphere, pumping it through the saturated salt solution in the base of the chamber. During experimental conditioning the temperature, $\mathrm{RH}$ level and $\mathrm{CO}_{2}$ concentration were periodically checked (every 24 hours where possible) using a Rotronic Hydrolog and Testo $535 \mathrm{CO}_{2}$ probe to ensure values remained within reasonable limits $\left(24^{\circ} \mathrm{C}+/-2^{\circ} \mathrm{C}\right.$, RH levels $72.6 \%+/-\approx 5 \%$, [CO2] $\left.300-400 \mathrm{ppm}\right)$.

In order to promote exposure of the sample surfaces to the ambient $\mathrm{CO}_{2}$ levels within the chamber, samples were stacked vertically in specially designed holders, as shown in Figure 3.4(b).

The non-carbonated $\left(0 \% \mathrm{CO}_{2}\right)$ samples were conditioned in exactly the same way but kept in a $\mathrm{CO}_{2}$ free environment. The sample chamber was sealed from the atmosphere and stored inside a glove box in which the $\mathrm{CO}_{2}$ concentration was always below $30 \mathrm{ppm}$, this allowed the container to be opened as needed when adding or removing samples for analysis. 

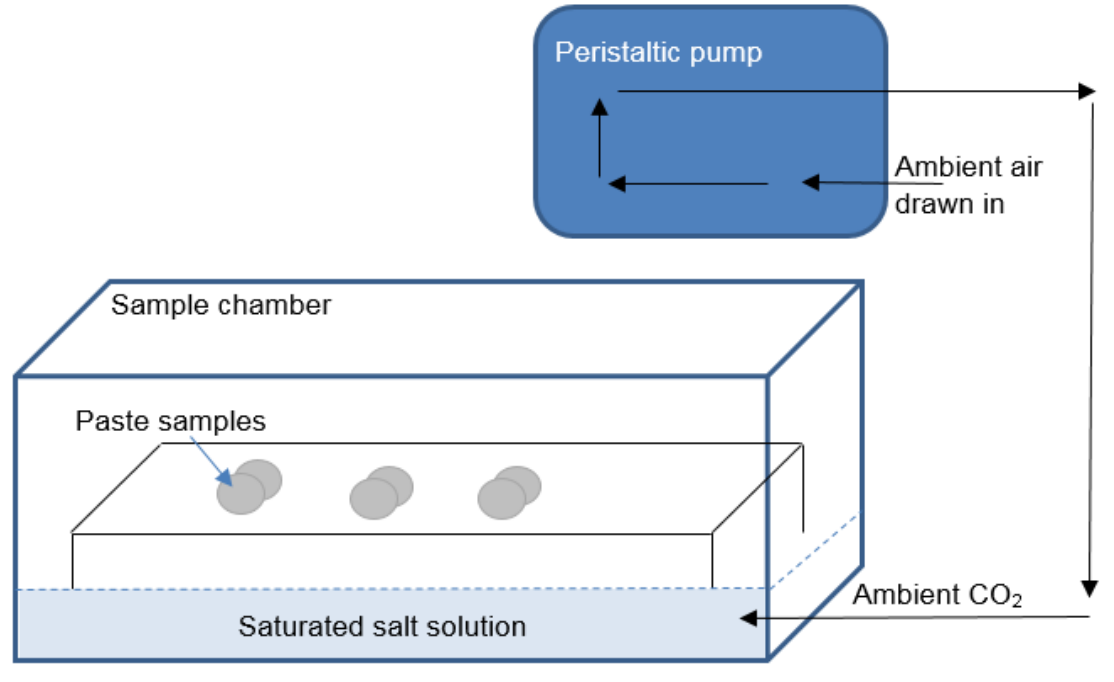

Figure 3.3. Schematic diagram showing experimental configuration of carbonation chamber
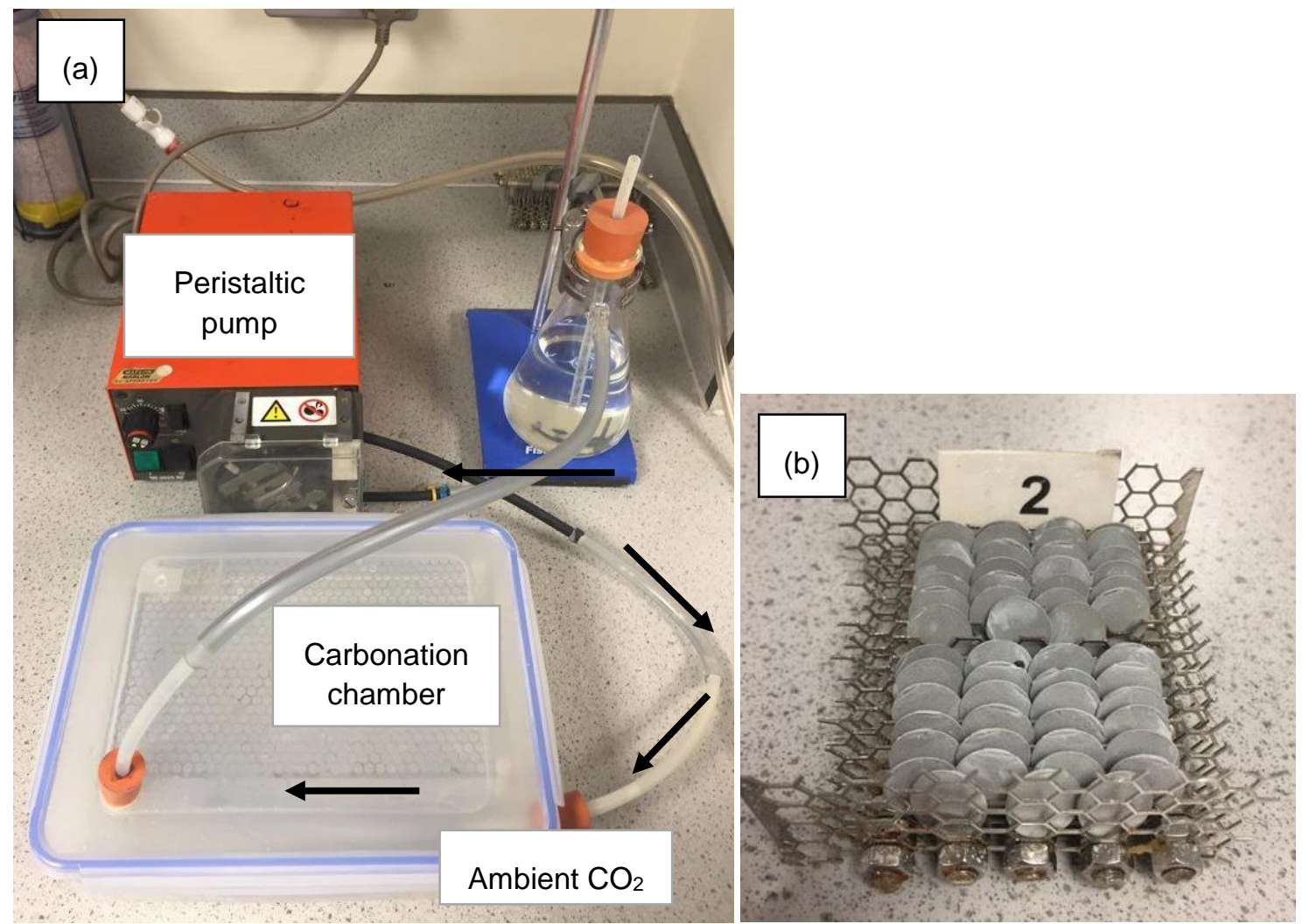

Figure 3.4. (a) Carbonation chamber for ambient carbonation of paste samples and (b) prepared paste samples in sample stand 


\subsubsection{Preparation of mortar samples}

General characterisation (compressive strength and carbonation depth testing) was performed on mortar prisms exposed to ambient $\mathrm{CO}_{2}$ concentrations, Table 3.5. The mortar samples were prepared with a CEN reference sand (David Ball Specialist Sands BS EN 196-1 Standard Sand) conforming to the criteria specified in BS EN 196-1: 2005 [92] and test specimens were made in accordance with the procedure outlined in BS EN 196-1: 2005 [92] modified to correspond with the $\mathrm{w} / \mathrm{b}$ ratios studied in the paste systems.

BS EN 196-1:2005 [92] states 450g of cement and 1350g of sand is to be used to produce each batch of 3 test specimens $(3 \times[40 \times 40 \times 160 \mathrm{~mm})$ prisms). As partial replacement of the Portland cement by the SCMs was carried out by volume, rather than weight, the equivalent calculated quantity of binder, taking into account volumetric substitution, was used for the composite materials. Mixing of the mortar was done using an automatic programmable mixer (Controls Auto-Mix 65-L0006/AM) with a pre-programmed procedure for BS EN 196-1:2005[92].

Curing of the specimens in water was also adapted to correspond to the periods studied in the detailed characterisation and were selected following an experimental scoping study, the results of which are discussed and presented in Chapter 4. Carbonation of the specimens was allowed to occur naturally in the laboratory $\left(\mathrm{RH} \approx 50 \%+/-10 \%,\left[\mathrm{CO}_{2}\right] \approx 450 \mathrm{ppm}\right)$ and testing was carried out following exposures of $1,2,7,28$ and 90 days, and 6,9 and 18 months.

Table 3.5. Sample matrix for general characterisation

\begin{tabular}{|c|c|c|c|}
\hline \multirow[b]{3}{*}{ CEMI } & \multirow{2}{*}{\multicolumn{2}{|c|}{$w / b$}} & \multirow{3}{*}{$\frac{\left[\mathrm{CO}_{2}\right]}{\text { ambient }}$} \\
\hline & & & \\
\hline & 0.40 & 0.57 & \\
\hline CEMI + 30\% PFA & 0.40 & 0.57 & ambient \\
\hline CEMI + 30\% GGBS & 0.40 & 0.57 & ambient \\
\hline CEMI + 60\% GGBS & 0.40 & 0.57 & ambient \\
\hline
\end{tabular}

ambient $\left[\mathrm{CO}_{2}\right] \approx 450 \mathrm{ppm}$ 


\subsection{Hydration stopping}

\subsubsection{Principle of hydration stopping}

In order to study cement samples at defined degrees of hydration and following defined times of exposure, it is important to remove unbound water remaining in the capillary pores. Hydration is arrested once the remaining free water is no longer present, however care should be taken that the chemically bound water in the hydrates is left unaffected. Removal of chemically bound water leads to alteration of the hydration products, modifying the phase assemblage and microstructure. Zhang and Scherer [93] recently published a comprehensive review of the available drying techniques and their suitability for preservation of the phase assemblage and microstructure, concluding that solvent exchange is the least damaging, particularly for young pastes.

Konecny and Naqvi [94] showed solvent replacement preserved pores less than $5 \mathrm{~nm}$ in size $(r<5 \mathrm{~nm})$, while Collier et al. [95] reported no major observable differences for a range of drying techniques tested (solvent exchange, freeze, oven and vacuum drying), however solvent exchange was perceived to preserve the pores the best.

The choice of solvent can have additional effects on cement samples through interactions with hydrate phases $[93,96]$. Zhang and Scherer [93] showed a clear weight loss above $600^{\circ} \mathrm{C}$ in TGA curves, not present in the undried sample, for different solvents. The smallest weight loss was observed with isopropanol, whereas acetone showed the greatest. These effects were ascribed to the adsorbtion of diacetone alcohol, which is said to form in the presence of a base catalyst, onto the surface of portlandite crystals. A subsequent reaction with $\mathrm{Ca}(\mathrm{OH})_{2}$ to form $\mathrm{CaCO}_{3}$ then produces a weight loss upon decarbonation at elevated temperatures $[93,96]$. Methanol has been reported to decompose ettringite and slightly reduce the number of water molecules attached to monosulfate (from 12 to 10) [97] and isopropanol is generally reported to cause the least alteration. Secondary replacement with a more volatile solvent such as diethyl ether allows removal of the exchange solvent and is easily and quickly removed by heating at low temperature $\left(40^{\circ} \mathrm{C}\right)$ [96]. 


\subsubsection{Experimental procedure}

The cement discs $(12 \mathrm{~mm} \varnothing, 0.5 \mathrm{~mm}$ thickness) were hydration stopped in isopropanol using a minimum solvent to sample ratio of 300 times that of the total sample volume. A 2 hour exchange period was determined to be suitable for the sample dimensions and diffusivity. Figure 3.5 displays TGA data for a CEMI system following 72 hours curing and subsequent solvent exchange in isopropanol for soaking times of $0,2,4$ and 24 hours. The calculated $\mathrm{Ca}(\mathrm{OH})_{2}$ content of the fresh and hydration stopped specimens are consistent, indicating an exchange period of 2 hours is suitable to properly arrest hydration. The samples were removed from the isopropanol and subjected to secondary solvent replacement using diethyl ether. Specimens were washed three times before removing the volatile ether by heating at $44^{\circ} \mathrm{C}$ on a hotplate for 10 minutes. Samples were stored in a desiccator under vacuum with silica gel until measurements could be performed.

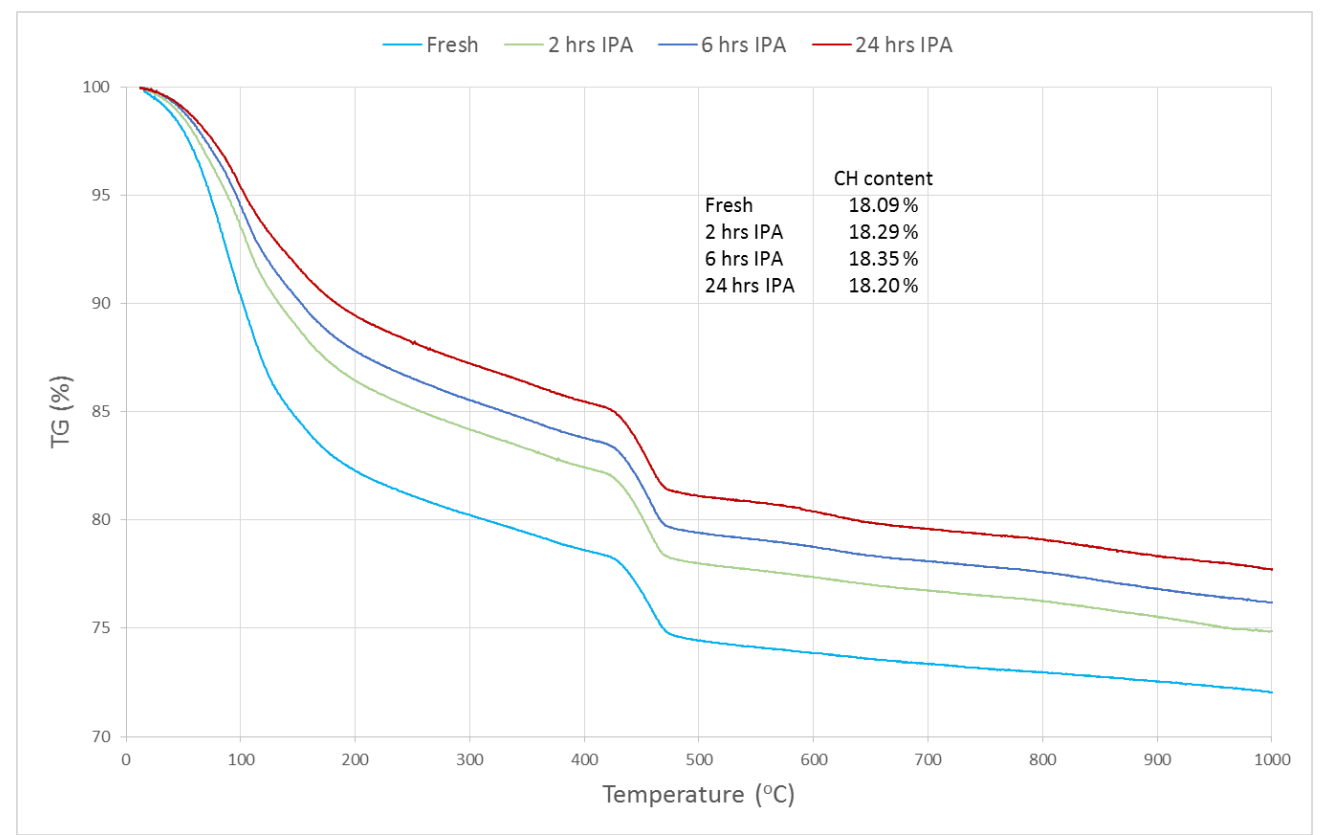

Figure 3.5. The effects of varying length of solvent exchange in isopropanol for a CEMI $0.57-72$ hour cured system 


\subsection{Phase assemblage characterisation}

\subsubsection{Isothermal conduction calorimetry (ICC)}

\subsubsection{Principle of isothermal conduction calorimetry}

The exothermic nature of cement hydration means the kinetics of the reaction can be followed using an isothermal conduction calorimeter. The heat released during the reaction is recorded in parallel (twin channel instrument) with an analogous reference material. The purpose of the reference is to eliminate noise and drift to the signal potentially caused by external factors, therefore it is important both materials possess similar thermal properties. As cement has a specific heat capacity of $0.75 \mathrm{J.g}$ ${ }^{1} . \mathrm{K}^{-1}$, quartz (specific heat capacity of $0.8 \mathrm{~J} \cdot \mathrm{g}^{-1} \cdot \mathrm{K}^{-1}$ ) is a suitable reference material for the measurement.

\subsubsection{Experimental setup}

Calorimetric measurements were collected for paste samples with a $\mathrm{w} / \mathrm{b}$ ratio of 0.57 only. Data was collected as part of the experimental scoping study and used to inform the final selection of the curing lengths to be investigated (Chapter 4).

A TAM-Air 8 twin channel calorimeter was used to measure the heat evolution of the hydrating pastes. $9 \mathrm{~g}$ of paste $\left(5.73 \mathrm{~g}\right.$ binder $+3.27 \mathrm{~g}$ deionised $\mathrm{H}_{2} \mathrm{O}$ ) was placed in a $20 \mathrm{ml}$ plastic ampoule and shaken at a low-medium speed for 2 minutes on an orbital shaker. The ampoules were immediately placed in the sample channel of the instrument and an analogue quartz paste placed in the reference channel. The temperature was set at $20^{\circ} \mathrm{C}$ and the measurements were carried out for 28 days.

\subsubsection{Simultaneous thermal analysis (STA)}

\subsubsection{Principle of simultaneous thermal analysis}

Thermogravimetric analysis (TGA) provides information on the changes in mass of a sample subjected to a constant heating rate, while differential thermal analysis (DTA) indicates differences in temperature between the sample and an inert reference material, or empty crucible. Measurements are taken simultaneously under identical conditions and the combination of the two techniques is referred to as simultaneous thermal analysis (STA). 
In cement samples the heating process results in dehydroxylation of the hydrate phases and decarbonation of carbonate species. As the temperature increases, water is removed firstly from the C-S-H, AFt and AFm phases (Figure 3.6). Ramachandran [98] states mass loss due to dehydration of C-S-H occurs below $150^{\circ} \mathrm{C}$, whereas a much larger temperature range of $50-600^{\circ} \mathrm{C}$ is reported by Lothenbach et al. [99]. Decomposition of ettringite is observed between $100-150^{\circ} \mathrm{C}$ and several weight loss regions up to $350^{\circ} \mathrm{C}$ for the $\mathrm{AFm}$ phases have been detected $[69,99]$. A sharp mass loss between $450-550^{\circ} \mathrm{C}$ is attributed to water released from $\mathrm{Ca}(\mathrm{OH})_{2}$, producing $\mathrm{CaO}$, and then at temperatures above this, decomposition of $\mathrm{CaCO}_{3}$ phases to $\mathrm{CaO}+\mathrm{CO}_{2}$ takes place.

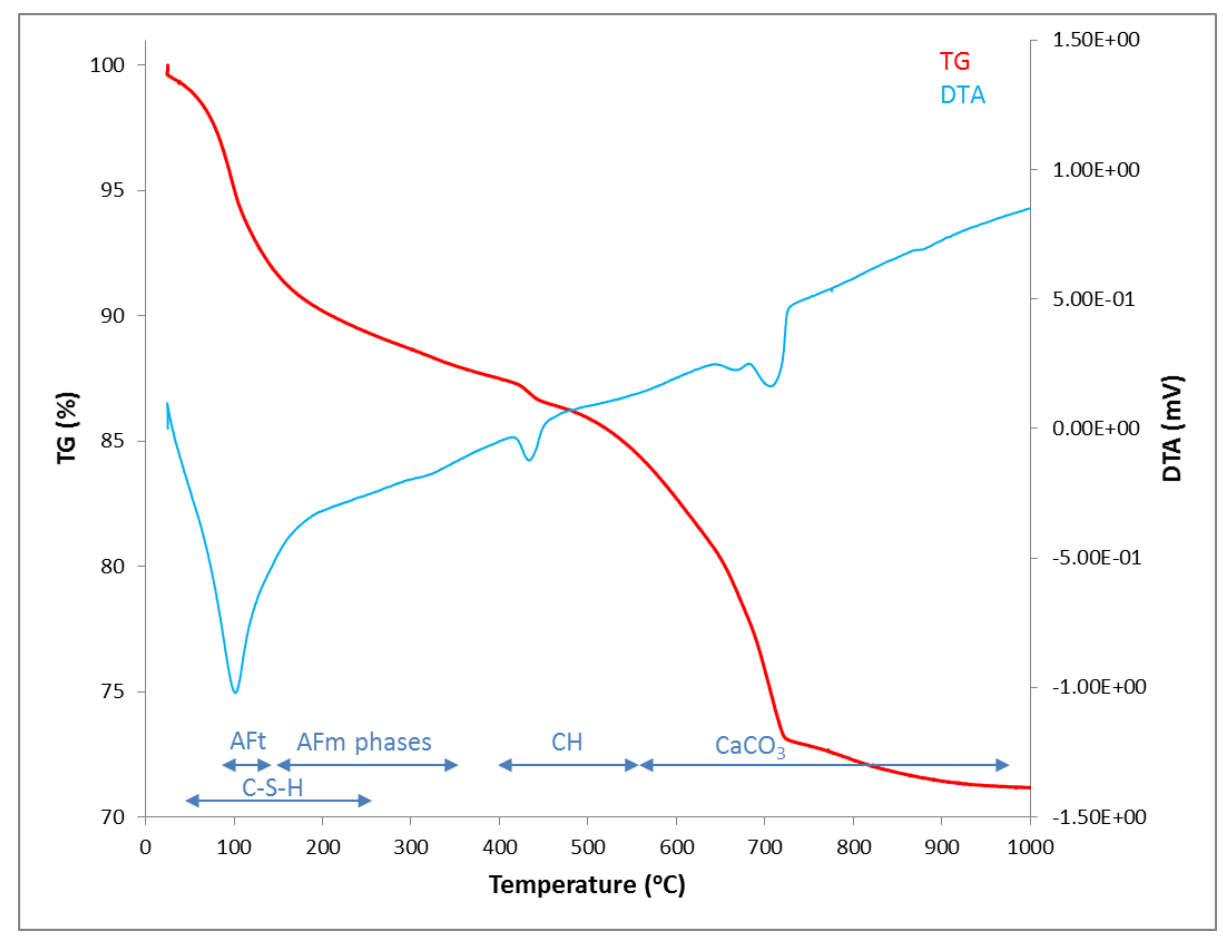

Figure 3.6. TG and DTA plots for CEMI (w/b 0.57) sample cured for 72 hours and exposed to ambient $\left[\mathrm{CO}_{2}\right]$ for 7 days highlighting temperature ranges in which mass loss due to decomposition of the hydrate phases and $\mathrm{CaCO}_{3}$ is expected to occur

The carbonate species, and even its crystallite size [99], have an effect on the decomposition temperature and position of the endotherm/endotherms in the TGA and DTA curves respectively. Thiery et al. [61] reports 3 decomposition modes associated with carbonation: mode I $\left(780-990^{\circ} \mathrm{C}\right)$, 
mode II $\left(680-780^{\circ} \mathrm{C}\right)$ and mode III $\left(550-680^{\circ} \mathrm{C}\right)$. The higher decomposition modes, mode I \& II, are attributed to crystalline polymorphs of $\mathrm{CaCO}_{3}$ (calcite, vaterite and aragonite), with mode I being principally attributed to calcite. Mode III is believed to be associated with amorphous $\mathrm{CaCO}_{3}$. Similar behaviour was described by Villain et al. [100] for highly hydrated mortar samples subjected to accelerated carbonation, in which dissociation of stable $\mathrm{CaCO}_{3}$ (calcite), attributed to $\mathrm{Ca}(\mathrm{OH})_{2}$ carbonation, occurred between $650-950^{\circ} \mathrm{C}$, while unstable forms of vaterite and aragonite resulting from $\mathrm{C}-\mathrm{S}-\mathrm{H}$ carbonation dissociated between $530-650^{\circ} \mathrm{C}$. A much lower temperature range, $300-660^{\circ} \mathrm{C}$, for decomposition of aragonite and vaterite was observed by Chang and Fang [101], however the authors studied carbonation of synthetic C-S-H samples, which is expected to produce more amorphous/less well ordered carbonate phases [100]. Partial decomposition of amorphous $\mathrm{CaCO}_{3}$ to $\mathrm{CaO}$ and calcite was reported by Goto et al. [102] between $400-600^{\circ} \mathrm{C}$.

\subsubsection{Experimental setup}

Hydration stopped samples were ground to a fine powder in an agate pestle and mortar and 15 $18 \mathrm{mg}$ added to a platinum crucible. Samples were heated from $20-1000^{\circ} \mathrm{C}$ on a Stanton Redcroft Simultaneous Thermal Analyser STA 780 under a $\mathrm{N}_{2}$ atmosphere at a uniform rate of $10^{\circ} \mathrm{C} / \mathrm{minute}$ (note heating rate for experimental scoping was performed at $20^{\circ} \mathrm{C} / \mathrm{min}$ ).

The weight loss due to decomposition of $\mathrm{Ca}(\mathrm{OH})_{2}$ and $\mathrm{CaCO}_{3}$ to $\mathrm{CaO}+\mathrm{H}_{2} \mathrm{O}$ and $\mathrm{CaO}+\mathrm{CO}_{2}$ respectively, and the molecular masses of the phases can be used to calculate the quantity of portlandite and $\mathrm{CaCO}_{3}$ present in the sample. The weight loss associated with dehydration of $\mathrm{CH}$ and decarbonation of $\mathrm{CaCO}_{3}$ is measured using the tangent method. Inflection points on the DTA curve identify the region of mass loss and tangents are drawn before and after the change in mass. The weight loss due to dehydration or decarbonation is then measured at the mid-point of this range between the tangent lines, and example for $\mathrm{CH}$ is given in Figure 3.7. This approach is particularly relevant for determining the mass loss due to portlandite where simultaneous decomposition of the hydrate phases occurs over large and similar temperature ranges. 


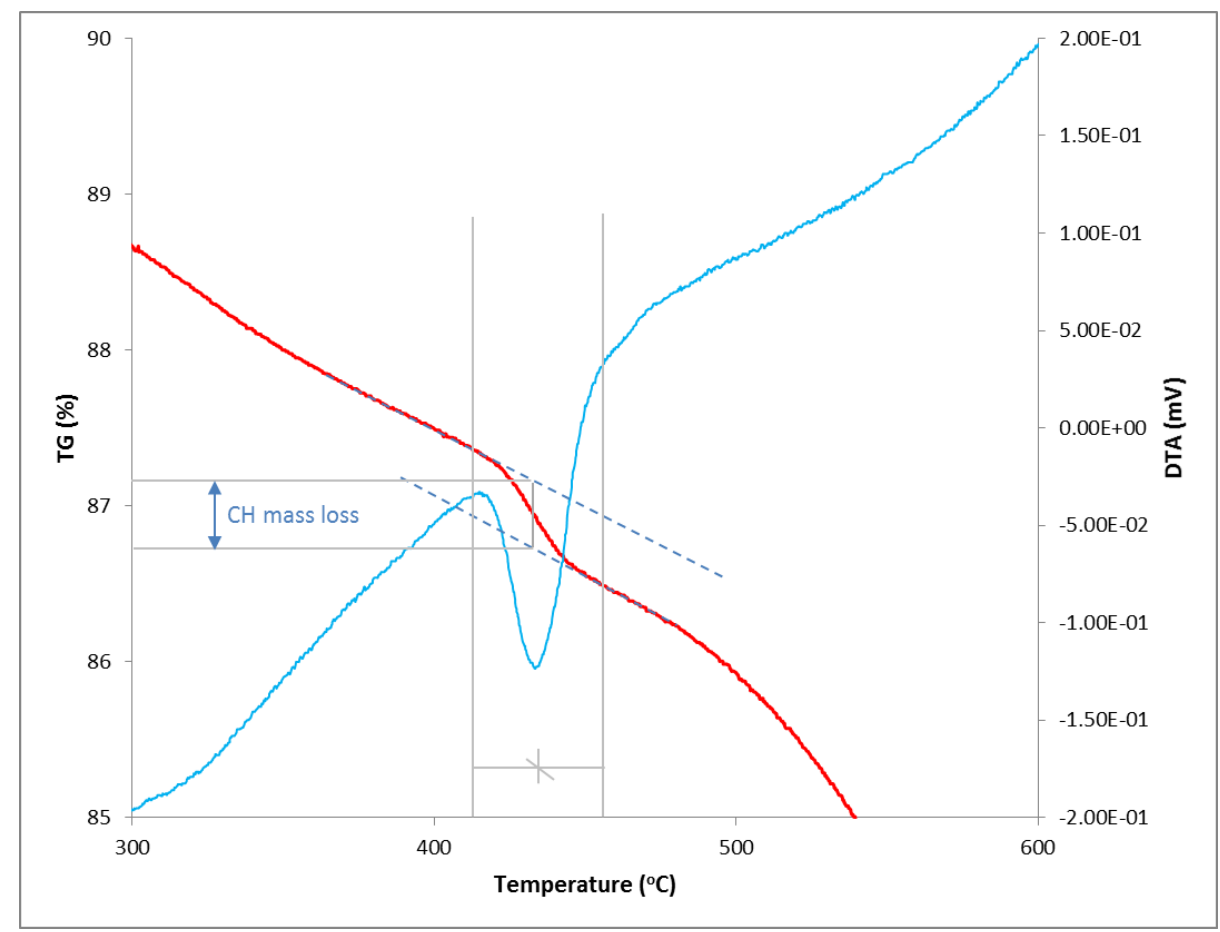

Figure 3.7. Example of determination of mass loss due to decomposition of $\mathrm{CH}$ using the tangent method

The measured weight losses can then be used in the equations below to calculate the quantities present in the hydrated cement. Measurements are normalised to dry weight, in this case to the mass of the sample at $1000^{\circ} \mathrm{C}$, effectively reporting the values per $100 \mathrm{~g}$ of anhydrous material.

$$
\% \mathrm{CH}=\mathrm{CH}_{\mathrm{WL}} \times \frac{m m \cdot C H}{m m \cdot H 2 O}
$$

where:

$\mathrm{CH}_{\mathrm{WL}}=$ weight loss associated with $\mathrm{CH}$

$m m \cdot \mathrm{CH}=$ molar mass of $\mathrm{CH}\left(74 \mathrm{~g} \cdot \mathrm{mol}^{-1}\right)$

$m m \cdot H 2 O=$ molar mass of $\mathrm{H}_{2} \mathrm{O}\left(18 \mathrm{~g} \cdot \mathrm{mol}^{-1}\right)$

$$
\% \mathrm{CaCO} 3=\mathrm{CaCO}_{\mathrm{wL}} \times \frac{\mathrm{mm} \cdot \mathrm{CaCO} 3}{\mathrm{~mm} \cdot \mathrm{CO} 2}
$$


where:

$\mathrm{CaCO}_{3}$ wL $=$ weight loss associated with $\mathrm{CaCO}_{3}$

$m m \cdot C a C O 3=$ molar mass of $\mathrm{CaCO}_{3}\left(100 \mathrm{~g} \cdot \mathrm{mol}^{-1}\right)$

$\mathrm{mm} \cdot \mathrm{CO} 2=$ molar mass of $\mathrm{CO}_{2}\left(44 \mathrm{~g} \cdot \mathrm{mol}^{-1}\right)$

Finally, the bound water content of the paste samples was calculated as the change in mass between 50 and $550^{\circ} \mathrm{C}$. At $550^{\circ} \mathrm{C}$ all hydrate phases are considered to have decomposed, and again values are reported with respect to the dry weight at high temperature $\left(1000^{\circ} \mathrm{C}\right)$. The bound water calculation is given below.

$$
\mathrm{H}_{2} \mathrm{O}_{\text {bound }}=\frac{W 50-W 550}{W 550} \times 100
$$

$W_{50}=$ weight at $50^{\circ} \mathrm{C}$

$w_{550}=$ weight at $550^{\circ} \mathrm{C}$

\subsubsection{Attenuated total reflectance - Fourier transform infrared spectroscopy (ATR-FTIR)}

\subsubsection{Principle of Attenuated total reflectance - FTIR}

FTIR techniques measure changes in the intensities of electromagnetic radiation passed through a sample. Molecules absorb electromagnetic radiation at characteristic frequencies corresponding to the frequency of vibrations between atomic bonds, measuring changes in the intensity at particular wavenumbers of an infrared spectrum allows identification of the groups present in the material. Fundamentally, FTIR provides a molecular fingerprint and is not dependent on a solid possessing long range order, making it an ideal technique for the study of cement [103].

In ATR-FTIR, the infrared radiation is passed through a crystal, or internal reflectance element (IRE), with a high refractive index (i.e. larger than that of the sample). The internal reflectance produces an evanescent wave which extends just beyond the crystal surface, penetrating a few microns into the sample surface. The changes in the internally reflected beam following contact with the sample are measured and reported as peaks over a large spectral range in which their intensity is related to 
the amount present. Diamond is an ideal choice for cement as it has a high refractive index (2.41) [104] and is chemically and physically durable.

ATR-FTIR provided a more detailed and complete carbonation profile, allowing identification of both crystalline and amorphous carbonate polymorphs. Furthermore, information regarding changes in $\mathrm{CH}$ content due to carbonation and the detection of silica gel as a product of decalcification of C-S$\mathrm{H}$ was possible.

\subsubsection{Experimental setup}

ATR-FTIR spectroscopy data was collected using a Thermo Scientific Nicolet Is10 spectrometer, fitted with a Thermo Scientific Smart Diamond ATR sampling accessory over a $0-4000 \mathrm{~cm}^{-1}$ wavenumber range. Hydration stopped samples were ground to a fine powder in an agate pestle and mortar and just enough sample was placed onto the crystal (IRE) to cover it. A top crystal, positioned in a pressure arm, was locked into place over the crystal/sample area and clamped down applying force to the sample. In order to obtain high quality spectra the contact between the sample and the crystal is crucial[103]. This can be a problem for solid samples, however grinding the cement samples to a sufficient fineness and clamping the sample onto the crystal provides suitable contact between the crystal and sample surface to produce good quality spectra [103]. The output was the sum of 32 spectra and a background spectra was collected initially and then after every third sample. The background was collected on the cleaned crystals, when no sample was present.

\subsubsection{Magic angle spinning nuclear magnetic resonance (MAS NMR)}

\subsubsection{Principle of magic angle spinning nuclear magnetic resonance}

NMR uses nuclei that posess a property called spin (having a value of an integer or half integer) to analyse materials. In a nucleus the number of spin energy levels is given by $21+1$ and each has a value of I, I-1, I-2,....,-I. When a magnetic field is not present each level has the same energy, however when a magnetic field is present, an energy difference exists between the energy states and is referred to as Zeeman splitting $[105,106]$. This is illustrated in Figure 3.8 for a nucleus with spin $\mathrm{I}=1 / 2$. 


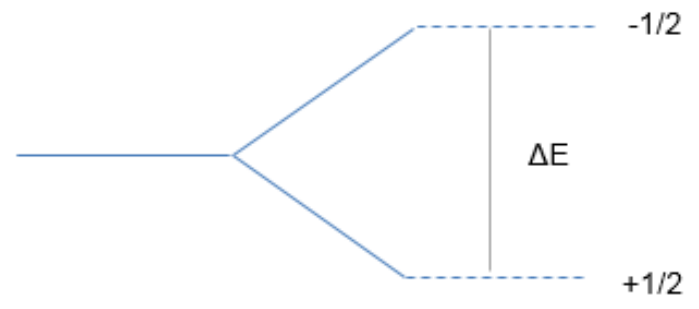

No magnetic field Zeeman splitting

Figure 3.8. Energy level diagram for nucleus with spin I=1/2 (reproduced from [105])

The nucleus is then excited by a pulse of radiofrequency radiation which causes transitions to occur between the energy levels. Once the radiofrequency pulse is turned off, the nucleus relaxes back to its original state inducing a current in a radiofrequency coil. This measured frequency of energy is reported as a chemical shift $(\delta)$ and relates to the local structural environment of the sample.

Solid-state NMR experiences line broadening effects which result from interactions of the spin nuclei (dipolar broadening, quadrupole interaction, spin-spin couplings). These interferences produce either different resonance frequencies to be recorded for nuclei in sites orientated differently with respect to the applied magnetic field, or a range of magnetic fields to be recorded for an individual nucleus. In solution NMR molecular tumbling means these effects are of no concern. Replication of this phenomenon in solid-state studies by magic angle spinning (MAS) considerably reduces these interactions and therefore the line broadening usually observed. MAS rotates the sample around a fixed axis relative to the magnetic field. The coupling effects contain a geometrical dependence $\left(3 \cos ^{2} \theta-1\right)$ and when $\theta$ is equal to $54.7^{\circ}$, i.e. $3 \cos ^{2} \theta-1=0$, mimicking molecular tumbling in solutions, the interactions are substantially lessened. Therefore, in solid-state NMR the magic angle is set to $54.7^{\circ}[105,106]$.

The sensitivity of NMR spectroscopy to local structural ordering allows characterisation of noncrystalline phases, making it particularly useful for the study of cementitious materials. ${ }^{29} \mathrm{Si}$ and ${ }^{27} \mathrm{Al}$ MAS NMR have been extensively used to investigate the hydration of neat cement and blended 
cement systems by investigating the connectivity of $\mathrm{SiO}_{4}$ tetrahedron and $\mathrm{Al}^{3+}$ correspondingly [52, 64, 107-110].

Silicate tetrahedra are connected via oxygen and denoted as $Q^{n}$ where $0 \leq n \leq 4$. $Q^{0}$ species represent isolated tetrahedra present in unreacted alite and belite, while $Q^{1}$ and $Q^{2}$ designate end chain and middle chain species in the hydrate C-S-H phase respectively [111]. $\mathrm{Q}^{2}(1 \mathrm{Al})$ indicates a middle chain group in which an adjacent tetrahedron is occupied by Al [111]. Cross linking and branching sites give rise to $\mathrm{Q}^{3}$ and $\mathrm{Q}^{4}$ species which reveal condensation of the $\mathrm{Si}$ in $\mathrm{C}-\mathrm{S}-\mathrm{H}$ to form an amorphous silica phase. This is usually the result of removal of $\mathrm{Ca}$ from $\mathrm{C}-\mathrm{S}-\mathrm{H}$, as in the carbonation reaction [63].

In ${ }^{27} \mathrm{Al}$ NMR spectra, Al incorporated in the calcium sulfoaluminate phases, or as a guest ion in C-S$\mathrm{H}$, produce resonances for octahedral (AFt, AFm) and tetrahedral (C-S-H) coordinations. Peaks at $\approx 9 \mathrm{ppm}$ and $\approx 13 \mathrm{ppm}$ are indicative of $\mathrm{Al}$ incorporated into the AFm phases and AFt respectively, whereas a broad peak at $\approx 65 \mathrm{ppm}$ is ascribed to Al incorporated in C-S-H $[63,110]$.

\subsubsection{Experimental setup}

${ }^{29} \mathrm{Si}$ and ${ }^{27} \mathrm{AI}$ MAS MNR spectra were obtained at the EPSRC UK National Solid-State NMR service at Durham University. Hydration stopped samples were ground to a fine powder in an agate pestle and mortar before being sent to the NMR facility.

Direct excitation ${ }^{29} \mathrm{Si}$ NMR experiments were performed on a Varian VNMRS 400 spectrometer with a $6 \mathrm{~mm}$ rotor and tetramethylsilane as the reference standard. The direct excitation used a pulse duration of $4.0 \mu$ s and a spin rate of $6000 \mathrm{~Hz}$. An acquisition time of $30 \mathrm{~ms}$, a 10 second recycle time and between 5000-6000 repetitions were used for each of the samples.

${ }^{27} \mathrm{AI}$ NMR direct excitation were performed on a Varian VNMRS 400 spectrometer using a $4 \mathrm{~mm}$ rotor and $1 \mathrm{M}$ aqueous $\mathrm{Al}\left(\mathrm{NO}_{3}\right)_{3}$ as the reference. The direct excitation used a pulse duration of $1.0 \mu \mathrm{s}$ and a spin rate of between $12000-14000 \mathrm{~Hz}$. The acquisition time, recycle time and number of repetitions were $10 \mathrm{~ms}, 0.2 \mathrm{~s}$ and 7000 respectively.

Deconvolution of the ${ }^{29} \mathrm{Si}$ NMR spectra provides quantitative information on the structural ordering of the sample. Deconvolutions were performed using a user made procedure for Igor Pro (WaveMetrics) developed by Brough (1993) and further developed by Love and Brough [112]. The baseline was fitted using a cubic multinomial function and the individual peaks fitted with a Voigt 
line shape. Intensity, peak shift and peak shape and width peak parameters were released sequentially until the residual plot between the experimental and simulated spectra was at a minimum. Integrated areas of each of the fitted peaks were then used to calculate mean aluminosilicate chain length (MCL) and $\mathrm{Al} / \mathrm{Si}$ ratio as shown in the equations below.

$$
\begin{aligned}
M C L & =\frac{2}{\frac{Q^{1}}{Q^{1}+Q^{2}+3 / 2 Q^{2}(1 A l)}} \\
\mathrm{Al} / \mathrm{Si} & =\frac{1 / 2 Q^{2}(1 A l)}{Q^{1}+Q^{2}+Q^{2}(1 A l)}
\end{aligned}
$$

\subsubsection{X-ray diffraction (XRD)}

\subsubsection{Principle of x-ray diffraction}

X-ray diffraction is used to identify and quantify crystalline phases in a sample. Materials in which atoms are held in a periodic lattice (i.e. having long range order / crystalline) cause elastic scattering of x-ray photons, constructive interference occurs at characteristic angles, giving the appearance of the $x$-rays being reflected. The characteristic angles plus relative intensities allow identification by reference to databases (ICSD (Inorganic Crystal Structure Database), ICDD (International Centre for Diffraction Data), COD (Crystallography Open Database)).

Constructive interference occurs when x-rays at different lattice planes are in phase, producing a peak in intensity which is recorded by a detector. Bragg's Law, given below, uses constructive interference of reflected $\mathrm{x}$-rays to calculate lattice spacings which are unique for each crystal [113].

$$
\mathrm{n} \lambda=2 \mathrm{~d} \sin \theta
$$

where:

$\mathrm{n}=$ integer, called the order of reflection

$\lambda=$ wavelength of $x$-rays

$d=$ characteristic spacing between lattice planes

$\theta=$ angle of incidence 
XRD measurements allow the development of the cement hydrate phase assemblage to be studied [114-116] and quantitative measurements can also be used to determine its degree of hydration. Although many of the hydrate phases are crystalline ( $\mathrm{CH}, \mathrm{AFt}, \mathrm{AFm}$ phases, hydrotalcite-like phase), C-S-H and unreacted slag and PFA are amorphous, appearing as broad humps across a range of angles. In regards to carbonation studies, the presence of crystalline $\mathrm{CaCO}_{3}$ phases (calcite, vaterite and aragonite) will produce strong Bragg reflections, however the formation of amorphous $\mathrm{CaCO}_{3}$ will potentially result in an underestimation of total carbonate content.

\subsubsection{Experimental setup - qualitative XRD}

Qualitative phase analysis was used to study samples included in the experimental scoping study (Chapter 4), focusing on changes in $\mathrm{CH}$ and $\mathrm{CaCO}_{3}$ as a result of carbonation. Hydration stopped samples were ground to a fine powder in an agate pestle and mortar and back loaded into a sample holder. Diffraction patterns were collected with a Bruker D2 Phaser operated at 30kV and 10mA equipped with CuKa radiation source between $5-70^{\circ} 2 \theta$, a step size of 0.008 and a dwell time of 1.0 second were used.

\subsubsection{Principle of the Rietveld method}

The Rietveld method is a crystal structure refinement that can be used to determine quantitative phase content information. It uses whole powder pattern fitting to match a simulated diffraction pattern with that of an experimentally measured one using a least squares approach by minimising the difference between the calculated and measured patterns at each data point $[117,118]$. The intensity (i) at any given point can be a combination of many Bragg reflections. The calculated intensities $\left(\mathrm{y}_{\mathrm{ci}}\right)$ are determined from structural function values $\left(\mathrm{F}_{\mathrm{k}}\right)$ calculated from the structural model by summing the calculated contributions of the background and all neighbouring Bragg reflections of the phases as in the equation below [117].

Global (background, sample displacement) and phase dependent (scale factor, unit cell, peak profile function) parameters are included in the refinement, while it is not recommended to perform refinement of crystal structure parameters such as atomic positions, atomic displacement and site occupancies [118]. 


$$
y_{c i}=s \sum L_{k}\left|F_{k}\right|^{2} \phi\left(2 \theta_{i}-2 \theta_{k}\right) P_{k} A+y_{b i}
$$

where:

$s=$ scale factor

$\mathrm{K}=$ miller indices for a Bragg reflection

$L_{k}=$ Lorentz, polarization and multiplicity factors

$\Phi=$ reflection profile function

$\mathrm{P}_{\mathrm{k}}=$ preferred orientation function

$A=$ absorption factor

$F_{k}=$ structure factor

$\mathrm{Y}_{\mathrm{bi}}=$ background intensity

\subsubsection{Selective dissolution}

Stutzman [119] provides methods for selective extractions that can be used to improve identification of the correct crystal structure of the main anhydrous phases in cement clinker. The selective elimination of particular phases removes complications in the diffraction pattern caused by peak overlap, allowing the correct structures to be more easily determined.

The aluminate and ferrite interstitial phases were dissolved using a potassium hydroxide/sugar solution $(\mathrm{KOH} / \mathrm{S})$, enriching the silicate phases. Meanwhile, a salicylic acid/methanol solution $(\mathrm{SA} / \mathrm{M})$ was used to dissolve the silicates, enriching the interstitial phases. Figure 3.9 displays the XRD data collected for the as received cement and the extracted residues. 


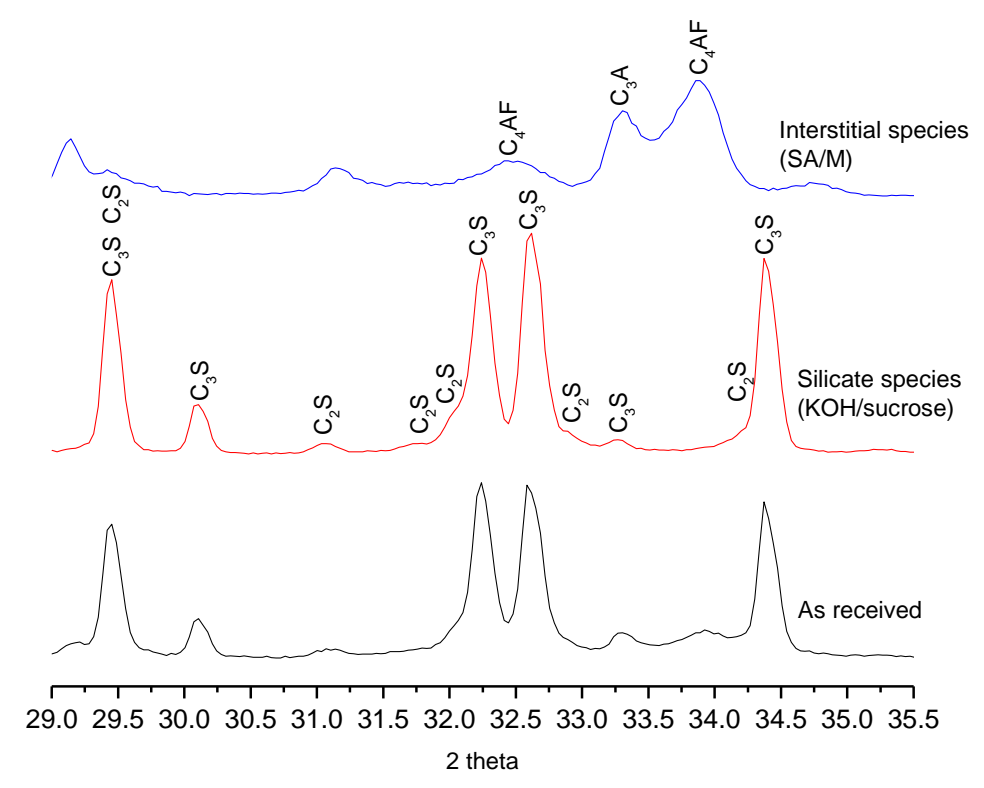

Figure 3.9. XRD patterns of as received CEM 52.5R, potassium hydroxide/sugar $(\mathrm{KOH} / \mathrm{S})$ selective extraction residue and salicylic acid/methanol (SA/M) selective extraction residue

Using the XRD patterns collected for the enriched residues, the polymorphs of the main clinker phases were identified. Courtial et al. [120] suggests analysing particular angular windows to assist in differentiating between the different monoclinic forms of alite. Using the approach proposed by Courtial et al. [120] and guidance provided by Stutzman [119], both $M_{1}$ and $M_{3}$ structures of $C_{3} S$ were observed to be present. Although the selection of alite polymorph has been shown not to have a large influence on quantification results, recommended practice suggests selecting just one structure to limit the inclusion of redundant parameters in the refinement [114]. The $M_{3}$ structure was selected for the $C_{3} S$ phase, the $\beta$ form for $C_{2} S$, as this was the only polymorph observed, and both cubic and orthorhombic structures of $\mathrm{C}_{3} \mathrm{~A}$ were found to co-exist.

\subsubsection{Control file}

The structural models identified in the anhydrous cement were then used to develop a control file, this acts as the initial input model for the quantitative analysis. Refinement of both phase dependent (lattice parameters, scale factor \& preferred orientation) and global parameters (sample displacement, coefficient of background function) were first carried out on the main clinker phases $\left(C_{3} S, C_{2} S, C_{3} A, C_{4} A F\right)$ using the enriched residue patterns. Constraints on lattice constants were set 
to $\pm 1 \%$ of the initial values in order to ensure the results remained chemically sensible [118]. The structure files were then used in the fitting of the as received cement with the addition of minor phases such as calcium sulphates, lime and alkali sulphates. The experimental and calculated patterns for the anhydrous CEM52.5R are shown in Figure 3.10 below.

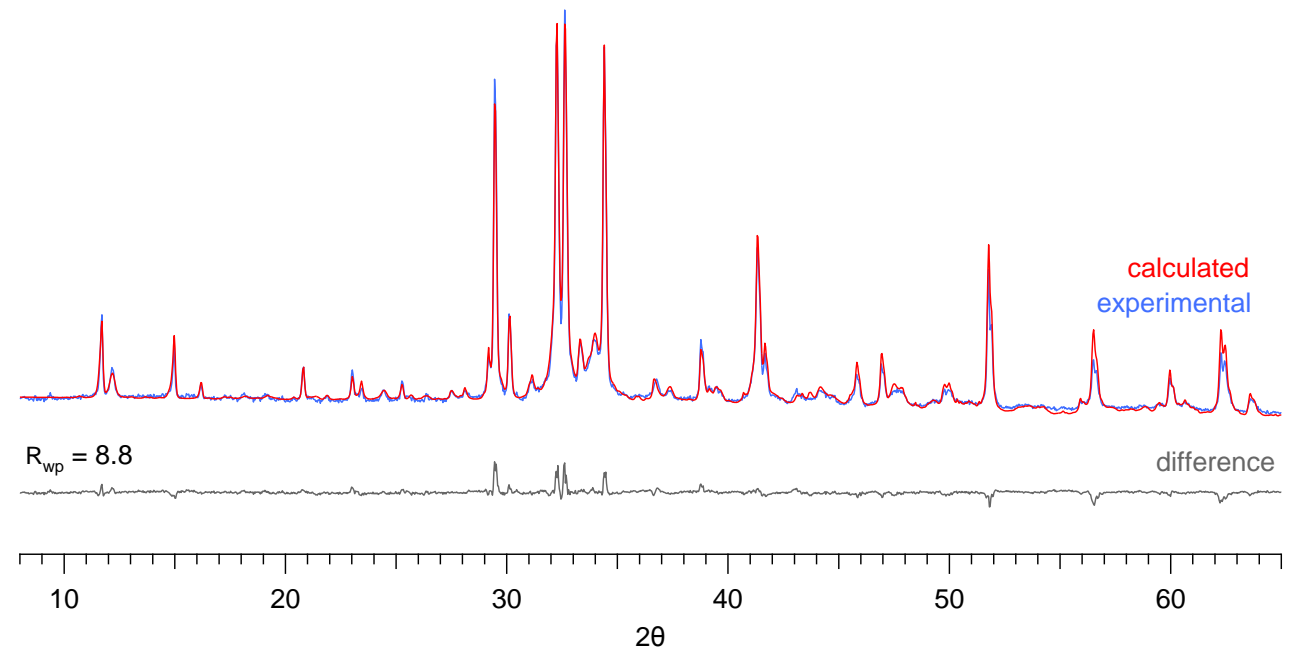

Figure 3.10. Rietveld refinement of anhydrous CEM52.5R showing the experimental data, the calculated pattern and the difference plot

In the hydrated samples, additional hydrated crystalline phases were included. Table 3.6 provides information of the phases used in the quantitative analysis, including ICSD codes, structural models and phase dependent refined parameters. Global parameters such as sample displacement and the coefficient of background function were refined for all structures.

Although sample back loading can reduce the effects of preferred orientation, it can be quite difficult to eliminate completely [121]. Phases such as alite, portlandite and calcium sulphates are more prone to preferred orientation, therefore when it is clearly observed in a XRD pattern an intensity correction is included in the refinement. Preferred orientation was optimised last and only when necessary using the March-Dollase model [122]. 
Table 3.6. Table of structures and phase dependent parameters used in Rietveld refinement

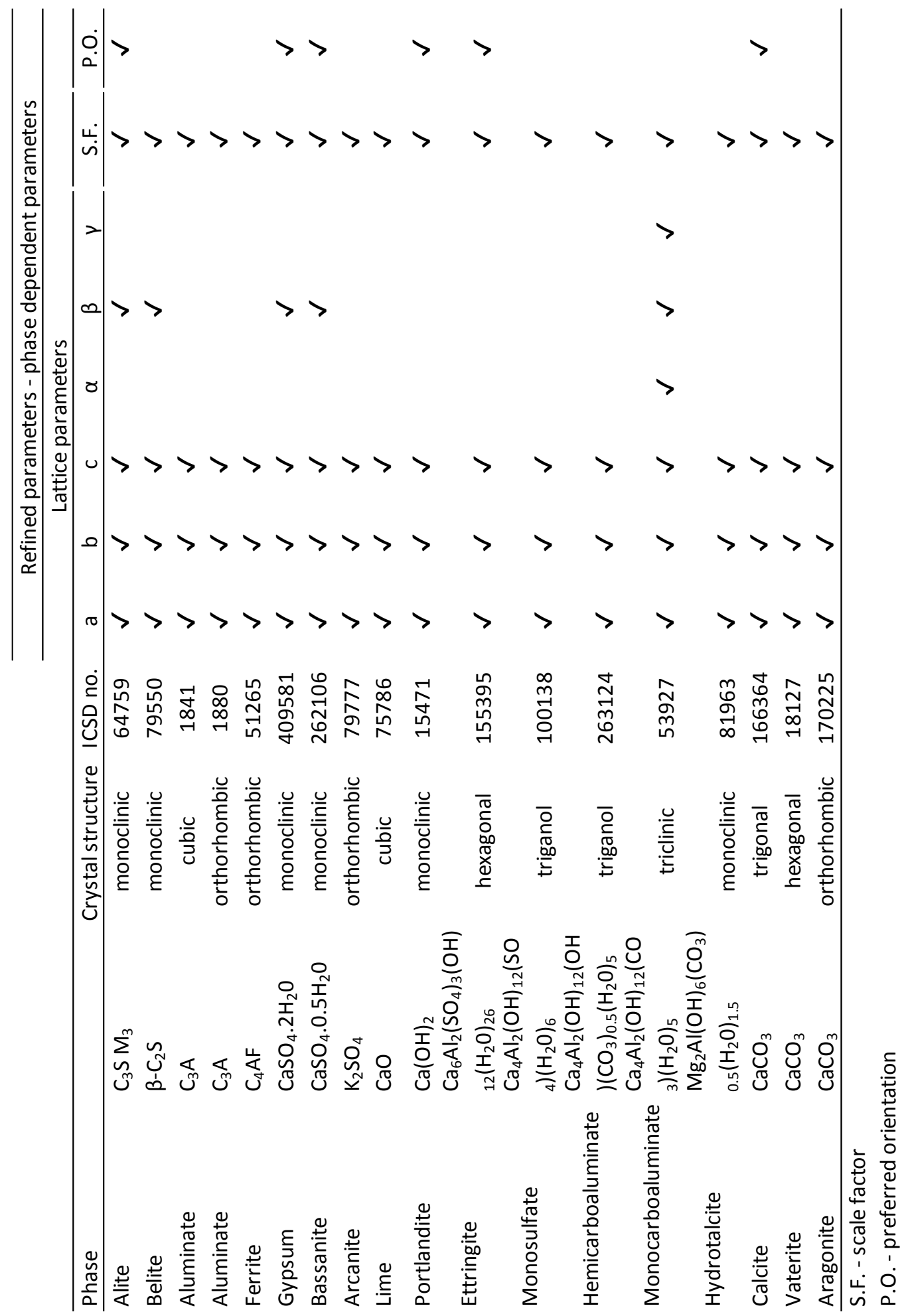




\subsubsection{Quantification using the G-factor method}

The values calculated by the Rietveld refinement for crystalline phases are given as $100 \%$ by weight. This approach is therefore suitable when analysing anhydrous cement in which levels of amorphous phases have been shown to be negligible $[114,123,124]$. However, hydrated cement systems and materials incorporating SCMs require an alternative approach to account for amorphous species.

The external standard method, or the G factor method, has been successfully used to quantify cement systems $[114,116,118,125]$ and has the added advantage that additional preparation processes, such as homogenisation of the sample and standard as in the internal standard method, are not required. By comparing a scale factor determined for a sample to that of a standard reference material measured under identical experimental conditions, the real weight fractions can be calculated. Corundum ( $\alpha-\mathrm{Al}_{2} \mathrm{O}_{3}$ - Alfa Aesar) was used as the reference material in the quantification procedure applied here, where its crystallinity was determined by comparison with a NIST-certified $\mathrm{Al}_{2} \mathrm{O}_{3}$ reference.

The weight content of a phase is determined using the equation below. Calculation of the mass attenuation coefficient (MAC) of the sample was done using the oxide composition of the asreceived cement as measured by XRF. MAC values for each oxide can be found in the International Tables for Crystallography [126], the individual oxide values were weighted and summed to give a total MAC value for the sample. In hydrated systems the water content also needs to be considered and was accounted for in the MAC calculation.

The degree of hydration of the cement is then calculated by comparing the total content of the main clinker phases $\left(C_{3} S, C_{2} S, C_{3} A \& C_{4} A F\right)$ with that of the initial total content determined in the anhydrous material $[12,118]$.

$$
C_{j}=S_{j} \frac{\rho_{j} V_{j}^{2} \mu_{\text {sample }}}{G}
$$

where:

$$
G=S_{c} \frac{\rho_{c} V_{c}^{2} \mu_{c}}{C_{c}}
$$

where: 


$\begin{array}{ll}\mathrm{C}_{\mathrm{j}}=\text { content of phase } \mathrm{j} & \mathrm{S}_{\mathrm{c}}=\text { scale factor of corundum } \\ \mathrm{S}_{\mathrm{j}}=\text { scale factor of phase } \mathrm{j} & \rho_{\mathrm{c}}=\text { density of corundum } \\ \rho_{\mathrm{j}}=\text { density of phase } \mathrm{j} & \mathrm{V}_{\mathrm{c}}=\text { cell volume of corundum } \\ \mathrm{V}_{\mathrm{j}}=\text { cell volume of phase } \mathrm{j} & \mu_{\mathrm{ce}}=\text { MAC of corundum } \\ \mu_{\text {sample }}=\text { MAC of sample } & \mathrm{C}_{\mathrm{c}}=\text { content of corundum }\end{array}$

\subsubsection{Experimental setup}

The effects of drying on the decomposition of ettringite and the AFm-phases can be significant. Snellings [118] compared XRD data collected for fresh samples and samples exposed to solvent exchange (slices and powder for both) in isopropanol for a week and concluded that solvent exchange was particularly detrimental to AFt and hemicarboaluminate, and crushing of samples caused some decomposition of monocarboaluminate. Although Snellings [118] reported that shorter solvent exchange periods would mitigate these effects and be suitable for quantitative XRD measurements, data in this study were collected on fresh powders to prevent decomposition of these phases as much as possible.

Fresh samples were crushed to a fine powder in an agate pestle and mortar and back loaded into a sample holder. Data was collected with a Bruker D2 Phaser with a $141 \mathrm{~mm}$ goniometer radius operated at $30 \mathrm{kV}$ and $10 \mathrm{~mA}$ equipped with CuKa radiation source. A LYNXEYE linear position sensitive detector was used for data acquisition and data was collected over an angular range of $5^{\circ}$ $-70^{\circ} 2 \theta$ with a 0.034 step size, a dwell time of 2 seconds and a continuous rotation of 15 rotations/min.

Rietveld quantitative phase analysis was carried out using Topas Academic 4.2 software using the external standard method. Corundum was used as the reference material and reference structure files were exported from ICSD (Inorganic Crystal Structure Database). 


\subsection{Microstructural characterisation}

\subsubsection{Analytical transmission electron microscopy (TEM)}

\subsubsection{Principle of analytical transmission electron microscopy}

Analytical TEM allows information on both the morphology of the microstructure and its chemical composition (via energy dispersive x-ray (EDX) analysis) to be obtained. This high resolution technique allows characterisation of the finely intermixed hydrate phases to be determined, many of which are amorphous or poorly crystalline, and information regarding their spatial distribution to be collected. Richardson [127] provides a comprehensive review of analytical TEM techniques, discussing their application to the examination of cement systems. The review highlights and discusses various studies in the literature that have employed TEM to analyse the microstructure of hardened cement paste samples [22, 128-130].

The ability of the high resolution technique to analyse phases free from intermixing becomes of particular importance in carbonation studies. Microcrystalline $\mathrm{CaCO}_{3}$ is known to form within the C$\mathrm{S}-\mathrm{H}$ gel [79], therefore determination of an accurate $\mathrm{Ca} / \mathrm{Si}$ ratio using lower resolution microanalysis techniques, such as SEM-EDX, would not be possible. TEM-EDX allows compositional changes in the C-S-H due to carbonation, as well as visual changes in the morphology, to be established with confidence. Before EDX data was collected on an area of $\mathrm{C}-\mathrm{S}-\mathrm{H}$, a selected area electron diffraction pattern (SAEDP) was obtained. Only if the SAEDP indicated the area was completely amorphous was the EDX data collected and used to calculate the composition of the C-S-H phase. Figure 3.11 below provides an example of a SAEDP collected in this study, the diffuse rings and absence of spots confirm a completely amorphous area of $\mathrm{C}-\mathrm{S}-\mathrm{H}$, free from intermixing from crystalline species.

TEM analysis of cement paste samples does however present a number of limitations. Preparation of electron transparent specimens can be extensive and time consuming, but more importantly samples have the potential to become damaged during both imaging and EDX analysis. Richardson's review [127] discusses electron-beam damage, providing an overview of examples in the literature in which beam damage is evident in TEM micrographs. In practice, minimising exposure to the electron beam by using lower magnifications for general viewing and sensitive areas, and using higher magnifications only when necessary, as it is at higher magnifications in which the fastest damage is seen to occur, should be observed $[108,127,131]$. 


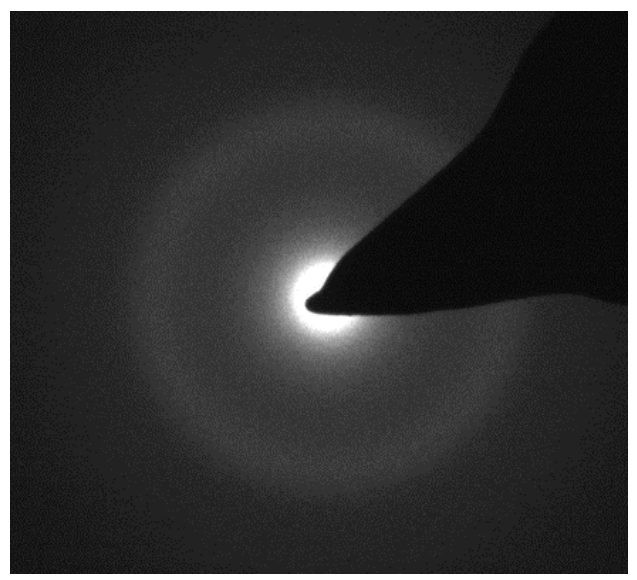

Figure 3.11. Selected area electron diffraction pattern collected on an area of C-S-H showing area is completely free of microcrystalline phases

\subsubsection{Experimental setup}

In order to provide information on the bulk microstructure and spatial relationships of the hydrate phases, as well as the products of carbonation, TEM analysis was performed on ion-beam milled sections.

Hydration stopped $0.5 \mathrm{~mm}$ discs were flattened using $600 \mu \mathrm{m} \mathrm{SiC} \mathrm{paper,} \mathrm{removing} \mathrm{the} \mathrm{surface} \mathrm{layer.}$ Comparison of ${ }^{29} \mathrm{Si}$ MAS NMR spectra and Ca/Si ratios determined from TEM-EDX data indicated sampling effects on carbonated samples. The surface of the carbonated discs suggested a much lower $\mathrm{Ca} / \mathrm{Si}$ ratio than that indicated from bulk analysis techniques such as ${ }^{29} \mathrm{Si}$ NMR. XRD measurements taken from the surface of samples and at subsequent depths towards the centre, confirmed the presence of a carbonate gradient. Therefore, care was taken to remove the outermost, most heavily carbonated, layer in order to provide a more representative section of the sample.

The flattened sections were attached to a glass slide with cyanoacrylate glue and thinned by hand using progressively finer grades of SiC paper $(600 \mu \mathrm{m}, 800 \mu \mathrm{m}, 1200 \mu \mathrm{m}$, and $2400 \mu \mathrm{m})$. Thinning was performed as uniformly as possible until a thickness of approximately $30 \mu \mathrm{m}$. Specimens were then removed from the glass slides by submersion in acetone and glued between two $3 \mathrm{~mm}$ diameter copper TEM grids using quick drying epoxy. The sample was exposed via a central hole with 
dimensions of $2 \times 1 \mathrm{~mm}$. Samples were then argon ion-beam milled in one of two machines: Fischione Model 1010 low angle miller or Gatan Precision Ion Polishing System (PIPS). Milling was performed under vacuum until a hole had formed in the centre of the sample, the region around the hole then expected to be electron transparent.

The stage of the Fischione low angle miller was cryo-cooled using liquid nitrogen in order to avoid heat damage to the sample from the milling process $[127,132]$. The ion beam for each gun was set at $4 \mathrm{kV}$ with a current of $3 \mathrm{~mA}$ (thinning rate of $<4 \mu \mathrm{m} / \mathrm{h}$ [127]) and milling was performed at an angle of $15^{\circ}$ (sample stage) with continuous rotation.

The Gatan PIPS was set at $3 \mathrm{keV}$. As cooling of the stage was not an option for the equipment, the guns were set at a milling angle of $4^{\circ}$. The glancing incidence of the guns to the specimen vastly reduces the input energy to the sample, preventing damage due to thermal effects. The advantage of this preparation technique is a much larger electron transparent area is produced.

Samples were stored in a desiccator and carbon coated using an Agar Turbo Carbon Coater prior to observation.

TEM samples were examined using a FEI Tecnai F20 200kV FEG TEM fitted with a Gatan Orius SC600 CCD camera and an Oxford Instruments $80 \mathrm{~mm}^{2}$ SDD EDX detector running INCA or Aztec software. General viewing of the microstructure was done at a magnification of $5 k$, increasing the magnification if necessary on sites of interest and to collect micrographs (usually collected between $5-10 k)$. Collection of EDX data was done at $22 k$ with a spot size of $5 / 6$ and an acquisition time of 20s. As previously discussed, prior to EDX analysis of areas of C-S-H, the SAED aperture was inserted to confirm the area was free from intermixed microcrystalline phases $\left(\mathrm{CaCO}_{3}\right.$ or $\left.\mathrm{CH}\right)$. SAEDP were also collected on $\mathrm{CaCO}_{3}$ crystals, or clusters of crystals, in order to identify the crystalline polymorph. The $d$-spacing between lattice planes can be calculated by measuring the distance from the central point to pairs of reflections in the collected diffraction pattern using the equation below.

$$
d=\lambda . l / r
$$

where:

$d=$ lattice spacing 
$\lambda=$ wavelength of electrons

$I=$ camera focal length

$r=$ radial distance

Calibration of the equipment by the operator in Leeds Electron Microscopy and Spectroscopy Centre modifies the calculation to give the real space value as:

$$
\mathrm{d} \text {-spacing }(\mathrm{nm})=1 / \mathrm{r}
$$

A series of d-spacing values were then compared to standard crystallographic patterns for calcite, vaterite and aragonite.

\subsubsection{Scanning electron microscopy}

\subsubsection{Principle scanning electron microscopy - back scattered electron (SEM-BSE) imaging}

In an SEM, images of a sample are constructed by scanning an electron beam across the sample surface. Emitted, or scattered, electrons can be secondary electrons, back scattered electrons or xrays where each response provides different information. Back scattered electron imaging allows compositional information to be determined from a sample and was the technique used in this study. The higher energy electrons (compared to secondary electrons) penetrate further into the sample, the intensity of the reflected electrons is recorded by a detector and is dependent on the average atomic number of the local area. Effectively it allows phases to be determined according to their brightness. Anhydrous materials have higher atomic numbers than hydrated phases, therefore appearing brightest. $\mathrm{CH}$ is typically light grey followed by $\mathrm{C}-\mathrm{S}-\mathrm{H}$ (dark grey) and finally the porosity (black). As AFt and AFm phases are intermixed within the C-S-H phase, they cannot be differentiated from the other hydrates on grey scale alone. Figure 3.12 shows a SEM-BSE image of a $30 \%$ GGBS sample cured for 72 hours with its accompanying grey level histogram. The technique is reliant on using flat polished sections and uses the principle of stereology to relate the 2D area fraction to its equivalent 3D volume (i.e. 2D area is equal to 3D volume). 

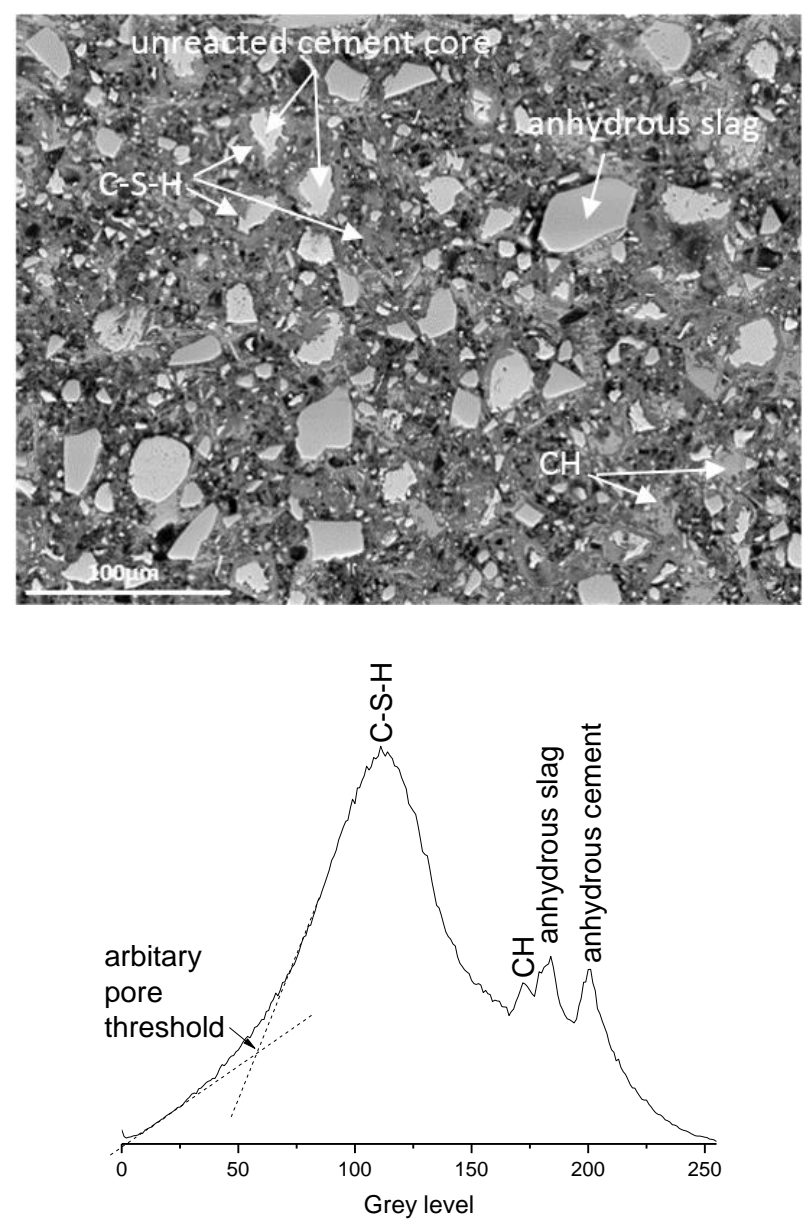

Figure 3.12. SEM-BSE image of $30 \%$ GGBS sample cured for 72 hours ( $w / b$ 0.40) and accompanying grey level histogram

\subsubsection{Determining degree of hydration}

The degree of hydration of either the cement or the slag can be determined by subtracting the remaining volume fraction of anhydrous material at a specified time from the initial fraction prior to hydration, as in the equation below [12]:

$$
\mathrm{DoH}=\frac{\text { Vf.anhy }(\mathrm{t}=0)-\mathrm{Vf} \cdot \operatorname{anhy}(\mathrm{t}=\mathrm{t})}{\operatorname{Vf} \cdot \operatorname{anhy}(\mathrm{t}=0)}
$$

where:

Vf.anhy $(t=0)=$ initial volume fraction

Vf.anhy $(t=t)=$ volume fraction at time $(t)$ 
In neat cement systems the volume fraction at time $(\mathrm{t})$ is determined using the grey level histogram, in which the peak relating to the anhydrous material is easily separated by setting a threshold at the minimum value.

In slag systems, however, there exists a large overlap of the grey levels of the anhydrous slag and portlandite (Figure 3.12) making isolation of the anhydrous slag fraction via grey level thresholding not possible. In order to properly segregate the unreacted slag grains, Mg mapping of each image can be collected and used to threshold the slag fraction from that of the $\mathrm{CH}$. Slag materials are typically $\mathrm{Mg}$ rich, in contrast to portlandite, and its low solubility, and therefore mobility, confines the element to within the original slag grain boundary. The segmented image is used to calculate the degree of reaction of the slag as shown in the equation above. Figure 3.13 Provides an SEM-BSE micrograph for a 30\% slag sample cured for 28 days with corresponding Mg map and mask indicating the position and area of the anhydrous slag fraction.

The number of images collected to ensure the calculated value is representative of the bulk sample is dependent on the magnification. Higher magnifications provide better resolution, identifying smaller features, whereas lower magnifications allow for larger areas to be measured. Mouret et al. [133] reported that 30 images at 200x magnification is adequate for determining the anhydrous portion in neat cement systems ( $<0.2 \%$ error), while Kocoba et al. [43] used 50 fields at the same magnification level. For early age studies involving slag, a potential source of error exists when the detection of small slag grains may be missed[134]. These smaller particles are likely to have reacted at later ages, however in investigations focusing on early age reactions, better resolutions are desirable. Whittaker et al. [47] showed that 50 images collected at $800 x$ magnification is sufficient to give a representative area of analysis at suitable resolution to minimise the amount of material remaining undetected. 

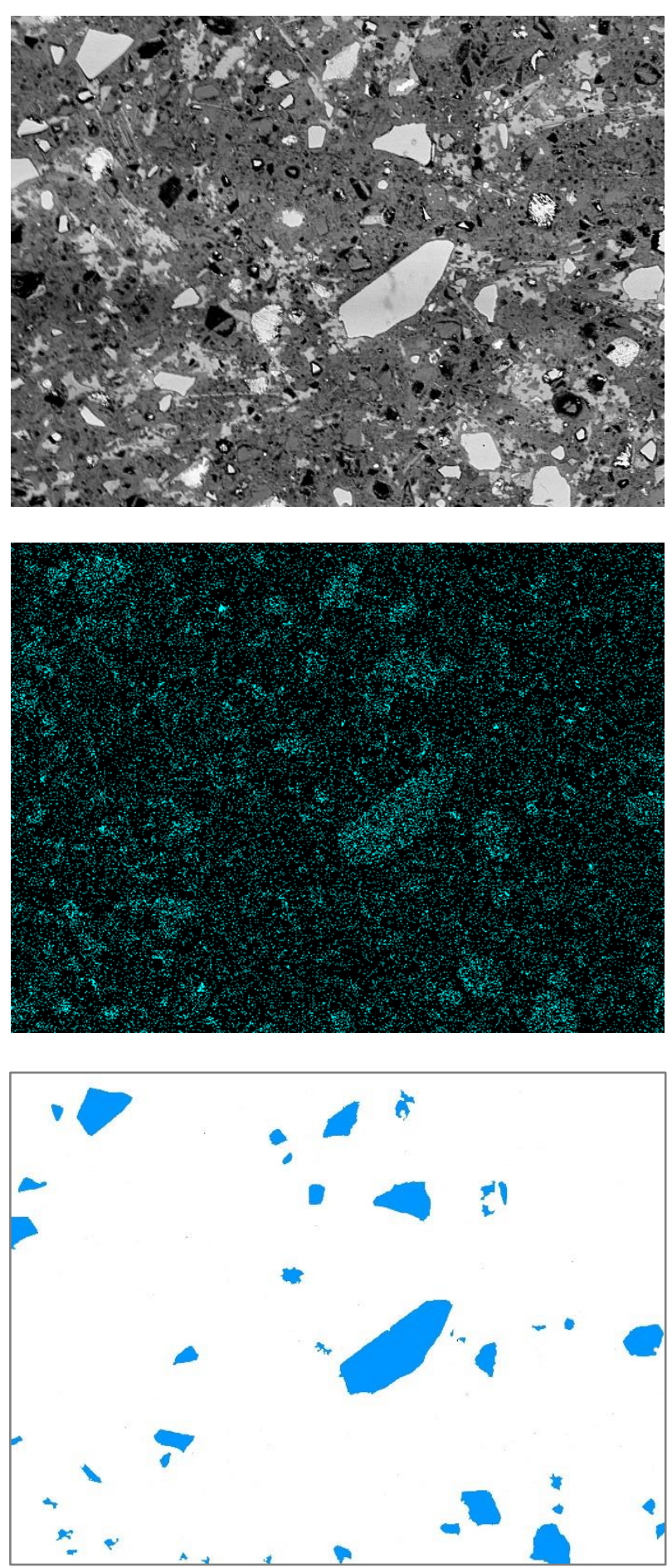

Figure 3.13. SEM-BSE image of $30 \%$ GGBS sample cured for 28 days ( $w / b$ 0.57) with corresponding Mg map and mask showing position and area of anhydrous slag fraction 


\subsubsection{Experimental setup}

SEM-IA was used to determine the degree of hydration of the samples immediately following specified curing periods (i.e. at $t_{0}$ ). Hydration stopped sections were resin impregnated under vacuum and the sample surface was exposed using progressively finer grades of SiC paper (600, $1200,2500)$. The samples were then polished using diamond paste up to a fineness of $0.25 \mu \mathrm{m}$ and carbon coated prior to analysis.

50 images at $800 x$ magnification, a working distance of $8.5 \mathrm{~mm}$ and an accelerating voltage of $15 \mathrm{keV}$ were collected for each sample on a Carl Zeiss EVO MA15 SEM. Mg maps were collected for the slag systems using an Oxford Instrument Xmax $800 \mathrm{~mm}^{2}$ SDD detector with an acquisition time of $100 \mathrm{~s}$.

\subsection{Analysis of engineering performance}

Analysis of engineering performance was carried out on mortar prisms, section 3.2 .2 provides details regarding the sample preparation.

\subsubsection{Unconfined compressive strength (UCS)}

At predetermined testing ages, mortar prisms were split using a hammer and chisel and tested in compression accordance with BS EN 196-1:2005[92] on a Dennison Compressive Loading T42 B4 using $40 \times 40 \mathrm{~mm}$ machine manufactured steel plates. Measurements were collected on 3 samples.

\subsubsection{Carbonation depth}

Carbonation depth measurements were taken on mortar prisms following predetermined exposure lengths. Specimens were taken from the corresponding test batch used in compressive strength measurements. Prisms were split laterally using a hammer and chisel and the freshly broken surfaces sprayed with a $1 \%$ phenolphthalein indicator solution. The second broken surface was sprayed with a $1 \%$ thymolphthalein indicator solution in order to compare the two techniques. Once dried, the depth of carbonation, measured from the sample edge to the colour change boundary, was determined at five equally spaced points on each of the four sides $(n=20)$. Phenolphthalein indicator turns colourless below pH level 8.2 and fuchsia above 9, while thymolphthalein turns colourless below pH 9.5 and blue above $\mathrm{pH} 10$. 


\section{Chapter 4}

\section{Experimental scoping}

The humidity range in which carbonation is considered to occur at an optimum is $50-70 \% \mathrm{RH}$. Materials with slower rates of reaction and limited extents of hydration are expected to have open and underdeveloped microstructures, where the same reduction in rates of $\mathrm{CO}_{2}$ diffusion observed at higher humidity levels in well-developed Portland cement might not necessarily be observed. Furthermore, curing regimes typically employ curing to equivalent strength development or equal periods of time but there is a lack of information about the carbonation behaviour of different composite materials subjected to the same, limited periods of curing. This chapter presents the results from a scoping study which investigated a range of $\mathrm{RH}$ levels and curing periods. The results generated were used to properly orientate the project.

\subsection{Curing length $\left(t_{0}\right)$}

Preliminary work to determine the minimum strength development needed for sample preparation and conditioning indicated that $11 \mathrm{MPa}$ of compressive strength would be required. Table 4.1 displays the age (in hours) at which the paste samples had developed approximately $11 \mathrm{MPa}$ compressive strength.

Table 4.1. Age (hrs) by which samples had developed approximately 11MPa of compressive strength

\begin{tabular}{lr}
\hline & Age (hrs) \\
\hline CEMI (0.40) & 10 \\
CEMI (0.57) & 17 \\
30\% PFA (0.40) & 14 \\
30\% PFA (0.57) & 72 \\
30\% GGBS (0.40) & 13 \\
30\% GGBS (0.57) & 24 \\
60\% GGBS (0.40) & 25.5 \\
60\% GGBS (0.57) & 72 \\
\hline
\end{tabular}


There was a considerable range in curing duration. It is expected that the difference in the microstructure and phase assemblage of the samples between the minimum curing length of $10 \mathrm{hrs}$ and the maximum of $72 \mathrm{hrs}$ would be very large. This posed practical problems, with some of the curing lengths being unpractical in terms of laboratory work; suggesting that these would also be unrealistic in terms of curing lengths used in construction practice. The original project proposal aimed to mimic the early removal of formwork in construction practice, therefore it is important to consider which curing period would represent this most suitably.

Characterisation of the systems at $\mathrm{w} / \mathrm{b}$ ratio 0.57 were performed following curing for (i) $11 \mathrm{MPa}$ equivalent strength, (ii) 24 hours and (iii) 72 hours.

Table 4.2. Sample matrix and experimental parameters used for scoping study

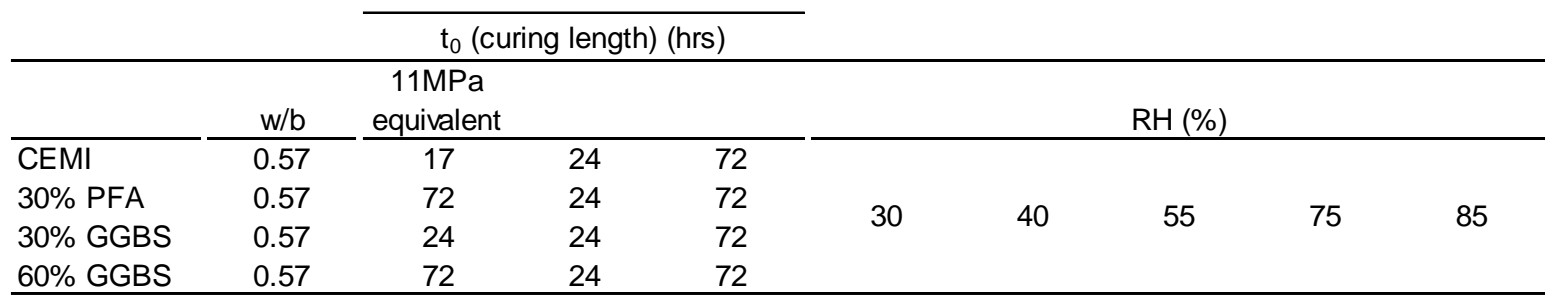

\subsection{Isothermal Conduction Calorimetry}

Isothermal conduction calorimetry allows the extent and rate of hydration of each of the systems to be followed and compared. The total heat output of the four systems between $0-72$ hours is shown in Figure 4.1. The CEM I system showed a greater overall degree of hydration, and as expected, this decreased with increasing level of replacement. There was a sizeable difference in the extent of hydration of the four systems at reaction times of 24 and 72 hours, with deviations in the heat of hydration of 80 and $95 \mathrm{~J} / \mathrm{g}$ respectively. Whereas at reaction times corresponding to $11 \mathrm{MPa}$ of strength development, as indicated by the red circles, the total heat output of the systems was much less variable with a deviation of around $30 \mathrm{~J} / \mathrm{g}$. 


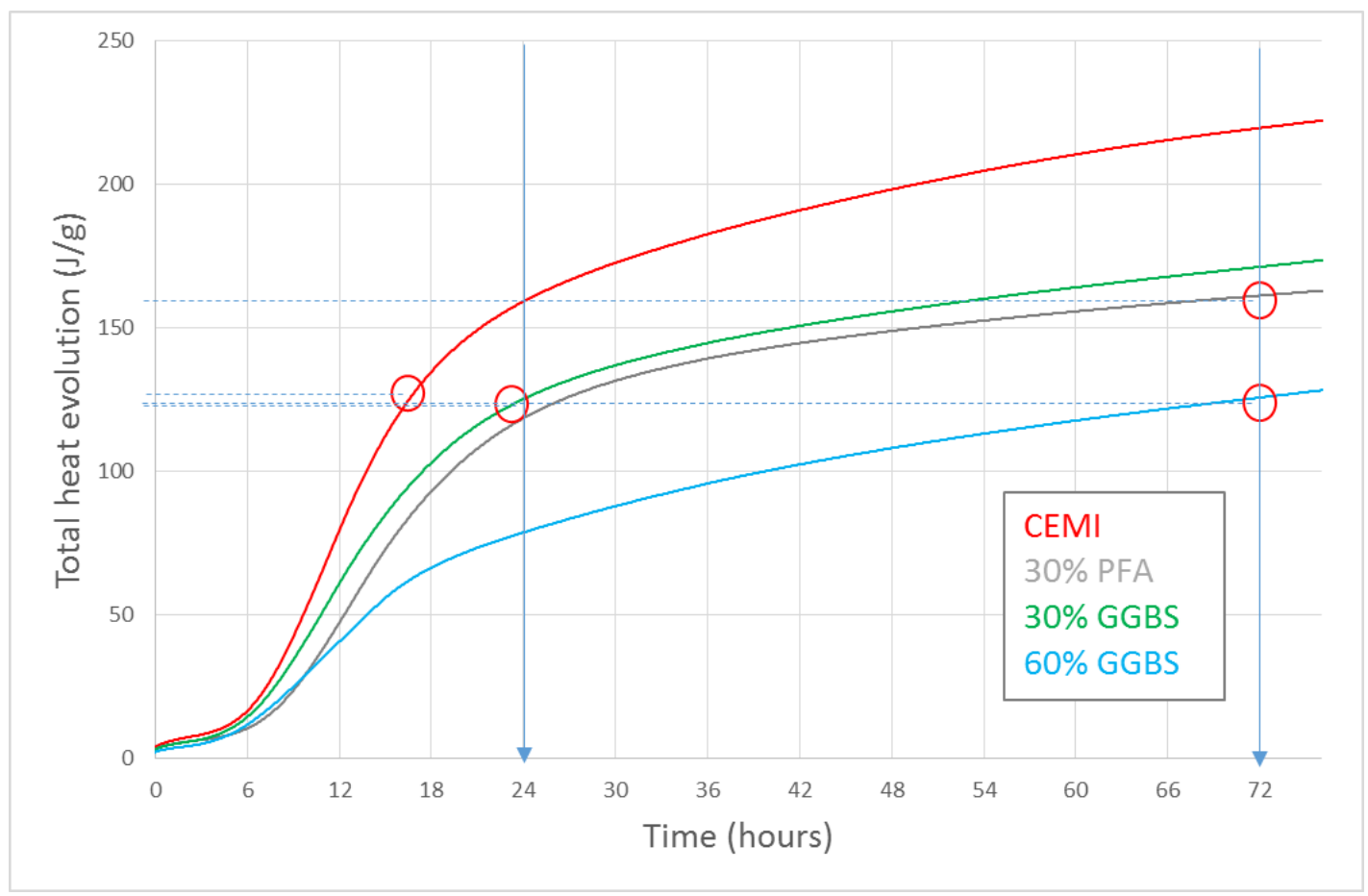

Figure 4.1. Isothermal calorimetry data showing the total heat evolution between $0-72$ hours.

The rate of heat evolution between 0 and 72 hours is shown in Figure 4.2. Each of the systems were characterised by the main alite hydration peak at around $9-11$ hours, which was closely followed by the aluminate peak indicating secondary formation of ettringite (AFt). A low broad peak beginning at approximately 26 hours in the CEM I system denoted the formation of calcium monosulfoaluminate ( $\mathrm{AFm}$ ), this was more pronounced in the $60 \%$ slag system, with a sharper maxima occurring much earlier as a shoulder on the alite peak at around 13 hours. 


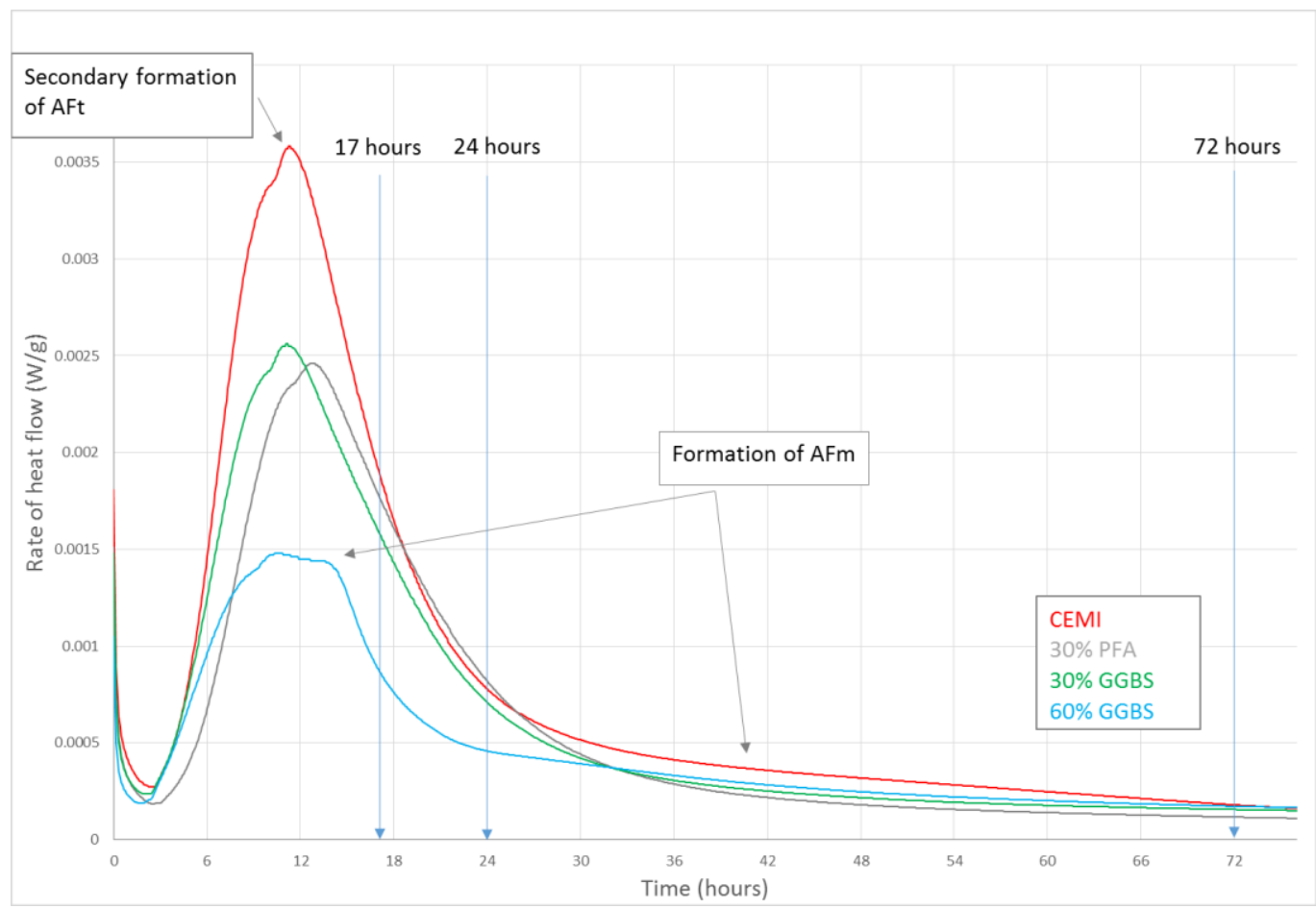

Figure 4.2. Isothermal calorimetry data showing rate of heat evolution between $0-72$ hours.

Figure 4.3 displays the rate of heat evolution normalised to cement content in which a slight increase and acceleration of the aluminate peak for the slag systems could be seen compared to the CEM I material. Enhancement of the aluminate peak in systems containing SCMs has been attributed by several researchers to the reaction of the replacement material $[31,135]$, however other studies have shown it is the result of dilution and nucleation effects which accelerates the reaction of $\mathrm{C}_{3} \mathrm{~A}$. Dittrich et al. [30] reported acceleration of the $C_{3} A$ reaction, compared to OPC, for both cement-fly ash and cement-quartz systems, demonstrating it is the provision of additional nucleation sites that promotes the reaction. Quennoz and Scrivener meanwhile [136] established that dilution effects result in an increase of the peak height by showing that an increase in $\mathrm{w} / \mathrm{c}$ ratio results in enhancement of the peak. Both Dittrich et al. [30] and Berodier [15] also established the effect of the fineness of the replacement material on the aluminate reaction, in which an increase in material fineness, and therefore an increase in surface availability for nucleation of hydrates, again speeds up the rate of reaction. However, the chemical composition of the added material may also have a notable effect. Although Dittrich et al. [30] reported accelerated dissolution of $\mathrm{C}_{3} \mathrm{~A}$ in cement-fly ash 
and cement-quartz systems, a retarding effect was exhibited when a fly ash of increased fineness and increased quantities of readily soluble $\mathrm{SO}_{3}$ was used, the additional $\mathrm{SO}_{3}$ being responsible for the delayed aluminate dissolution.

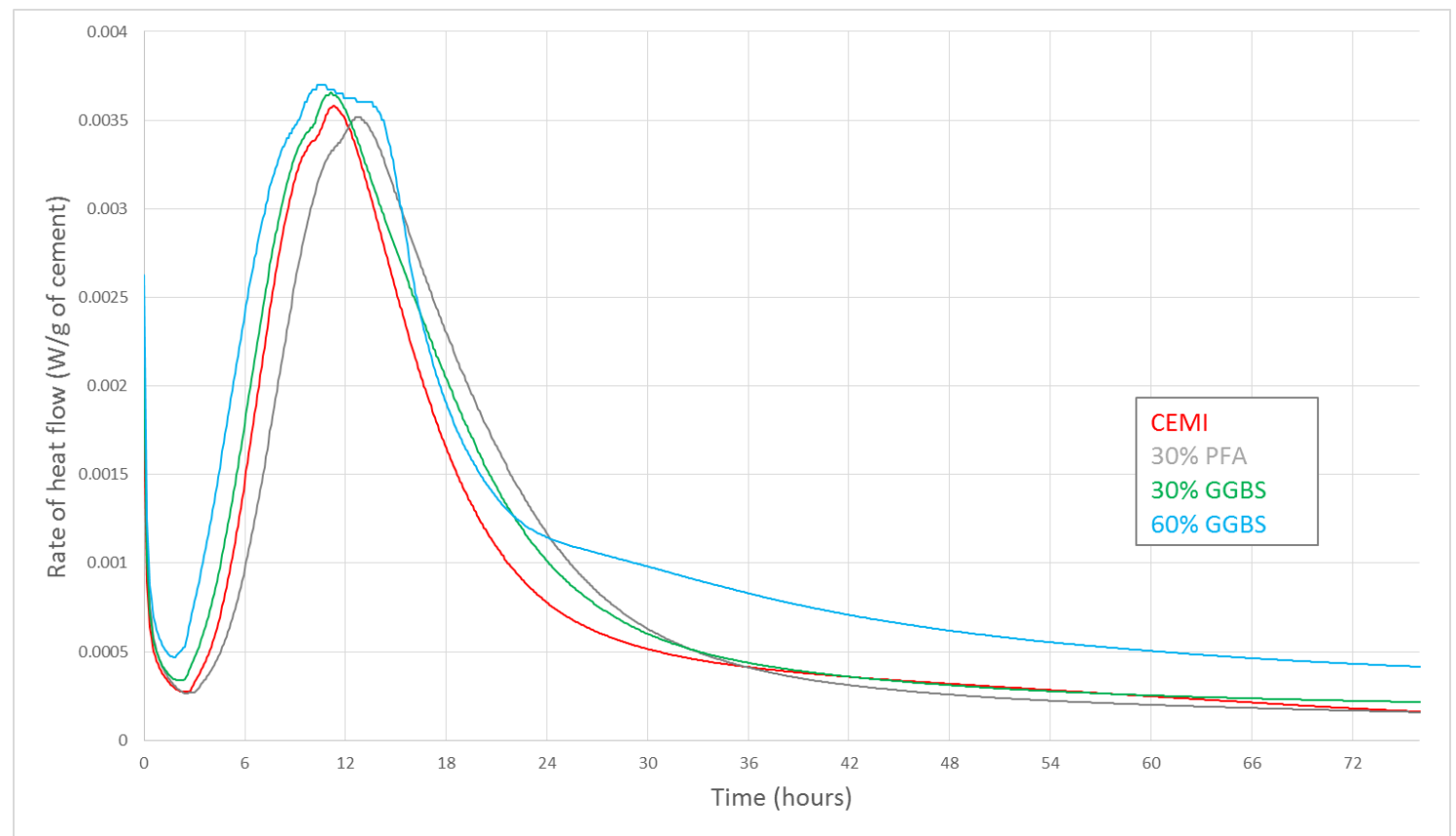

Figure 4.3. Isothermal calorimetry data between $0-72$ hours showing rate of heat evolution normalised to cement content.

When normalised to cement content, there was an increase in the maximum heat rate of the main hydration peak (Figure 4.3) and the total cumulative heat output (Figure 4.4) for the slag systems compared to the CEM I system. The effect was both greater and accelerated with increasing replacement levels. As with the aluminate peak, the hydration rate enhancement was the result of dilution and nucleation effects. Gutteridge and Dalziel $[137,138]$ reported this behaviour for both SCMs and inert materials and the filler effect has been widely accepted to be a result of an effective increase in the water/cement ratio and the provision of extra nucleation sites for the reacting Portland cement[25]. However, Berodier and Scrivener [139] published work to show that the additional nucleation sites were not able to account for the total increase in reaction rate, but rather 
demonstrated that it was dependent on the interparticle distance, a result of shearing effects when filler particles are present $[14,139]$.

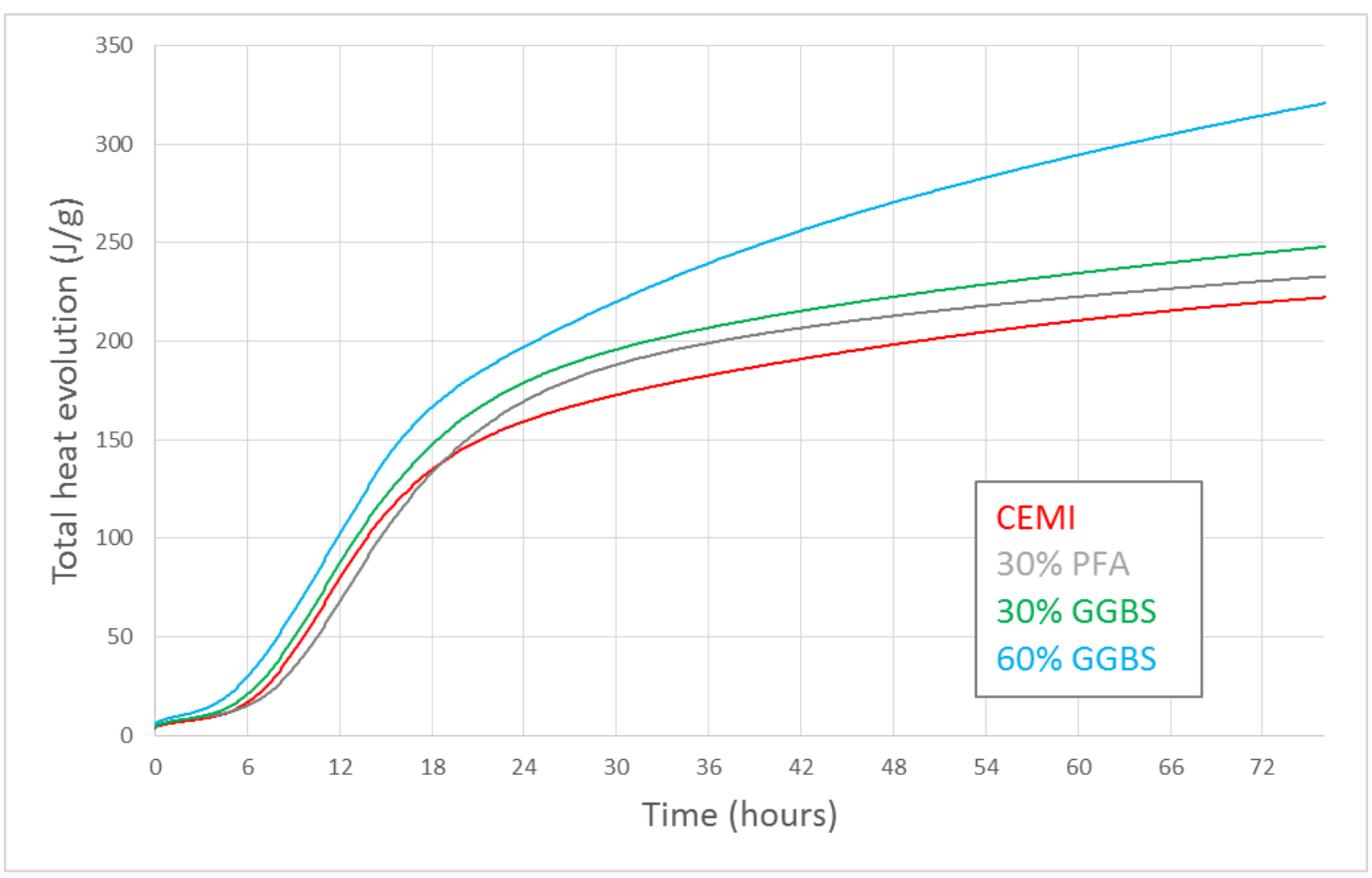

Figure 4.4. Isothermal calorimetry data showing the total heat evolution normalised to cement content between $0-72$ hours.

However, the PFA system (Figure 4.3) showed a delay in the onset of the acceleration period of the main alite peak and a lower maximum heat rate in comparison to the CEM I sample. This was subsequently accompanied by a delay in both the maxima of the alite and aluminate peaks compared to the remaining three systems. This retardation of the cement reaction could also be clearly seen in Figure 4.4, where the total heat output was lower compared to all the systems up to approximately 19 hours, after which the influence of the filler takes effect and the heat output overtakes that of the CEM I cement. This behaviour was recently discussed by Richardson et al., [29] in which data collected by the authors and that published in several other studies was discussed and compared. In all of the PFA-cement blends examined, the presence of PFA particles caused an initial retardation of the cement hydration, as clearly shown this study (Figure 4.4). Richardson et al., 
calculated the corresponding expected values of $\mathrm{CH}$, confirming that the lower cumulative heat output is a result of the retarded hydration of the cement. $\mathrm{CH}$ contents calculated by Richardson relative to expected values mirrored the behaviour seen here in the calorimetric heat evolution curves, remaining initially lower than expected but then increasing at intermediate ages indicating acceleration of the cement reaction. This was accompanied by an increase in the heat output of the PFA samples compared to the reference cement.

Dittrich et al., [30] reported similar behaviour when they examined the influence of fly ash on the hydration kinetics of cement - fly ash, and cement - quartz, systems within the first 44 hours of reaction. Calorimetry heat flow data showed a retardation in the onset of the main hydration peak by 1.5 hours for fly ash $\left(d_{50}=19.2 \mu \mathrm{m}\right)$ sample, the effect increasing to 6 hours with increasing particle fineness $\left(d_{50}=2.1 \mu \mathrm{m}\right)$, whereas only minimal affects were observed in the quartz blends. Although at 44 hours the cumulative heat was higher in all the binary systems compared to the neat Portland cement system, a lower heat of hydration was observed initially, only exceeding that of the Portland cement sample after 18 hours.

\subsection{Simultaneous Thermal Analysis}

$\mathrm{CaCO}_{3}$ contents calculated from TGA data following 48 hours exposure to ambient $\mathrm{CO}_{2}$ concentrations at $\mathrm{RH}$ levels of $30,40,55,75$ and $85 \%$ are displayed in Figure 4.5. Carbonate values are given as the change in $\mathrm{CaCO}_{3}$ content from $\mathrm{t}_{0}$ and normalised to ignited mass. Figures $4.5(\mathrm{a}(\mathrm{i}))$, $(b(i))$ and $(c(i))$ show the calculated values following curing for 11MPa equivalent, 24 hours and 72 hours respectively. The carbonate content normalised to cement content is displayed in Figures 4.5 (a(ii)), (b(ii)) and (c(ii)). 

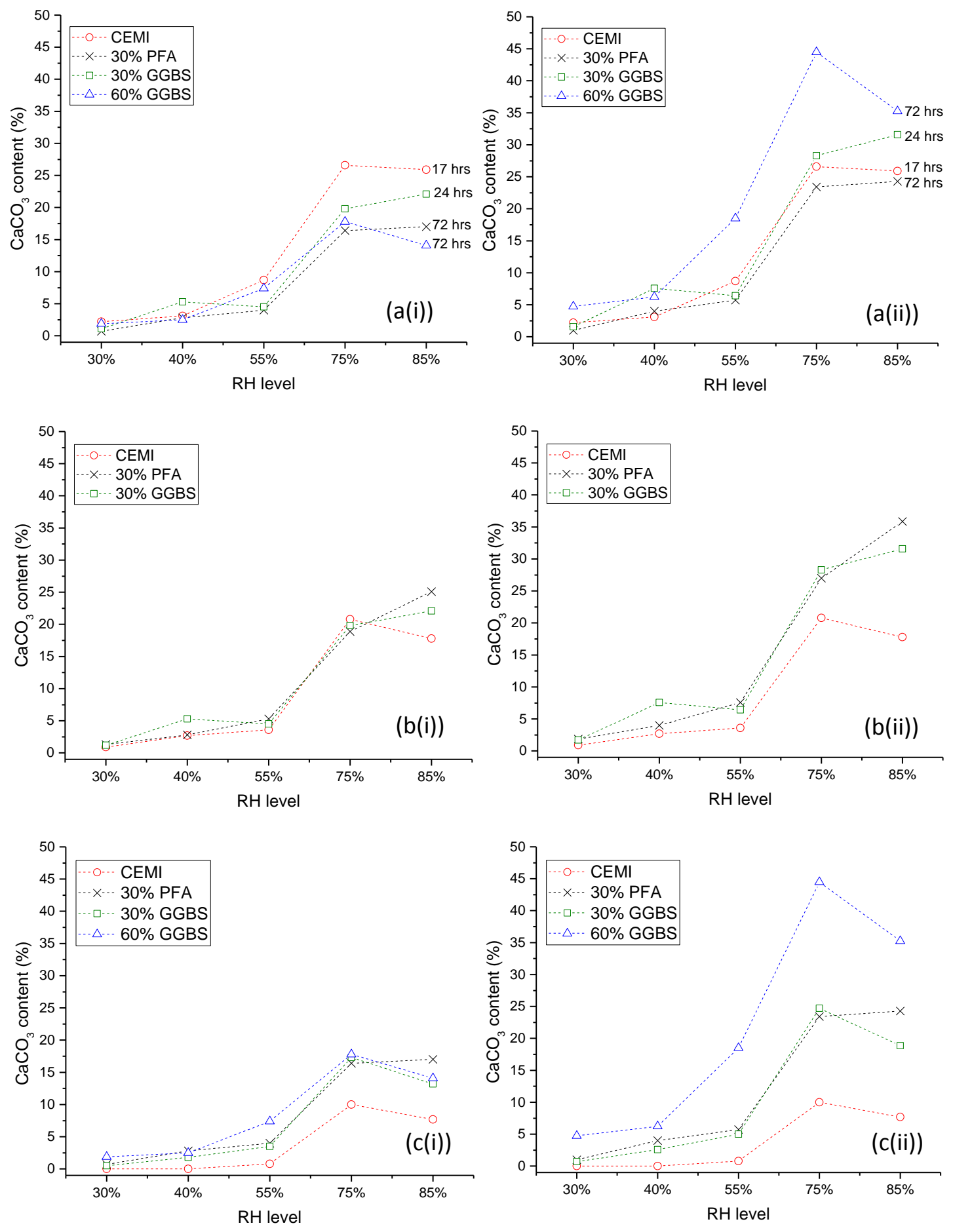

Figure 4.5. Calculated $\mathrm{CaCO}_{3}$ content from TGA data showing change in $\mathrm{CaCO}_{3}$ content from $\mathrm{t}_{0}$ following curing periods of (a(i)) 11MPa equivalent, (b(i)) 24 hours and (c(i)) 72 hours. Figures (a(ii)), (b(ii)) and (c(ii)) display the $\mathrm{CaCO}_{3}$ content normalised to cement content. 
An increase in carbonate content with increasing $\mathrm{RH}$ level was evident for all samples, but greater carbonation was observed at higher humidity levels (75\% and $85 \%)$. Drying of the capillary pores at low $\mathrm{RH}$ greatly reduces the dissolution rate of both $\mathrm{CO}_{2}$ and the hydrate phases, resulting in a much slower rate of carbonation. Conversely, high $\mathrm{RH}$ delayed the diffusion of $\mathrm{CO}_{2}$ into the cement microstructure due to water condensation in the capillary pores. The optimum RH range for carbonation to proceed lies between 50 and $70 \%$. Figure 4.5 clearly show that an optimum humidity range exists for the carbonation of cement, however the data suggests that for samples cured for only very short periods of time ( $<72$ hours), the $\mathrm{RH}$ range for optimum carbonation is slightly higher ( $\approx 65-85 \%)$ than that reported for 28 day cured systems. The very early ages of the samples are expected to exhibit underdeveloped microstructures with high levels of porosity, consequently not delaying the diffusion of $\mathrm{CO}_{2}$ and therefore the carbonation rate in the same way. According to the Washburn equation, the more open pore structures require higher humidities before the pores are saturated.

The effects of curing duration on the extent of carbonation have also been demonstrated. Figure 4.5(a(i)) clearly shows that at higher $\mathrm{RH}$, where the greatest carbonation occurs, the $\mathrm{CaCO}_{3}$ content decreased with increasing curing duration, regardless of material. Following 24 hours' curing, carbonation was fairly comparable for all the systems, apart from at $85 \% \mathrm{RH}$ where a notable increase in carbonate content was observed for the composite materials. In general the systems cured for 72 hours show greater carbonation at all humidity levels compared to the CEM I sample, with carbonate content increasing with increasing level of replacement.

When normalised to cement content (Figure 4.5 (a(ii)), (b(ii)) and (c(ii)), the differences in carbonate content became more evident. Following equal curing lengths, i.e. $24 \mathrm{hrs}$ or $72 \mathrm{hrs}$, the extent of carbonation was related more clearly to the replacement level, where the carbonate content decreased with decreasing percentage substitution. Composite systems cured to an $11 \mathrm{MPa}$ equivalent strength (a(ii)) remained linked to length of curing (increasing $\mathrm{CaCO}_{3}$ content with decreasing curing length), however the CEMI sample (17hr cured) had a performance more closely related to the $72 \mathrm{hr}$ cured PFA system, demonstrating the much larger effect curing has on blended materials compared with near Portland cement pastes.

Figure 4.6 displays the TGA and DTA plots for the $30 \%$ GGBS system cured for 72 hours. It should be noted that the data in the figure is representative of all the STA results obtained and only the data 
for humidity levels of $30 \%, 55 \%$ and $75 \%$ have been plotted for clarity. With increasing $\mathrm{RH}$, a much greater proportion of mass loss associated with $\mathrm{CaCO}_{3}$ was observed at a higher temperature. This behaviour was also mirrored in the DTA plots, where a clear shift in decomposition temperature to a higher value was observed with increasing $\mathrm{RH}$. Typically three decomposition modes are associated with carbonation; mode I $\left(780-900^{\circ} \mathrm{C}\right)$, mode II $\left(680-780^{\circ} \mathrm{C}\right)$ and mode III $\left(550-680^{\circ} \mathrm{C}\right)$. Modes I and II are largely attributed to the crystalline polymorphs of $\mathrm{CaCO}_{3}$ (calcite, vaterite and aragonite), mode I indicating decomposition of very crystalline $\mathrm{CaCO}_{3}$, i.e. calcite, while an amorphous, or less well ordered, polymorph is associated with mode III [61]. The shift in decomposition temperature indicates the presence of a better structured/crystalline $\mathrm{CaCO}_{3}$ phase, demonstrating there is some modification in the carbonation mechanism depending on the relative humidity.

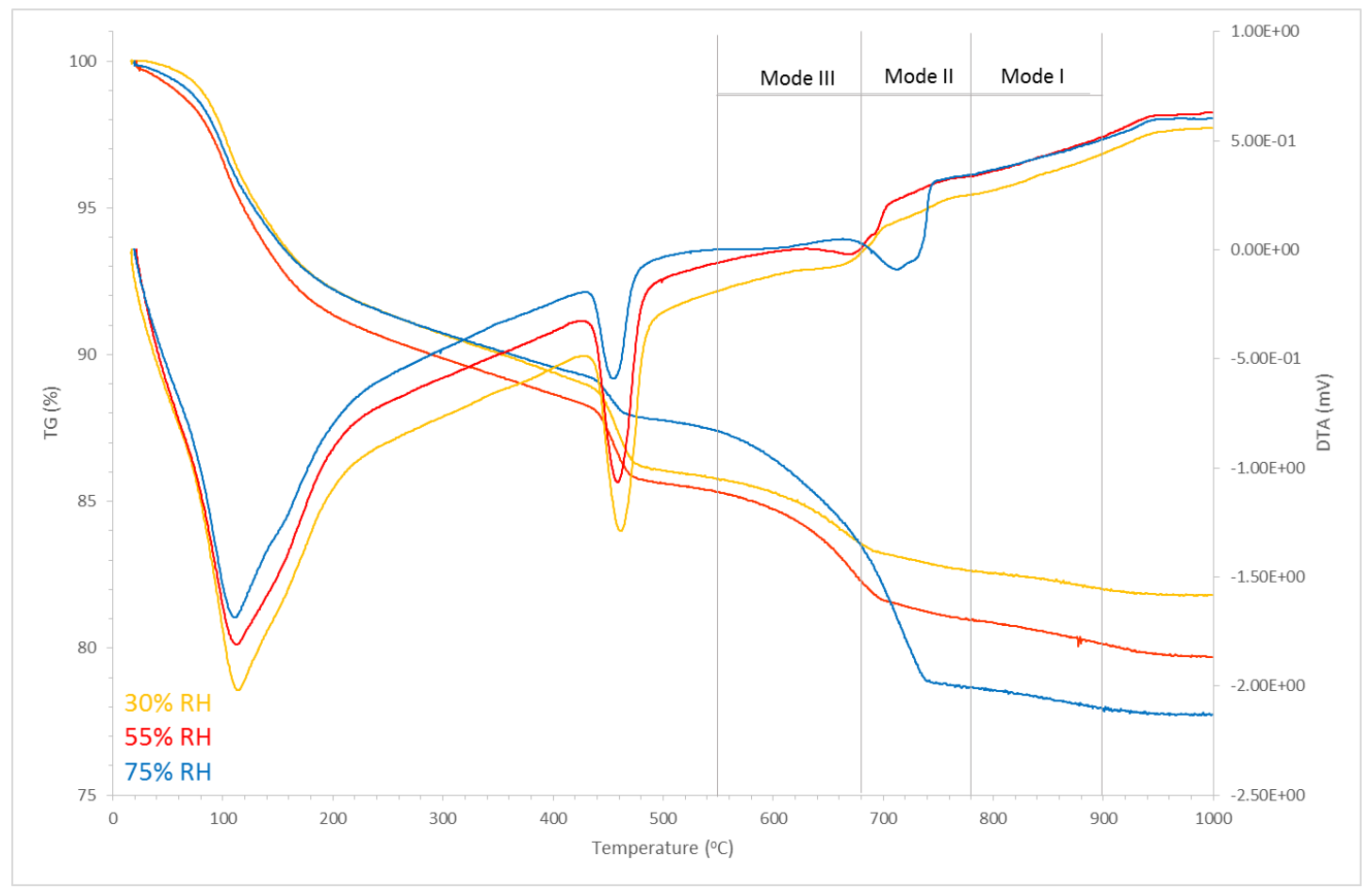

Figure 4.6. TGA and DTA plots for $30 \%$ GGBS - 72 hours cured after 48 hours exposure to ambient $\left[\mathrm{CO}_{2}\right]$ at $\mathrm{RH}$ levels of $30 \%, 55 \%$ and $75 \%$. 


\subsection{Attenuated Total Reflectance - Fourier Transform Infrared Spectroscopy}

The variation in carbonation rate and carbonation mechanism as a result of atmospheric humidity level was also demonstrated in ATR-FTIR data. Figure 4.7 displays the ATR-FTIR data collected for the 72 hour cured $30 \%$ slag samples conditioned at humidity levels of $40 \%, 55 \%$ and $75 \%$. As before, the results displayed in the figure are representative of all the samples analysed.

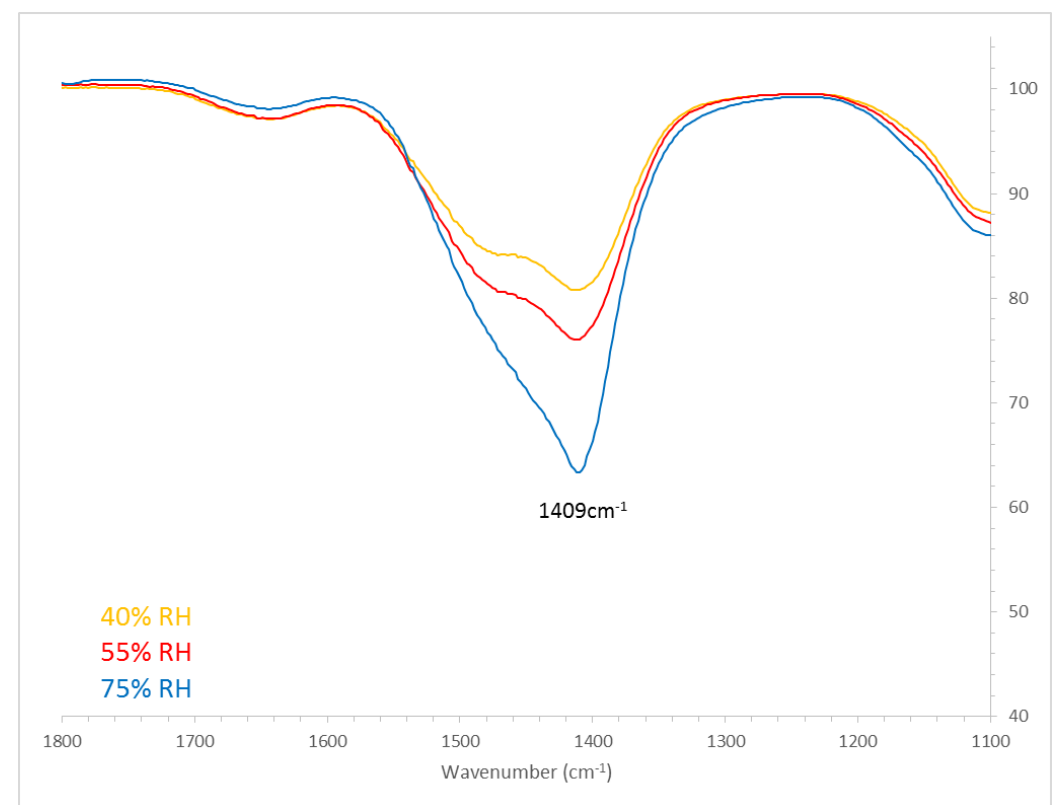

Figure 4.7 ATR-FTIR data showing $\mathrm{CaCO}_{3}$ content between $1100-1800 \mathrm{~cm}^{-1}$ for $30 \%$ GGBS -72 hours cured after 48 hours exposure to ambient $\left[\mathrm{CO}_{2}\right]$ at $\mathrm{RH}$ levels of $40 \%, 55 \%$ and $75 \%$.

The characteristic absorbance band for the carbonate ion in the amorphous and the three crystalline $\mathrm{CaCO}_{3}$ polymorphs lies between $\approx 1400-1500 \mathrm{~cm}^{-1}$ and the integrated area in this region provides a good indication of the relative amount of carbonation [140]. Increasing $\mathrm{CaCO}_{3}$ content was evident with increasing RH, consistent with the TGA data. In addition to this, transformation of the shape of the carbonation band to a sharper asymmetrical peak was evident with increasing $\mathrm{RH}$. Peak sharpening indicates the presence of a more crystalline phase, while broadening of the band suggests the presence of a phase with a less well ordered structure $[140,141]$. The shape of the carbonate band allowed the nature of the carbonate phase to be determined, Figure 4.8 displays a 
modified version of a figure taken from [141] which shows the infrared spectra collected for amorphous $\mathrm{CaCO}_{3}$ (Figure 4.8(a)) and calcite (Figure 4.8(b)). Comparing the spectra in Figures 4.7 and 4.8 confirms the formation of both crystalline and non-crystalline polymorphs. At $40 \% \mathrm{RH}$ an amorphous $\mathrm{CaCO}_{3}$ component was clearly present, however this became predominantly crystalline as the RH increased. This verifies the behaviour observed in both the TGA and DTA data where a shift in decomposition temperature indicates presence of crystalline carbonate phases at higher humidity levels, the ATR-FTIR data confirming the formation of calcite at $75 \% \mathrm{RH}$.
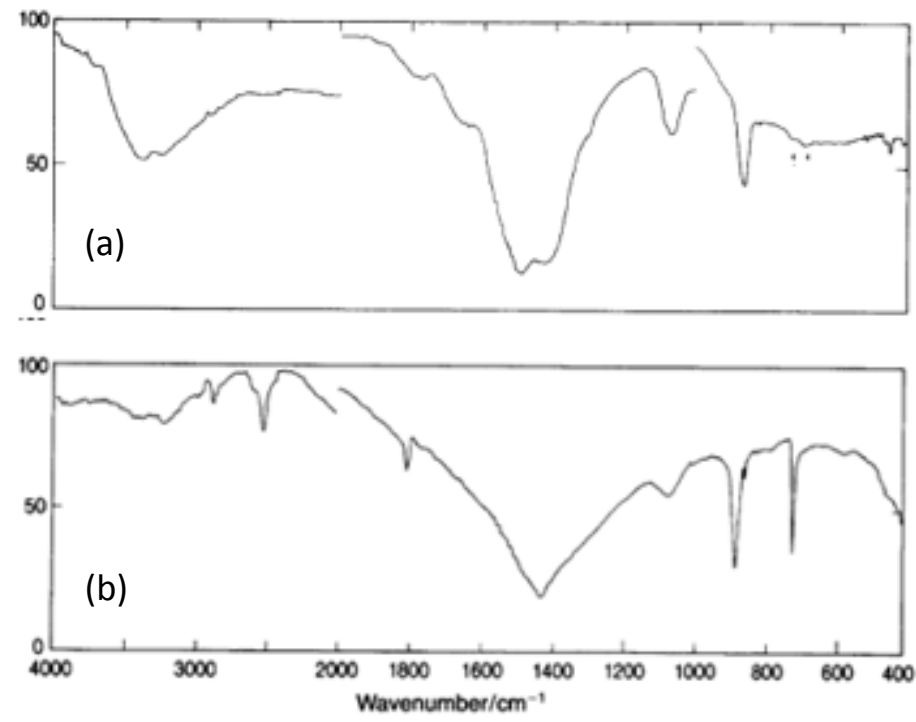

Figure 4.8. Infrared spectra of (a) amorphous $\mathrm{CaCO}_{3}$ and (b) calcite. Figure modified Figure 1 in [141] 'Figure 1. Infrared spectra of (A) amorphous $\mathrm{CaCO}_{3},(B)$ vaterite, (C) aragonite and 9D) calcite in $\mathrm{KBr}$ pellets cooled by liquid nitrogen with about 0.4-0.6 $\mathrm{mg}$ of sample in each pellet.'

\subsection{X-Ray Diffraction}

XRD data shown in Figure 4.9 further corroborate that the nature of the carbonate species formed was dependent on the $\mathrm{RH}$. At lower $\mathrm{RH}(30,40$ \& 55\%) there was minimal change in calcite content, whereas at $75 \%$ and $85 \% \mathrm{RH}$ a significant increase was evident. While TGA and ATR-FTIR data revealed greater carbonate contents with increasing RH between 30, 40 and 55\%, XRD data indicated almost no change in calcite content. As XRD only detects crystalline components, the 
carbonate phases not accounted for at lower RH must be poorly crystalline/amorphous, as previously suggested in STA and ATR-FTIR data. The significant increase in calcite content at higher $\mathrm{RH}$ also verifies the shift to a higher decomposition temperature and transformation to a sharper asymmetrical peak observed in the DTA and ATR-FTIR data respectively.

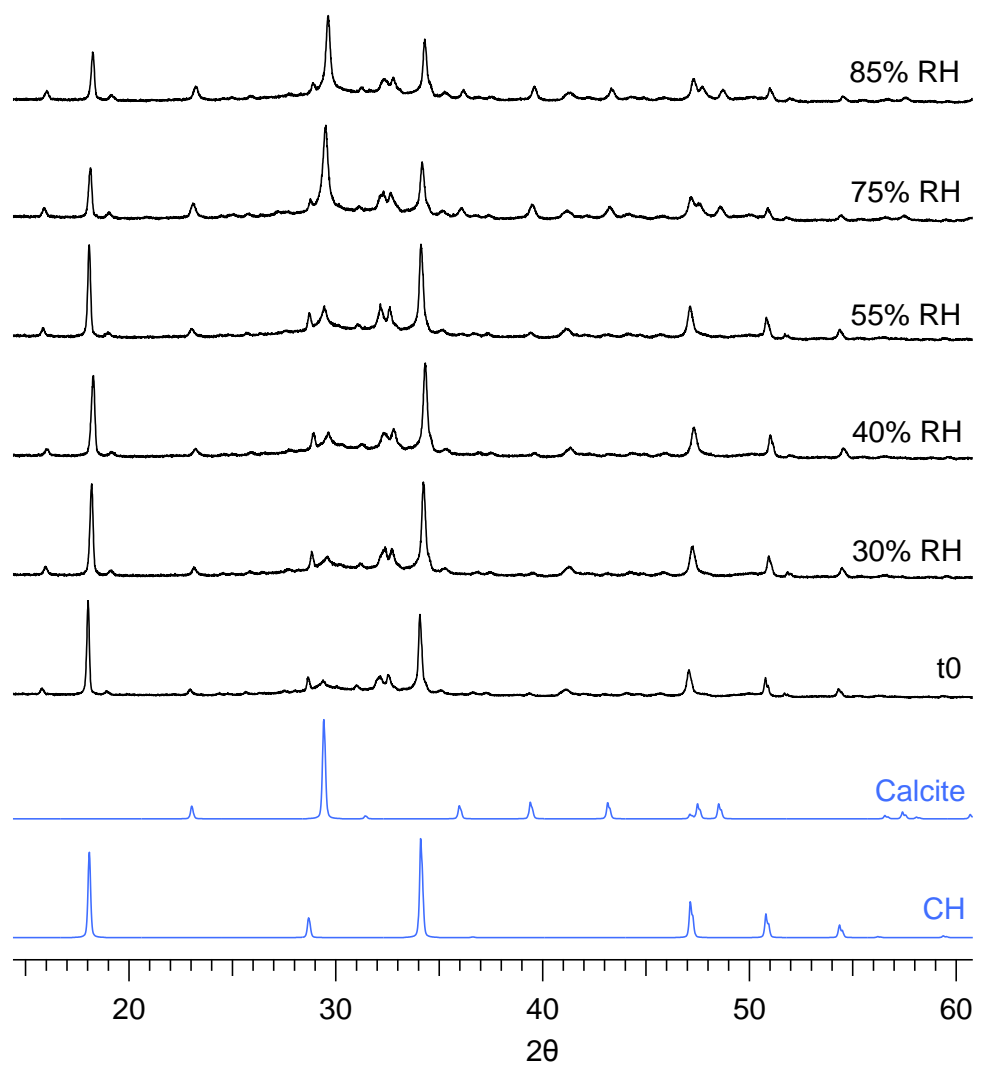

Figure 4.9. XRD traces for $30 \% \mathrm{GGBS}-72$ hours cured after 48 hours exposure to ambient $\left[\mathrm{CO}_{2}\right]$ at RH levels of $30 \%, 40 \%, 55 \%, 75 \%$ and $85 \%$. Standard traces for calcite and $\mathrm{CH}$ are shown in blue.

\subsection{Discussion and Selection of Experimental Conditions}

\subsubsection{Curing length $\left(t_{0}\right)$}

If curing length is considered in terms of hydration, isothermal conduction calorimetry shows that curing to an equivalent compressive strength, in this case $11 \mathrm{MPa}$, produces samples with a relatively comparable hydration degree. However, concerns regarding the applicability of this approach and how it relates to procedures followed in practice exist when considering the varying lengths of 
curing (17, 24 \&72hrs). Furthermore, sample carbonation/conditioning should begin once the main alite hydration peak is primarily complete. This is the case for the blended systems, however a curing length of 17 hours for the CEM I sample means that hydration of $C_{3} S$ is still taking place. One potential option would be to increase the target compressive strength, however, as the 30\% PFA and $60 \%$ slag system already require 72 hours curing in order to be suitably robust for sample preparation and conditioning, a further increase in curing length begins to deviate from the intended focus of this study. 24 hours curing is also unsuitable for the $30 \%$ PFA and $60 \%$ slag systems where insufficient strength development prevented handling and preparation of the samples. Moreover, up to approximately 19 hours hydration the PFA particles are shown to retard the reaction of the cement, therefore at 24 hours curing the accelerating effect ultimately caused by the presence of the PFA addition will have just begun. 72 hours curing allows enough time for the hydration of alite to be wholly complete in all the systems and allows the samples enough time to have developed considerable strengths and hydration properties before exposure to experimental conditioning. 72 hours has therefore been selected to represent a 'short' period of curing.

\subsubsection{RH level}

In order to study the effect of curing length, w/b ratio and replacement material and replacement level, it is important to allow carbonation to occur at an optimum rate. Previous research has shown that the optimum range for carbonation lies between $50-70 \% \mathrm{RH}$ for properly cured / 28 day cured samples. This scoping study, however, indicates that this range is shifted to a higher set of values $(\approx$ 65-85\%) when shorter curing lengths are considered. As both a short and 'idealised' (28 day) curing lengths will be investigated, a RH level of $\approx 70 / 75 \%$ will be used. This level of humidity lies just at the top of the range for optimum carbonation of 28 day cured samples and within the higher optimum range for the carbonation of samples cured for much shorter lengths of time. 


\section{Chapter 5}

\section{Characterisation of $t_{0}$ samples}

The phase assemblage and microstructure of Portland cement systems is expected to be reasonably well developed following curing for 72 hours, with only relatively minor changes occurring up to 28 days. This, however, will not be the case for composite cement materials which exhibit markedly slower rates of hydration that are further affected by replacement material, replacement level and water/binder (w/b) ratio. Following 72 hours curing composite materials are expected to exhibit underdeveloped microstructures that are largely different from those in ideally cured (28 days) samples. This chapter studies the differences in the extent of reaction, development of the phase assemblage and changes in the microstructure between immature ( $t_{0} 72$ hours) and ideally cured ( $\mathrm{t}_{0} 28$ days) neat and composite systems at high $(0.57)$ and low $(0.40) \mathrm{w} / \mathrm{b}$ ratios.

\subsection{Extent of reaction}

\subsubsection{Hydration kinetics and degree of reaction of cement clinker}

XRD measurements of the anhydrous cement and the hydrated samples at curing lengths $\left(t_{0}\right)$ of 72 hours and 28 days provide some insight into the hydration kinetics of the clinker phases of each of the systems. Anhydrous clinker phase contents were determined and compared with those derived from the Bogue formula (Table 5.1). These indicated discrepancies of 9 and $11 \%$ for the $C_{3} S$ and $C_{2} S$ phases respectively. Although it is well established that the Bogue calculation is largely inaccurate $[142,143]$ due to the assumption that the phases are in their pure form, rather than accounting for substitution of guest ions (accounted for in the modified Bogue calculation [142]), the Bogue formula typically gives an underestimate for the alite content. Here the Rietveld refinement measures a lower alite and higher belite content than that derived from the oxide composition. The aluminate and ferrite contents were measured to be $2.5 \%$ and $11 \%$ respectively. While variabilities in the individual clinker phases were evident, the total content of the four main clinker phases in both cases is $\sim 94 \%$. $\mathrm{CaSO}_{4}$ phases made up $\sim 3.5 \%, 2.5 \%$ of which was gypsum, and small amounts of arcanite $\left(\mathrm{K}_{2} \mathrm{SO}_{4}\right)$ were detected. 
Table 5.1 Comparison of phase composition of CEM 52.5R determined from the Bogue formula and XRD - Rietveld refinement

\begin{tabular}{lccccc}
\hline CEM 52.5R & & $\mathrm{C}_{3} \mathrm{~S}$ & $\mathrm{C}_{2} \mathrm{~S}$ & $\mathrm{C}_{3} \mathrm{~A}$ & $\mathrm{C}_{4} \mathrm{AF}$ \\
\hline Bogue & $\%$ & 68 & 10 & 9 & 7 \\
XRD & $\%$ & 59 & 21 & 2.5 & 11 \\
\hline
\end{tabular}

The small initial $C_{3} A$ content resulted in virtually complete reaction following 72 hours curing for almost all the systems. The changes in the remaining clinker phases at curing times of 0,3 and 28 days are shown in Figures $5.1-5.3$ below.

Dissolution of alite was rapid in all the system with $>85 \%$ having reacted following 72 hours hydration (Figure 5.1). Although a slightly greater extent of reaction was observed at 72 hours for the systems with a higher $\mathrm{w} / \mathrm{b}$ ratio $(0.57)$, the composite systems had equivalent levels of reaction at 28 days regardless of water content and showed accelerated reactions compared to the CEMI systems at both ages. The neat system, however, showed a difference in the degree of alite hydration depending on the water content of the sample, where percentages of 2 and 9 were measured for the high and low $\mathrm{w} / \mathrm{b}$ ratios respectively.

The enhanced reaction rate of alite in the blended materials reflects the filler effect expected in cements containing SCMs, where an effective increase in the water to cement ratio and additional nucleation sites promote accelerated growth of hydrates [137, 139]. Berodier [15] studied the effects of different $w / b$ ratios on the later stages of hydration (from 1 day) proposing that hydration rates become controlled by the availability of space for hydrate phases, explaining the greater degree of reaction of the CEMI system at $\mathrm{w} / \mathrm{b}$ ratio 0.57 . 

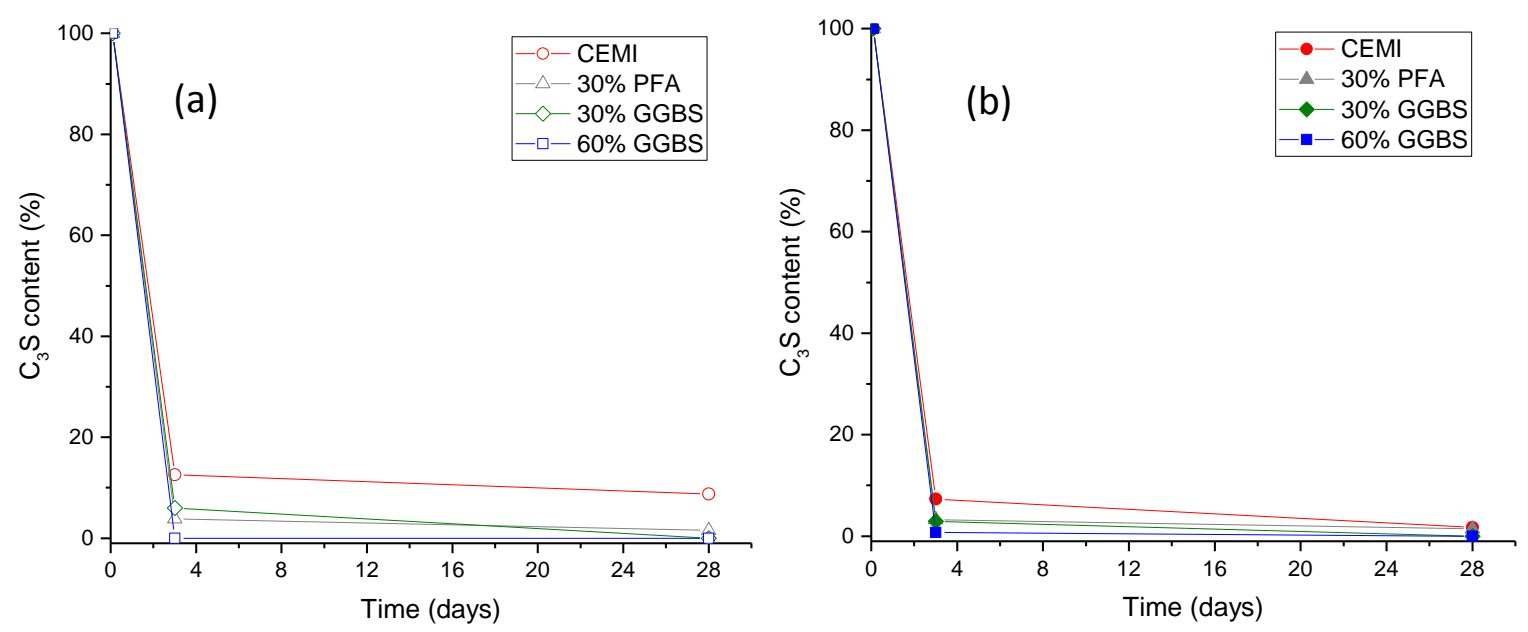

Figure 5.1. Changes in $C_{3} S$ content with curing length measured by XRD - Rietveld refinement for systems with $\mathrm{w} / \mathrm{b}$ ratio (a) 0.40 and (b) 0.57

The reaction of belite was low at early ages $(72 \mathrm{hrs})$ for the neat cement systems but somewhat higher for the blended materials (Figure 5.2). The more rapid reaction of alite at $\mathrm{w} / \mathrm{b}$ ratio 0.57 seemed to inhibit the dissolution of belite and a higher degree of belite hydration was observed at 72 hours for the systems with $\mathrm{w} / \mathrm{b}$ ratio 0.40 . This relationship reversed at later ages, where belite contents for the 0.57 systems dropped below those of the 0.40 samples. Alite hydration has been shown to hinder the dissolution of belite, with high solution concentrations produced during the reaction of alite being higher than the solubility of belite and thus prevent significant reaction from occurring ([144] cited in[53]).

For all systems at the lower w/b ratio of 0.40 (Figure $5.2(\mathrm{a})$ ), the subsequent reaction of belite from 72 hours onwards was very small. The similar levels of reaction of all the systems between 72 hours and 28 days $(<6 \%)$ indicates that the $\mathrm{w} / \mathrm{b}$ ratio, or the availability of space, is the predominant factor in continuing reaction of $\mathrm{C}_{2} \mathrm{~S}$. 

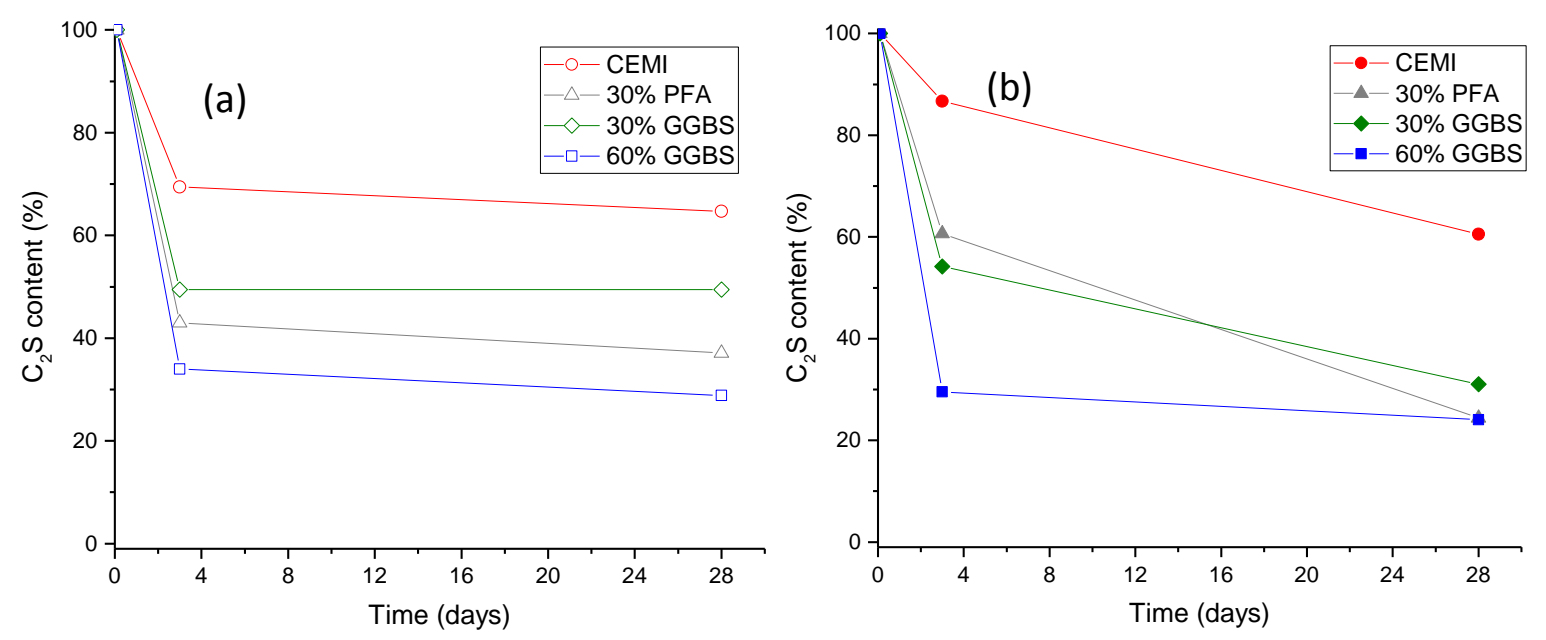

Figure 5.2. Changes in $C_{2} S$ content with curing length measured by XRD - Rietveld refinement for systems with $\mathrm{w} / \mathrm{b}$ ratio (a) 0.40 and (b) 0.57

Conversely when space was not as limited, as for the samples with w/b ratio 0.57 (Figure 5.2 (b)), there was moderate reaction of belite between 72 hours and 28 days for the neat cement (26\% reaction) and $30 \%$ replacement systems. However the reaction was least for the slag sample (PFA $37 \%$ reaction, GGBS $23 \%$ reaction). The retarding effect observed for the slag cement compared with the equivalent fly ash sample and neat system was also observed by Kocaba [12]. As the slag begins to react, and compete for space, the reaction of belite is suppressed. The results demonstrate firstly the more reactive nature of the GGBS compared to the PFA and may possibly suggest a more efficient filling of space by the C-S-H produced from slag hydration compared to that produced from PFA hydration as discussed in [145]. The slowing of the reaction seems to be related to competition for space and the solution conditions created as the slag begins to react, as observed with alite dissolution. The retarding effect of slag on belite hydration was most marked for the $60 \%$ GGBS systems, which had similar kinetics irrespective of water content. Nevertheless, the reaction of belite was accelerated in all the composite systems in relation to the CEMI samples. 

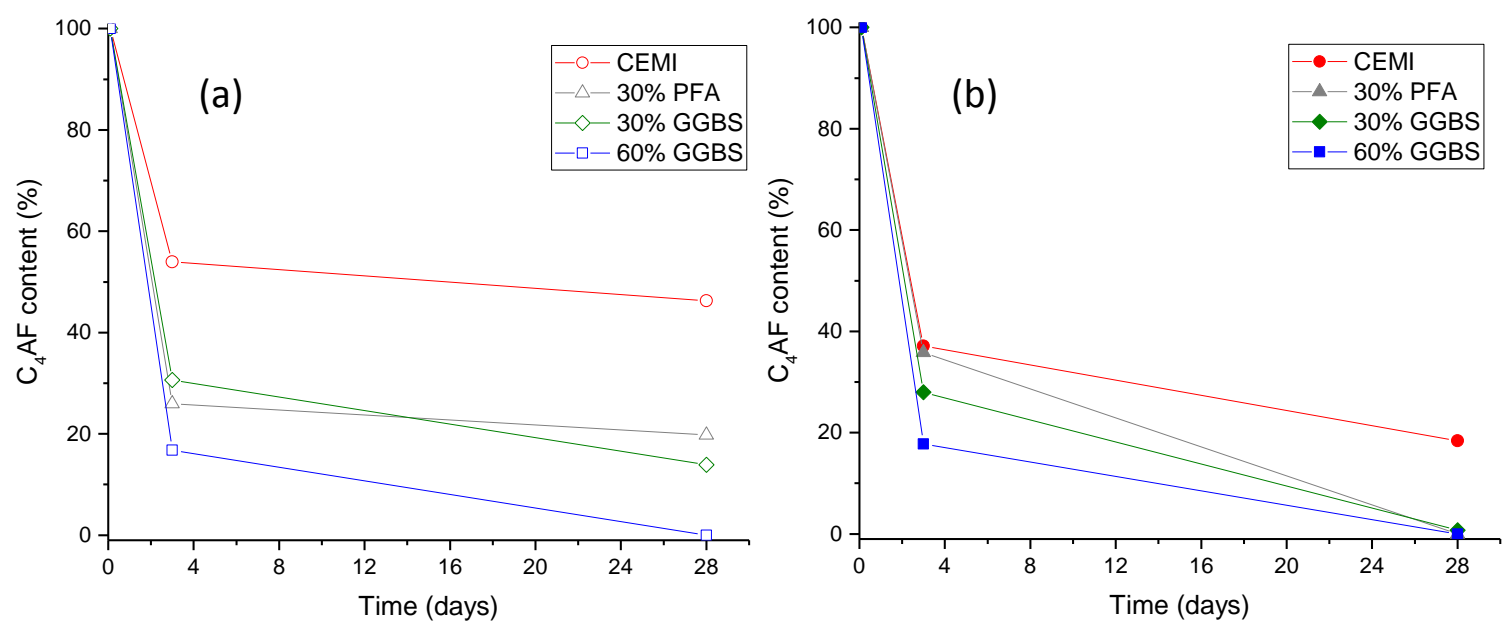

Figure 5.3. Changes in $\mathrm{C}_{4} \mathrm{AF}$ content with curing length measured by XRD - Rietveld refinement for systems with $\mathrm{w} / \mathrm{b}$ ratio (a) 0.40 and (b) 0.57

Ferrite hydration was modest for the CEMI 0.40 sample, with $46 \%$ having reacted at 28 days (Figure 5.3 (a)). Hydration was enhanced in the composite systems, however the effect was slightly amplified for the slag containing samples, particularly from 72 hours onwards. Following 28 days hydration at $\mathrm{w} / \mathrm{b}$ ratio 0.57 (Figure 5.3 (b)) complete reaction of $\mathrm{C}_{4} \mathrm{AF}$ was observed in all the blended materials and $>80 \%$ had reacted in the neat system. Similar findings were reported by Kocaba [12] where $40 \%$ reaction had occurred at 1 day and accelerated reactions were measured in the presence of slag which resulted in complete reaction within a few weeks. A comparatively faster reaction of ferrite in fly ash containing ternary cements compared to a Portland cement system was also observed by de Weerdt et al. [146].

Despite variations in the hydration kinetics of the individual clinker phases, the differences in the overall degree of cement hydration between each set of samples (i.e. $w / b 0.40-t_{0} 72 \mathrm{hrs}, \mathrm{w} / \mathrm{b} 0.40$ $-\mathrm{t}_{0} 28 \mathrm{~d}, \mathrm{w} / \mathrm{b} 0.57-\mathrm{t}_{0} 72 \mathrm{hrs}, \mathrm{w} / \mathrm{b} 0.57-\mathrm{t}_{0} 28 \mathrm{~d}$ ) as measured by SEM-IA (Figure 5.4), was only slight. This was in agreement with other studies published in the literature $[146,147]$. Slight increases in the extent of reaction were measured for the composite samples and increased levels of reaction were observed with increased curing length and $w / b$ ratio.

Figure 5.5 displays the degree of clinker hydration measured by SEM-IA and by XRD-Rietveld refinement confirming good correlation between the two techniques in which values typically 
agreed within $+/-5 \%$. In general, SEM-IA overestimated the extent of reaction, however this is to be expected, particularly at early ages of hydration where the resolution of the imaging excludes very small anhydrous cement grains. Degree of hydration values are also displayed in Table 5.2.

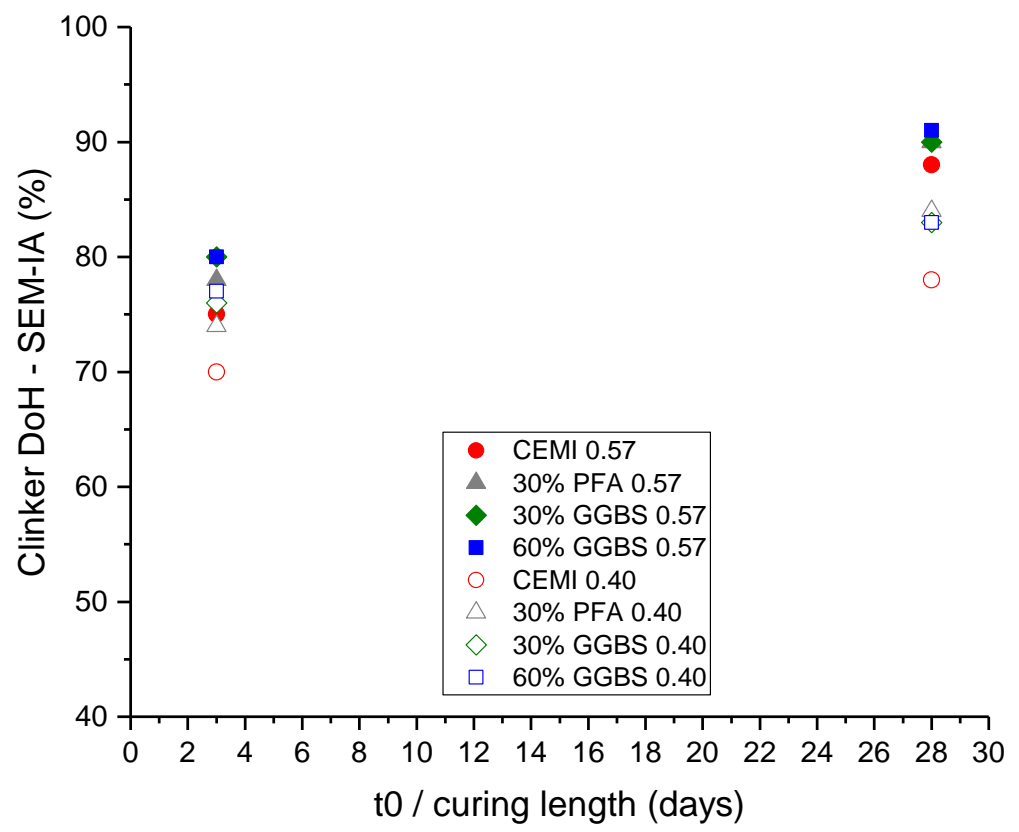

Figure 5.4. Degree of hydration of the cement clinker measured by SEM-IA 


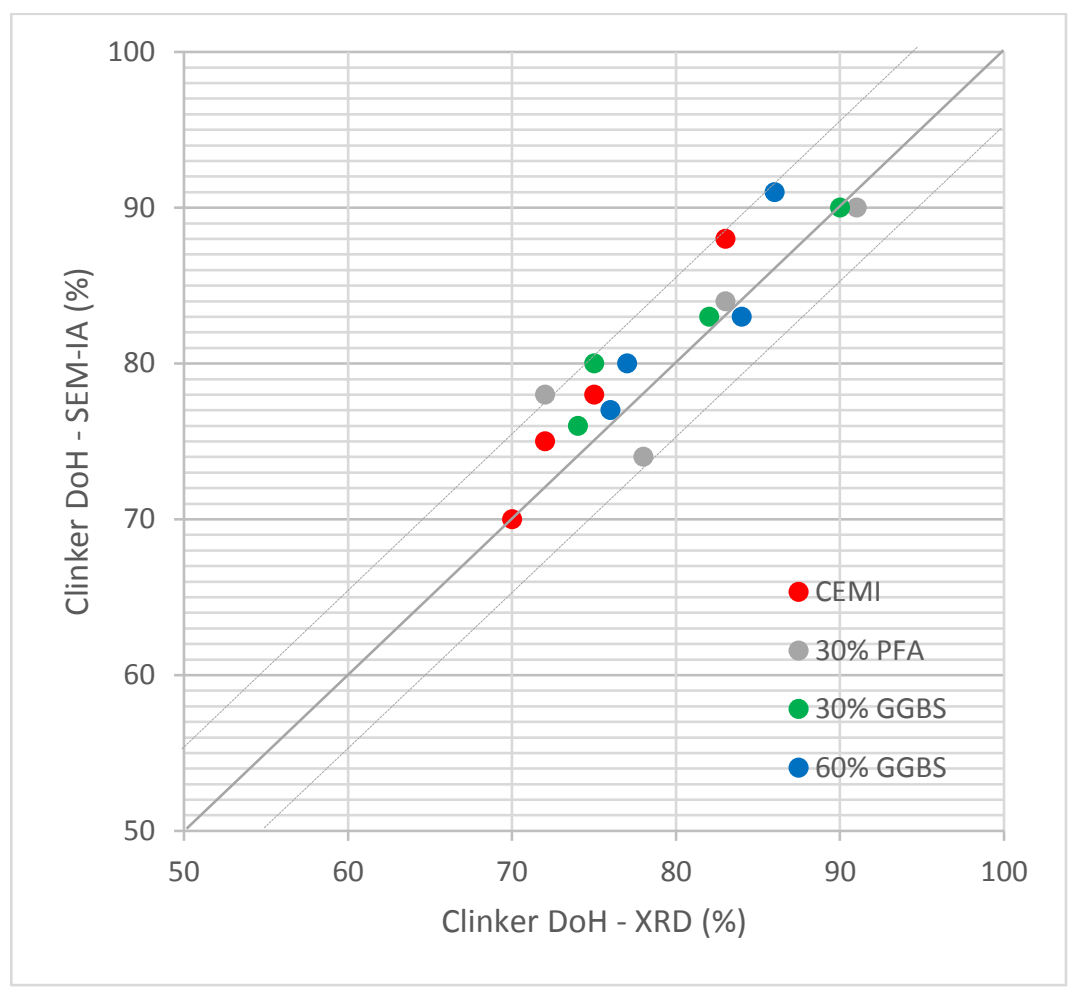

Figure 5.5. Degree of hydration of the cement clinker measured by SEM-IA and XRD - Rietveld refinement (agreement typically within $+/-5 \%$ )

Portlandite contents determined by TG analysis are displayed in Figure 5.6. Values have been normalised to cement content to allow for direct comparison with the neat systems. At early ages (72hrs) a very similar relationship was evident between the systems for both $\mathrm{w} / \mathrm{b}$ ratios. All the composite samples had increased $\mathrm{CH}$ contents in relation to the CEMI systems, further corroborating the accelerated reaction rates previously observed in SEM-IA and XRD data.

As curing length increased to 28 days increased quantities of $\mathrm{CH}$ were measured for the $\mathrm{CEMI}$ systems while portlandite contents decreased in relation to the neat samples for the PFA and GGBS containing materials. The comparative changes in phase content indicates varying degrees of reaction of the slag and fly ash fractions, this will be discussed further in section 5.1.2.1. 


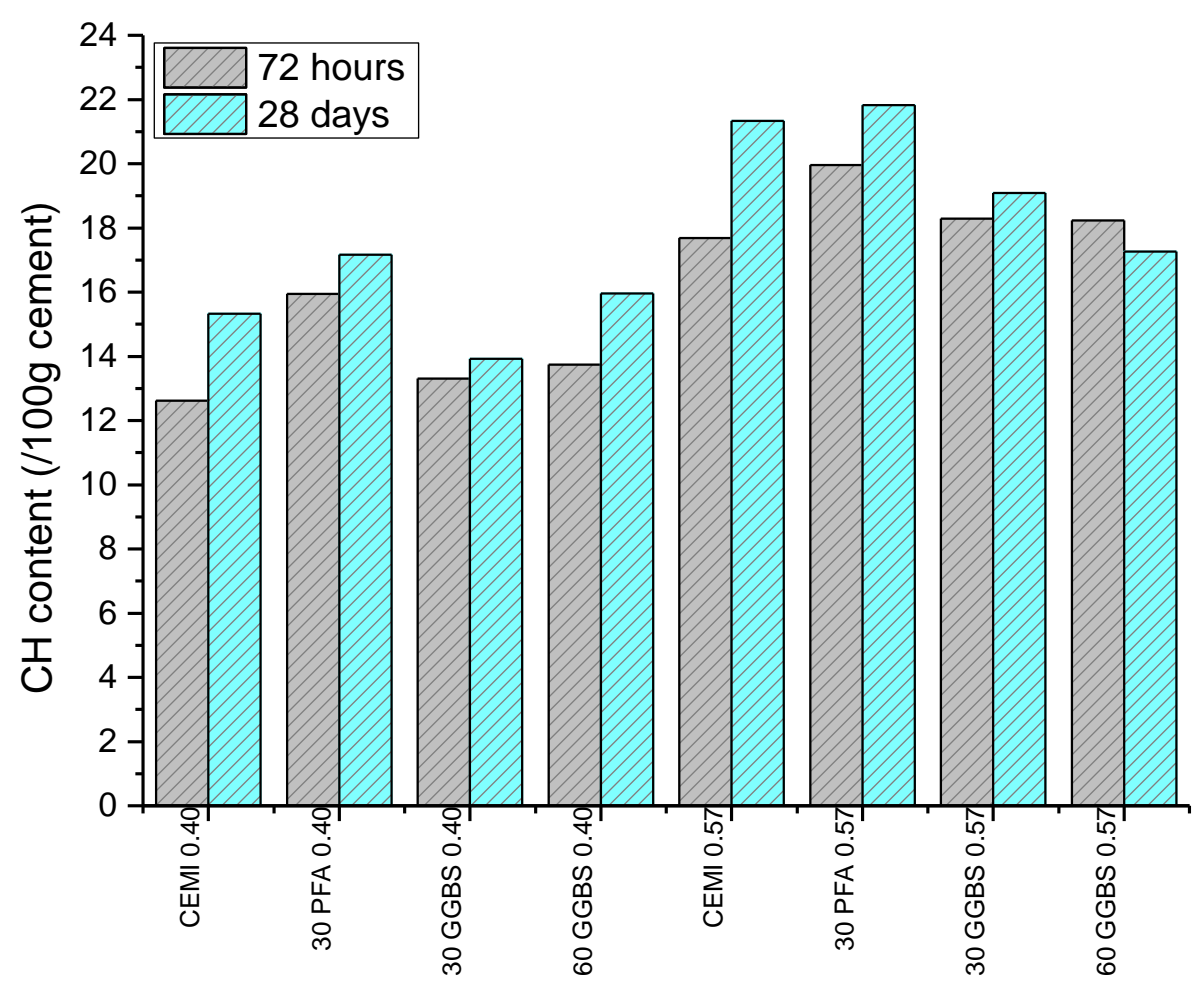

Figure 5.6. $\mathrm{CH}$ content at $\mathrm{t}_{0}$ measured by TGA

\subsubsection{Degree of reaction of the PFA and GGBS cement systems}

\subsubsection{Degree of reaction of the PFA and GGBS}

Richardson et al. [29] recently used the ratio of $\mathrm{CH}$ measured ( $\mathrm{CH}$ actual) to the expected $\mathrm{CH}$ content ( $\mathrm{CH}$ expected - i.e. from simple dilution) to investigate the effects of PFA on cement hydration. By dividing the values measured for the blend by those for the neat cement, then normalising to cement content, values are obtained which indicate both the effects of SCMs on cement hydration as well as the beginning of the pozzolanic reaction. Values $>1$ indicate enhancement of the clinker reaction and a subsequent decrease to $<1$ signals consumption of $\mathrm{CH}$ by the reacting glass (PFA or GGBS). Richardson's study focused on the retarding effects of PFA on clinker hydration at early ages. Retardation of the cement reaction in the PFA systems does occur (as discussed in Section 4.2) but only up to 19 hours hydration, after which accelerated reaction of the clinker is evident, However, here $\mathrm{CH}$ contents at 3 and 28 days only are considered. 
Figure 5.7 shows the $\mathrm{CH}_{\text {actual }} / \mathrm{CH}_{\text {expected }}$ for each of the systems following curing for 72 hours and 28 days. At 72 hours' hydration a similar relationship existed for the samples at both $\mathrm{w} / \mathrm{b}$ ratios. The PFA containing samples had much greater portlandite contents compared to the slag systems indicating enhanced portlandite consumption in the latter. Increased consumption of $\mathrm{CH}$ by the slag glass reflects its greater reactivity compared to PFA which is generally expected to react more slowly [5-7]. As the $\mathrm{w} / \mathrm{b}$ ratio increased the difference in the $\mathrm{CH}$ content between the $\mathrm{CEMI}$ and the PFA sample reduced, indicating increased reaction of the fly ash with increasing water content.
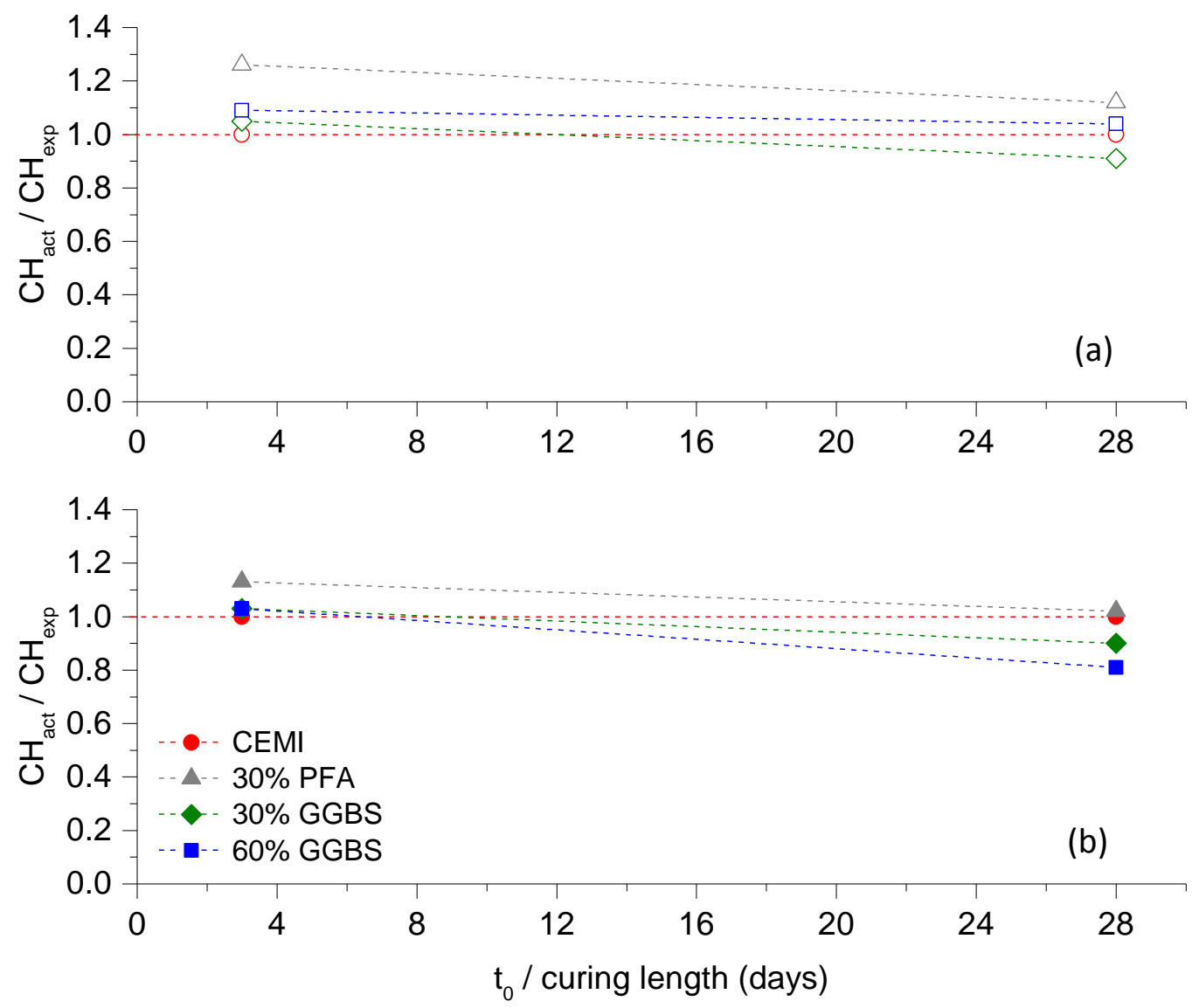

Figure 5.7. Measured $\mathrm{CH}$ contents divided by expected $\mathrm{CH}$ contents - values $>1$ and $<1$ indicating more $\mathrm{CH}$ and less $\mathrm{CH}$ than expected respectively on the basis of dilution: (a) w/b ratio 0.40 and (b) $\mathrm{w} / \mathrm{b}$ ratio 0.57 
At longer lengths of curing, portlandite contents decreased further with regards to the neat system (i.e. value of 1 ) and for samples with $\mathrm{w} / \mathrm{b}$ ratio 0.57 values dropped below 1 for both slag blends indicating significant reaction of the slag fraction had occurred. Relatively higher values for the samples at $\mathrm{w} / \mathrm{b}$ ratio 0.40 indicated a decrease in the extent of reaction of the fly ash and slag with decreasing water content. For all the systems, reactivity of the replacement material increased with increasing $\mathrm{w} / \mathrm{b}$ ratio and length of curing but was observed to be notably greater for the slag containing systems.

This behaviour is also reflected in degree of hydration measurements for the slag determined by SEM-IA, as plotted in Figure 5.8 (values also given in Table 5.2). Following 72 hours' curing similar degrees of reaction were evident for all of the systems, with degrees of hydration between 30 and $40 \%$ regardless of replacement level or water content. However, at curing lengths of 28 days, differences in slag reactivity due to loading and $\mathrm{w} / \mathrm{b}$ ratio became more apparent. At $\mathrm{w} / \mathrm{b}$ ratio 0.40 , between 3 and 28 days, the degree of slag reaction increased by $36 \%$ and $27 \%$ for the $30 \%$ and $60 \%$ replacement systems respectively. The increase for the corresponding systems at $\mathrm{w} / \mathrm{b}$ ratio 0.57 was $38 \%$ and $31 \%$, and a larger disparity between equivalent systems for the two water contents was observed for the lower level of slag replacement. Significant proportions of the GGBS had reacted following 28 days' hydration (values range from 38 - 55\%) agreeing well with calculated basicity values of 1.31 and 1.21 for commonly used ratios $\left(\mathrm{CaO}+\mathrm{MgO} / \mathrm{SiO}_{2} \& \mathrm{CaO} / \mathrm{SiO}_{2}\right)$ which determine slags to have good reactivity for values greater than 1 .

Various factors have been shown to influence the reaction of slag and typically changes in $\mathrm{w} / \mathrm{b}$ ratio, material fineness, replacement level and curing temperature are known to affect its hydration [7, 148]. The results presented in Figure 5.8 correlate well with previous studies in which reaction degrees of $40-50 \%$ and $30-50 \%$ at 1 month were measured by Luke and Glasser [46] and Lumley et al. [45] respectively. Kocaba [12] determined a percentage reaction of between $30-37 \%$ for a reactive slag following 3 days' hydration and at 2 days Whittaker [147] measured a degree of reaction of $24-34 \%$ for 2 different slags.

Escalante-Garcia et al. [7] and Lumley et al. [45] both reported increasing reactivity with increasing water/solids ratio and Esclante-Garcia et al. [7] and Taylor et al. [42] observed reduced degree of reaction with increasing slag loading. Conversely, Hinrichs and Odler [149] reported no significant 
difference in reaction for replacement levels between $30-60 \%$, but a decline in reactivity at much higher loadings (80\%).

Increases in $\mathrm{w} / \mathrm{b}$ ratio result in greater availability of space for hydrates to form and accelerated hydration of the clinker, promoting, or enhancing, the alkaline activating effect necessary for the slag to react. Figure 5.8 illustrates these effects for the slag systems studied, where higher $\mathrm{w} / \mathrm{b}$ ratios and lower loadings, leading to higher $\mathrm{CH}$ contents, resulted in greater levels of reaction.

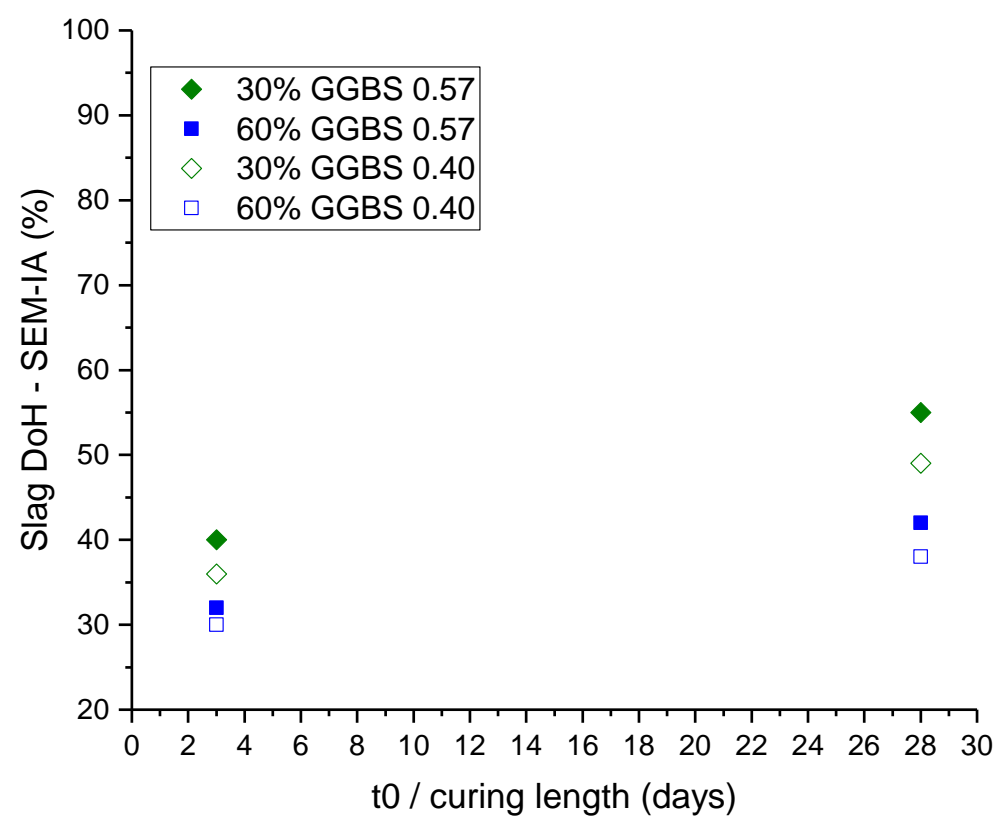

Figure 5.8. Degree of hydration of the GGBS measured by SEM-IA

Quantification of the degree of reaction of the PFA has not been carried out. However indications regarding level of reactivity can be considered in relation to that of the GGBS. Dividing the measured $\mathrm{CH}$ content by the expected content (Figure 5.7) indicates that the reaction of the PFA at the equivalent level of replacement to that of the slag is somewhat lower $(<40 \%$ at $72 \mathrm{hrs}$ and $<50 \%$ at 28 days (from SEM-IA of the GGBS)). However, increased curing lengths had similar effects on reactivity of the PFA and GGBS in both systems, perceived from an almost parallel change in $\mathrm{CH}$ ratio (i.e. gradient of slope) regardless of water content. 
Typically much lower degrees of reaction of fly ash are reported in the literature even at low/moderate levels of replacement. Ben Haha et al. [32] measured levels of reaction of $2 \%, 21 \%$ and $35 \%$ for a $35 \%$ PFA sample at 1,28 and 140 days respectively. As with slag, increased loadings of fly ash result in decreased reactivity. Kovacs [33] studied two fly ash systems measuring reactions of $16-20 \%$ for a $10 \%$ replacement system and $10-12 \%$ at $40 \%$ replacement at a hydration age of 28 days. Following 1 year of reaction, maximum values of $37 \%$ (10\% PFA) and $25 \%$ (40\% PFA) were reported.

Additional information for the PFA systems studied here regarding extent of reaction has been determined from TEM and ${ }^{29} \mathrm{Si}$ NMR data where the lowering of the $\mathrm{Ca} / \mathrm{Si}$ ratio and increased mean chain length compared to that of the neat sample is observed, this will be discussed in further detail in Section 5.3.1.

\subsubsection{Weighted degree of reaction of the GGBS cement systems}

The degree of hydration of the neat systems and the weighted degree of reaction of the slag systems are plotted in Figure 5.9. The overall degree of reaction was lower in the slag containing materials compared to the CEMI samples within each set of systems $(0.40-72 \mathrm{hrs}, 0.40-28 \mathrm{~d}, 0.57-72 \mathrm{hr}, 0.57$ 28d). It has already been shown that clinker hydration occurs more rapidly than the reaction of the slag which is reliant on alkaline activation, however the clinker hydration occurs to a similar degree for a particular $\mathrm{w} / \mathrm{b}$ ratio and curing length. It therefore follows that the weighted degree of reaction of the slag systems is dependent upon the reactivity of the slag and level of replacement. As water content and curing time increase and slag loading decreases, so does the percentage reaction of the slag glass. The overall level of reaction for the $60 \%$ slag samples at the low w/b ratio at 72 hours and 28 days was $49 \%$ and $56 \%$ respectively, while the higher $\mathrm{w} / \mathrm{b}$ ratio had values of $51 \%$ and $62 \%$. As slag loading was reduced (to $30 \%$ ) degrees of hydration increased and percentage reactions of $64 \%$ and $73 \%$ for the $\mathrm{w} / \mathrm{b}$ ratio of 0.40 and $68 \%$ and $80 \%$ for the $\mathrm{w} / \mathrm{b}$ ratio of 0.57 were calculated. 


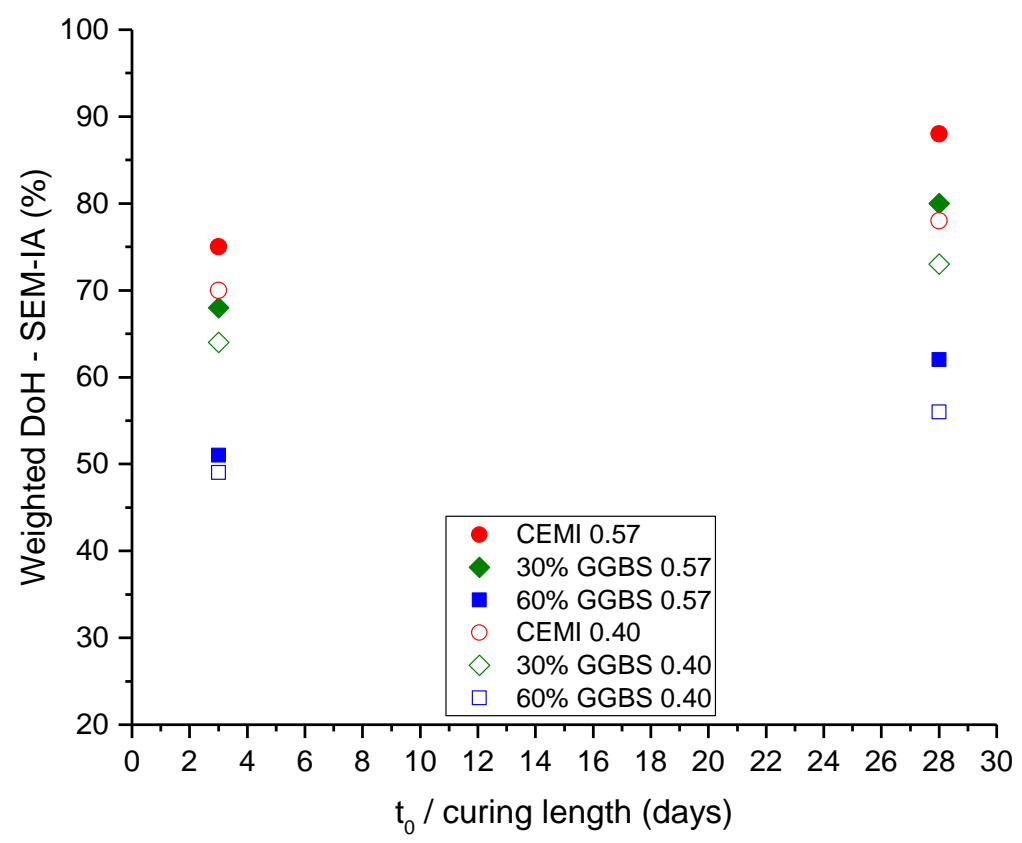

Figure 5.9. Weighted of hydration of the CEMI and GGBS cement systems measured by SEM-IA

\subsection{Phase assemblage}

\subsubsection{Crystalline phase assemblage}

The crystalline phase assemblage of each system was determined by XRD - Rietveld refinement, Figure 5.10 presents the diffraction patterns between $7-13^{\circ} 2 \theta$ for each of the systems at $t_{0}$, displaying $\mathrm{AFt}, \mathrm{C}_{4} \mathrm{AF}$ and $\mathrm{AFm}$ peak reflections. Measured $\mathrm{CH}$ and $\mathrm{AFt}$ contents are presented in Table 5.2, given in $\mathrm{g} / 100 \mathrm{~g}$ of binder. Verification of the analysis was assessed by comparison of $\mathrm{CH}$ contents measured by XRD and TGA. Figure 5.11 displays the correlation in which agreement was typically within $+/-2.5 \%$, although an underestimate was generally observed by XRD analysis. As TGA measures total $\mathrm{CH}$ content, both crystalline and poorly crystalline species, comparatively higher contents calculated by TGA are not unreasonable. 


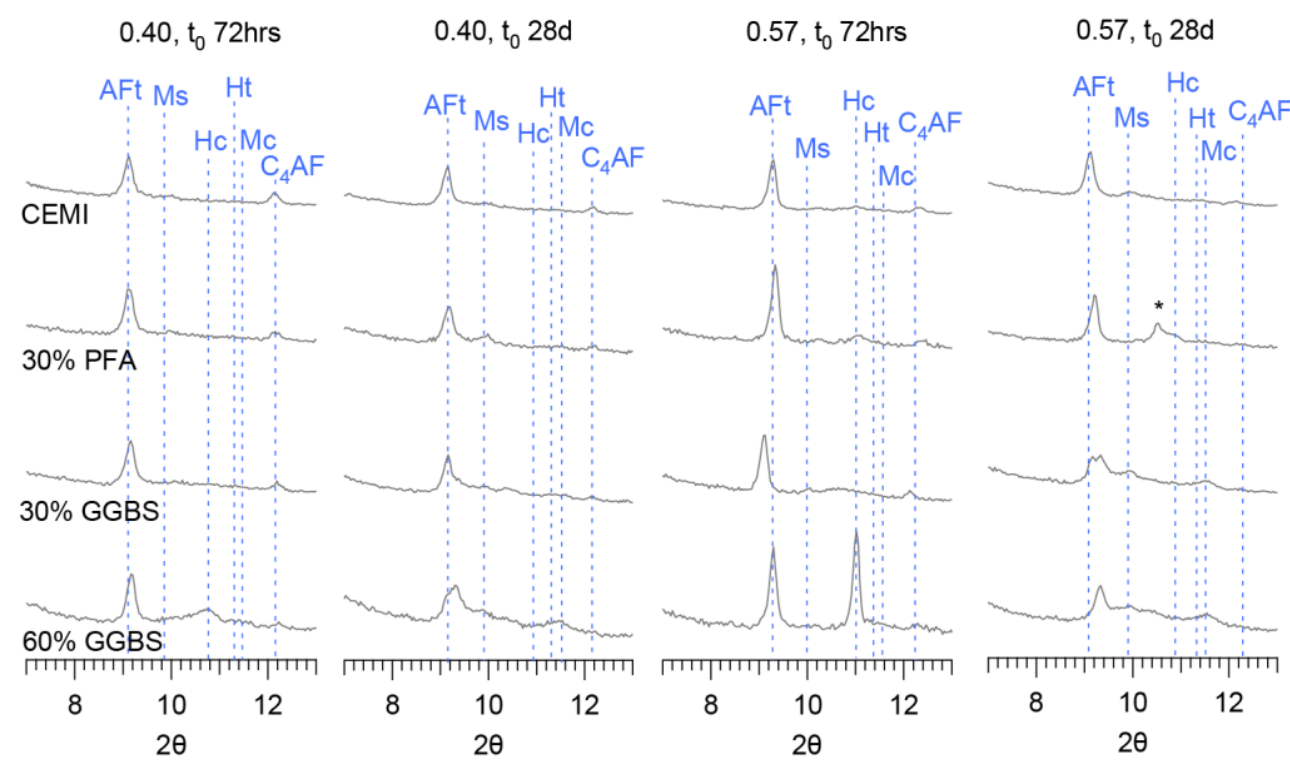

$\mathrm{AFt}$ - ettringite, Ms - monosulfoaluminate, $\mathrm{Hc}$ - hemicarboaluminate, $\mathrm{Mc}$ - monocarboaluminate,

$\mathrm{Ht}$ - hydrotalcite, * hydroxyl-AFm

Figure 5.10. XRD patterns between $7-13^{\circ} 2 \theta$ for $t_{0}$ samples following 72 hours and 28 days hydration.

Table 5.2. $\mathrm{CH}$ (error $+/-2.5 \%$ ) content, AFt content and degree of hydration of cement clinker (error $+/-5 \%$ ), slag and weighted degree of reaction following 72 hours and 28 days.

\begin{tabular}{|c|c|c|c|c|c|c|c|c|c|}
\hline & \multirow[b]{2}{*}{$w / b$} & \multirow[b]{2}{*}{ Time (days) } & \multicolumn{2}{|c|}{$\mathrm{CH}$ (/100g binder) } & \multirow{2}{*}{$\frac{\mathrm{AFt}(/ 100 \mathrm{~g} \text { binder })}{\mathrm{XRD}}$} & \multicolumn{2}{|c|}{ DoH Clinker (\%) } & \multirow{2}{*}{$\begin{array}{c}\text { DoH slag (\%) } \\
\text { SEM-IA }\end{array}$} & \multirow{2}{*}{$\frac{\text { Weighted DoH (\%) }}{\text { SEM-IA }}$} \\
\hline & & & XRD & TGA & & XRD & SEM-IA & & \\
\hline \multirow[t]{2}{*}{ CEMI } & 0.40 & 3 & 9.8 & 12.6 & 9.8 & 70 & 70 & - & 70 \\
\hline & & 28 & 13.2 & 15.3 & 12.9 & 75 & 78 & - & 78 \\
\hline \multirow[t]{2}{*}{$30 \%$ PFA } & 0.40 & 3 & 7.7 & 11.2 & 7.3 & 78 & 74 & - & - \\
\hline & & 28 & 10.4 & 12.0 & 10.0 & 83 & 84 & - & - \\
\hline \multirow[t]{2}{*}{$30 \%$ GGBS } & 0.40 & 3 & 7.6 & 9.3 & 7.8 & 74 & 76 & 36 & 64 \\
\hline & & 28 & 9.3 & 9.7 & 8.5 & 82 & 83 & 49 & 73 \\
\hline \multirow[t]{2}{*}{$60 \%$ GGBS } & 0.40 & 3 & 4.3 & 5.5 & 5.6 & 76 & 77 & 30 & 49 \\
\hline & & 28 & 4.7 & 6.4 & 5.6 & 84 & 83 & 38 & 56 \\
\hline \multirow[t]{2}{*}{ CEMI } & 0.57 & 3 & 18.0 & 17.7 & 12.9 & 72 & 75 & - & 75 \\
\hline & & 28 & 22.6 & 21.3 & 11.9 & 83 & 88 & - & 88 \\
\hline \multirow[t]{2}{*}{$30 \%$ PFA } & 0.57 & 3 & 11.4 & 14.2 & 10.0 & 72 & 78 & - & - \\
\hline & & 28 & 16.5 & 15.6 & 8.6 & 91 & 90 & - & - \\
\hline \multirow[t]{2}{*}{$30 \%$ GGBS } & 0.57 & 3 & 9.8 & 12.8 & 9.3 & 75 & 80 & 40 & 68 \\
\hline & & 28 & 10.0 & 12.0 & 8.4 & 90 & 90 & 55 & 80 \\
\hline \multirow[t]{2}{*}{$60 \%$ GGBS } & 0.57 & 3 & 3.6 & 7.3 & 5.1 & 77 & 80 & 32 & 51 \\
\hline & & 28 & 4.7 & 6.9 & 4.4 & 86 & 91 & 42 & 62 \\
\hline
\end{tabular}




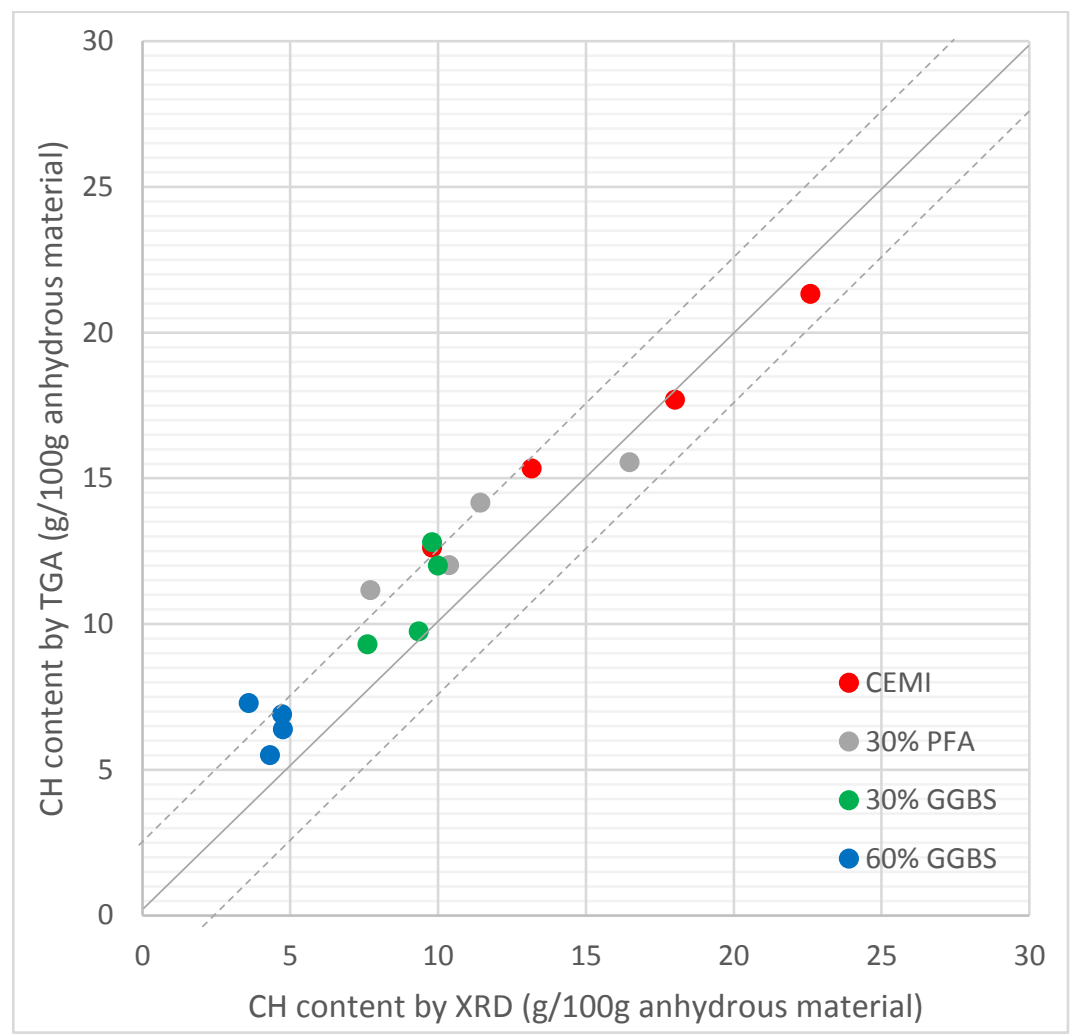

Figure 5.11. CH content measured by TGA and XRD - Rietveld refinement (agreement typically within +/- 2.5\%)

Decreased quantities of Portlandite were measured for the fly ash and slag systems in relation to the CEMI samples, decreasing further with increasing reaction of the replacement material (i.e. GGBS more reactive than PFA) and increasing percentage substitution. At both $\mathrm{w} / \mathrm{b}$ ratios, increased quantities of $\mathrm{CH}$ were observed for the CEMI samples with increasing length of curing, and small increases were measured for the fly ash systems. Replacement by slag resulted in equivalent, or slightly decreased, Portlandite contents between 72 hours and 28 days, at both w/b ratios, resulting from the higher reactivity of the slag glass.

This has interesting implications for differences in carbonation behaviour that might be observed as curing time and mix design ( $\mathrm{w} / \mathrm{b}$ ratio) change. Similar initial portlandite contents mean changes, or differences, in material behaviour upon exposure to $\mathrm{CO}_{2}$ will be a result of modifications in the material pore structure. $\mathrm{CH}$ is the main alkalinity buffer but the accessibility and reaction of $\mathrm{CO}_{2}$ with 
hydrate phases is also controlled by its rate of diffusion through the microstructure. Although composite cement systems are expected to have lower initial portlandite contents, lowering their chemical resistance to carbonation induced corrosion, enhancement of the microstructure is anticipated to mitigate these effects by significantly reducing diffusivity rates assuming sufficient reaction has occurred.

Cement replacement reduced the amount of AFt formed relative to the CEMI samples. Following 72 hours hydration, greater quantities of AFt were precipitated in the systems at w/b 0.57 compared to the 0.40 samples, however extended curing (28d) resulted in an increase in AFt for the 0.40 samples but a decrease for the 0.57 systems. The poor crystallinity and susceptibility of the AFm phases to changes in composition and structure, resulting in modifications in peak shift, peak broadening and intensity [68] mean reliable phase content values are difficult to obtain by XRD measurements.

Partial replacement of Portland cement by PFA or GGBS resulted in lower AFt contents but greater AFm contents compared to the neat systems. At 30\% replacement similar quantities of AFt were measured for each of the equivalent samples (PFA or GGBS) however greater quantities of AFm were detected for the slag containing materials, particularly at higher replacement level (60\%), higher $w / b$ ratio and longer curing lengths $(28 \mathrm{~d})$, where higher degrees of slag reactivity release aluminium, aiding conversion of AFt to AFm.

At the higher $w / b$ ratio (0.57) small reductions in AFt occurred at 28 days relative to 72 hours, appearing to be partially at the expense of increased quantities of AFm phases in the composite systems. Small hydrotalcite peak reflections were detected for the GGBS systems only.

Thermodynamic calculations presented by Lothenbach et al. [25] for varying replacement levels of Portland cement by PFA predict complete consumption of $\mathrm{CH}$ at substitution levels of $30 \%$. Considerable quantities of portlandite were measured in each of the fly ash systems studied here however discrepancies between the modelled and experimental phase assemblage can be attributed to the reaction degree of the fly ash. Lothenbach et al. [25] assumed 50\% reaction of the fly ash to have occurred which is estimated to be significantly greater than the reactivity of the PFA used in this study for the reaction times considered. This is also significantly larger than the percentage reaction measured in other studies for similar systems at 28 days hydration, Ben Haha 
et al. [32] measured a degree of hydration of $21 \%$ for a $35 \%$ PFA sample and Kovacs measured 10 $12 \%$ for a $40 \%$ PFA system. Increased AFm and decreased AFt contents are in good agreement with the modelled calculations and with experimental studies in the literature $[31,44,146]$. Enhanced quantities of $\mathrm{Al}_{2} \mathrm{O}_{3}$ but reduced $\mathrm{SO}_{3}$ contents favour the formation of $\mathrm{AFm}$ species over AFt which is evident in the systems where the degree of fly ash hydration is higher (i.e. increased curing length ( $\left.t_{0} 28 d\right)$ and increased $\mathrm{w} / \mathrm{b}$ ratio (0.57)). Dyer and Dhir [150] reported similar findings observing conversion of AFt to monosulfate with increasing levels of fly ash replacement. The authors concluded that small increases in the total content of AFt and AFm with increasing PFA content were a result of contribution from the replacement material.

Phase assemblage predictions for the slag systems compare well with modelled data [25]. $\mathrm{CH}$ is predicted to be present up to much higher levels of substitution $(<65 \%)$ compared with equivalent fly ash composites even at considerable levels of reaction (75\%). The portlandite content is predicted to decrease with increasing replacement, as observed for the slag systems studied here. Calculations predict monocarbonate formation over monosulfate, with decreased quantities of AFt and increased quantities of hydrotalcite formed with increasing replacement levels. Generally experimental studies show lower amounts of AFt and AFm in slag cement materials compared to neat systems, resulting from greater uptake of Al in C-S-H $[12,42,49]$. However, the results presented in Figure 5.10 suggest enhanced formation of AFm phases for the slag systems compared with the CEMI sample. The hydration of $\mathrm{C}_{3} \mathrm{~A}$ was rapid for all the systems with almost complete reaction following 72 hours indicating contribution of $\mathrm{Al}_{2} \mathrm{O}_{3}$ from the slag glass, behaviour also reported in [47]. Increased degrees of reaction were measured for the GGBS fraction in these systems at both replacement levels supporting the suggestion that the slag is providing a source of Al for increased AFm precipitation.

In nearly all the systems a mixture of AFm phases existed; predominantly monosulfate (Ms), with small amounts of hemicarbonate $(\mathrm{Hc})$ present. A combination of monosulfate, hemicarboaluminate and monocarboaluminate (Mc) was observed for the 60\% GGBS system at w/b ratio 0.57 and 28 days' hydration. The two carbonate AFm phases are considered to be thermodynamically stable under ambient conditions [151] and it is expected that in the presence of carbonates, $\mathrm{SO}_{3}$ will be displaced to form hemicarboaluminate before subsequently transforming to monocarboaluminate [68]. Many studies have observed the initial formation of hemicarboaluminate $[47,69,146,152]$ 
which is stable in cements with small contents of calcite (2-3wt\%) [153]. Mixtures of monosulfate and hemicarboaluminate were observed in the majority of systems investigated here (Figure 5.10) where the formation is likely a result of minor quantities of carbonate species, formed during sample preparation and data collection, present as calcite. The conversion of hemicarboaluminate to monocarboaluminate is only evident in one system ( $60 \%$ GGBS, $0.57,28$ days) and appeared to only occur partially.

\subsubsection{Aluminium bearing phases}

DTA data and ${ }^{27} \mathrm{Al}$ MAS NMR spectra provide further insight into the location of $\mathrm{Al}$ in the hydrate phases. Figure 5.12 displays the DTA plots between $0-250^{\circ} \mathrm{C}$ for each of the systems at time $t_{0}$. The large endothermic peak centered at $\sim 100^{\circ} \mathrm{C}$ corresponds to dehydration of $\mathrm{C}-\mathrm{S}-\mathrm{H}$ and $\mathrm{AFt}$ and emphasises the variations in volume of hydration products formed for the different systems following 72 hours' curing (Figure 5.12 (a)\&(c)). These differences became less obvious at longer curing lengths (Figure 5.12 (b)\&(d)) when additional formation of $\mathrm{C}-\mathrm{S}-\mathrm{H}$ from the reacting replacement materials was significant. The small peak observed at $\sim 160^{\circ} \mathrm{C}$ confirmed the presence of AFm phases $[69,99,153]$ agreeing with the XRD measurements previously discussed.
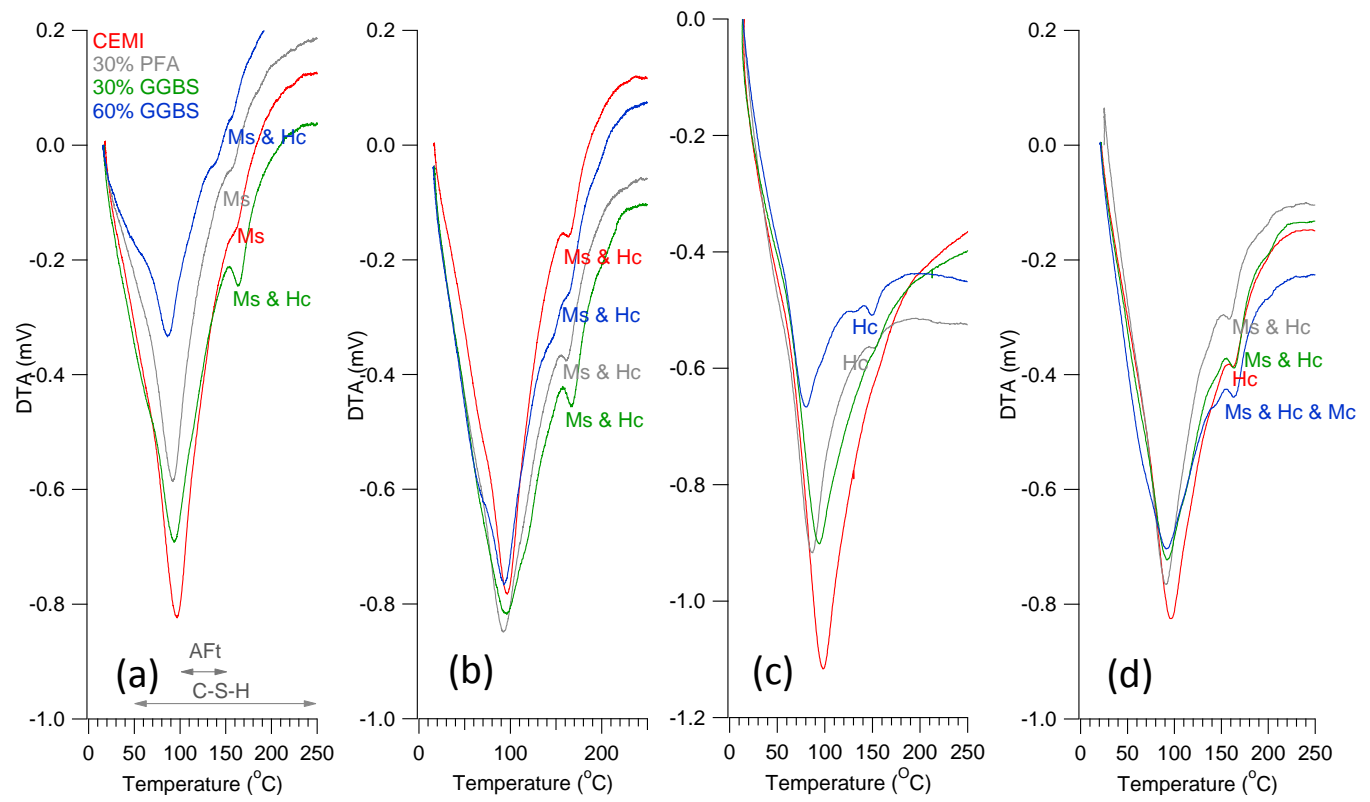

Figure 5.12. DTA plots between $0-250^{\circ} \mathrm{C}$ for each system at $t_{0} ;(a) w / b 0.40, t_{0} 72$ hours (b) $w / b$ $0.40, \mathrm{t}_{0} 28$ days (c) w/b $0.57, \mathrm{t}_{0} 72$ hours (d) w/b 0.57, $\mathrm{t}_{0} 28$ days 
The ${ }^{27} \mathrm{Al}$ MAS NMR spectra collected for each of the systems are displayed in Figure 5.13. Three main resonances exist for all the samples and are attributed to incorporation of aluminium in C-S-H and the calcium aluminate hydrate phases. Resonances for octahedrally coordinated aluminium are generally observed between 10-20ppm and this is the main environment observed for all the systems in Figure 5.13. Responses at $\sim 13 p p m$ and $\sim 9 p p m$ are assigned to aluminium located in AFt and AFm phases respectively. In slag containing systems, where hydrotalcite is expected to form, as confirmed by XRD and TEM analysis, the peak at 9ppm is likely to be a convolution of the two phases which have the same chemical shift $[110,154,155]$. Identical chemical shifts are also observed for the various AFm phases (monosulfate, monocarbonate and hemicarbonate) preventing separate identification in ${ }^{27} \mathrm{Al}$ NMR spectra [155]. A small peak or shoulder at $~ 5 \mathrm{ppm}$ is evident in some of the samples and is assigned to a third aluminate hydrate (TAH) which was proposed by Anderson et al. [156] to be a disordered aluminate hydrate phase precipitated on the surface of C-S-H. Tetrahedrally coordinated aluminium (AI(IV)) produces resonances in the range $\sim 40-90 \mathrm{ppm}$ in which broad signals centred at $\sim 70 \mathrm{ppm}$ in all of the systems originate from substitution of $\mathrm{Al}$ for $\mathrm{Si}$ in $\mathrm{C}-\mathrm{S}-\mathrm{H}$ [63]. These responses are relatively low and contributions from unreacted slag and fly ash glass at $\sim 56-58 \mathrm{ppm}$ and $\sim 50-55 \mathrm{ppm}$ respectively (observed from anhydrous material spectra) were detected.

Although quantification of the individual calcium aluminate phases (from ${ }^{27} A I N M R$ ) hasn't been performed, the peak intensities corresponding to AFm deviate considerably when compared to XRD results (Figure 5.10). XRD peak intensities suggested significantly lower amounts of AFm compared to AFt in nearly all cases, however ${ }^{27} \mathrm{Al}$ NMR data suggest similar levels of each, or in some instances more of the former. This is illustrated in Figure 5.13(a) where XRD peak intensities suggested minor, or negligible, AFm contents for each of the systems. However, the NMR data suggests much larger amounts of AFm are present in each of the systems than previously indicated, in line with observations made by Lothenbach et al. [69]. 

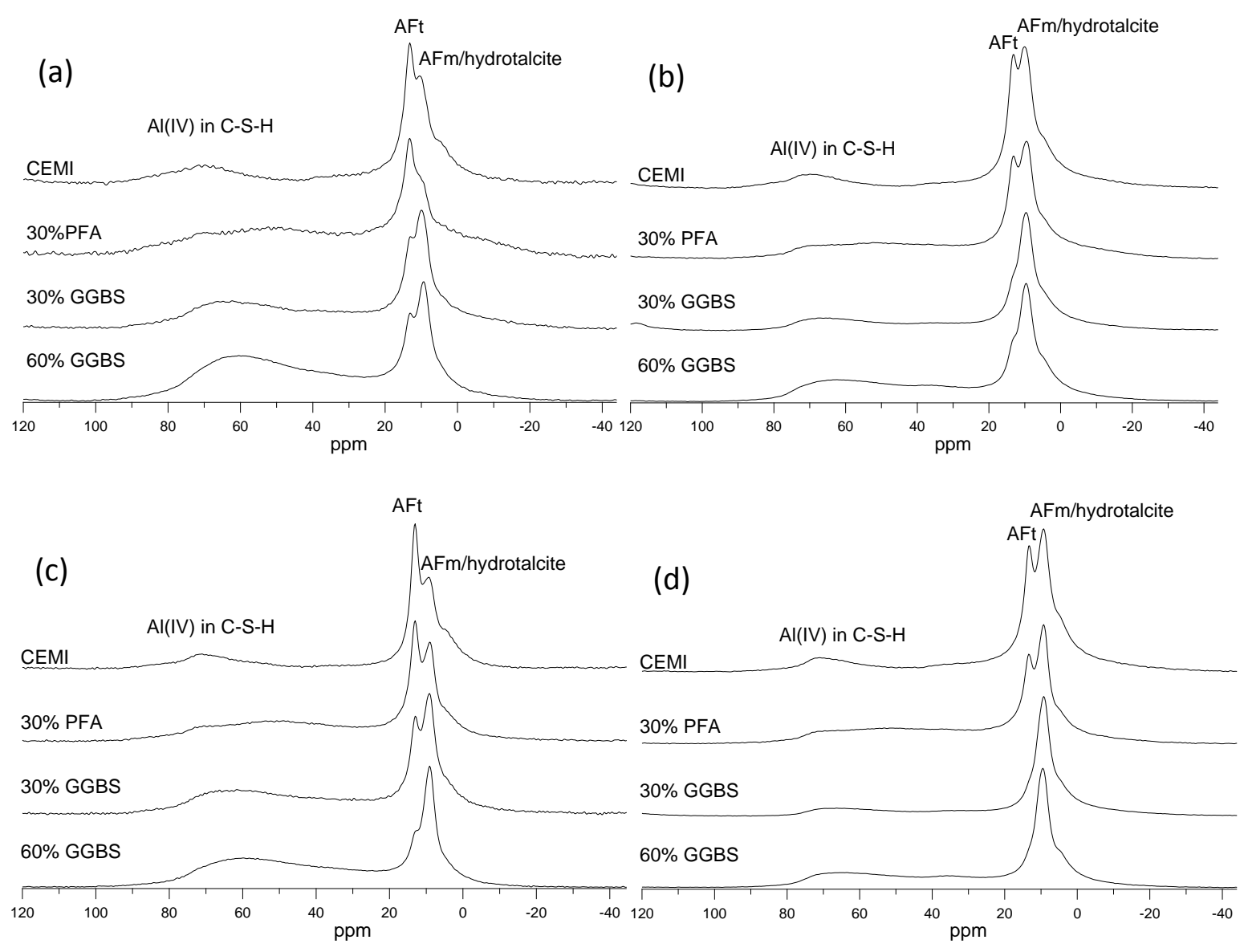

Figure 5.13. Single-pulse ${ }^{27} A L$ MAS NMR spectra for each system at $t_{0} ;(a) w / b 0.40, t_{0} 72$ hours (b) $\mathrm{w} / \mathrm{b} 0.40, \mathrm{t}_{0} 28$ days (c) w/b 0.57, $\mathrm{t}_{0} 72$ hours (d) w/b 0.57, $\mathrm{t}_{0} 28$ days

\subsection{Microstructure}

\subsubsection{TEM-EDX}

TEM micrographs were collected for selected samples at $w / b$ ratio 0.57 to investigate the microstructure and morphology of the hydrate phases. For the neat system after 72 hours' curing (Figure 5.14) the reference microstructure was well established, agreeing with previous studies on both Portland cement and $C_{3} S$ pastes $[17,22,132]$. Inner product (Ip) regions with homogenous 
fine-scale morphology (Figure 5.14 (d)) and Op regions consisting of both coarse and fine fibrillar CS-H were observed (Figure 5.14 (a) \& (b)). AFt crystals occupied outer product (Op) regions and were evidenced by relicts in the microstructure outlining their original shape. This is illustrated in Figure 5.14 (b) where a hexagonal prism shaped relict ( $300 \mathrm{~nm} \varnothing)$ is present in the Op region. AFt is largely unstable under the electron beam, readily decomposing during TEM preparation and observation [127] and as such only impressions of their original structures can be seen.
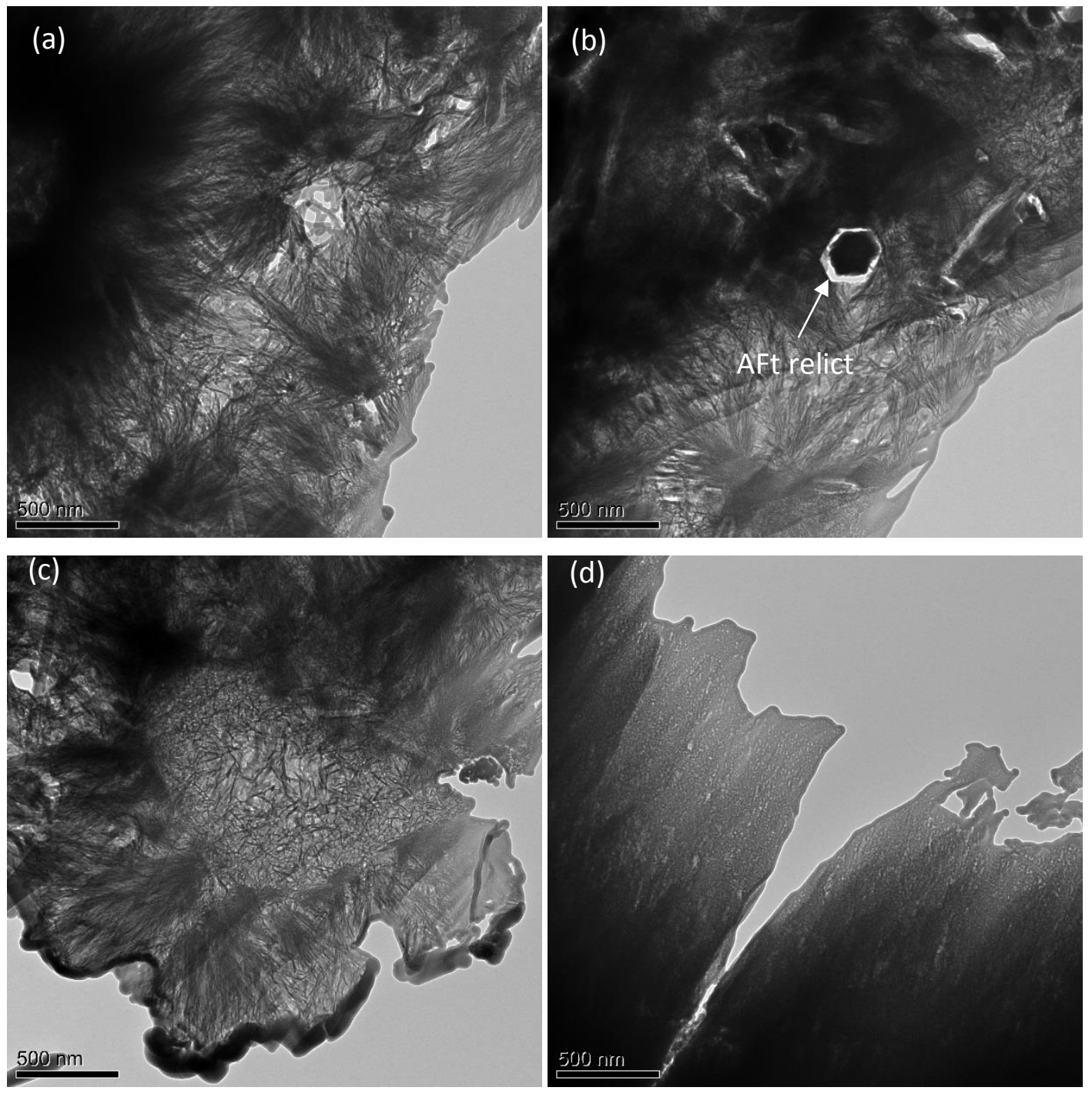

Figure 5.14. TEM micrographs of CEMI $0.57(72 \mathrm{hr})-\mathrm{t}_{0}$ sample showing fibrillar Op regions with relicts of $A F t((a) \&(b))$ and fine Ip regions $((c) \&(d))$. 
Figure 5.14 (c) displays a fully reacted cement grain in which a coarse, or less dense, core is surrounded by relatively dense C-S-H. This feature is typical of small, wholly reacted particles in $\mathrm{C}_{3} \mathrm{~S}$, Portland cement or composite cement samples [17].

At 72 hours the neat system has already undergone substantial hydration ( 75\% SEM-IA) and changes with time, although relatively small, are expected to primarily include continued formation of C-S-H producing finer Op regions as space becomes more constrained [157].

The microstructures at 72 hours for the $30 \%$ fly ash and 30\% slag systems are reasonably similar (Figures 5.15 \& 5.16). Typically Op regions displayed both coarse and fine fibrillar C-S-H, although it appeared somewhat coarser than for the neat sample. Foil-like morphologies in Op regions confirmed reaction of both the PFA and the GGBS $[34,36,41,42]$ and very slight reaction rims on PFA particles (Figure 5.15 (a)) further established some reaction of the fly ash at this age. Ip regions, assumed to be predominantly alite, displayed fine textured homogenous microstructures and large irregular AFm plates, observed as solid and dense phases (Figures 5.15(a) \& 5.16(c)), were located in the relatively open Op regions.

Unfortunately due to the very high level of replacement, the high water content and short curing length, it was not possible to prepare a sample for the $60 \%$ GGBS 0.57 ( $72 \mathrm{hr}$ ) system for observation in the TEM.
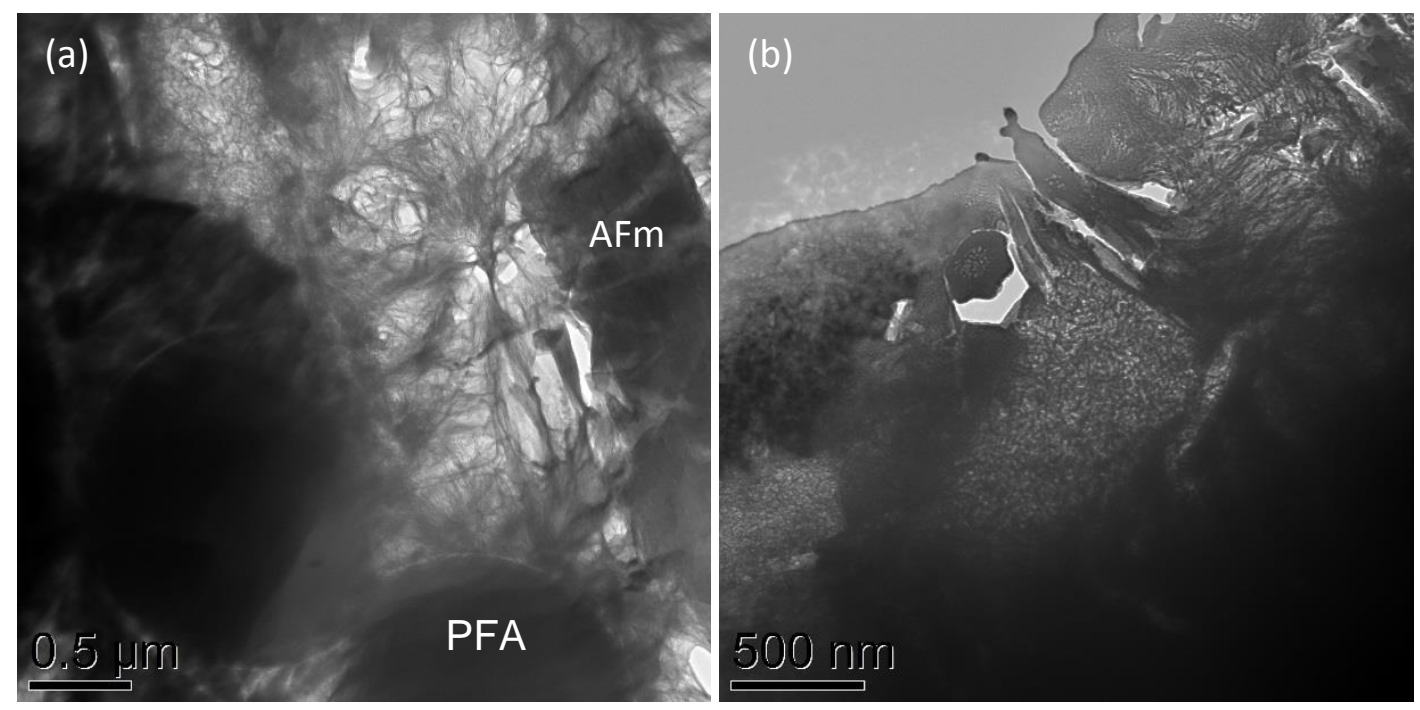

Figure 5.15. TEM micrographs of 30\% PFA 0.57 (72hr) - $t_{0}$ sample showing fibrillar and foil-like Op regions, fine Ip regions and slight reaction rims on PFA particles. 

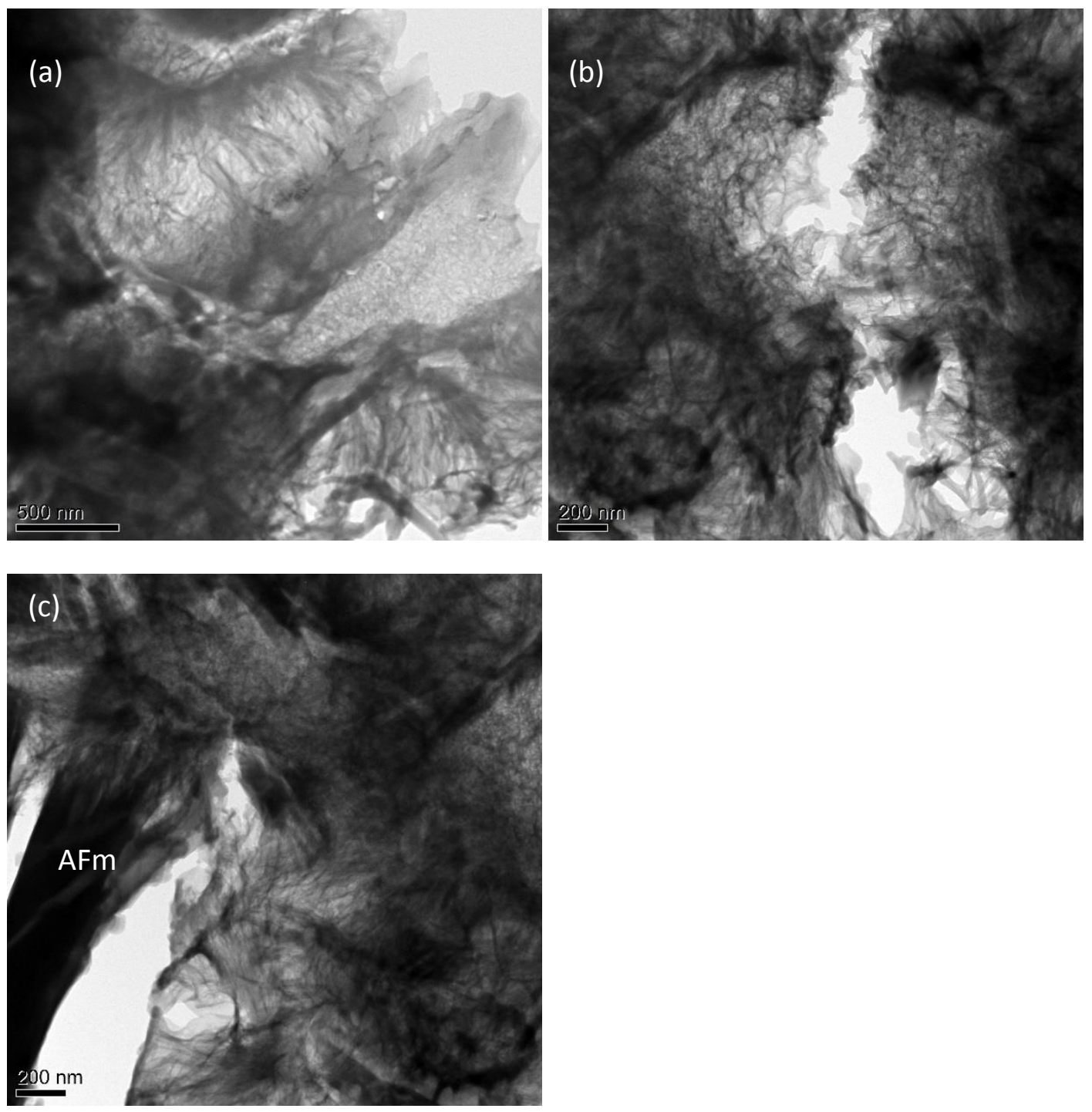

Figure 5.16. TEM micrographs of $30 \%$ GGBS $0.57(72 \mathrm{hr})-\mathrm{t}_{0}$ sample showing fibrillar and foil-like Op regions, fine Ip regions and AFm plates.

Much finer Op C-S-H was observed in samples cured for 28 days compared to the equivalent 72 hour cured systems. In the fly ash sample (Figure 5.17) Op regions, again displaying both fibrillar and foillike morphologies, accommodated AFt and AFm phases (Figure 5.17 (a)\&(b)) and appeared more dense and fine. Regions of Ip C-S-H were more readily observed however reaction rims on PFA grains remained relatively small (Figure $5.17(\mathrm{a}) \&(\mathrm{c})$ ) and almost no fully reacted particles were detected. This is in contrast to the work of Girao et al. [34] who presented numerous micrographs of almost entirely reacted fly ash grains following 28 days' hydration in an equivalent replacement system 
(30\% PFA). While variations in chemical composition of the PFA, namely CaO contents ( $4.49 \%$ Girao : $0.06 \%$ for this study), and the methodologies (curing temperature of $55^{\circ} \mathrm{C}$ in [34]) will certainly contribute to the disparities observed between the studies, the large differences highlight the huge variability associated with reactivity of fly ash materials. A series of small sized AFm plates bridging areas of Op C-S-H are observed in Figure 5.17(b) and fully reacted cement grains displaying both fine homogenous morphology, as in Figures 5.17 (a) and (b), and Ip C-S-H centred around a less dense core, as in Figure 5.17 (d), are evident.
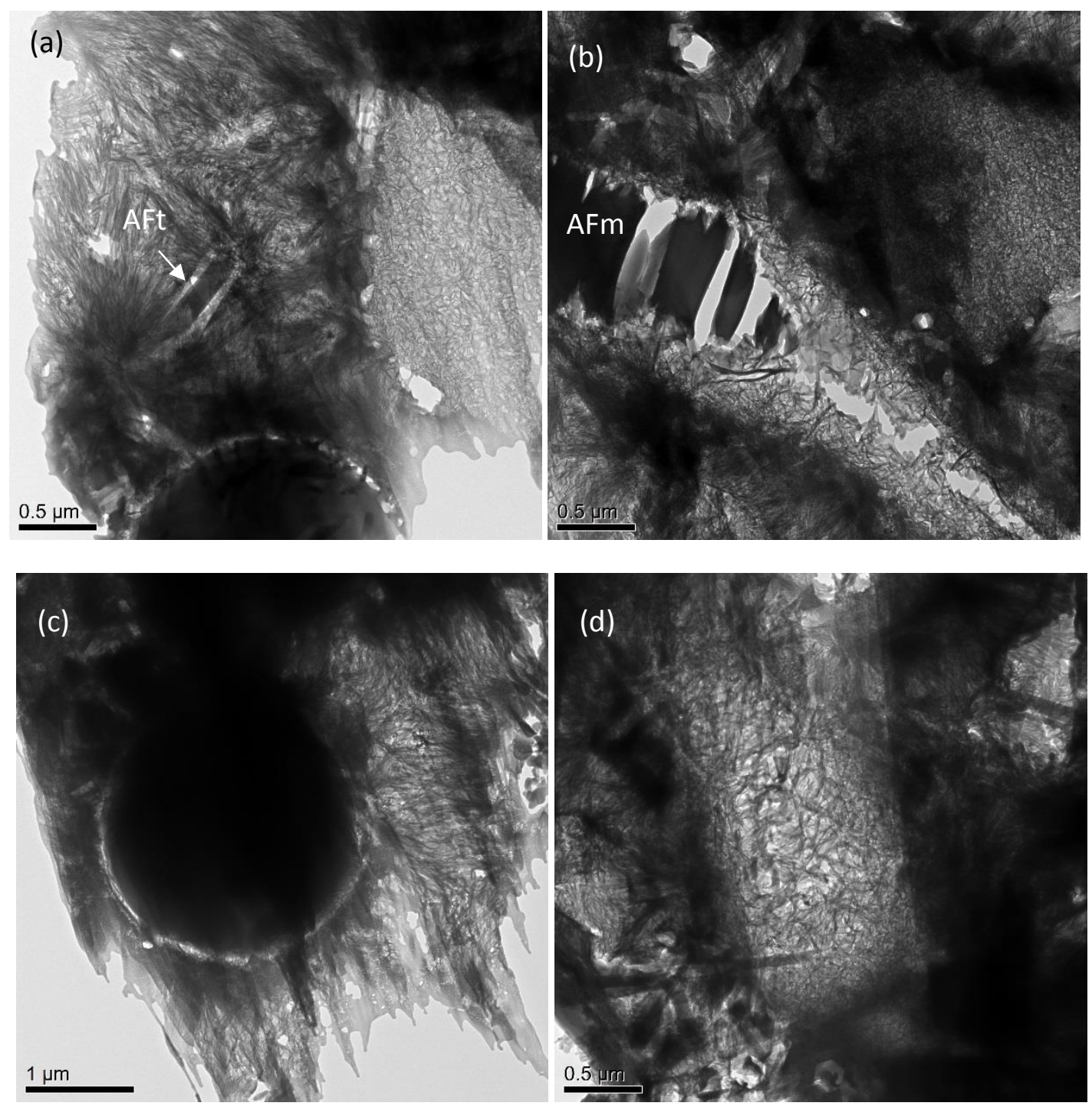

Figure 5.17. TEM micrographs of 30\% PFA $0.57(28 d)-t_{0}$ sample showing fibrillar and foil-like Op regions, fine Ip regions, PFA reaction rims, AFM plates and AFt relicts. 
Comparison of the $30 \%$ fly ash and slag systems (Figure 5.18 ) after 28 days' hydration reflects the higher degree of slag reaction previously observed in the SEM and TGA data. Op regions displayed very fine fibrillar morphology (Figure 5.18 (c)), and foil-like C-S-H was more prevalent, as demonstrated in Figure 5.18(b). Fine textured Ip C-S-H is observed in Figure 5.18 (a) and is assigned to be slag Ip due to the presence of laths of hydrotalcite. This was confirmed by the identification of Mg in EDX data. AFm plates can be seen in the top left hand corner of the micrograph (d).
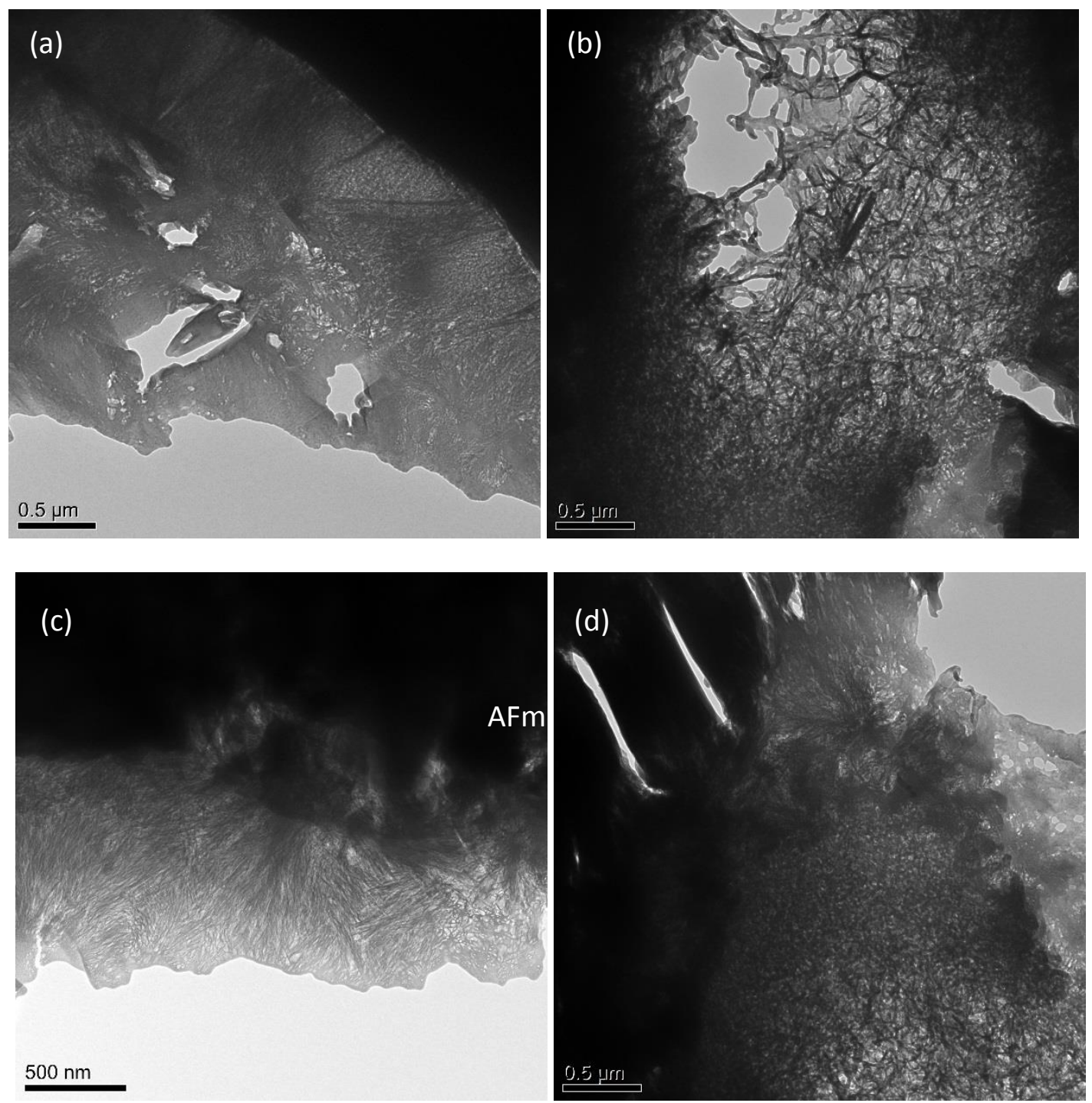

Figure 5.18. TEM micrographs of $30 \%$ GGBS $0.57(28 d)-t_{0}$ sample showing fine textured Ip regions intermixed with laths of hydrotalcite, foil-like and fine fibrillar Op and AFm plates. 
As replacement by slag increased (60\% - Figure 5.19) the morphology of the Op C-S-H changed from fibrillar to that of crumpled foils (Figure 5.19 (e)\&(f)), as reported previously [42], [41]. Although fine fibrillar C-S-H was observed in some areas (Figure 5.19 (c)) the Op regions were governed by foillike morphology. Examples of fine textured Ip C-S-H are presented in Figures 5.19 (a), (b) and (d) where Figure 5.19 (d) exhibits intermixing of Ip C-S-H and laths of hydrotalcite as previously observed for the $30 \%$ GGBS system and in agreement with XRD measurements.

Enhancement of the cement microstructure resulting in improved performance in regards to durability is accepted to be a result of transformation of fibrillar to foil-like morphology of the Op CS-H. Foil-like C-S-H fills space with a more finely distributed porosity, reducing interconnectivity and rates of diffusion $[41,53]$. Improved performance of PFA and slag composite cements to that of neat Portland cement systems has been widely reported experimentally $[54,55,57]$ however these studies typically investigate highly hydrated materials which may not be realistic when considering curing regimes employed in practice. Furthermore, the choice of replacement material and replacement level may have very different effects on the development of the microstructure as demonstrated here.

Figure 5.14 and Table 5.3 display the EDX data collected for the samples. C-S-H regions were established to be free from intermixing with other crystalline phases by selected area electron diffraction (SAED) before EDX analysis. Where contribution from other phases was evident the data was excluded from mean $\mathrm{Ca} / \mathrm{Si}$ and $\mathrm{Al} / \mathrm{Si}$ ratio calculations. Compositional trends relating to analyses of more than one phase are observed on the $\mathrm{Ca}-\mathrm{Al}$-Si ternary plots (Figure 5.14) for both AFt and $\mathrm{AFm}$ phases. Mean $\mathrm{Ca} / \mathrm{Si}$ and $\mathrm{Al} / \mathrm{Si}$ ratios are presented in Table 5.3. $\mathrm{Mg} / \mathrm{Si}-\mathrm{Al} / \mathrm{Si}$ scatter plots for slag containing systems (Figure 5.22) confirmed Ip regions to be mixtures of $\mathrm{C}-\mathrm{S}-\mathrm{H}$ and a $\mathrm{Mg}$ rich hydrotalcite like phase (as previously observed in TEM micrographs) where the gradient of the line of linear regression provides the $\mathrm{Mg} / \mathrm{Al}$ ratio of this phase and the $\mathrm{Al} / \mathrm{Si}$ ratio of the $\mathrm{C}-\mathrm{S}-\mathrm{H}$ is denoted by the intersect with the $x$-axis (i.e. at $\mathrm{Mg} / \mathrm{Si}=0$ ) [52]. 

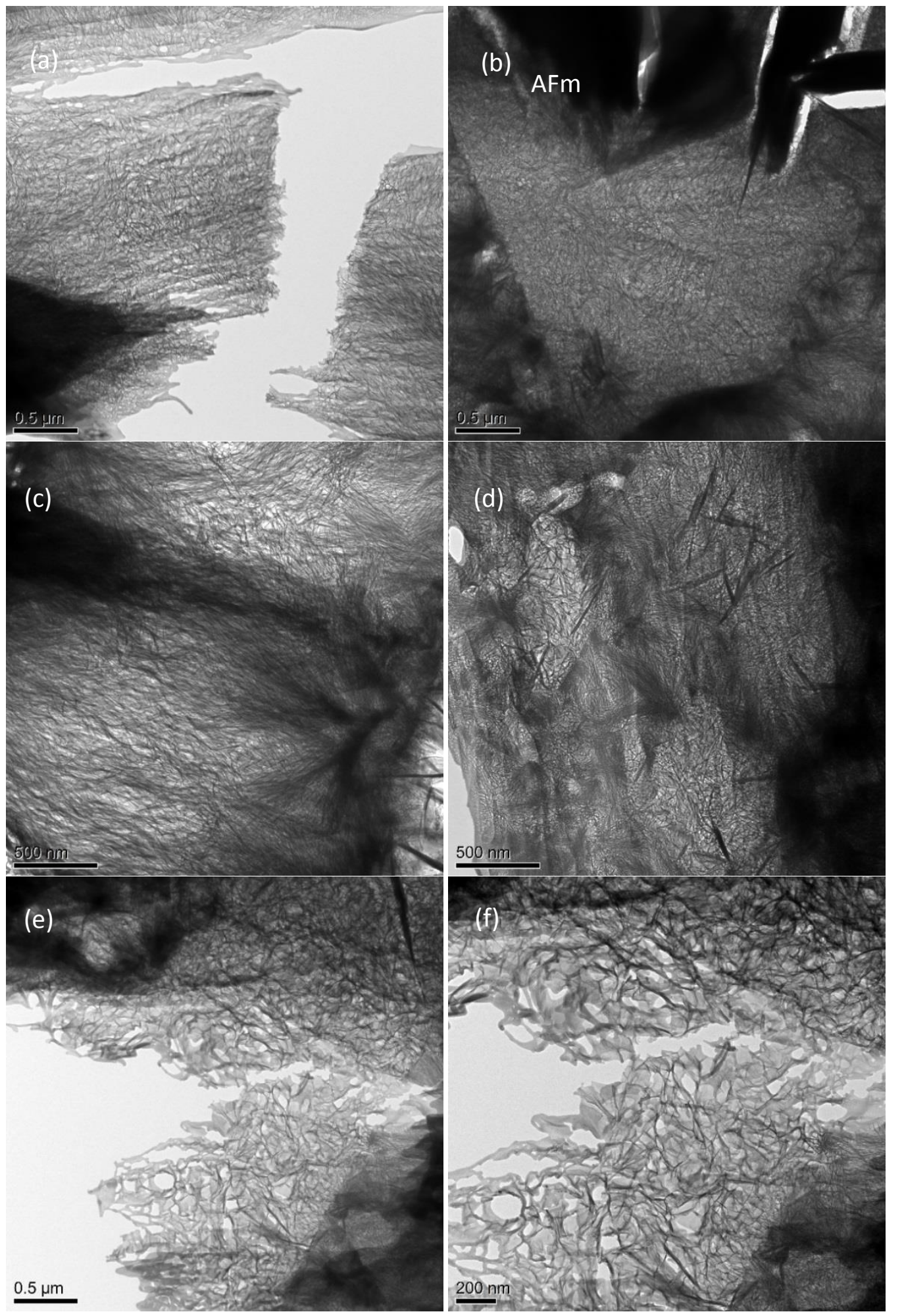

Figure 5.19. TEM micrographs of $60 \%$ GGBS 0.57 (28d) - $t_{0}$ sample showing fine textured Ip regions intermixed with laths of hydrotalcite, foil-like and fine fibrillar Op C-S-H and AFm plates. 

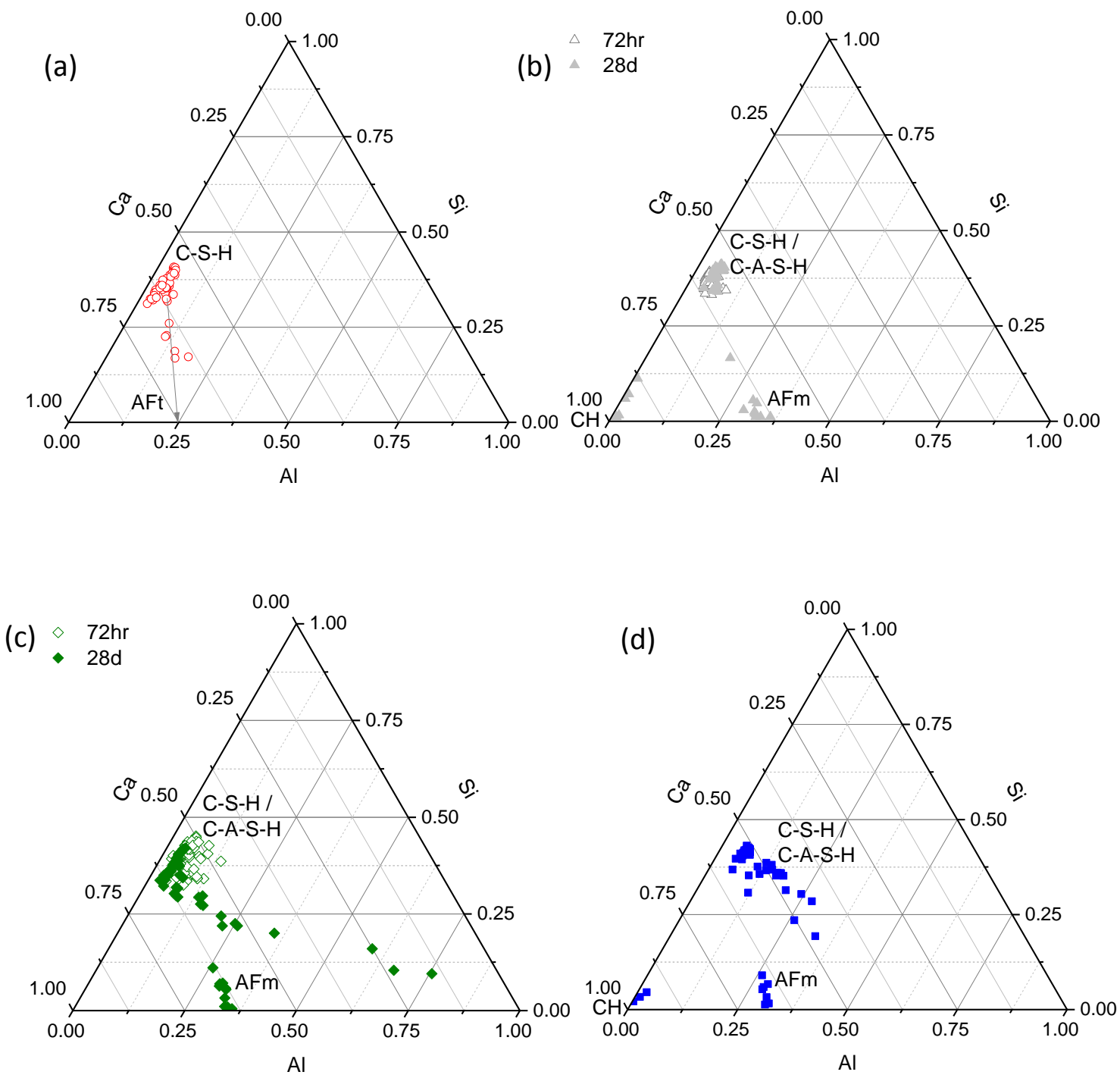

Figure 5.20. Ca-Al-Si ternary diagrams for (a) CEMI, (b) 30\% PFA, (c) $30 \%$ GGBS and (d) $60 \%$ GGBS systems with $\mathrm{w} / \mathrm{b}$ ratio 0.57 at time $\mathrm{t}_{0}$. Values are plotted as atomic percentages normalised to $100 \%$ where empty markers indicate samples cured for 72 hours and solid markers indicate samples cured for 28 days.

The average $\mathrm{Ca} / \mathrm{Si}$ ratio for the neat system at 72 hours was 1.67, in good agreement with both expected [22] and experimentally observed values. Richardson and Groves [17] reported Ca/Si ratios of 1.69 and 1.65 for Op and Ip C-S-H in a one week old Portland cement paste. Decreased Ca/Si and increased $\mathrm{Al} / \mathrm{Si}$ ratios were observed for all the composite systems analysed compared to the CEMI 
sample, confirming varying degrees of reaction of the fly ash and slag. This is reflected in the ternary diagrams where shifts in the position of the C-S-H cluster to lower $\mathrm{Ca}$ and higher Al contents were evident. This was most marked for the $60 \%$ slag sample for which the $\mathrm{C}-\mathrm{S}-\mathrm{H}$ had the lowest $\mathrm{Ca} / \mathrm{Si}$ ratio (1.27) and highest $\mathrm{Al} / \mathrm{Si}$ ratio $(0.15 \mathrm{Op} / 0.14 \mathrm{lp}$ ) of all the systems examined. The comparatively lower $\mathrm{Ca} / \mathrm{Si}$ ratio of the $30 \%$ slag system (1.39) to that of the $30 \%$ fly ash system (1.55) at 72 hours confirms previous discussions relating to their reactivity. Lowering of the $\mathrm{Ca} / \mathrm{Si}$ ratio compared to the neat sample verifies reaction of both glassy materials even at very early ages, however the lower value determined for the GGBS system highlights its higher degree of reaction to that of the PFA. This is further emphasised by the greater uptake of $\mathrm{Al}$ in the $\mathrm{C}-\mathrm{S}-\mathrm{H}$ of the slag containing material (0.16 Op / $0.11 \mathrm{Ip}$ compared to 0.13 / 0.11). Increased curing length show some, albeit relatively small, subsequent reaction of the fly ash where the $\mathrm{Ca} / \mathrm{Si}$ ratio falls further to 1.49 .

Chemical analysis of the $30 \%$ GGBS sample following 28 days' curing indicated the presence of microcrystalline $\mathrm{CH}$. SAED patterns collected for seemingly pure $\mathrm{C}-\mathrm{S}-\mathrm{H}$ regions produced crystalline diffraction patterns closely matching XRD d-spacing values for portlandite, an example of which is given in Figure 5.21. Although microcrystalline $\mathrm{CH}$ is typically formed in alkali-activated systems [49, 52] there are reports of its presence in Portland cement pastes and water activated blended cements with high water/solid ratios [51]. The presence of a Ca rich phase intermixed with the Op $\mathrm{C}-\mathrm{S}-\mathrm{H}$ was reflected in the EDX results which gave an abnormally high $\mathrm{Ca} / \mathrm{Si}$ ratio. A small number (19) of Ip analyses were used to determine a mean $\mathrm{Ca} / \mathrm{Si}$ and $\mathrm{Al} / \mathrm{Si}$ ratio for the sample however the calculated value of 1.56 was still comparatively high compared to that determined at shorter curing lengths, where the value is expected to be greater. This potentially indicates analysis of predominantly alite and belite grains which is further supported by an unexpectedly low $\mathrm{Al} / \mathrm{Si}$ ratio of 0.09 . 
Table 5.3. Mean $\mathrm{Ca} / \mathrm{Si}$ and $\mathrm{Al} / \mathrm{Si}$ ratios for selected samples analysed by TEM-EDX.

\begin{tabular}{|c|c|c|c|c|c|c|c|}
\hline & & \multicolumn{3}{|c|}{$\mathrm{Ca} / \mathrm{Si}$} & \multicolumn{2}{|l|}{$\mathrm{Al} / \mathrm{Si}$} & \multirow[t]{2}{*}{$\mathrm{Mg} / \mathrm{Al}$} \\
\hline & & $N$ & Mean & S.D. & Mean & S.D. & \\
\hline \multirow[t]{3}{*}{ CEMI 0.57 (72hr) } & Op & 20 & 1.61 & 0.14 & 0.11 & 0.03 & - \\
\hline & Ip & 25 & 1.72 & 0.21 & 0.07 & - & - \\
\hline & All & 45 & 1.67 & 0.19 & - & - & - \\
\hline \multirow[t]{3}{*}{ 30\% PFA 0.57 (72hr) } & Op & 25 & 1.62 & 0.10 & 0.13 & 0.05 & - \\
\hline & $\mathrm{Ip}$ & 19 & 1.53 & 0.08 & 0.11 & 0.02 & - \\
\hline & All & 44 & 1.55 & 0.10 & 0.12 & 0.04 & - \\
\hline \multirow[t]{3}{*}{ 30\% GGBS 0.57 (72hr) } & Op & 50 & 1.48 & 0.18 & 0.16 & 0.07 & - \\
\hline & Ip & 25 & 1.22 & 0.08 & $0.11^{*}$ & - & 2.78 \\
\hline & All & 75 & 1.39 & 0.2 & - & - & - \\
\hline \multirow[t]{3}{*}{ 30\% PFA 0.57 (28d) } & Op & 16 & 1.5 & 0.08 & 0.13 & 0.03 & - \\
\hline & Ip & 27 & 1.49 & 0.14 & 0.13 & 0.01 & - \\
\hline & All & 43 & 1.49 & 0.12 & 0.13 & 0.03 & - \\
\hline \multirow[t]{3}{*}{ 30\% GGBS 0.57 (28d) } & Op & - & - & - & - & - & \\
\hline & Ip & 19 & 1.56 & 0.09 & $0.09^{*}$ & - & 2.72 \\
\hline & All & - & - & - & - & - & - \\
\hline \multirow[t]{3}{*}{ 60\% GGBS $0.57(28 d)$} & Op & 32 & 1.27 & 0.07 & 0.15 & 0.01 & - \\
\hline & Ip & 18 & 1.28 & 0.07 & $0.14^{*}$ & - & 2.5 \\
\hline & All & 50 & 1.27 & 0.07 & - & - & - \\
\hline
\end{tabular}

*Determined from regression analysis of $\mathrm{Mg} / \mathrm{Si}-\mathrm{Al} / \mathrm{Si}$ plots at $\mathrm{Mg} / \mathrm{Si}=0$

$\mathrm{Mg} / \mathrm{Al}$ ratio corresponds to $\mathrm{Mg} / \mathrm{Al}$ ratio of hydrotalcite-like phase and was derived from regression analysis of $\mathrm{Mg} / \mathrm{Si}-\mathrm{Al} / \mathrm{Si}$ plots

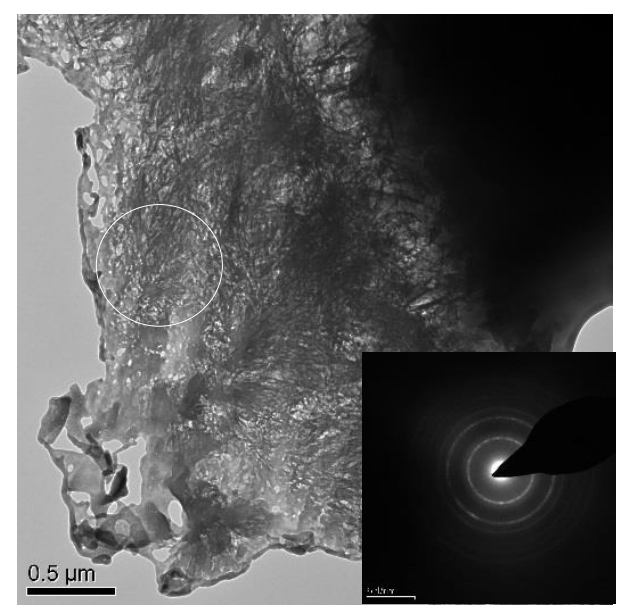

Figure 5.21. TEM micrograph with SAED pattern collected for circled Op C-S-H region showing presence of microcrystalline $\mathrm{CH}$.

As the slag and fly ash begin to react, increased chain lengths are expected, allowing for greater substitution of $\mathrm{Al}$ for $\mathrm{Si}$ in the $\mathrm{C}-\mathrm{S}-\mathrm{H}$ structure $[41,50]$. As the $\mathrm{Ca} / \mathrm{Si}$ ratio reduces, the morphology of the C-S-H begins to change. This was investigated by Tajuelo-Rodriguez [36] who observed that 
C-S-H morphology is dependent upon chemical composition and the chemical environment in which it forms. Controlled hydration of $\mathrm{C}_{3} \mathrm{~S}$ in lime solution revealed fibrillar $\mathrm{C}-\mathrm{S}-\mathrm{H}$ for $\mathrm{Ca} / \mathrm{Si}$ ratios between 1.6 - 1.65, a mixture of fibrillar and foil like $\mathrm{C}-\mathrm{S}-\mathrm{H}$ for $\mathrm{Ca} / \mathrm{Si}$ ratios of $\sim 1.55$ and crumpled foil morphology for ratios between 1.25 - 1.4. This is consistent with studies on slag and fly ash containing cements which display progressively foil-like $\mathrm{C}-\mathrm{S}-\mathrm{H}$ as the mean chain length (MCL) increases, $\mathrm{Ca} / \mathrm{Si}$ ratios decrease and uptake of aluminium in $\mathrm{C}-\mathrm{S}-\mathrm{H}$ is greater.

Taylor et al. [42] reported $\mathrm{Ca} / \mathrm{Si}$ and $\mathrm{Al} / \mathrm{Si}$ ratios of 1.81 and 0.09 and 1.08 and 0.19 for pastes containing $0 \%$ and $100 \%$ GGBS respectively at ages of 20 years. Substitution levels of $25 \%$ corresponded to a Ca/Si ratio of 1.55 (Al/Si 0.11) and a ratio of 1.32 (Al/Si $0.14 \mathrm{Op} / 0.09 \mathrm{Ip}$ ) was recorded at 50\% replacement. Richardson and Groves [41] examined a slag and white Portland cement with ratio 9:1, reporting values of 1.26/1.27 and 0.19/0.15 for $\mathrm{Ca} / \mathrm{Si}$ and $\mathrm{Al} / \mathrm{Si}$ in Op and Ip regions. Deschner et al. [6] established a Ca/Si ratio of 1.3 in a 50\% PFA system and slightly higher values were determined by Rodger and Groves [158] (1.4-1.5) and Girao et al. [34] (1.46 and Al/Si $0.16)$ for lower levels of replacement (30\%).

Variations in the $\mathrm{Mg} / \mathrm{Al}$ ratio of the hydrotalcite like phase are demonstrated in Figure 5.22 where the expected trend $[42,157]$ of decreasing ratio with increasing age and percentage substitution by GGBS is evident. Values decreased slightly from 2.78 to 2.72 as curing length increased in the $30 \%$ slag samples while 28 day cured systems saw a further reduction ( $\mathrm{Mg} / \mathrm{Al} 2.5)$ as replacement increased from 30 to $60 \%$.

Hydrotalcite-like phases formed in slag composite cements typically have $\mathrm{Mg} / \mathrm{Al}$ ratios close to 2 $[47,159]$ but modifications in chemical composition such as increased $\mathrm{Al}_{2} \mathrm{O}_{3}$ contents of the slag glass and increased hydration times have been shown to reduce the value further $[42,157,160]$. Although the ratios determined here are relatively high they are a result of the relatively short curing lengths studied ( 72 hours $\& 28$ days) and further reductions are expected with continued hydration. 

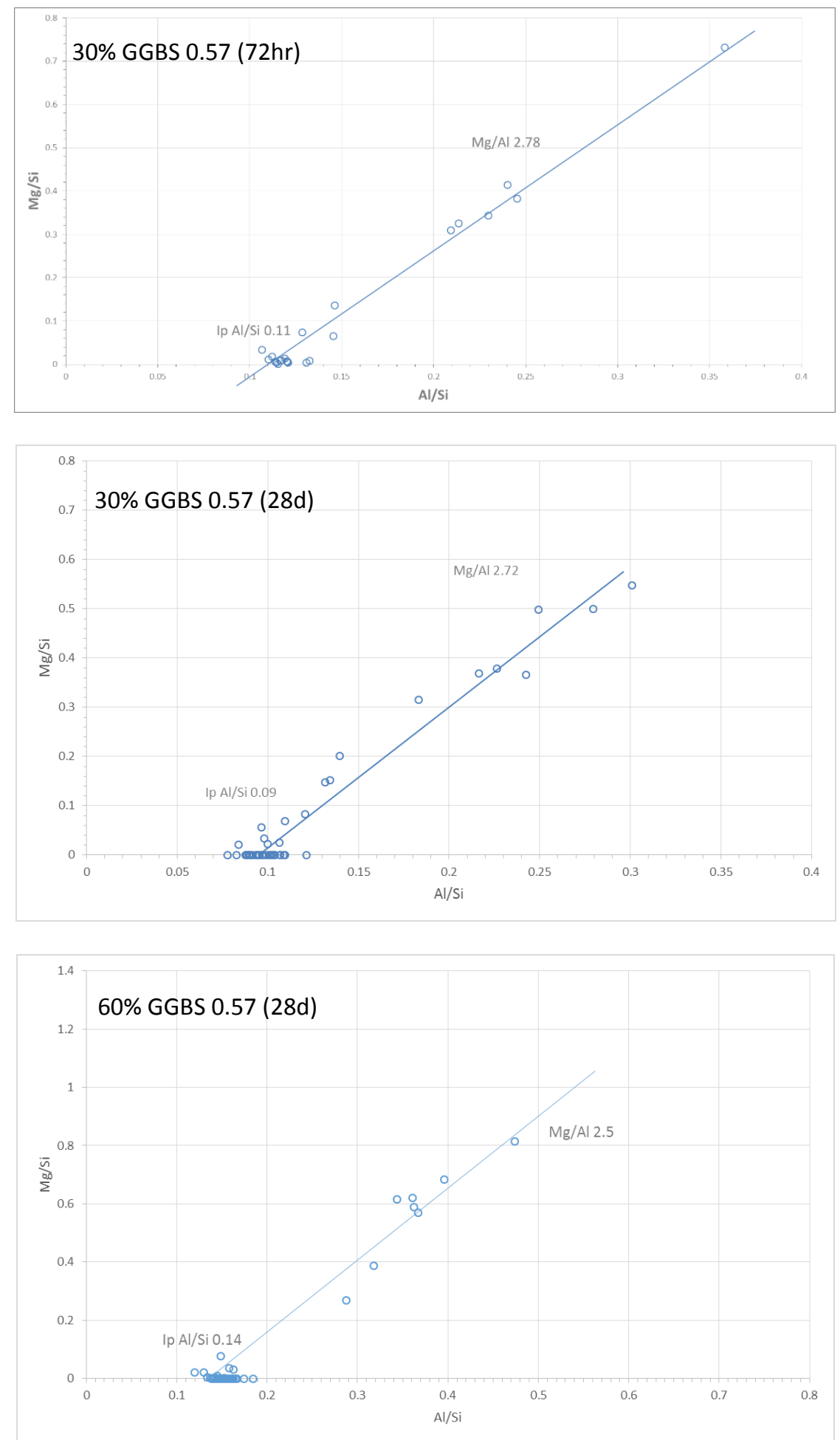

Figure 5.22. Mg/Si against Al/Si atomic ratio plots of TEM-EDX analyses of Ip and Op C-S-H in slag containing systems 


\subsection{2 ${ }^{29}$ Si MAS NMR}

Quantitative information regarding the structure of C-S-H can be obtained by deconvolution of ${ }^{29} \mathrm{Si}$ MAS NMR spectra. Resolved peaks relating to the fractions of silicon present in different tetrahedral environments are fitted to produce a simulated spectra where the peaks correspond to $Q^{0}, Q^{1}$, $Q^{2}(1 \mathrm{Al})$ and $\mathrm{Q}^{2}$ species. Isolated tetrahedra present in alite and belite $\left(Q^{0}\right)$ produce a resonance at -71ppm and resonances relating to silicon tetrahedra in the C-S-H structure are assigned $\mathrm{Q}^{1}(\sim-$ 79ppm), $Q^{2}(\sim-85 p p m)$ and $Q^{2}(1 \mathrm{Al})(\sim-82 \mathrm{ppm})$ notations corresponding to dimer and end chain groups, middle chain groups and middle chain groups in which an adjacent tetrahedral group is occupied by aluminium [50,52, 111, 161]. Broad resonances relating to unreacted slag and fly ash are observed at $\sim-76 \mathrm{ppm}$ and $\sim-101 \mathrm{ppm}$ respectively (determined from spectra collected for the anhydrous materials).

The shape and form parameters defined by fitting the anhydrous slag were then used in fitting the unreacted portion remaining in the hydrated systems, allowing intensity and shift constraints to vary only. The results from the deconvolution of the ${ }^{29} \mathrm{Si} \mathrm{NMR} \mathrm{spectra} \mathrm{for} \mathrm{each} \mathrm{of} \mathrm{the} \mathrm{samples} \mathrm{at} t_{0}$ are shown in Figures 5.23 - 5.26 and the chemical shifts $(\delta)$ and relative fractions of the $Q^{1}, Q^{2}(1 \mathrm{Al})$ and $\mathrm{Q}^{2}$ sites are presented in Table 5.4. Mean aluminosilicate chain lengths (MCL) and $\mathrm{Al} / \mathrm{Si}$ ratios were determined using the equations presented in Section 3.4.4.2 (derived by Richardson and Groves [41]) and Al/Si ratios determined by TEM-EDX have been included for comparison.

Figure 5.23 displays the NMR spectra for the 72 hour cured 0.40 systems. The largely similar degree of reaction observed by SEM-IA in section 5.1.1 (Figure 5.4) are mirrored in the deconvolution results. Generally similar relative fractions are observed across samples for the $Q^{1}, Q^{2}(1 A l)$ and $Q^{2}$ sites indicating similar levels of hydration of the cement and composition of the C-S-H which is concurrent the small degree of reaction of the replacement materials at this age. Slight increases in $\mathrm{MCL}$ (3.7) and $\mathrm{Al} / \mathrm{Si}$ ratios (0.10 30\% GGBS, $0.0960 \% \mathrm{GGBS}$ ) were detected for the slag systems compared with the neat cement and fly ash samples ( $\mathrm{MCL} 3.1 \& \mathrm{Al} / \mathrm{Si} 0.07$ for both) indicating some reaction of the slag glass had occurred, consistent with SEM-IA data previously discussed. 

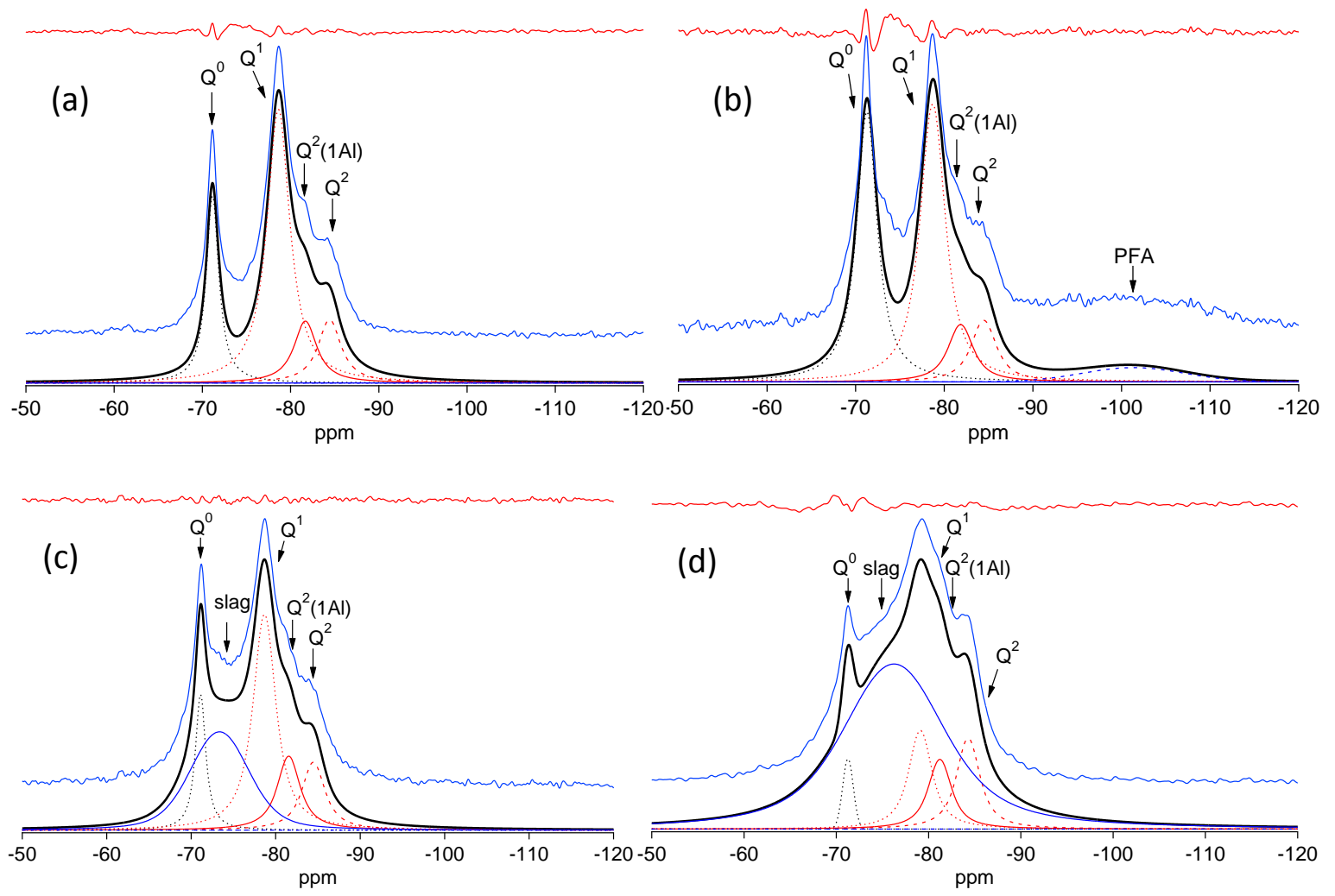

Figure 5.23. Single pulse ${ }^{29}$ Si MAS NMR spectra for samples at $w / b$ ratio 0.40 and cured for 72 hours; (a) CEMI, (b) 30\% PFA, (c) 30\% GGBS, (d) 60\% GGBS. Figures include the fitted peaks and spectra (bottom), the experimental spectra (middle) and the residual spectra ( $x 1$ ) (top).

As the $\mathrm{w} / \mathrm{b}$ ratio increased to 0.57 (Figure 5.25 ) changes in the $\mathrm{C}-\mathrm{S}-\mathrm{H}$ became more evident. For the $30 \%$ slag system relative $\mathrm{Q}^{1}, \mathrm{Q}^{2}(1 \mathrm{Al})$ and $\mathrm{Q}^{2}$ fractions, $\mathrm{MCL}$ values and $\mathrm{Al} / \mathrm{Si}$ ratios generally remained similar. However, increased polymerisation (decrease in $Q^{1}$ and subsequent increase in $Q^{2}$ ) and increased substitution of aluminium were clear for the 30\% PFA and 60\% slag samples corroborating increased levels of reaction demonstrated at higher water contents established previously $(\mathrm{CH}$ contents from TGA data \& SEM-IA). 

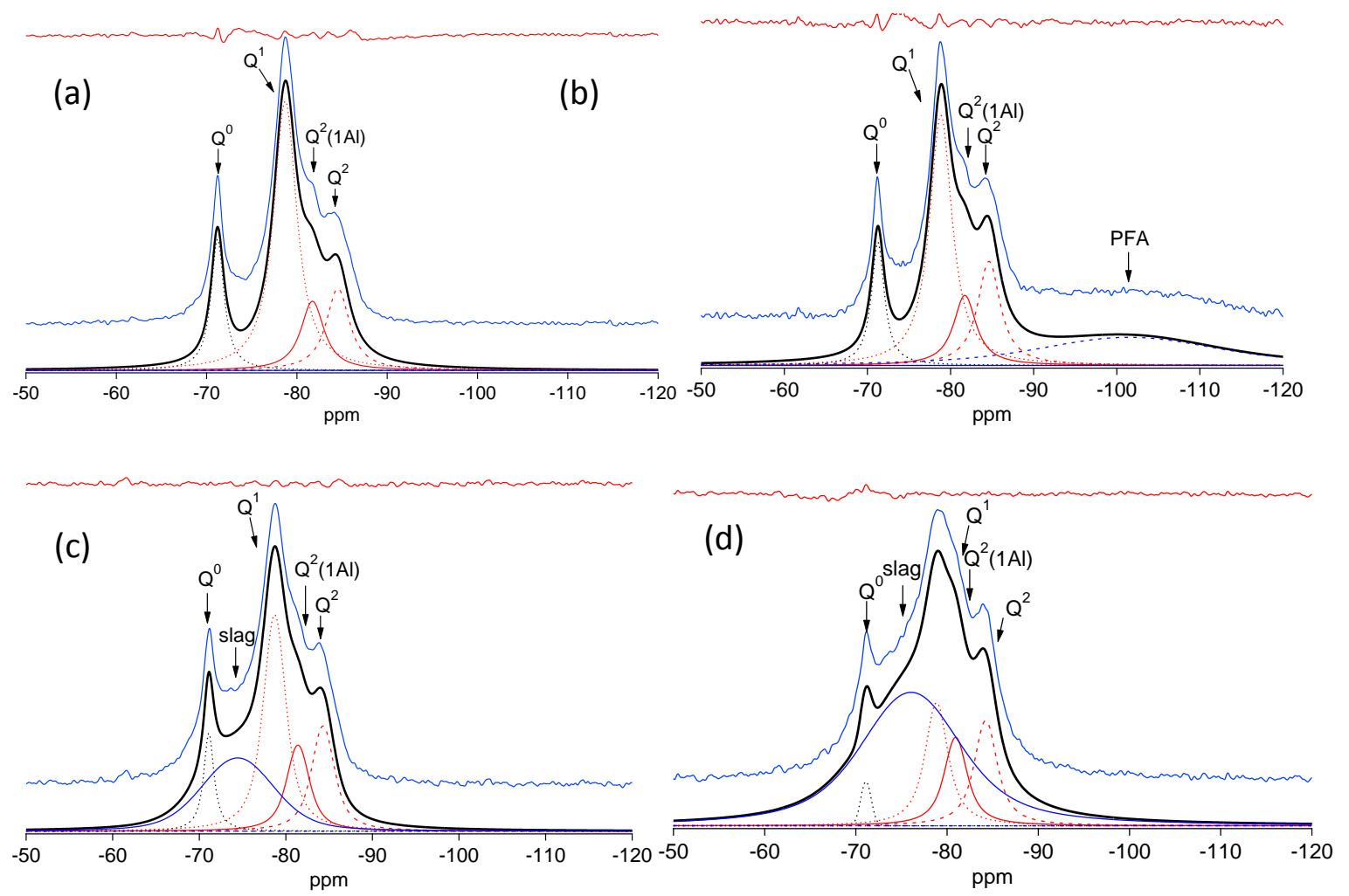

Figure 5.24. Single pulse ${ }^{29} \mathrm{Si}$ MAS NMR spectra for samples at $\mathrm{w} / \mathrm{b}$ ratio 0.40 and cured for 28 days; (a) CEMI, (b) 30\% PFA, (c) 30\% GGBS, (d) 60\% GGBS. Figures include the fitted peaks and spectra (bottom), the experimental spectra (middle) and the residual spectra (x1) (top).

$Q^{1}$ responses for the systems cured for 28 days at $w / b$ ratios 0.40 (Figure 5.24) and 0.57 (Figure 5.26) showed comparable trends in which $Q^{2}$ and $Q^{2}(1 \mathrm{Al})$ species increased the expense of $Q^{1}$ sites, resulting in increased $\mathrm{MCL}$ and $\mathrm{Al} / \mathrm{Si}$ ratios as levels of substitution increased. These changes were more pronounced for samples produced with $\mathrm{w} / \mathrm{b}$ 0.57. Longer chain lengths with increasing age were observed for the CEM I systems however incorporation of aluminium remained virtually constant. 

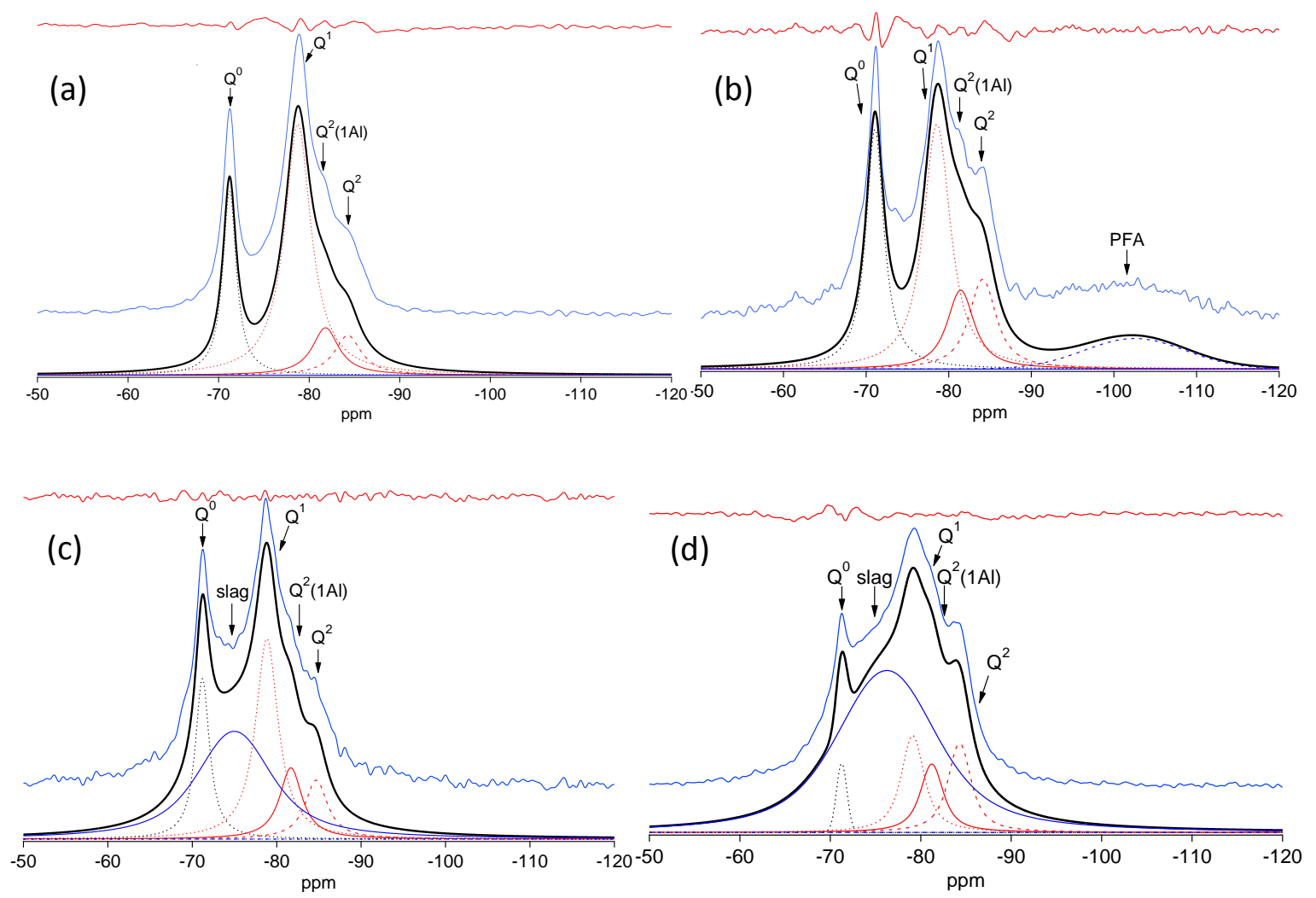

Figure 5.25. Single pulse ${ }^{29} \mathrm{Si}$ MAS NMR spectra for samples at $\mathrm{w} / \mathrm{b}$ ratio 0.57 and cured for 72 hours; (a) CEMI, (b) 30\% PFA, (c) 30\% GGBS, (d) 60\% GGBS. Figures include the fitted peaks and spectra (bottom), the experimental spectra (middle) and the residual spectra (x1) (top).

Substantial quantities of unreacted slag were present in the GGBS blends agreeing with calculations for calculated degrees of reaction by SEM-IA in which the greatest level of hydration was measured to be 55\% (30\% GGBS 0.57 (28d) sample). Taylor et al. [42] showed the presence of residual unhydrated slag in 20 year old pastes for a range of replacement levels $(10-100 \%)$ demonstrating that GGBS isn't expected to fully react, even at later ages. Due to the unpredictability of the signal contained within the side and centre bands of PFA containing materials [34] the broad resonance assigned to unreacted fly ash provides no reliable information regarding its reaction extent. 

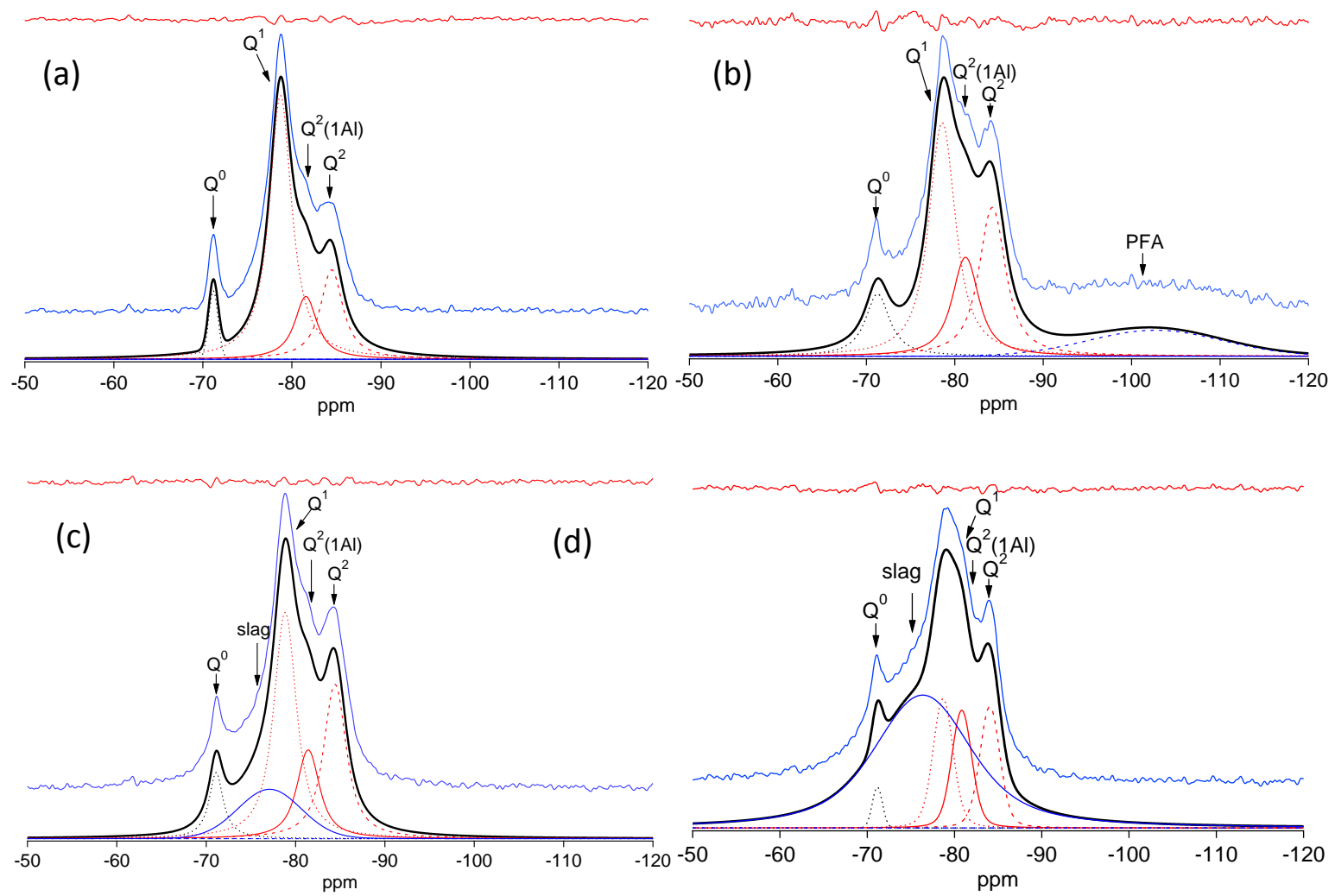

Figure 5.26. Single pulse ${ }^{29} \mathrm{Si}$ MAS NMR spectra for samples at $\mathrm{w} / \mathrm{b}$ ratio 0.57 and cured for 28 days; (a) CEMI, (b) 30\% PFA, (c) 30\% GGBS, (d) 60\% GGBS. Figures include the fitted peaks and spectra (bottom), the experimental spectra (middle) and the residual spectra ( $x 1$ ) (top). 


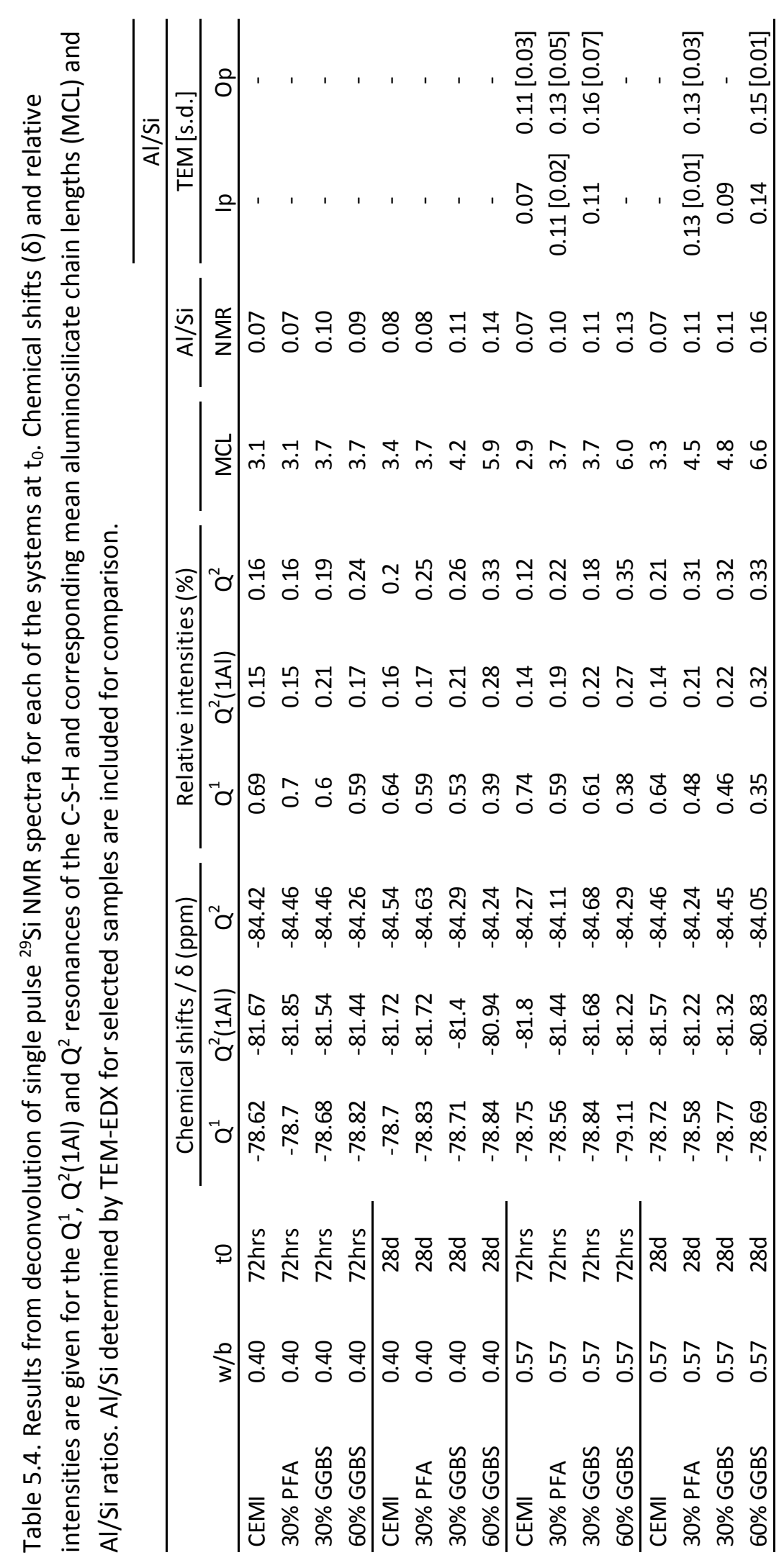


At early ages (72 hours) the composition of $\mathrm{C}-\mathrm{S}-\mathrm{H}$, or $\mathrm{C}-\mathrm{A}-\mathrm{S}-\mathrm{H}$, was dominated by $\mathrm{Q}^{1}$ resonances corresponding to the hydration of alite [162]. As hydration times lengthened $Q^{2}$ sites increased and $\mathrm{Q}^{1}$ sites correspondingly decreased but little, or no, variation was observed for the $\mathrm{Q}^{2}(1 \mathrm{Al})$ species consistent with a water activated neat white Portland cement studied in [29]. An increase in MCL with age is in agreement with other studies $[163,164]$ and the proportions of $Q^{1}, Q^{2}(1 A l)$ and $Q^{2}$ sites were similar for equivalent ages regardless of $\mathrm{w} / \mathrm{b}$ ratio.

Changes in the distribution of $Q^{1}, Q^{2}(1 A l)$ and $Q^{2}$ species in the composite materials became more apparent as the fly ash and slag reacted. Tajuelo-Rodriguez [36] studied the silicate structures of C$\mathrm{S}-\mathrm{H}$ samples with low $(<1.2)$ and high $(>1.2) \mathrm{Ca} / \mathrm{Si}$ ratios reporting higher proportions of $\mathrm{Q}^{2}$ sites for lower ratios whereas higher percentages of $Q^{1}$ sites were evident for ratios greater than 1.2.

$\mathrm{Ca} / \mathrm{Si}$ ratios determined for selected samples by examination in the TEM were higher than 1.2 in all cases. 30\% replacement systems had $\mathrm{Ca} / \mathrm{Si}$ ratios ranging from $1.39-1.55$ in which $\mathrm{Q}^{1}$ species were dominant in line with [47]. As the $\mathrm{Ca} / \mathrm{Si}$ ratio approached 1.2 , as for the $60 \%$ slag sample (w/b 0.57) cured for 28 days, the relative proportions of $Q^{1}$ and $Q^{2}$ became almost equivalent.

In all cases the highest chain lengths calculated were observed for the $60 \%$ GGBS systems confirming the higher degrees of polymerisation expected with increasing slag (or PFA) loading [34, 41, 42, 157]. This is related to the higher degree of clinker hydration observed in the $60 \%$ slag blend. However, the longest MCL here was still only 6.6 which is relatively low when compared to values determined for blended cements in similar studies. The values determined here reflect the $\mathrm{MCL}$ of reasonably young pastes ( $<28$ days) and, as with the neat systems, chain lengths are expected to increase as length of hydration increases.

\subsection{Conclusions}

- In systems of equivalent $\mathrm{w} / \mathrm{b}$ ratio and hydration length similar degrees of reaction were observed for the cement clinker however, slight increases were apparent for the composite systems. Levels of reaction were observed with increasing curing length and $\mathrm{w} / \mathrm{b}$ ratio.

- The slag was observed to be more reactive than the fly ash at equivalent levels of replacement and a higher degree of hydration for both materials was observed with 
following longer curing lengths and at higher water contents. Slag reactivity decreased with increased loading.

- For the CEMI and 30\% PFA systems large variabilities existed in the initial portlandite contents due to the variations in curing length and $\mathrm{w} / \mathrm{b}$ ratio and the low reactivity of the fly ash. However, slag systems had very similar $\mathrm{CH}$ contents regardless of hydration length and $\mathrm{w} / \mathrm{b}$ ratio attributed to increased reaction of the slag glass at later ages of hydration and the higher $\mathrm{CaO}$ contents of the slag compared to the PFA.

- Although XRD analysis indicated more sizeable quantities of AFt in nearly all the samples, ${ }^{27} \mathrm{Al}$ NMR spectra revealed that for the majority of systems the phase contents are in the same range of order, or in some instances even greater quantities of AFm exist, highlighting the larges errors associated with AFm phase quantification by XRD measurements. The poor crystallinity and susceptibility of the AFm phases to changes in composition and structure, resulting in modifications in peak shift, peak broadening and intensity mean reliable phase content values are difficult to obtain. In general, composite systems showed deceased quantities of AFt and increased AFm phase contents.

- The poor crystallinity and susceptibility of the AFm phases to changes in composition and structure, resulting in modifications in peak shift, peak broadening and intensity mean reliable phase content values are difficult to obtain by XRD measurements.

- TEM micrographs demonstrated differences in microstructural development for different replacement materials at different replacement levels following a short (72hours) and longer (28 days) curing time. Open, coarse Op morphology was observed at 72 hours for both 30\% PFA and 30\% slag systems where a mixture of both fibrillar and foil-like morphologies confirmed reaction of both materials at this age. The effects were more apparent after 28 days where a much finer better developed microstructure was evident for the more reactive slag system ( $30 \%$ replacement) compared to the equivalent PFA sample. As slag loading increased Op regions were progressively dominated by crumpled foil like C-S-H.

- Decreased $\mathrm{Ca} / \mathrm{Si}$ ratios and increased $\mathrm{Al} / \mathrm{Si}$ ratios were observed for blended materials compared to the neat system at both 72 hour and 28 days hydration. Ratios reduced further 
as curing length increased and this was mirrored by increased $\mathrm{MCL}$ lengths determined from ${ }^{29}$ Si NMR spectra.

- At 72 hours hydration and $w / b$ ratio 0.40 relative $Q^{1}, Q^{2}(1 A l)$ and $Q^{2}$ sites were generally comparable indicating predominantly reaction of only the cement clinker had occurred. Changes became more marked as curing length and $\mathrm{w} / \mathrm{b}$ ratio increased as relative fractions of $Q^{2}$ sites increased at the expense of $Q^{1}$ and aluminium uptake was greater. 


\section{Chapter 6}

\section{Early age carbonation behaviour}

The carbonation mechanism of composite cement systems following short periods of curing is not well understood. Carbonation studies focus on more mature systems in which carbonation reactions are typically accelerated by exposure to elevated $\mathrm{CO}_{2}$ concentrations. Modifications in carbonation behaviour exist between natural and accelerated conditions and are expected to exist for immature and well developed microstructures where, for poorly developed pastes, the carbonation reaction may be principally controlled by the chemical kinetics. This chapter focuses on the early age reactions of short ( 72 hours) and idealised (28 days) cured composite systems, studying changes in carbonation behaviour between fly ash and slag containing cements at varying replacement levels $(30 \% \& 60 \%)$ and $\mathrm{w} / \mathrm{b}$ ratios $(0.40 \& 0.57)$. The mechanism of carbonation that results from exposure of immature composite materials to ambient $\mathrm{CO}_{2}$ concentrations for up to 7 days is discussed.

\subsection{Carbonation of systems at $\mathrm{w} / \mathrm{b}$ ratio 0.57}

\subsubsection{Thermal analysis}

$\mathrm{CH}$ contents calculated from TGA data are displayed in Figure 6.1 for the 72 hour cured systems conditioned in a $0 \% \mathrm{CO}_{2}$ atmosphere for up to 60 days. The virtually constant portlandite contents measured confirm no continued hydration of the systems occurred during sample conditioning at $\mathrm{RH} 72.6 \%$, which is in agreement with other studies reporting no significant hydration below $\mathrm{RH}$ levels of $80 \%$ [165]. Therefore, any changes observed in the samples exposed to ambient $\mathrm{CO}_{2}$ concentrations are a direct result of the carbonation reaction. 


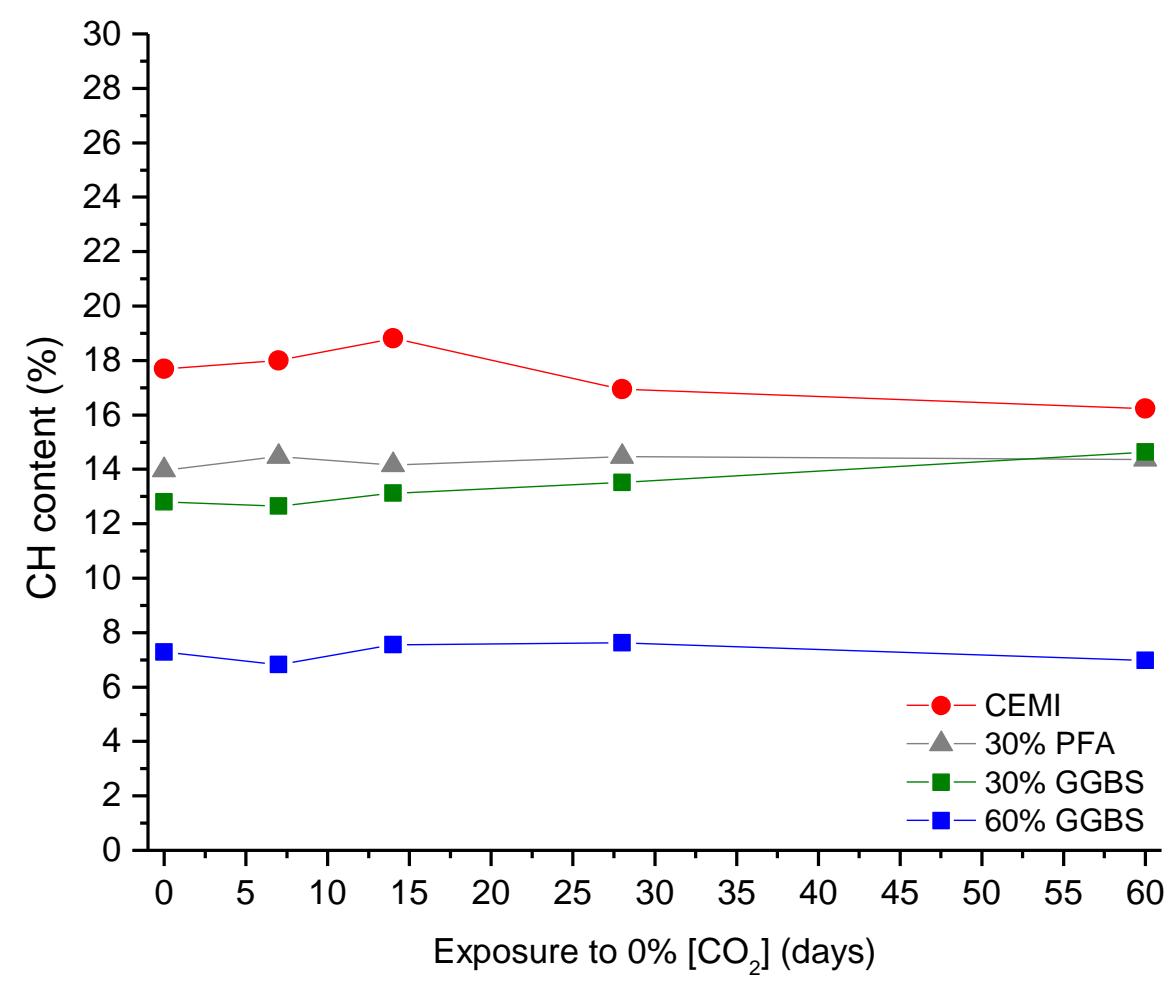

Figure 6.1. $\mathrm{CH}$ contents determined from TGA data for samples cured for 72 hours and conditioned at $0 \%\left[\mathrm{CO}_{2}\right]$

Figure 6.2 displays the $\mathrm{Ca}(\mathrm{OH})_{2}$ and $\mathrm{CaCO}_{3}$ contents in mol/100g calculated from TGA data for the 72 hour cured and 28 day cured systems. Increased exposure to $\mathrm{CO}_{2}$ led to an increase in total carbonate content, however substantial increases were observed for the 72 hour cured samples (Figure 6.2 (a)) with the complete, or almost complete, consumption of $\mathrm{CH}$. The considerable increase in carbonate content coinciding with the depletion of portlandite was demonstrated by all of the systems, occurring at earlier exposure times with increasing levels of replacement: between 4- 7 days for the neat system, $2-4$ days for the $30 \%$ replacement systems and between $1-2$ days for the $60 \% \mathrm{GGBS}$ system. The quantity of $\mathrm{CaCO}_{3}$ produced was also greater in all the composite materials, particularly at early ages, compared to that of the neat system. 
(a)

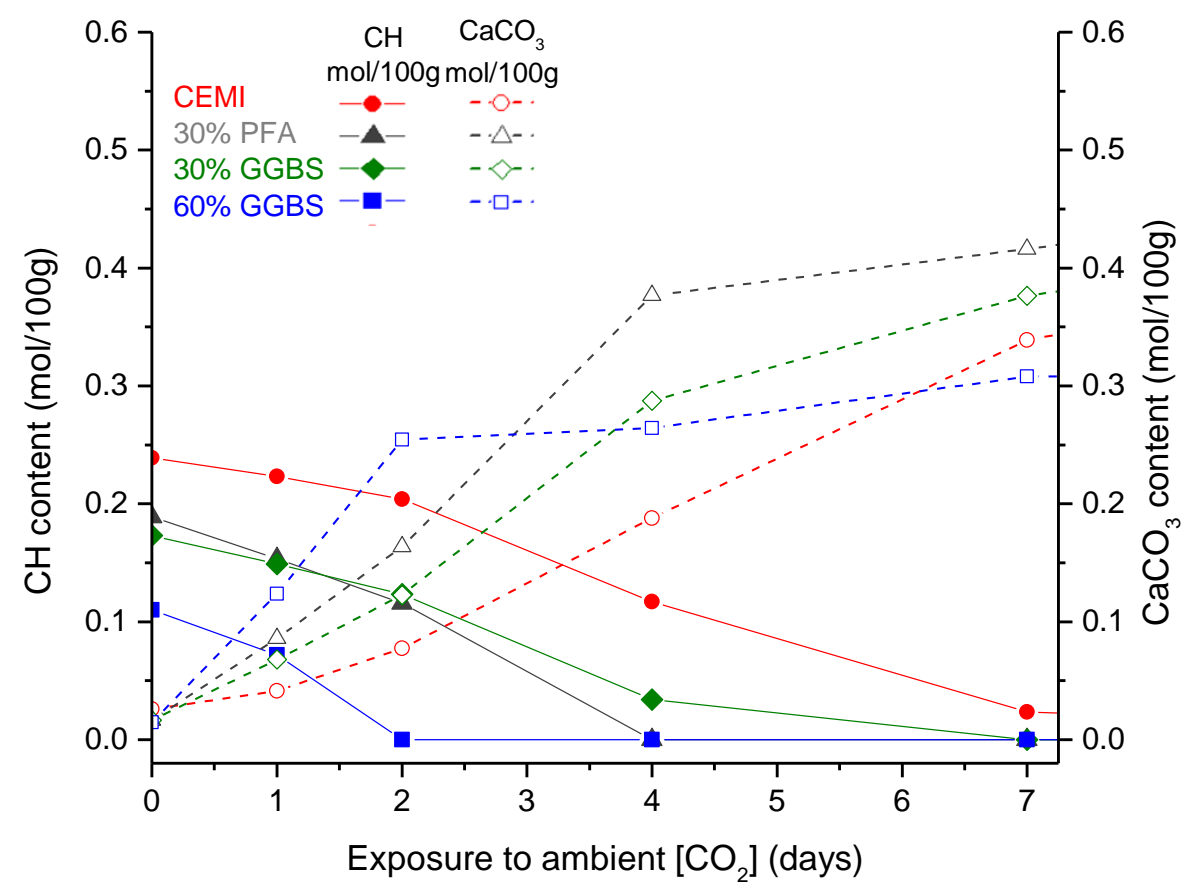

(b)

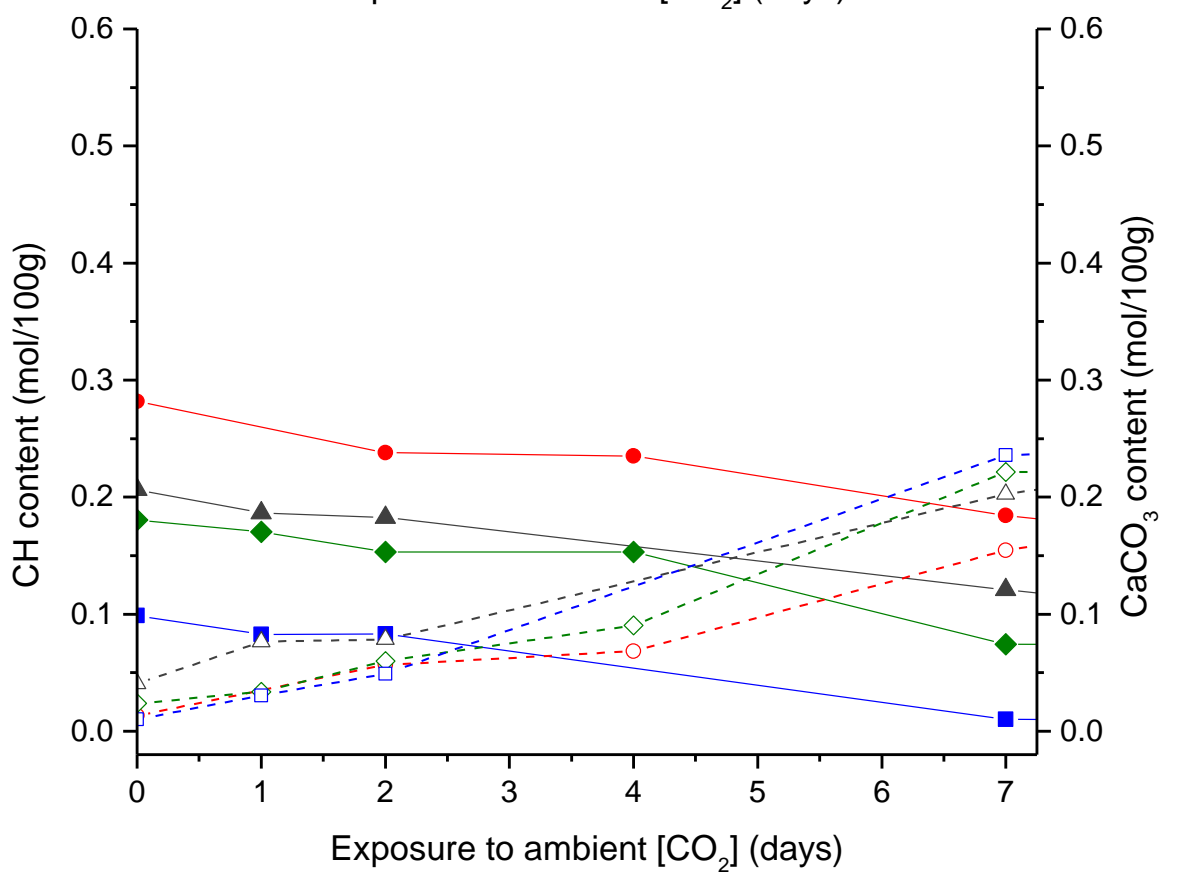

Figure 6.2. $\mathrm{CH}$ and $\mathrm{CaCO}_{3}$ contents determined from TGA data for 72 hour cured (a) and 28 day cured (b) systems following exposure to ambient $\left[\mathrm{CO}_{2}\right]$ for up to 7 days. Values are shown in $\mathrm{mol} / 100 \mathrm{~g}$. 
The loss of buffering capacity in the samples allowed carbonation to progress much more rapidly and the substantial production of carbonate indicated carbonation of the other phases had become significant. This is reflected in Table 6.1 which displays the consumption of $\mathrm{CH}$ and corresponding production of $\mathrm{CaCO}_{3}$ between $0\left(\mathrm{t}_{0}\right)$ and 7 days exposure to $\mathrm{CO}_{2}$ for each of the systems. $\mathrm{CaCO}_{3}$ produced from hydrate phases other than $\mathrm{CH}(\mathrm{C}-\mathrm{S}-\mathrm{H}, \mathrm{AFt}, \mathrm{AFm})$ is shown in the last column. While $\mathrm{CH}$ is present, or available, although carbonation of the other phases is evident, it is relatively minor, and it was only once the main alkalinity buffer had been depleted the carbonation of the other phases progressed much more rapidly.

Table 6.1. Consumption of $\mathrm{CH}$ versus production of $\mathrm{CaCO}_{3}$ calculated from TGA data between $\mathrm{t}_{0}-7$ days for 72 hour cured systems. Values are shown in $\mathrm{mol} / 100 \mathrm{~g}$.

\begin{tabular}{|c|c|c|c|}
\hline CEMI & $\begin{array}{c}\mathrm{CH} \\
\text { consumed } \\
\text { (mol/100g) }\end{array}$ & $\begin{array}{c}\mathrm{CaCO}_{3} \\
\text { produced } \\
(\mathrm{mol} / 100 \mathrm{~g}) \\
\end{array}$ & $\begin{array}{c}\mathrm{CaCO}_{3} \text { produced } \\
\text { from other hydrates } \\
(\mathrm{mol} / 100 \mathrm{~g})\end{array}$ \\
\hline 1 day & 0.02 & 0.02 & 0.00 \\
\hline 2 days & 0.04 & 0.05 & 0.01 \\
\hline 4 days & 0.12 & 0.16 & 0.04 \\
\hline 7 days & 0.22 & 0.31 & 0.09 \\
\hline \multicolumn{4}{|c|}{$30 \%$ PFA } \\
\hline 1 day & 0.04 & 0.07 & 0.03 \\
\hline 2 days & 0.07 & 0.15 & 0.08 \\
\hline 4 days & 0.19 & 0.36 & 0.17 \\
\hline 7 days & 0.19 & 0.40 & 0.21 \\
\hline \multicolumn{4}{|c|}{$30 \%$ GGBS } \\
\hline 1 day & 0.02 & 0.05 & 0.03 \\
\hline 2 days & 0.05 & 0.11 & 0.06 \\
\hline 4 days & 0.14 & 0.27 & 0.13 \\
\hline 7 days & 0.17 & 0.36 & 0.19 \\
\hline \multicolumn{4}{|c|}{$60 \%$ GGBS } \\
\hline 1 day & 0.03 & 0.11 & 0.08 \\
\hline 2 days & 0.10 & 0.24 & 0.14 \\
\hline 4 days & 0.10 & 0.25 & 0.15 \\
\hline 7 days & 0.10 & 0.29 & 0.19 \\
\hline
\end{tabular}

Furthermore the extent of carbonation was affected by both replacement material and level. Although similar carbonation behaviour was observed for the materials with equivalent levels of replacement, carbonation occurred to a greater degree and at a faster rate for the PFA blend 
compared with the corresponding slag blend. This reflected the PFA's slower reaction rate, as previously observed and reported in other studies, for example Lam et al. [166] measured the degree of reaction of a Portland cement paste (w/b 0.5) to be $65 \%$ following 7 days' curing, while the degree of reaction of the fly ash in a $25 \%$ PFA system was just $6.4 \%$ at the same age. In the same study, increased percentage substitution resulted in a lower degree of reaction where the authors reported that more than $80 \%$ of the fly ash remained unreacted in systems with $45-55 \%$ replacement following 90 days' hydration. The adverse effects of slower hydration rates on carbonation resistance are expected to be magnified with decreasing curing length and increasing level of substitution. This is reflected in the much faster initial carbonation rate of the $60 \%$ GGBS system ( $1-2$ days) in which the overall degree of reaction of the system was measured to be just $\sim 55 \%$ (SEM-IA) at 72 hours. As carbonation progressed, however, a plateau was reached (from 2 days onwards) where it appeared that all hydrate phases available for carbonation had reacted at this time.

The TGA data highlights the adverse effects of improper curing on blended cement materials where slower rates of hydration coupled with curing lengths of only a few days produced materials with open and underdeveloped microstructures in which $\mathrm{CO}_{2}$ was able to diffuse readily. This poor carbonation resistance was further exacerbated by reduced initial quantities of $\mathrm{CH}$, which decreased further as substitution levels increased.

Similar behaviour was reported by Thiery et al. [61] where 8 month cured cylindrical prisms $(\varnothing=$ $3.2 \mathrm{~cm}, \mathrm{~h}=8 \mathrm{~cm}$ ) were carbonated for up to 28 days in a $\sim 50 \% \mathrm{CO}_{2}$ atmosphere. The reaction of $\mathrm{CH}$ was observed to occur initially much faster than that of $\mathrm{C}-\mathrm{S}-\mathrm{H}$, however it was proposed that the formation of $\mathrm{CaCO}_{3}$ microcrystals at the portlandite crystal surfaces inhibited further decomposition, allowing decalcification of $\mathrm{C}-\mathrm{S}-\mathrm{H}$ to then proceed more vigorously. Groves et al. [64] discussed the carbonation of $\mathrm{C}_{3} \mathrm{~S}$ pastes in both air and pure $\mathrm{CO}_{2}$. Again, a much faster initial reaction rate of $\mathrm{CH}$ was observed, followed by a significant decrease and continuing reaction of the $\mathrm{C}-\mathrm{S}-\mathrm{H}$ phase for both $\mathrm{CO}_{2}$ concentrations. Although, this was determined to be a result of coating of microcrystalline carbonate on the portlandite crystals in the pure $\mathrm{CO}_{2}$ carbonated samples, there was no evidence to suggest this being the cause in the air carbonated specimens. 
The thermal analysis data here, however, show that for the 72 hour cured samples at $\mathrm{w} / \mathrm{b}$ ratio 0.57 it was the complete consumption of $\mathrm{CH}$, rather than the inaccessibility of the crystals, that permitted the rate of carbonation of C-S-H and the other hydrate phases to increase.

The $\mathrm{CH}$ and $\mathrm{CaCO}_{3}$ contents for the equivalent systems cured for 28 days are displayed in Figure 6.2 (b). Prolonged exposure led to increased production of $\mathrm{CaCO}_{3}$ but to considerably lower extents than was observed in the less mature systems. $\mathrm{CH}$ was present in appreciable quantities for the neat and $30 \%$ replacement systems following 7 days exposure to $\mathrm{CO}_{2}$, while portlandite had been almost entirely consumed for the $60 \%$ slag sample. The lower level of carbonation resistance observed for the $60 \%$ GGBS systems is again attributed to a combination of its much lower initial $\mathrm{CH}$ content and degree of reaction. Borges et al. [82] related the mechanism of carbonation of slag containing materials to the content of portlandite available prior to exposure to $\mathrm{CO}_{2}$. At high levels of substitution (90\%) in a highly hydrated paste (90 days' cured) depletion of $\mathrm{CH}$ was observed from 7 days following accelerated carbonation $\left(5 \% \mathrm{CO}_{2}\right)$ testing. Consumption of $\mathrm{CH}$ was reported to then facilitate a greater extent of decalcification of C-S-H which was not observed for the $30 \%$ slag systems in which $\mathrm{CH}$ remained present.

As with the short cured samples, simultaneous carbonation of the other hydrates (C-S-H, AFt, AFm) had occurred in the presence of $\mathrm{CH}$ following 28 days' curing (Table 6.2). This, however, was to a significantly lesser degree compared with the $\mathrm{CH}$ depleted systems at equivalent exposure ages for 72 hour cured systems (Table 6.1). Despite this, there still existed a similar relationship between extent of carbonation and replacement level where lower quantities of carbonate had been produced at 7 days in the neat systems and increased with increasing substitution. Additionally, the proportion of $\mathrm{CaCO}_{3}$ produced from $\mathrm{CH}$ to that produced from the other phases varied with substitution with approximately $30 \%, 50 \%$ and $60 \%$ of the total carbonate content being attributed to phases other than portlandite for $0 \%, 30 \%$ and $60 \%$ replacement systems respectively.

Chen et al. [80] concluded from experimental investigations on decalcification shrinkage that the C$\mathrm{S}-\mathrm{H}$ gel in systems that exhibit lower $\mathrm{Ca} / \mathrm{Si}$ ratios and reduced quantities of $\mathrm{CH}$ are effectively more vulnerable to decomposition via the removal of $\mathrm{Ca}$. Additional carbonate to that produced from the reaction of portlandite is likely to be a result of carbonation of $\mathrm{C}-\mathrm{S}-\mathrm{H}, \mathrm{AFt}$ and AFm phases however it is not clear how the calcium aluminate phases react, or to what extent they react, in the presence 
of $\mathrm{CH}$ during very early ages in an ambient $\mathrm{CO}_{2}$ atmosphere. Early age carbonation of AFt and AFm phases has been observed but under accelerated conditions $[66,67]$.

Table 6.2. Consumption of $\mathrm{CH}$ versus production of $\mathrm{CaCO}_{3}$ calculated from TGA data following 7 days' exposure to ambient $\left[\mathrm{CO}_{2}\right]$ for 28 day cured systems. Values are shown in mol/100g.

\begin{tabular}{lccc}
\hline & $\begin{array}{c}\mathrm{CH} \\
\text { consumed } \\
(\mathrm{mol} / 100 \mathrm{~g})\end{array}$ & $\begin{array}{c}\mathrm{CaCO} 3 \\
\text { produced } \\
(\mathrm{mol} / 100 \mathrm{~g})\end{array}$ & $\begin{array}{c}\mathrm{CaCO} 3 \text { produced } \\
\text { from other hydrates } \\
(\mathrm{mol} / 100 \mathrm{~g})\end{array}$ \\
\hline CEMI & 0.10 & 0.14 & 0.04 \\
$30 \%$ PFA & 0.09 & 0.16 & 0.08 \\
$30 \%$ GGBS & 0.11 & 0.20 & 0.09 \\
$60 \%$ GGBS & 0.08 & 0.23 & 0.14 \\
\hline
\end{tabular}

Thiery et al. [61] discussed the kinetics of the chemical reactions, principally that of $\mathrm{CH}$, as being the rate determining process, rather than diffusion of $\mathrm{CO}_{2}$ for Portland cement systems. The reaction of Portland cement is substantial at very early ages, and although differences in porosity and permeability will exist between different curing lengths and $\mathrm{w} / \mathrm{c}$ ratios, these are likely to be moderate. In blended cement materials much larger variations will exist, being further exaggerated as curing length decreases and $w / b$ ratio and replacement increase. In highly porous systems the availability of $\mathrm{CH}$ will govern the rate and extent of carbonation, as demonstrated for the $0.57-72$ hour cured samples. However, comparison of the $30 \%$ slag systems following short and idealised curing indicated this is not necessarily the case for properly hydrated composite materials where both systems had equivalent $\mathrm{CH}$ contents at $\mathrm{t}_{0}$. Following 72 hours' curing and 7 days' exposure to ambient $\mathrm{CO}_{2}$ concentrations, portlandite had been completely consumed and decalcification of the other Ca bearing hydrate phases was substantial. At the same exposure age following 28 days' curing, $\mathrm{CH}$ was still present in the sample and carbonate products from the other phases (C-S-H, AFt, $\mathrm{AFm}$ ) was $50 \%$ lower than that of the immature paste. Here, although the presence of $\mathrm{CH}$ prevents more extensive carbonation of the other hydrates from occurring, its accessibility is also substantially reduced due to the enhancement of the microstructure (as observed in TEM micrographs) resulting in reduced rates of $\mathrm{CO}_{2}$ diffusion. In ideally cured systems both the kinetics of the reactions and the diffusion of $\mathrm{CO}_{2}$ play a principal role, but as porosity increases resistance to carbonation becomes reliant on the chemical kinetics. This has serious implications for improperly 
cured blended materials in which reduced $\mathrm{CH}$ contents are expected and where microstructures may permit continuous replacement of $\mathrm{CO}_{2}$.

As carbonation progressed the mass loss associated with $\mathrm{CaCO}_{3}$ decomposition was observed to occur at a lower temperature (Table 6.3) for some of the systems. This behaviour coincided with both the loss of $\mathrm{CH}$ and the significant increase in carbonate content previously observed. This strongly indicated carbonation via decalcification of $\mathrm{C}-\mathrm{S}-\mathrm{H}$ where the carbonation of $\mathrm{C}-\mathrm{S}-\mathrm{H}$ is considered to form poorly crystalline and metastable forms of $\mathrm{CaCO}_{3}$. Typically 3 decomposition modes are associated with carbonation [61]; mode I $\left(780^{\circ}-990^{\circ} \mathrm{C}\right)$, mode II $\left(680^{\circ}-780^{\circ} \mathrm{C}\right)$ and mode III $\left(550^{\circ}-680^{\circ} \mathrm{C}\right)$. The higher decomposition modes, mode I \& II, are attributed to crystalline polymorphs of $\mathrm{CaCO}_{3}$ (calcite, vaterite and aragonite), with mode I being principally attributed to calcite. Mode III is believed to be associated with amorphous $\mathrm{CaCO}_{3}$. Thiery et al. [61] reported similar findings in which the thermal stability of the $\mathrm{CaCO}_{3}$ species produced at high levels of carbonation was lower. The authors ascribed these poorly crystalline, thermally unstable polymorphs with the decalcification of C-S-H. Villain et al. [100] also suggested that for highly hydrated (3 months' cured) mortar samples subjected to accelerated carbonation, the dissociation of stable $\mathrm{CaCO}_{3}$ (calcite), from the reaction of $\mathrm{CO}_{2}$ with portlandite, occurred between $650^{\circ}-950^{\circ} \mathrm{C}$, while unstable forms of vaterite and aragonite resulting from $\mathrm{C}-\mathrm{S}-\mathrm{H}$ carbonation dissociated between $530^{\circ}-650^{\circ} \mathrm{C}$. Shi et al. [167] reported decomposition of $\mathrm{CaCO}_{3}$ beginning at lower temperatures for heavily carbonated surface regions of mortar samples, observing decomposition temperatures as low as $250^{\circ} \mathrm{C}$ for metakaolin and limestone containing materials. Comparison of a white Portland cement system to a $30 \%$ limestone system with much higher measured pore connectivity and porosity indicated a greater proportion of thermally unstable carbonate species formed from the carbonation of $\mathrm{C}-\mathrm{S}-\mathrm{H}, \mathrm{AFt}$ and $\mathrm{AFm}$ phases, resulting from improved accessibility for $\mathrm{CO}_{2}$. 
Table 6.3. Temperature at which mass loss due to $\mathrm{CaCO}_{3}$ decomposition begins

0.57 (72hrs)

\begin{tabular}{lccccc}
\hline \multicolumn{5}{c}{ Temperature $\mathrm{CaCO}_{3}$ decomposition begins $\left({ }^{\circ} \mathrm{C}\right)$} \\
\hline \multicolumn{5}{c}{ Length of exposure to ambient $\mathrm{CO}_{2}$ (days) } \\
\hline CEMI & $0 / \mathrm{t}_{0}$ & 1 & 2 & 4 & 7 \\
\cline { 2 - 6 } $30 \%$ PFA & 550 & 560 & 550 & 530 & $\mathbf{4 5 5}$ \\
$30 \%$ GGBS & 550 & 540 & 530 & $\mathbf{4 1 0}$ & 400 \\
$60 \%$ GGBS & 550 & 540 & 530 & $\mathbf{4 5 0}$ & 450 \\
\hline
\end{tabular}

$0.57(28 d)$

\begin{tabular}{lccccc}
\hline \multicolumn{5}{c}{ Temperature $\mathrm{CaCO}_{3}$ decomposition begins $\left({ }^{\circ} \mathrm{C}\right)$} \\
\hline \multicolumn{5}{c}{ Length of exposure to ambient $\mathrm{CO}_{2}$ (days) } \\
\hline CEMI & $0 / \mathrm{t}_{0}$ & 1 & 2 & 4 & 7 \\
\cline { 2 - 6 } $30 \%$ PFA & 560 & 580 & 550 & 550 & 540 \\
$30 \%$ GGBS & 550 & 540 & 550 & & 550 \\
$60 \%$ GGBS & 580 & 560 & 560 & 540 & 540 \\
\hline
\end{tabular}

This behaviour was further reinforced when examining the carbonation of a $\mathrm{CH}$ free $\mathrm{C}-\mathrm{S}-\mathrm{H}$ sample. Figure 6.3 displays the TGA plots of a synthesised C-S-H sample (free from $\mathrm{CH}$ and with a $\mathrm{Ca} / \mathrm{Si} 1.33$ ), before and after carbonation. The sample was carbonated under the same conditions as the cement samples in this study for a period of four days. The carbonates produced as a result of $\mathrm{C}-\mathrm{S}-\mathrm{H}$ carbonation decomposed at a much lower temperature than those from $\mathrm{CH}$ carbonation. The decomposition temperature here was, in fact, lower than the three decomposition modes typically considered for $\mathrm{CaCO}_{3}$ and indicated the formation of an amorphous calcium carbonate species.

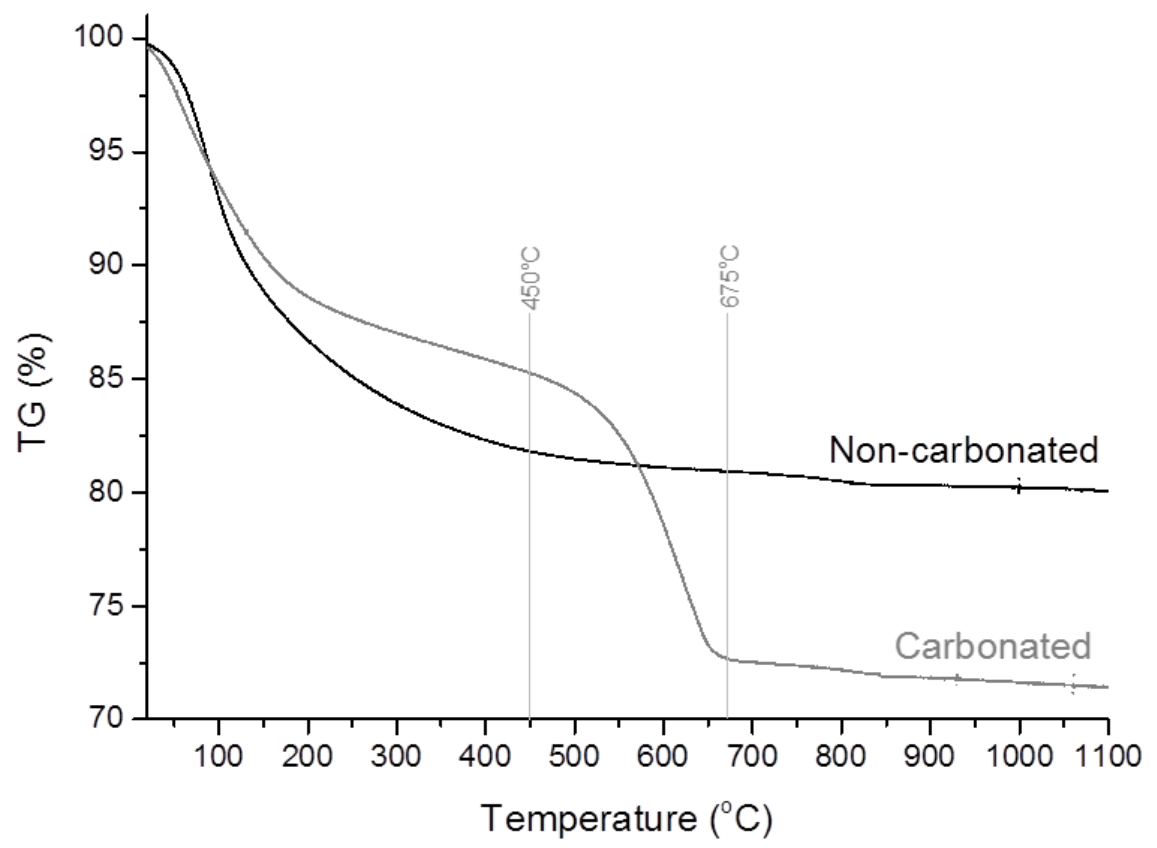

Figure 6.3. TGA plot from a synthetic $\mathrm{C}-\mathrm{S}-\mathrm{H}(\mathrm{Ca} / \mathrm{Si}$ ratio 1.33$)$ sample before and carbonation $\left(24^{\circ} \mathrm{C}\right.$, $72.6 \% \mathrm{RH}$, ambient $\left[\mathrm{CO}_{2}\right]$, exposure time 4 days) 
TG-FTIR was performed on selected samples in order to correctly identify the mass loss associated $\mathrm{CaCO}_{3}$ at these unconventionally lower temperatures. Figure 6.4 displays a TG-FTIR plot for the 30\% GGBS - 72 hour cured sample exposed to ambient $\mathrm{CO}_{2}$ for 4 days, verifying the mass loss due to $\mathrm{CaCO}_{3}$ from $450^{\circ} \mathrm{C}$. In this sample a small amount of portlandite was also present (Figure 3(a)), however the FTIR data for $\mathrm{H}_{2} \mathrm{O}$ and $\mathrm{CO}_{2}$ confirm that the mass loss below $450^{\circ} \mathrm{C}$ can be attributed predominantly to bound water from hydate phases, including mass loss associated with $\mathrm{CH}$, and above this temperature the mass loss was clearly a result of carbonate species. Although a minor mass loss above $450^{\circ} \mathrm{C}$ was detected for $\mathrm{H}_{2} \mathrm{O}$, this was only slight and observed in all the systems. TG-FTIR analysis was performed on the samples in which a drop in $\mathrm{CaCO}_{3}$ decomposition temperature had been observed but there was also portlandite present, the results were consistent, supporting previous observations and assumptions.

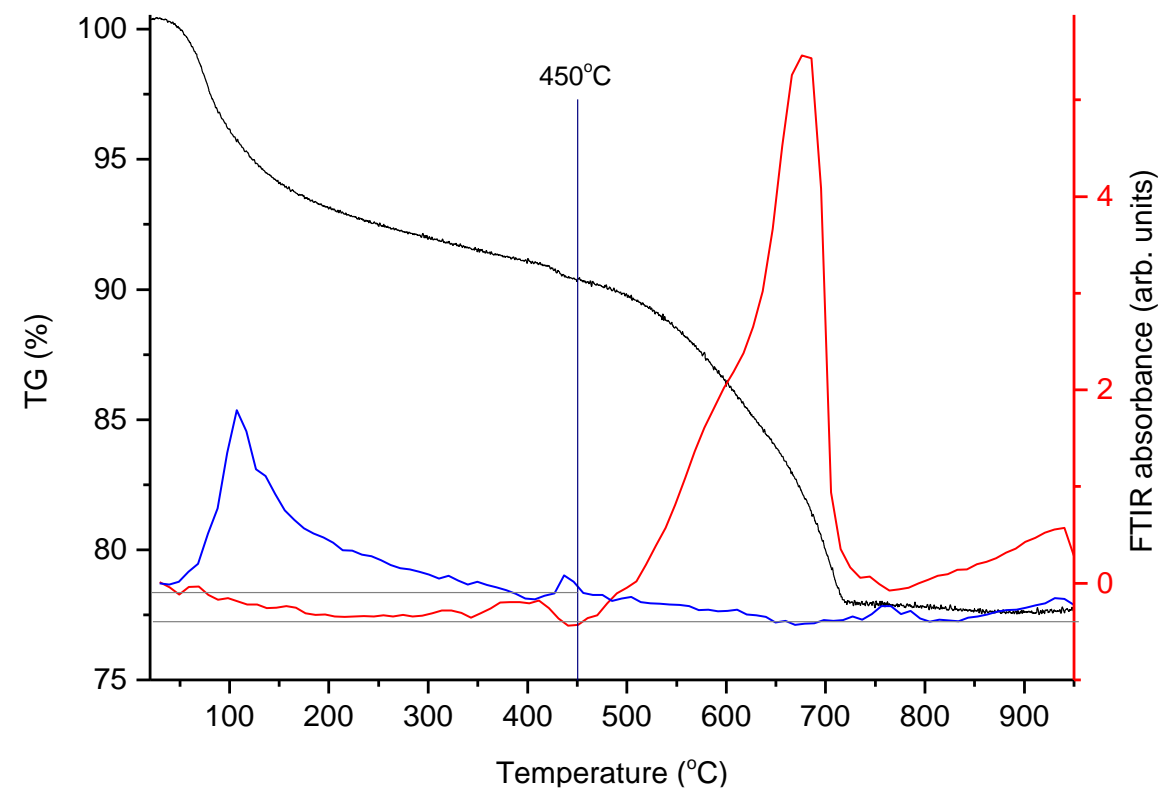

Figure 6.4. TG-FTIR plots for $30 \%$ GGBS $0.57(72 \mathrm{hr})$ sample exposed to ambient $\left[\mathrm{CO}_{2}\right]$ for 4 days. FTIR spectra shown for $\mathrm{H}_{2} \mathrm{O}$ (blue) and $\mathrm{CO}_{2}$ (red).

The presence of a small peak, or shoulder, at $\sim 150-170^{\circ} \mathrm{C}$ in DTA data corresponding to AFm was observed for all the systems at $t_{0}$. The DTA plots between $0-250^{\circ} \mathrm{C}$ for the samples with increasing exposure to $\mathrm{CO}_{2}$ are displayed in Figures 6.5 (72hrs) and 6.6 (28d). Dehydration of monosulfoaluminate is expected to occur at slightly higher temperatures than monocarboaluminate [99] and respective temperatures of 180 and $150^{\circ} \mathrm{C}$ have been reported for monosulfoaluminate 
and the carboaluminate phases (hemi and mono) in other studies [69, 153]. These temperatures have been indicated on the figures as guidance.

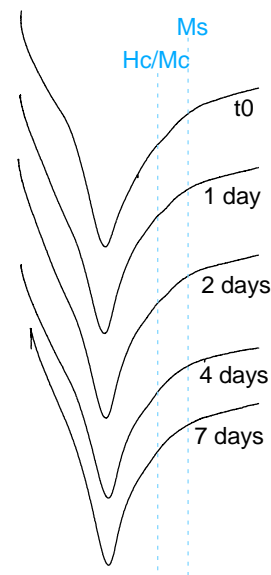

(a)

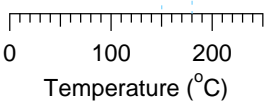

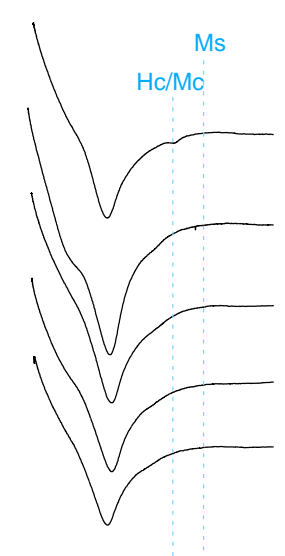

(b)

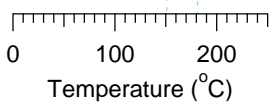

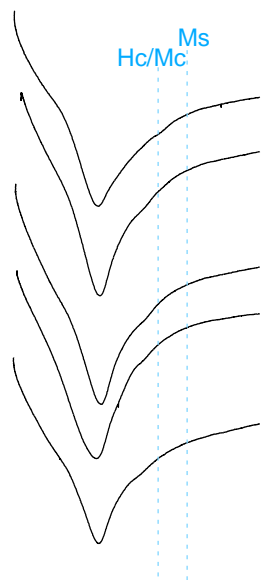

(c)

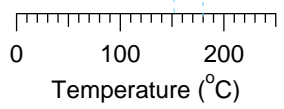

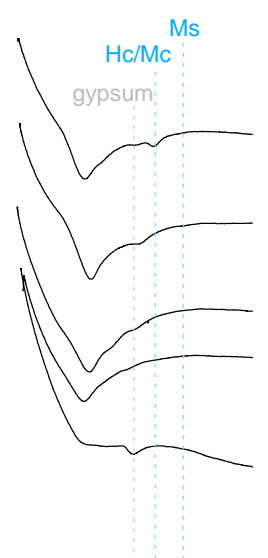

(d)

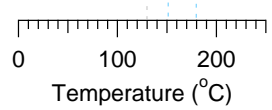

Figure 6.5. DTA plots between $0-250^{\circ} \mathrm{C}$ for 72 hour cured CEMI (a), 30\% PFA (b), 30\% GGBS and $60 \%$ GGBS (d) systems exposed to ambient $\left[\mathrm{CO}_{2}\right]$ for up to 7 days (Ms - monosulfoaluminate, $\mathrm{Hc}-$ hemicarboaluminate, $\mathrm{Mc}$ - monocarboaluminate) 


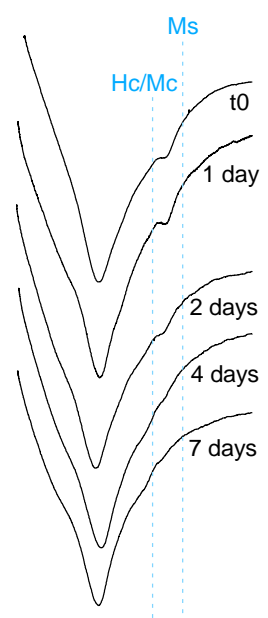

(a)

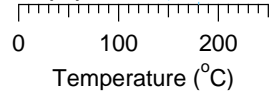

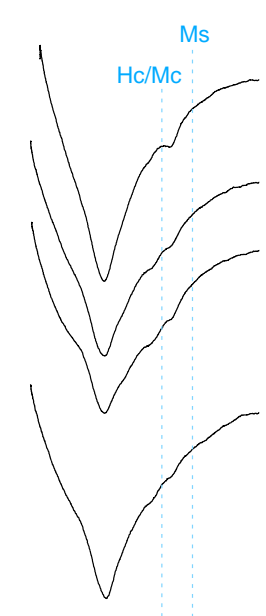

(b)

$\begin{array}{ccc}0 & 100 & 200 \\ & \text { Temperature } & \left({ }^{\circ} \mathrm{C}\right)\end{array}$
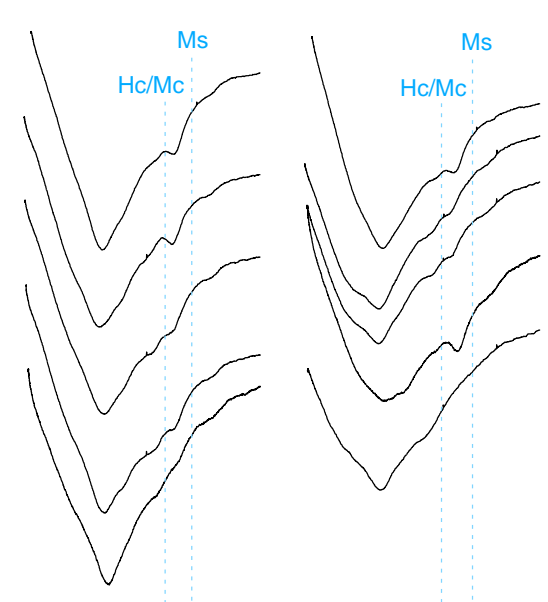

(c)

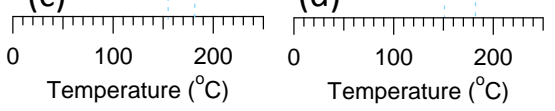

Figure 6.6. DTA plots between $0-250^{\circ} \mathrm{C}$ for 28 day cured CEMI (a), 30\% PFA (b), 30\% GGBS and $60 \%$ GGBS (d) systems exposed to ambient $\left[\mathrm{CO}_{2}\right]$ for up to 7 days (Ms - monosulfoaluminate, $\mathrm{Hc}-$ hemicarboaluminate, $\mathrm{Mc}$ - monocarboaluminate)

The production of carbonate from phases other than $\mathrm{CH}$ was evident from TGA calculations (Tables $6.1 \&$ 6.2). As the carbonate content increased, the decrease, or disappearance, of AFm peaks was observed, demonstrating the involvement of AFm species in early-age carbonation reactions. Small peak intensities, or only very slight shoulders in the data, for the 72 hour cured samples meant changes in decomposition temperatures were difficult to determine. However, a shift in peak temperature to a lower value before almost complete disappearance was observed for the $60 \%$ slag system between $0-4$ days, indicating transformation of the AFm species [68] before complete decalcification. The subsequent formation of a distinct peak at $130^{\circ} \mathrm{C}$ in the same system at 7 days revealed the presence of gypsum, indicating carbonation of AFt had occurred $[65,66]$.

The DTA plots in Figure 6.6 show similar behaviour where AFm peak intensities decreased with increasing levels of carbonation, shifting to lower temperature values as carbonates displaced sulphates [68]. Complete disappearance of AFm, however, was not observed evidenced by small 
peaks and shoulders at 7 days in all the systems. The presence of several small peaks also indicated the co-existence of several phases.

Carbonation of AFm occurred almost immediately upon exposure to $\mathrm{CO}_{2}$, transforming from monosulfoaluminate, to hemi- and monocarboaluminate before complete decalcification. In the presence of $\mathrm{CH}$, conversion to carboaluminate phases occurred, where a mixture of AFm phases appeared to exist, but complete decomposition was not observed. In systems where $\mathrm{CH}$ had been consumed, decomposition of the AFm phases was rapid, potentially transforming initially very quickly, and the carbonation of AFt, producing gypsum as a decomposition product, was observed to occur following portlandite depletion only for the $60 \%$ GGBS system.

Many studies describe simultaneous carbonation of $\mathrm{CH}$ and $\mathrm{C}-\mathrm{S}-\mathrm{H}$, assigning additional $\mathrm{CaCO}_{3}$ contents to that produced from $\mathrm{CH}$ solely to $\mathrm{C}-\mathrm{S}-\mathrm{H}[61,82]$. Here it has been shown that AFm phases are involved in the very early reactions, likely contributing to the production of carbonate species.

\subsubsection{XRD}

XRD data was in good agreement with the STA results, Figures 6.7 and 6.8 display the diffractograms between $7-19^{\circ} 2 \theta$ and $26-35^{\circ} 2 \theta$ for the 72 hour cured and 28 day cured samples respectively. As carbonation progressed in the short cured systems, predominantly calcite was determined as the crystalline polymorph to form. Sizeable increases in its content, observed by increased intensities in the main reflection at $\sim 29.5^{\circ} 2 \theta$, were observed, corresponding to substantial decreases in the $\mathrm{CH}$ peaks. Small amounts of vaterite were also detected in the slag and fly ash containing materials (but not in the CEM I system). AFm reflections had low intensities and poor resolution, however, small peak shifts and decreased peak intensities were apparent, particularly for the composite materials at higher levels of carbonation (i.e. upon near depletion of portlandite). AFt contents remained relatively constant until $\mathrm{CH}$ had almost entirely reacted. Following this, intensities of the peak at $\sim 9^{\circ}$ $2 \theta$ were observed to notably reduce, consistent with assumptions made from DTA data where the formation of gypsum was attributed to the carbonation of AFt.

As for the thermal analysis data, the production of $\mathrm{CaCO}_{3}$ was observed to be much lower in the ideally cured samples, in which sizeable quantities of portlandite remained up to 7 days' exposure (Figure 6.8). Peak resolutions for the AFm phases were improved and conversion of AFt to 
monosulfoaluminate or hemicarboaluminate between $t_{0}$ and 1 day occurred in nearly all the systems. Subsequent changes due to carbonation showed phase transformation from monosulfoaluminate to hemicarboaluminate and monocarboaluminate, as inferred from DTA plots. This is illustrated in the fly ash sample (Figure 6.8(b)) where predominantly monosulfoaluminate and a small amount of hemicarboaluminate existed initially (determined from XRD analysis at $t_{0}$ in Section 5.2.1) but progressively converted to hemicarboaluminate and monocarboaluminate with increasing exposure and uptake of $\mathrm{CO}_{2}$. AFm phase transformation was accompanied by decreased peak intensities as carbonation proceeded, again indicating contribution of these phases to carbonate production at early ages. AFt, however, remained relatively consistent further supporting the opinion that while portlandite is available, decomposition of this phase remains relatively low. 
(a) calcite

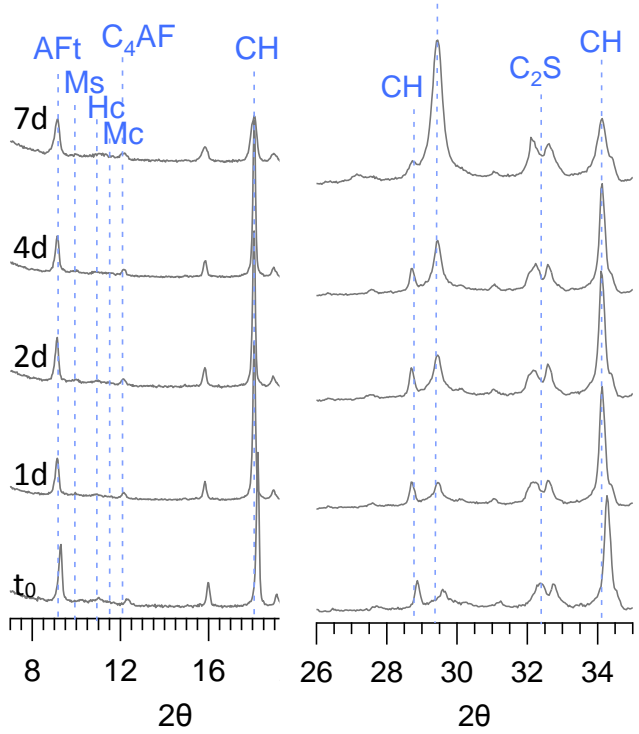

(c)

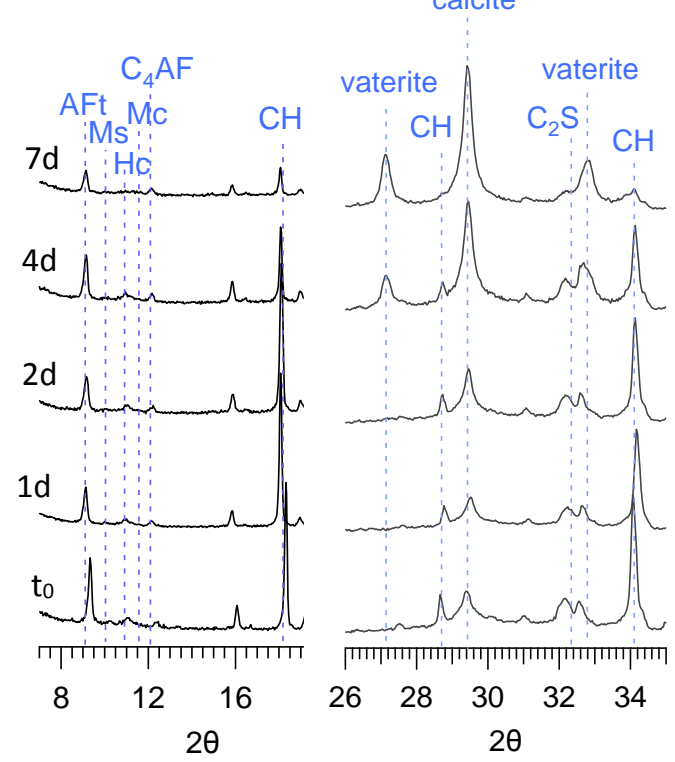

(b) calcite

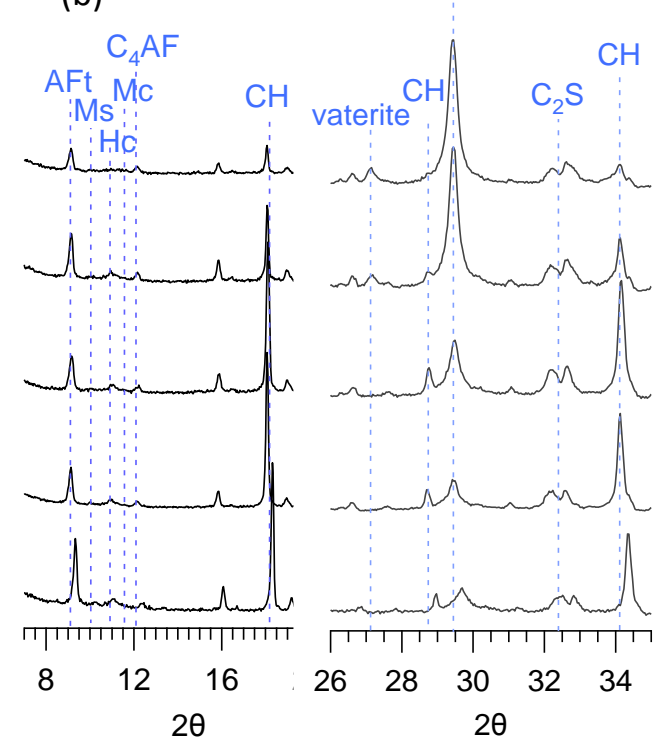

(d)

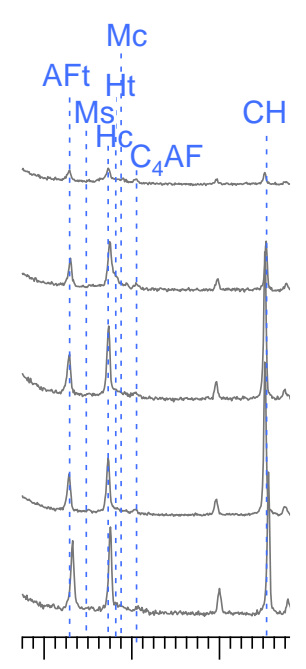

calcite

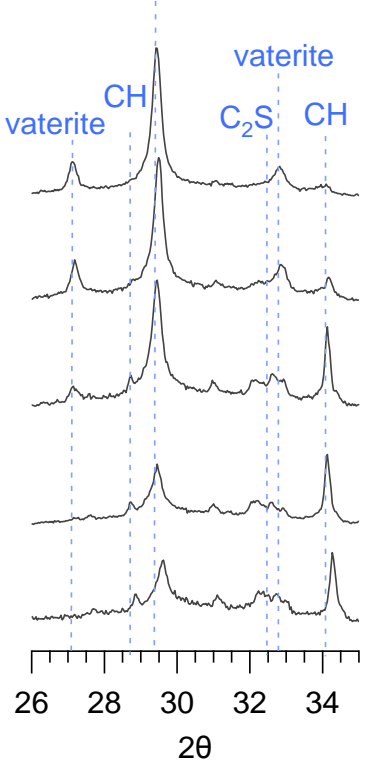

Figure 6.7. XRD patterns between $7-19^{\circ} 2 \theta$ and $26-35^{\circ} 2 \theta$ showing the changes in the crystalline phase assemblage with increasing exposure to ambient $\left[\mathrm{CO}_{2}\right]\left(\mathrm{t}_{0}-7\right.$ days $)$ for 72 hour cured samples (a) CEMI, (b) 30\% PFA, (c) 30\% GGBS, (d) 60\% GGBS (AFt - ettringite, Ms monosulfoaluminate, $\mathrm{Hc}$ - hemicarboaluminate, $\mathrm{Mc}$ - monocarboaluminate, $\mathrm{Ht}$ - hydrotalcite). 


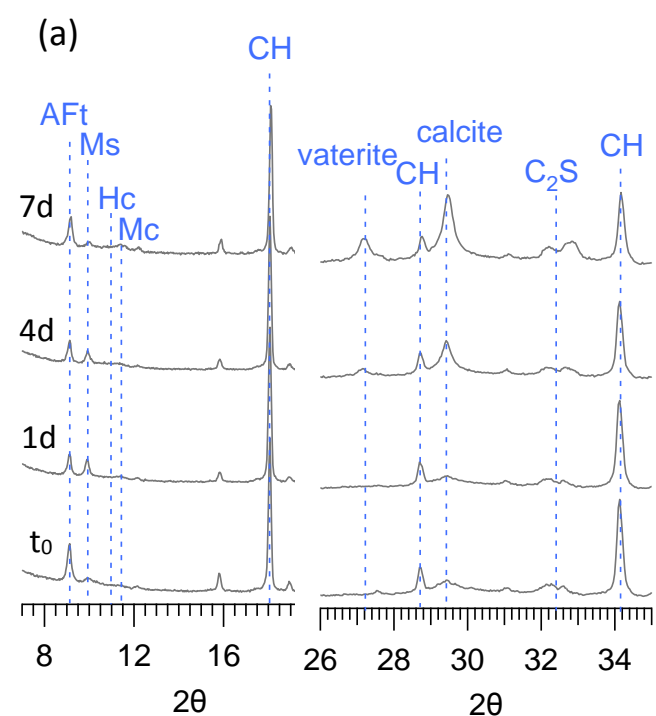

(c)

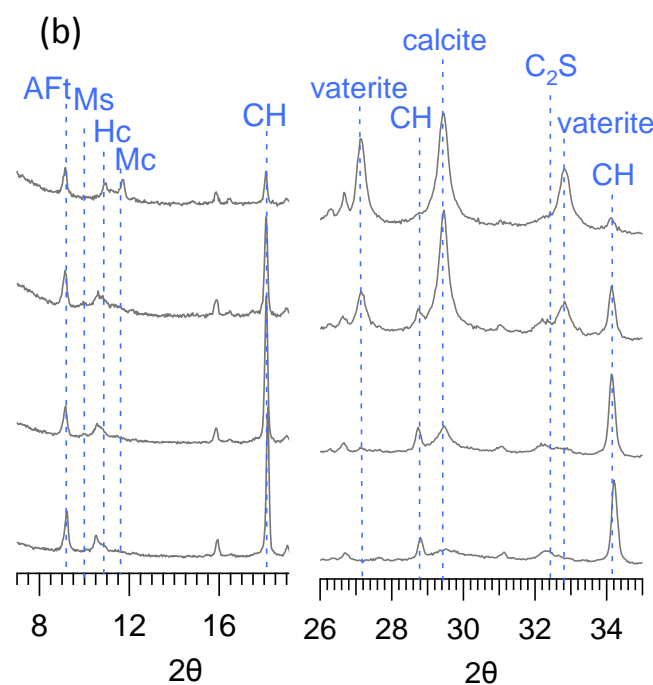

(d)

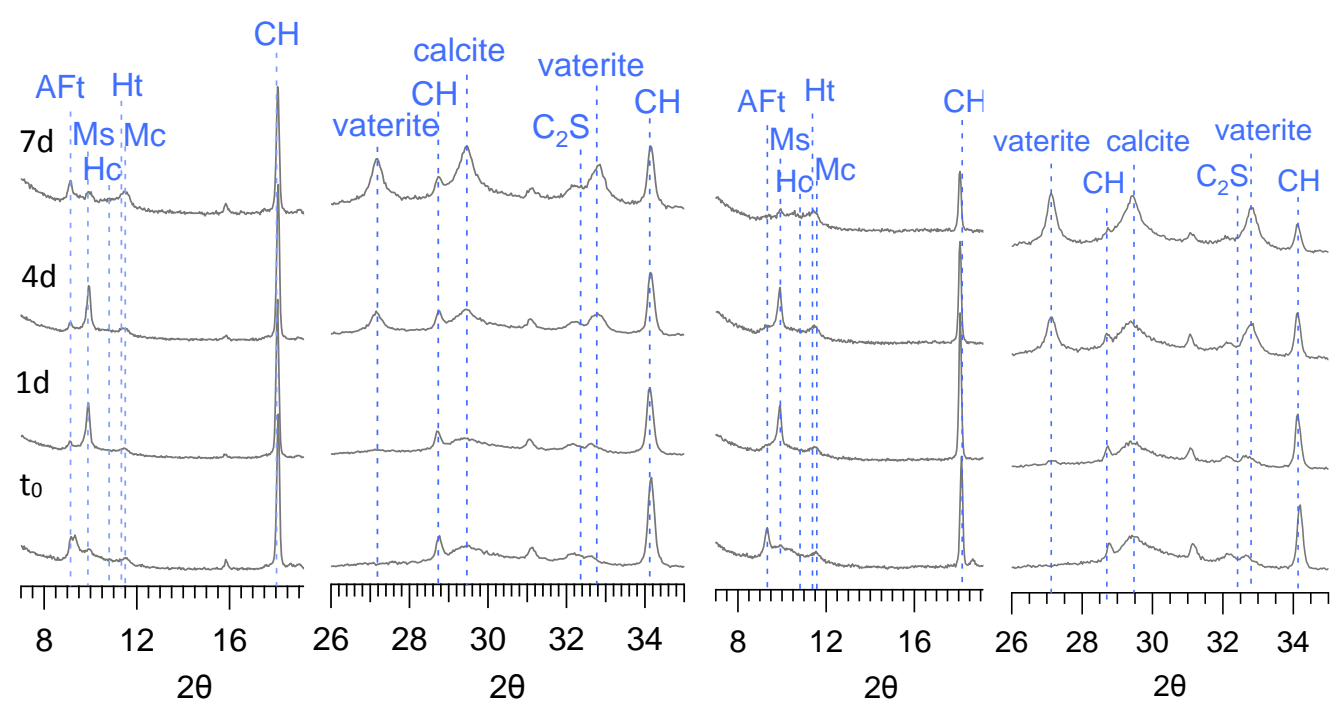

Figure 6.8. XRD patterns between $7-19^{\circ} 2 \theta$ and $26-35^{\circ} 2 \theta$ showing the changes in the crystalline phase assemblage with increasing exposure to ambient $\left[\mathrm{CO}_{2}\right]\left(\mathrm{t}_{0}-7\right.$ days) for 28 day

cured samples (a) CEMI, (b) 30\% PFA, (c) 30\% GGBS, (d) 60\% GGBS (AFt - ettringite, Ms monosulfoaluminate, $\mathrm{Hc}$ - hemicarboaluminate, $\mathrm{Mc}$ - monocarboaluminate, $\mathrm{Ht}$ - hydrotalcite).

Furthermore, differences in the crystalline carbonate polymorph formed appeared to vary between the two curing conditions, particularly for the composite materials. Short curing periods resulted in the formation predominantly of calcite, although small vaterite reflections were determined from 4 
days' exposure in the fly ash and slag samples. With increased curing duration, however, vaterite became more prevalent with respect to calcite. This was most prominent for the slag materials where the formation of vaterite from 4 days onwards became almost equivalent to that of calcite (estimated from peak intensities of the main reflections (vaterite $\sim 27^{\circ} 2 \theta$, calcite $\sim 29.5^{\circ} 2 \theta$ ).

The formation of calcite and vaterite in carbonated cements is not uncommon, Groves et al. [64] observed both polymorphs in air and pure $\mathrm{CO}_{2}$ carbonated $\mathrm{C}_{3} \mathrm{~S}$ pastes. XRD measurements on sample surfaces indicated mainly calcite to be present, however reflections became more comparable in intensity just below the sample surface, remaining relatively constant at increasing depths. In a similar study [79] including a $\mathrm{C}_{3} \mathrm{~S}$ - silica fume blend, both calcite and vaterite were again detected, however the relation of the vaterite reflection to that of calcite was described to fluctuate with time, almost entirely disappearing following carbonation for 8 days in pure $\mathrm{CO}_{2}$. Fluctuations in vaterite in respect to calcite at later exposure ages was also observed by Li [168] for 20 year old slag-bearing pastes exposed to natural and accelerated $\mathrm{CO}_{2}$ conditions. Lower slag loadings yielded earlier formations of vaterite while at later ages, higher loadings resulted in reduced vaterite fractions attributed to transformation to the more stable polymorph, calcite. Thiery et al. [61] and Villain et al. [100] both determined carbonate species such as vaterite to be the products of decalcification of C-S-H, which is further supported by Sauman [169] who observed the carbonation of C-S-H to initially form vaterite, later transforming to calcite. Dubina et al. [170] detected an amorphous carbonate as the first product to form when $\mathrm{CaO}$ was exposed to moist air, with all three crystalline polymorphs existing at RH levels between $20-60 \%$ and calcite becoming dominant as the humidity level increased further (60-80\%). Fernandez-Carrasco et al. [67] reported both vaterite and aragonite in varying proportions for carbonated ternary cements and Slegers and Rouxhet [171] discussed the formation of aragonite in carbonated $C_{3} S$ samples as being associated with a low degree of hydration.

Aragonite was almost entirely absent from the carbonated systems studied here and the prevalence of vaterite didn't seem to be related to increased levels of carbonation, which was greater for the short cured systems. Black et al. [73] studied the carbonation of synthetic C-S-H in which the initial $\mathrm{Ca} / \mathrm{Si}$ ratio appeared to influence the crystalline carbonate species formed. For $\mathrm{Ca} / \mathrm{Si}$ ratios greater than 0.67 , principally vaterite was observed and for ratios below 0.50 aragonite was most prevalent. Here, a similar relationship appears to exist. Composite systems subjected to short periods of curing 
exhibited low degrees of reaction and only slightly reduced $\mathrm{Ca} / \mathrm{Si}$ ratios to that of the neat system. TEM-EDX measurements determined mean ratios of 1.39 and 1.55 for the $30 \%$ slag and fly ash systems respectively. As degree of hydration increases, as for the 28 day cured samples, Ca/Si ratios are expected to reduce further, confirmed by TEM-EDX data for the 30\% PFA and $60 \%$ GGBS materials where $\mathrm{Ca} / \mathrm{Si}$ ratios were 1.49 and 1.27 were measured. Reflections of calcite and vaterite appeared to become more comparable as reaction degree of the SCM increased (as for the slag compared to the PFA) and when replacement level was greater (60\% GGBS).

\subsubsection{ATR-FTIR}

ATR-FTIR data were collected for all the samples exposed to ambient $\mathrm{CO}_{2}$. Figure 6.9 displays the characteristic absorbance band for carbonates between $1400-1500 \mathrm{~cm}^{-1}[140,141,172]$ collected for the 72 hour cured CEMI and 30\% PFA systems. Increased length of exposure to $\mathrm{CO}_{2}$ led to an increase in $\mathrm{CaCO}_{3}$ content with a sizeable increase observed between 4 and 7 days and 2 and 4 days for the neat and fly ash samples respectively. Considering the normalised spectra for the silicate band and the $\mathrm{CH}$ peak (3643 $\mathrm{cm}^{-1}$ [140]) (Figure 6.10), this considerable increase coincided with both the consumption of $\mathrm{CH}$ and decalcification of $\mathrm{C}-\mathrm{S}-\mathrm{H}$, as demonstrated by a shift in the silicate band to slightly higher wavenumbers [172]. The loss of buffering capacity allows carbonation to progress much more rapidly in the sample, behaviour that occurred in all the systems but at earlier lengths of exposure with increasing level of replacement and decreasing initial $\mathrm{CH}$ contents, consistent with STA and XRD data discussed previously. 

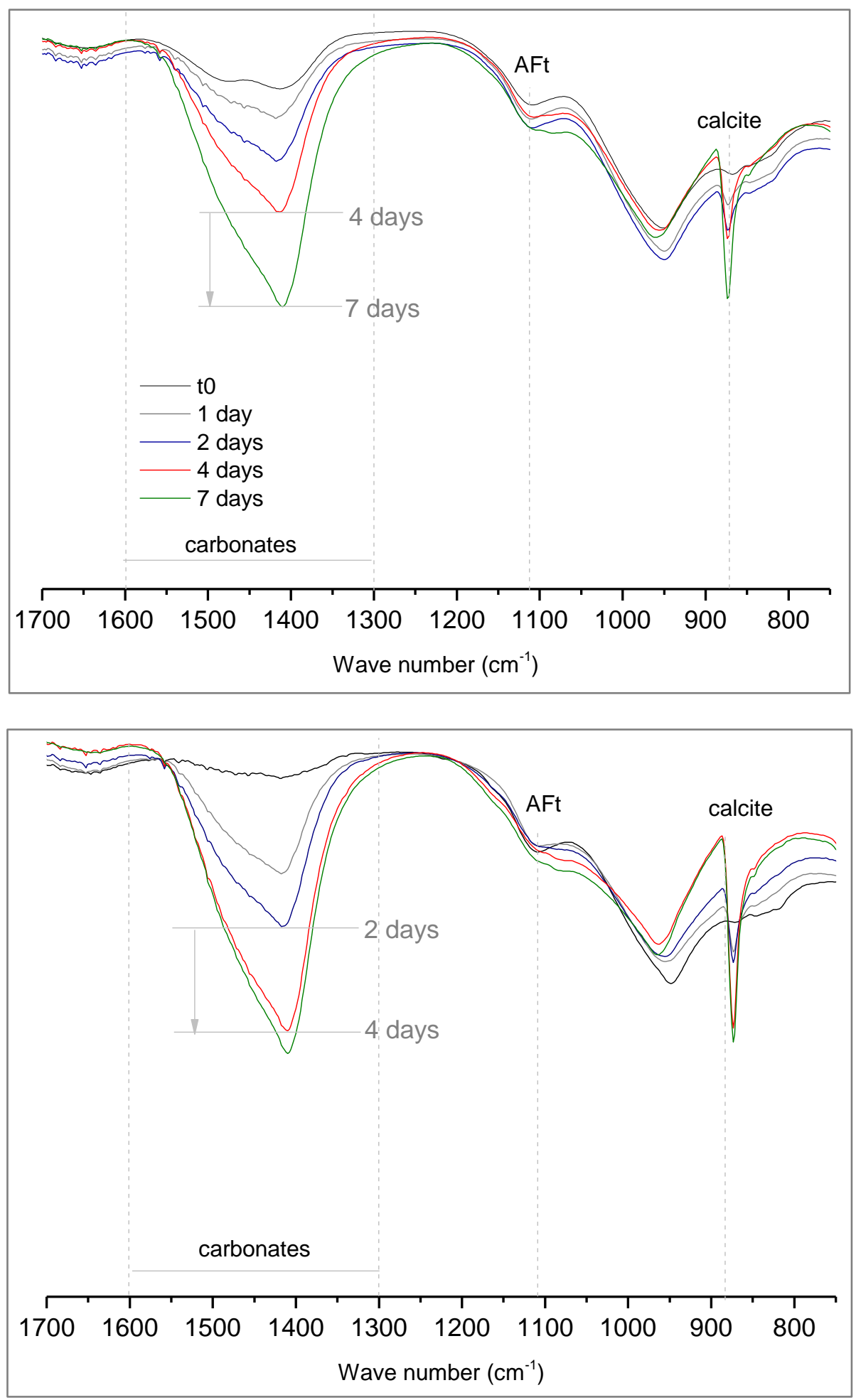

Figure 6.9. ATR-FTIR spectra for $72 \mathrm{hr}$ CEMI (top) and 30\% PFA (bottom) blends showing carbonate $\left(1400-1500 \mathrm{~cm}^{-1}\right)$, AFt $\left(\sim 1120 \mathrm{~cm}^{-1}\right)$, silicate $\left(\sim 950-1000 \mathrm{~cm}^{-1}\right)$ and calcite $\left(\sim 870 \mathrm{~cm}^{-1}\right)$ bands 


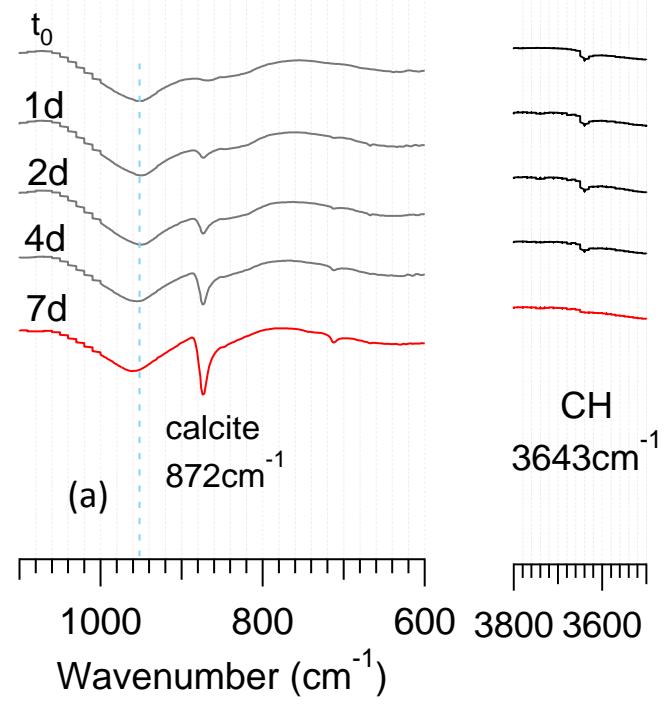

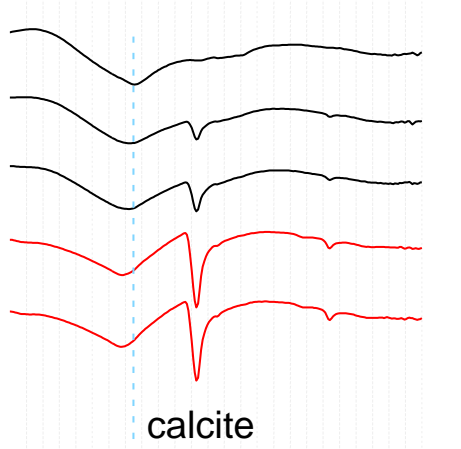

(b)

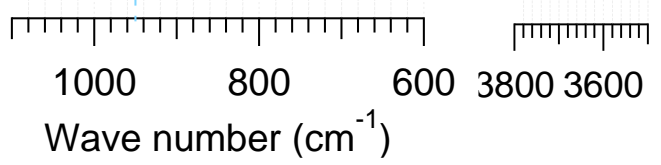

Figure 6.10. ATR-FTIR spectra showing normalised silicate $\left(\sim 950 \mathrm{~cm}^{-1}\right)$ and hydroxide $\left(3643 \mathrm{~cm}^{-1}\right)$ (i.e. $\mathrm{CH}$ ) bands for 72 hour cured systems with increasing exposure to ambient $\mathrm{CO}_{2}$ for (a) $\mathrm{CEMI}$,

(b) $30 \%$ PFA

The formation of poorly crystalline, thermally unstable carbonate species following depletion of portlandite in TGA plots was proposed to be from the carbonation of the C-S-H gel, ATR-FTIR confirms a lowering of the $\mathrm{Ca} / \mathrm{Si}$ ratio with increasing formation of carbonate species supporting these observations. This, however, is not necessarily reflected in the spectra of the main carbonate band where other analysis techniques have determined several polymorphs (crystalline and amorphous) to co-exist. The strong broad absorption between $1400-1500 \mathrm{~cm}^{-1}$ for $\mathrm{CO}_{3}$ is assigned to the asymmetrical stretching band $v 3$ and a much narrower out of plane bending band $(v 2)$ is observed between $\sim 850-880 \mathrm{~cm}^{-1}[141,172]$. Anderson and Brecevic [141] reported very similar $v 2$ frequencies for calcite and vaterite $\left(\sim 877 \mathrm{~cm}^{-1}\right)$ and lower vibrations for aragonite $\left(\sim 854 \mathrm{~cm}^{-1}\right)$ and amorphous species $\left(\sim 864 \mathrm{~cm}^{-1}\right)$. For amorphous carbonate the $v 3$ band is split, showing two maxima (Figure 1(a) in [141]), while crystalline modifications typically produce sharper/narrower forms. XRD measurements determined calcite to be the predominant crystalline polymorph formed in the 72 hour cured samples, however at early ages the presence of a broader split $\mathrm{v} 3$ band in ATR-FTIR data potentially suggested the formation of an amorphous product initially (Figure 6.9 CEMI 1d), as reported to be the first product of carbonation in other studies $[73,170]$. As carbonation progressed, 
transformation into a much sharper asymmetrical form was observed, accompanied by an increasingly intense band at $872 \mathrm{~cm}^{-1}$. Peak sharpening is an indication of a more crystalline phases, agreeing well with XRD reflections for calcite. Nevertheless, lower decomposition temperatures witnessed in TGA data following consumption of portlandite suggested that a poorly crystalline carbonate had also been formed. It is not clear whether if both are present they could be easily differentiated, potentially calcite is more dominant, making it more easily detected.

AFt presents a strong asymmetrical stretching frequency at $\sim 1120 \mathrm{~cm}^{-1}$ related to the relative isolation of the $\mathrm{SO}_{4}$ ion in the hexagonal prismatic structure $[173,174]$. Changes in this band were relatively minor during early age exposure, agreeing well with XRD results.

In the ideally cured systems, vaterite was more prominent, particularly for the slag containing cements. Initially very broad $v 3 \mathrm{CO}_{3}$ bands sharpened, pertaining mainly to calcite for the $30 \%$ system, while a peak shape more typical of vaterite (Figure 1(b) in [141]) was observed to form for the $60 \%$ sample (Figure 6.11). The almost identical $v 2$ band for both crystal structures makes specific identification difficult. Normalised silicate bands show no change in frequency (Figure 6.12), verifying no significant modifications to the $\mathrm{C}-\mathrm{S}-\mathrm{H}$ phase due to carbonation while $\mathrm{CH}$ is still present. 


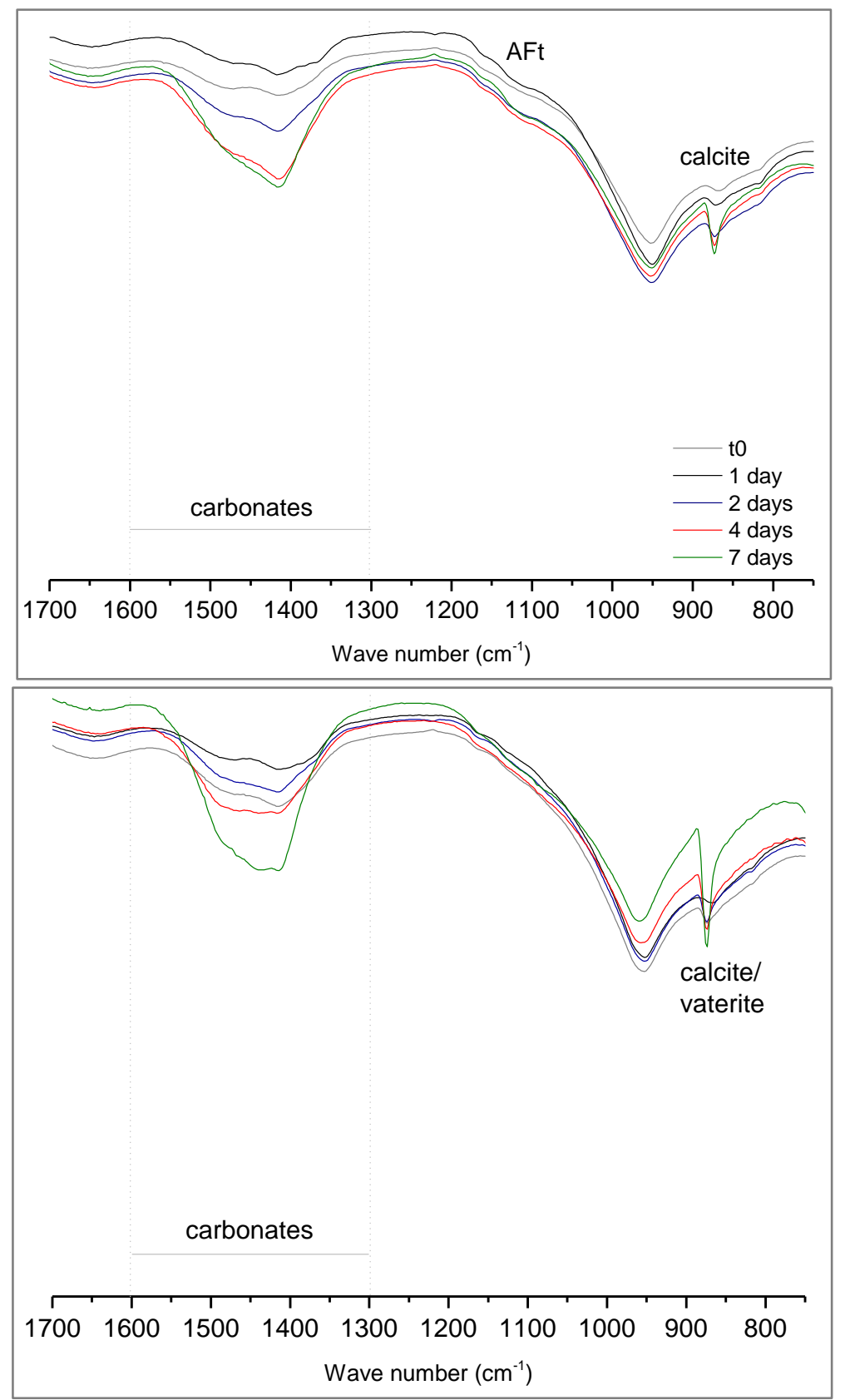

Figure 6.11. ATR-FTIR spectra for 28 day 30\% (top) and 60\% GGBS (bottom) blends showing carbonate $\left(1400-1500 \mathrm{~cm}^{-1}\right)$, AFt $\left(\sim 1120 \mathrm{~cm}^{-1}\right)$, silicate $\left(\sim 950-1000 \mathrm{~cm}^{-1}\right)$ and calcite $\left(\sim 870 \mathrm{~cm}^{-1}\right)$ bands 


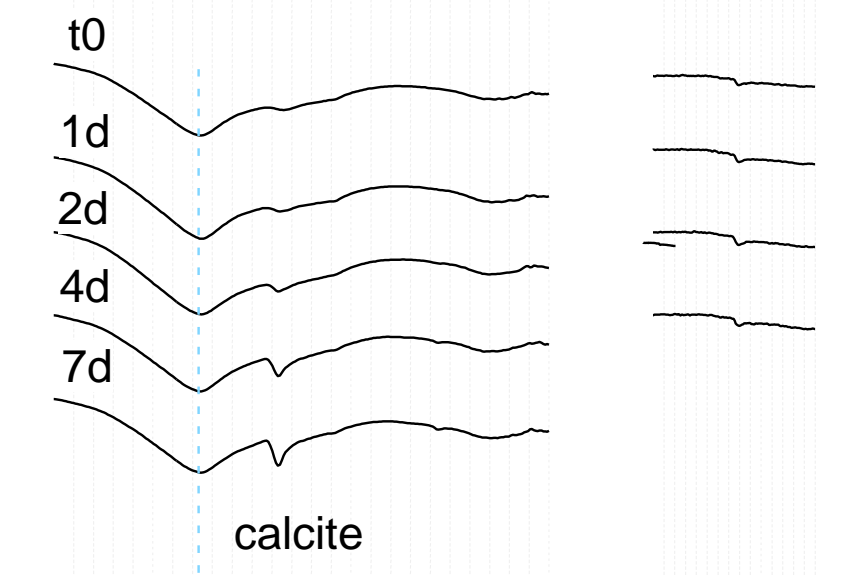

(a)
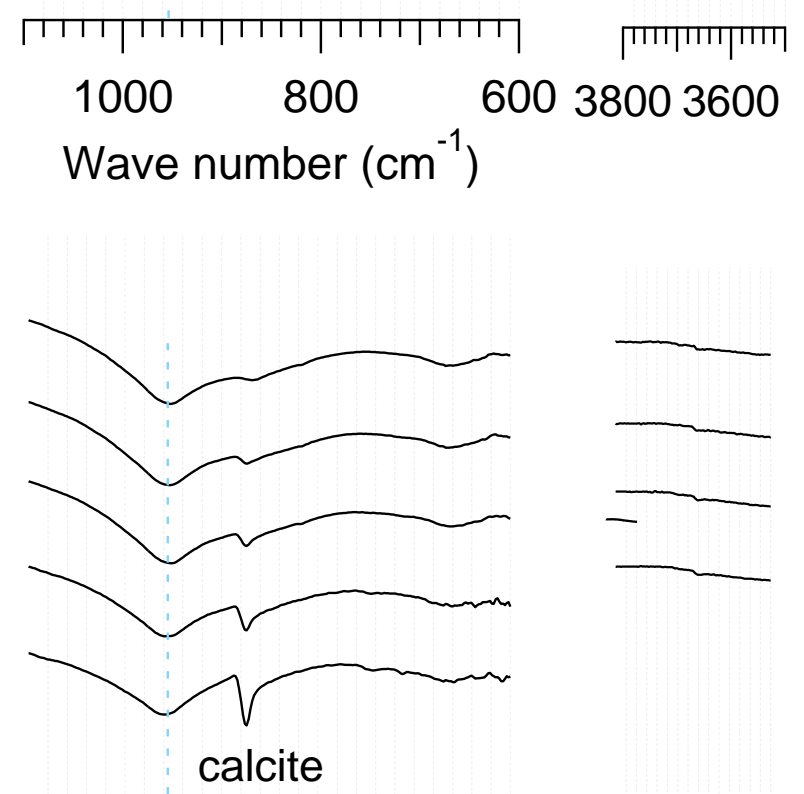

(b)

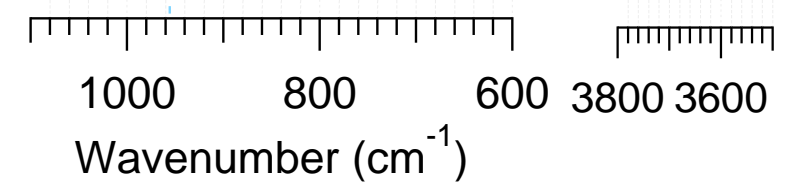

Figure 6.12. ATR-FTIR spectra showing normalised silicate bands $\left(\sim 950 \mathrm{~cm}^{-1}\right)$ and hydroxide $\left(3643 \mathrm{~cm}^{-1}\right.$ ) (i.e. $\mathrm{CH}$ ) bands for 28 day cured systems with increasing exposure to ambient $\mathrm{CO}_{2}$ for

(a) $30 \%$ GGBS, (b) $60 \%$ GGBS 


\subsection{4 ${ }^{27} \mathrm{AI}$ MAS NMR}

${ }^{27} \mathrm{AI}$ MAS NMR spectra collected for the non-carbonated samples confirmed no significant continued hydration of the aluminate phases had occurred during conditioning at $\mathrm{RH} 72.6 \%$, consistent with thermal analysis data. Figure 6.13 displays virtually identical results for $30 \%$ slag 0.57 ( $72 \mathrm{hr}$ ) samples at ages of $t_{0}$ and after exposure to $\mathrm{CO} 2$ free air for 60days.

Selected carbonated samples were studied by ${ }^{27} \mathrm{Al}$ NMR corresponding to exposure ages in which significant changes had previously been observed to occur (i.e. consumption of $\mathrm{CH}$ and increased uptake of $\mathrm{CO}_{2}$ ), the spectra are shown in Figure 6.13 (b). Figure 6.13 (a) displays the spectra obtained for the $t_{0}$ samples previously presented in Chapter 5 (section 5.2.2) and have been included for comparison.

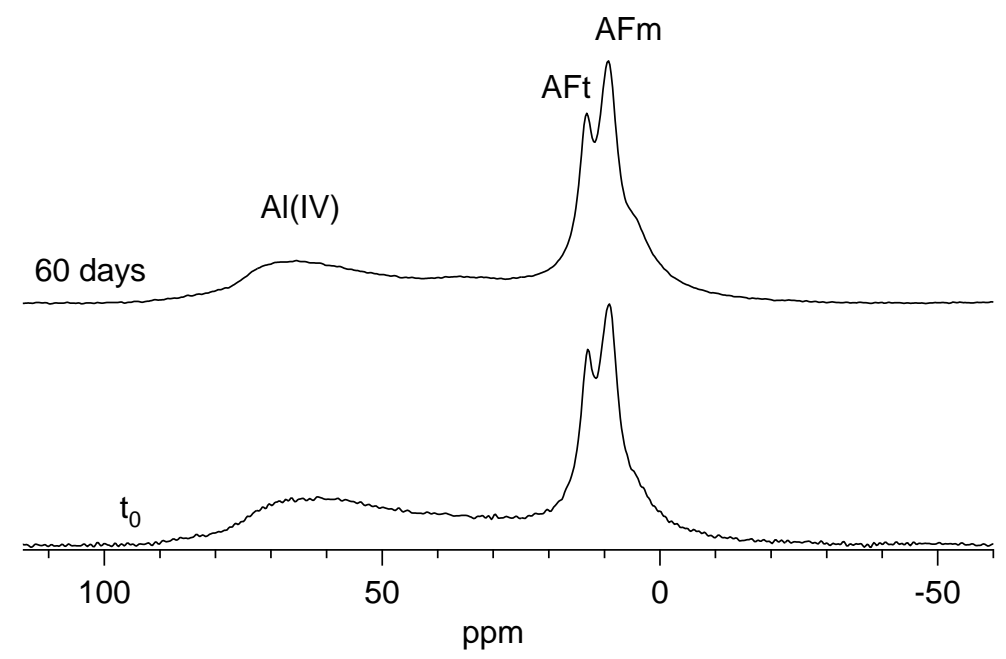

Figure 6.13. Single-pulse ${ }^{27} \mathrm{Al}$ NMR spectra for non-carbonated $30 \%$ GGBS 0.57 ( $72 \mathrm{hr}$ ) samples at $\mathrm{t}_{0}$ and 60 days 

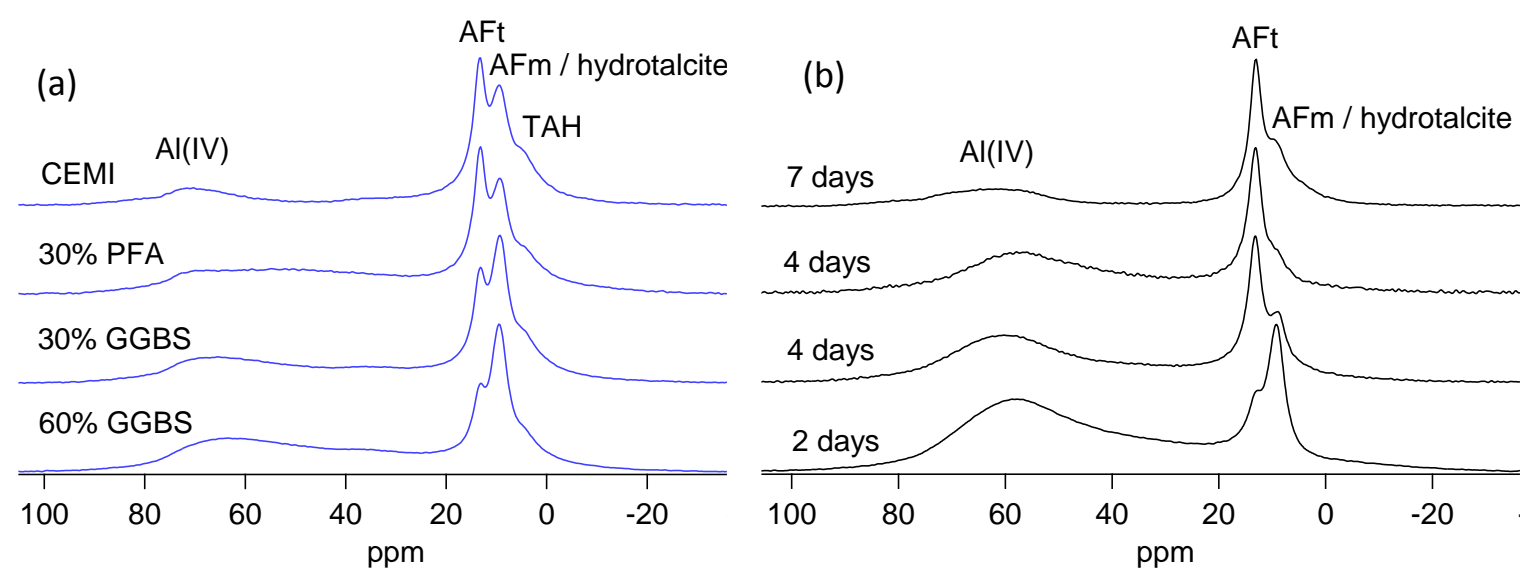

Figure 6.13. Single-pulse ${ }^{27} A I$ NMR spectra $0.57-72 \mathrm{hr}$ cured (a) to samples and (b) early age carbonated samples in which $\mathrm{CH}$ had been consumed and uptake of $\mathrm{CO}_{2}$ had significantly increased

The spectra included resonances from aluminium in octahedral coordination ( 13ppm, 9ppm, $5 \mathrm{ppm})$ and tetrahedral environments ( 65-70ppm). The resonances from tetrahedral aluminium originate from incorporation of $\mathrm{Al}$ in AFt ( 13ppm), the AFm and/or hydrotalcite phases ( 9ppm) and the 'third aluminate hydrate' (TAH) ( 5ppm), associated with an aluminate rich surface precipitate on the C-S-H gel $[110,156]$. The broad resonance at $\sim 65-70 \mathrm{ppm}$ originates from aluminium incorporated in the bridging sites of the silicate chains $[154,155]$.

Substantial decreases in the resonance at $9 \mathrm{ppm}$ in relation to the resonance at $13 \mathrm{ppm}$ was observed upon carbonation for the neat and 30\% replacement systems. AFt peak reflections in XRD data (Figure 6.7) indicated minimal change in intensities at these ages, confirming that it is the AFm phases involved in the carbonation reactions initially compared to AFt. Only very slight changes in AFt and AFm resonances were evident for the $60 \%$ GGBS system following exposure to $\mathrm{CO}_{2}$ for 2 days, consistent with XRD results. The disappearance of the resonance at $\sim 5 p p m(T A H)$ was detected for all the samples, behaviour also observed for the early age exposure of synthetic C-S-H samples ( 1 and 2 weeks for $\mathrm{C}-\mathrm{S}-\mathrm{H}$ with $\mathrm{Ca} / \mathrm{Si}$ ratios of 1.0 and 1.5 respectively) to ambient $\mathrm{CO}_{2}$ concentrations [63]. Responses for tetrahedrally coordinated aluminium (AI(IV)) decreased upon exposure to $\mathrm{CO}_{2}$ and the presence of a new more intense peak centred at $\sim 58 \mathrm{ppm}$ was observed. 
Sevelsted and Skibsted [63] reported the almost complete absence of original Al(IV) resonances with the corresponding formation of a new resonance at 57ppm following 1 week of exposure to ambient $\mathrm{CO}_{2}$ concentrations of a C-S-H sample, with $\mathrm{Ca} / \mathrm{Si}$ ratio 1.0. As the sample was exposed for longer periods of time, the new resonance was observed to become narrower, shifting to a slightly lower frequency $(\sim 55 \mathrm{ppm})$. The same effects were reported for a C-S-H with a higher initial $\mathrm{Ca} / \mathrm{Si}$ ratio (1.50), however they were reported to occur following longer exposure times. Here, the decrease in the $\mathrm{Al}(\mathrm{IV})$ resonance at $~ 65-70 \mathrm{ppm}$ revealed the extraction of $\mathrm{Al}$ from $\mathrm{C}-\mathrm{S}-\mathrm{H}$ bridging sites and its subsequent incorporation into an amorphous silica phase, i.e. that produced from the decalcification of $\mathrm{C}-\mathrm{S}-\mathrm{H}$, as a result of carbonation. More pronounced chemical shifts for Al(IV) to a new lower frequency response were accompanied by increased intensities and narrowing of the resonance as substitution levels in the systems increased. C-S-H with higher initial $\mathrm{Ca} / \mathrm{Si}$ ratios proved to be more resilient to carbonation induced effects, consistent with the behaviour reported in [63], and ${ }^{27} \mathrm{AL} \mathrm{NMR}$ confirmed increasingly greater modifications to the C-A-S-H phase, including removal of $\mathrm{Al}$, for the composite materials compared to the neat system.

The carbonation of the AFm phases has been shown to occur in 2 stages, as indicated by DTA and XRD data. Firstly $\mathrm{CO}_{3}$ displaces $\mathrm{SO}_{4}$ resulting in phase transformation from sulphate to carbonate bearing phases. Following this, $\mathrm{Ca}$ is removed resulting in phase decomposition. Differentiation of the individual AFm phases is not possible [175], so potential phase transformations due to the uptake of $\mathrm{CO}_{3}$ and removal of $\mathrm{SO}_{4}$ for the $60 \%$ slag sample in Figure 6.13 (b) wouldn't be detected. For the remaining systems, compete decomposition due to decalcification is evident but with relatively little effects on the AFt phase.

The mechanism of carbonation of synthetic AFt was studied by Zhou and Glasser [66] who reported the existence of a definite induction period during which decomposition of AFt was minimal. This induction period was related to saturation and dissolution of the phase, effectively raising the $\mathrm{pH}$ of the environment and enhancing the kinetics of the carbonation reaction (more rapid dissolution of $\mathrm{CO}_{2}$ ). Degradation of AFt then occurred, forming gypsum, vaterite, alumina gel and water. Generally, increases in carbonation following the depletion, or inaccessibility, of $\mathrm{CH}$ are discussed in relation to $\mathrm{C}-\mathrm{S}-\mathrm{H}$ only. Here, the same concept can also be applied to the calcium aluminate phases. Highly alkaline pore solution promotes dissociation of carbonic acid $\left(\mathrm{HCO}_{3}{ }^{-}+\mathrm{H}^{+}\right)$and the dissolution of $\mathrm{CH}$ is very fast, thermodynamically having priority over $\mathrm{C}-\mathrm{S}-\mathrm{H}$ [62]. While $\mathrm{Ca}$ is supplied by $\mathrm{CH}$, relatively 
little decalcification of the other phases occurs; potentially minor levels of decalcification of C-S-H and $\mathrm{AFt}$ and phase transformation of $\mathrm{AFm}$ in which $\mathrm{CO}_{3}$ replaces $\mathrm{SO}_{4}$. Once $\mathrm{CH}$ is no longer able to supply $\mathrm{Ca}^{2+}$ ions to solution, and buffer the reaction, $\mathrm{Ca}$ is provided by the remaining phases and levels of carbonation are observed to increase. The ability of portlandite to dissolve in solution prevents significant decomposition of all the Ca bearing hydrate phases, not just C-S-H.

\subsubsection{TEM-EDX}

TEM specimens were initially prepared on surface regions of the carbonated samples. EDX data collected for 72 hour cured 30\% PFA and 30\% GGBS specimens following carbonation for 4 days revealed severe decalcification of the $\mathrm{C}-\mathrm{S}-\mathrm{H}$ where mean $\mathrm{Ca} / \mathrm{Si}$ ratios were determined to be 0.86 (Ip only) and 0.57 respectively. However, the absence of $Q^{3}$ and $Q^{4}$ species in ${ }^{29} \mathrm{Si} N M R$ spectra suggested the presence of a carbonate gradient in which localised regions of carbonated zones existed at sample surfaces and the observed properties changed as a function of depth. This was later confirmed by XRD measurements at increasing distance from the sample surface. Subsequent analysis was performed at regions just below the surface in order to avoid further sampling effects. EDX data collected for the $30 \%$ GGBS 72 hour cured and 60\% GGBS 28 day cured samples exposed to $\mathrm{CO}_{2}$ for 4 and 2 days respectively are displayed in Figure 6.14 and in Table 6.4. The XRD plot shown in Figure 6.15 verified the presence of $\mathrm{CH}$ in the region used to make the $60 \%$ slag sample, confirming decalcification of C-S-H in the presence of portlandite. Bulk techniques might indicate simultaneous carbonation of portlandite and $\mathrm{C}-\mathrm{S}-\mathrm{H}$ but this may not necessarily be a true representation of the reaction kinetics. Here, however, both phases are shown to be involved in the carbonation reaction at the same time. 

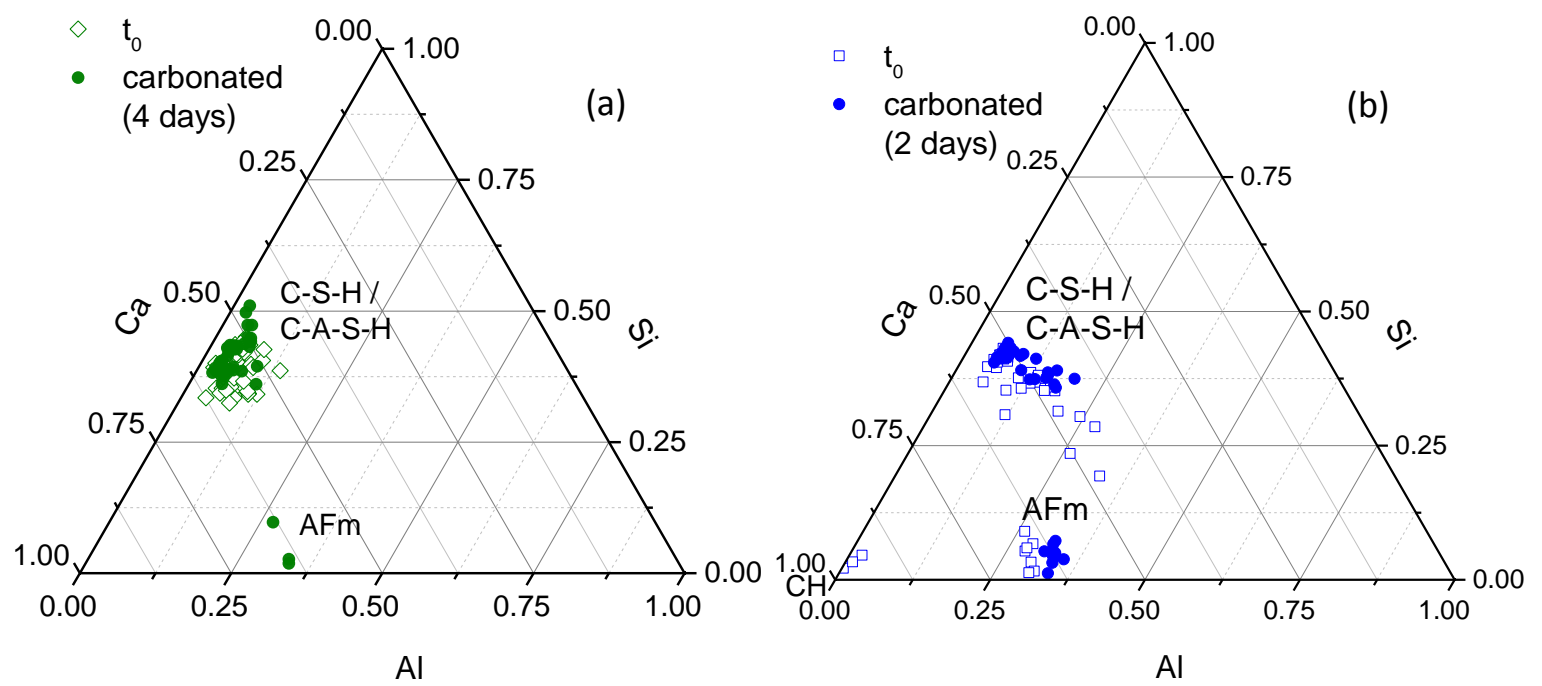

Figure 6.14. Ca-Al-Si ternary diagrams for (a) 30\% GGBS 0.57 (72hr) and (b) 60\% GGBS 0.57 (28d) systems showing EDX data collected for $t_{0}$ and carbonated samples. Values are plotted as atomic percentages normalised to $100 \%$.

Table 6.4. Mean $\mathrm{Ca} / \mathrm{Si}$ and $\mathrm{Al} / \mathrm{Si}$ ratios for selected samples analysed by TEM-EDX

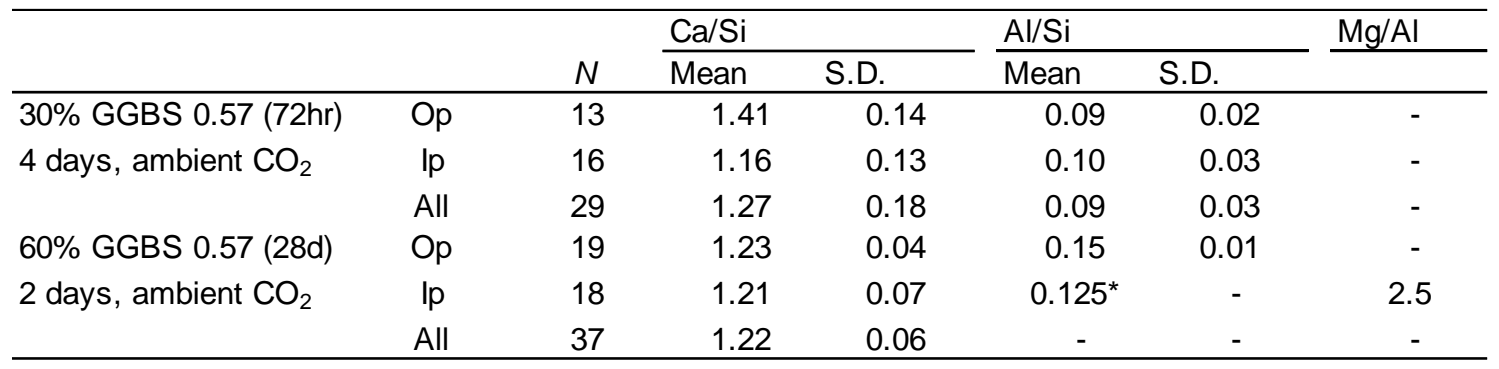

* Determined form regression analysis of $\mathrm{Mg} / \mathrm{Si}-\mathrm{Al} / \mathrm{Si}$ plots at $\mathrm{Mg} / \mathrm{Si}=0$

$\mathrm{Mg} / \mathrm{Al}$ ratio corresponds to $\mathrm{Mg} / \mathrm{Al}$ ratio of hydrotalcite-like phase and was derived from regression analysis of $\mathrm{Mg} / \mathrm{Si}-\mathrm{Al} / \mathrm{Si}$ plots 


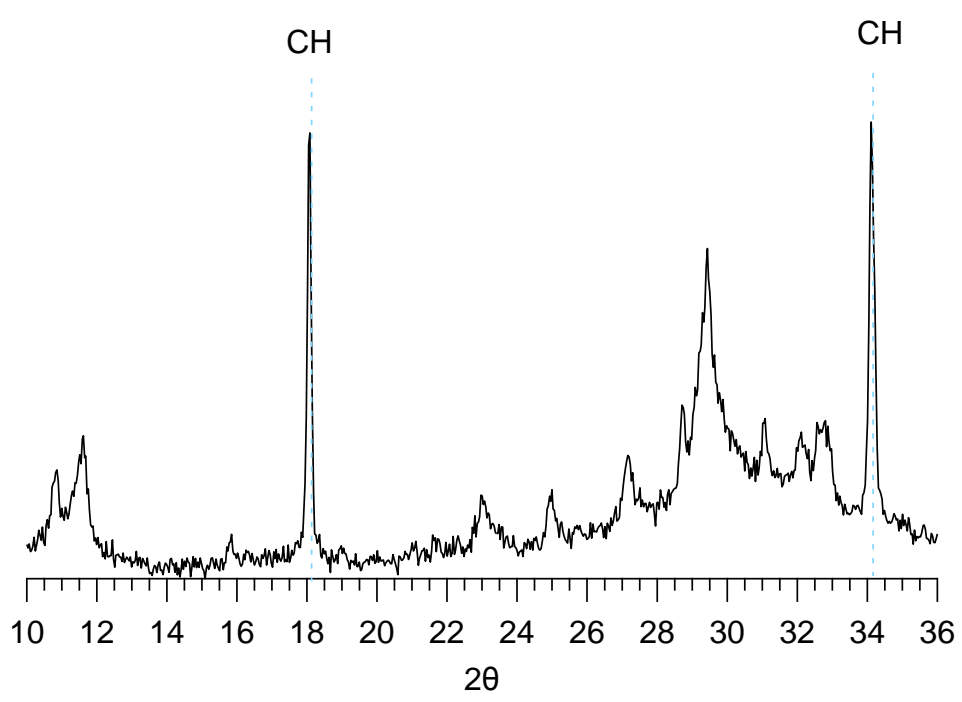

Figure 6.15. XRD scan between $10-36^{\circ} 2 \theta$ just below sample surface showing presence of $\mathrm{CH}$ in region used in TEM-EDX analysis - 60\% GGBS 0.57 (28d) - 2 days, ambient $\left[\mathrm{CO}_{2}\right]$

Lower $\mathrm{Ca} / \mathrm{Si}$ ratios for both Ip and Op regions confirmed decalcification of the C-S-H phase in both systems, as illustrated on the $\mathrm{Ca}-\mathrm{Al}-\mathrm{Si}$ ternary plots, where the analyses corresponding to $\mathrm{C}-\mathrm{S}-\mathrm{H}$ have shifted to slightly lower Ca contents following exposure to $\mathrm{CO}_{2}$. Dealumination of Ip and Op regions was also observed for the $30 \%$ slag system, consistent with ${ }^{27} \mathrm{Al}$ NMR results. This indicated extraction of aluminium from the bridging sites of the silicate chains in the same sample. The $\mathrm{Al} / \mathrm{Si}$ ratio of the Op product C-S-H remained unchanged for the $60 \%$ slag system, while a slight decrease was determined for $\mathrm{Ip}$ regions. $\mathrm{Mg} / \mathrm{Si}-\mathrm{Al} / \mathrm{Si}$ atomic ratio plots displayed in Figure 6.16 revealed no change in the $\mathrm{Mg} / \mathrm{Al}$ ratio of the hydrotalcite-like phase located in slag Ip regions for the $60 \% \mathrm{GGBS}$ system before and after carbonation (Figure 6.16 (b)). Ip analyses collected for the 30\% GGBS sample (Figure 6.16 (a)) suggested the presence of only one phase (C-S-H) in the carbonated material. Interestingly, a similar result was obtained for initial TEM analysis performed on the surface region of the same sample (heavily decalcified surface layer with mean $\mathrm{Ca} / \mathrm{Si}$ ratio 0.57 ) discussed previously. 
Figure 6.16. $\mathrm{Mg} / \mathrm{Si}-\mathrm{Al} / \mathrm{Si}$ atomic ratio plots of TEM-EDX analyses of Ip and $\mathrm{Op} \mathrm{C}-\mathrm{S}-\mathrm{H}$ in carbonated and non-carbonated (a) 30\% GGBS (0.57 - 72he cured) and (b) 60\% GGBS (0.57 - 28d cured) samples 
The production of $\mathrm{CaCO}_{3}$ from phases other than $\mathrm{CH}$ was determined by thermal analysis, TEM-EDX data confirmed $\mathrm{Ca}$ is supplied by the C-S-H phase both in the presence and absence of portlandite. Furthermore, the removal of Ca from the AFm phases is evidenced by the shift in the compositional trend line of the AFm products to a lower Ca content (Figure 6.14 (b)). ATR-FTIR data determined changes in the silicate structure upon the consumption of $\mathrm{CH}$, here, however, decalcification of the $\mathrm{C}-\mathrm{S}-\mathrm{H}$ silicate chains is evident in both systems. The shift in the silicate bands to a higher wavenumber is indicative of lowering of the $\mathrm{Ca} / \mathrm{Si}$ ratio [172] but was only observed for the almost $\mathrm{CH}$ free $30 \%$ slag system. TEM-EDX data determined similar levels of decalcification in both samples, by calculating the change in the $\mathrm{Ca} / \mathrm{Si}$ ratio before and after exposure to $\mathrm{CO}_{2},(5 \%$ for both $\mathrm{Ip}$ and Op regions $-30 \%$ slag, $5 \%$ and $3 \%$ respectively for Ip and Op regions $-60 \%$ slag) however, more significant quantities of $\mathrm{Al}$ were removed in the sample (30\% GGBS) exhausted of $\mathrm{CH}$ (44\% for Op regions in the $30 \%$ slag sample compared to $0 \%$ for the Op regions of the $60 \%$ system). It is possible that changes in the silicate bands of the ATR-FTIR spectra correspond to significant changes in the $\mathrm{C}-\mathrm{S}-\mathrm{H}$ structure which are only permitted to occur when portlandite is no longer available.

The decalcification of $\mathrm{C}-\mathrm{S}-\mathrm{H}$ in ambient $\mathrm{CO}_{2}$ atmospheres $(\sim 0.03 \%)$ is reported to be a relatively slow process. Groves et al. [64] reported a decrease in the $\mathrm{Ca} / \mathrm{Si}$ ratio of a 9 month cured $\mathrm{C}_{3} \mathrm{~S}$ paste $(0.5 \mathrm{~mm}$ disc, w/c $0.5,72.6 \% \mathrm{RH})$ subjected to natural $\mathrm{CO}_{2}$ exposure for 2 months to be 1.02 (carbonation \% - 40\%) compared to 1.7 for a non-carbonated sample. Castellote et al. [72] published similar findings, observing a decrease from 1.87 to 1.23 (carbonation $\%-34 \%$ ) for a 28 day cured Portland cement paste ( $3 \times 9 \mathrm{~mm}$ cylindrical sample, w/c $0.5,30-60 \% \mathrm{RH}$ ) exposed to natural $\mathrm{CO}_{2}$ concentrations for 8 months.

The rate of decalcification is much faster in the systems studied here, where carbonation percentages of up to 5\% were determined following only 2 and 4 days' exposure. Li [168] measured $\mathrm{Ca} / \mathrm{Si}$ ratios in a 25 year old $25 \%$ slag sample at carbonation ages (ambient $\left.\left[\mathrm{CO}_{2}\right]\right)$ of 15 days $(0.5 \mathrm{~mm}$ thick paste samples, $\mathrm{w} / \mathrm{b} 0.40,72.6 \% \mathrm{RH}$ ) to be $1.45-1.55$, where the lowest ratio up to exposure ages of 60 days reached 1.1-1.35. Early age carbonation (15 days) for $75 \%$ and $90 \%$ GGBS systems resulted in $\mathrm{Ca} / \mathrm{Si}$ ratios of $\sim 1.15-1.2$ and $\sim 0.75$ respectively. Removal of Al was observed to occur at a more rapid rate then the removal of $\mathrm{Ca}$, demonstrated by $\mathrm{Al} / \mathrm{Si}$ ratios of zero measured for a $25 \%$ slag sample in which considerable quantities of Ca were still present. The EDX data collected here 
for the $30 \%$ slag system suggested similar behaviour, where the removal of Al had occurred to a greater degree compared to Ca.

Li [168] also discussed changes in the hydrotalcite-like phase due to carbonation, concluding that the hydrotalcite-like phases acted as an aluminium sink where migration of $\mathrm{Al}$ from the $\mathrm{C}-\mathrm{S}-\mathrm{H}$ gel resulted in decreased $\mathrm{Mg} / \mathrm{Al}$ ratios. This is in contrast to the findings here where the $\mathrm{Mg} / \mathrm{Al}$ ratio for the 28 day cured $60 \%$ slag system remained unaffected (Figure 6.16). The absence of data indicating the presence of a solid solution of C-S-H and a hydrotalcite-like phase in the carbonated $30 \%$ GGBS sample could potentially indicate decomposition due to carbonation. Carbonation of hydrotalcite in alkali activated slag systems has been shown to occur [176]. New Mg-carbonates are formed and Al is ejected resulting in broadening and a reduction in the intensity of the octahedral aluminium resonance ( 9ppm) in ${ }^{27} \mathrm{Al}$ NMR spectra.

Carbonation of the microstructure occurred without significant change in the morphology, demonstrated by TEM micrographs in Figures 6.17 and 6.18. For both the 72 hour cured (30\% slag) and 28 day cured (60\% slag) samples at early ages of carbonation the AFm plates remained solid and dense and Ip regions retained the fine scale homogenous morphology observed in the nonexposed materials. Slight coarsening of foil-like Op regions in the 72 hour cured sample was observed (Figure 6.17 (b)) in some areas, but generally the morphology remained unaltered in agreement with previous studies $[71,79,168]$. Microcrystals of calcite were detected to form in Op regions only (Figure 6.17 (d)), producing strong Bragg reflections. Relatively little evidence of carbonation was observed in the 60\% GGBS system (cured for 28 days and exposed for 2 days). Visually, regions of Op C-S-H were generally observed to be free from microcrystalline $\mathrm{CaCO}_{3}$, although some areas produced partially crystalline SAED patterns. Conversely, Figure 6.18 (a) displays a region in which carbonate microcrystals had appeared to form on Op C-SH fibrils, however, SAED patterns collected on these areas produced diffuse rings relating to an amorphous phase. The loss of Ca from Ip C-S-H with no visual change in the microstructure (determined by EDX analysis for both samples) indicated shrinkage of the Ip regions had occurred. Groves et al. [79] proposed this to be the cause of carbonation shrinkage; the $\mathrm{Ca}^{2+}$ cations migrating from Ip to Op regions in order to maintain equilibrium due to a concentration gradient. The absence of microcrystals supports this theory. 

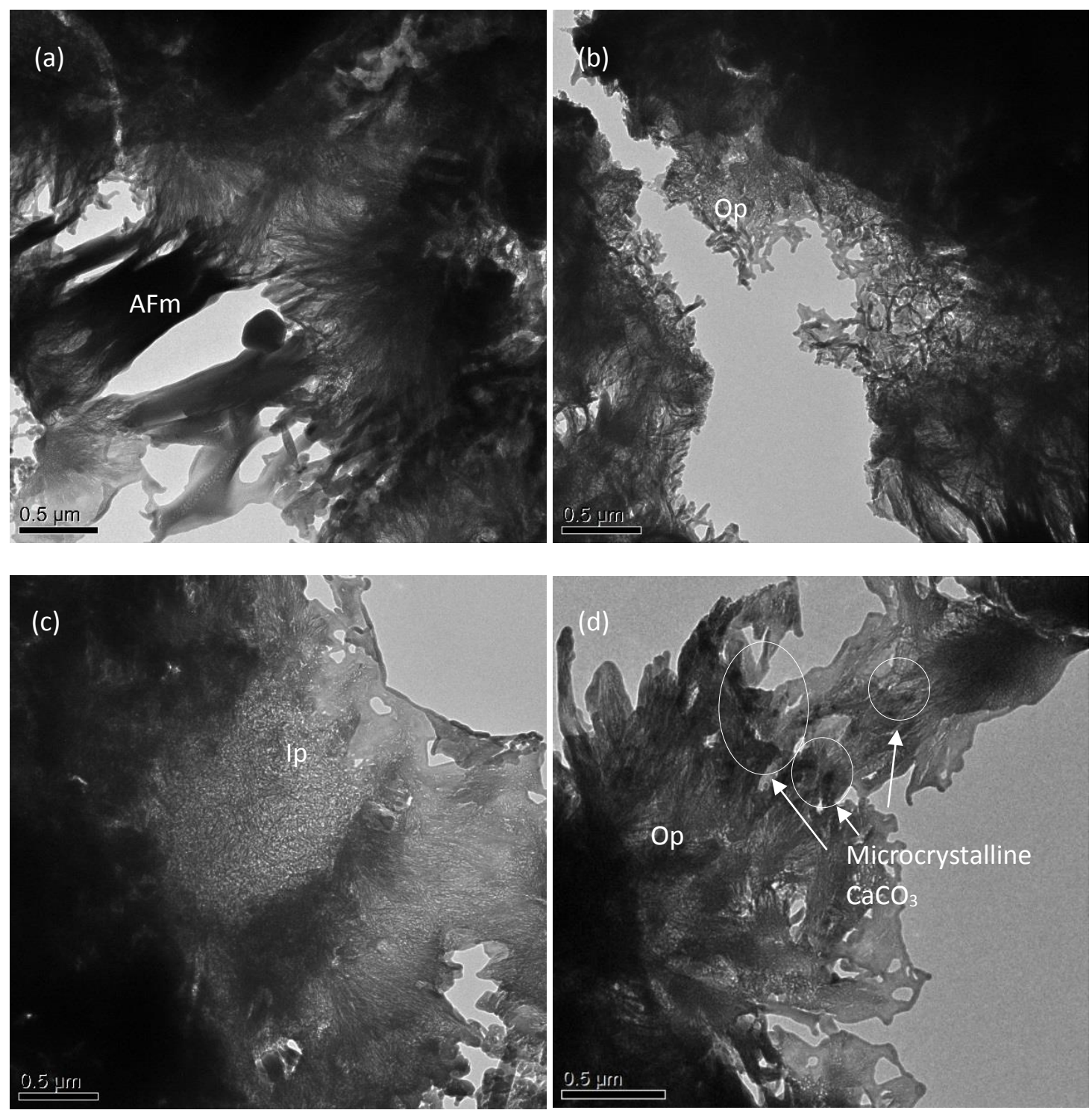

Figure 6.17. TEM micrographs of $30 \%$ GGBS 0.57 (72hr) sample exposed to ambient $\left[\mathrm{CO}_{2}\right]$ for 4 days 

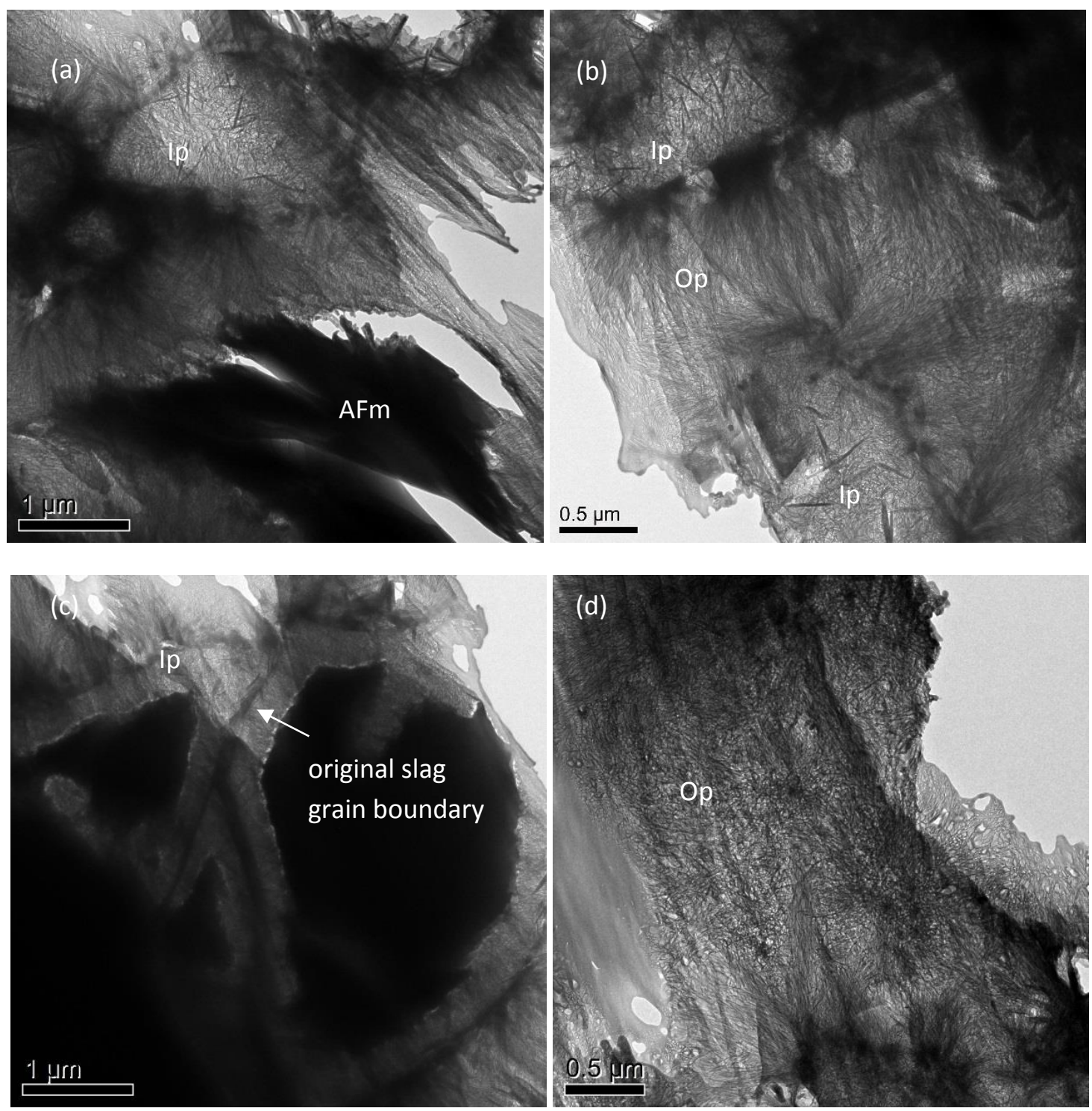

Figure 6.18. TEM micrographs of $60 \%$ GGBS 0.57 (28d) sample exposed to ambient $\left[\mathrm{CO}_{2}\right]$ for 2 days

\subsection{6 ${ }^{29} \mathrm{Si}$ MAS NMR}

The deconvolution result of ${ }^{29} \mathrm{Si}$ NMR spectra are presented in Table 6.5 for the $30 \%$ fly ash and $30 \%$ GGBS systems (72 hour cured) prior to (2 days' exposure) and following (4 days' exposure) large observed increases in carbonation rate, results from the $t_{0}$ samples have been included for comparison. Figure 6.19 displays the fitted spectra for the slag samples, comparing the $t_{0}$ and 4 day carbonated materials. 
(a)

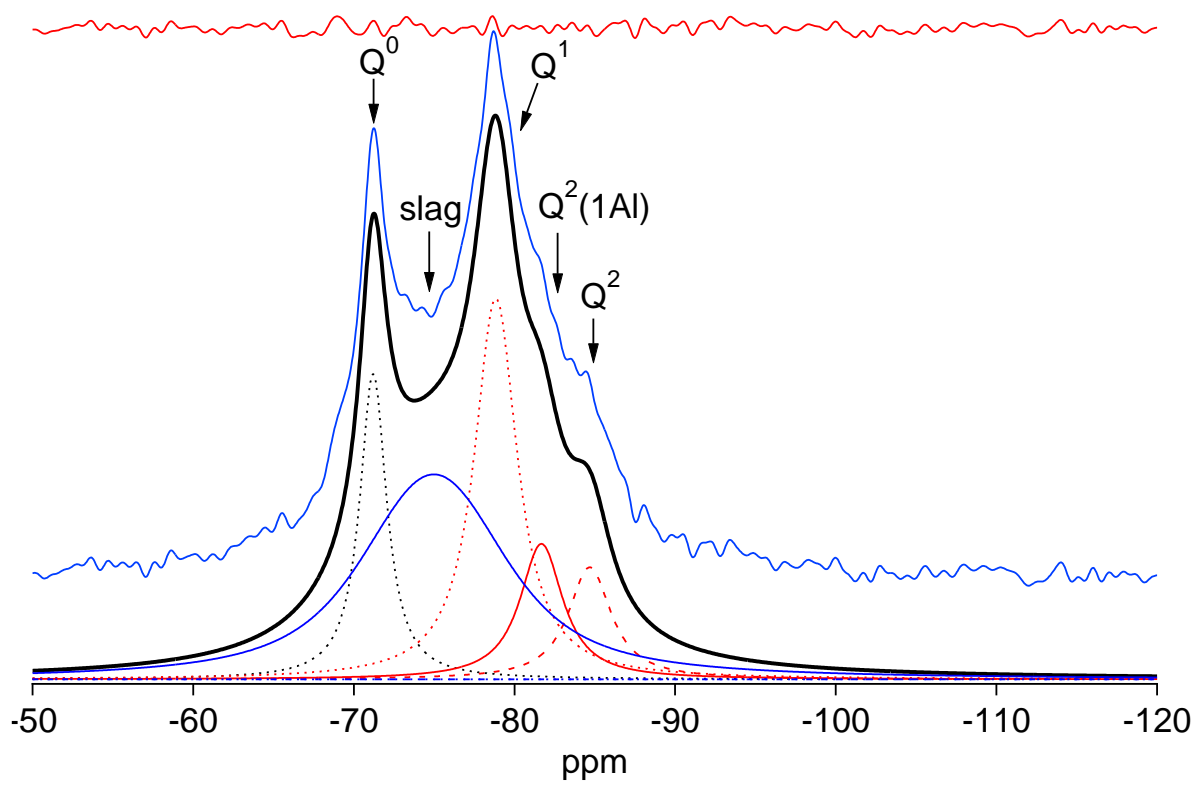

(b)
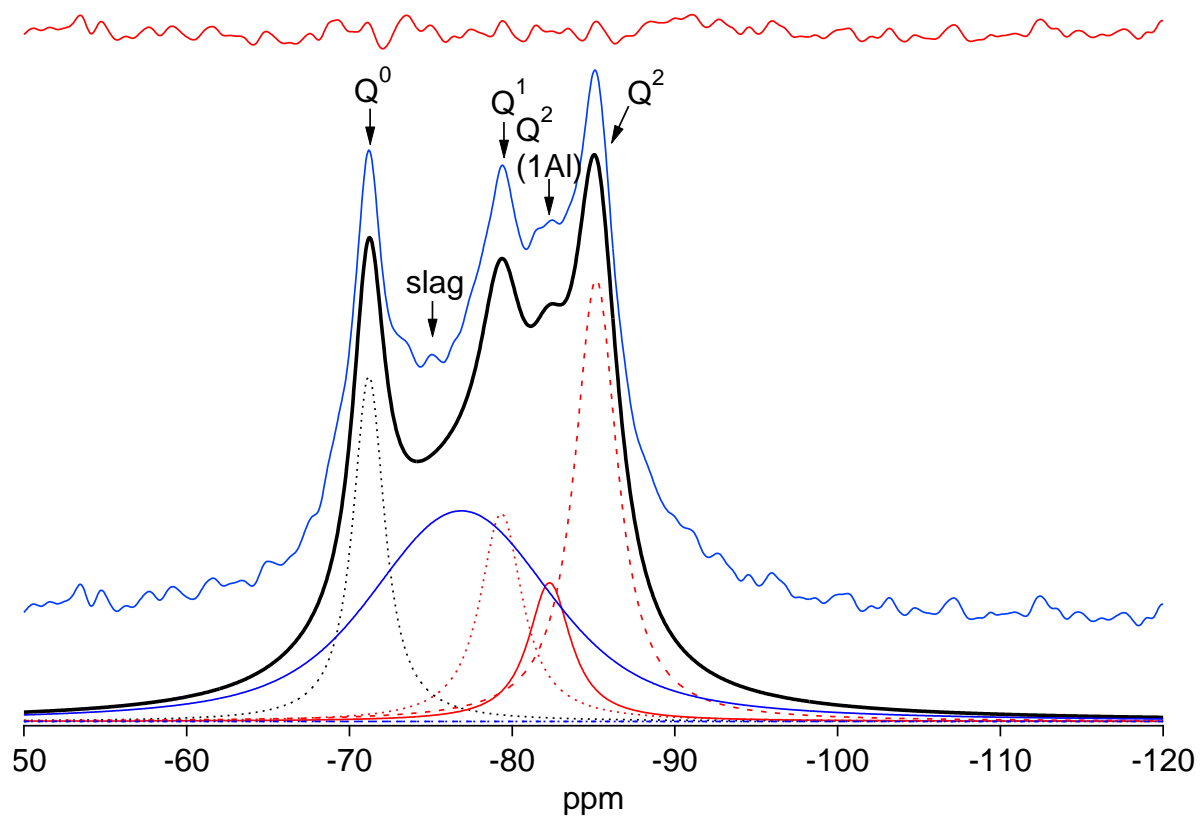

Figure 6.19. Single pulse ${ }^{29}$ Si MAS NMR spectra for $30 \%$ GGBS $0.57-72$ hour cured samples (a) $t_{0}$ and (b) exposed to ambient $\left[\mathrm{CO}_{2}\right]$ for 4 days

Carbonation resulted in the transformation of $Q^{1}$ silicate species to $Q^{2}$ sites, increasing the polymerisation of the silicate chains, evidence by increased mean chain lengths (MCL). Ca is removed from the $\mathrm{C}-\mathrm{S}-\mathrm{H}$ gel and the chains increase in length, consistent with lower $\mathrm{Ca} / \mathrm{Si}$ ratios 
determined by TEM-EDX analysis. In the presence of $\mathrm{CH}$, however, polymerisation of the silicate dimers $\left(Q^{1}\right)$ to silicate chains $\left(Q^{2}\right)$ occurred to a relatively moderate extent. Spectra remained dominated by $Q^{1}$ species and chain lengths increased from 3.6 to 4.2 and from 3.7 to 4.6 for the fly ash and slag systems respectively. At 4 days' exposure, $\mathrm{CH}$ was almost entirely depleted and carbonation has been measured to dramatically increase. This was reflected in the ${ }^{29} \mathrm{Si}$ NMR results where the fractions of silicon present as $Q^{1}$ and $Q^{2}$ species effectively reversed from the nonexposed sample $\left(\mathrm{t}_{0}\right), \mathrm{Q}^{2}$ sites became prevalent, resulting in substantially longer silicate chains (MCL 7.9 and 8.2). This considerable change in the $\mathrm{C}-\mathrm{S}-\mathrm{H}$ structure corresponds to the shift observed in the silicate bands (to a higher wavenumber) in the ATR-FTIR spectra. Similar behaviour was also reported from naturally carbonated (2 months) $\mathrm{C}_{3} \mathrm{~S}$ pastes [64] and for high $\mathrm{Ca} / \mathrm{Si}$ ratio $\mathrm{C}-\mathrm{S}-\mathrm{H}$ samples using Raman spectroscopy [73]. Sevelsted and Skibsted [63] discussed a two-step process for the carbonation of synthetic C-S-H sample in which the gradual decalcification of $\mathrm{C}-\mathrm{S}-\mathrm{H}$ was observed to occur initially, removing $\mathrm{Ca}$ from the interlayer and defect sites until $\mathrm{Ca} / \mathrm{Si}$ ratio 0.67 was reached. The authors observed variations in the carbonation behaviour of the C-S-H specimens, relating a period of increased retention to the decomposition reaction to higher $\mathrm{Ca} / \mathrm{Si}$ ratios. $\mathrm{A}$ period of gradual decalcification of leached samples was also reported by Chen et al. [80] in which accelerated effects only began once $\mathrm{Ca} / \mathrm{Si}$ ratios of 1.2 and lower had been reached. However, this gradual period of shrinkage did not occur for the blended cement (silica fume - white Portland cement) studied, rapidly decalcifying almost immediately, behaviour attributed to the material's low initial $\mathrm{Ca} / \mathrm{Si}$ ratio (1.35) and almost complete absence of portlandite.

These more sizeable changes in the silicate structure resulting from the consumption of portlandite coincide with a shift in the silicate band in ATR-FTIR data and the production of greater quantities of carbonates including a poorly crystalline species, as demonstrated by a notably lower decomposition temperature for $\mathrm{CaCO}_{3}$ in TGA data. Decalcification of the $\mathrm{C}-\mathrm{S}-\mathrm{H}$ was confirmed by TEM-EDX analysis in which Al was also observed to be removed, consistent with changes in ${ }^{27} \mathrm{Al} N \mathrm{NR}$ spectra. 


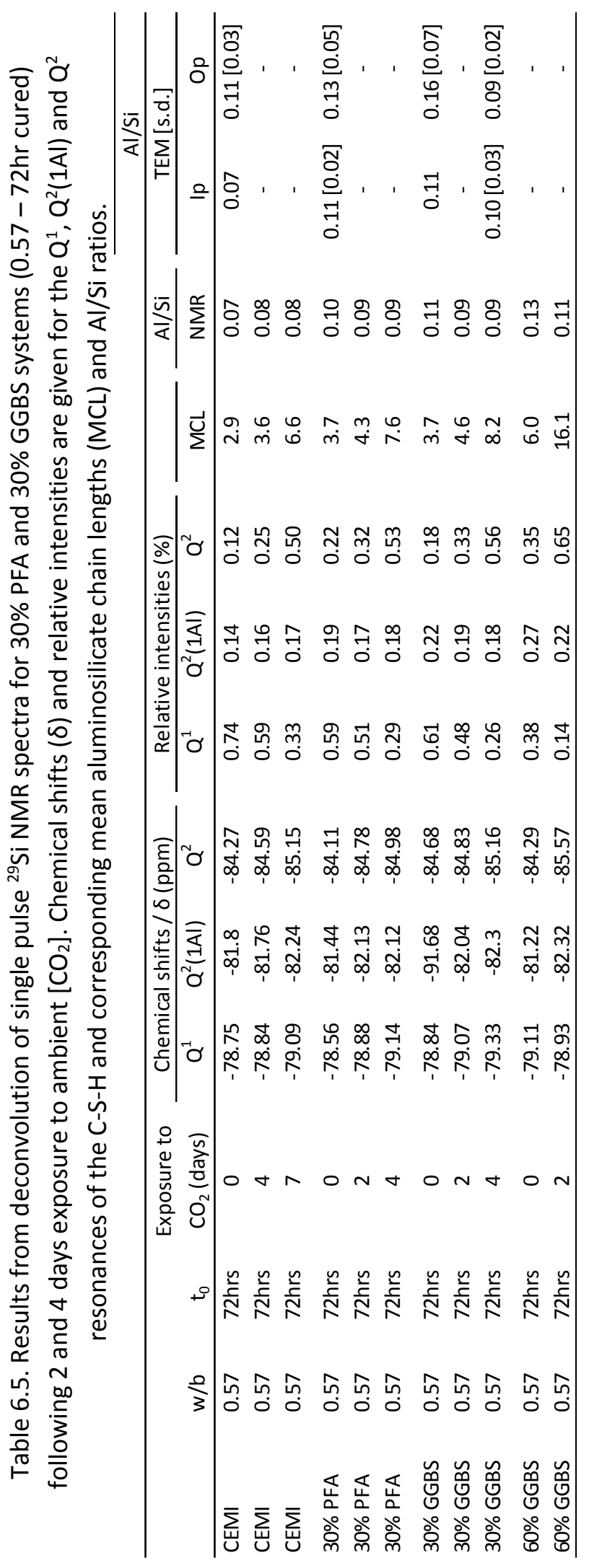




\subsection{Carbonation of systems at $\mathrm{w} / \mathrm{b}$ ratio 0.40}

\subsubsection{Thermal analysis}

Figure 6.20 displays the $\mathrm{CH}$ and $\mathrm{CaCO}_{3}$ contents for both the 72 hour (Figure 6.20 (a)) and 28 day (Figure 6.20 (b)) cured samples with $w / b$ ratios of 0.40 . Table 6.6 presents the consumption of $\mathrm{CH}$ and corresponding production of $\mathrm{CaCO}_{3}$. In all cases carbonation had occurred to a lesser degree that that for the corresponding systems at $\mathrm{w} / \mathrm{b}$ ratio 0.57 . Despite the lower water content resulting in lower initial $\mathrm{CH}$ contents, $\mathrm{CH}$ was still present following exposure for 7 days in the neat and $30 \%$ replacement systems cured for 72 hours. This was in contrast to the complete consumption of portlandite observed for the equivalent samples with $\mathrm{w} / \mathrm{b}$ of 0.57 . However, for the $60 \%$ slag system $\mathrm{CH}$ was almost entirely consumed, indicating poor resistance to carbonation following short curing periods at low $\mathrm{w} / \mathrm{b}$ ratios. TGA plots displayed in Figure 6.21 further established that the loss of buffering capacity led to a substantial increase in carbonate content, accompanied by a significant decrease in carbonate decomposition temperature. In light of the carbonation behaviour of the 0.57 samples previously discussed, the beginning of a more aggressive carbonation mechanism in which more vigorous decalcification (and dealumination of the $\mathrm{C}-\mathrm{S}-\mathrm{H}$ gel) of the remaining Ca bearing hydrate phases is proposed to have begun. Similar differences in the 72 hour and 28 day cured samples existed to those observed at $\mathrm{w} / \mathrm{b}$ ratio 0.57 . Carbonation rate decreased with increasing curing length and increasing initial $\mathrm{CH}$ content.
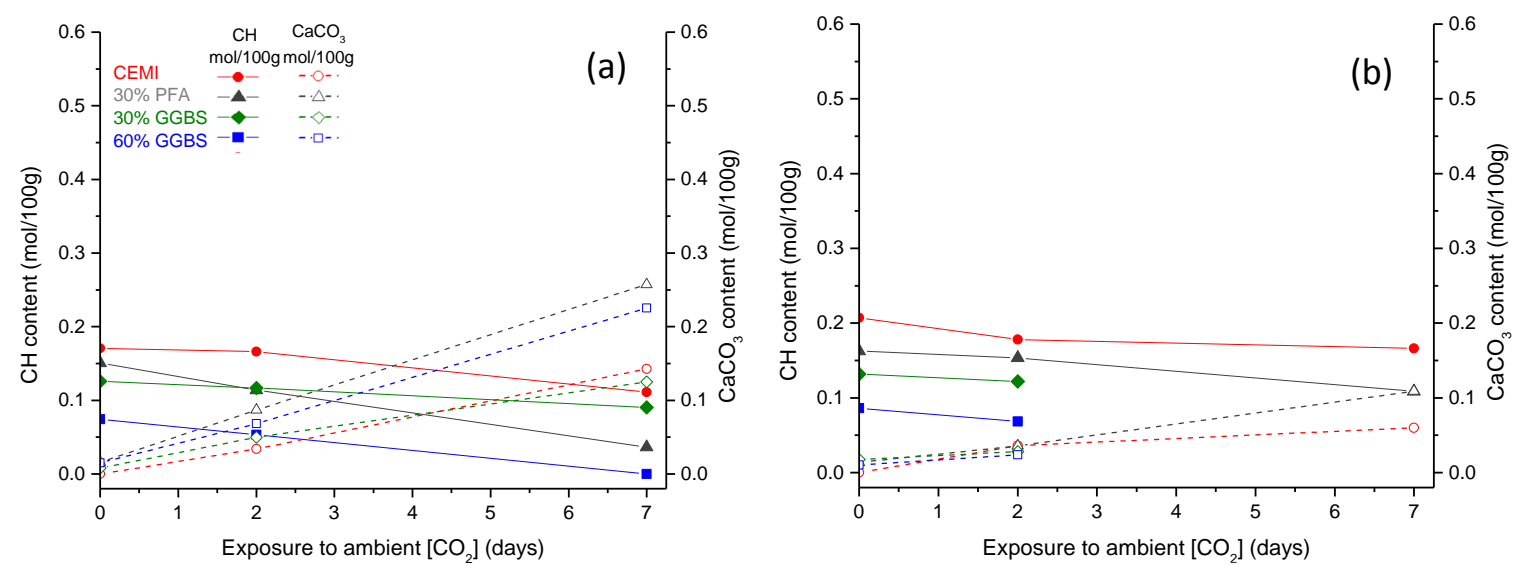

Figure 6.20. $\mathrm{CH}$ and $\mathrm{CaCO}_{3}$ contents determined from TGA data for 72 hour cured (a) and 28 day cured (b) systems following exposure to ambient $\left[\mathrm{CO}_{2}\right]$ for up to 7 days. Values are shown in $\mathrm{mol} / 100 \mathrm{~g}$. 
Table 6.6. Consumption of $\mathrm{CH}$ versus production of $\mathrm{CaCO}_{3}$ calculated from TGA data following 7 days exposure to ambient $\left[\mathrm{CO}_{2}\right]$ for $72 \mathrm{hr}$ and 28 day cured systems. Values are shown in $\mathrm{mol} / 100 \mathrm{~g}$.

\begin{tabular}{|c|c|c|c|c|c|c|c|}
\hline \multicolumn{4}{|l|}{$\mathrm{t}_{0}=72 \mathrm{hrs}$} & \multicolumn{4}{|c|}{$\mathrm{t}_{0}=28$ days } \\
\hline & $\begin{array}{c}\mathrm{CH} \\
\text { consumed } \\
\text { (mol/100g) }\end{array}$ & $\begin{array}{c}\mathrm{CaCO}_{3} \\
\text { produced } \\
(\mathrm{mol} / 100 \mathrm{~g}) \\
\end{array}$ & $\begin{array}{c}\mathrm{CaCO}_{3} \text { produced } \\
\text { from other hydrates } \\
(\mathrm{mol} / 100 \mathrm{~g})\end{array}$ & & $\begin{array}{c}\mathrm{CH} \\
\text { consumed } \\
\text { (mol/100g) }\end{array}$ & $\begin{array}{c}\mathrm{CaCO}_{3} \\
\text { produced } \\
(\mathrm{mol} / 100 \mathrm{~g}) \\
\end{array}$ & $\begin{array}{c}\mathrm{CaCO}_{3} \text { produced } \\
\text { from other hydrates } \\
(\mathrm{mol} / 100 \mathrm{~g})\end{array}$ \\
\hline CEMI & 0.06 & 0.14 & 0.08 & CEMI & 0.04 & 0.06 & 0.02 \\
\hline $30 \%$ PFA & 0.11 & 0.24 & 0.13 & $30 \%$ PFA & 0.05 & 0.10 & 0.04 \\
\hline $30 \%$ GGBS & 0.04 & 0.16 & 0.12 & $30 \%$ GGBS & $0.01^{*}$ & $0.01^{*}$ & $0.00^{*}$ \\
\hline $60 \%$ GGBS & 0.07 & 0.21 & 0.14 & $60 \%$ GGBS & $0.02^{*}$ & $0.02^{*}$ & $0.00^{*}$ \\
\hline
\end{tabular}

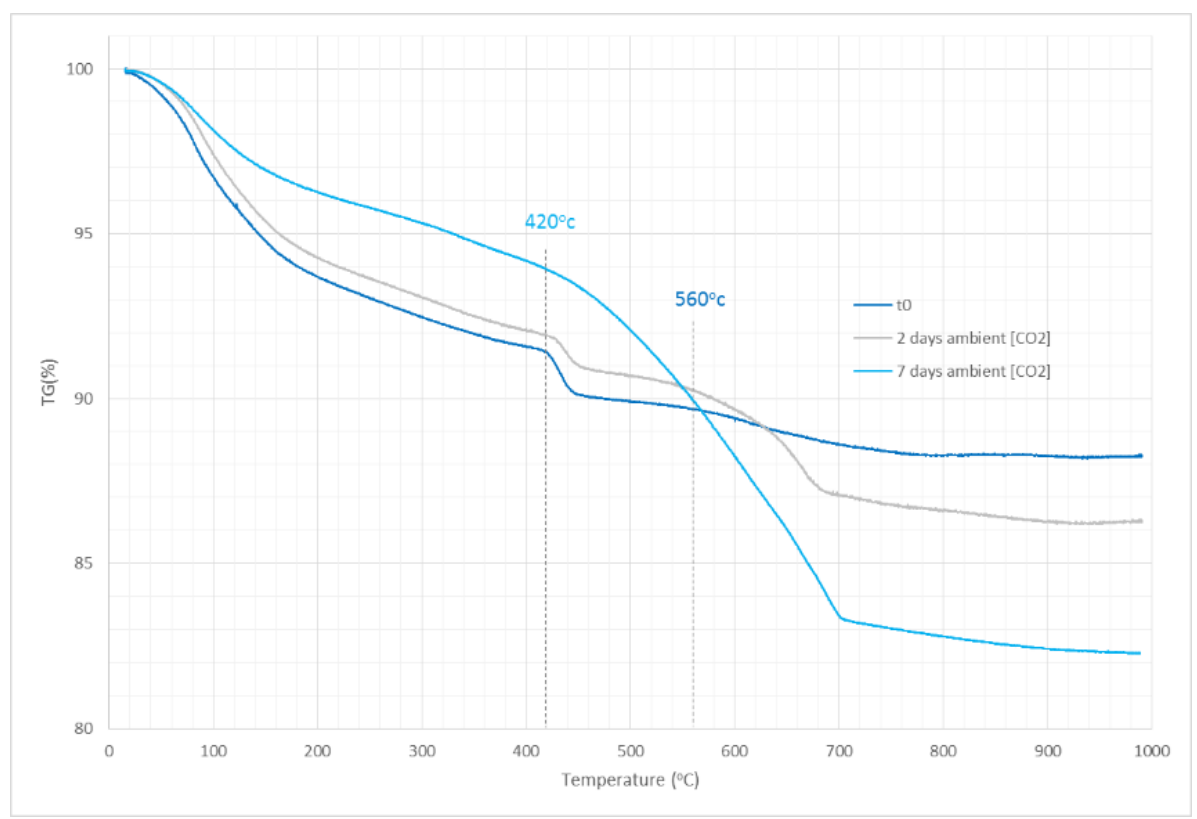

Figure 6.21. TGA plots for $60 \%$ GGBS $0.40-72$ hour cured sample at $t_{0}$ and following 2 and 4 days exposure to ambient $\left[\mathrm{CO}_{2}\right]$

The modifications in the carbonation behaviour observed following short periods of curing at high (0.57) and low (0.40) w/b ratios emphasises the effect of porosity, particularly for composite cement materials. Systems hydrated with higher initial water contents produced greater quantities of $\mathrm{CH}$, effectively increasing their resistance to carbonation induced effects. However, where microstructures are underdeveloped, as expected at early ages for slower reacting SCM materials, 
porosity is expected to be high, allowing $\mathrm{CO}_{2}$ to diffuse readily and resulting in greater levels of reaction. As the $\mathrm{w} / \mathrm{b}$ ratio, and porosity, are reduced diffusion rates are greatly reduced, even here for samples with high volume to surface area ratios, and both the chemical kinetics and the porosity become principal rate determining factors. Kim et al. [177] showed an increase of $150 \%$ in porosity for Portland cement mortars made with $\mathrm{w} / \mathrm{c}$ ratio of 0.60 compared to sample with $\mathrm{w} / \mathrm{c}$ ratio 0.45 . Significantly increased air permeability (192\%) and $\mathrm{Cl}$ diffusion measurements (157\%) were also reported. However, high levels of cement replacement will also result in high levels of porosity as reported by Hill and Sharp [26] for slag cement pastes. This is demonstrated here, where reduced $\mathrm{w} / \mathrm{b}$ ratios were unable to mitigate the effects of high levels of replacement (60\% GGBS) to the same degree as for materials with moderate replacement levels (30\%).

\subsubsection{XRD}

XRD plots for each of the systems following 72 hours' curing at $t_{0}$ and following 7 days exposure to ambient $\mathrm{CO}_{2}$ are shown in Figure 6.22. Relatively minor changes in the hydrate assemblages were observed for the neat and 30\% replacement systems, AFt reflections appeared to remain unchanged and slightly decreased quantities of $\mathrm{CH}$ were evident. As for the 72 hour cured 0.57 systems, AFm reflections were poorly resolved but still present following exposure for 7 days. The $60 \%$ slag system however, showed complete consumption of $\mathrm{CH}$ and a sizeable increase in calcite content. Peak reflections for AFt and AFm phases significantly decreased due to carbonation, with only small amounts still present at 7 days. Calcite was predominant in all the systems, however small reflections for vaterite were also observed for the $60 \%$ GGBS sample. Following 28 days' curing, the CEMI and 30\% PFA sample showed almost no change in the crystalline phase assemblage except for small reflections due to calcite following exposure to $\mathrm{CO}_{2}$. 
(a)

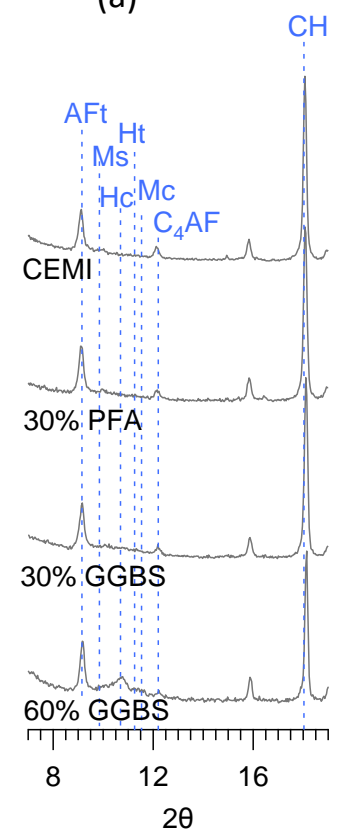

西

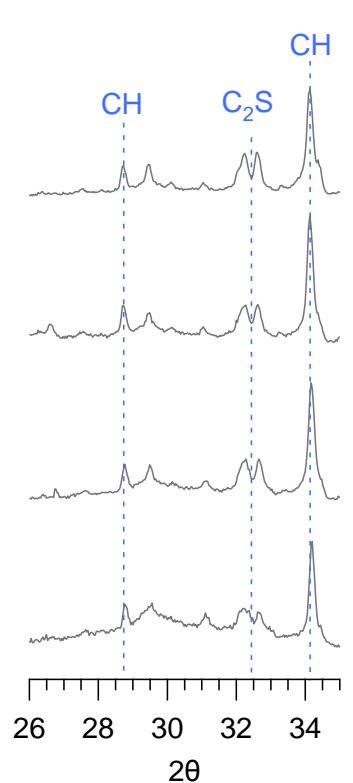

(b)

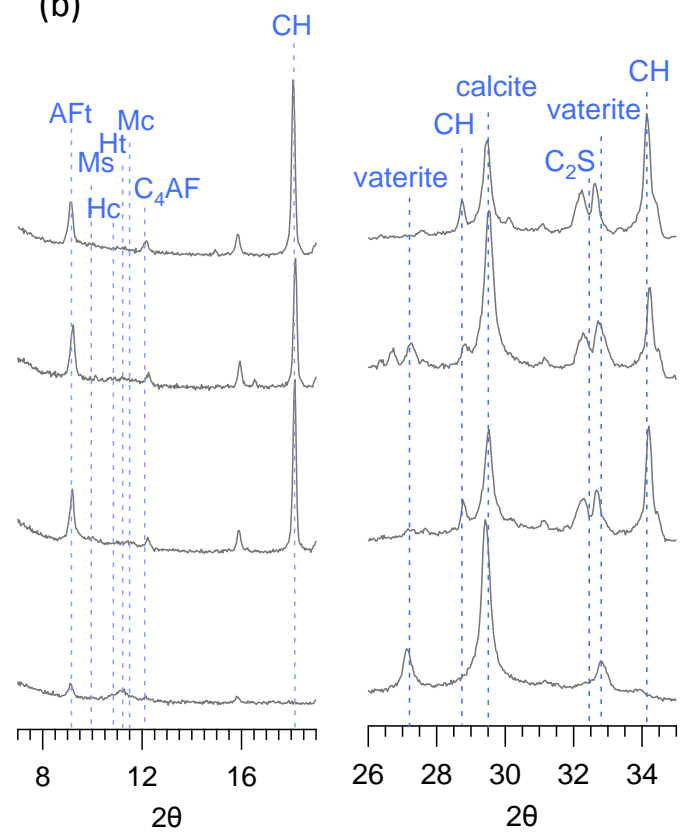

Figure 6.22. XRD patterns between $7-19^{\circ} 2 \theta$ and $26-35^{\circ} 2 \theta$ showing the crystalline phase assemblage of 72 hour cured systems at (a) $t_{0}$ and (b) following 7 days exposure to ambient $\mathrm{CO}_{2}$

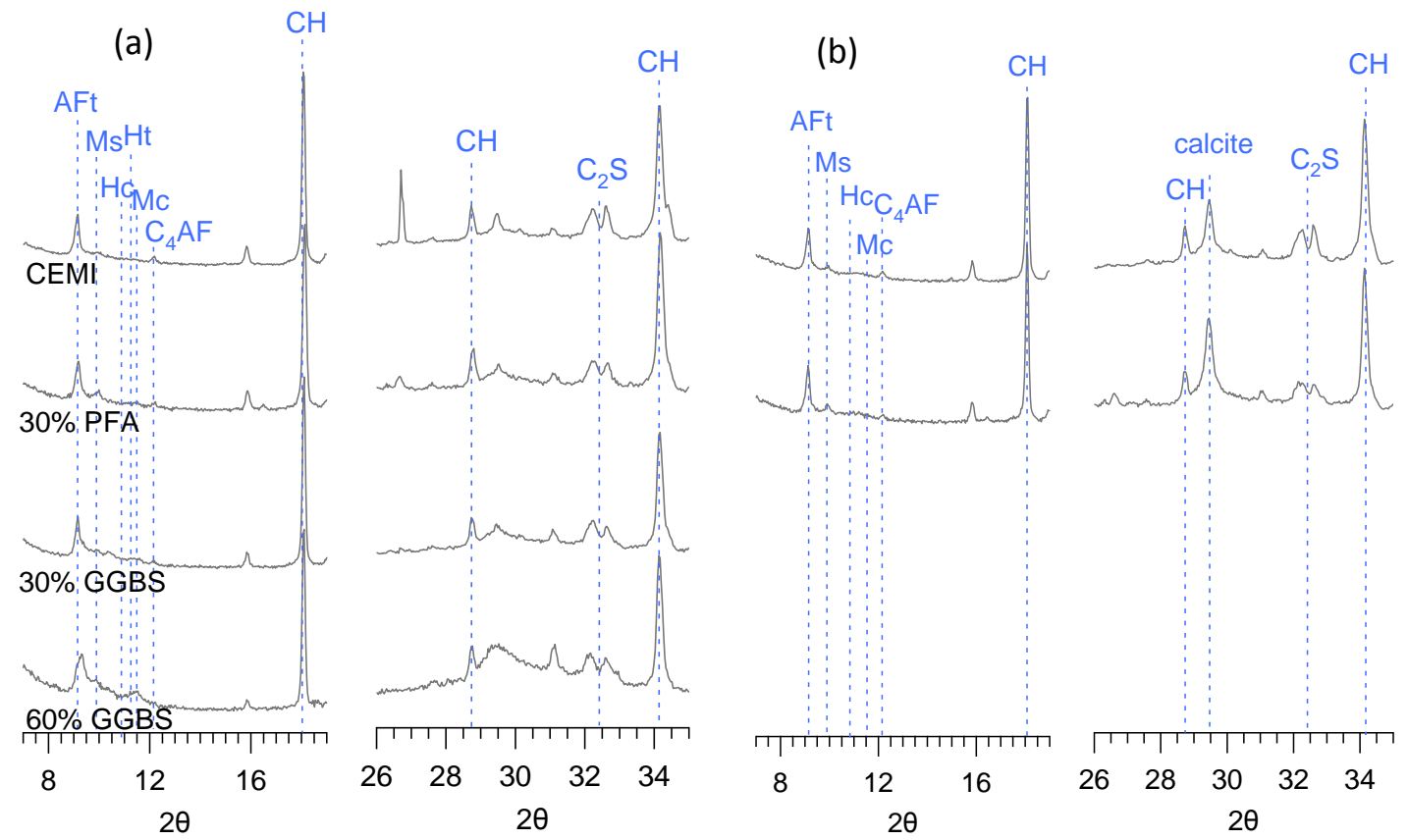

Figure 6.23. XRD patterns between $7-19^{\circ} 2 \theta$ and $26-35^{\circ} 2 \theta$ showing the crystalline phase assemblage of 28 days cured systems at (a) $t_{0}$ and (b) following 7 days exposure to ambient $\mathrm{CO}_{2}$ 


\subsubsection{ATR-FTIR}

ATR-FTIR data was in good agreement with the thermal analysis and XRD data. Decreased quantities of $\mathrm{CH}$ and subsequent increased quantities of carbonate were observed with increasing exposure to $\mathrm{CO}_{2}$. Carbonation of the short cured systems was greater than of the ideally cured samples and increased carbonation levels were observed with increasing replacement level and decreasing initial portlandite content. All the systems showed an initially amorphous carbonate peak shape in the main $\mathrm{CO}_{3}$ stretching band ( $v 31400-1550 \mathrm{~cm}^{-1}$ ), transforming to a more asymmetrical peak shape typical of the polymorph calcite [141] (Figure 6.24).

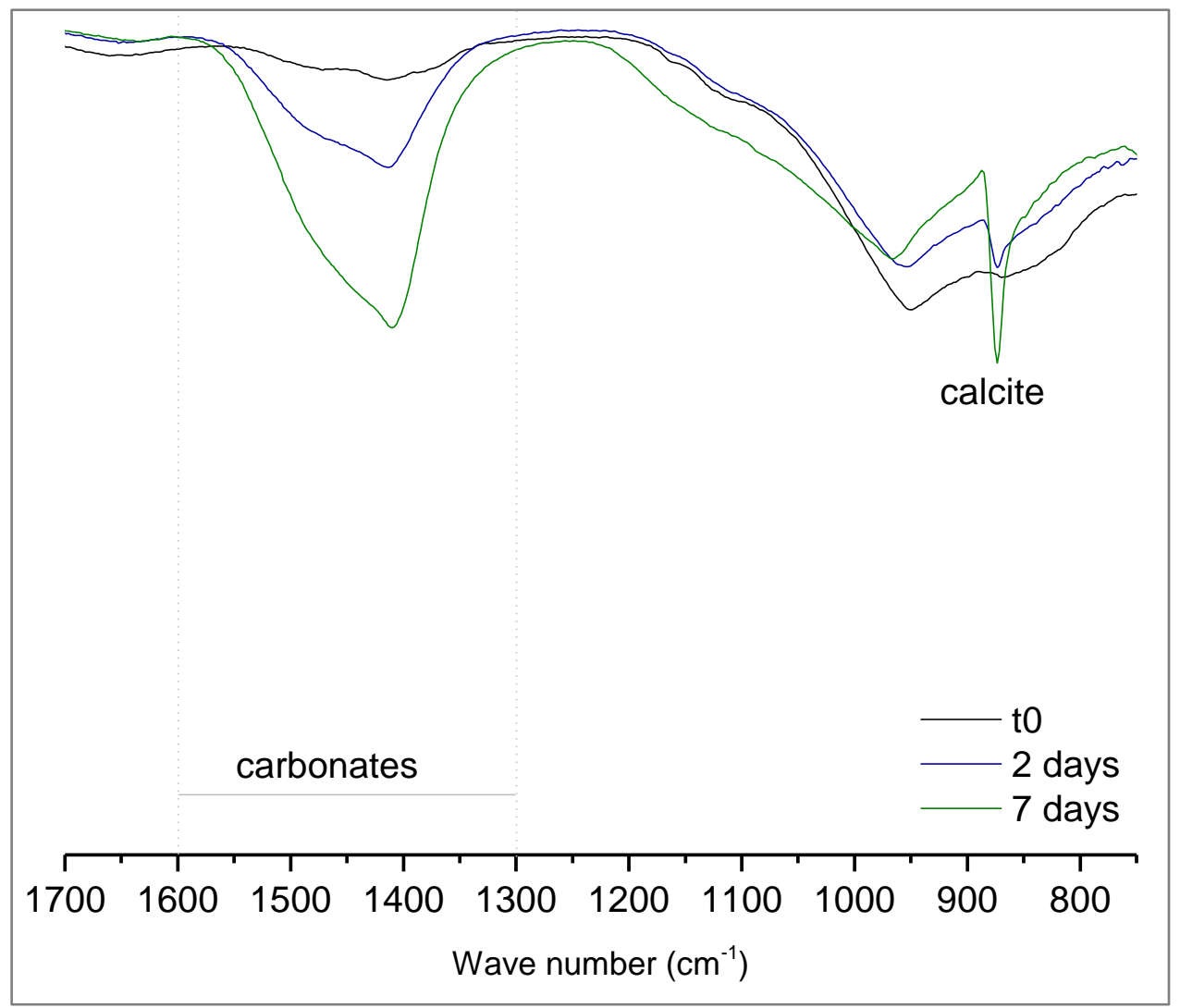

Figure 6.24. ATR-FTIR spectra for $60 \%$ GGBS (72hr) system showing $\mathrm{CaCO}_{3}$ contents (1400$\left.1500 \mathrm{~cm}^{-1}\right)$, AFt band $\left(\sim 1120 \mathrm{~cm}^{-1}\right)$, silicate band $\left(\sim 950-1000 \mathrm{~cm}^{-1}\right)$ and calcite band $\left(\sim 870 \mathrm{~cm}^{-1}\right)$ 
A shift in the silicate band to a higher wavenumber was observed only for the $60 \%$ slag sample cured for 72 hours and exposed to ambient $\mathrm{CO}_{2}$ for 7 days. This shift is related to a significantly increased degree of polymerisation in the silicate chains of the $\mathrm{C}-\mathrm{S}-\mathrm{H}\left(\mathrm{Q}^{2}\right.$ species becoming dominant over $\left.\mathrm{Q}^{1}\right)$ resulting from more severe levels of decalcification (denoted by increased production of $\mathrm{CaCO}_{3}-$ Figure 6.23), as previously established in ${ }^{29} \mathrm{Si} \mathrm{NMR} \mathrm{spectra.} \mathrm{This} \mathrm{sizeable} \mathrm{change} \mathrm{in} \mathrm{the} \mathrm{C-S-H}$ structure occurred following complete consumption of $\mathrm{CH}$ (loss of $\mathrm{CH}$ peak at $3643 \mathrm{~cm}-1$ in Figure 6.25), demonstrating the more vulnerable nature of high replacement systems to carbonation, particularly following short periods of hydration.

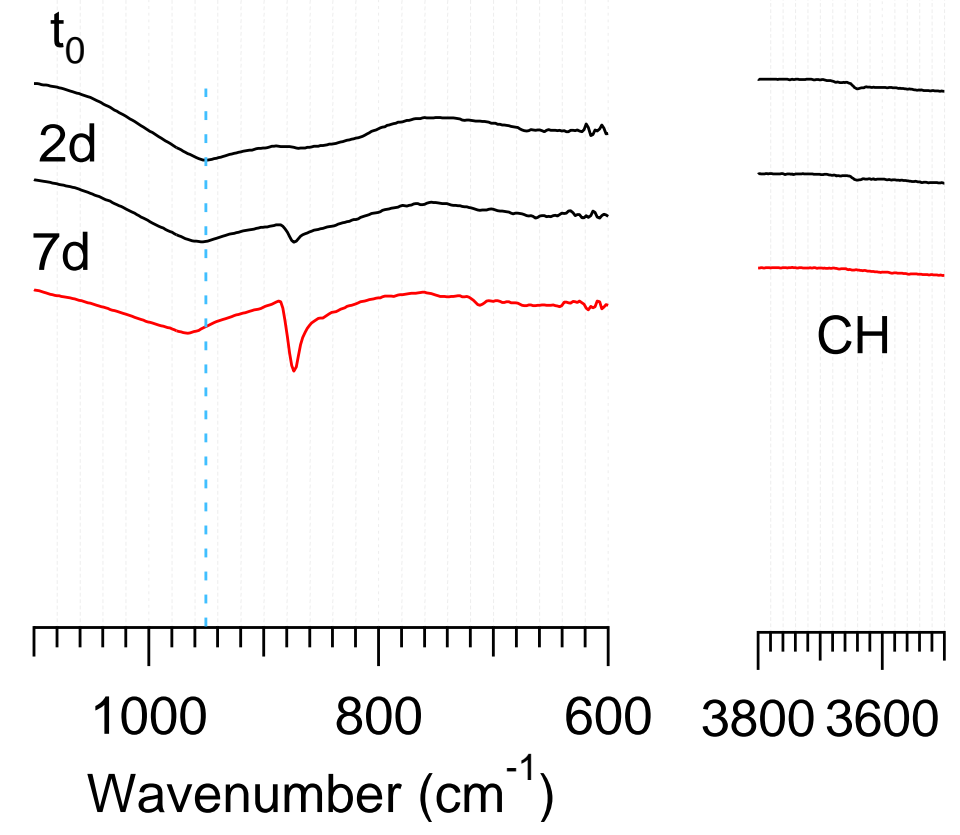

Figure 6.25. ATR-FTIR spectra showing normalised silicate $\left(\sim 950 \mathrm{~cm}^{-1}\right)$ and hydroxide $\left(3643 \mathrm{~cm}^{-1}\right)$ bands for 72 hour cured 60\% GGBS system, upon increasing exposure to ambient $\mathrm{CO}_{2}$

\subsection{Conclusions}

- The early-age carbonation reactions of cement pastes are controlled by both the chemical kinetics and the porosities of the materials. High $w / b$ ratios and short periods of curing resulted in open and underdeveloped microstructures, exacerbated in composite materials and with increasing replacement level, in which $\mathrm{CO}_{2}$ is permitted to diffuse easily. The 
availability of $\mathrm{CH}$ becomes the rate determining factor, and was observed to be completely consumed in all systems during early age exposure to ambient $\mathrm{CO}_{2}$ concentrations. As curing length increased and $\mathrm{w} / \mathrm{b}$ ratio decreased the rate determining factor was shown to be $\mathrm{a}$ combination of the chemical reactions and the porosity of the systems. Low $\mathrm{w} / \mathrm{b}$ ratios mitigated the effects of carbonation following short curing periods for systems with moderate levels of substitution but this was not the case for higher replacement materials.

- Carbonation of all the Ca bearing hydrate phases appeared to occur to some extent in the presence of $\mathrm{CH}$, however this was relatively minor. Once $\mathrm{CH}$ had been consumed, more aggressive decalcification of the other phases was observed to occur.

- TEM-EDX confirmed the removal of both $\mathrm{Ca}$ and Al from C-S-H gel (also observed in ${ }^{27} \mathrm{Al}$ NMR spectra) and ${ }^{29} \mathrm{Si} \mathrm{NMR} \mathrm{showed} \mathrm{significant} \mathrm{increases} \mathrm{in} \mathrm{silicate} \mathrm{polymerisation} \mathrm{due} \mathrm{to}$ decalcification following depletion of portlandite. $\mathrm{CaCO}_{3}$ microcrystals were observed to form in Op regions only, taking the form of calcite or vaterite while the removal of $\mathrm{Ca}$ from Ip regions without any visual change in the microstructure suggested carbonation shrinkage had occurred.

- $\quad{ }^{27} \mathrm{Al}$ NMR, XRD and DTA all showed that carbonation of the AFm phases occurred during early ages of exposure, transforming from monosulfoaluminate to hemi- and monocarboaluminate before complete decalcification. In $\mathrm{CH}$ free systems the decomposition of AFt and the AFm was observed to take place, while in the presence of portlandite the phases appeared to remain present.

- Reduced $\mathrm{w} / \mathrm{b}$ ratios improved the carbonation resistance of all the systems following both short and ideal curing lengths, behaviour attributed to significantly reduced porosity of the materials. However, lower water contents were unable to mitigate the effects of high levels of replacement (60\% GGBS), and subsequently high levels of porosity, to the same degree as for materials with moderate substitution (30\%) following 72 hours hydration. 


\section{Chapter 7}

\section{Later age carbonation behaviour}

Studies in the literature show that, following longer lengths of exposure, accelerated carbonation of properly cured CEMI cement pastes leads to passivation of the portlandite crystals. The isolation of the $\mathrm{CH}$ phase then permits decalcification of $\mathrm{C}-\mathrm{S}-\mathrm{H}$ to proceed more quickly, and the final product of C-S-H decomposition is an amorphous silica gel. This is typically only observed following accelerated carbonation testing, owing to the slow reaction rate at ambient concentrations $(0.03 \%)$ and differences in the rate at which the silicate chains polymerise by natural and accelerated methods (i.e. ambient concentrations appear to allow longer chains to form before cross-linking occurs). In Chapter 6 the short curing of composite cements was shown to allow carbonation to occur to greater extents and in some cases the complete consumption of $\mathrm{CH}$ was observed during early exposure to ambient $\mathrm{CO}_{2}$ concentrations (between 0 - 7 days). This chapter focuses on the effects of carbonation at later lengths of exposure (7-60 days), comparing the capacity of immature and mature blended and CEM I cement systems to resist carbonation induced effects.

\subsection{Carbonation of systems at $\mathrm{w} / \mathrm{b}$ ratio 0.57}

\subsubsection{Thermal analysis}

Figure 7.1 displays the $\mathrm{CH}$ and $\mathrm{CaCO}_{3}$ contents of the systems cured for 72 hours (Figure 7.1 (a)) and 28 days (Figure 7.1 (b)) between exposure ages of 7 and 60 days. Following 72 hours' curing $\mathrm{CH}$ was observed to be entirely consumed during the early age carbonation reactions ( $t_{0}-7$ days), resulting in considerable increases in carbonate content. At later ages of exposure (7-60 days), for the CEM I and 30\% replacement systems, the carbonate content continued to increase, progressively stabilising at later ages of reaction. The rate and quantity of $\mathrm{CaCO}_{3}$ produced was comparable between the three systems, although slightly greater amounts of carbonate were observed for the composite materials, suggesting that the absence of portlandite resulted in equivalently poor performance regardless of the sample. As discussed previously, the much lower carbonate content measured for the $60 \%$ slag system appeared to be related to its limited degree of hydration, with the phases available for carbonation having reacted rapidly at early age. At later exposure lengths, 
the remaining systems also gradually reached, or began to reach, a plateau, potentially corresponding to the maximum $\mathrm{CO}_{2}$ binding capacity of the systems.
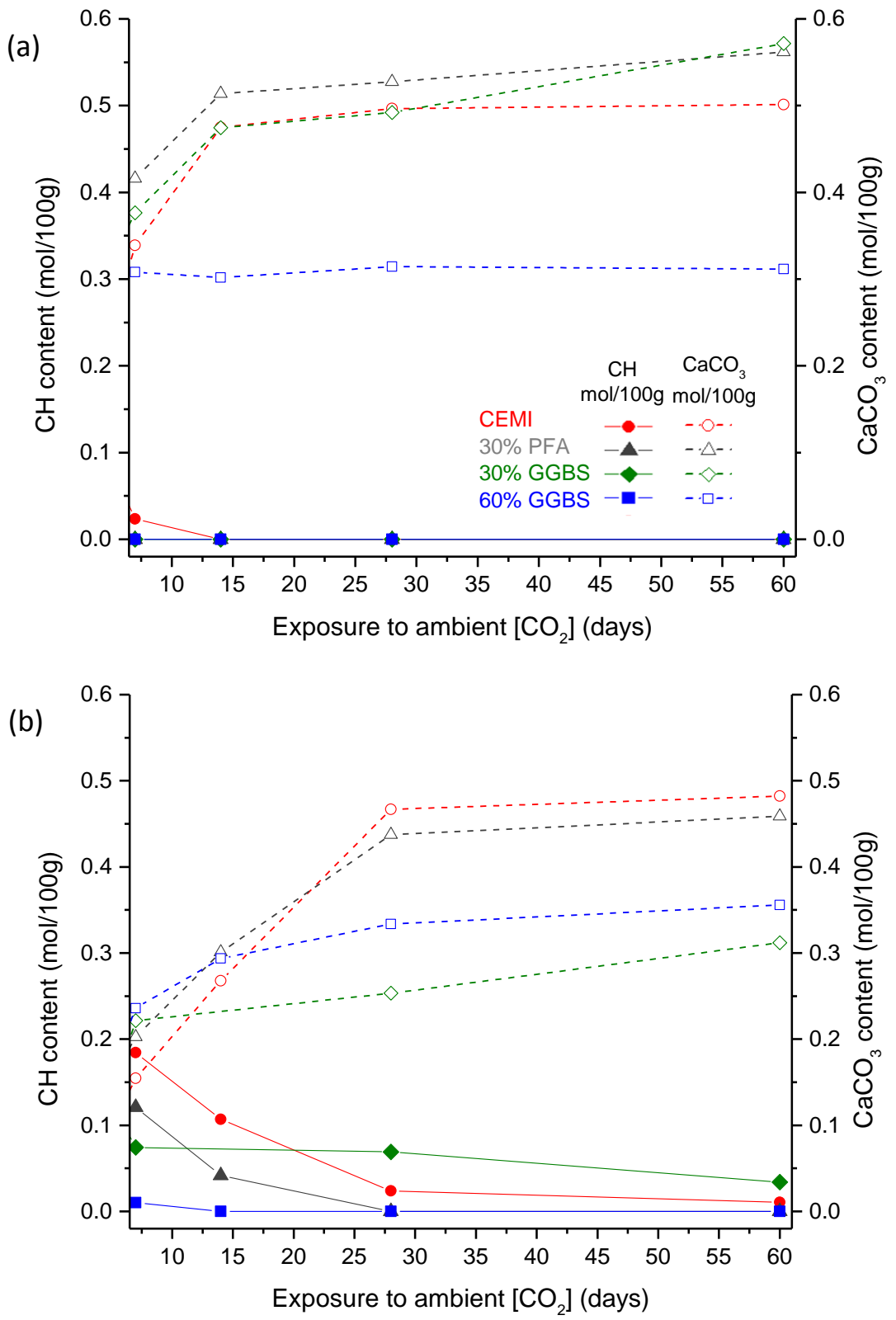

Figure 7.1. $\mathrm{CH}$ and $\mathrm{CaCO}_{3}$ contents determined from TGA data for 72 hour cured (a) and 28 day cured (b) systems following exposure to ambient $\left[\mathrm{CO}_{2}\right]$ between 7 and 60 days. Values are shown in $\mathrm{mol} / 100 \mathrm{~g}$. 
The carbonation resistance of neat Portland cement systems is considered to be higher than that of blended materials due to its ability to bind greater quantities of $\mathrm{CO}_{2} . \mathrm{As} \mathrm{CO}_{2}$ permeates through the microstructure, it reacts with $\mathrm{Ca}$ in the hydrate phases. The higher the $\mathrm{CaO}$ content for a given volume of paste, the greater the quantity of $\mathrm{CO}_{2}$ can be bound per volume of material, effectively slowing the rate at which the carbonation front can advance [178]. As Portland cement is partially replaced by SCMs with significantly lower $\mathrm{CaO}$ contents and slower rates of reaction, the $\mathrm{CO}_{2}$ binding

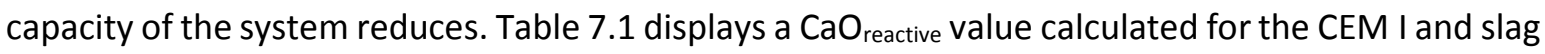
containing systems studied here. The CaO contents measured by XRF for the CEM I 52.5R and the GGBS were multiplied by their corresponding degrees of hydration, as measured by SEM-IA (following either 72 hours' or 28 days' curing) and given as a function of their \% weight $/ 100 \mathrm{~g}$ of

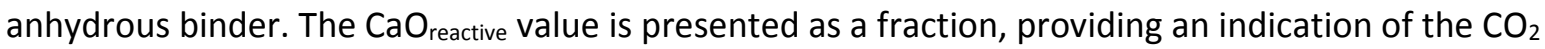
binding capacity for a given system following a given period of hydration. As expected, the CEM I had the highest binding capacity and the value decreased with increasing replacement level. Concerning the short cured samples ( $72 \mathrm{hr}$ ), the value for the $30 \%$ GGBS material was $~ 15 \%$ lower than the CEMI system, and it can also be assumed that the $\mathrm{CaO}_{\text {reactive }}$ value for the $30 \%$ fly ash system would be lower than that calculated for the equivalent slag blend due to its lower reactivity (as previously observed) and extremely low $\mathrm{CaO}$ content $(0.06 \%)$. The total carbonate content measured at 60 days' exposure, however, contradicted the indicated binding capacity values where greater $\mathrm{CaCO}_{3}$ contents were observed for both the 30\% PFA and 30\% GGBS systems compared with the CEM I sample.

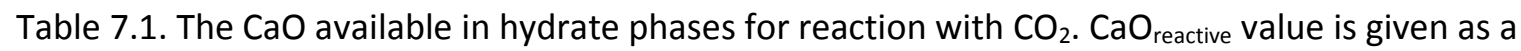
fraction relating to $/ 100 \mathrm{~g}$ anhydrous binder.

\begin{tabular}{|c|c|c|c|c|c|c|c|}
\hline & \multicolumn{2}{|c|}{ CEM 52.5R } & \multicolumn{4}{|c|}{ GGBS } & \multirow[b]{2}{*}{$\mathrm{CaO}$ reactive. $0.57 .72 \mathrm{hr}$} \\
\hline & $\mathrm{CaO}$ & $\mathrm{DoH}_{0.57 .72 \mathrm{hr}}(\%)$ & $\%$ in binder & $\mathrm{CaO}(\%)$ & $\mathrm{DoH}_{0.57 .72 \mathrm{hr}}(\%)$ & $\%$ in binder & \\
\hline CEMI & 63.4 & 75 & 100 & 43.32 & - & 0 & 0.48 \\
\hline $30 \%$ GGBS & 63.4 & 80 & 72 & 43.32 & 40 & 28 & 0.41 \\
\hline \multirow[t]{3}{*}{$60 \%$ GGBS } & 63.4 & 80 & 42 & 43.32 & 32 & 58 & 0.29 \\
\hline & \multicolumn{2}{|c|}{ CEM 52.5R } & & \multicolumn{2}{|c|}{ GGBS } & & \\
\hline & $\mathrm{CaO}$ & $\mathrm{DoH}_{0.57 .28 \mathrm{~d}}(\%)$ & $\%$ in binder & $\mathrm{CaO}(\%)$ & $\mathrm{DoH}_{0.57 .28 \mathrm{~d}}(\%)$ & $\%$ in binder & $\mathrm{CaO}$ reactive.0.57.28d \\
\hline CEMI & 63.4 & 88 & 100 & 43.32 & - & 0 & 0.56 \\
\hline $30 \%$ GGBS & 63.4 & 90 & 72 & 43.32 & 55 & 28 & 0.48 \\
\hline $60 \%$ GGBS & 63.4 & 91 & 42 & 43.32 & 42 & 58 & 0.35 \\
\hline
\end{tabular}


The $\mathrm{CH}$ and $\mathrm{CaCO}_{3}$ contents for the equivalent systems cured for 28 days are displayed in Figure 7.1 (b). During early ages of exposure ( $t_{0}-7$ days) the carbonation resistance of the systems, indicated by total carbonate content, appeared to be related to the replacement level, and therefore $\mathrm{CO}_{2}$ binding capacity. The CEM I performed the best and performance decreased with increasing percentage substitution. However, following prolonged exposure this was no longer the case. Portlandite was almost entirely consumed at 7 days for the $60 \%$ slag sample and the carbonate content was observed to increase as the reaction of the other hydrate phases became more extensive (Table 7.1). The reaction progressively stabilised at later ages, again related to the lower degree of reaction of the system and therefore its lower $\mathrm{CO}_{2}$ binding ability $\left(\mathrm{CaO}_{\text {reactive }}\right.$ value as shown in Table 7.1). Depletion of $\mathrm{CH}$ occurred between 14 and 28 days for the 30\% PFA system while a small amount remained in both the CEM I and 30\% slag samples at carbonation ages of 60 days. In the fly ash sample, the large increase in carbonate content corresponded to the consumption of portlandite, resulting in increased production of $\mathrm{CaCO}_{3}$ from the other hydrate phases (Table 7.2) where a decrease in the carbonate decomposition temperature indicated decalcification of C-S-H (as previously discussed in Chapter 6). Similar behaviour was evident for the CEM I system, in which the carbonate content was measured to be the greatest, however a small quantity of $\mathrm{CH}$ was measured up to the full length of exposure tested (60 days), suggesting the residual amount had become inaccessible.

Table 7.2. Consumption of $\mathrm{CH}$ versus production of $\mathrm{CaCO}_{3}$ calculated from TGA data between 7 and 60 days exposure to ambient $\left[\mathrm{CO}_{2}\right]$ for 28 day cured systems. Values are shown in mol/100g.

\begin{tabular}{lccc}
\hline & $\begin{array}{c}\mathrm{CH} \\
\text { consumed } \\
(\mathrm{mol} / 100 \mathrm{~g})\end{array}$ & $\begin{array}{c}\mathrm{CaCO} 3 \\
\text { produced } \\
(\mathrm{mol} / 100 \mathrm{~g})\end{array}$ & $\begin{array}{c}\mathrm{CaCO} \text { produced } \\
\text { from other hydrates } \\
(\mathrm{mol} / 100 \mathrm{~g})\end{array}$ \\
\hline CEMI & 0.18 & 0.33 & 0.15 \\
30\% PFA & 0.12 & 0.26 & 0.14 \\
30\% GGBS & 0.04 & 0.09 & 0.05 \\
60\% GGBS & 0.01 & 0.12 & 0.11 \\
\hline
\end{tabular}

Thiery et al. [61] related the almost complete disappearance of C-S-H gel in the presence of residual $\mathrm{CH}$ to passivation of the portlandite crystals. Microcrystalline $\mathrm{CaCO}_{3}$ forms a coating around the $\mathrm{CH}$ crystals, inhibiting further dissolution and preventing continued buffering of the pore solution. The much larger reactive surface of $\mathrm{C}-\mathrm{S}-\mathrm{H}$ makes it far less susceptible to the formation of an 
impermeable layer, resulting in its continued, and increased, reaction. Groves et al. [64] reported similar behaviour and experimentally observed the formation of $\mathrm{CaCO}_{3}$ layer on portlandite crystal surfaces in carbonated $C_{3} S$ pastes by TEM microanalysis. In both studies [61, 64], however, the results corresponded to accelerated carbonation testing, and Thiery et al. [61] concluded that the observed mechanism might be a feature of accelerated testing procedures in which ion mobility is reduced (due to pre-treatment by oven drying) and enhanced reaction rates ( $\mathrm{Ca}^{2+}$ ions in pore solution unable to migrate very far before reaction with $\mathrm{CO}_{3}{ }^{2-}$ ) potentially result in precipitation of $\mathrm{CaCO}_{3}$ at $\mathrm{CH}$ crystal surfaces.

The results presented here indicated that following short curing lengths (at $w / b \quad 0.57$ ) it was the complete consumption of $\mathrm{CH}$ that allowed carbonation rates to increase, decalcification of the remaining hydrate phases then occurred more extensively. Following longer periods of curing, the same mechanism of portlandite depletion was observed for the blended materials (30\% PFA \& 60\% GGBS). For the CEM I samples however, increased carbonation of the remaining phases was a result of residual $\mathrm{CH}$ being coated in carbonate crystals, so no longer accessible.

At 60 days' exposure, the total $\mathrm{CaCO}_{3}$ produced for the $\mathrm{CEM} \mathrm{I} \mathrm{and} \mathrm{fly} \mathrm{ash} \mathrm{systems} \mathrm{exceeded} \mathrm{that}$ corresponding to the complete reaction of $\mathrm{CH}$ by approximately $50 \%$ (Table 7.2), agreeing well with other studies employing natural carbonation testing $[72,179]$.

For the 72 hour cured samples at $\mathrm{w} / \mathrm{b}$ ratio 0.57 , the rate determining factor for carbonation was established to be almost solely related to the chemical kinetics of the reactions. The carbonation resistance of the systems was determined to decrease with increasing level of replacement, and therefore decreasing initial $\mathrm{CH}$ content. As curing time increased to 28 days, $\mathrm{CH}$ was observed to remain in the systems for much longer, however the $30 \%$ slag sample showed the greatest resistance to carbonation, producing the lowest carbonate content and retaining a small quantity of $\mathrm{CH}$. The consumption of $\mathrm{CH}$ and corresponding production of $\mathrm{CaCO}_{3}$ was substantially lower compared to the CEM I and the equivalent fly ash samples (Table 7.2) and furthermore, the temperature at which thermal decomposition of carbonate species began remained above $500^{\circ} \mathrm{C}$ (Figure 7.2). While a more severe degree of carbonation had been observed for the remaining systems $\left(\mathrm{CaCO}_{3}\right.$ decomposed from below $500^{\circ} \mathrm{C}$ - Figure 7.2$)$, the $30 \%$ slag sample exhibited moderate carbonation, regulated by the availability of portlandite. 


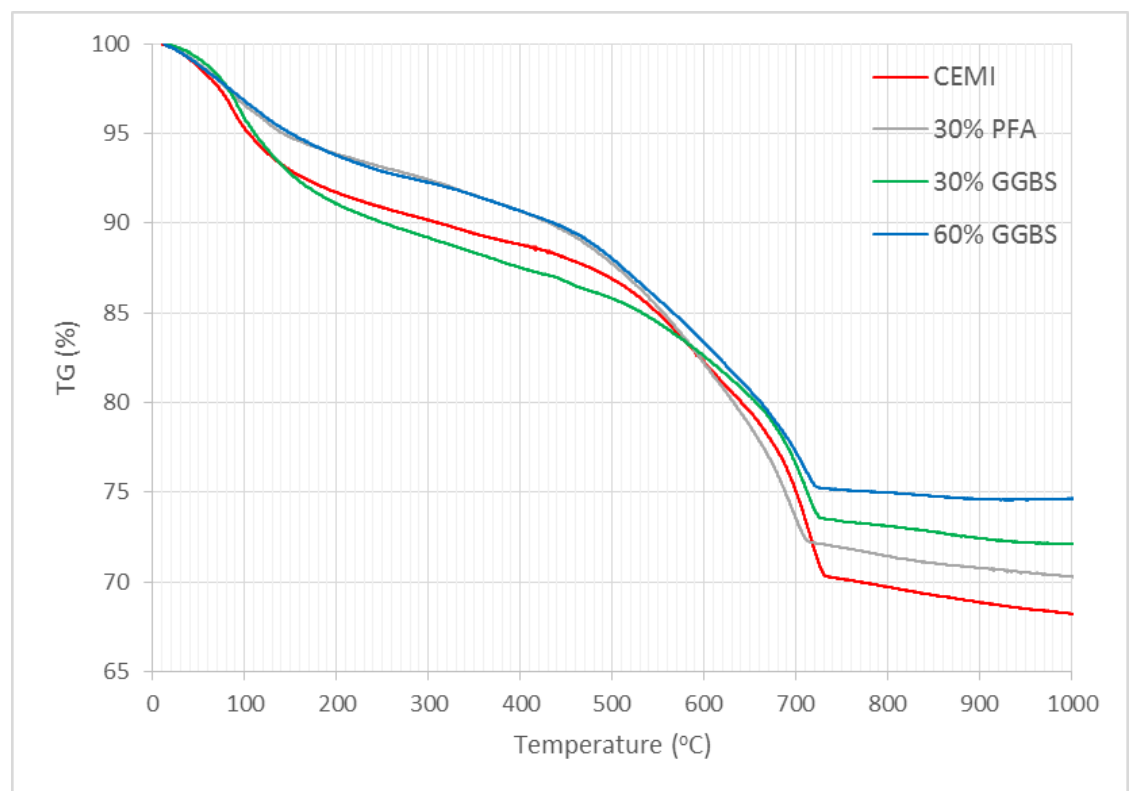

Figure 7.2. TG plots for the 28 day cured systems following exposure to ambient $\left[\mathrm{CO}_{2}\right]$ for 60 days

Although the binding capacity of the CEM I system was indicated to be the highest $\left(\mathrm{CaO}_{\text {reactive }}\right.$ values - Table 7.1), the improved resistance observed for the $30 \%$ slag blend was related to enhancement of the microstructure which is expected to result in a finer pore structure and lower total porosity. Shi et al. [167] studied the carbonation of neat Portland cement, metakaolin- and limestonecontaining mortars, reporting a higher $\mathrm{CO}_{2}$ binding capacity but lower carbonation resistance for the limestone cement compared to the metakaolin blend. This behaviour was related to MIP measurements which showed a lower intruded porosity and refined pore structure for the metakaolin-containing material, which was conducive to capillary condensation at middle-ranging $\mathrm{RH}$ levels, subsequently delaying the carbonation reaction. In slag cements, as the slag reacts and the $\mathrm{Ca} / \mathrm{Si}$ ratio decreases, foil-like morphology progressively replaces the $\mathrm{C}-\mathrm{S}-\mathrm{H}$, filling space with a more finely distributed porosity that reduces the interconnectivity of the microstructure $[36,41]$.

Berodier and Scrivener [145] investigated the way in which hydrates formed from the reaction of Portland cement, slag and fly ash filled space by isolating the effect of the SCM using ternary systems of cement, GGBS/PFA and quartz. The slag reaction was observed to begin from 2-3 days hydration and reported to have a significant effect on porosity reduction from 14 days. Although the total porosity was measured to be higher in a $40 \%$ slag sample at 28 days, compared to a CEM I system, both materials were determined to have a similar critical radius (related to pore entry size of 
connecting porosity), demonstrating the greater ability of the slag reaction to refine the pore structure. However, in a 40\% PFA system, no significant impact on porosity was measured to occur until 14-21 days and the reaction of the fly ash between 14-28 days was determined to be $10-20 \%$, and dependent on the volume replacement. At 28 days the contribution of the fly ash was reported to be more evident but it was concluded that the PFA was required to react to a much greater extent than the slag before significantly improving the pore volume. Bijen [54] discussed similar results saying that, although the total porosity of composite systems remained relatively unchanged compared to a neat cement reference, the pore size distribution was finer for PFA and slag composites, which showed a lower percentage of capillary porosity and a higher percentage of gel porosity in MIP measurements. At early ages, however, the fly ash containing material exhibited initially coarser porosity, only becoming finer with time. This was further supported by Marsh et al. [55] where permeability measurements for fly ash pastes were high at early age (moderate reaction of PFA measured by $\mathrm{CH}$ depletion, $0-40 \%$ ), but dramatically decreased between 28 days and 3 months (samples cured at $20^{\circ} \mathrm{C}$ ) corresponding with a significant reaction of the fly ash glass.

The refinement of the pore structure in slag cements will increase the moisture content of the pores due to capillary condensation and subsequently impede the ingress of $\mathrm{CO}_{2}$. For an equivalent fly ash system, a lower capacity for porosity refinement is expected, requiring significant extent of reaction before significantly impacting the pore volume. As a result, the porosity and permeability of fly ash cements will be higher compared to CEM I systems following equal hydration durations, consequently permitting the diffusion of $\mathrm{CO}_{2}$ to occur more readily. This is demonstrated in the TGA data presented here which indicated a large difference in the carbonation resistance of the $30 \%$ PFA and 30\% GGBS samples following 28 days' curing. While the $30 \%$ slag system showed the highest resistance to carbonation, the PFA sample performed poorly, comparing more closely with the $60 \%$ GGBS blend.

During early age exposure, DTA plots indicated the transformation of AFm species from $\mathrm{SO}_{4}$ to $\mathrm{CO}_{3}$ containing phases before complete decomposition. The presence of a new peak at $\sim 130^{\circ} \mathrm{C}$ was observed from 7 days' exposure for the 60\% GGBS 0.57 - $72 \mathrm{hr}$ sample and was related to the formation of gypsum due to carbonation of AFt. At prolonged exposure lengths for the short cured samples (Figure 7.3), the $30 \%$ replacement systems were observed to develop a peak at $130^{\circ} \mathrm{C}$ from 14 days, increasing in intensity with continued carbonation. Reductions in the main AFt reflection in 
XRD data $\left(\sim 9^{\circ} 2 \theta\right)$ at 7 days for all the composite cements confirmed decomposition of AFt due to carbonation had begun, corresponding to the consumption of $\mathrm{CH}$. Gypsum was absent in the CEM I system and it was observed to form in the blended materials at earlier ages with increasing replacement level.
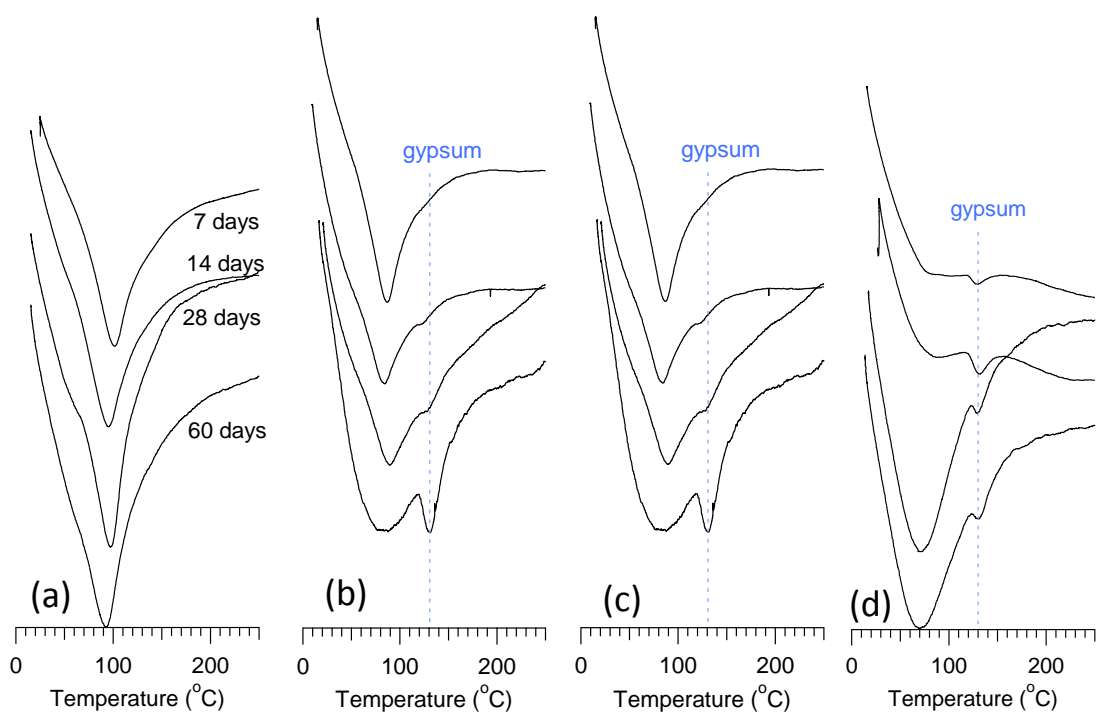

Figure 7.3. DTA plots between $0-250^{\circ} \mathrm{C}$ for 72 hour cured CEMI (a), $30 \%$ PFA (b), $30 \%$ GGBS and $60 \%$ GGBS (d) systems exposed to ambient $\left[\mathrm{CO}_{2}\right]$ between 7 and 60 days

During early age carbonation of the 28 day cured systems, several AFm phases were observed to coexist and the presence of a peak corresponding to gypsum was not evident after 7 days' exposure in any of the materials. At extended exposure durations (7-60 days Figure 7.4) gypsum formed in the fly ash sample from 28 days but was not detected in the remaining systems. Although the XRD data showed AFt existed at $t_{0}$ for the $60 \%$ GGBS system, it had been almost entirely converted to monosulfoaluminate by 1 day (Section 6.1.2). This suggested that while data sets confirmed no continued hydration of the samples during conditioning at $72.6 \% \mathrm{RH}$, there was sufficient water available to permit very small changes to occur initially. Furthermore, a change in the DTA relating to $\mathrm{C}-\mathrm{S}-\mathrm{H}$ was apparent with increasing levels of carbonation for the 72 hour cured composite systems and the 28 day cured $60 \%$ slag sample. Transformation to a much broader shape suggested significant changes to the C-S-H structure. The production of gypsum appeared to be related to the decomposition of AFt, occurring only for the samples in which portlandite had entirely reacted. 

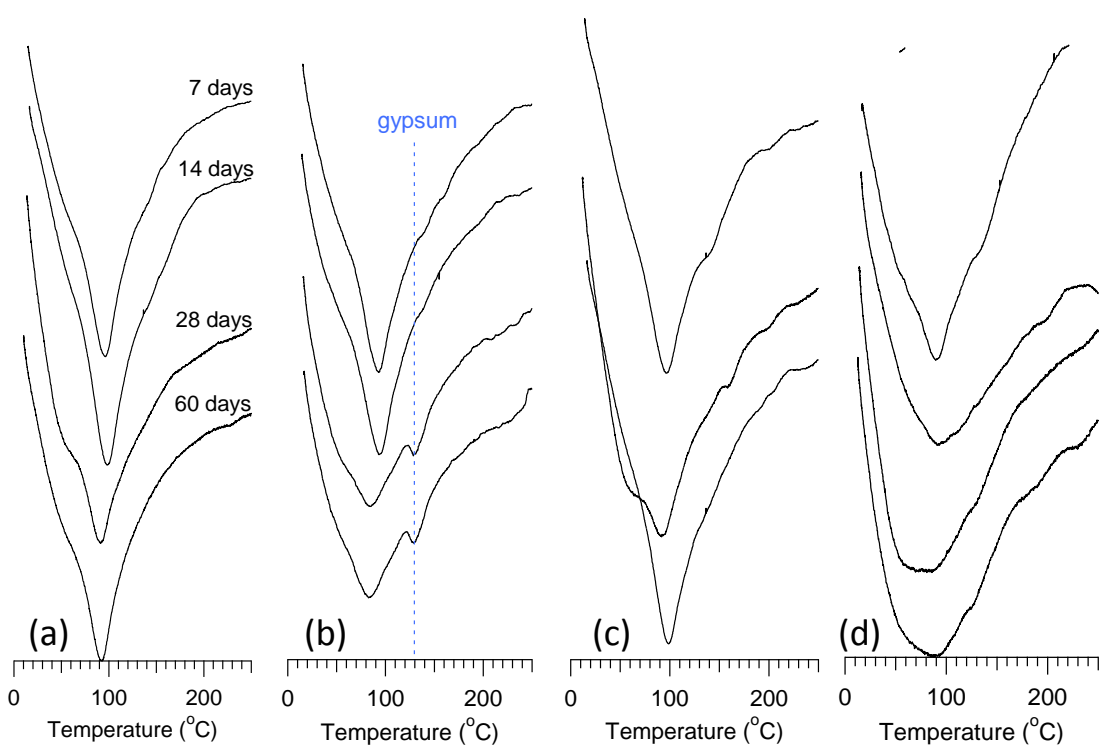

Figure 7.4. DTA plots between $0-250^{\circ} \mathrm{C}$ for 28 day cured CEMI (a), 30\% PFA (b), 30\% GGBS and $60 \%$ GGBS (d) systems exposed to ambient $\left[\mathrm{CO}_{2}\right]$ between 7 and 60 days

The complete reaction of $\mathrm{CH}$ due to carbonation has previously been reported, however it is typically observed to occur following accelerated carbonation tests only [64, 72, 82]. Here, following both short and ideal curing lengths, $\mathrm{CH}$ was entirely consumed during exposure to ambient $\mathrm{CO}_{2}$ concentrations, permitting more aggressive decalcification of the remaining phases to occur. Moreover, although short periods of hydration resulted in poor overall performance regardless of the sample, longer curing periods had significantly greater impacts on each of the systems. The blend with higher percentage replacement (60\% GGBS) performed poorly, but carbonation resistance at moderate replacement levels was dependent upon the replacement material. Replacement by $30 \%$ slag resulted in the highest carbonation resistance of the four systems studied, attributed to enhancement of the cement microstructure, whereas PFA at the same level of substitution had relatively low resilience, emphasising its much lower degree of reaction. In the composite materials the onset of a more severe carbonation reaction (when $\mathrm{CH}$ was no longer available) resulted in the decomposition of AFt to gypsum (and presumably alumina gel), however the CEM I samples appeared to buffer against this effect, which is likely related to the higher initial $\mathrm{Ca} / \mathrm{Si}$ ratio of the C-S-H phase. 


\subsubsection{XRD}

At later ages of exposure, changes in the crystalline phase assemblage were relatively minor for the systems cured for 72 hours (Figure 7.5). $\mathrm{CH}$ had been consumed during the early age carbonation reactions, resulting in substantially increased intensities of the main reflection peak for calcite $\left(29.5^{\circ}\right.$ $2 \theta$ ) and decreased peak intensities for AFt and the AFm phases. At 60 days' exposure, peaks corresponding to AFt and AFm species had entirely disappeared and a small peak assigned to gypsum was evident at $\sim 21^{\circ} 2 \theta$, consistent with DTA data. A small peak for AFt remained in the CEM I system and the small reflection corresponding to $\mathrm{C}_{4} \mathrm{AF}$ appeared to remain unaffected in all the samples. As for the early age reactions, calcite was predominant in all the systems, but small peak reflections for vaterite were increasingly evident at prolonged exposures. A small aragonite reflection was also seen for the $60 \%$ GGBS sample at 60 days.

Total carbonate contents calculated from TGA data (Section 7.1.1) suggested Ca had been supplied from an additional source other than the hydrate phases for the 30\% GGBS and 30\% PFA samples. $\mathrm{CaO}_{\text {reactive }}$ values provided a basic indication of the $\mathrm{Ca}$ available from cement hydrates for reaction with $\mathrm{CO}_{2}$ in which the $\mathrm{CEM}$ I system had the highest $\mathrm{CO}_{2}$ binding capacity and the value decreased with increasing percentage substitution. However, the total quantity of $\mathrm{CaCO}_{3}$ produced at 60 days was higher for both $30 \%$ blends compared with the CEM I sample. XRD data showed that as the carbonation reaction progressed (Figure 7.5), the characteristic peak doublet corresponding to residual belite in the samples (centred just below $32.5^{\circ} 2 \theta$ ) began to fade. In the CEM I system the intensity decreased, while it disappeared entirely for the composite materials, being replaced with a small vaterite reflection just above $32.5^{\circ} 2 \theta$. The consumption of belite accounted for the increased $\mathrm{CO}_{2}$ binding of the $30 \%$ replacement materials, but was observed to occur in all of the systems to a varying degree. 

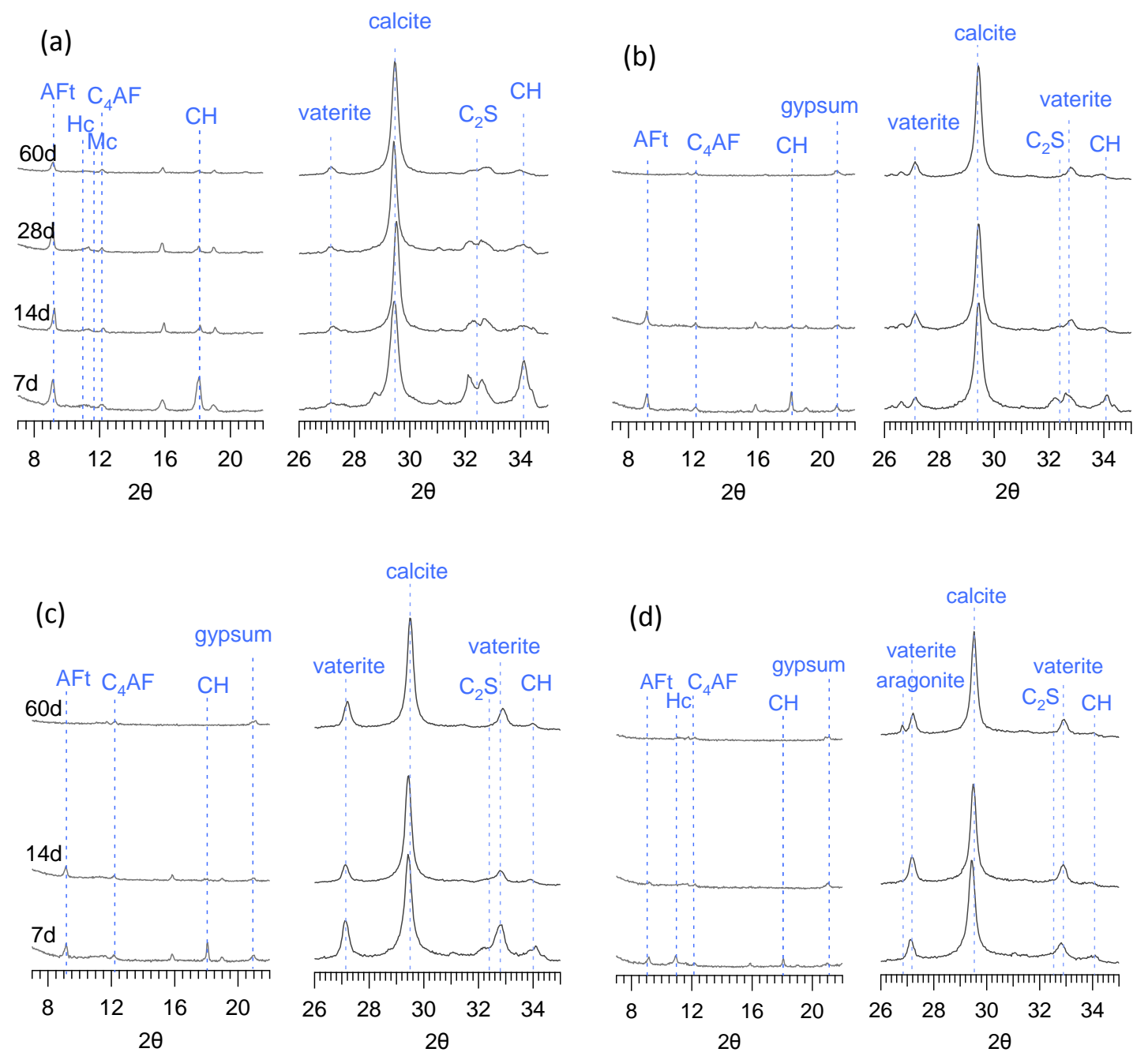

Figure 7.5. XRD patterns between $7-22^{\circ} 2 \theta$ and $26-35^{\circ} 2 \theta$ showing the changes in the crystalline phase assemblage with increasing exposure to ambient $\left[\mathrm{CO}_{2}\right]$ (7 - 60 days) for 72 hour cured samples (a) CEMI, (b) 30\% PFA, (c) 30\% GGBS, (d) 60\% GGBS (AFt - ettringite, Ms monosulfoaluminate, $\mathrm{Hc}$ - hemicarboaluminate, $\mathrm{Mc}$ - monocarboaluminate, $\mathrm{Ht}$ - hydrotalcite).

Castellote et al. [72] observed the complete disappearance of AFt during the accelerated carbonation of 28 day cured Portland cement pastes at $\mathrm{CO}_{2}$ concentrations of 10 and $100 \%$. Following carbonation at natural $(0.03 \%)$ and $3 \% \mathrm{CO}_{2}$ concentrations, AFt was reported to remain (test ages of 8 months and 103 days for ambient and 3\% conditions respectively) and $\mathrm{CH}$ was completely consumed in accelerated tests only. In agreement with the findings presented here, $\mathrm{C}_{4} \mathrm{AF}$ 
was unaffected by $\mathrm{CO}_{2}$, remaining constant in all the samples, but the reaction of $\mathrm{C}_{2} \mathrm{~S}$ was reported to occur, increasing with $\mathrm{CO}_{2}$ concentration and observed to be absent for $100 \% \mathrm{CO}_{2}$ test conditions. Fernandez-Carrasco [67] investigated the carbonation $\left(4 \% \mathrm{CO}_{2}\right)$ of short-cured (4 days) ternary (calcium aluminate, fly ash, calcium sulphate) cements in which the relative intensities of AFt XRD reflections decreased following 14 days' exposure and had completely disappeared at 90 days. Monosulfoaluminate and hemicarboaluminate were reported to react entirely with $\mathrm{CO}_{2}$ and crystalline carbonation products were determined to be $\mathrm{CaCO}_{3}$, aluminium hydrate and gypsum. Alumina gel is expected to be the product of AFm and AFt decomposition (with gypsum and $\mathrm{CaCO}_{3}$ ), however XRD data showed no crystalline alumina species to form following carbonation testing here. Zhou and Glasser [66] saw gibbsite (crystalline $\mathrm{Al}(\mathrm{OH})_{3}$ ) to form from the decomposition of synthetic AFt at $40^{\circ} \mathrm{C}$ but not at $25^{\circ} \mathrm{C}$. The authors inferred the formation of an amorphous alumina gel product from mass balance calculations.

The XRD data collected for the ideally cured systems ( 28 days) is displayed in Figure 7.6. Portlandite was consumed in the 30\% PFA and 60\% GGBS samples and resulted in a sizeable increase in calcite and vaterite contents. Although a small reflection for portlandite was detected at 60 days for the CEM I cement, a substantial increase in calcite was evident between 7-14 days exposure, consistent with TGA results. The depletion, or inaccessibility of residual $\mathrm{CH}$ (as for the $\mathrm{CEM}$ I system) allowed increased rates and extents of carbonation to occur. AFt and AFm decomposed (small AFt peak present for CEM I at 60 days similar to 72 hour cured sample), producing gypsum, and reflections for belite progressively faded. The final products in each case were virtually identical compared with the corresponding 72 hour cured samples, where only the relative proportions of the crystalline carbonate species were modified. The $30 \%$ slag sample, however, demonstrated a different carbonation mechanism. $\mathrm{CH}$ was present up to 60 days and the considerably smaller changes in the other hydrate peaks established that is was still accessible. Decreased intensities of the reflections for AFt and AFm were evident, producing small quantities of calcite and vaterite, however complete decomposition was not observed. $\mathrm{C}_{2} \mathrm{~S}$ appeared to remain unaffected, although the progressive formation of a vaterite peak reflection at the same $2 \theta$ angle made this difficult to verify. 
(a)

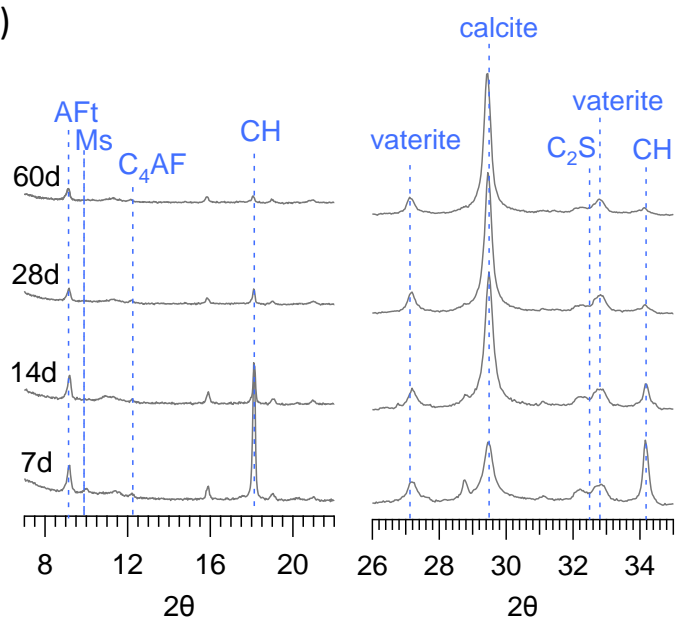

(c)

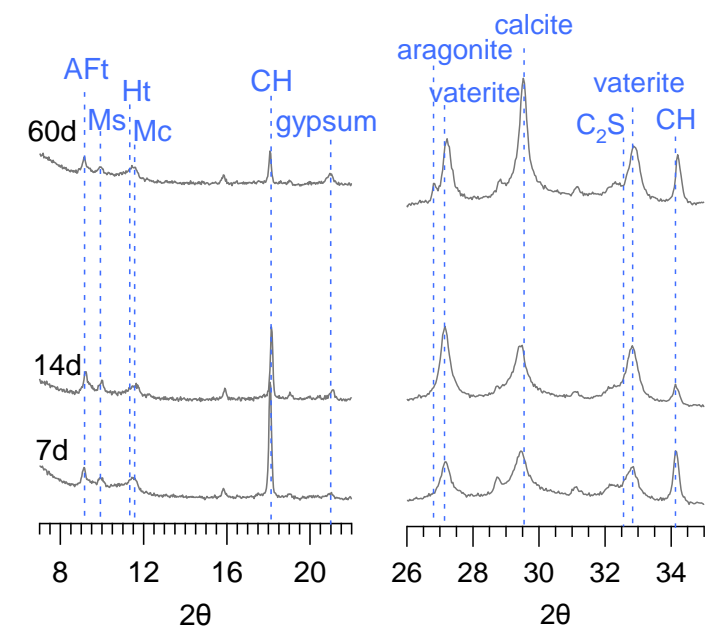

(b)
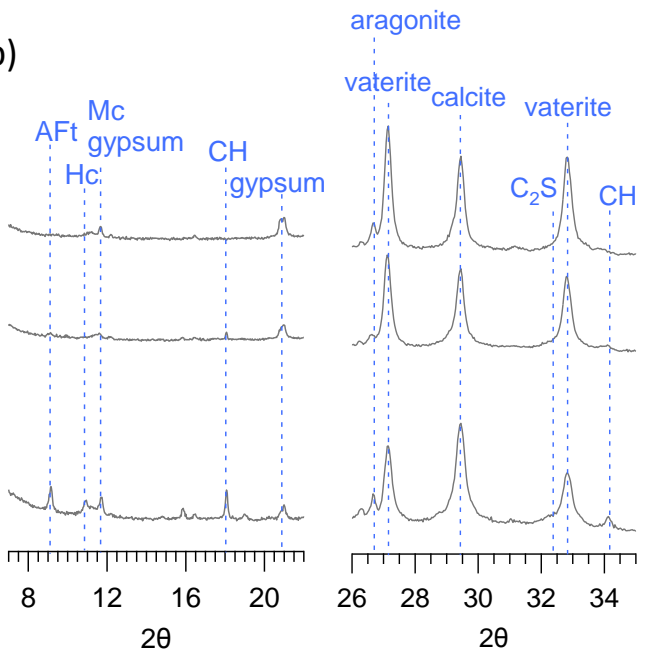

(d)

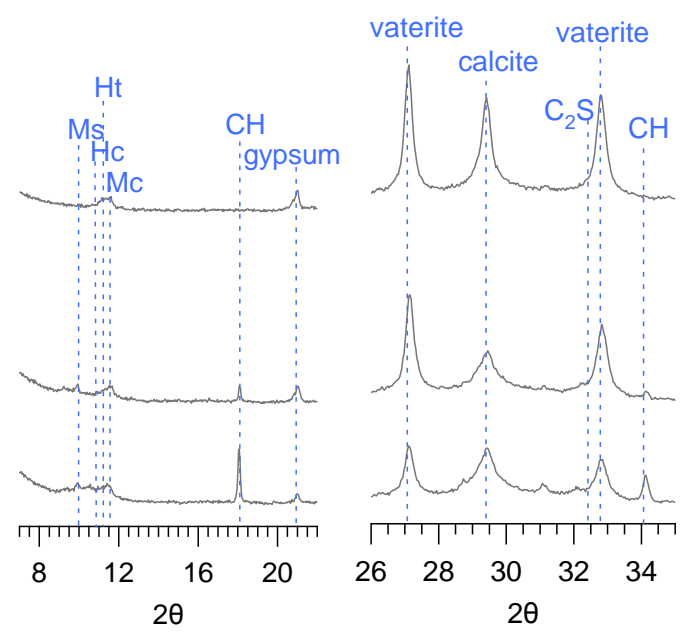

Figure 7.6. XRD patterns between $7-22^{\circ} 2 \theta$ and $26-35^{\circ} 2 \theta$ showing the changes in the crystalline phase assemblage with increasing exposure to ambient $\left[\mathrm{CO}_{2}\right]$ (7 - 60 days) for 28 day cured samples (a) CEMI, (b) 30\% PFA, (c) 30\% GGBS, (d) 60\% GGBS (AFt - ettringite, Ms monosulfoaluminate, $\mathrm{Hc}$ - hemicarboaluminate, $\mathrm{Mc}$ - monocarboaluminate, $\mathrm{Ht}$ - hydrotalcite).

The presence of $\mathrm{CH}$, or more precisely, its ability to buffer the pore solution makes it the rate determining factor for carbonation induced effects. Once depleted, or passivated, carbonation is permitted to progress more aggressively, and effectively the final product is the same regardless of the initial curing length, although this final stage was observed to occur at later ages with increased degree of hydration. XRD and TGA data indicated this final product to be a Ca modified C-S-H gel 
intermixed with both amorphous and crystalline $\mathrm{CaCO}_{3}$ species, gypsum and potentially a small quantity of unreacted belite (as for the CEM I systems). The ability of portlandite to continue to supply $\mathrm{Ca}$ to the pore solution, however, protected the remaining hydrate phases from complete decalcification. Carbonation of all the phases was determined to occur, but to a significantly lesser degree than when it was no longer available. The rate at which $\mathrm{CH}$ was depleted was dependent upon the microstructure and the rate at which $\mathrm{CO}_{2}$ was able to diffuse. SCMs have the capacity to refine porosity and reduce rates of diffusion but this is dependent upon its significant reaction, the replacement level and the replacement material.

As for the early age carbonation reactions, differences in the crystalline carbonate polymorph produced were observed between the short and ideally cured and the CEM I and blended systems. For 72 hour cured samples at early ages of exposure calcite dominated, although small reflections for vaterite were observed as carbonation progressed (up to 7 days) in the composite materials. This was most evident for the $30 \%$ slag sample, however subsequent changes in the crystalline phase assemblage were relatively minor at prolonged exposure lengths for all the systems (7-60 days Figure 7.5). More sizeable differences were evident between the short and ideally cured samples, in which composite materials exhibited greater proportions of vaterite in relation to calcite. During early age reactions ( $t_{0}-7$ days), peak intensities were almost equivalent, particularly for the slag containing materials, and as carbonation progressed (7-60 days - Figure 7.6) the vaterite reflections became more intense in relation to calcite for the 30\% PFA and 60\% GGBS samples. Zhou and Glasser [66] related vaterite to the carbonation of AFt while Dubina et al. [170] reported traces of vaterite from the partial carbonation of $\mathrm{CH}$, observing calcite and aragonite to be prevalent. Sauman [169] and Black et al. [73] determined vaterite to form from the carbonation of C-S-H. Sauman observed vaterite to form initially, transforming to calcite at later stages, whereas Black et al. detected vaterite to be predominant for samples with initial $\mathrm{Ca} / \mathrm{Si}>0.67$ (C-S-H samples with $\mathrm{Ca} / \mathrm{Si}$ ratios up to a maximum of 1.50 were studied). It was previously discussed that the difference in the crystalline carbonate species formed was thought to be related to the $\mathrm{Ca} / \mathrm{Si}$ ratio of the $\mathrm{C}-\mathrm{S}-\mathrm{H}$ in the systems. TEM-EDX measured the Ca/Si ratio of the CEM I system to be 1.67 . Following 72 hours' reaction the $30 \%$ fly ash and the $30 \%$ slag samples were determined to have mean $\mathrm{Ca} / \mathrm{Si}$ ratios of 1.55 and 1.39 respectively. Calcite was the principally detected phase for all the short cured systems, however the composite materials developed progressively increasing, although still relatively small, reflections 
for vaterite corresponding to increased rates of carbonation (i.e. increased decalcification of C-S-H) due to the depletion of portlandite. For the ideally cured samples, vaterite was more prevalent at early ages for the composite materials and appeared to be more dominant as the initial $\mathrm{Ca} / \mathrm{Si}$ ratio of the samples decreased, i.e. for the slag sample (higher DoH) compared to the equivalent PFA system (Ca/Si 1.49) and lowest for the 60\% GGBS blend (Ca/Si 1.27). Furthermore, there was very little difference for the CEM I systems between the two curing lengths. As carbonation proceeds, the $\mathrm{Ca} / \mathrm{Si}$ ratios of the samples were reduced further as a result of decalcification of the C-S-H gel. The $30 \%$ PFA and the $60 \%$ GGBS samples were carbonated to greater extents and exhibited significantly increased peak intensities for vaterite. The $30 \%$ slag system was shown to carbonate the least and vaterite peak intensities remained lower in relation to calcite. The results indicated that vaterite was produced from the carbonation of $\mathrm{C}-\mathrm{S}-\mathrm{H}$ in systems where $\mathrm{Ca} / \mathrm{Si}$ ratios were reduced. The carbonation of $\mathrm{C}-\mathrm{S}-\mathrm{H}$ resulted in the progressive removal of $\mathrm{Ca}$, further lowering the $\mathrm{Ca} / \mathrm{Si}$ ratio and resulting in increased production of the vaterite polymorph.

\subsubsection{ATR-FTIR}

The ATR-FTIR spectra collected for the 72 hour cured CEM I and 30\% PFA systems are displayed in Figure 7.7. The spectra for the blends were all very similar, and as such only the fly ash data has been shown. In agreement with TGA and XRD results, the carbonate content was observed to increase with increasing exposure length, progressively stabilising at later ages. The strong $\mathrm{CO}_{3}$ absorption band ( $v_{3}$ asymmetric stretching band) between $1400-1500 \mathrm{~cm}^{-1}$ and the narrow band at $\sim 870 \mathrm{~cm}^{-1}\left(\mathrm{~V}_{2}\right)$ confirmed calcite to be predominant at all ages $[140,141,172,180]$, while carbonation of AFt was evidenced by a decreased intensity of the band at $\sim 1120 \mathrm{~cm}^{-1}$ with increased uptake of $\mathrm{CO}_{2}$. 

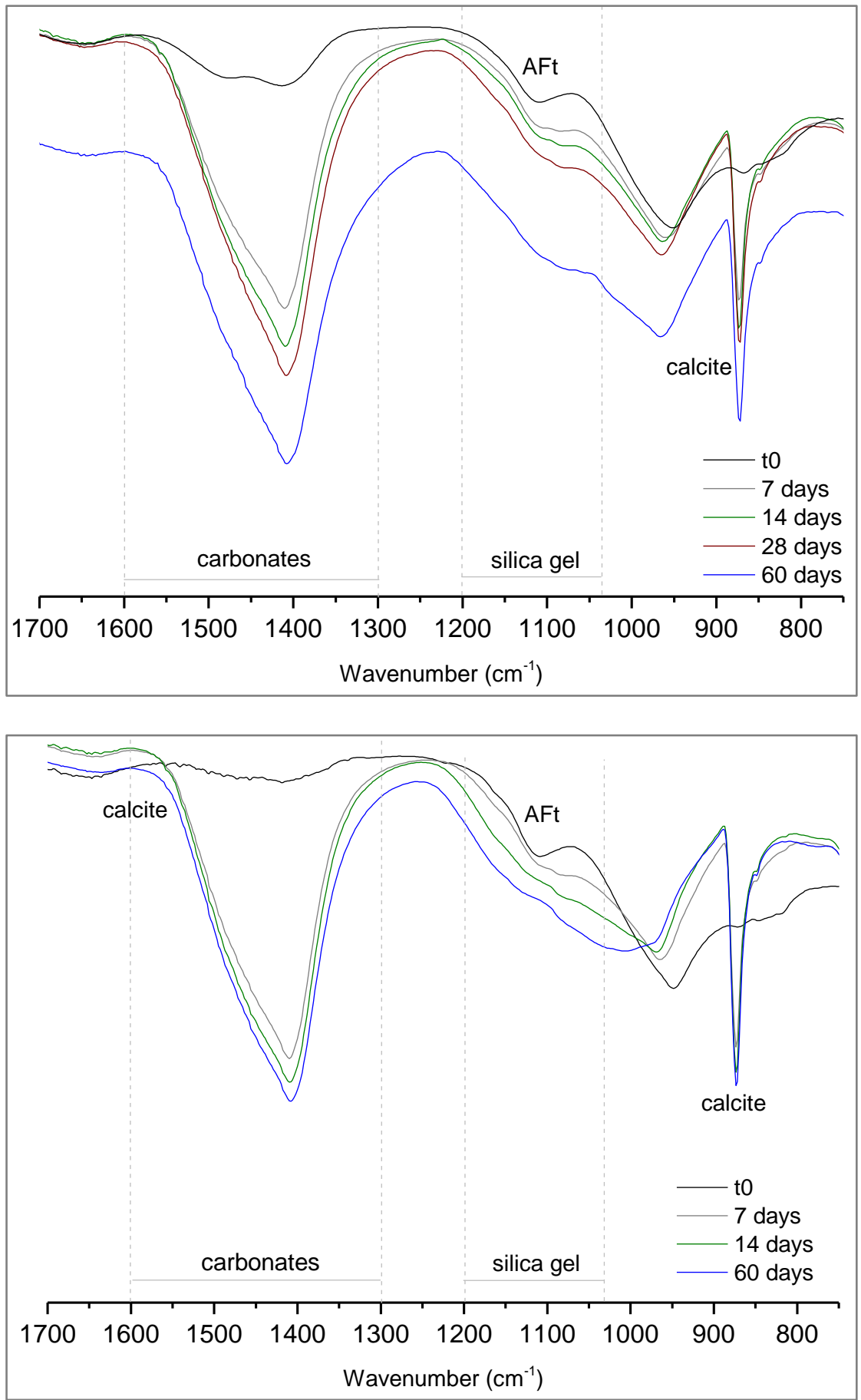

Figure 7.7. ATR-FTIR spectra for $72 \mathrm{hr}$ CEMI (top) and 30\% PFA (bottom) blends showing carbonate $\left(1400-1500 \mathrm{~cm}^{-1}\right)$, AFt $\left(\sim 1120 \mathrm{~cm}^{-1}\right)$, silicate $\left(\sim 950-1000 \mathrm{~cm}^{-1}\right)$ and calcite $\left(\sim 870 \mathrm{~cm}^{-1}\right)$ bands 
In the $t_{0}$ samples, the band centred at $\sim 950 \mathrm{~cm}^{-1}$ was assigned to the $v_{3}$ asymmetric stretching vibration of the Si-O bonds in the silicate chains of the C-S-H. The position of this band is dependent on the $\mathrm{Ca} / \mathrm{Si}$ ratio [172] and is expected to shift to a higher wavenumber with increasing degree of polymerisation (i.e. with decreasing $\mathrm{Ca} / \mathrm{Si}$ ratio) due to an increase in bond strength of the Si-O [181]. During early age carbonation ( $\mathrm{t}_{0}-7$ days), the consumption of $\mathrm{CH}$ corresponded to a shift in the silicate band to higher wavenumber and deconvoluted ${ }^{29} \mathrm{Si}$ NMR spectra (Section 6.1.6) confirmed a significant increase in the lengths of the silicate chains. As the carbonation reaction progressed (7-60 days - Figure 7.7), and Ca was increasingly removed from the C-S-H structure, the shift in the $\mathrm{v}_{3} \mathrm{Si}-\mathrm{O}$ bond became progressively more pronounced, particularly for the blends. Furthermore, as the carbonation degree increased in the blended cements, the silicate band intensity successively decreased suggesting partial decomposition of the C-S-H gel. For all the systems, progressive decalcification (intimated from increased polymerisation evidenced by increasing frequency of the $\mathrm{Si}-\mathrm{O} \mathrm{v}_{3}$ band) was observed to occur initially, ultimately decomposing to form a highly polymerised C-S-H gel phase that produced a new band at $1130-1200 \mathrm{~cm}^{-1}$.

Ashraf and Olek [182] studied the carbonation behaviour of synthetic calcium silicate samples $\left(\mathrm{C}_{3} \mathrm{~S}\right.$, $\left.\beta C_{2} S, \gamma C_{2} S, C_{3} S_{2}, C S\right)$ under accelerated conditions $\left(100 \% \mathrm{CO}_{2}\right)$ at a high $\mathrm{RH}(94 \%)$. The results showed two ranges of mean wavenumbers relating to $\mathrm{Si}-\mathrm{O}$ bonds of silicate species. Hydration of the samples produced C-S-H which produced absorption bands in the range $920-960 \mathrm{~cm}^{-1}$. Subsequent carbonation of the newly formed hydrates resulted in increased polymerisation, followed by decomposition (at a certain degree of carbonation) to form Ca modified silica gel which produced a frequency band between $1030-1170 \mathrm{~cm}^{-1}$.

Sevelsted and Skibsted [63] described the decomposition of C-S-H by carbonation to occur in two stages. Calcium is gradually removed from the interlayer and defect sites of the silicate chains resulting in increased polymerisation as $Q^{1}$ species transform to $Q^{2}$ (i.e. dimers become chains). This manifests itself as an increase in the frequency of the $v_{3}$ Si-O band in the ATR-FTIR spectra as observed in Figure 7.7. The second step corresponds to withdrawal of Ca from the principal layers $(\mathrm{Ca} / \mathrm{Si}<0.67)$ resulting in final decomposition of the $\mathrm{C}-\mathrm{S}-\mathrm{H}$ and the formation of an amorphous silica phase, i.e. cross linked $\left(Q^{3}\right)$ and fully condensed $\left(Q^{4}\right) \mathrm{SiO}_{4}$ tetrahedra. In the ATR-FTIR data, this corresponds to the new band, assigned as silica gel, between $1130-1200 \mathrm{~cm}^{-1}$. 
Silica gel is the final product formed from the carbonation of $\mathrm{C}-\mathrm{S}-\mathrm{H}$, signifying the complete decomposition of the structure. The carbonation of C-S-H in Portland cement is typically a very slow process and is slowed further by the faster dissolution rate of $\mathrm{CH}$, as such the formation of silica gel in naturally carbonated cements is seldom reported. Groves et al. [64] investigated the accelerated (pure $\left.\mathrm{CO}_{2}\right)$ and natural carbonation of $\mathrm{C}_{3} \mathrm{~S}$ pastes $\left(0.046 \% \mathrm{CO}_{2}\right)(0.5 \mathrm{~mm}$ thick discs $\& 72.6 \% \mathrm{RH})$, reporting a Ca modified silica gel to have formed following just 4 hours exposure to pure $\mathrm{CO}_{2}$. At 16 hours (maximum exposure length studied) the sample was a mixture of silica rich gel and decalcified $\mathrm{C}-\mathrm{S}-\mathrm{H}$, while the naturally carbonated pastes exhibited higher degrees of polymerisation following 2 months exposure but silica gel was not detected to have formed. The authors concluded that the less aggressive attack of the ambient $\mathrm{CO}_{2}$ atmosphere allowed a more homogenous gel structure to be maintained, remaining in a state closer to equilibrium. Similar results were reported by Castellote et al. [72] in which greater a greater degree of polymerisation was observed with exposure to increasing concentrations of $\mathrm{CO}_{2}$. Deconvoluted ${ }^{29} \mathrm{Si} \mathrm{NMR}$ spectra showed peaks related to silica gel $\left(Q^{3}\right.$ and $\left.Q^{4}\right)$ to have formed in all the carbonated samples, where greater proportions were formed in the accelerated tests. Although the authors fitted a broad $Q^{4}$ peak for the naturally carbonated spectra, the high signal to noise ratio makes its assignment questionable. Furthermore, while considerable fractions of $Q^{1}$ and $Q^{2}$ remained, a peak corresponding to $Q^{3}$ was almost entirely absent. $Q^{3}$ species are expected to form following the decalcification of the silicate chains up to $\mathrm{Ca} / \mathrm{Si}$ ratio 0.67 (or infinite chains $/ \mathrm{no}^{1}$ ) after which further carbonation results in condensation of the silicate species to form $\mathrm{Q}^{4}$ [63]. In any case, modifications in the mechanism of C-S-H carbonation exist between natural and accelerated test conditions where the presence of silica gel is typically a feature of the rapid reactions that result from high $\mathrm{CO}_{2}$ concentrations. Here, the formation of silica gel following natural carbonation of CEM I and blended materials following short curing periods is evident, emphasising that differences in the carbonation behaviour of poorly and ideally cured cement materials exist even at ambient concentrations of $\mathrm{CO}_{2}$.

The decomposition of the synthetic C-S-H samples carbonated [63] under ambient $\mathrm{CO}_{2}$ concentrations was described to occur faster than typically observed for the C-S-H present in hardened Portland cement pastes. The accelerated reaction was described as a result of the absence of Portlandite (to act as a buffer), the high humidity and the finely powdered nature of the specimens. However, the results presented here for poorly cured blended cement pastes relate 
more closely to the results observed for the $\mathrm{CH}$ free synthesised $\mathrm{C}-\mathrm{S}-\mathrm{H}$ materials compared to investigations on highly hydrated neat cement systems in the literature.

In the ideally cured systems, large increases in carbonate content were observed for the CEM I, 30\% PFA and $60 \%$ GGBS samples at exposure ages where consumption or passivation of $\mathrm{CH}$ had occurred, consistent with TGA and XRD data. The spectra for the 30\% PFA blend are displayed in Figure 7.8 (top). The $\mathrm{v}_{3} \mathrm{CO}_{3}$ band $\left(1400-1500 \mathrm{~cm}^{-1}\right)$ appeared to be a combination of both the vaterite and calcite polymorphs $[141,180]$ and the depletion of portlandite resulted in a shift of the $v_{3}$ silicate (Si-O) band $\left(\sim 950 \mathrm{~cm}^{-1}\right)$ to a higher wavenumber (normalised bands presented in Figure 7.9 (top)), indicating significant polymerisation of the $\mathrm{C}-\mathrm{S}-\mathrm{H}$ silicate chains, and therefore supporting the beginning of a more extensive decalcification reaction in the absence of $\mathrm{CH}$. Following 60 days' exposure, the spectra were similar to those obtained for the short cured samples at equivalent carbonation ages, where the loss of portlandite ultimately resulted in silicate polymerisation and decomposition of the C-S-H phase (decreased intensity of silicate band) to form a Ca modified silica gel $\left(1030-1200 \mathrm{~cm}^{-1}\right)$.

The spectra collected for the 30\% slag sample are shown in Figure 7.8 (bottom). The vaterite polymorph was predominant at 14 and 28 days, in agreement with XRD results, however transformation to a band shape relating more closely to calcite was observed at 60 days. Sauman [169] reported vaterite to form initially from the carbonation of $\mathrm{C}-\mathrm{S}-\mathrm{H}$, subsequently transforming to calcite with continued reaction. During early age exposure, the presence of $\mathrm{CH}$ inhibited silicate polymerisation and so shifts in the silicate bands were not seen. The normalised spectra displayed in Figure 7.9 (bottom) indicated a small shift to higher frequency in the presence of portlandite from 14 days' exposure. Results from ${ }^{29} \mathrm{Si}$ NMR deconvolutions (Section 6.1.6) suggested shifts in the frequency attributed to the lengthening of the silicate chains may be related to the ratio of $Q^{1}$ to $Q^{2}$ species. It is only when $\mathrm{Q}^{2}$ becomes dominant that the $\mathrm{v}_{3} \mathrm{Si}-\mathrm{O}$ band moved to a higher wavenumber. If this is the case, it can be inferred that the MCL has increased due to decalcification of the C-S-H phase, although to a relatively lower degree than in the $\mathrm{CH}$ free systems. 

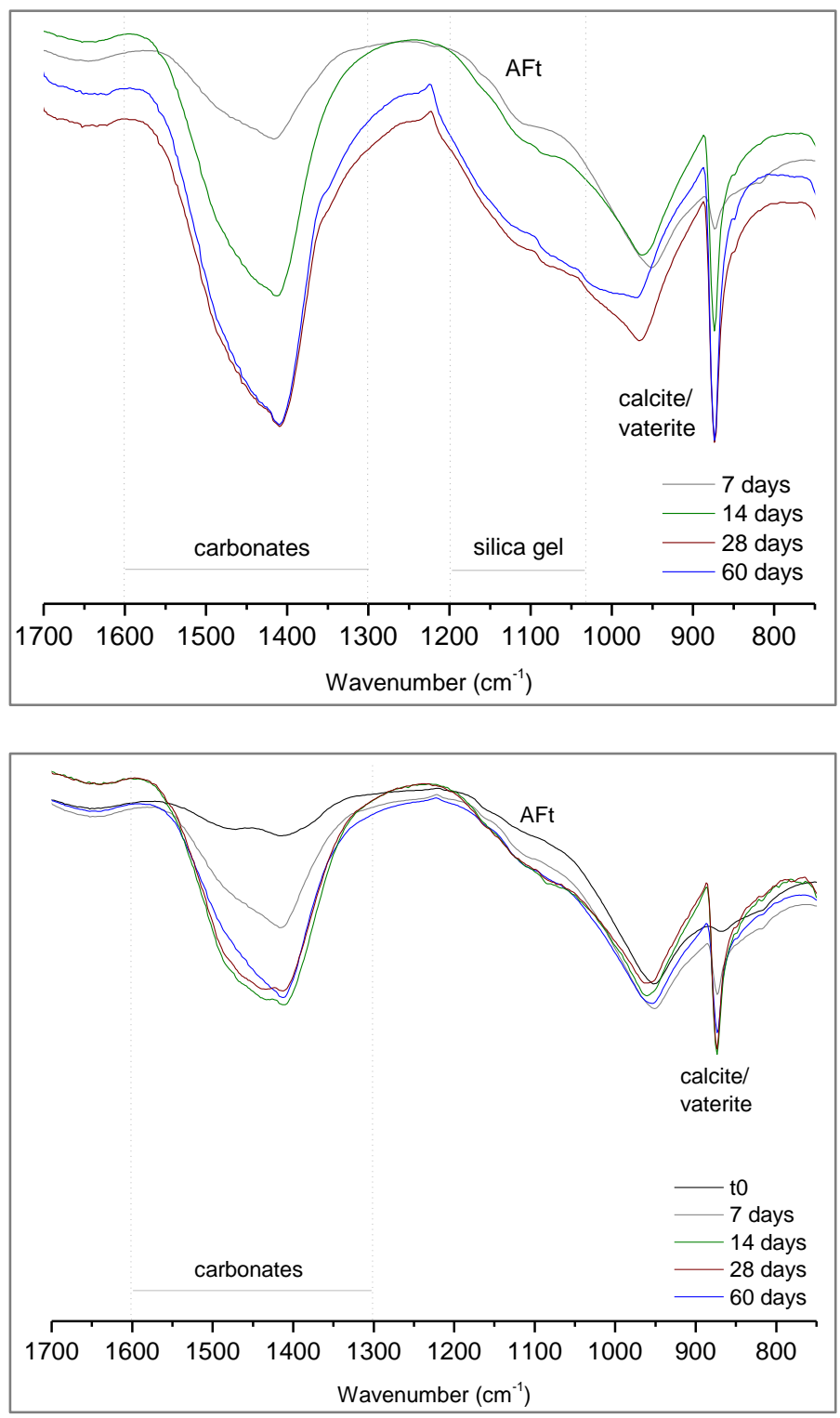

Figure 7.8. ATR-FTIR spectra for 28d 30\% PFA (top) and 30\% GGBS (bottom) blends showing carbonate $\left(1400-1500 \mathrm{~cm}^{-1}\right)$, AFt $\left(\sim 1120 \mathrm{~cm}^{-1}\right)$, silicate $\left(\sim 950-1000 \mathrm{~cm}^{-1}\right)$ and calcite $\left(\sim 870 \mathrm{~cm}^{-1}\right)$ bands 
(a)

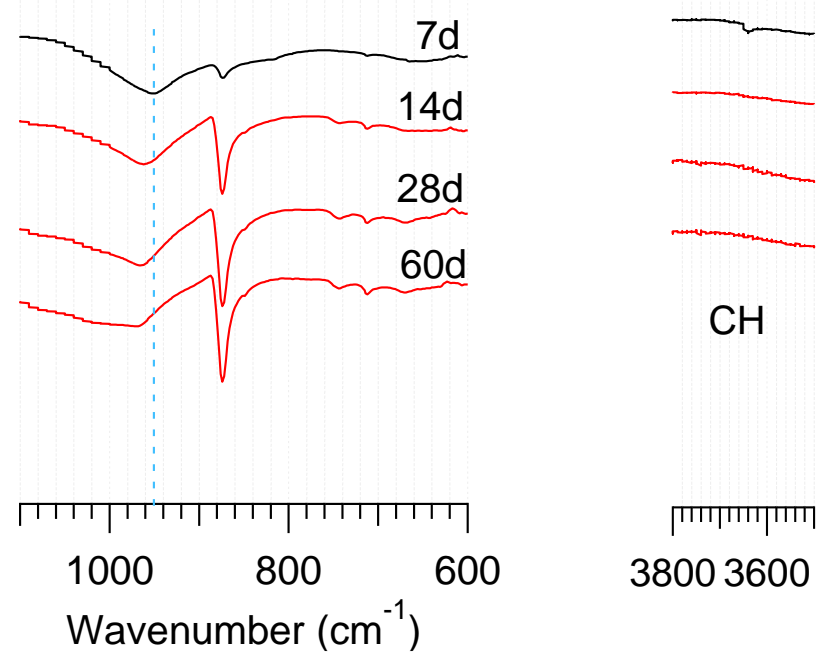

(b)

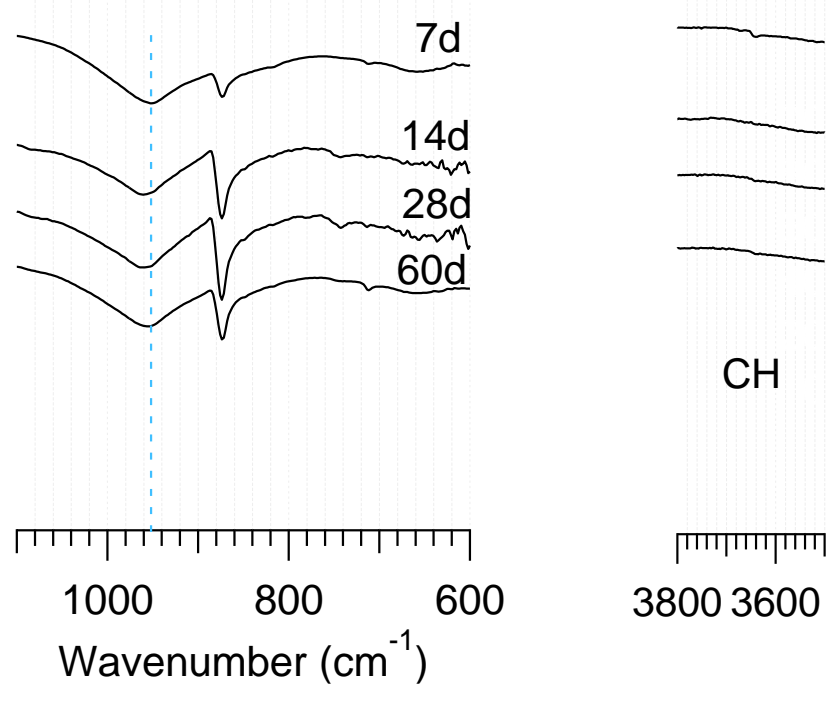

Figure 7.9. ATR-FTIR spectra showing normalised silicate $\left(\sim 950 \mathrm{~cm}^{-1}\right)$ and hydroxide $\left(3643 \mathrm{~cm}^{-1}\right)$ (i.e. $\mathrm{CH}$ ) bands for 28 day cured systems with increasing exposure to ambient $\mathrm{CO}_{2}$ for (a) $30 \%$ PFA and (b) $30 \%$ GGBS 


\subsection{4 ${ }^{27} \mathrm{AI}$ MAS NMR}

${ }^{27} \mathrm{AI}$ NMR spectra collected for the short and ideally cured samples following exposure to ambient $\mathrm{CO}_{2}$ for 60 days are displayed in Figures 7.10 and 7.11 respectively. Almost complete decomposition of both AFt and the AFm phases was evident for all the blended systems in which $\mathrm{CH}$ was consumed (72hr - 30\% PFA, 30\% GGBS \& 60\% GGBS, 28d - 30\% PFA \& 60\% GGBS). The octahedral resonances at $9 \mathrm{ppm}$ and $13 \mathrm{ppm}$ were almost entirely absent (a small signal was observed for the 28 day cured $60 \%$ GGBS sample but was assigned to be hydrotalcite corresponding to a small hydrotalcite diffraction peak observed at 60 days in XRD data (Figure 7.6)) and were accompanied by a more prominent shift of tetrahedrally coordinated aluminium (AI(IV)) to an intense, narrower resonance centred at $55 \mathrm{ppm}$. This is consistent with the withdrawal of aluminium from C-S-H bridging sites and its subsequent incorporation into the silica phase produced from the decalcification of C-S-H [63]. Moreover, the decomposition of AFt and the AFm phases is expected to produce $\mathrm{CaCO}_{3}$, gypsum and alumina gel as the products of carbonation [65-67], however, the ${ }^{27} \mathrm{Al}$ NMR spectra does not seem to show a new octahedral resonance for alumina gel following their carbonation. DTA and XRD data confirmed the formation of gypsum but alumina gel was not detected. Zhou and Glasser [66] observed crystalline gibbsite $\left(\mathrm{Al}(\mathrm{OH})_{3}\right)$ to form at $40^{\circ} \mathrm{C}$, but it was thought to be amorphous ( $\mathrm{x}$-ray silent) at experiments carried out at $25^{\circ} \mathrm{C}$. Aluminium hydroxide $\left(\mathrm{Al}(\mathrm{OH})_{3} /\right.$ gibbsite $)$ is composed of stacked sheets of linked octahedrons of aluminium hydroxides (Al bonded to six hydroxides) and is therefore expected to produce an octahedral resonance. The absence of a new resonance relating to alumina gel suggests a different decomposition mechanism, in which aluminium appeared to be incorporated into the amorphous silica phase (evidenced by transformation of AI(IV) signal), rather than producing a new alumina rich phase. This modified process may be a result of the relatively lower contents of calcium aluminate hydrate phases formed in Portland cement based systems compared with much higher quantities, and higher Al uptake in the $\mathrm{C}-\mathrm{S}-\mathrm{H}$, in calcium aluminate cements, which have been shown to produce $\mathrm{Al}(\mathrm{OH})_{3}$ during carbonation [67]. 


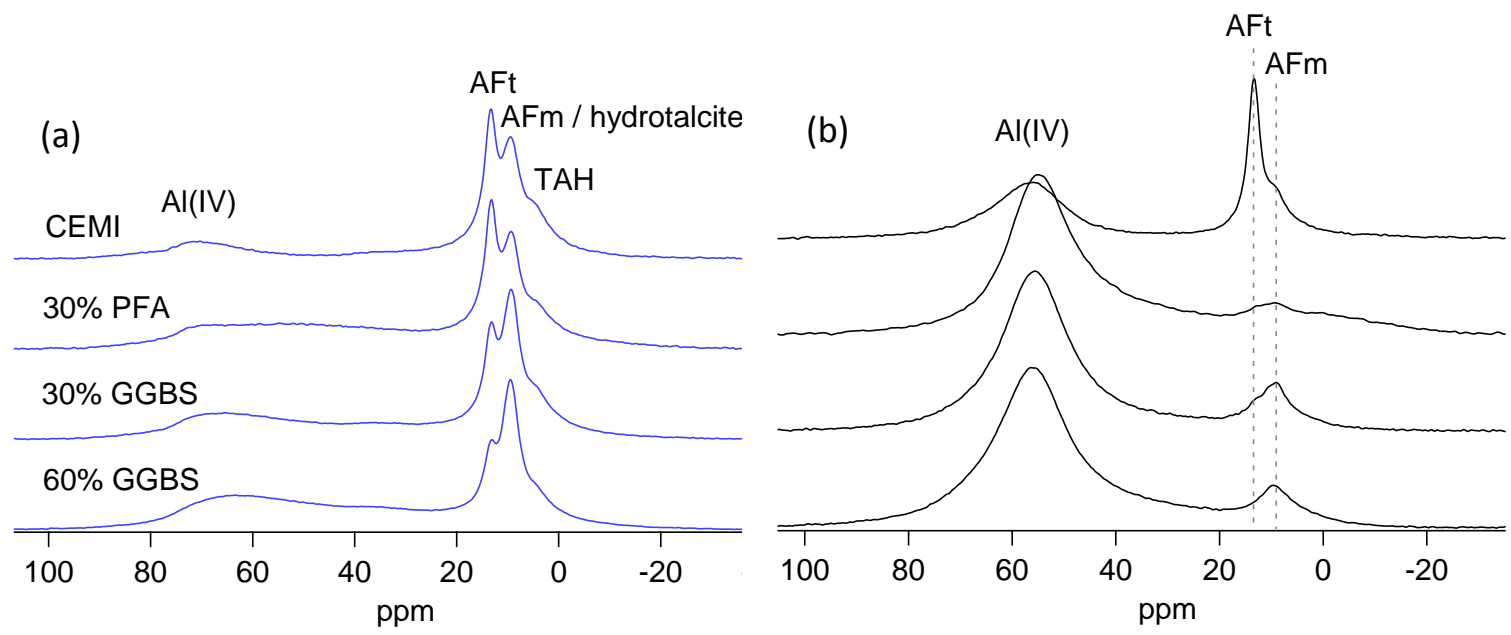

Figure 7.10. Single pulse ${ }^{27}$ AI NMR spectra $0.57-72 \mathrm{hr}$ cured (a) to samples and (b) following exposure to ambient $\left[\mathrm{CO}_{2}\right]$ for 60 days
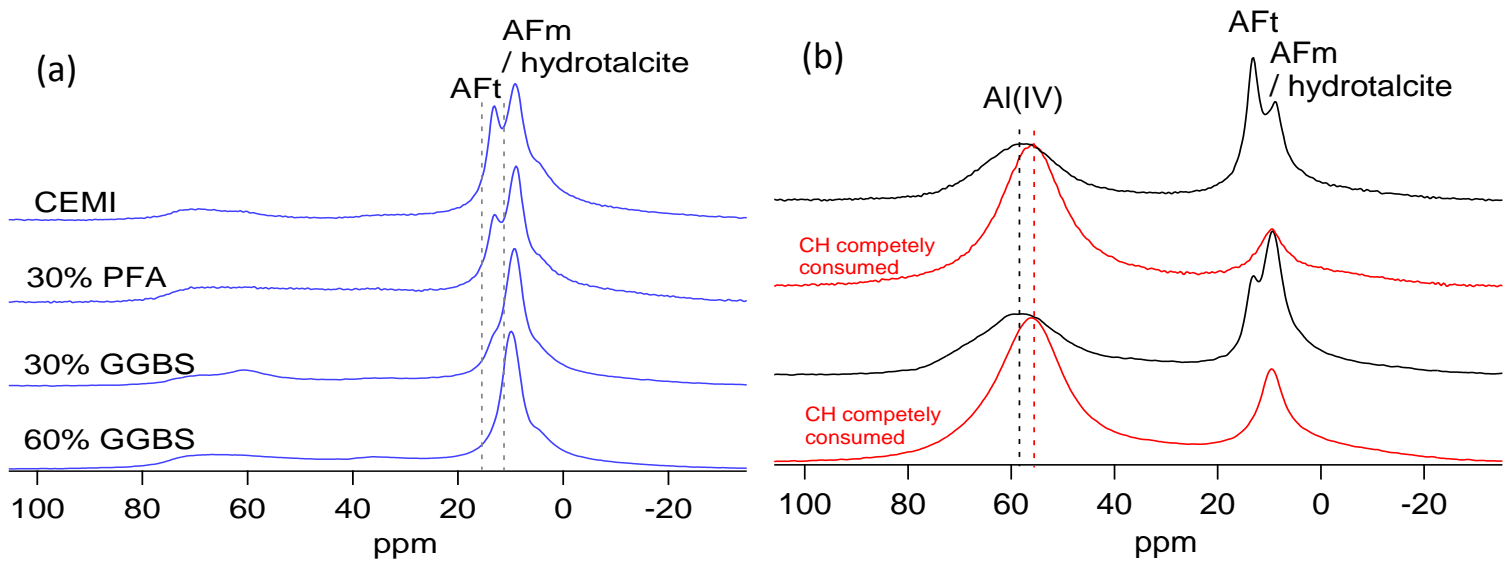

Figure 7.11. Single pulse ${ }^{27}$ AI NMR spectra $0.57-28 d$ cured (a) to samples and (b) following exposure to ambient $\left[\mathrm{CO}_{2}\right]$ for 60 days

The greater carbonation resilience of the CEM I was demonstrated for both curing lengths. TGA, XRD and ATR-FTIR data showed a more extensive carbonation reaction had begun from 4-7 days and 714 days exposure for the short and ideally cured systems respectively. In the blended materials, this more aggressive carbonation reaction resulted in decomposition of the calcium aluminate hydrate phases, whereas AFt was observed to remain in the CEM I system with some AFm also present for 
the 28 day cured materials. Thermodynamic calculations included in the work of Shi et al. [167] predicted the carbonation of portlandite to have little impact on the $\mathrm{pH}$ while some high $\mathrm{Ca} \mathrm{C}-\mathrm{S}-\mathrm{H}$ is still available. The first stage of C-S-H decomposition (as discussed by Sevelsted and Skibsted [63]) involves the removal of Ca from the interlayer, Shi et al. [167] predicted that this would result in a reduction in the $\mathrm{pH}$ level to 9.6, only falling further as calcium is removed from the principal layers (second stage) and C-S-H is completely decomposed. This higher $\mathrm{CO}_{2}$ binding capacity provided by the high $\mathrm{Ca} / \mathrm{Si}$ ratio of the $\mathrm{C}-\mathrm{S}-\mathrm{H}$ in the CEM I cement presents a slower decrease in alkalinity of the pore solution, and a longer length of retention before final breakdown of the C-S-H structure.

The spectra for the 28 day cured $30 \%$ GGBS sample confirmed the impact of $\mathrm{CH}$ on the resistance to carbonation. STA and XRD data showed $\mathrm{CH}$ to still be available, and the significantly lower degree of carbonation of the system demonstrated that it was also still able to sufficiently buffer the pore solution. The ${ }^{27} \mathrm{Al}$ NMR data further demonstrated that it is not only more severe decalcification of the C-S-H phase that is inhibited by dissolution of portlandite, but also the decalcification of the AFt and the AFm phases. Although carbonation of these phases was observed to have occurred, it was comparatively minor compared to the systems in which $\mathrm{CH}$ had been depleted.

\subsubsection{TEM-EDX}

TEM analysis was performed on selected samples following exposure to ambient $\left[\mathrm{CO}_{2}\right]$ for 60 days. Due to the high extent of carbonation in nearly of all of the systems, areas of C-S-H free from crystalline $\mathrm{CaCO}_{3}$ (as determined from selected area electron diffraction (SAED)) were almost nonexistent, preventing the collection of EDX data. A small number of Ip analyses were collected for the $60 \%$ GGBS 0.57 (28d) sample, the $\mathrm{Mg} / \mathrm{Si}-\mathrm{Al} / \mathrm{Si}$ atomic ratio plot is displayed in Figure 7.12 and the EDX results for Ip regions at exposure ages of $0\left(t_{0}\right), 2$ and 60 days are presented in Table 7.3. 


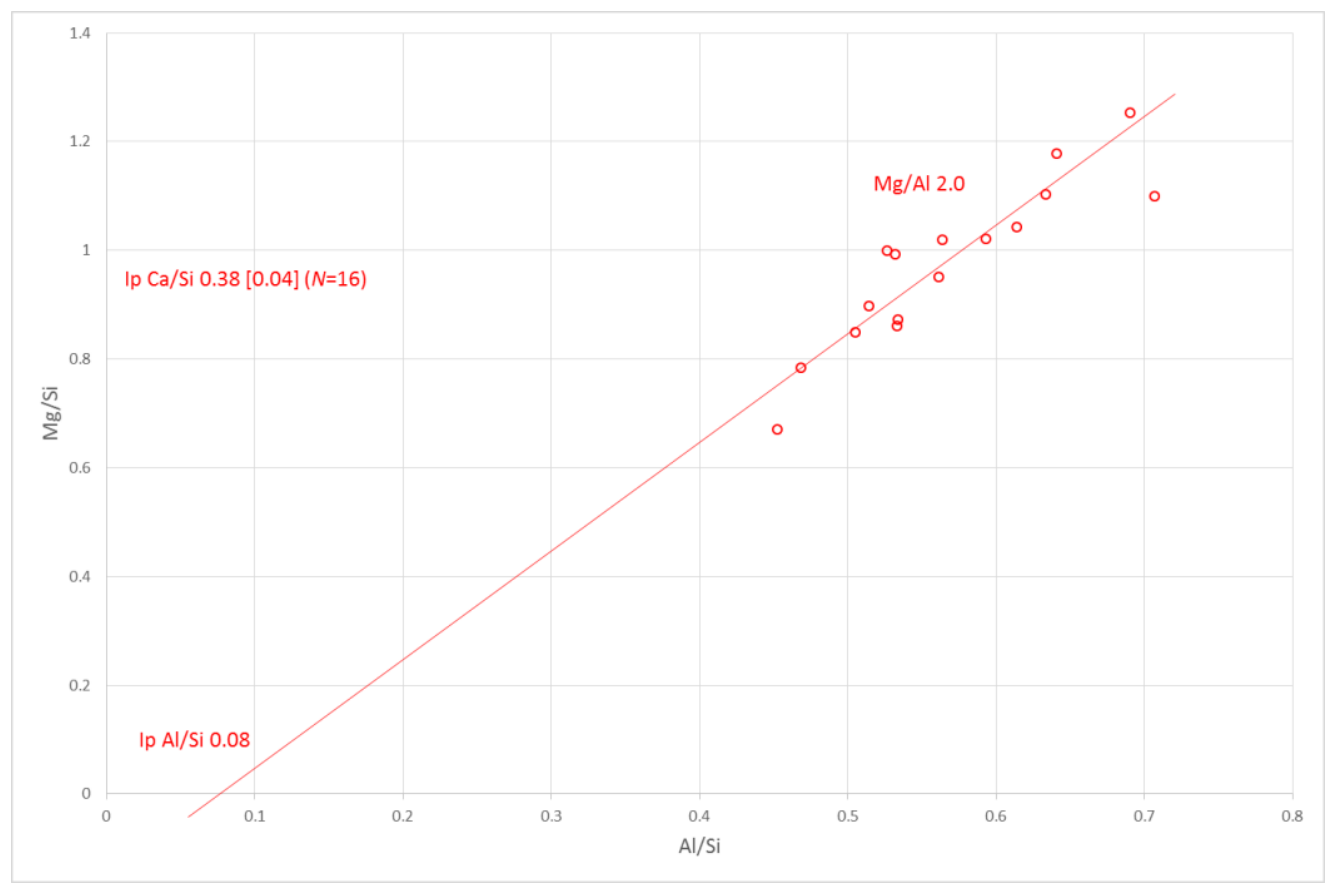

Figure 7.12. $\mathrm{Mg} / \mathrm{Si}$ - Al/Si atomic plot ratios of TEM-EDX analyses of Ip product in $60 \%$ GGBS $(0.57$ $28 \mathrm{~d}$ cured) sample exposed to ambient $\left[\mathrm{CO}_{2}\right]$ for 60 days

Table 7.3. Mean Ca/Si and Al/Si ratios for Ip regions of $60 \%$ GGBS 0.57 (28d) sample exposed to ambient $\left[\mathrm{CO}_{2}\right]$ for $0\left(\mathrm{t}_{0}\right), 2$ and 60 days

\begin{tabular}{|c|c|c|c|c|c|}
\hline & & $\mathrm{Ca} / \mathrm{Si}$ & & $\mathrm{Al} / \mathrm{Si}$ & $\mathrm{Mg} / \mathrm{Al}$ \\
\hline & $\mathrm{N}$ & Mean & S.D. & Mean & \\
\hline t0 & 18 & 1.28 & 0.07 & 0.14 & 2.5 \\
\hline 2 days & 18 & 1.21 & 0.07 & 0.125 & 2.5 \\
\hline 60 days & 16 & 0.38 & 0.04 & 0.08 & 2.0 \\
\hline
\end{tabular}

Prolonged exposure to $\mathrm{CO}_{2}$ resulted in severe decalcification of the $\mathrm{C}-\mathrm{S}-\mathrm{H}$ phase. The $\mathrm{Ca} / \mathrm{Si}$ ratio of 0.38 for the Ip region supported previous observations which indicated decomposition of the silicate chains to form a Ca modified silica rich phase (as determined in ATR-FTIR data). At Ca/Si ratios below $0.67, \mathrm{Ca}$ in the interlayer is expected to have been completely withdrawn, resulting in the removal of Ca from the principal layers to ultimately produce a condensed silica gel [63]. During early ages of exposure, the hydrotalcite-like phase was determined to be unaffected by the carbonation 
reaction, in contradiction to Li [168] who observed the phase to act as a sink for Al extracted from the $\mathrm{C}-\mathrm{S}-\mathrm{H}$ gel. At prolonged exposure, however, the $\mathrm{Mg} / \mathrm{Al}$ ratio of the hydrotalcite-like phase was determined to have decreased from 2.5 to 2.0 (agreeing with Li's observations), suggesting that additional $\mathrm{Al}$ had been incorporated into its structure.

Prolonged exposure to $\mathrm{CO}_{2}$ resulted in no change to the morphology of the $\mathrm{C}-\mathrm{S}-\mathrm{H}$, consistent with previous studies $[71,79,168]$ and the early age carbonation of the samples (Section 6.1.5). Some coarsening of the microstructure was evident for the 72 hour cured systems (Figures 7.13, 7.14 \& 7.15) and the nucleation of $\mathrm{CaCO}_{3}$ microcrystals on Op C-S-H fibrils was abundant. SAED identified calcite to have principally formed in all the systems, precipitating as crystals approximately 50 $100 \mathrm{~nm}$ in size.
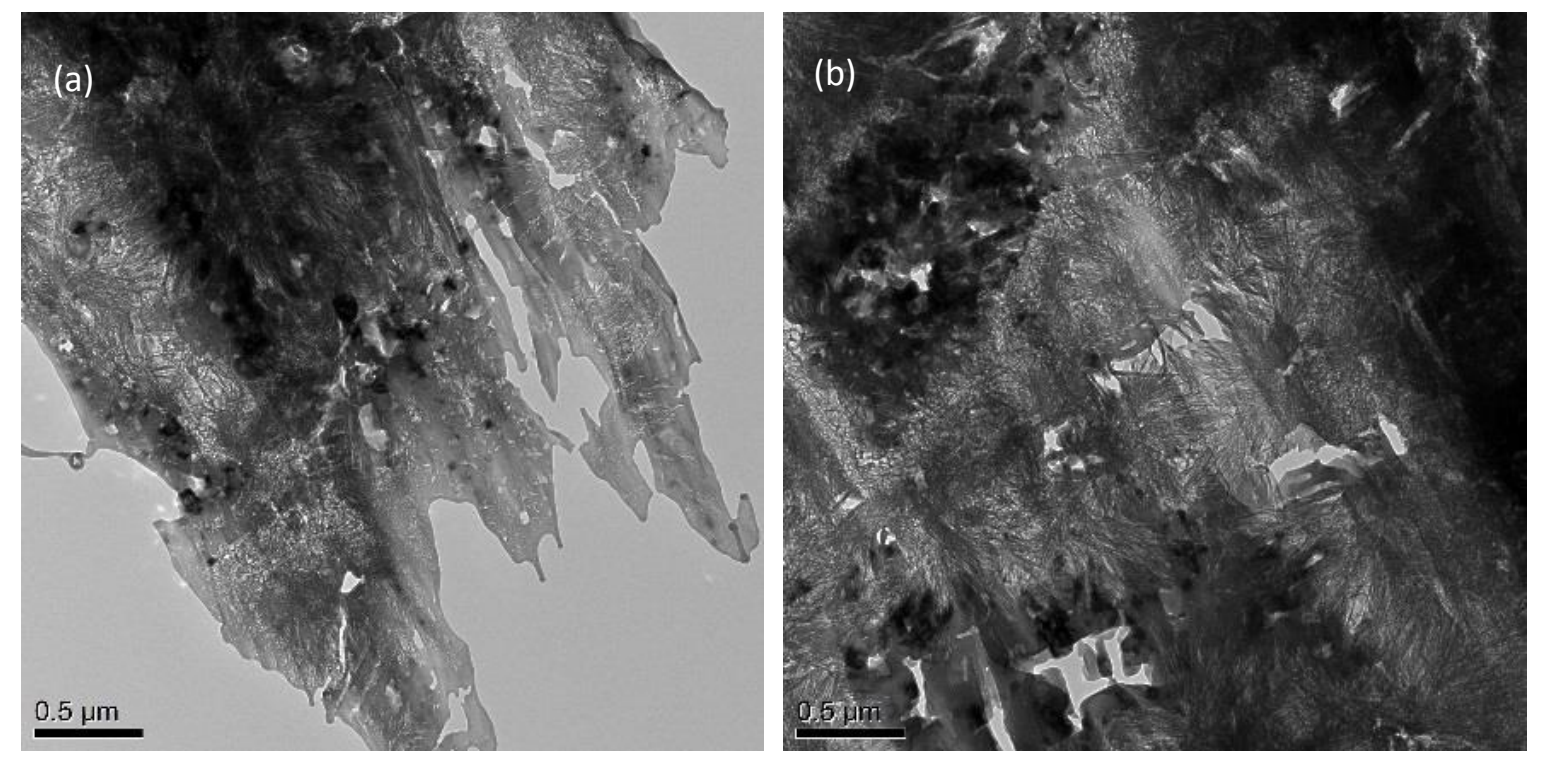

Figure 7.13. TEM micrographs of CEMI 0.57 (72hr) sample exposed to ambient $\left[\mathrm{CO}_{2}\right]$ for 60 days

The limited hydration and high $\mathrm{w} / \mathrm{b}$ ratio of the samples is expected to produce materials with open and underdeveloped microstructures (particularly the composite cements) in which the diffusion of $\mathrm{CO}_{2}$ will be permitted to occur easily. The presence of carbonate microcrystals throughout the microstructure was evident in all the micrographs (Figure 7.13, 7.14 \& 7.15), forming in large masses relatively uniformly in the Op zones. Carbonate microcrystals in Ip regions were typically not observed, or were not readily observed by strong Bragg reflections of the crystals in the TEM. 
However, crystalline SAED patterns for Ip C-S-H confirmed carbonate species to be present and EDX data collected at both early age and after prolonged exposure ( 28 day cured $60 \%$ slag sample - Table 7.3) indicated the migration of Ca from Ip to Op regions had also occurred. The effects of carbonation on the AFm phases is demonstrated in Figures 7.14 (c) and 7.15 (c) where originally dense and solid plates (Section 5.3.1) were observed to have significantly shrunk and split.
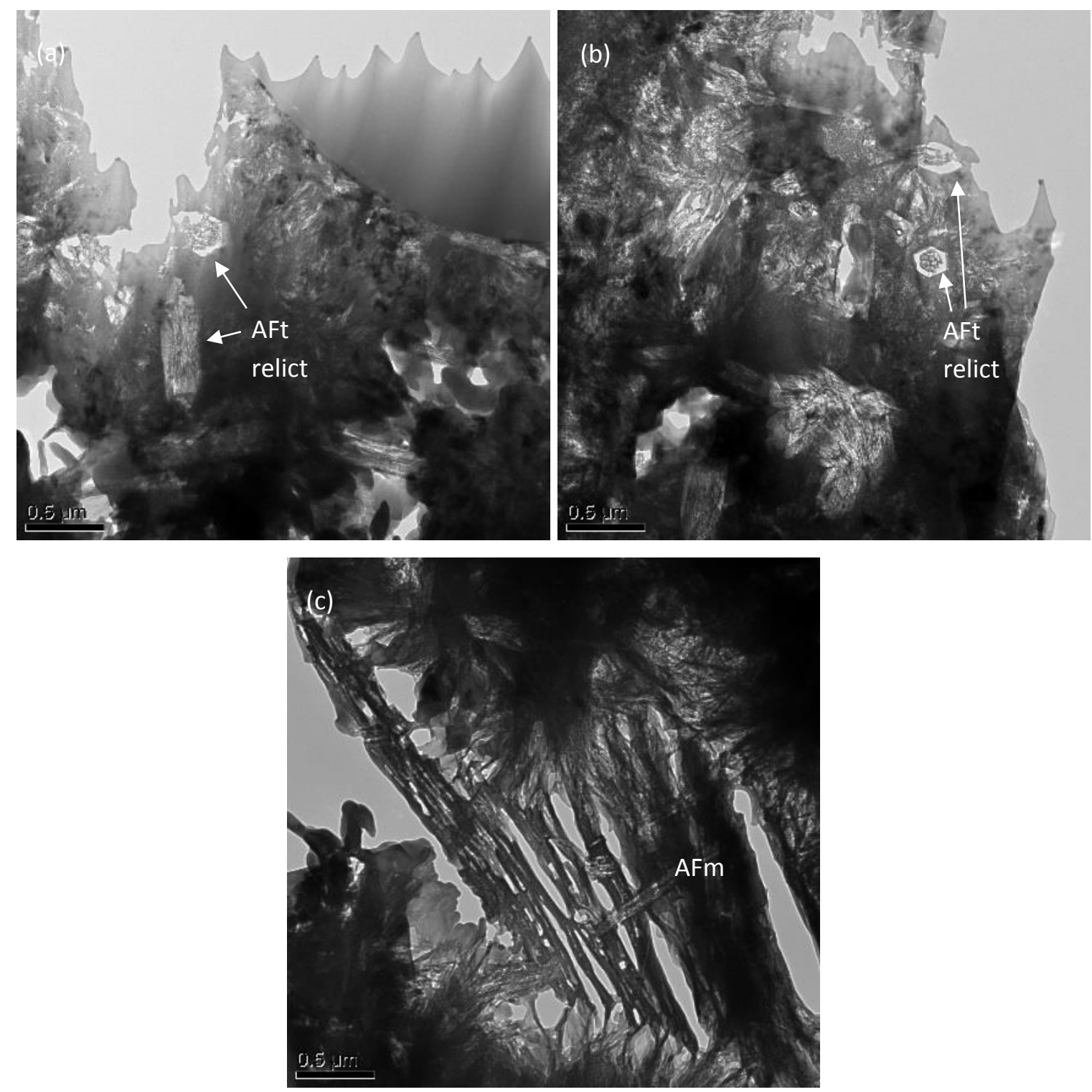

Figure 7.14. TEM micrographs of $30 \%$ PFA $0.57(72 \mathrm{hr})$ sample exposed to ambient $\left[\mathrm{CO}_{2}\right]$ for 60 days 
ATR-FTIR data showed partial decomposition of the C-S-H to silica gel at 60 days for all the 72 hour cured samples. Transformation of Op C-S-H fibrils to microporous silica in accelerated carbonation of $\mathrm{C}_{3} \mathrm{~S}$ pastes was reported by Groves et al. [79]. The fibrillar morphology observed in noncarbonated systems was reported to be preserved, while Ip regions became inhomogeneous, displaying large ranges of $\mathrm{Ca} / \mathrm{Si}$ ratios (0.26-1.0) and exhibiting silica rich gel in some areas and vaterite reflections in others. Although vaterite reflections were detected in Ip C-S-H regions, EDX data confirmed considerable migration of $\mathrm{Ca}$ to $\mathrm{Op}$ zones, contributing to the formation of carbonate crystals in Op capillary pores.
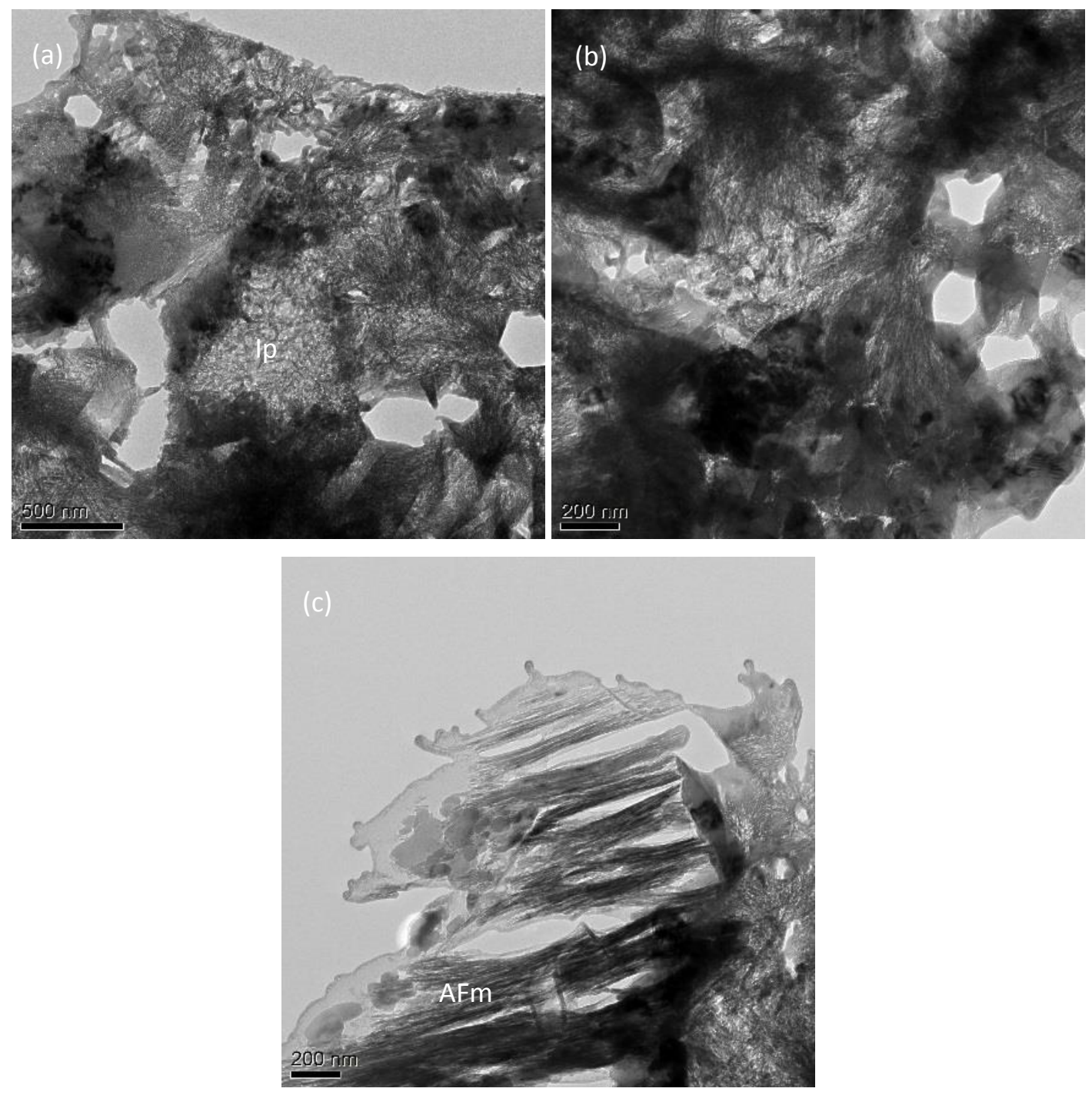

Figure 7.15. TEM micrographs of $30 \%$ GGBS 0.57 (72hr) sample exposed to ambient $\left[\mathrm{CO}_{2}\right]$ for 60 days 
The micrographs collected for the 28 day cured $30 \%$ and $60 \%$ slag samples following 60 days exposure to ambient $\mathrm{CO}_{2}$ are displayed in Figure 7.16 and 7.17 respectively. As for the short cured samples, carbonate microcrystals were observed to form in Op regions only. This is illustrated in Figure 7.16 (c) in which carbonate crystals have formed on Op C-S-H fibrils immediately next to a carbonate free Ip zone. No visual change in the C-S-H morphology was detected to have occurred, however the heavily decalcified Ip C-S-H of the $60 \%$ GGBS system, as measured by EDX (Table 7.3), demonstrated migration of $\mathrm{Ca}$ to $\mathrm{Op}$ areas, contributing to the formation of $\mathrm{CaCO}_{3}$. The fine, homogenous morphology of Ip C-S-H is expected to inhibit the growth of carbonate crystals, resulting in the relocation of $\mathrm{Ca}$ to $\mathrm{Op}$ regions where microcrystals are able to form easily in capillary pores. The effects of carbonation on the AFm phases was observed to be similar to that of the short cured systems, where originally dense plates appeared shrunken and split following decalcification (Figure 7.17(b). 

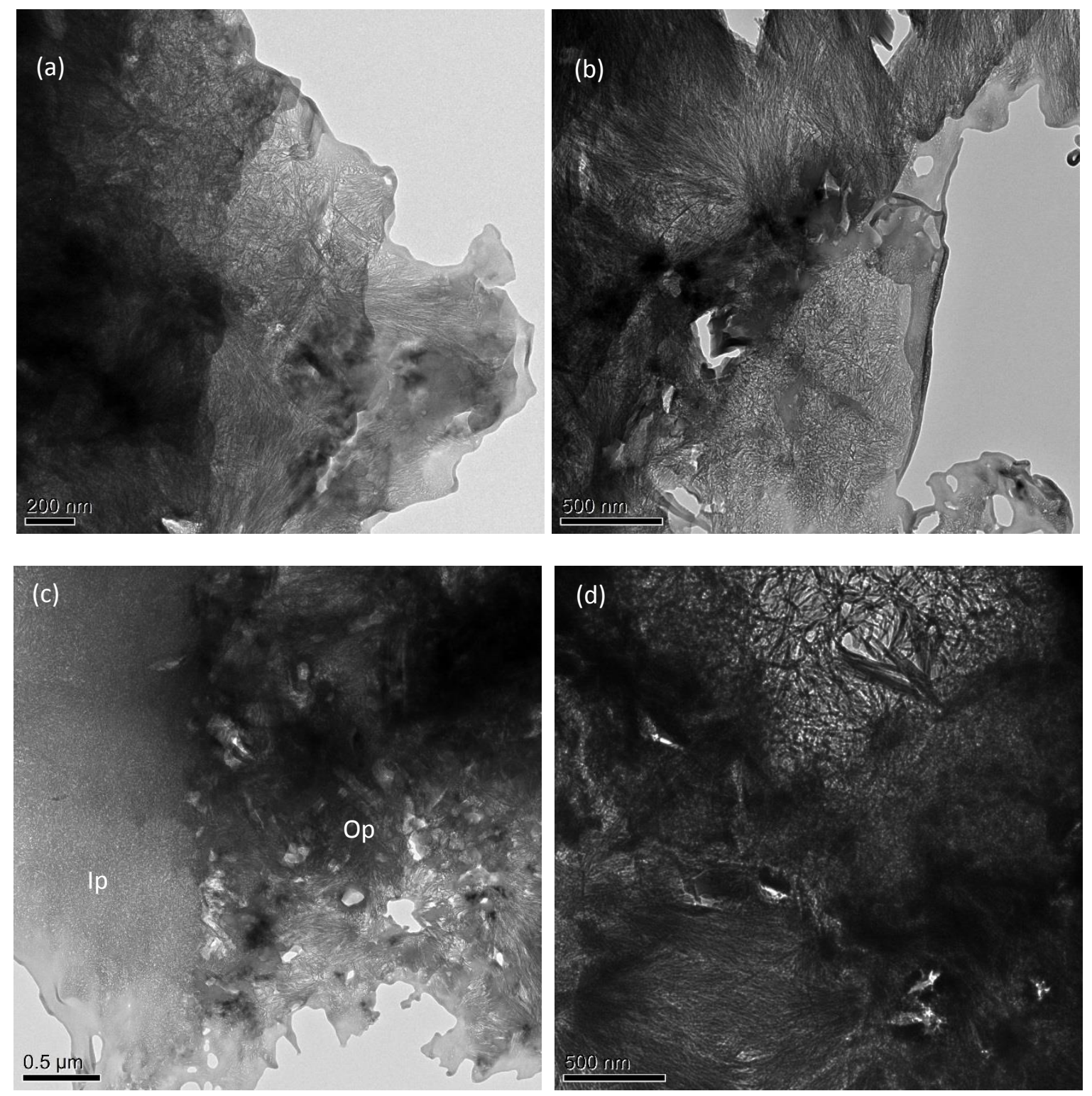

Figure 7.16. TEM micrographs of $30 \%$ GGBS 0.57 (28d) sample exposed to ambient $\left[\mathrm{CO}_{2}\right]$ for 60 days 

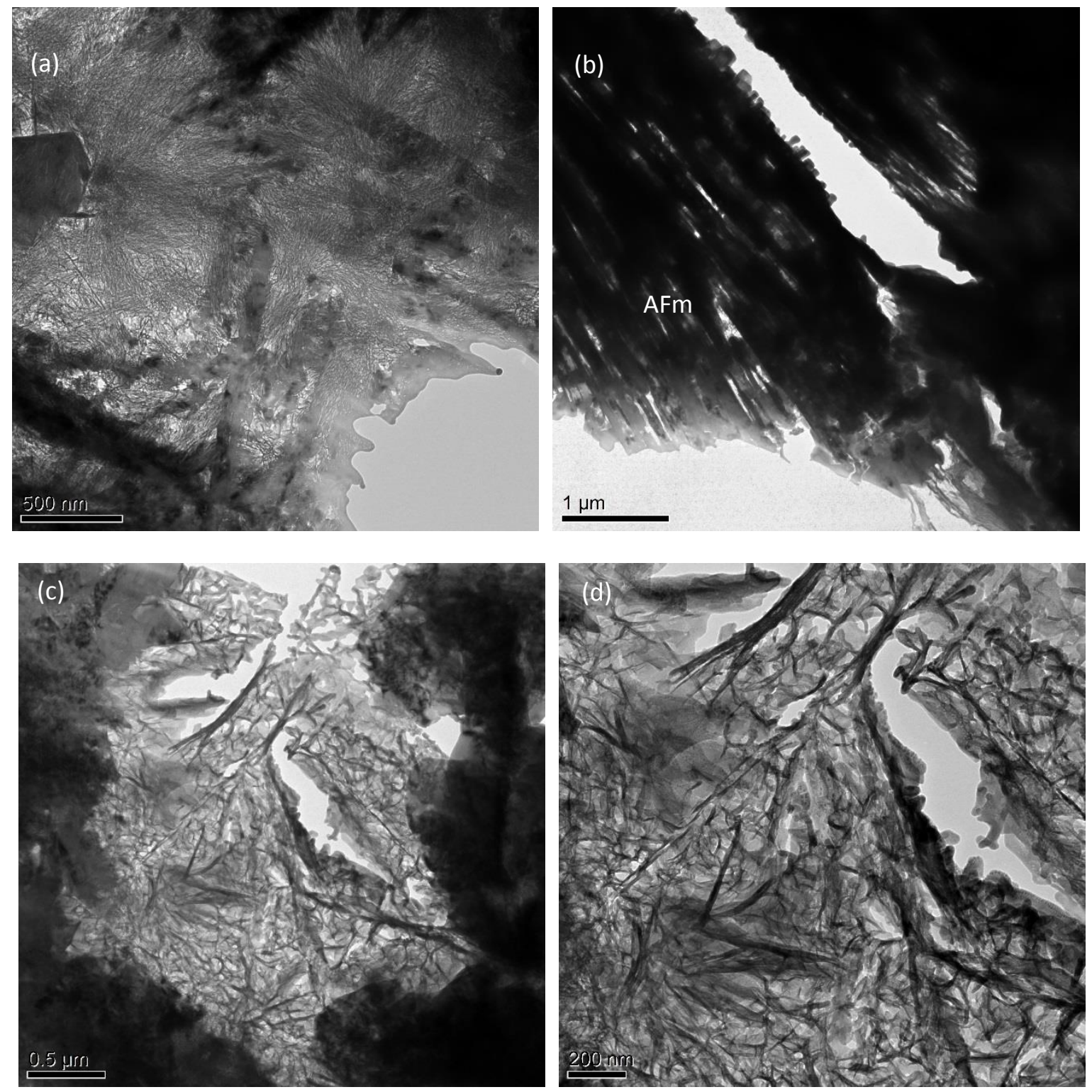

Figure 7.17. TEM micrographs of $60 \%$ GGBS 0.57 (28d) sample exposed to ambient $\left[\mathrm{CO}_{2}\right]$ for 60 days

\subsection{6 ${ }^{29}$ Si MAS NMR}

The deconvolution results of the ${ }^{29}$ Si NMR spectra are presented in Table 7.4 for the 72 hour cured samples, following 60 days' exposure to ambient $\mathrm{CO}_{2}$. Figure 7.18 displays the fitted spectra. At early ages of exposure, transformation of $Q^{1}$ silicate species to $Q^{2}$ sites was observed, resulting in 
lengthening of the silicate chains. At prolonged exposure, two new broad resonances appeared at approximately -90 and $-100 \mathrm{ppm}$, corresponding to the formation of a Ca modified silica phase [63, 64], in agreement with ATR-FTIR data (Section 7.1.3). As decalcification of the C-S-H progresses and $\mathrm{Ca}$ is withdrawn from the principal layers (after all the interlayer $\mathrm{Ca}$ has been removed) the $\mathrm{SiO}_{4}$ tetrahedra begin to form cross linked chains $\left(Q^{3},-93 p p m\right)$ [63]. Continued reaction causes conversion of the cross linked chains into a fully condensed silica phase $\left(Q^{4},-111 p p m\right)$ and the C-S$\mathrm{H}$ decomposes [63]. In accordance with the ATR-FTIR results, Ca modified silica gel formed in all the short cured samples, however ${ }^{29} \mathrm{Si}$ NMR results indicated that the degree to which this occurred was dependent on the system. First, silicate chains increased in length, $Q^{2}$ became dominant over $Q^{1}$ (early age carbonation, Section 6.1.6) and eventually the C-S-H structure began to break down and cross linked $Q^{3}$ sites were formed. As cross-linked chains decomposed further, condensing to amorphous silica, $Q^{3}$ transformed to $Q^{4}$. In the CEM I system, only $Q^{3}$ sites were observed, while the $30 \%$ replacement samples exhibited a combination of $Q^{3}$ and $Q^{4}$ species (greater proportion of $Q^{4}$ for PFA) and the $60 \%$ slag samples had a large broad peak for $\mathrm{Q}^{4}$ only. This correlated with changes in the $v_{3} \mathrm{Si}-\mathrm{O}$ band $\left(\sim 950 \mathrm{~cm}^{-1}\right)$ in the ATR-FTIR data where a shift to higher wavenumber indicated increased polymerisation (which corresponds to a lower chemical shift in the NMR - Table 7.3 [181]), and the presence of a new band at $1030-1200 \mathrm{~cm}^{-1}$ was related to a highly polymerised silica rich phase. In addition, a decrease in the intensity of the silicate band $\left(\sim 950 \mathrm{~cm}^{-1}\right)$ was evident for the composite materials at 60 days, and was attributed to decomposition of the C-S-H. The ${ }^{29} \mathrm{Si}$ NMR results confirmed this, showing the presence of fully condensed Si tetrahedra in the blended materials, where the CEM I system was only observed to have cross-linked chains $\left(Q^{3}\right.$ ) (and no changes in intensity were detected for the silicate band in the ATR-FTIR). Furthermore, the consumption of belite observed in XRD results (Section 7.1.2) at very high levels of carbonation was confirmed by ${ }^{29} \mathrm{Si}$ NMR which showed the absence of $\mathrm{Q}^{0}$ in the composite samples, and a decreased resonance for the CEM I system. At 60 days all the systems were a mixture of silica rich gel and highly decalcified C-S-H.

The fitting for the 30\% PFA and 60\% GGBS samples in Figure 7.18 do not include a peak for $\mathrm{Q}^{1}$, indicating infinite chains of silicate tetrahedra. A small quantity of $Q^{1}$ will be present, regardless of the degree of polymerisation, however it is not possible to include them in the fitting and consequently MCL values cannot be calculated for those samples. It should also be noted that the 
$\mathrm{Q}^{3}$ and $\mathrm{Q}^{4}$ resonances are not considered to be associated with the C-S-H silicate chains, but rather the amorphous silica gel, and therefore they have not been included in the calculation of the silicate chain lengths.
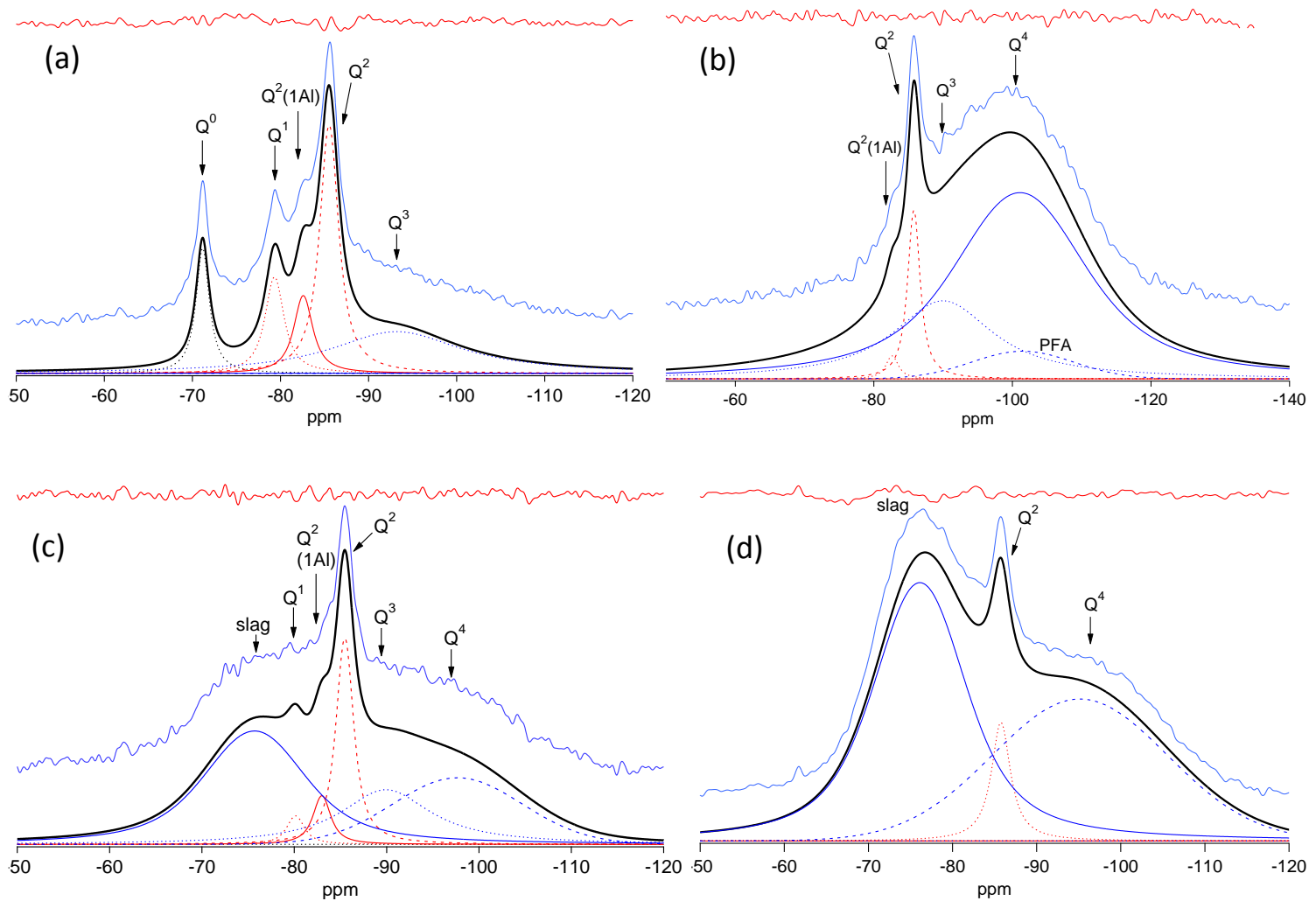

Figure 7.18. Single pulse ${ }^{29}$ Si NMR spectra for 72 hr (a) CEMI, (b) $30 \%$ PFA, (c) $30 \%$ GGBS, (d) $60 \%$ GGBS samples exposed to ambient $\left[\mathrm{CO}_{2}\right]$ for 60 days

Figure 7.19 displays the ${ }^{29} \mathrm{Si}$ NMR spectra collected for the 28 day cured samples exposed to ambient $\mathrm{CO}_{2}$ for 60 days. The deconvolution results for the 30\% PFA and 30\% GGBS samples are presented in Table 7.4 and the fittings are shown in Figure 7.20. 


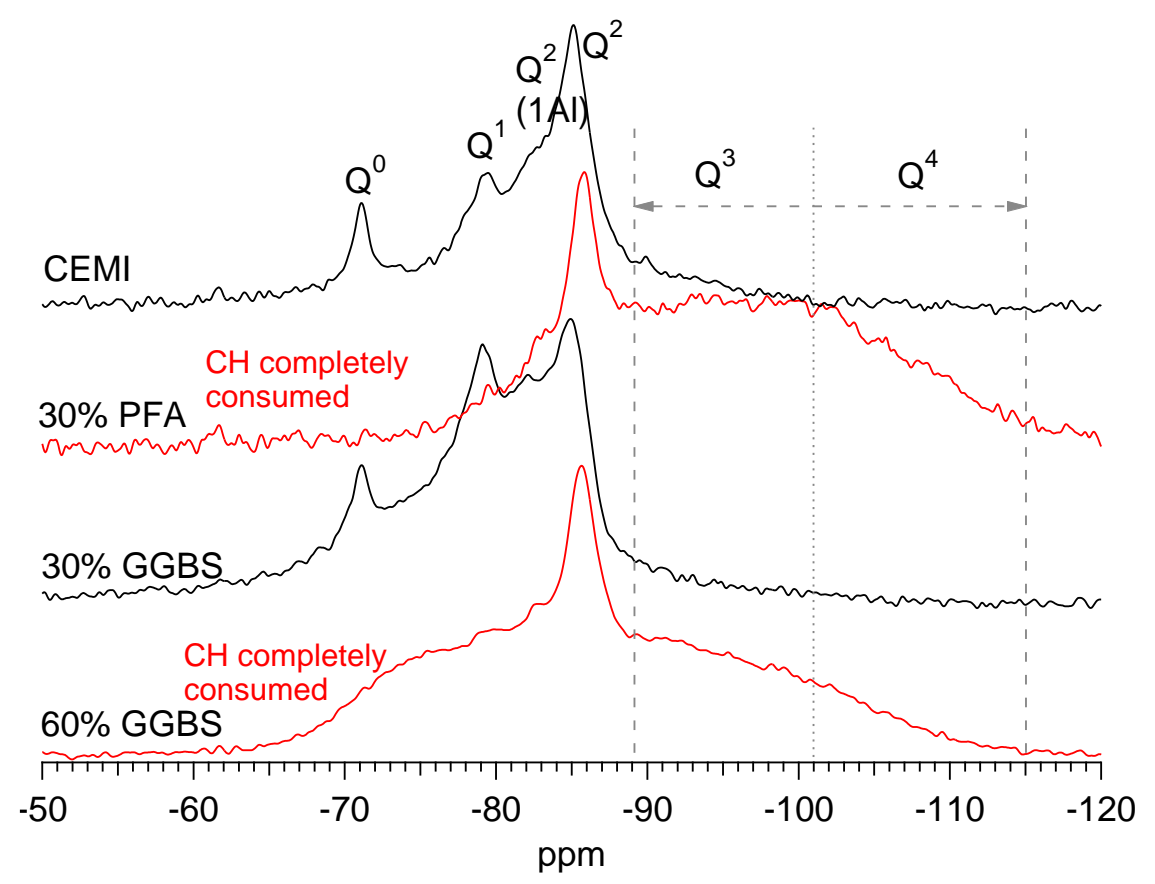

Figure 7.19. Single pulse ${ }^{29} \mathrm{Si}$ NMR spectra for 28 day cured samples exposed to ambient $\left[\mathrm{CO}_{2}\right]$ for 60 days

The spectra in Figure 7.19 illustrate the impact which the availability of $\mathrm{CH}$ had on the blended cement systems in regards to carbonation induced effects. For the $30 \% \mathrm{GGBS}$ sample (i.e. $\mathrm{CH}$ was still available), C-S-H decalcification occurred, evidenced by conversion of $Q^{1}$ species to $Q^{2}$ (Table 7.3), but this was relatively minor, and no $Q^{3}$ or $Q^{4}$ sites developed. In samples where $\mathrm{CH}$ was completely consumed (30\% PFA and 60\% GGBS), the spectra were remarkably similar to that observed for the same exposure age in the corresponding short cured systems. The final product was a silica rich gel intermixed with decalcified C-S-H in which chains were almost of infinite length (very slight $Q^{1}$ ) and any residual anhydrous cement $\left(Q^{0}\right)$ had been consumed.

Although increased carbonation rates had been observed for the CEM I system, changes in the C-S$\mathrm{H}$ structure were not as severe compared to the composite materials. The decomposition rate, due to carbonation, of synthetic C-S-H samples was reported to decrease with increasing $\mathrm{Ca} / \mathrm{Si}$ ratio [63], where blended systems with both lower $\mathrm{Ca} / \mathrm{Si}$ ratios and lower initial $\mathrm{CH}$ contents are expected to exhibit greater vulnerability to decalcification [80]. The two stage decalcification mechanism 
outlined by Sevelsted and Skibsted [63] describes gradual decalcification (until Ca/Si 0.67 - infinite chain lengths) of interlayer $\mathrm{Ca}$, followed by decomposition of the $\mathrm{C}-\mathrm{S}-\mathrm{H}$ via removal of $\mathrm{Ca}$ in the principal layers. As the $\mathrm{Ca} / \mathrm{Si}$ ratio decreases, as for composite materials, the Ca available in the interlayer is lower, effectively shortening the initial period of gradual reaction. The authors described a C-S-H with $\mathrm{Ca} / \mathrm{Si}$ ratio of 0.66 as containing no interlayer $\mathrm{Ca}$. The higher resilience to carbonation observed for the CEM I system is related directly to its higher $\mathrm{Ca} / \mathrm{Si}$ ratio. Chen et al [80] reported similar findings in decalcification studies using leaching, but reported accelerated decalcification shrinkage to occur from $\mathrm{Ca} / \mathrm{Si}$ of 1.2 and below.

Groves et al. [64] discussed differences in the polymerisation of the silicate chains following exposure to natural and accelerated $\mathrm{CO}_{2}$ conditions. In accelerated testing, the development of $\mathrm{Q}^{3}$ and $Q^{4}$ species was observed to occur before the intensity of $Q^{2}$ had overtaken that of $Q^{1}$. However, natural carbonation allowed $Q^{2}$ to increase in intensity in relation to $Q^{1}$ while no $Q^{3}$ and $Q^{4}$ peaks were detected. The results presented here are in good agreement with the authors' findings, gradual polymerisation of the C-S-H was observed as $Q^{2}$ increased in intensity over $Q^{1}$ (even in the presence of portlandite as for the $30 \%$ slag 0.57 (28d) sample) before silica gel formed. The shift in the silicate band $\left(v_{3} \mathrm{Si}-\mathrm{O} \sim 950 \mathrm{~cm}^{-1}\right)$ in the ATR-FTIR spectra for the ideally cured $30 \%$ slag sample appeared to be related to the ratio of $Q^{1}$ and $Q^{2}$ species. As $Q^{2}$ became predominant over $Q^{1}$, higher polymerisation of the silicate tetrahedra was reflected as a shift in wavenumber in the infrared spectrum.

The changes in the degree of polymerisation in the $30 \%$ slag system between 72 hour and 28 day cured samples reinforced the huge differences that exist for properly and poorly cured blended materials. At 4 days' carbonation, the 72 hour cured system had a MCL of 8.2, while at 60 days exposure the 28 day cured sample had a MCL of 6.6. Carbonation studies on highly hydrated composite cements may not be an accurate reflection of their behaviour following much shorter periods of curing. Furthermore, the higher $\mathrm{Ca} / \mathrm{Si}$ ratio of CEM I materials provides greater resistance to carbonation induced effects and as a result differences in carbonation behaviour of short and ideal curing periods are much less evident compared with composite materials. 
(a)

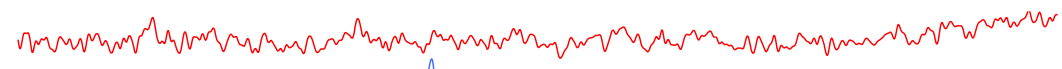

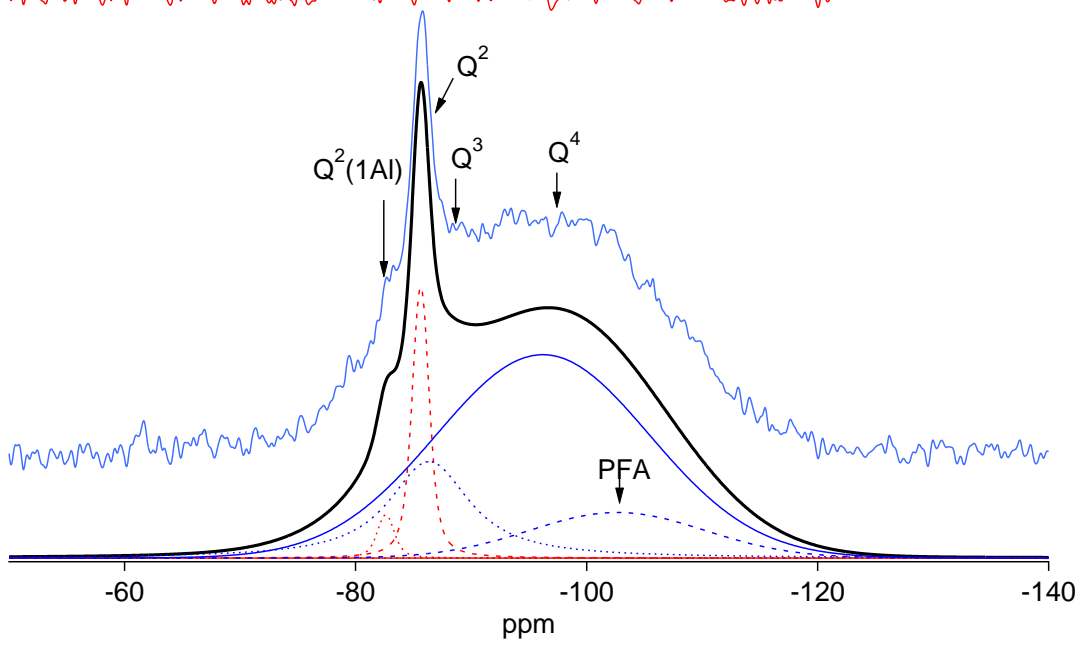

(b)
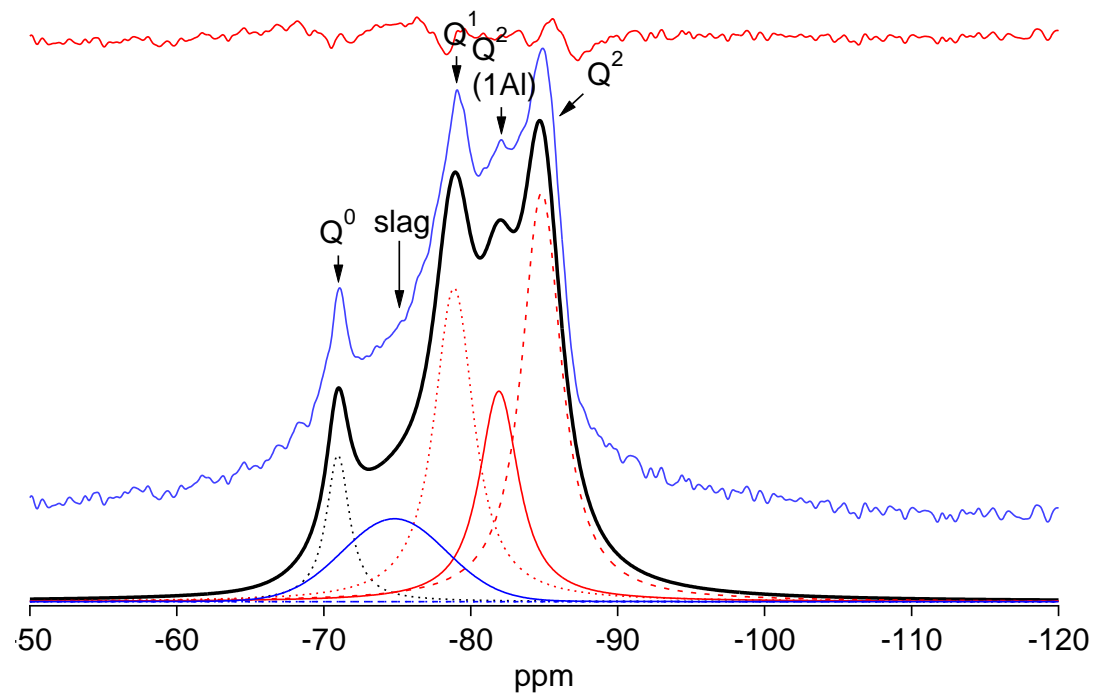

Figure 7.20. Single pulse ${ }^{29}$ Si NMR spectra for 28 day (a) 30\% PFA and (b) $30 \%$ GGBS samples exposed to ambient $\left[\mathrm{CO}_{2}\right]$ for 60 days 


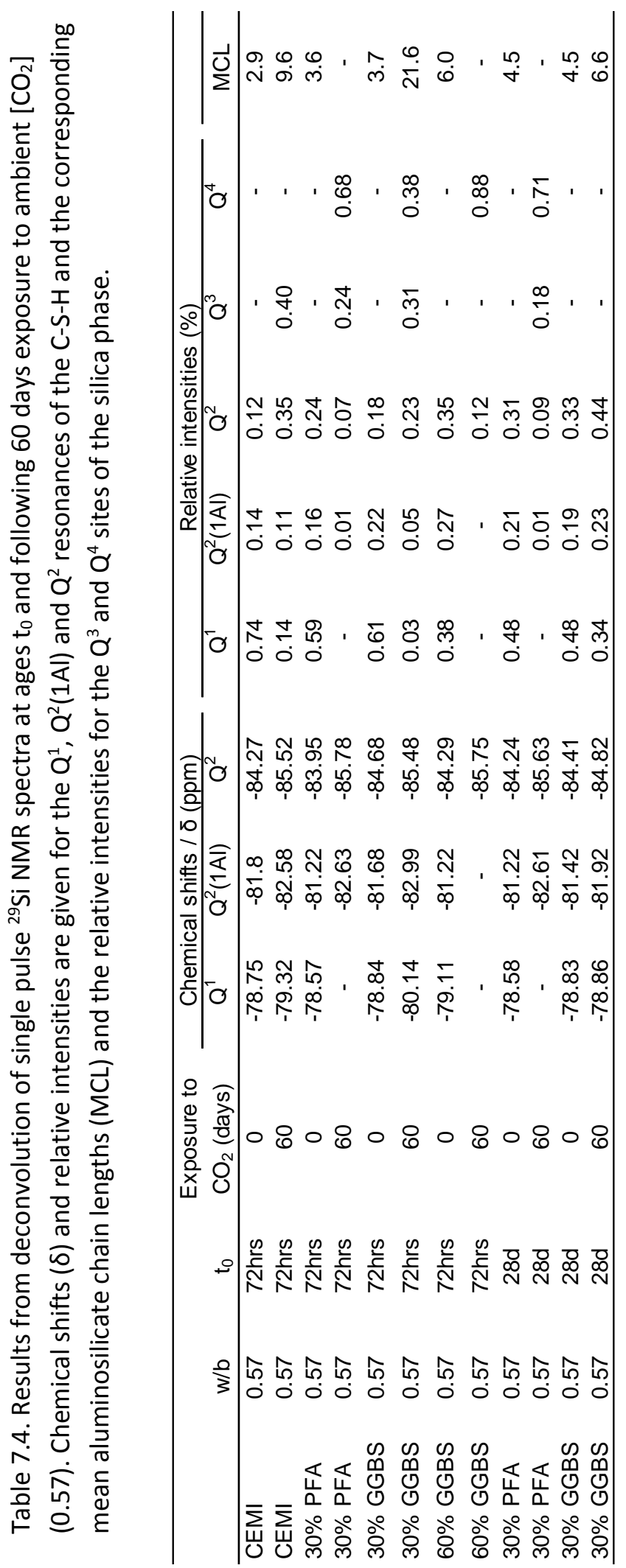




\subsection{Carbonation of systems at $\mathrm{w} / \mathrm{b}$ ratio 0.40}

\subsubsection{Thermal analysis}

The $\mathrm{CH}$ and $\mathrm{CaCO}_{3}$ contents for both the $72 \mathrm{hr}$ and the 28 day cured samples with $\mathrm{w} / \mathrm{b} 0.40$ are shown in Figure 7.21. The consumption of $\mathrm{CH}$ from 7 days in the $72 \mathrm{hr}$ cured $60 \%$ slag system resulted in a large increase in carbonate content, and a notable decrease in carbonate decomposition temperature (as previously discussed in Section 6.2.1). At 60 days, the $\mathrm{CaCO}_{3}$ content was similar to that observed for the higher w/b ratio systems following equivalent lengths of reaction (between $0.3-0.35 \mathrm{~mol} / 100 \mathrm{~g}$ in all cases). For the remaining systems ( $72 \mathrm{hr}$ ), both the CEMI and fly ash samples demonstrated improved performance compared to the corresponding ideally cured (28d) samples at higher w/b ratio (0.57), where lower quantities of carbonate were produced and $\mathrm{CH}$ remained present for the full exposure length tested. The $30 \%$ slag sample exhibited poorer carbonation resistance compared with its ideally cured 0.57 equivalent, demonstrating consumption of $\mathrm{CH}$ at 60 days, however all the systems showed improved resilience when compared with the short cured samples at higher water content. Following 28 days curing, small quantities of portlandite remained in all the samples, and the refining effects of the slag on the pore structure resulted in comparable performance of the materials to the CEMI sample despite much lower initial $\mathrm{CH}$ contents. The limited degree of reaction of the fly ash (which is predicted to be inhibited further by the decreasing water content), however, resulted in much the more rapid carbonation of $\mathrm{CH}$ and a subsequently greater increase in carbonate content.

At lower $\mathrm{w} / \mathrm{b}$ ratios the carbonation resistance of CEMI and moderate replacement (30\%) composite materials was observed to improve as a result of the lower porosity of the systems following short periods of curing. For CEMI and 30\% PFA materials, their performance was superior to that of the ideally cured samples at higher w/b ratio. However, at high levels of replacement these effects can't be mitigated and materials demonstrated similar behaviour to that observed for the higher $\mathrm{w} / \mathrm{b}$ ratio materials. Ideally cured, low $\mathrm{w} / \mathrm{b}$ ratio systems exhibited the best resistance to carbonation in which both slag containing samples (30 and 60\%) outperformed the $30 \%$ fly ash paste. 
(a)

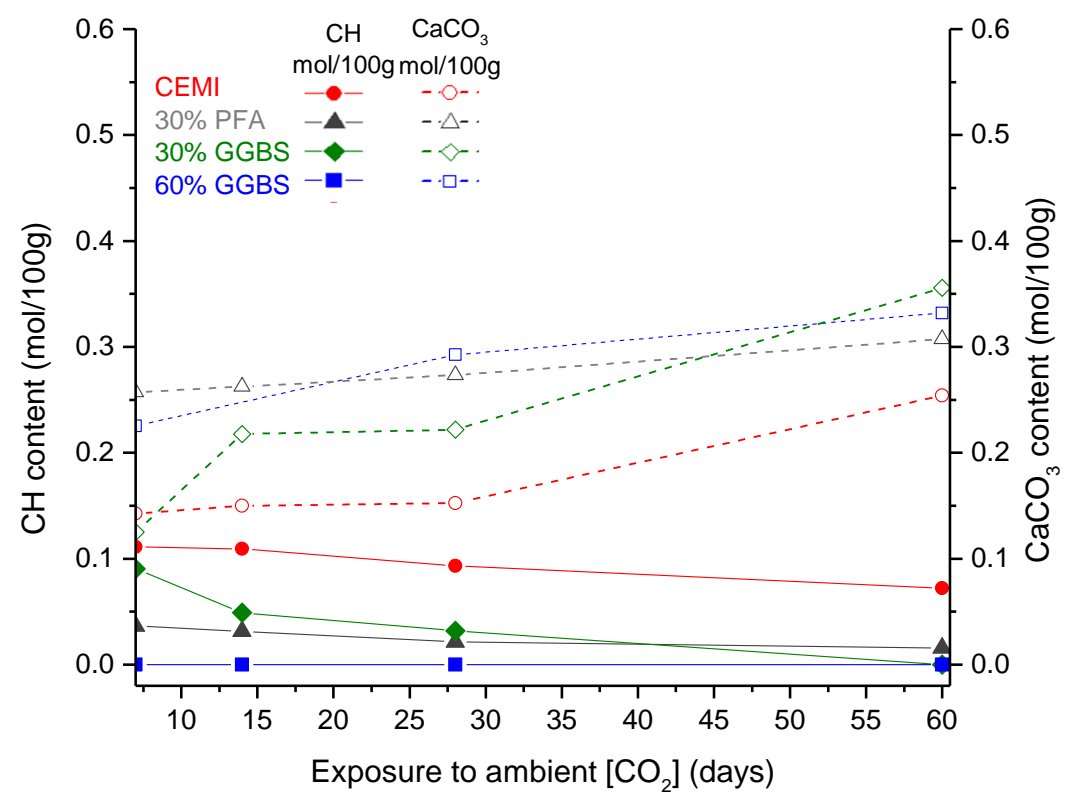

(b)

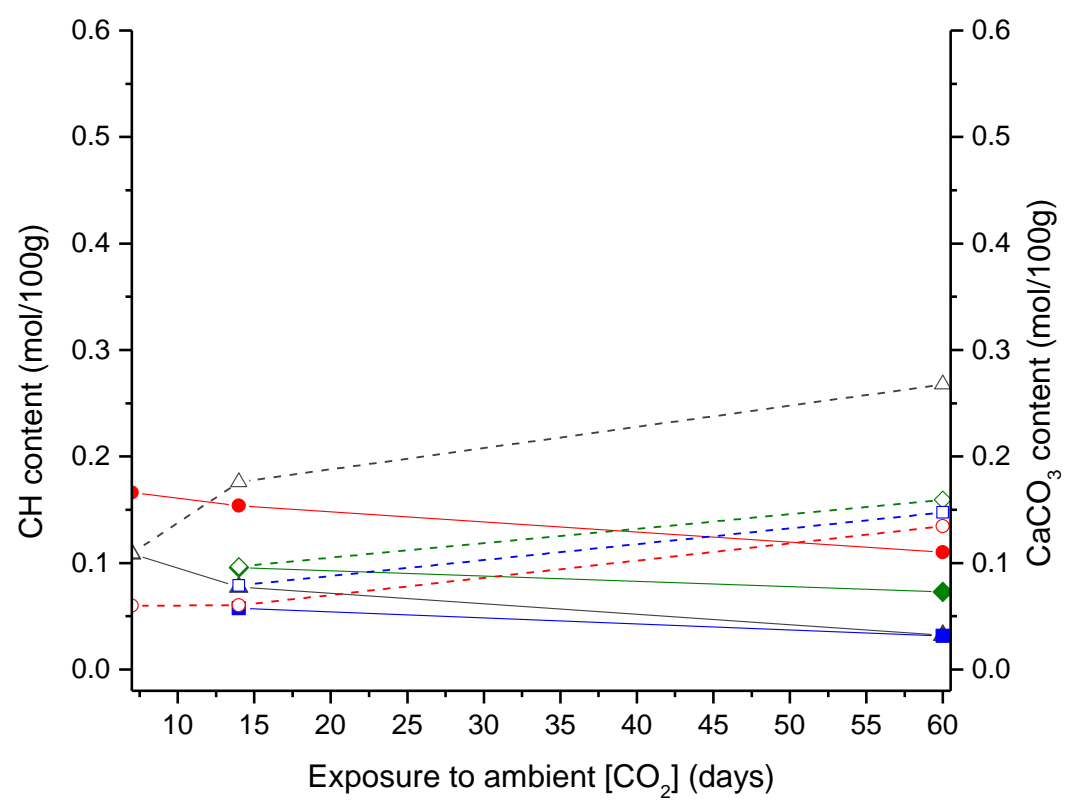

Figure 7.21. $\mathrm{CH}$ and $\mathrm{CaCO}_{3}$ contents determined from TGA data for 72 hour cured (a) and 28 day cured (b) systems following exposure to ambient $\left[\mathrm{CO}_{2}\right]$ between 7 and 60 days. Values are shown in $\mathrm{mol} / 100 \mathrm{~g}$. 


\subsubsection{XRD}

XRD data was in good agreement with the TGA results. Figure 7.22 confirmed $\mathrm{CH}$ to be present in the CEMI system, and a small quantity in the $30 \%$ fly ash and slag samples. The resulting changes in the phase assemblage were relatively minor, calcite dominated as the carbonate polymorph formed in all the systems and small quantities of AFt remained in the composite materials. AFt appeared to remain unchanged for the CEMI sample, as did the intensity of the reflections of belite. Small decreases in the intensity of the belite diffraction peak were observed for the $30 \%$ fly and slag samples, and it had almost entirely disappeared for the $60 \%$ slag material. Complete consumption of all the hydrate phases was detected for the $60 \%$ GGBS material following prolonged exposure to $\mathrm{CO}_{2}$. Ideally cured samples demonstrated much smaller changes in the crystalline phase assemblage, relating mainly to decreases in the intensity of the portlandite reflections and the presence of calcite diffraction peaks. AFt and $\mathrm{C}_{2} \mathrm{~S}$ appeared to remain unaffected.
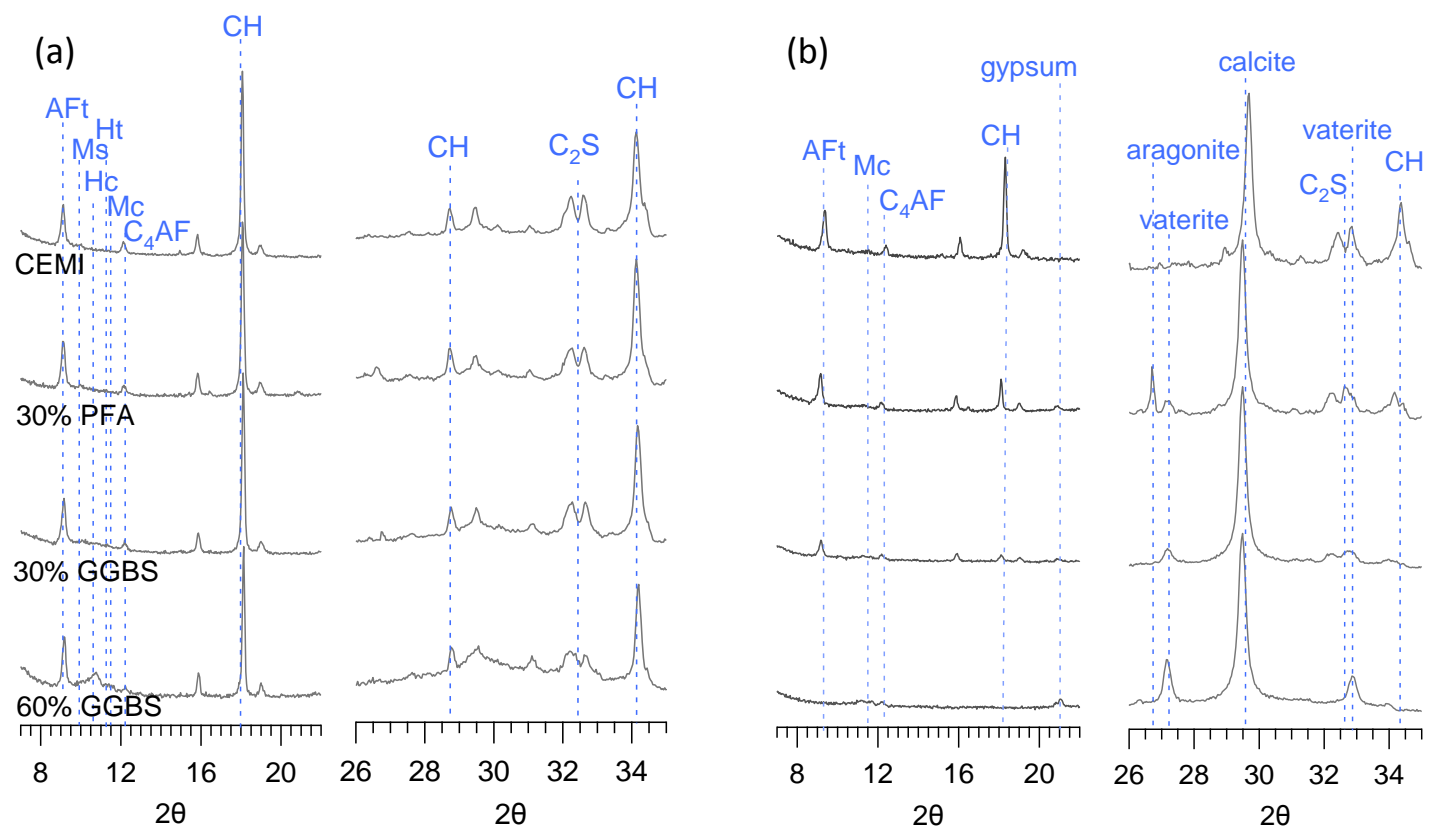

Figure 7.22. XRD patterns between $7-22^{\circ} 2 \theta$ and $26-35^{\circ} 2 \theta$ showing the crystalline phase assemblage of 72 hour cured systems at (a) $t_{0}$ and (b) following 60 days exposure to ambient $\mathrm{CO}_{2}$ 

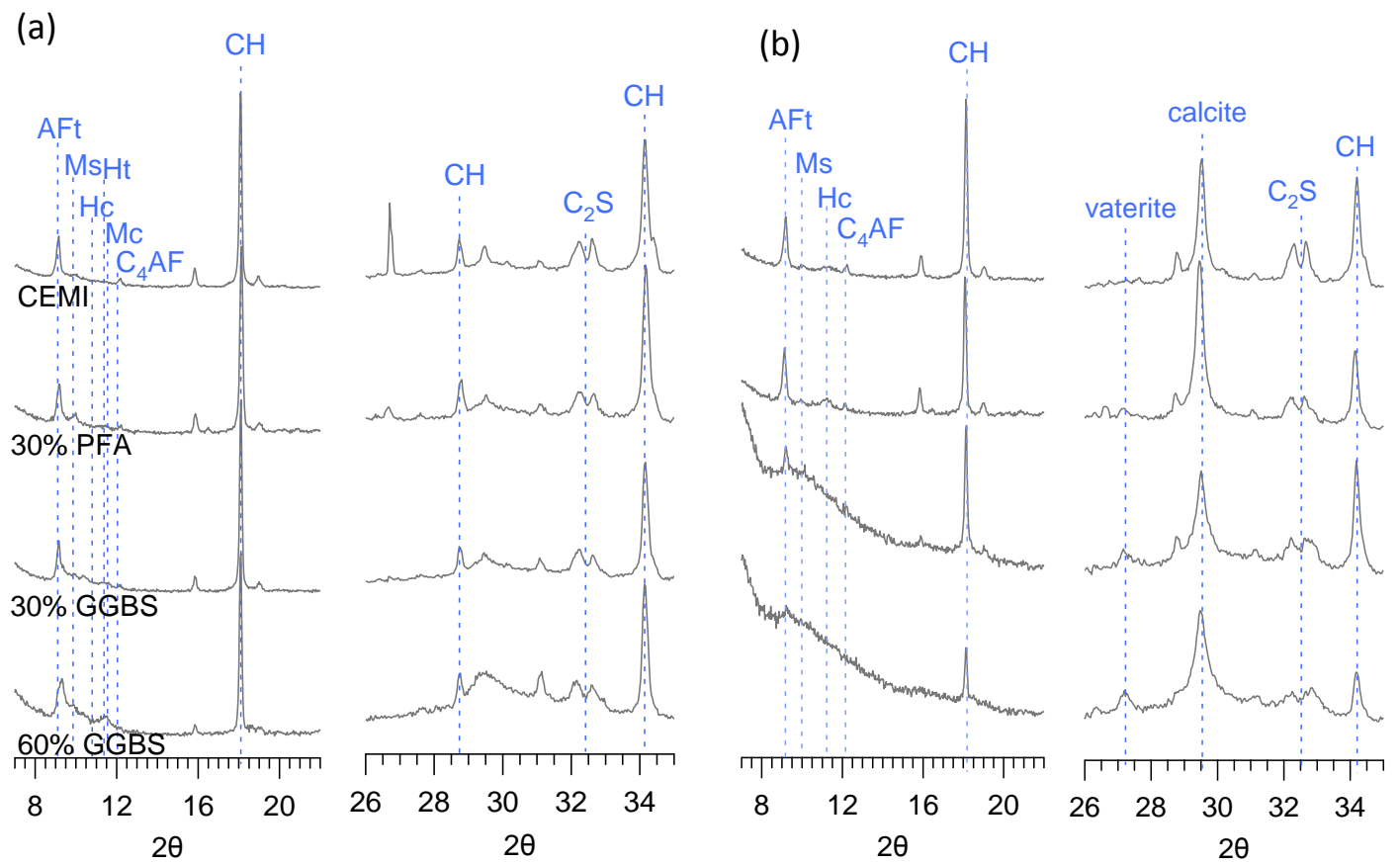

Figure 7.23. XRD patterns between $7-22^{\circ} 2 \theta$ and $26-35^{\circ} 2 \theta$ showing the crystalline phase assemblage of 28 day cured systems at (a) $t_{0}$ and (b) following 60 days exposure to ambient $\mathrm{CO}_{2}$

\subsection{3 ${ }^{27} \mathrm{AI}$ MAS NMR}

The ${ }^{27} \mathrm{AI}$ NMR spectra collected for the 72 hour cured samples following 60 days exposure to ambient $\mathrm{CO}_{2}$ are displays in Figure 7.24. Carbonation of both AFt and the AFm phases was observed for all the systems, however complete decomposition was determined for the $60 \%$ slag samples in which $\mathrm{CH}$ had been consumed from 7 days reaction. Much larger decreases in the intensity of the resonance at $\sim 9 \mathrm{ppm}$ (relating to $\mathrm{AFm}$ ) in relation to the resonance at $\sim 13 \mathrm{ppm}$ (relating to $\mathrm{AFt}$ ), for the remaining systems, confirmed the primary involvement of the AFm phases in the carbonation reaction compared to AFt. The spectra illustrate the rate determining effect of $\mathrm{CH}$ on the carbonation of the remaining phases. In its presence, simultaneous reaction of the hydrates is observed to occur with $\mathrm{CO}_{2}$, however to a relatively minor degree. When portlandite is no longer available, however, the Ca bearing hydrates react at a much faster rate and are permitted to decompose completely. 


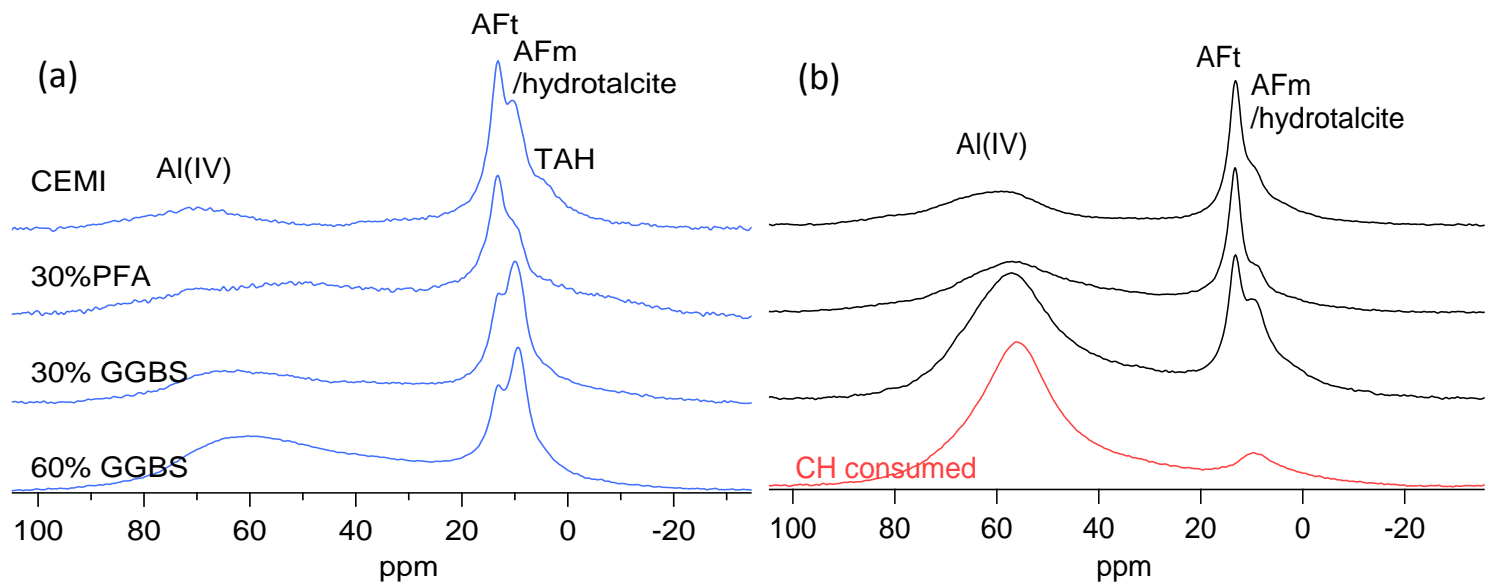

Figure 7.24. Single pulse ${ }^{27} \mathrm{Al}$ NMR spectra $0.40-72 \mathrm{hr}$ cured (a) to samples and (b) following exposure to ambient $\left[\mathrm{CO}_{2}\right]$ for 60 days

\subsection{Conclusions}

- $\mathrm{CH}$ is the rate determining factor for the carbonation resistance of cement systems. In its presence, simultaneous reaction of the hydrates is observed to occur with $\mathrm{CO}_{2}$, however to a relatively minor degree. When portlandite is no longer available, however, the Ca bearing hydrates react at a much faster rate and are permitted to decompose completely. Its consumption, however, is controlled by the ability of $\mathrm{CO}_{2}$ to diffuse through the microstructure.

- At high $\mathrm{w} / \mathrm{b}$ ratios, increased curing (28 days) resulted in the presence of $\mathrm{CH}$ for much longer in all the systems, however when it was consumed, or passivated, the carbonation behaviour was very similar to the short cured samples in which large increases in carbonate content were observed indicating a more aggressive decalcification reaction.

- The impact of increased curing was most evident for the $30 \%$ slag system, which exhibited the highest resistance to carbonation ( $w / b 0.57,28 d)$. The improved effects were predicted to a result of refinement of the porosity but were not observed to occur for the equivalent fly ash sample.

- Following 72 hours, the reaction of the fly ash and slag is relatively low. Positive impacts on the microstructure that might be expected in composite materials were not observed to occur due to insufficient reaction of the slag or fly ash glass. The lower reaction of the PFA 
results in poor performance of the systems following 28 days curing, emphasising the differences in the replacement materials even following 'ideal' curing lengths (i.e. greater reactivity of GGBS and more efficient porosity refinement).

- Low Ca/Si C-S-H is more susceptible to decalcification, however, refinement of the porosity has the ability to offset this but is dependent upon significant reaction of the SCM. Low reactivity permits greater diffusion throughout the system.

- The carbonation of the AFm phases was observed to occur in two stages. First, phase transformation from $\mathrm{SO}_{4}$ (monosulfoaluminate) to $\mathrm{CO}_{3}$ (hemi- and monocarboaluminate) bearing species was observed to occur, ultimately decomposing by decalcification. The availability of $\mathrm{CH}$, however, prevented complete decomposition.

- During later ages of carbonation when $\mathrm{CH}$ had been entirely consumed, the carbonation of remaining anhydrous material was observed (XRD and $\left.{ }^{29} \mathrm{Si} N \mathrm{NM}\right)$ to occur. The release of water from the rapid carbonation of the remaining hydrate phases, particularly AFt, resulting in the hydration of remaining anhydrous clinker grains.

- During elevated rates of carbonation (i.e. when $\mathrm{CH}$ no longer accessible) CEM I was shown to be more resilient to carbonation induced effects (XRD, ${ }^{29} \mathrm{Si} N M R$, ATR-FTIR). Small quantities of AFt remained in the samples up to 60 days exposure and changes in C-S-H structure (polymerisation and formation of silica gel) were observed to occur more slowly, demonstrating a longer period of retention even when portlandite is no longer present.

- The fate of aluminium from the carbonation AFm and AFt was unclear. ${ }^{27} \mathrm{Al}$ NMR spectra indicated it was incorporated into the amorphous silica phase produced from the carbonation of $\mathrm{C}-\mathrm{S}-\mathrm{H}$. This was further reinforced by the absence of a new octahedral resonance relating to alumina gel.

- The production of vaterite in XRD and ATR-FTIR data appeared to be related to the carbonation of $\mathrm{C}-\mathrm{S}-\mathrm{H}$, particularly low $\mathrm{Ca} \mathrm{C}-\mathrm{S}-\mathrm{H}$. Greater proportions of vaterite in relation to calcite were evident in composite materials following longer periods of hydration. As the rate of decalcification was perceived to increase (XRD, STA, ATR-FTIR), Ca/Si ratios decreased further and vaterite became dominant.

- Silica gel formed in all short cured systems following exposure to ambient $\mathrm{CO}_{2}$ concentrations at w/b $0.57\left({ }^{29} \mathrm{Si}\right.$ NMR, ATR-FTIR). The formation of $\mathrm{Q}^{4}$ sites was related to 
total decomposition of the $\mathrm{C}-\mathrm{S}-\mathrm{H}$ which resulted in a decrease in the intensity of the v3 Si-O band. No decrease was observed for the CEMI sample in which only $Q^{3}$ species had formed.

- Low $\mathrm{w} / \mathrm{b}$ ratios were unable to mitigate the effects of short curing periods for systems with high levels of substitution. The performance of the short cured $(72 \mathrm{hr})$ low w/b ratio $(0.40)$ CEMI and 30\% PFA systems was determined to be greater than for the equivalent ideally cured $(28 \mathrm{~d})$ samples at $\mathrm{w} / \mathrm{b}$ ratio 0.57 . 


\section{Chapter 8}

\section{The effect of carbonation on engineering properties and its implications for}

\section{durability and cover depth}

The service life of concrete structures is largely focused on sustainable design and is reflected in building and design codes which now require longer service lives of up to $75-100$ years. In reinforced concrete structures the service life is ultimately determined by the time to corrosion initiation of the steel, which is governed by the concrete cover depth. The cover depth is thought to provide a reliable prediction of a structure's service life, however the number of reinforced concrete structures reported to have problems relating to reinforcement corrosion has increased in recent years $[183,184]$ suggesting that poor quality concrete and inadequate cover depths are the major cause of vastly reduced initiation periods. This chapter relates the depth of carbonation of mortar samples to the carbonation mechanisms of the corresponding paste samples studied in the previous chapters. The potential implications on engineering and durability properties and design specifications is discussed.

\subsection{Carbonation depth of mortar samples}

Figure 8.1 displays the carbonation depth measured on the mortar prisms using phenolphthalein indicator (distance from edge of sample to colour change boundary) following exposure to ambient concentrations for 18 months. Mortar prisms were stored in a structures laboratory in which ambient conditions were approximately: $\mathrm{RH} 50 \%+/-10 \%,\left[\mathrm{CO}_{2}\right] \approx 450 \mathrm{ppm}$.

Phenolphthalein solution gives an approximate indication of the depth of carbonation $/ \mathrm{CO}_{2}$ ingress by turning colourless at $\mathrm{pH}<8.2$ and fuchsia/purple at $\mathrm{pH}>9$. The carbonation reaction slowly neutralises the cement pore solution, the degree of carbonation can be expected to be between 0 - 50\% between pH 9 - 11.5 [185] resulting in some limitations in the accuracy of the technique. Chang and Chen [185] discussed the relationship between true carbonation depth, as measured by TGA, XRD and FTIR, and the depth measured using phenolphthalein indicator and observed the carbonation depth measured using the base indicator to be half of that compared to the more 
advanced techniques (TGA, XRD, FTIR). Although phenolphthalein has some limitations, the test is still regarded as a good gauge for corrosion initiation.

Figure 8.1 indicates that for the CEMI and 30\% replacement systems, the ingress of $\mathrm{CO}_{2}$ was principally controlled by the $w / b$ ratio. At $a \mathrm{w} / \mathrm{b}$ ratio of 0.57 , the mean carbonation depth was markedly higher for both lengths of curing, and this was amplified in the blended materials. The slag system, however, was observed to have greater carbonation resistance compared with the equivalent fly ash system, the slower reaction rate of PFA $[5,6]$ negatively affecting overall degree of hydration and total porosity. This was most striking for the 28 day cured PFA samples which showed an extremely large carbonation depth $(\sim 11 \mathrm{~mm})$, having a greater mean value than that the corresponding $60 \%$ slag system $(\sim 7 \mathrm{~mm})$, where both systems had equal initial strengths ( $\sim 5 \mathrm{MPa}$ at 1 day). The effect of curing was more apparent for the $60 \%$ GGBS system, where for both $\mathrm{w} / \mathrm{b}$ ratios the difference in carbonation depth was much greater between the two curing lengths. Curing for 72 hours had a significant impact on the extent of carbonation ingress at both high and low water contents, emphasising the need for extended curing periods at higher levels of substitution. 

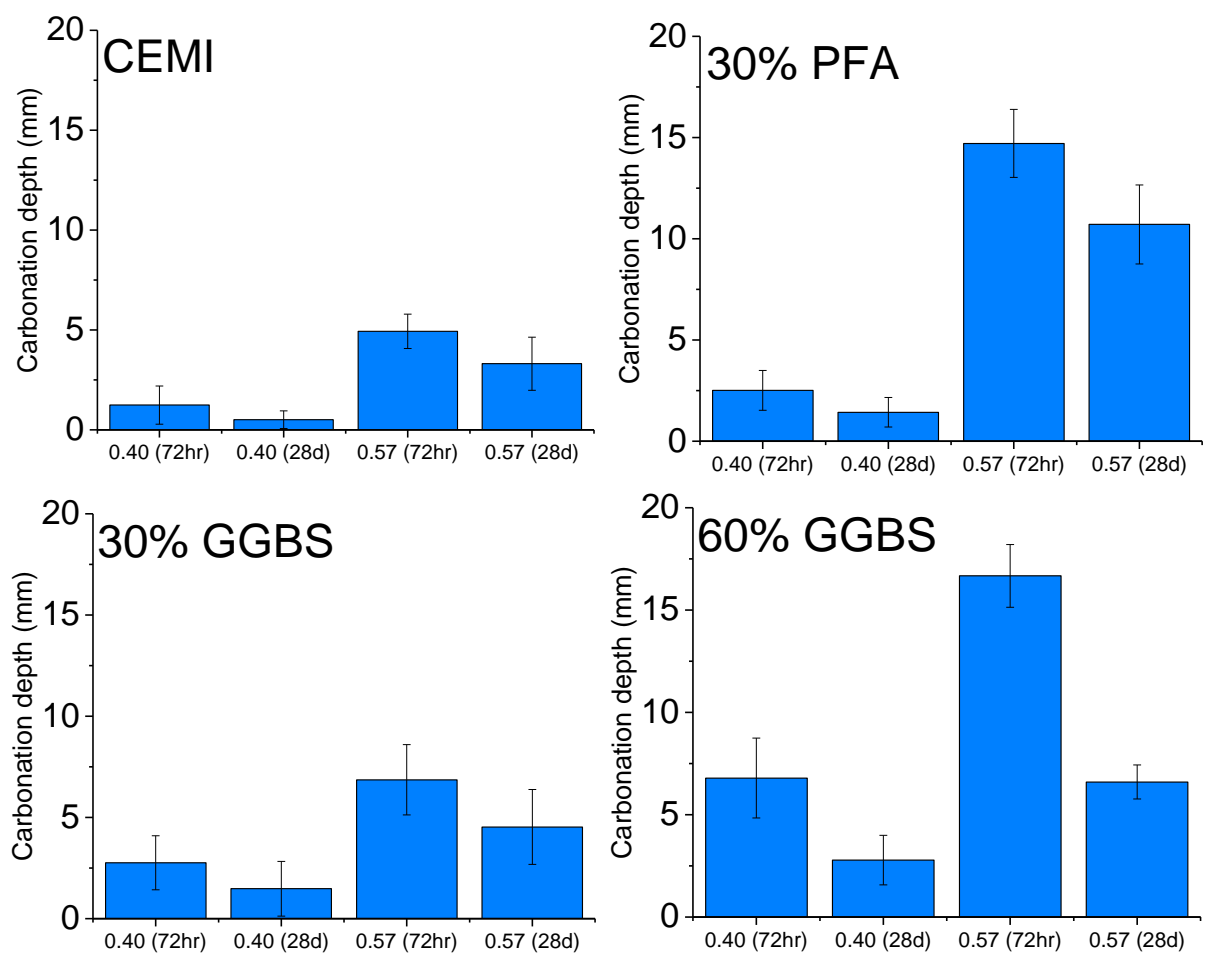

Figure 8.1. Carbonation depth of mortar samples exposed to ambient $\mathrm{CO}_{2}$ concentrations for 18 months. Depth of carbonation was measured using phenolphthalein indicator.

Khunthongkeaw et al. [186] observed similar behaviour for fly ash concretes in which better resistance to carbonation was reported with decreasing $\mathrm{w} / \mathrm{b}$ ratio and decreasing content of fly ash. Improved performance was reported for fly ash with higher $\mathrm{CaO}$ content, compared to a low $\mathrm{CaO}$ fly ash, at equivalent levels of substitution. Ho and Lewis [187] determined the w/c ratio, rather than the $\mathrm{w} / \mathrm{b}$ ratio, to be the most reliable parameter in predicting the resistance of concretes to carbonation following limited initial curing. This relationship is somewhat applicable for the CEMI and slag containing systems studied here, however equal replacement by PFA and GGBS (30\%, w/c 0.81) gave vastly different results in which the depth of carbonation ingress was measured to be almost double for $30 \%$ PFA samples at $\mathrm{w} / \mathrm{b} 0.57$ compared to the corresponding slag systems. Figure 8.2 displays the mortar samples for the 72 hour cured systems at $w / b 0.57$ following exposure to ambient conditions for 18 months, illustrating the difference in the carbonation resistance of fly ash and slag at equivalent substitution levels and the almost complete carbonation of the $60 \%$ slag sample. 

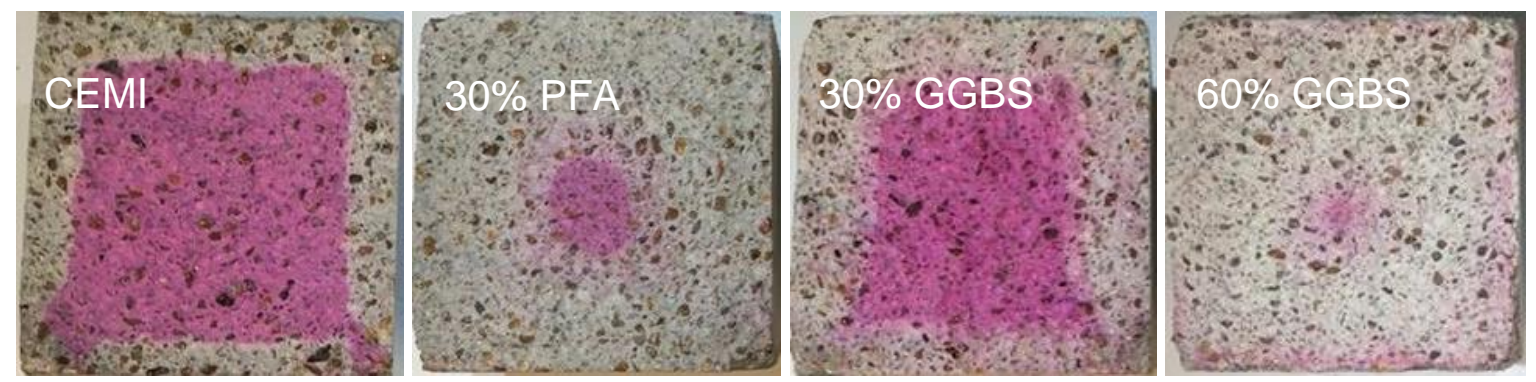

Figure 8.2. Mortar samples with w/b 0.57 cured for 72 hours sprayed with phenolphthalein solution following exposure to ambient conditions for 18 months $\left(\mathrm{RH} 50 \%+/-10 \%,\left[\mathrm{CO}_{2}\right] \approx\right.$ 450ppm).

At $\mathrm{w} / \mathrm{b}$ ratio 0.40 , the carbonation behaviour of the paste systems (as discussed in Chapters 6 and 7) correlated well to the carbonation depths observed in the mortar samples. The carbonation resistance of the CEMI and 30\% replacement systems was significantly improved following both short and ideal curing, the lower porosity and permeability of the microstructure limiting ingress of $\mathrm{CO}_{2}$ (Figure 8.1) and ultimately access to $\mathrm{CH}$. However, at higher levels of replacement (60\% GGBS), the low water content was unable to mitigate the effects of the more slowly hydrating low clinker cement following 72 hours curing to the same extent as for materials with moderate substitution (30\%). Low $\mathrm{w} / \mathrm{b}$ ratio paste systems subjected to insufficient curing and high cement substitution demonstrated similar behaviour to the higher $\mathrm{w} / \mathrm{b}$ ratio $(0.57)$ materials, corresponding well to carbonation measurements for the mortar samples in which equivalent depths were measured for the $60 \%$ GGBS 0.4072 hour cured samples and the 72 hour cured $30 \%$ GGBS sample at w/b 0.57 .

At the higher $\mathrm{w} / \mathrm{b}$ ratio $(0.57)$, the mortar prisms cured for 72 hours all demonstrated poor carbonation resistance, as previously observed for the paste systems. Although the depth of carbonation ingress generally decreased with decreasing percentage replacement, 30\% PFA and 30\% GGBS systems had markedly different carbonation depths following 18 months (Figures 8.1 \& 8.2), in which the slag containing cement was measured to have approximately half the carbonation depth $(\sim 7 \mathrm{~mm})$ compared with the equivalent fly ash sample $(\sim 14.5 \mathrm{~mm})$. This behaviour correlates poorly with the paste systems, where samples with high surface to volume ratios exhibited similar behaviour (30\% PFA \& 30\% GGBS) following exposure to ambient $\mathrm{CO}_{2}$ concentrations. The lower degree of reaction of the PFA is expected to contribute to greater porosity and permeability of the 
cement microstructure, however following 72 hours hydration the difference in the extent of reaction is likely to be minor. The reaction of GGBS compared with PFA has been shown to fill space with a more finely distributed porosity for a given degree of reaction [145], here resulting in a greater capacity to delay the rate of diffusion of $\mathrm{CO}_{2}$. This is further demonstrated in the 28 day cured (w/b 0.57) systems in which the $30 \%$ fly ash mortar again exhibited depths of carbonation double to that of the corresponding slag sample (30\% PFA $\sim 10.5 \mathrm{~mm} \& 30 \%$ GGBS $\sim 4.5 \mathrm{~mm}$ ), and nearly $40 \%$ higher than the $60 \%$ GGBS system $(6.5 \mathrm{~mm})$. Following 28 days curing, the $30 \%$ slag paste (Chapter 7) was observed to have the greatest resistance to carbonation, whereas the CEMI and $30 \%$ slag mortar samples had very similar depths of $\mathrm{CO}_{2}$ ingress (CEMI $~ 3.5 \mathrm{~mm} \& 30 \% \mathrm{GGBS}$ $\sim 4.5 \mathrm{~mm}$ ) (Figure 8.1). This highlights the important role of $\mathrm{CH}$ and its ability to buffer the pore solution as well as the greater binding capacity per unit volume of the CEMI sample.

Studies relating the carbonation depth of concrete and mortar samples to compressive strength have determined strength to act as a good indicator of carbonation resistance $[188,189]$. Figure 8.3 displays the mean compressive strength of the mortar samples plotted against the carbonation depth measured using phenolphthalein indicator. Although the data shows a generally negative correlation, supporting the theory that depth of carbonation increases as strength decreases, samples with lower compressive strengths (<50MPa) correlate quite poorly, exhibiting large variations in depth of carbonation for a given strength. This poor correlation relates predominantly to the short cured ( $72 \mathrm{hrs}$ - open markers) blended systems, suggesting that although strength may provide a reasonable indication of carbonation resistance for properly cured cements with high strength development, low strength development (i.e. low clinker contents and inadequate curing length) does not provide a clear relationship with depth of ingress of $\mathrm{CO}_{2}$. This is illustrated in Figure 8.3 for samples with $~ 30 \mathrm{MPa}$ compressive strength in which carbonation depth measurements ranged from approximately 3 to $17 \mathrm{~mm}$. 


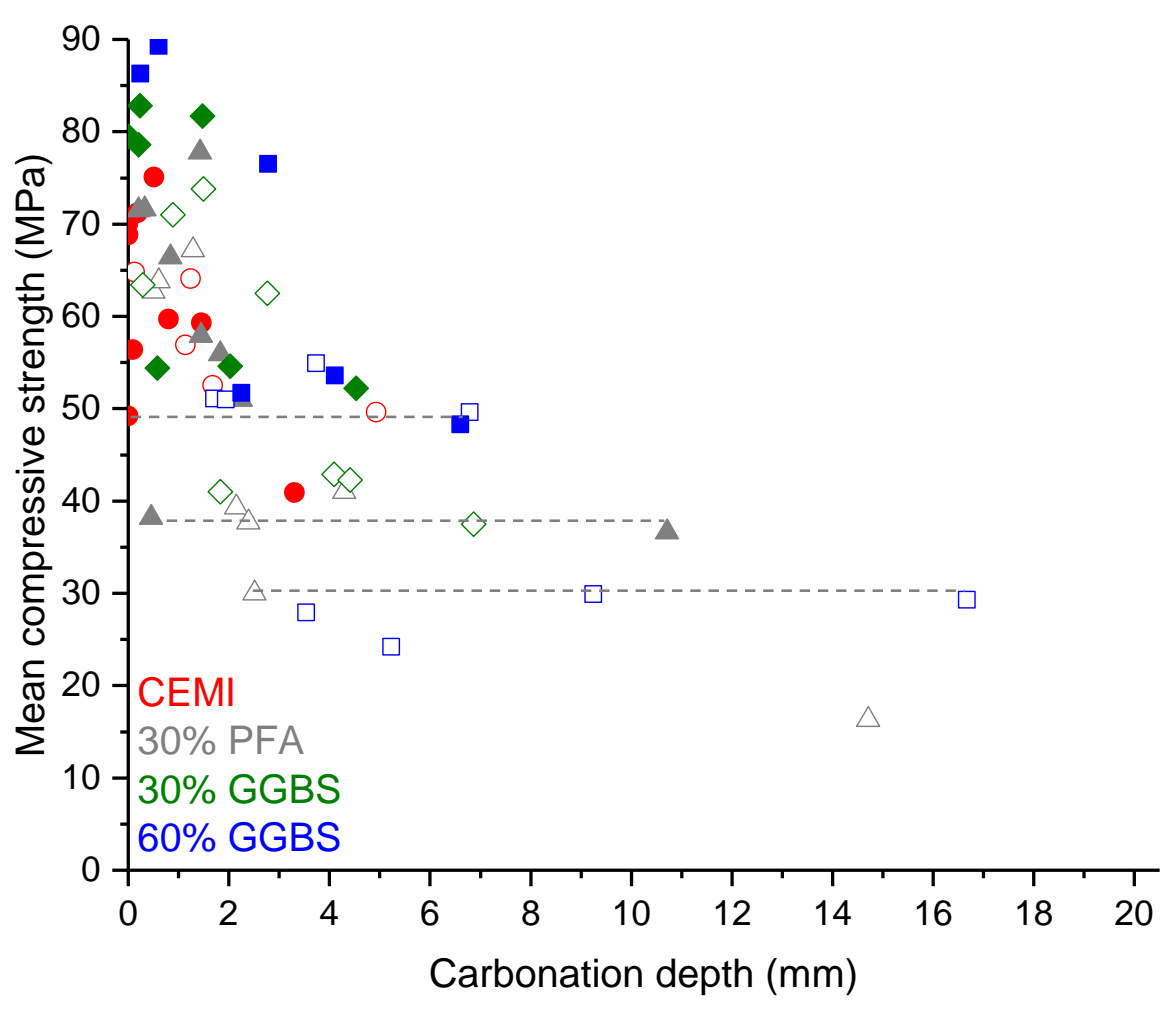

Figure 8.3. Mean compressive strength vs carbonation depth (measured by phenolphthalein indicator) of mortar samples exposed to ambient $\mathrm{CO}_{2}$ concentrations for 18 months ( $\mathrm{t}_{0} 72 \mathrm{hrs}$ open markers, $\mathrm{t}_{0} 28 \mathrm{~d}$ - solid markers).

\subsection{Durability implications}

The durability of concrete structures is defined as the ability to resist significant deterioration during their serviceable life. The number of reinforced concrete structures reported to have performed inadequately has increased in recent years $[183,184]$ and is predominantly related to the corrosion of the steel reinforcement. This premature deterioration resulting from reinforcement degradation is largely a result of both carbonation induced effects and chloride ingress, ultimately producing technical and economic problems and concerns regarding sustainable design $[184,190]$.

The passivation of the steel reinforcement in concrete is a result of the highly alkaline environment of the cement pore solution, which is typically greater than $\mathrm{pH} 13$. As the carbonation front moves through the concrete microstructure, the pore solution is neutralised $(\mathrm{pH} \sim 8)$ and the passivation 
layer is destroyed (Section 2.3.1), allowing the formation of corrosion products such as ferrous hydroxide $\left(\mathrm{Fe}(\mathrm{OH})_{2}\right)$ and ferric oxide $\left(\mathrm{Fe}_{2} \mathrm{O}_{3}\right)$. The corrosion products occupy a much larger volume (up to six times) than the original steel, generating tensile stresses which result in cracking and spalling of the concrete. It is this loss of strength and integrity of both the concrete and the steel rebar that cause considerable loss of structural serviceability.

The corrosion process can be simplified into two stages; the initiation stage and the propagation stage. During the initiation period, the passivation of the reinforcement is lost and conditions become conducive to corrosion. The subsequent degradation of the steel marks the beginning of the propagation stage in which sectional losses of the reinforcement and cracking and spalling of the cover concrete occur. The service life of concrete structures is considered to be determined by the length of the initiation period, or the time for aggressive species to reach the steel, and is primarily controlled by the quality and quantity of the concrete cover [184].

Fick's first law of linear diffusion can be applied to determine the depth of carbonation in concrete as a function of time, as shown in Equation 8.1 below. The rate of carbonation is controlled by the diffusion of $\mathrm{CO}_{2}$ through the cement pore structure $(D)$, the volume of carbonatable matter available (a) and the concentration gradient of $\mathrm{CO}_{2}\left(\mathrm{C}_{1}-\mathrm{C}_{2}\right)$. These parameters are combined to give one constant of carbonation (k), resulting in the well-known equation shown in Equation 8.2.

$$
x^{2}=\frac{2 D\left(C_{1}-C_{2}\right)}{a} \mathrm{t}
$$

where:

$x=$ thickness of penetrated concrete $(m)$

$D=$ diffusion coefficient for $\mathrm{CO}_{2}$ through carbonated concrete $\left(\mathrm{m}^{2} / \mathrm{s}\right)$

$\mathrm{C}_{1}=$ external concentration of $\mathrm{CO}_{2}\left(\mathrm{~g} / \mathrm{m}^{3}\right)$

$\mathrm{C}_{2}=$ concentration of $\mathrm{CO}_{2}$ at carbonation front $\left(\mathrm{g} / \mathrm{m}^{3}\right)$

$\mathrm{a}=$ required amount of $\mathrm{CO}_{2}$ for the carbonation of the alkaline compounds contained in a unit volume of concrete $\left(\mathrm{g} / \mathrm{m}^{3}\right)$

$\mathrm{t}=$ time $(\mathrm{s})$ 


$$
x(t)=k \sqrt{t}
$$

where:

$\mathrm{x}=$ carbonation depth $(\mathrm{m})$

$\mathrm{t}=$ time $(\mathrm{s})$

$\mathrm{k}=$ carbonation coefficient $/$ rate of carbonation or $=\frac{2 D(C 1-C 2)}{a}$

Ultimately the carbonation resistance of a material is controlled by the diffusion resistance of the carbonated concrete (D) and the amount of $\mathrm{CaO}$ available to react with $\mathrm{CO}_{2}(\mathrm{a})$. These parameters are taken to be constant material properties, however, their values are dependent upon numerous variables.

The carbonation reaction begins at the surface, proceeding inwards to produce an increasingly thicker carbonated layer of material. The coefficient of diffusion of $\mathrm{CO}_{2}$ through this carbonated region (D) is controlled by changes in the pore structure that result from the ongoing carbonation reactions. For Portland cement systems the effects of carbonation typically result in densification of the microstructure, reducing the total porosity of the material and retarding the rate of ingress of $\mathrm{CO}_{2}[62,74-76]$. In contrast, for blended cements many durability studies report poor carbonation resistance resulting from coarsening of the microstructure, increasing diffusivity and consequently the carbonation coefficient $(\mathrm{k})[76,84-86]$. $\mathrm{D}$ is also affected by temperature and $\mathrm{RH}$, increasing with increasing temperature and requiring partially filled pores (typically $50-70 \% \mathrm{RH}$ ) to proceed at an optimum rate (Section 2.3.1).

The amount of $\mathrm{CO}_{2}$ required for the reaction of the alkaline phases contained within a unit volume of cementitious material (a) is governed by the $\mathrm{CaO}$ content of the cement and additional pozzolans/SCMs, the mix proportions of the cement or concrete $(\mathrm{w} / \mathrm{b}$ ratio) and the degree of hydration. The variability of these values for Portland cement materials is expected to be relatively small. However, for blended cement systems, lower clinker contents and highly variable SCMs 
(variable in both composition and reactivity) result in much larger deviations, affecting the carbonation coefficient $(\mathrm{k})$ more considerably.

Figure 8.4 displays a schematic representation of the parameters $(D, a)$ affecting the carbonation coefficient (k). k values calculated from carbonation depth data (Appendix B) for the systems with $\mathrm{w} / \mathrm{b}$ ratio 0.57 have been indicated on the diagram.

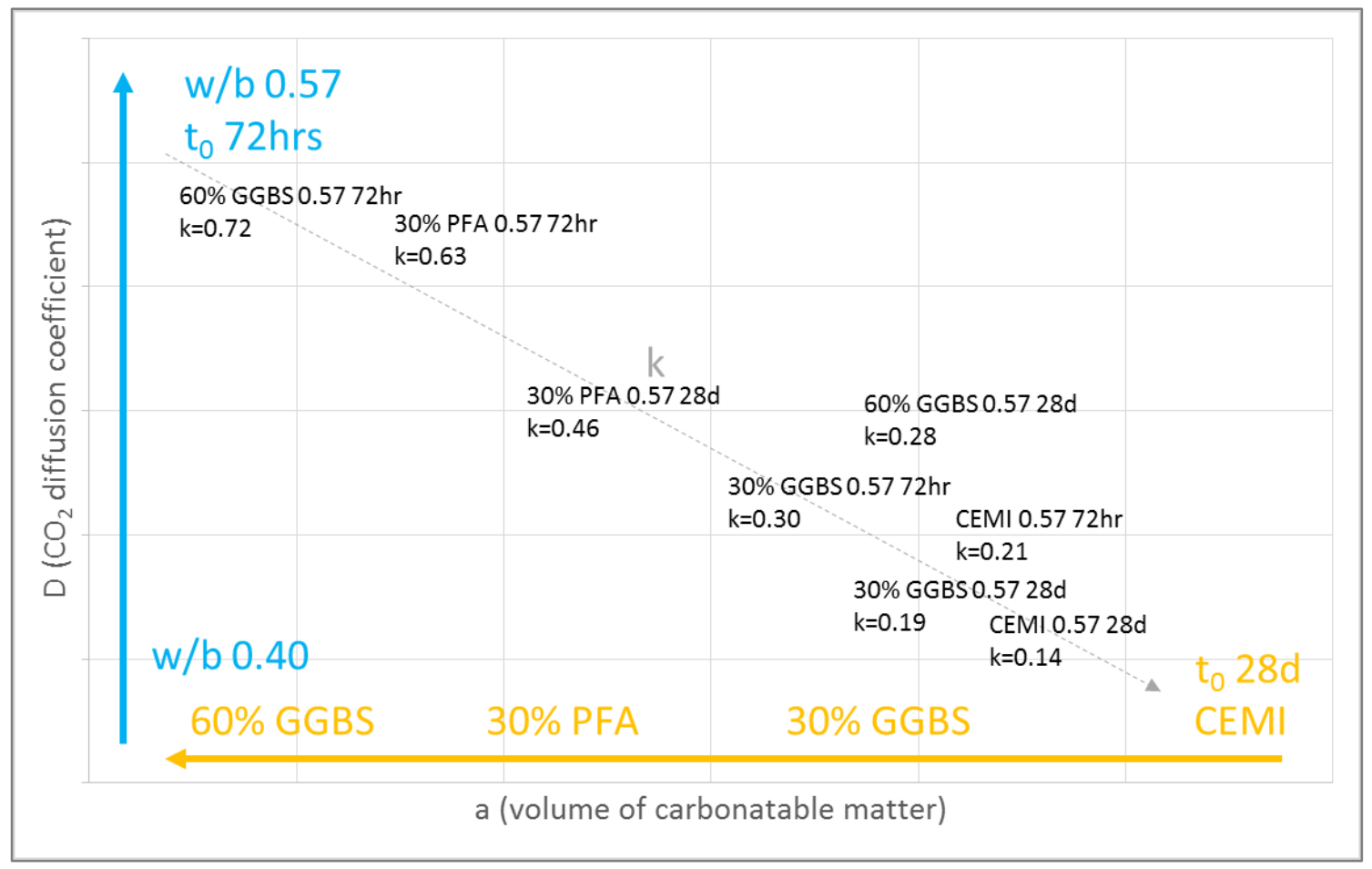

Figure 8.4. Schematic representation of the parameters affecting the carbonation coefficient $(\mathrm{k}) . \mathrm{k}$ values calculated from carbonation depth data (Appendix B) for systems with w/b 0.57 have been indicated on the diagram.

The $k$ values demonstrate the much greater effect curing length has on the carbonation resistance of blended cements compared with Portland cement systems. As curing length was increased from 72 hours to 28 days, the carbonation coefficient for the CEMI samples reduced by $33 \%$. This decrease was slightly greater for the $30 \%$ slag systems (37\%) and was almost double for the $60 \%$ GGBS samples (61\%). Although the smallest reduction was observed for the $30 \%$ PFA system (27\%), 
this is a reflection of its poor performance following both short and ideal curing lengths. The calculated carbonation coefficients further establish the more detrimental effect inadequate curing has on blended cement materials, compared to neat Portland cements, where the effects are amplified with increasing level of replacement. Paste samples were designed to study the effects of carbonation on the microstructure and phase assemblage where influences from porosity and permeability were relatively small, although notable influences were still observed. For the mortar samples, however, the transport properties have a significant contribution and differences in the fly ash containing and slag containing materials were more evident.

At equivalent substitution levels (30\% PFA and 30\% GGBS), paste systems cured for 72 hours showed comparable carbonation resistance, both experiencing the complete consumption of portlandite at 4 days exposure to ambient $\mathrm{CO}_{2}$ concentrations (Chapter 6 ), and subsequently resulting in the rapid carbonation of the remaining hydrate phases. As previously discussed (Section 8.1), the corresponding mortar samples exhibited markedly different carbonation depths (30\% GGBS 7mm and $30 \%$ PFA $\sim 14.5 \mathrm{~mm}$ ) at 18 months, indicating the critical role of the microstructure in delaying the ingress of $\mathrm{CO}_{2}$. Furthermore, for 28 day cured paste samples (w/b 0.57), the low degree of hydration (51\% (Table 5.2)) and low initial CH content ( 7g (/100g binder) (Table 5.2)) of the 60\% slag system resulted in poor performance, having the lowest carbonation resistance of the four systems investigated ( $\mathrm{w} / \mathrm{b} 0.57, \mathrm{t}_{0} 28 \mathrm{~d}$ (Chapter 7)). For the mortar systems, although the $30 \% \mathrm{fly}$ ash sample had a greater capacity to resist carbonation chemically, i.e. greater binding capacity and higher $\mathrm{CH}$ content (15.6g (/100g binder) (Table 5.2)), and was anticipated to have a greater degree of reaction (inferred from the higher clinker content), a higher carbonation depth was measured $(\sim 11 \mathrm{~mm})$ in relation to the highly substituted slag systems $(60 \% \mathrm{GGBs} \sim 7 \mathrm{~mm})$. The chemical resistance of cement is determined by the availability of $\mathrm{CH}$, as discussed in Chapters 6 and 7, the capacity of portlandite to buffer the carbonation reaction prevents significant deterioration of the remaining phases. Its consumption, however, is controlled by the ability of $\mathrm{CO}_{2}$ to diffuse through the microstructure.

The progressively foil like C-S-H resulting from increasing replacement by fly ash and slag (see TEM micrographs Section 5.3.1), reduces the diffusivity and permeability of the microstructure, offsetting the lower portlandite contents and binding capacities that provide reduced chemical resistance. This microstructural development, however, is dependent upon considerable reaction of the slag or fly 
ash glass, which is primarily dependent on adequate curing. In addition to sufficient curing, the reactivity of the replacement material is of key importance. While higher clinker contents may provide better binding capacity, as for the $30 \%$ PFA sample compared to the $60 \%$ GGBS samples, the more reactive nature of the slag glass (Section 5.1.2) following 28 days curing, contributed more significantly to retarding the rate of diffusion of $\mathrm{CO}_{2}$ (Figure 8.1). The required reactivity of SCMs to be used to partially replace Portland cement is broadly defined in EN 197-1:2011. GGBS is required to have a value $>1.0$ for the basicity ratio, $(\mathrm{CaO}+\mathrm{MgO}) /\left(\mathrm{SiO}_{2}\right)$, whereas guidelines state that for siliceous PFA, the proportion of reactive $\mathrm{CaO}$ shall be less than $10 \%$ by mass and the reactive $\mathrm{SiO}_{2}$ content shall not be less than $25 \%$ by mass. Although both the slag and fly ash investigated in this study satisfied the conditions above, hugely variable results were observed in relation to hydration and the resulting effects on carbonation resistance. Caution should be exercised regarding the reactivity of SCMs based on such recommendations, particularly for low Ca fly ash materials, and a more comprehensive assessment performed to determine more accurate expected reaction rates.

The $\mathrm{k}$ values determined for the $0.40 \mathrm{w} / \mathrm{b}$ ratio systems were omitted from Figure 8.4 for clarity (values given in Appendix B), however short cured (72hr) CEMI, 30\% PFA and 30\% GGBS systems had carbonation coefficients $<0.14$, i.e. lower than the coefficients of carbonation of all the 28 day cured 0.57 systems (lowest $\mathrm{k}$ value 0.14 for CEMI 0.57 (28d).

The results for both the mortar (Figure 8.1 and Appendix B) and paste samples (Chapters 6 \& 7) demonstrate that although lower water contents $(w / b 0.40)$ result in a lower degree of hydration (Chapter 5), limiting the amount of hydrate phases available to react with $\mathrm{CO}_{2}$, the coefficient of diffusion can be sufficiently controlled for systems with moderate levels of replacement (30\%) following short periods of curing ( $72 \mathrm{hrs})$. At high levels of replacement $(60 \%)$, limited hydration and highly permeable microstructures allow the carbonation reaction to proceed rapidly, highlighting the adverse effects of improper curing at high substitution levels.

In design, the time to initiation is controlled, theoretically, by limiting values for cover depth, compressive strength, w/c ratio, cement type and cement content. In EN 206-1: 2000 (Concrete. Specification, performance, production and conformity), corrosion induced by carbonation is designated as four exposure classes relating to mild, moderate and severe risk, defined as XC1, XC2/3 and XC4 respectively. Maximum w/c ratios range from 0.50 to 0.65 for XC4 and XC1 correspondingly, and EN 1992-1-1 (Eurocode 2: Design of concrete structures. General rules and 
rules for buildings) only stipulates an increase of $10 \mathrm{~mm}$ for the minimum cover depth for XC4 when increasing a structures working life from 50 to 100 years (i.e. structural class $4: C_{\min }=30 \mathrm{~mm}$ for 50 year working life and $C_{\min }=400 \mathrm{~mm}$ for 100 year working life). In BS EN 206-1 (Concrete. Specification, performance, production and conformity), the nominal cover for a particular exposure class is linked to the quality of the concrete, which is defined by values for compressive strength, $\mathrm{w} / \mathrm{c}$ ratio, cement type and cement content. For exposure classes $\mathrm{XC1}$ and $\mathrm{XC2}$, all cement types can be used, the maximum $\mathrm{w} / \mathrm{c}$ ratio is stated to be 0.70 and the cement grade is limited to a minimum of $\mathrm{C} 20 / 25$. For moderate and severe exposure classes, the cover depth varies a function of the $\mathrm{w} / \mathrm{c}$ ratio (0.45-0.65) and the strength grade (C25/30 - C40/50) and only cement type IVB-V (36-55\% siliceous fly ash) is prohibited from use.

These ranges of parameters seem unsuitable to guarantee sufficient quality of the concrete cover, and cannot be related directly to decreased penetrability. High w/c contents with high levels of replacement (for example blast furnace cement (CEMIII) has replacement levels of $36-65 \%(A), 66$ $80 \%$ (B) and $81-95 \%$ (C)) are dependent upon adequate hydration and reactivity of the SCM, as well as low $\mathrm{w} / \mathrm{b}$ ratios to effectively resist the ingress of $\mathrm{CO}_{2}$.

Although durability standards provide some guidelines on the length of curing (BS EN 13670:2009 Execution of concrete Structures), these recommendations focus on the ratio of compressive strength development in the surface zone. Such an approach fails to account for the large variability, and performance, of different binder types and the considerable effect curing will have on the material's capacity to resistance carbonation induced corrosion. Despite classifications being based upon the rate of strength development (ratio of strength at 2 days and 28 days - designated as rapid, medium and slow) and the surface temperature of the concrete, for curing class 3 (used in most concrete structures [184]) minimum curing lengths only range from 1.5 - 18 days, and when surface temperatures of $15^{\circ}$ and above are considered the minimum curing period is defined as between 1.5 - 7 days. Although compressive strength is widely used as a durability indicator, its ability to provide accurate predictions for composite materials is relatively poor. Figure 8.3 illustrates the large range of carbonation depths measured for samples of equivalent compressive strength values, while equal strength development ( $\sim 5 \mathrm{MPa}$ ) at 1 day for $30 \%$ PFA and $60 \%$ GGBS mortar prisms ( $w / b$ 0.57, $t_{0} 28 \mathrm{~d}$ ) resulted in sizeably different results (carbonation depths: 30\% PFA $\sim 11 \mathrm{~mm}, 60 \%$ GGBS $7 \mathrm{~mm}$ ) after only 18 months. 
Design codes require better defined, and more controlled, limits for prescriptive controls on mix design where blended cement materials are concerned. At moderate replacement (30\%), the coefficient of diffusivity (D) can be controlled by the $\mathrm{w} / \mathrm{b}$ ratio, however as percentage substitution increases, inadequately cured materials will have poor chemical (a) and physical (D) resistance. Curing lengths based on surface strength development are unsuitable for composite materials and have no real reflection on durability. It is imperative that greater emphasis is placed on curing length, particularly at higher substitution levels $(>30 \%)$ and higher $\mathrm{w} / \mathrm{b}$ ratios $(>0.45 / 0.50)$. Furthermore, minimum periods of curing should consider the reactivity of the replacement material, and where possible, the penetrability of the concrete cover should be assessed on site, determining the real quality achieved and providing reliable durability and service life predictions. 


\section{Chapter 9}

\section{Conclusions and further work}

\subsection{Conclusions}

The carbonation resistance of neat Portland cement systems is considered to be higher than that of blended materials due to its ability to bind greater quantities of $\mathrm{CO}_{2}$. As $\mathrm{CO}_{2}$ permeates through the microstructure, it reacts with $\mathrm{Ca}$ in the hydrate phases. The partial replacement of Portland cement by more slowly hydrating $\mathrm{SCMs}$ with lower $\mathrm{CaO}$ contents, reduces the $\mathrm{CO}_{2}$ binding capacity of composite materials. Despite lower binding capacities and reduced quantities of $\mathrm{CH}$, refinement of the pore structure has the potential to significantly reduce the rate of diffusion of $\mathrm{CO}_{2}$, improving carbonation resistance compared to CEMI systems, however these properties are dependent upon significant reaction of the replacement material which is reliant on adequate periods of curing. It is well understood that modifications in the carbonation behaviour exist between natural and accelerated conditions and they are expected to exist for immature and well-developed microstructures. This is of importance when considering the early removal of formwork in practice, where the reliance is on models established for properly cured PC systems. Furthermore, the existing models do not consider the effects that insufficient curing and phase carbonation have on the phase assemblage composition, development of the microstructure and the subsequent consequences for the transport properties in more slowly hydrating blended cement materials.

The results presented here indicated that following short curing lengths (at w/b 0.57) it was the complete consumption of $\mathrm{CH}$ that allowed carbonation rates to increase, decalcification of the remaining hydrate phases then occurred more extensively (Sections 6.1 \& 7.1). Following longer periods of curing, the same mechanism of portlandite depletion was observed for the blended materials (30\% PFA \& 60\% GGBS), whereas for the CEM I system, increased carbonation of the remaining phases appeared to be a result of isolation of residual $\mathrm{CH}$, preventing further reaction (Section 7.1).

Following short periods of curing ( $72 \mathrm{hrs})$, cement pastes with high w/b ratios (0.57) exhibit open and underdeveloped microstructures, exacerbated further in composite systems as replacement 
level increases. The availability of $\mathrm{CH}$ becomes the rate determining factor, and was observed to be completely consumed in all systems during early age exposure to ambient $\mathrm{CO}_{2}$ concentrations (Section 6.1). As curing length increased (28d) and $w / b$ ratio decreased $(0.40)$ the rate determining factor was shown to be a combination of the chemical kinetics and the transport of the systems. Reduced $\mathrm{w} / \mathrm{b}$ ratios improved the carbonation resistance of all the systems following both short and ideal curing lengths, behaviour attributed to significantly reduced porosity of the materials (Sections $6.2 \& 7.2)$ delaying the rate of diffusion of $\mathrm{CO}_{2}$. However, lower water contents were unable to mitigate the effects of high levels of replacement (60\% GGBS), and subsequently high levels of porosity, to the same degree as for materials with moderate substitution (30\%) following 72 hours hydration.

At $\mathrm{w} / \mathrm{b}$ ratio 0.57 , the impact of increased curing was most evident for the $30 \%$ slag system, which exhibited the highest resistance to carbonation ( $w / b \quad 0.57,28 d)$, demonstrating the dependency of blended systems on sufficient curing regimes. The improved effects were predicted to be a result of refinement of the porosity, foil-like C-S-H morphology reducing permeability (TEM micrographs Section 6.1.5), but were not observed to occur to the same degree for the equivalent fly ash sample. TEM-EDX confirmed the removal of both $\mathrm{Ca}$ and $\mathrm{Al}$ from $\mathrm{C}-\mathrm{S}-\mathrm{H}$ gel (also observed in ${ }^{27} \mathrm{Al}$ NMR spectra) (Sections 6.1.4, 6.1.5 \& 7.1.5) and ${ }^{29} \mathrm{Si} \mathrm{NMR} \mathrm{showed} \mathrm{significant} \mathrm{increases} \mathrm{in} \mathrm{silicate}$ polymerisation due to decalcification following depletion of portlandite (Sections 6.1.6 \& 7.1.6).

The carbonation of the AFm phases was observed to occur in two stages. First, phase transformation from $\mathrm{SO}_{4}$ (monosulfoaluminate) to $\mathrm{CO}_{3}$ (hemi- and monocarboaluminate) bearing species was observed to occur, ultimately decomposing by decalcification. The availability of $\mathrm{CH}$, however, prevented complete decomposition $\left({ }^{27} \mathrm{Al} \mathrm{NMR}\right.$ - Sections 6.1.4 \& 7.2.3).

During elevated rates of carbonation (i.e. when $\mathrm{CH}$ no longer accessible) CEM I was shown to be more resilient to carbonation induced effects (XRD, ${ }^{29} \mathrm{Si} N M R$, ATR-FTIR). Small quantities of AFt remained in the samples up to 60 days exposure and changes in C-S-H structure (polymerisation and formation of silica gel) were observed to occur more slowly, demonstrating a longer period of retention when portlandite was no longer available.

The fate of aluminium from the carbonation AFm and AFt was unclear. ${ }^{27} \mathrm{Al}$ NMR spectra indicated it was incorporated into the amorphous silica phase produced from the carbonation of $\mathrm{C}-\mathrm{S}-\mathrm{H}$ 
(Sections 6.1.4 \& 7.2.3). This was further reinforced by the absence of a new octahedral resonance relating to alumina gel.

The production of vaterite in XRD and ATR-FTIR data appeared to be related to the carbonation of C-S-H, particularly low Ca C-S-H. Greater proportions of vaterite in relation to calcite were evident in composite materials following longer periods of hydration. As the rate of decalcification was perceived to increase (XRD, STA, ATR-FTIR), Ca/Si ratios decreased further and vaterite became dominant.

Silica gel formed in all short cured $\left(72 \mathrm{hr}\right.$ ) systems following exposure to ambient $\mathrm{CO}_{2}$ concentrations at $\mathrm{w} / \mathrm{b} 0.57\left({ }^{29} \mathrm{Si} N M R, A T R-F T I R\right)$. The formation of $\mathrm{Q}^{4}$ sites was related to total decomposition of the $\mathrm{C}-\mathrm{S}-\mathrm{H}$ which resulted in a decrease in the intensity of the v3 Si-O band. No decrease was observed for the CEMI sample in which only $Q^{3}$ species had formed.

Carbonation studies on highly hydrated composite cements may not be an accurate reflection of their behaviour following much shorter periods of curing. Furthermore, the higher $\mathrm{Ca} / \mathrm{Si}$ ratio of CEMI materials provides greater resistance to carbonation induced effects and as a result differences in carbonation behaviour of short and ideal curing periods are much less evident compared with composite materials. The selection of replacement material can also have a significant impact on resistance to carbonation induced effects even at moderate levels of replacement. Severe decomposition of the C-S-H phase is typically a feature of accelerated carbonation testing, however here it has been shown that short curing periods and highly porous systems result in decomposition to silica gel following exposure to ambient $\mathrm{CO}_{2}$ concentrations for relatively short periods of time (60 days) (Sections 7.1.3 \& 7.1.6). The availability of $\mathrm{CH}$ was determined to the rate determining factor for carbonation, but its consumption is primarily controlled by the ability of $\mathrm{CO}_{2}$ to diffuse through the microstructure.

Ultimately the carbonation resistance of a material is controlled by the diffusion resistance of the carbonated concrete and the amount of $\mathrm{CaO}$ available to react with $\mathrm{CO}_{2}$. These parameters are taken to be constant material properties and are contained within the carbonation coefficient k, however, their values are dependent upon numerous variables. For composite cement materials, slower rates of hydration and variable reactivity of the SCM have a more sizeable effect on the coefficient of carbonation, making durability predictions more challenging. 
In design, the time to initiation is controlled, theoretically, by limiting values for cover depth, compressive strength, $\mathrm{w} / \mathrm{c}$ ratio, cement type and cement content. These ranges of parameters are unsuitable to guarantee sufficient quality of the concrete cover, and cannot be related directly to decreased penetrability. Curing guidelines established from surface strength development fail to account for the large variability, and performance, of different binder types and, for composite materials, do not provide an accurate indication of the material's ability to resist carbonation induced corrosion.

Design codes require better defined, and more controlled, limits for prescriptive controls on mix design where blended cement materials are concerned. At moderate replacement (30\%), the coefficient of diffusivity (D) can be controlled by the $\mathrm{w} / \mathrm{b}$ ratio, however as percentage substitution increases, inadequately cured materials will have poor chemical (a) and physical (D) resistance. It is imperative that greater emphasis is placed on curing length, particularly at higher substitution levels $(>30 \%)$ and higher $\mathrm{w} / \mathrm{b}$ ratios $(>0.45 / 0.50)$. Furthermore, minimum periods of curing should consider the reactivity of the replacement material, and where possible, the penetrability of the concrete cover should be assessed on site, determining the real quality achieved and providing reliable durability and service life predictions.

\subsection{Further work}

The study here has focused on the effects of carbonation on the phase assemblage and microstructure. Small paste samples with high surface to volume ratios that were designed to minimise the effects from porosity. The results showed that even on such a small scale the effects of the pore structure had a very large influence on the carbonation resistance of the materials. A second PhD project based at IFSTTAR, Paris, is investigating the effects of carbonation on the transport properties of the same set of systems, relating the microstructural behaviour observed for the paste samples to mortar and concrete specimens. The large changes in the rate of carbonation, and resulting decomposition of $\mathrm{C}-\mathrm{S}-\mathrm{H}$, are a result of depletion of $\mathrm{CH}$, further work investigating the porosity and permeability's of these system prior to, and following these changes would be of great value to the work presented here. In addition, the mechanism for the carbonation 
of AFt and the AFm phases is not clear. It is possible that the aluminium released from the decomposition of these phases is incorporated in the amorphous silica phase from decalcification of C-S-H. The carbonation of the calcium aluminate phases is of great interest currently due to the increasing focus in high alumina containing cements, therefore further work to could be performed to study differences in the carbonation mechanism of the aluminate phases in different cements materials. 


\section{References}

1. Poon, C.S., Y.L. Wong, and L. Lam, The influence of different curing conditions onthe pore structure and related properties of fly-ash cement pastes and mortars. Construction and Building Materials, 1997. 11(7): p. 383393.

2. Çakır, Ö. and F. Aköz, Effect of curing conditions on the mortars with and without GGBFS. Construction and Building Materials, 2008. 22(3): p. 308314.

3. Balayssac, J.P., C.H. Détriché, and J. Grandet, Effects of curing upon carbonation of concrete. Construction and Building Materials, 1995. 9(2): $\mathrm{p}$. 91-95.

4. Güneyisi, E., et al., Estimation of chloride permeability of concretes by empirical modeling: Considering effects of cement type, curing condition and age. Construction and Building Materials, 2009. 23(1): p. 469-481.

5. Fraay, A.L.A., J.M. Bijen, and Y.M. de Haan, The reaction of fly ash in concrete a critical examination. Cement and Concrete Research, 1989. 19(2): p. 235-246.

6. Deschner, F., et al., Hydration of Portland cement with high replacement by siliceous fly ash. Cement and Concrete Research, 2012. 42(10): p. 13891400.

7. Escalante, J.I., et al., Reactivity of blast-furnace slag in Portland cement blends hydrated under different conditions. Cement and Concrete Research, 2001. 31(10): p. 1403-1409.

8. Taylor, H.F.W., Cement chemistry, 2nd Edition. Thomas Telford Ltd, 1997. London.

9. Bullard, J.W., et al., Mechanisms of cement hydration. Cement and Concrete Research, 2011. 41(12): p. 1208-1223.

10. Bullard, J.W. and R.J. Flatt, New Insights Into the Effect of Calcium Hydroxide Precipitation on the Kinetics of Tricalcium Silicate Hydration. Journal of the American Ceramic Society, 2010. 93(7): p. 1894-1903.

11. Juilland, P. and E. Gallucci, Morpho-topological investigation of the mechanisms and kinetic regimes of alite dissolution. Cement and Concrete Research, 2015. 76: p. 180-191.

12. Kocaba, V., Development and Evaluation of Methods to Follow Microstructural Development of Cementitious Systems Including Slags. 2009, École Polytechnique Federale de Lausanne. 
13. Minard, $\mathrm{H}$., et al., Mechanisms and parameters controlling the tricalcium aluminate reactivity in the presence of gypsum. Cement and Concrete Research, 2007. 37(10): p. 1418-1426.

14. Scrivener, K.L., P. Juilland, and P.J.M. Monteiro, Advances in understanding hydration of Portland cement. Cement and Concrete Research, 2015. 78, Part A: p. 38-56.

15. Berodier, E., Impact of the supplementary cementitious materials on the kinetics and microstructural development of cement hydration. 2015, Thesis EPFL.

16. Odler, I., 6 - Hydration, Setting and Hardening of Portland Cement A2 Hewlett, Peter C, in Lea's Chemistry of Cement and Concrete (Fourth Edition). 1998, Butterworth-Heinemann: Oxford. p. 241-297.

17. Richardson, I.G. and G.W. Groves, Microstructure and microanalysis of hardened ordinary Portland cement pastes. Journal of Materials Science, 1993. 28(1): p. 265-277.

18. Dobson, C.M., et al., 29Si MAS NMR study of the hydration of tricalcium silicate in the presence of finely divided silica. Journal of Materials Science, 1988. 23(11): p. 4108-4114.

19. Richardson, I.G., The calcium silicate hydrates. Cement and Concrete Research, 2008. 38(2): p. 137-158.

20. Richardson, I.G., Tobermorite/jennite- and tobermorite/calcium hydroxidebased models for the structure of $\mathrm{C}-\mathrm{S}-\mathrm{H}$ : applicability to hardened pastes of tricalcium silicate, $\beta$-dicalcium silicate, Portland cement, and blends of Portland cement with blast-furnace slag, metakaolin, or silica fume. Cement and Concrete Research, 2004. 34(9): p. 1733-1777.

21. Taplin, J.H., A method for following the hydration reaction in Portland cement paste. Australian J Appl Science, 1959. 10: p. 329-345.

22. Richardson, I.G., The nature of the hydration products in hardened cement pastes. Cement and Concrete Composites, 2000. 22(2): p. 97-113.

23. Odler, I. and M. Rößler, Investigations on the relationship between porosity, structure and strength of hydrated Portland cement pastes. II. Effect of pore structure and of degree of hydration. Cement and Concrete Research, 1985. 15(3): p. 401-410.

24. Mehta, P.K., Concrete. Structure, properties and materials. 1986, Englewood Cliffs, NJ 07632 USA: Prentice-Hall, Incorporated.

25. Lothenbach, B., K. Scrivener, and R.D. Hooton, Supplementary cementitious materials. Cement and Concrete Research, 2011. 41(12): p. 1244-1256. 
26. Hill, J. and J.H. Sharp, The mineralogy and microstructure of three composite cements with high replacement levels. Cement and Concrete Composites, 2002. 24(2): p. 191-199.

27. Weng, J.K., B.W. Langan, and M.A. Ward, Pozzolanic reaction in portland cement, silica fume, and fly ash mixtures. Canadian Journal of Civil Engineering, 1997. 24(5): p. 754-760.

28. Sakai, E., et al., Hydration of fly ash cement. Cement and Concrete Research, 2005. 35(6): p. 1135-1140.

29. Richardson, I.G., et al., Hydration of water- and alkali-activated white Portland cement pastes and blends with low-calcium pulverized fuel ash. Cement and Concrete Research, 2016. 83: p. 1-18.

30. Dittrich, S., J. Neubauer, and F. Goetz-Neunhoeffer, The influence of fly ash on the hydration of OPC within the first $44 h-A$ quantitative in situ XRD and heat flow calorimetry study. Cement and Concrete Research, 2014. 56: $p$. 129-138.

31. Escalante-Garcia, J.I. and J.H. Sharp, The chemical composition and microstructure of hydration products in blended cements. Cement and Concrete Composites, 2004. 26(8): p. 967-976.

32. Ben Haha, M., K. De Weerdt, and B. Lothenbach, Quantification of the degree of reaction of fly ash. Cement and Concrete Research, 2010. 40(11): p. 16201629.

33. Kovács, R., Effect of the hydration products on the properties of fly-ash cements. Cement and Concrete Research, 1975. 5(1): p. 73-82.

34. Girão, A.V., et al., Composition, morphology and nanostructure of $\mathrm{C}-\mathrm{S}-\mathrm{H}$ in $70 \%$ white Portland cement-30\% fly ash blends hydrated at $55{ }^{\circ} \mathrm{C}$. Cement and Concrete Research, 2010. 40(9): p. 1350-1359.

35. Rodger, S.A. and G.W. Groves, The microstructure of tricalcium silicate/pulverized-fuel ash blended cement pastes. Advances in Cement Research, 1988. 1(2): p. 84-91.

36. Tajuelo Rodriguez, E., Relation between composition, structure and morphology in C-S-H, in School of Civil Engineering 2015, The University of Leeds.

37. Lang, E., Blastfurnace cements, in Structure and performance of cements. Second ed, ed. J. Bensted and B. Barnes. 2002, 11 New Fetter Lane, London: Spon Press.

38. Mehta, P.K., Pozzolanic and Cementitious by-Products in Concrete--Another Look. Special Publication. 114.

39. BS EN 197-1:2011 Cement. Composition, specifications and conformity criteria for common cements. 
40. Mantel, D.G., Investigation Into the Hydraulic Activity of Five Granulated Blast furnace Slags With Eight Different Portland Cements. Materials Journal. 91(5).

41. Richardson, I.G. and G.W. Groves, Microstructure and microanalysis of hardened cement pastes involving ground granulated blast-furnace slag. Journal of Materials Science, 1992. 27(22): p. 6204-6212.

42. Taylor, R., I.G. Richardson, and R.M.D. Brydson, Composition and microstructure of 20-year-old ordinary Portland cement-ground granulated blast-furnace slag blends containing 0 to $100 \%$ slag. Cement and Concrete Research, 2010. 40(7): p. 971-983.

43. Kocaba, V., E. Gallucci, and K.L. Scrivener, Methods for determination of degree of reaction of slag in blended cement pastes. Cement and Concrete Research, 2012. 42(3): p. 511-525.

44. Luke, K. and E. Lachowski, Internal Composition of 20-Year-Old Fly Ash and Slag-Blended Ordinary Portland Cement Pastes. Journal of the American Ceramic Society, 2008. 91(12): p. 4084-4092.

45. Lumley, J.S., et al., Degrees of reaction of the slag in some blends with Portland cements. Cement and Concrete Research, 1996. 26(1): p. 139-151.

46. Luke, K. and F.P. Glasser, Internal chemical evolution of the constitution of blended cements. Cement and Concrete Research, 1988. 18(4): p. 495-502.

47. Whittaker, M., et al., The role of the alumina content of slag, plus the presence of additional sulfate on the hydration and microstructure of Portland cementslag blends. Cement and Concrete Research, 2014. 66: p. 91-101.

48. Richardson, I.G., The nature of $\mathrm{C}-\mathrm{S}-\mathrm{H}$ in hardened cements. Cement and Concrete Research, 1999. 29(8): p. 1131-1147.

49. Richardson, I.G. and G.W. Groves, The structure of the calcium silicate hydrate phases present in hardened pastes of white Portland cement/blastfurnace slag blends. Journal of Materials Science, 1997. 32(18): p. 47934802.

50. Richardson, I.G., et al., Location of Aluminum in Substituted Calcium Silicate Hydrate (C-S-H) Gels as Determined by 29Si and 27Al NMR and EELS. Journal of the American Ceramic Society, 1993. 76(9): p. 2285-2288.

51. Groves, G.W. and I.G. Richardson, Microcrystalline calcium hydroxide in pozzalanic cement pastes. Cement and Concrete Research, 1994. 24(6): p. 1191-1196.

52. Richardson, I.G., et al., Characterisation of cement hydrate phases by TEM, NMR and Raman spectroscopy. Advances in Cement Research, 2010. 22(4): p. 233-248. 
53. Scrivener, K.L. and A. Nonat, Hydration of cementitious materials, present and future. Cement and Concrete Research, 2011. 41(7): p. 651-665.

54. Bijen, J., Benefits of slag and fly ash. Construction and Building Materials, 1996. 10(5): p. 309-314.

55. Marsh, B.K., R.L. Day, and D.G. Bonner, Pore structure characteristics affecting the permeability of cement paste containing fly ash. Cement and Concrete Research, 1985. 15(6): p. 1027-1038.

56. Al-Amoudi, O., et al., Performance and Correlation of the Properties of Fly Ash Cement Concrete. 1996.

57. Canut, M.M.C., Pore structure in blended cement pastes. 2011, Technical University of Denmark, Department of Civil Engineering.

58. Bougara, A., C. Lynsdale, and N.B. Milestone, Reactivity and performance of blastfurnace slags of differing origin. Cement and Concrete Composites, 2010. 32(4): p. 319-324.

59. Oner, A. and S. Akyuz, An experimental study on optimum usage of GGBS for the compressive strength of concrete. Cement and Concrete Composites, 2007. 29(6): p. 505-514.

60. Andrade, C., et al., Passivation of reinforcing steel in concrete. Materials Science Forum, 1995. 192-194(pt 2): p. 891-898.

61. Thiery, M., et al., Investigation of the carbonation front shape on cementitious materials: Effects of the chemical kinetics. Cement and Concrete Research, 2007. 37(7): p. 1047-1058.

62. Morandeau, A., M. Thiéry, and P. Dangla, Investigation of the carbonation mechanism of $\mathrm{CH}$ and $\mathrm{C}$-S-H in terms of kinetics, microstructure changes and moisture properties. Cement and Concrete Research, 2014. 56: p. 153-170.

63. Sevelsted, T.F. and J. Skibsted, Carbonation of $C-S-H$ and $C-A-S-H$ samples studied by 13C, 27Al and 29Si MAS NMR spectroscopy. Cement and Concrete Research, 2015. 71: p. 56-65.

64. Groves, G.W., et al., Progressive Changes in the Structure of Hardened C3S Cement Pastes due to Carbonation. Journal of the American Ceramic Society, 1991. 74(11): p. 2891-2896.

65. Nishikawa, T., et al., Decomposition of synthesized ettringite by carbonation. Cement and Concrete Research, 1992. 22(1): p. 6-14.

66. Zhou, Q. and F.P. Glasser, Kinetics and mechanism of the carbonation of ettringite. Advances in Cement Research, 2000. 12(3): p. 131-136.

67. Fernández-Carrasco, L., D. Torréns-Martín, and S. Martínez-Ramírez, Carbonation of ternary building cementing materials. Cement and Concrete Composites, 2012. 34(10): p. 1180-1186. 
68. Matschei, T., B. Lothenbach, and F.P. Glasser, The AFm phase in Portland cement. Cement and Concrete Research, 2007. 37(2): p. 118-130.

69. Lothenbach, B., et al., Influence of limestone on the hydration of Portland cements. Cement and Concrete Research, 2008. 38(6): p. 848-860.

70. BS EN 12390-10:2015 Testing hardened concrete - Part 10: Determination of the carbonation resistance of concrete at atmospheric levels of carbon dioxide.

71. Richardson, I.G., et al., The carbonation of OPC and OPC/silica fume hardened cement pastes in air under conditions of fixed humidity. Advances in Cement Research, 1993. 5(18): p. 81-86.

72. Castellote, M., et al., Chemical changes and phase analysis of OPC pastes carbonated at different CO2 concentrations. Materials and Structures, 2009. 42(4): p. 515-525.

73. Black, L., et al., Structural Features of $C-S-H(I)$ and Its Carbonation in AirA Raman Spectroscopic Study. Part II: Carbonated Phases. Journal of the American Ceramic Society, 2007. 90(3): p. 908-917.

74. Pinlajavaara, S.E., Some results of the effect of carbonation on the porosity and pore size distribution of cement paste. Matériaux et Construction, 1968. 1(6): p. 521-527.

75. Vagelis G. Papadakis, C.G.V. and N.F. Michael, Physical and Chemical Characteristics Affecting the Durability of Concrete. Materials Journal. 88(2).

76. Ngala, V.T. and C.L. Page, Effects of carbonation on pore structure and diffusional properties of hydrated cement pastes. Cement and Concrete Research, 1997. 27(7): p. 995-1007.

77. Xiao, J., et al., Experimental study on strength and ductility of carbonated concrete elements. Construction and Building Materials, 2002. 16(3): p. 187192.

78. Johannesson, B. and P. Utgenannt, Microstructural changes caused by carbonation of cement mortar. Cement and Concrete Research, 2001. 31(6): p. $925-931$.

79. Groves, G.W., D.I. Rodway, and I.G. Richardson, The carbonation of hardened cement pastes. Advances in Cement Research, 1990. 3(11): p. 117-125.

80. Chen, J.J., J.J. Thomas, and H.M. Jennings, Decalcification shrinkage of cement paste. Cement and Concrete Research, 2006. 36(5): p. 801-809.

81. Hanehara, S., et al., Effects of water/powder ratio, mixing ratio of fly ash, and curing temperature on pozzolanic reaction of fly ash in cement paste. Cement and Concrete Research, 2001. 31(1): p. 31-39. 
82. Borges, P.H.R., et al., Carbonation of $\mathrm{CH}$ and $\mathrm{C}-\mathrm{S}-\mathrm{H}$ in Composite Cement Pastes Containing High Amounts of BFS. Cement and Concrete Research, 2010. 40: p. 284 - 292.

83. Wu, B., Y. Zhang, and G. Ye. The influences of CSH on the carbonation resistance of cement blended with supplementary cementitious materials. in 1st International Conference on Ageing of Materials \& Structures. 2014.

84. Gruyaert, E., P. Van den Heede, and N. De Belie, Carbonation of slag concrete: Effect of the cement replacement level and curing on the carbonation coefficient - Effect of carbonation on the pore structure. Cement and Concrete Composites, 2013. 35(1): p. 39-48.

85. Litvan, G.G. and A. Meyer, Carbonation of granulated blast furnace slag cement concrete during twenty years of field exposure. ACI SP, 1986. N91(2): p. $1445-62$.

86. Morandeau, A., M. Thiéry, and P. Dangla, Impact of accelerated carbonation on OPC cement paste blended with fly ash. Cement and Concrete Research, 2015. 67: p. 226-236.

87. BS EN 13670:2009 Execution of concrete structures.

88. Conrete library of JSCE NO.28. Recommendation for construction of concrete containing ground granulated blast-furnace slag as an admixture.

89. Apperley, D.C., R.K. Harris, and P. Hodgkinson, Solid-State NMR Basic Principles \& Practice 2012, 222 East 46th Street, New York, NY 10017: Momentum Press.

90. Smolczyk, H.G. Slag structure and identification of slags. in 7th International Congress on the Chemistry of Cement. 1980. Paris, France. p. III-1/4-III-1/17.

91. Dron, R., Structure and reactivity of glassy slags, in 8th International Congress on the Chemistry of Cement. 1986: Rio de Janeiro (Brasil). p. 8185, Vol IV, 3.

92. BS EN 196-1:2005. Methods of testing cement. Part 1: Determination of strength.

93. Zhang, J. and G.W. Scherer, Comparison of methods for arresting hydration of cement. Cement and Concrete Research, 2011. 41(10): p. 1024-1036.

94. Konecny, L. and S.J. Naqvi, The effect of different drying techniques on the pore size distribution of blended cement mortars. Cement and Concrete Research, 1993. 23(5): p. 1223-1228.

95. Collier, N.C., et al., The influence of water removal techniques on the composition and microstructure of hardened cement pastes. Cement and Concrete Research, 2008. 38(6): p. 737-744. 
96. Winnefeld, F., A. Scholer, and B. Lothenbach, Chapter 1. Sample preparation in A Practical Guide to Microstructural Analysis of Cementitious Materials. 2016, Boca Raton, FL 33487-2742: CRC Press Taylor \& Francis Group, p 1 $-35$.

97. Khoshnazar, R., et al., Solvent exchange in sulfoaluminate phases. Part II: monosulfate. Advances in Cement Research, 2013. 25(6): p. 322-331.

98. Ramachandran, V.S., Thermal Analysis in Handbook of Analytical Techniques in Concrete Science Technology - Principles, Techniques and Applications, ed. V.S. Ramachandran and J.J. Beaudoin. 2001: William Andrew Publishing, p 127-173.

99. Lothenbach, B., P. Durdziński, and K. De Weerdt, Chapter 5. Thermogravimetric Analysis in A Practical Guide to Microstructural Analysis of Cementitious Materials, ed. K. Scrivener, R. Snellings, and B. Lothenbach. 2016, Boca Raton, FL 33487-2742: CRC Press Taylor \& Francis Group, p 177-211.

100. Villain, G., M. Thiery, and G. Platret, Measurement methods of carbonation profiles in concrete: Thermogravimetry, chemical analysis and gammadensimetry. Cement and Concrete Research, 2007. 37(8): p. 11821192.

101. Chang, J. and Y. Fang, Quantitative analysis of accelerated carbonation products of the synthetic calcium silicate hydrate $(C-S-H)$ by $Q X R D$ and TG/MS. Journal of Thermal Analysis and Calorimetry, 2015. 119(1): p. 57-62.

102. Goto, S., et al., Calcium Silicate Carbonation Products. Journal of the American Ceramic Society, 1995. 78(11): p. 2867-2872.

103. Ylmén, E.R., Early Hydration of Portland Cement in Department of Chemical and Biological Engineering 2013, Chalmers University of Technology: Gothenburg, Sweden.

104. Griffiths, P.R. and J.A. de Haseth, Fourier Transform Infrared Spectrometry, Second edition. 2007, Hoboken, New Jersey: John Wiley \& Sons, Inc.

105. Kirkpatrick, R.J., Chapter 6. Nuclear Magnetic Resonance Spectroscopy in Handbook of Analytical Techniques in Concrete Science Technology Principles, Techniques and Applications, ed. V.S. Ramachandran and J.J. Beaudoin. 2001: William Andrew Publishing, p 205 - 230.

106. Skibsted, J., Chapter 6. High-resolution solid-state nuclear magnetic resonance spectroscopy of portland cement-based systems in A Practical Guide to Microstructural Analysis of Cementitious Materials. 2016, Boca Raton, FL 33487-2742: CRC Press Taylor \& Francis Group, p 213 - 286.

107. Skibsted, J. and C. Hall, Characterization of cement minerals, cements and their reaction products at the atomic and nano scale. Cement and Concrete Research, 2008. 38(2): p. 205-225. 
108. Richardson, I.G., et al., The characterization of hardened alkali-activated blast-furnace slag pastes and the nature of the calcium silicate hydrate (C-SH) phase. Cement and Concrete Research, 1994. 24(5): p. 813-829.

109. Francis Young, J., Investigations of Calcium Silicate Hydrate Structure Using Silicon-29 Nuclear Magnetic Resonance Spectroscopy. Journal of the American Ceramic Society, 1988. 71(3): p. C-118-C-120.

110. Skibsted, J., E. Henderson, and H.J. Jakobsen, Characterization of calcium aluminate phases in cements by aluminum-27 MAS NMR spectroscopy. Inorganic Chemistry, 1993. 32(6): p. 1013-1027.

111. Magi, M., et al., Solid-state high-resolution silicon-29 chemical shifts in silicates. The Journal of Physical Chemistry, 1984. 88(8): p. 1518-1522.

112. Love, C.A., Microstructure and silicate anion structure of hardened blended cement pastes, in School of Civil Engineering. 2002, University of Leeds.

113. Chatterjee, A.K., X-Ray Diffraction in Handbook of Analytical Techniques in Concrete Science Technology - Principles, Techniques and Applications, ed. V.S. Ramachandran and J.J. Beaudoin. 2001: William Andrew Publishing, $p$ $275-332$.

114. Le Saoût, G., V. Kocaba, and K. Scrivener, Application of the Rietveld method to the analysis of anhydrous cement. Cement and Concrete Research, 2011. 41(2): p. 133-148.

115. Scrivener, K.L., et al., Quantitative study of Portland cement hydration by Xray diffraction/Rietveld analysis and independent methods. Cement and Concrete Research, 2004. 34(9): p. 1541-1547.

116. Jansen, D., et al., The early hydration of Ordinary Portland Cement (OPC): An approach comparing measured heat flow with calculated heat flow from QXRD. Cement and Concrete Research, 2012. 42(1): p. 134-138.

117. Young, R.A., The Rietveld Method, Edited by R. A. Young. 1993, New York: Oxford University Press.

118. Snellings, R., Chapter 4. X-ray powder diffraction applied to cement in A Practical Guide to Microstructural Analysis of Cementitious Materials. 2016, Boca Raton, FL 33487-2742: CRC Press Taylor \& Francis Group, p 107 176.

119. Stutzman, P.E., Guide for X-Ray Powder Diffraction Analysis of Portland Cement and Clinker. NISTIR 5755, 1996: p. 1-38.

120. Courtial, M., et al., Polymorphism of tricalcium silicate in Portland cement: $A$ fast visual identification of structure and superstructure. Powder Diffraction, 2003. 18(1): p. 7-15.

121. McCusker, L.B., et al., Rietveld refinement guidelines. J. Appl. Cryst, 1999. 32: p. 36 - 50. 
122. Dollase, W.A., Correction of intensities for preferred orientation in powder diffractometry: application of the March model. Journal of Applied Crystallography, 1986. 19(4): p. 267-272.

123. Snellings, R., A. Bazzoni, and K. Scrivener, The existence of amorphous phase in Portland cements: Physical factors affecting Rietveld quantitative phase analysis. Cement and Concrete Research, 2014. 59: p. 139-146.

124. Leon-Reina, L., et al., Round robin on Rietveld quantitative phase analysis of Portland cements. Journal of Applied Crystallography, 2009. 42(5): p. 906916.

125. Jansen, D., et al., A remastered external standard method applied to the quantification of early OPC hydration. Cement and Concrete Research, 2011. 41(6): p. 602-608.

126. Prince, E., International Tables for Crystallography, Volume C. 2004.

127. Richardson, I.G., Electron microscopy of cements Chapter 22 in Structure and Performance of Cements, 2nd edition, ed. B. Barnes and J. Bensted. 2002: Spon Press, p 500-556.

128. Dalgleish, B.J. and K. Ibe, Thin-foil studies of hydrated Portland cement. Cement and Concrete Research, 1981. 11(5): p. 729-739.

129. Jennings, H.M., B.J. Dalgleish, and P.L. Pratt, Morphological Development of Hydrating Tricalcium Silicate as Examined by Electron Microscopy Techniques. Journal of the American Ceramic Society, 1981. 64(10): p. 567572.

130. Lachowski, E.E., et al., Analytical Electron Microscopy of Cement Pastes: II, Pastes of Portland Cements and Clinkers. Journal of the American Ceramic Society, 1980. 63(7-8): p. 447-452.

131. Viehland, D., et al., Mesostructure of Calcium Silicate Hydrate (C-S-H) Gels in Portland Cement Paste: Short-Range Ordering, Nanocrystallinity, and Local Compositional Order. Journal of the American Ceramic Society, 1996. 79(7): p. 1731-1744.

132. Groves, G.W., P.J. Le Sueur, and W. Sinclair, Transmission Electron Microscopy and Microanalytical Studies of lon-Beam-Thinned Sections of Tricalcium Silicate Paste. Journal of the American Ceramic Society, 1986. 69(4): p. 353-356.

133. Mouret, M., E. Ringot, and A. Bascoul, Image analysis: a tool for the characterisation of hydration of cement in concrete - metrological aspects of magnification on measurement. Cement and Concrete Composites, 2001. 23(2-3): p. 201-206. 
134. Scrivener, K., et al., Chapter 8. Electron Microscopy in A Practical Guide to Microstructural Analysis of Cementitious Materials. 2016, Boca Raton, FL 33487-2742: CRC Press Taylor \& Francis Group, p 351 - 417.

135. Wu, X., D.M. Roy, and C.A. Langton, Early stage hydration of slag-cement. Cement and Concrete Research, 1983. 13(2): p. 277-286.

136. Quennoz, A. and K.L. Scrivener, Interactions between alite and C3A-gypsum hydrations in model cements. Cement and Concrete Research, 2013. 44: $p$. 46-54.

137. Gutteridge, W.A. and J.A. Dalziel, Filler cement: The effect of the secondary component on the hydration of Portland cement: Part I. A fine non-hydraulic filler. Cement and Concrete Research, 1990. 20(5): p. 778-782.

138. Gutteridge, W.A. and J.A. Dalziel, Filler cement: The effect of the secondary component on the hydration of Portland cement: Part 2: Fine hydraulic binders. Cement and Concrete Research, 1990. 20(6): p. 853-861.

139. Berodier, E. and K. Scrivener, Understanding the Filler Effect on the Nucleation and Growth of C-S-H. Journal of the American Ceramic Society, 2014. 97(12): p. 3764-3773.

140. YImén, R. and U. Jäglid, Carbonation of Portland Cement Studied by Diffuse Reflection Fourier Transform Infrared Spectroscopy. International Journal of Concrete Structures and Materials, 2013. 7(2): p. 119-125.

141. Anderson, F.A. and L. Brečević, Infrared spectra of amorphous and crystalline calcium carbonate. Acta Chemica Scandinavica, 1991. 45: p. 1018 - 1024.

142. Taylor, H.F.W., Modification of the Bogue calculation. Advances in Cement Research, 1989. 2(6): p. 73-77.

143. Skibsted, J., H.J. Jakobsen, and C. Hall, Quantification of calcium silicate phases in Portland cements by 29Si MAS NMR spectroscopy. Journal of the Chemical Society, Faraday Transactions, 1995. 91(24): p. 4423-4430.

144. Barret, P. and D. Bertrandie, Fundamental hydration kinetic features of the major cement constituents: Ca3SiO5 and bCa2SiO4,. Journal de Chimie Physique 83 (11/12) (1986) 765-775.

145. Berodier, E. and K. Scrivener, Evolution of pore structure in blended systems. Cement and Concrete Research, 2015. 73: p. 25-35.

146. De Weerdt, K., et al., Hydration mechanisms of ternary Portland cements containing limestone powder and fly ash. Cement and Concrete Research, 2011. 41(3): p. 279-291.

147. Whittaker, M., The Impact of Slag Composition on the Microstructure of Composite Slag Cements Exposed to Sulfate Attack. 2014, Uinversity of Leeds. 
148. Tan, Z., et al., Influence of particle size on the early hydration of slag particle activated by $\mathrm{Ca}(\mathrm{OH}) 2$ solution. Construction and Building Materials, 2014. 52: p. $488-493$.

149. Hinrichs, W. and I. Odler, Investigation of the hydration of Portland blastfurnace slag cement: hydration kinetics. Advances in Cement Research, 1989. 2(5): p. 9-13.

150. Dyer, T.D. and R.K. Dhir, Hydration reactions of cement combinations containing vitrified incinerator fly ash. Cement and Concrete Research, 2004. 34(5): p. 849-856.

151. Damidot, D., et al., Thermodynamic investigation of the $\mathrm{CaO} \cdot \mathrm{Al} 2 \mathrm{O} 3$ $\mathrm{CaCO} 3 \cdot \mathrm{H} 2 \mathrm{O}$ closed system at $25^{\circ} \mathrm{C}$ and the influence of $\mathrm{Na} 2 \mathrm{O}$. Cement and Concrete Research, 1994. 24(3): p. 563-572.

152. Antoni, M., et al., Cement substitution by a combination of metakaolin and limestone. Cement and Concrete Research, 2012. 42(12): p. 1579-1589.

153. Zajac, M., et al., Influence of limestone and anhydrite on the hydration of Portland cements. Cement and Concrete Composites, 2014. 46: p. 99-108.

154. Andersen, M.D., H.J. Jakobsen, and J. Skibsted, Incorporation of Aluminum in the Calcium Silicate Hydrate $(\mathrm{C}-\mathrm{S}-\mathrm{H})$ of Hydrated Portland Cements: A High-Field 27Al and 29Si MAS NMR Investigation. Inorganic Chemistry, 2003. 42(7): p. 2280-2287.

155. Skibsted, J. and H.J. Jakobsen, Characterization of the calcium silicate and aluminate phases in anhydrous and hydrated Portland cements in Nuclear Magnetic Resonance Spectroscopy of Cement-Based Materials, pp3 -45. 1998.

156. Andersen, M.D., H.J. Jakobsen, and J. Skibsted, $A$ new aluminium-hydrate species in hydrated Portland cements characterized by 27Al and 29Si MAS NMR spectroscopy. Cement and Concrete Research, 2006. 36(1): p. 3-17.

157. Taylor, R., I.G. Richardson, and R.M.D. Brydson, Nature of $\mathrm{C}-\mathrm{S}-\mathrm{H}$ in 20 year old neat ordinary Portland cement and 10\% Portland cement-90\% ground granulated blast furnace slag pastes. Advances in Applied Ceramics, 2007. 106(6): p. 294-301.

158. Rodger, S.A. and G.W. Groves, Electron Microscopy Study of Ordinary Portland Cement and Ordinary Portland Cement-Pulverized Fuel Ash Blended Pastes. Journal of the American Ceramic Society, 1989. 72(6): p. 1037-1039.

159. Wang, S.-D. and K.L. Scrivener, Hydration products of alkali activated slag cement. Cement and Concrete Research, 1995. 25(3): p. 561-571. 
160. Ben Haha, M., et al., Influence of slag chemistry on the hydration of alkaliactivated blast-furnace slag - Part II: Effect of Al2O3. Cement and Concrete Research, 2012. 42(1): p. 74-83.

161. Cong, X. and R.J. Kirkpatrick, 29Si MAS NMR study of the structure of calcium silicate hydrate. Advanced Cement Based Materials, 1996. 3(3-4): p. 144-156.

162. Hirljac, J., Z.Q. Wu, and J.F. Young, Silicate polymerization during the hydration of alite. Cement and Concrete Research, 1983. 13(6): p. 877-886.

163. Andersen, M.D., H.J. Jakobsen, and J. Skibsted, Characterization of white Portland cement hydration and the $\mathrm{C}-\mathrm{S}-\mathrm{H}$ structure in the presence of sodium aluminate by 27Al and 29Si MAS NMR spectroscopy. Cement and Concrete Research, 2004. 34(5): p. 857-868.

164. Lippmaa, E., et al., A high resolution 29Si NMR study of the hydration of tricalciumsilicate. Cement and Concrete Research, 1982. 12(5): p. 597-602.

165. Ho, D.W.S., Q.Y. Cui, and D.J. Ritchie, The influence of humidity and curing time on the quality of concrete. Cement and Concrete Research, 1989. 19(3): p. 457-464.

166. Lam, L., Y.L. Wong, and C.S. Poon, Degree of hydration and gel/space ratio of high-volume fly ash/cement systems. Cement and Concrete Research, 2000. 30(5): p. 747-756.

167. Shi, Z., et al., Experimental studies and thermodynamic modeling of the carbonation of Portland cement, metakaolin and limestone mortars. Cement and Concrete Research, 2016. 88: p. 60-72.

168. Li, S., Carbonation of 20-year-old Blended Cement Pastes. 2011, The University of Leeds.

169. Šauman, Z., Carbonization of porous concrete and its main binding components. Cement and Concrete Research, 1971. 1(6): p. 645-662.

170. Dubina, E., et al., Influence of water vapour and carbon dioxide on free lime during storage at $80{ }^{\circ} \mathrm{C}$, studied by Raman spectroscopy. Spectrochimica Acta Part A: Molecular and Biomolecular Spectroscopy, 2013. 111: p. 299303.

171. Slegers, P.A. and P.G. Rouxhet, Carbonation of the hydration products of tricalcium silicate. Cement and Concrete Research, 1976. 6(3): p. 381-388.

172. Yu, P., et al., Structure of Calcium Silicate Hydrate (C-S-H): Near-, Mid-, and Far-Infrared Spectroscopy. Journal of the American Ceramic Society, 1999. 82(3): p. 742-748.

173. Fernández-Carrasco, L. and E. Vázquez, Reactions of fly ash with calcium aluminate cement and calcium sulphate. Fuel, 2009. 88(9): p. 1533-1538. 
174. Ylmén, R., et al., Early hydration and setting of Portland cement monitored by IR, SEM and Vicat techniques. Cement and Concrete Research, 2009. 39(5): p. $433-439$.

175. Sevelsted, T.F., D. Herfort, and J. Skibsted, $13 \mathrm{C}$ chemical shift anisotropies for carbonate ions in cement minerals and the use of 13C, 27Al and 29Si MAS NMR in studies of Portland cement including limestone additions. Cement and Concrete Research, 2013. 52: p. 100-111.

176. Bernal, S.A., et al., MgO content of slag controls phase evolution and structural changes induced by accelerated carbonation in alkali-activated binders. Cement and Concrete Research, 2014. 57: p. 33-43.

177. Kim, Y.-Y., et al., Effect of W/C Ratio on Durability and Porosity in Cement Mortar with Constant Cement Amount. Advances in Materials Science and Engineering.Volume 2014 (2014), Article ID 273460, 11 pages.

178. Leemann, A., et al., Relation between carbonation resistance, mix design and exposure of mortar and concrete. Cement and Concrete Composites, 2015. 62: p. 33-43.

179. Parrott, L.J., Carbonation, moisture and empty pores. Advances in Cement Research, 1992. 4(15): p. 111-118.

180. Fernández-Carrasco, L., et al., Chapter 19. Infrared Spectroscopy in the Analysis of Building and Construction Materials in Infrared spectroscopy: materials science, engineering and technology, pp 369-382, ed. T. Theophanides. 2012.

181. Okada, Y., et al., Relationship between NMR 29Si Chemical Shifts and FT-IR Wave Numbers in Calcium Silicates, in Nuclear Magnetic Resonance Spectroscopy of Cement-Based Materials, P. Colombet, et al., Editors. 1998, Springer Berlin Heidelberg: Berlin, Heidelberg. p. 69-78.

182. Ashraf, W. and J. Olek, Carbonation behavior of hydraulic and non-hydraulic calcium silicates: potential of utilizing low-lime calcium silicates in cementbased materials. Journal of Materials Science, 2016. 51(13): p. 6173-6191.

183. Branco, F.A. and J. de Brito, Handbook of Concrete Bridge Management. 2004: American Society of Civil Engineers.

184. Performance-Based Specifications and Control of Concrete Durability. 1 ed. RILEM State-of-the-art reports, ed. H. Beushausen and L. Fernandez Luco. Vol. 18. 2016: Springer Netherlands.

185. Chang, C.-F. and J.-W. Chen, The experimental investigation of concrete carbonation depth. Cement and Concrete Research, 2006. 36(9): p. 17601767. 
186. Khunthongkeaw, J., S. Tangtermsirikul, and T. Leelawat, A study on carbonation depth prediction for fly ash concrete. Construction and Building Materials, 2006. 20(9): p. 744-753.

187. Ho, D.W.S. and R.K. Lewis, Carbonation of concrete and its prediction. Cement and Concrete Research, 1987. 17(3): p. 489-504.

188. Sulapha, P., et al., Carbonation of Concrete Containing Mineral Admixtures. JOURNAL OF MATERIALS IN CIVIL ENGINEERING, 2003. 15(2): p. 134143

189. Parrott, L.J., Damage caused by carbonation of reinforced concrete. Materials and Structures, 1990. 23(3): p. 230-234.

190. Performance criteria for concrete durability, J.r. Kropp and H.K. Hilsdorf, Editors. 1995, E \& FN Spon: London :. 


\section{Appendix A}

A.1. $\mathrm{RH}$ and $\mathrm{CO}_{2}$ measurements for sample conditioning chambers
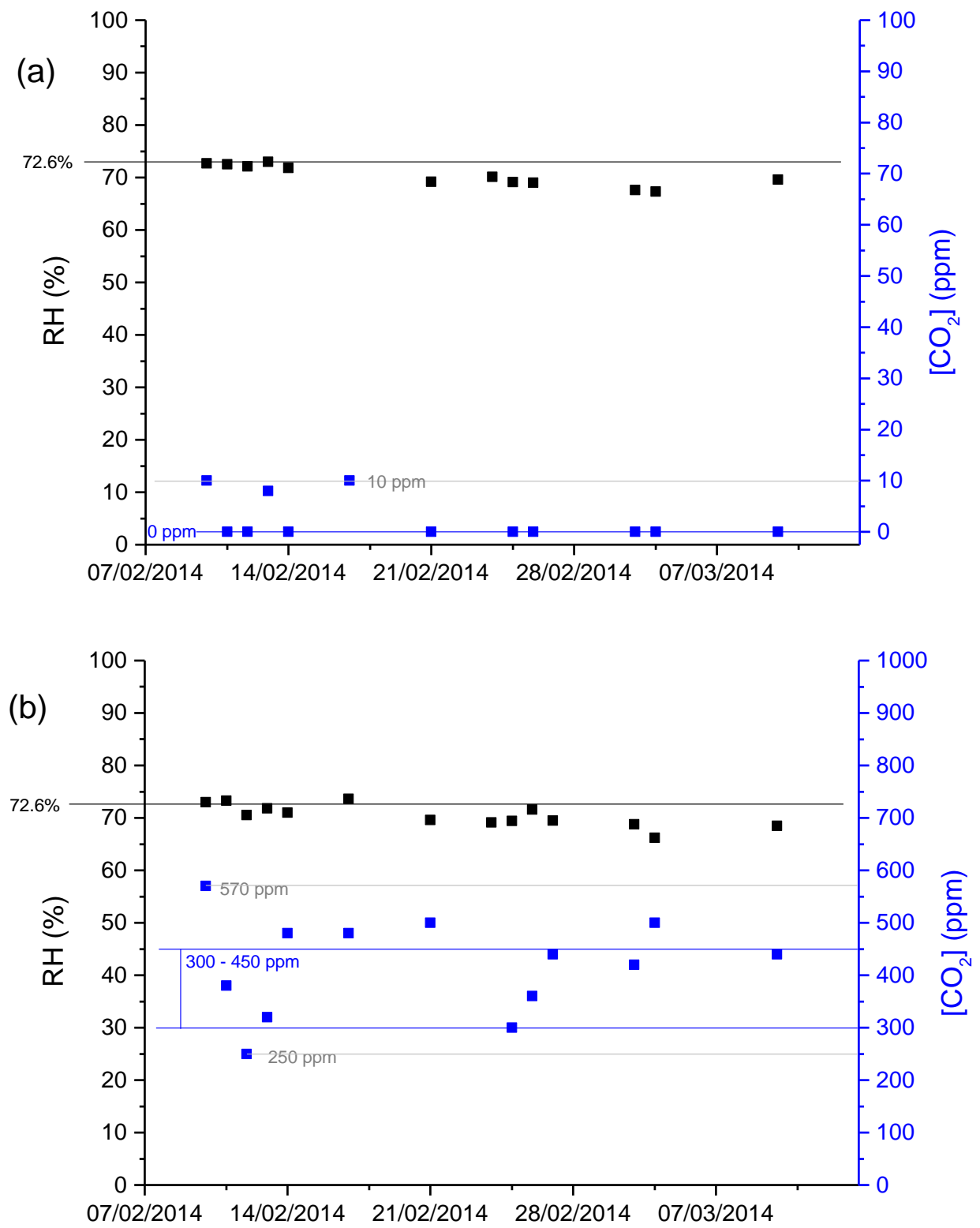

Figure A.1. $\mathrm{RH}$ and $\mathrm{CO}_{2}$ measurements taken over a 5 week period from sample conditioning chambers for (a) $0 \%\left[\mathrm{CO}_{2}\right]$ conditions $\left(\left[\mathrm{CO}_{2}\right]<10 \mathrm{ppm}, \mathrm{RH} 72.6 \%\right)$ and for $(\mathrm{b})$ ambient $[\mathrm{CO} 2]$ conditions ( $\left.\left[\mathrm{CO}_{2}\right] 300-450 \mathrm{ppm}, \mathrm{RH} 72.6 \%\right)$. Temperature remained at approx. $24^{\circ} \mathrm{C}+/-2^{\circ}$. 


\section{Appendix B}

\section{B.1. UCS and carbonation depth}
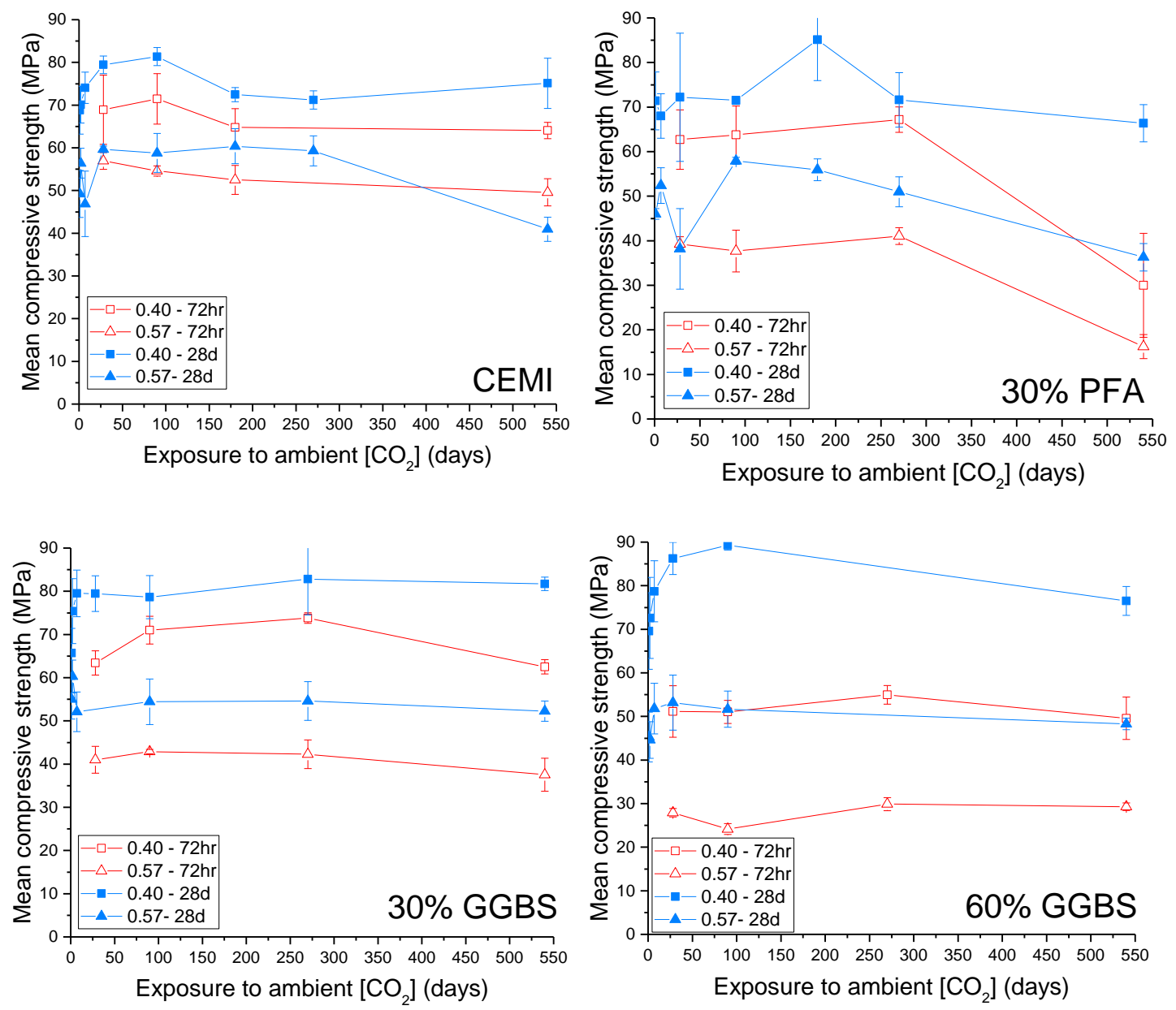

Figure B.1. Mean compressive strength of mortar prisms following exposure to ambient $\left[\mathrm{CO}_{2}\right]$. 

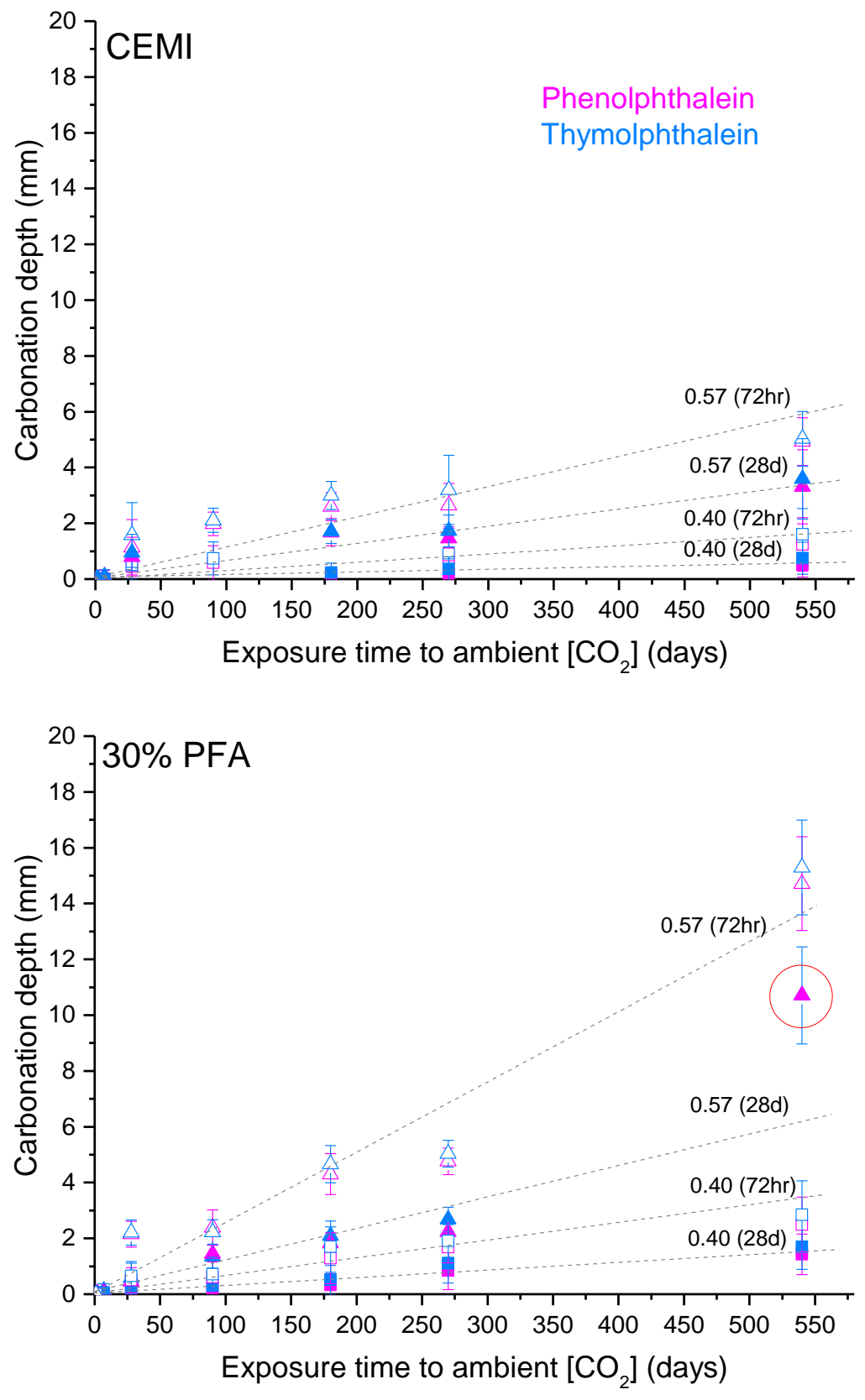

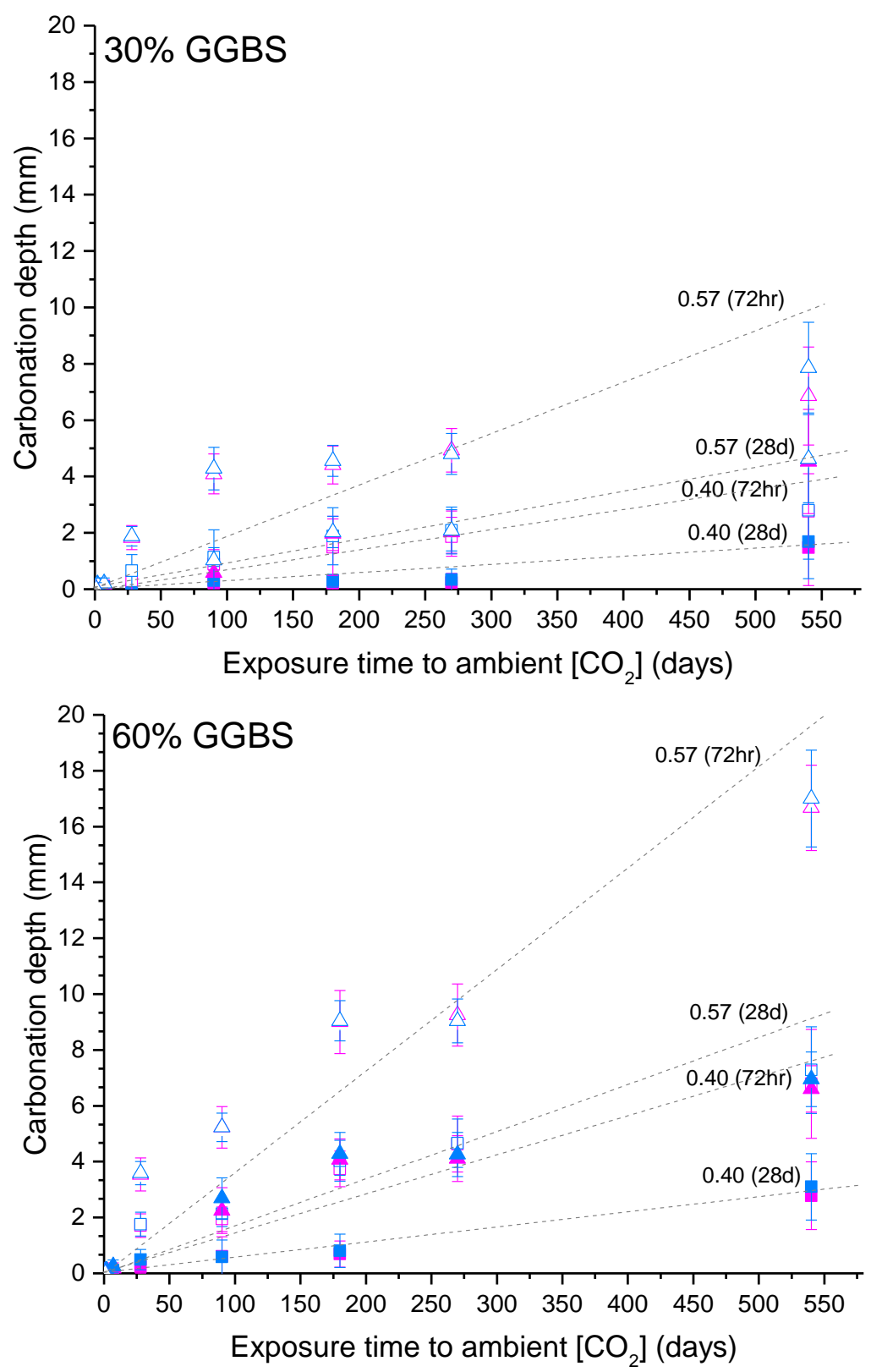

B.2. Carbonation depths measured on mortar samples exposed to ambient $\mathrm{CO}_{2}$ concentrations for up to 18 months $\left(\left[\mathrm{CO}_{2}\right] \sim 450 \mathrm{ppm}, \mathrm{RH} \sim 50 \%\right)$ using phenolphthalein and thymolphthalein indicator solutions. The carbonation coefficients $(\mathrm{k})$ determined from the linear fit of the data (shown as dashed line) are given in Table A.1 below. 
Table B.1. Carbonation coefficients $(\mathrm{k})$ for mortar samples

\begin{tabular}{|c|c|c|c|c|}
\hline & & & \multicolumn{2}{|c|}{$\mathrm{k}\left(\mathrm{mm} / \mathrm{d}^{0.5}\right)$} \\
\hline & $w / b$ & $t_{0}$ & $\mathrm{k}$ (linear regression) * & $\begin{array}{l}\mathrm{k} \text { (carbonation depth } \\
\text { measured by } \\
\text { phenolphthalein indicator } \\
\text { at } 18 \text { months) }\end{array}$ \\
\hline CEMI & 0.40 & $72 \mathrm{hr}$ & 0.07 & 0.05 \\
\hline $30 \%$ PFA & & & 0.15 & 0.11 \\
\hline $30 \%$ GGBS & & & 0.17 & 0.12 \\
\hline $60 \%$ GGBS & & & 0.33 & 0.29 \\
\hline CEMI & 0.40 & $28 d$ & 0.03 & 0.02 \\
\hline $30 \%$ PFA & & & 0.06 & 0.06 \\
\hline $30 \%$ GGBS & & & 0.07 & 0.06 \\
\hline $60 \%$ GGBS & & & 0.13 & 0.12 \\
\hline CEMI & 0.57 & $72 \mathrm{hr}$ & 0.26 & 0.21 \\
\hline $30 \%$ PFA & & & 0.59 & 0.63 \\
\hline $30 \%$ GGBS & & & 0.43 & 0.30 \\
\hline $60 \%$ GGBS & & & 0.85 & 0.72 \\
\hline CEMI & 0.57 & $28 d$ & 0.14 & 0.14 \\
\hline $30 \%$ PFA & & & 0.27 & 0.46 \\
\hline $30 \%$ GGBS & & & 0.20 & 0.19 \\
\hline $60 \%$ GGBS & & & 0.39 & 0.28 \\
\hline
\end{tabular}

${ }^{*}$ Carbonation coefficient obtained from linear fit of carbonation depth data (Figure A.2) as a function of square root of time $\left(x=k t^{0.5}\right)$ 